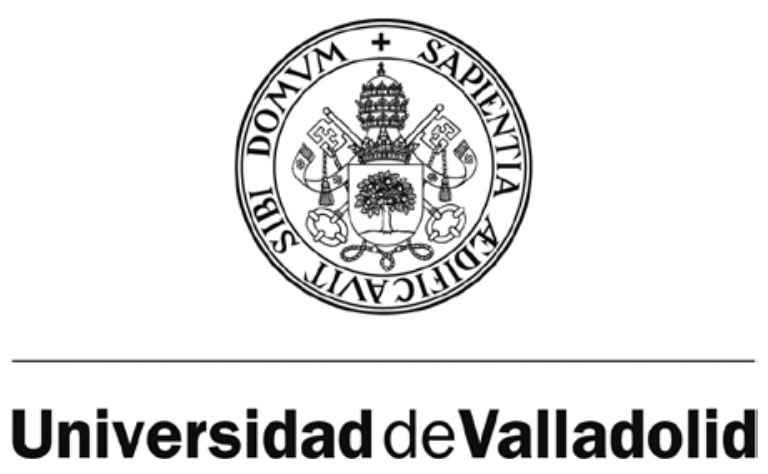

FACULTAD DE CIENCIAS ECONÓMICAS Y EMPRESARIALES

DEPARTAMENTO DE ORGANIZACIÓN DE EMPRESAS Y COMERCIALIZACIÓN E INVESTIGACIÓN DE MERCADOS

TESIS DOCTORAL:

\title{
COLLABORATION AND VALUE CREATION IN MULTI-PARTNER R\&D ALLIANCES: A LONGITUDINAL CASE-STUDY ON THE ACUISOST CONSORTIUM
}

Presentada por Isabel Estrada Vaquero para optar al grado de doctor con mención europea por la Universidad de Valladolid

Dirigida por:

Dra. Da Natalia Martín Cruz

Dra. Da María Pilar Pérez Santana 



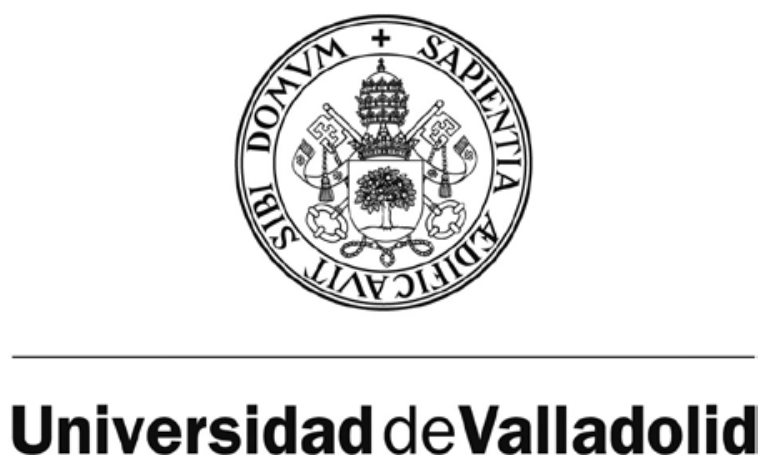

FACULTAD DE CIENCIAS ECONÓMICAS Y EMPRESARIALES

DEPARTAMENTO DE ORGANIZACIÓN DE EMPRESAS Y COMERCIALIZACIÓN E INVESTIGACIÓN DE MERCADOS

\section{COLLABORATION AND VALUE CREATION IN MULTI-PARTNER R\&D ALLIANCES: A LONGITUDINAL CASE-STUDY ON THE ACUISOST CONSORTIUM}

Valladolid, 2012 

In his curious discourse on arms and letters, Don Quixote stated that what the student has to undergo is basically "poverty... but for all that it is not so extreme but that he gets something to eat, though it may be at somewhat unseasonable hours ... and there is always some neighbor's brazier or hearth which... at least tempers the cold to them... though the soldier has more to endure, his reward is much less". Let these ingenious words to introduce the following ones.

First of all, I would like to thank my supervisors, Dr. Natalia Martín Cruz and Dr. Pilar Pérez Santana, for guiding me in so many discoveries and transmitting to me their passion for research, and the importance of rigor and perseverance. Their enthusiasm, cooperative behavior, and commitment have made this dissertation be a 'multi-partner alliance', with a marked flavor of 'long-term relationship of collaboration'.

Secondly, I would like to thank the lead firm of the Acuisost Consortium, Grupo Dibaq: its CEO, Carlos Tejedor, its Aquaculture Division Manager, Álvaro Rodríguez, and especially its R\&D Manager, José Luis Tejedor. This dissertation has been possible thanks to their trust and support. I would like to extend these words to all consortium participants who have kindly collaborated in this research. Moreover, I appreciate financial support from the Regional Government of Castilla y León (Contract for Novel Researchers 2009-2012 and funded research project No. VA 30A11-1).

I would also like to acknowledge the support from the members of the former Dept. of Business Economics of the University of Valladolid, first as professors in my degree and doctoral studies, and now as colleagues. A special mention is addressed to Dr. Juan Hernangómez Barahona, for his seminal lessons on strategic management and for those other, so useful, on 'how to think with your head'. I would also like to thank Dr. Gabriel de la Fuente Herrero for guiding the first period of my doctoral education (future collaboration is more than a real option to me).

I would also like to thank the Dept. of Business Administration 'Juan José Renau Piqueras' of the University of Valencia, for the opportunity to attend the Second and Third Editions of the Valencia Summer School and to visiting at the beginning of the PhD period. I also appreciate my visiting scholar in the Dept. of Innovation Management \& Strategy of the University of Groningen. I would like to thank Dr. Dries Faems for providing me such an opportunity and for his involvement in this research.

I turn to my colleagues of the 'third section', for all those conversations about the human, the divine, and the academic beings. Especially, I thank my office mates, Pablo Zarzuela and Víctor Martín, who have lived the joys and trials of this dissertation as relatives; Celia Martín, my confidant and friend; Rebeca San José and Javier Rodríguez, for their always loving advices; Víctor Hermano, for bringing fresh air to the Organization section (take the baton).

Now I go to my girls, who have put the spark (and a princess) in my life, and especially to Leti, for our eternal walks around the lake. I also thank to my friend Luisja, for living up my Saturday nights with good cuba libre and better conversation.

The most emotive words are addressed to my parents and Ana, my sister. Otherwise, this dissertation would be totally incomplete. For their wisdom, their love, their cooperation, for their endless patience, for being the 'loyal squires' in this trip (as in any), for making what I am today (only the good part).

I conclude by assuming the total responsibility of the mistakes that could be noticed in the following pages of this dissertation. 
En su curioso discurso de las armas y las letras, decía Don Quijote que el trabajo del estudiante es "principalmente pobreza... pero, con todo eso, no es tanta, que no coma, aunque sea un poco más tarde de lo que se usa... y no les falta algún ajeno brasero o chimenea, que, si no callenta, a lo menos entibie su frío... aunque es mucho mayor el trabajo del soldado, es mucho menor el premio". Sirvan estas ingeniosas líneas para introducir las que aquí siguen.

El primer agradecimiento para las doctoras $D^{a}$ Natalia Martín Cruz y Da Pilar Pérez Santana, directoras de esta tesis doctoral, maestras de tantos descubrimientos en estos años, que me han transmitido su pasión por la investigación, la importancia del rigor y la constancia. Su empuje, su comportamiento cooperativo y su compromiso han hecho de esta tesis una verdadera 'alianza multisocio', con un marcado matiz de 'relación de colaboración a largo plazo'.

En segundo lugar, agradezco a las personas del Grupo Dibaq, empresa líder del Proyecto Acuisost. A su Presidente, D. Carlos Tejedor, al Director de Dibaq Acuicultura, D. Álvaro Rodríguez, y, muy especialmente, al Director de I+D+i, D. José Luis Tejedor. Esta tesis doctoral no habría sido posible sin su confianza y apoyo. Extiendo estas palabras a todos los participantes del consorcio que han colaborado desinteresadamente en esta investigación. Igualmente, agradezco la financiación recibida de la Junta de Castilla y León (Contrato de Personal Investigador de Reciente Titulación 2009-2012 y Proyecto Ref. VA 30A11-1).

Es de ley agradecer a los miembros del antiguo Departamento de Economía de la Empresa de la Universidad de Valladolid, por sus enseñanzas y apoyo, primero como profesores de licenciatura y doctorado, y ahora ya como compañeros. Una mención especial para el doctor D. Juan Hernangómez Barahona, por sus lecciones magistrales de dirección estratégica y aquellas otras, tan útiles, sobre 'cómo pensar con la cabeza'. Igualmente, agradezco al doctor Don Gabriel de la Fuente Herrero, por guiarme durante mi primera etapa doctoral (para mí, la opción de seguir colaborando juntos es más que real).

Quisiera también agradecer al Departamento de Dirección de Empresas 'Juan José Renau Piqueras' de la Universidad de Valencia, por brindarme la oportunidad de asistir a las Segunda y Tercera Ediciones de la Valencia Summer School, y de realizar una breve estancia al principio de mi periodo doctoral. Igualmente, quisiera agradecer al doctor D. Dries Faems, por permitirme vivir esa fructífera estancia en el Departamento de Innovación y Estrategia de la Universidad de Groningen y por su implicación en esta investigación.

Con un especial cariño, a mis compañeros del 'tercer módulo', por todas aquellas conversaciones sobre lo humano, lo divino, y lo académico. A mis siempre compañeros de despacho, Pablo Zarzuela y Víctor Martín, que han vivido las penurias y alegrías de esta tesis cual consanguíneos; a Celia Martín, mi gran confidente y amiga; a Rebeca San José y Javier Rodríguez, por sus siempre cariñosos consejos; a Víctor Hermano, por traer su frescura al área de Organización (te paso el testigo).

En un plano aún más personal, me dirijo a mis chicas, por poner ese punto de sal (y alguna que otra princesa) en mi vida, y en especial a Leti, por nuestros eternos paseos por el lago. También a mi amigo Luisja, por amenizar las noches de sábado con buen cubalibre y mejor conversación.

Las más emotivas de mis palabras para mis padres y Ana, mi hermana. Sin ellas, esta tesis doctoral quedaría profundamente inacabada, aunque supongan una incursión en el ámbito de lo privado. Por su sabiduría, por su cariño, por su paciencia infinita, por su cooperación, por ser los ‘fieles escuderos' en este viaje (y en todos), por hacer de mí lo que soy (sólo lo bueno).

Como no podría ser de otra manera, finalizo asumiendo la responsabilidad única de todos los errores que pudieran contener las páginas que siguen. 


\section{Table of Contents}

INTRODUCTION.......................................................... 1

Motivation and aim of the dissertation....................................... 3

Structure of the dissertation.............................................. 8

CHAPTER 1. 'Literature Review and Research Objectives'................ 11

1.1. Literature Review.................................................... 13

1.1.1. The literature on strategic alliances.............................................. 14

1.1.1.1. Theoretical frameworks in alliance research................................. 15

1.1.1.2. Topics in alliance research.................................................. 24

1.1.1.3. Perspectives in alliance research............................................ 29

1.1.1.4. Levels of analysis in alliance research........................................ 33

1.1.1.5. Types of strategic alliances................................................. 35

1.1.1.6. Research on multi-partner R\&D alliances.................................... 36

1.1.2. The literature on dynamic capabilities.............................................. 43

1.1.2.1. Origins and conceptual development of the dynamic capabilities view......... 43

1.1.2.1.1. About the concept of routines: Sources of inertia or flexibility?.............. 46

1.1.2.1.2. Creation and evolution of dynamic capabilities: The capability $\quad 47$
lifecycle and some complementary insights...

lifecycle and some complementary insights............................. 49

1.1.2.2. Empirical research into dynamic capabilities............................... 49

1.1.2.3. Main shortcomings in the dynamic capabilities field........................ 52

1.1.3. Linking dynamic capabilities and strategic alliances................................. 54

1.1.3.1. Alliance capabilities: An overview of existing research........................ 55

1.1.3.2. Research on alliance capabilities: Main contributions and shortcomings..... 57

1.1.3.3. Alliance capabilities as dynamic capabilities: A focus on collaborative

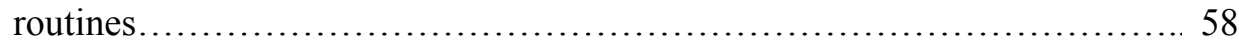

1.1.3.3.1. Collaborative routines: Two levels of analysis................................... 61

1.2. Research objectives of the dissertation............................... 63

1.2.1. Defining research objectives.................................................................. 63

1.2.2. Research gaps, research objectives, and introduction to empirical studies.... 64

CHAPTER 2. 'Methodology and Research Design: Data Collection and Analysis'.................................................... 71

2.1. Case study methodology and research design .......................... 73 
2.2. Research setting ................................................. 75

2.2.1. Selection and description of the Acuisost Consortium....................... 76

2.2.1.1. Overview of the Acuisost Consortium.......................................... 76

2.2.1.2. Selection of the Acuisost Consortium.................................... 77

2.2.1.3. Description of the Acuisost Consortium..................................... 80

2.2.1.3.1. Institutional framework: The CENIT Programme......................... 80

2.2.1.3.2. Industrial context: The field of aquaculture in Spain................. 82

2.2.1.3.3. Objectives and technical and organizational structure................. 84

2.2.1.3.4. Participants of the Acuisost Consortium................................ 88

2.2.1.4. A longitudinal description of the Acuisost Consortium....................... 95

2.2.1.4.1. The formation stage........................................... 96

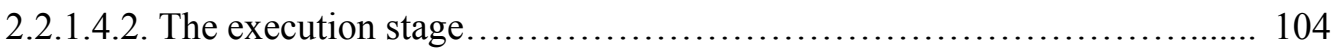

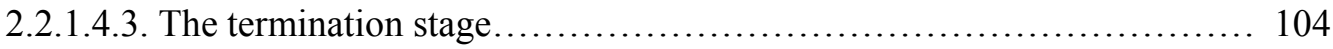

2.2.2. Selection of multi-cases for particular studies............................... 105

2.3. Data collection and analysis: Quality of the research.................. 106

2.3.1. Data collection: principles and process...................................... 106

2.3.1.1. Data collection principles............................................... 106

2.3.1.2. Process of data collection ............................................... 109

2.3.2. Data analysis: Process, levels and methods of analysis ...................... 114

2.3.2.1. Selection of diverse levels of analysis: multi-level research................ 115

2.3.2.2. Selection of diverse methods of analysis: multi-method research............. 116

2.3.3. Tests of quality research............................................... 118

2.4. Outline of methodology .............................................. 121

CHAPTER 3. 'The Formation Stage of the Acuisost Consortium'......... 123

Introduction to Chapter 3.............................................. 125

Study I. Rethinking Cooperative Behavior for Inexperienced Firms in the Formation Stage of MR\&D Alliances..................................... 127

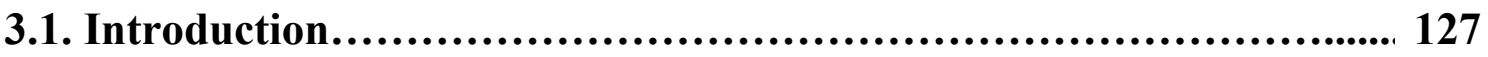

3.2. Conceptual background and propositions................................ 129

3.2.1. Direct competition and cooperative behavior........................................ 133

3.2.2. Learning orientation and cooperative behavior................................. 134

3.2.3. Strategic importance and cooperative behavior............................ 135

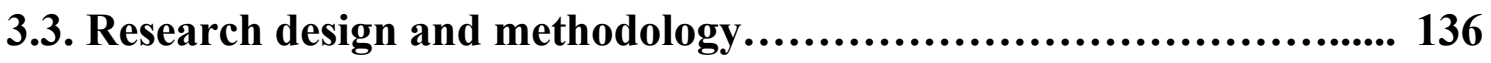

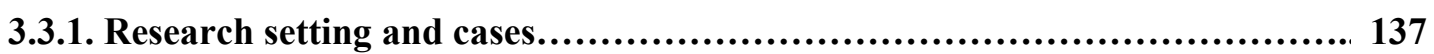

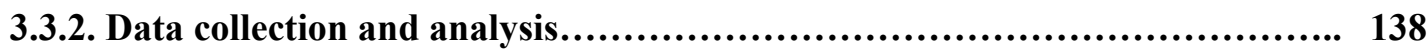

3.3.3. Operationalization of variables.............................................. 140 
3.4. Analysis of the cases.................................................... 143

3.4.1. Within-case analysis............................................................ 143

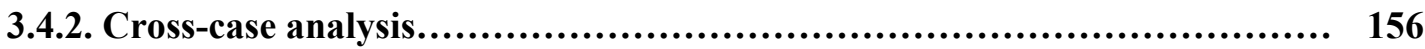

3.5. Discussion and conclusion.......................................... 160

3.5.1. Discussion of findings........................................................... 161

3.5.2. Implications for research................................................... 162

3.5.3. Implications for practice.................................................... 164

3.5.4. Limitations and future research.......................................... 164

CHAPTER 4. Firm-Research Organization Collaboration in the Acuisost Consortium.................................... 167

Introduction to Chapter 4 ................................................. 170

4.1. Study II.1.How do unfamiliar partners succeed in explorative $R \& D$ alliances? Psychological Contracts and Creation of knowledgesharing routines.......................................................... 172

4.1.1. Introduction........................................................................ 172

4.1.2. Conceptual background......................................................... 174

4.1.2.1. The two streams of research into ER\&D alliances: The need to focus on processes...................................................... 174

4.1.2.2. Psychological contracts in E\&D alliances formed by unfamiliar

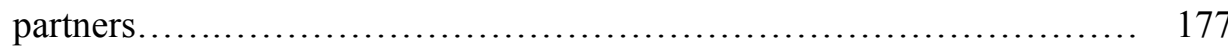

4.1.2.3. Inter-organizational knowledge-sharing routines and psychological

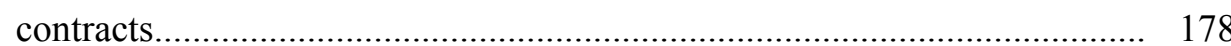

4.1.3. Methodology............................................................... 179

4.1.3.1. Research setting and the cases................................... 179

4.1.3.2. Data collection and analysis.................................... 182

4.1.4. Analysis of the cases: The OI-LF and CRAI-LF alliances............................... 183

4.1.4.1. Initiation of the OI-LF and CRAI-LF alliances........................ 183

4.1.4.2. The OI-LF alliance.............................................. 184

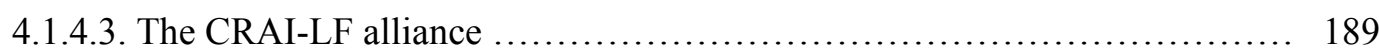

4.1.5. Discussion: The OI-LF and CRAI-LF alliances as marriages......................... 194

4.1.5.1. Starting the alliance: The honeymoon period.......................... 195

4.1.5.2. Facing the first problems: Marriage restoration vs. crisis.................. 197

4.1.5.3. Ending the alliance: marriage consolidation versus divorce............... 200

4.1.6. Conclusion and Implications ............................................. 202

4.1.6.1. Implications for research..................................... 202

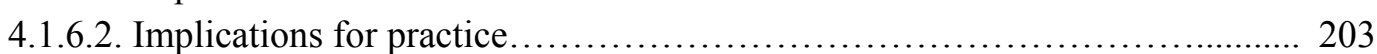

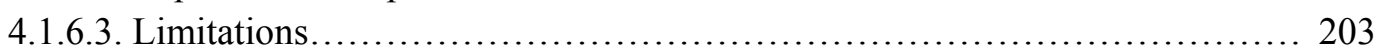

4.1.6.4. Future research................................................. 204 
4.2. Study II.2. How do familiar partners succeed in explorative and exploitative R\&D alliances? Real options reasoning and redeployment of knowledge-sharing routines...........................

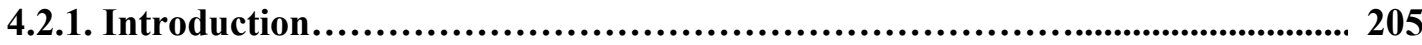

4.2.2. Conceptual background.................................................. 208

4.2.2.1. R\&D alliances from real options reasoning....................................... 208

4.2.2.2. R\&D alliances between familiar partners and real options reasoning......... 210

4.2.2.3. Real options reasoning and redeployment of inter-organizational routines... 210

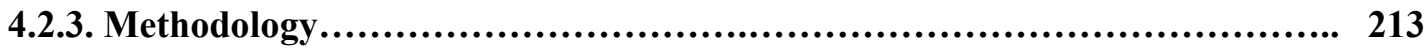

4.2.3.1. Research setting and the cases.......................................... 213

4.2.3.2. Data collection and analysis........................................... 214

4.2.4. Analysis of the cases: The CAH-LF and MAR-LF alliances............................ 216

4.2.4.1. The CAH-LF case.................................................. 216

4.2.4.2. The MAR-LF alliance................................................ 221

4.2.5. Discussion: Real options reasoning in the CAH-LF and MAR-LF alliances.... 226

4.2.5.1. Redeployment: A process of exploring and exploiting collective real options 226

4.2.5.2. Managerial cognition and the identification of collective real options........ 228

4.2.5.3. Redeployment and joint value realization: Managing uncertainty through flexibility........................................................ 229

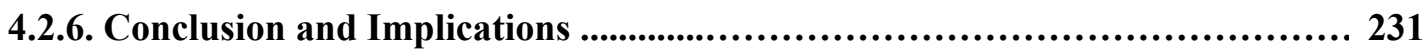

4.2.6.1. Implications for research........................................ 232

4.2.6.2. Implications for practice.................................................. 233

4.2.6.3. Limitations............................................................... 234

4.2.6.4. Future research....................................................... 234

CHAPTER 5. Conclusion, Implications, Limitations, and Future

Research....................................................... 237

5.1. Summary of findings and implications for research................... 240

5.1.1. Study I.: Understanding the creation of organizational collaborative routines.

5.1.1.1. Why some inexperienced partners are more cooperatively than others during the formation stage of multi-partner R\&D alliances.................. 240

5.1.1.2. Contributions to research objective (I )............................. 240

5.1.2. Study II.: Understanding the value-creation dynamics of $R \& D$ alliances:

Creation and evolution of inter-organizational collaborative routines.

5.1.2.1. Study II.1: How unfamiliar partners succeed in explorative alliances:

Creating knowledge-sharing routines.

5.1.2.2. Study II.2: How familiar partners succeed in exploitative and explorative alliances: Redeploying knowledge-sharing routines ..................... 242

5.1.2.3. Contributions to research objective (II) ............................. . 243

5.1.3. Methodological contributions.............................................. 244 
5.1.4. Overall conclusion: Towards a more comprehensive view on the collaboration and value-creation dynamics of MR\&D alliances

5.2. Implications for practice.......................................... 248

5.2.1. Managerial recommendations.............................................................. 248

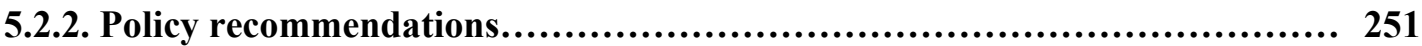

5.3. Limitations........................................................... 252

5.4. Future research..................................................... 254

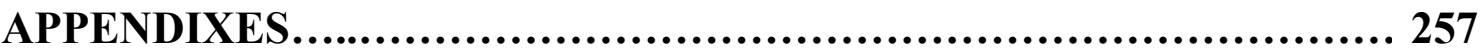

REFERENCES............................................................... 327

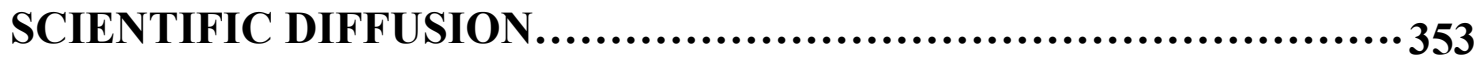




\section{List of Figures}

Figure I. Overview of this doctoral dissertation............................... 9

Figure 1.1 Relevant literatures for this doctoral dissertation........................ 13

Figure 1.2 Mapping out the literature on strategic alliances.......................... 14

Figure 1.3 Perspectives in alliance research.................................. 30

Figure 1.4 Levels of analysis in alliance research............................. 34

Figure 1.5 Illustration of two kinds of relationships in multi-partner alliances........... 40

Figure 1.6 Main points of consensus in dynamic capabilities literature.................. 44

Figure 1.7 Empirical research into dynamic capabilities............................ 49

Figure 1.8 Linking dynamic capabilities and strategic alliances..................... 54

Figure 1.9 Foci of analysis in alliance capabilities research......................... 55

Figure 1.10 Levels of alliance capabilities (and routines) ......................... 61

Figure 1.11 Research objectives and research questions in this dissertation............... 64

Figure 2.1 The Acuisost Consortium: Towards a sustainable aquaculture.............. 84

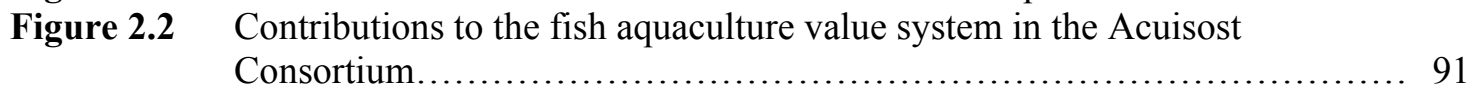

Figure 2.3 The technical timeline versus the real life cycle of the Acuisost Consortium.. 96

Figure 2.4 A longitudinal view on the formation stage of the Acuisost Consortium..... 98

Figure 2.5 Progress of the research (data collection efforts) ....................... 111

Figure 3.1 Position of Study I in this dissertation............................... 126

Figure 3.2 A longitudinal follow-up of partners' cooperative behavior.................. 141

Figure 3.3 Identified patterns in the extremes categories of cooperation................. 145

Figure 3.4 PLS analysis: Structural tested model................................. 157

Figure 3.5 Partitioning analysis (direct competition)............................ 158

Figure 3.6 Partitioning analysis (learning orientation) .............................. 158

Figure 3.7 Partitioning analysis (strategic importance)............................. 159

Figure 4.1 Position of Study II in this dissertation............................. 171

Figure 4.1.1 Co-evolution of psychological contracts and knowledge-sharing routines in ER\&D alliances formed by unfamiliar partners....................... 194

Figure 4.2.1 The option chain for R\&D alliances from a dynamic perspective............ 209

Figure 4.2.2 Main milestones in the CAH-LF relationship.......................... 217

Figure 4.2.3 The CAH-LF alliance within the chain of collective real options............ 219

Figure 4.2.4 Main milestones in the MAR-LF relationship........................ 222

Figure 4.2.5 The MAR-LF alliance within the chain of collective real options............ 224

Figure 5.1 Analytic generalization of findings in this dissertation.................... 239 


\section{List of Tables}

Table 1.1 Topics in alliance research............................................ 25

Table 1.2 Typologies of strategic alliances..................................... 36

Table 1.3 Case-study vs. Large-sample studies: Relative strengths and weaknesses....... 52

Table 1.4 'Dynamic' alliance capabilities and collaborative routines.................... 59

Table 2.1 Characterization of the Acuisost Consortium............................ 76

Table 2.2 Reasons for selection of the Acuisost Consortium as the research setting....... 78

Table 2.3 The CENIT Programme............................................... 81

Table 2.4 Correspondence between technical activities and aquaculture challenges....... 84

Table 2.5 Initial technical structure of the Acuisost Consortium....................... 85

Table 2.6 Organizational structure of the Acuisost Consortium: Figures and roles........ 87

Table 2.7 Evolution of membership in the Acuisost Consortium........................ 90

Table 2.8 The Acuisost Consortium as a portfolio of dyadic R\&D alliances............. 93

Table 2.9 Summary of interviewing actions.................................. 107

Table 2.10 Phases and actions of data collection in the dissertation as a whole............. 114

Table 2.11 Processess of analysis in this dissertation.............................. 115

Table 2.12 Quality of research in this dissertation according to Yin (2003) and Gibbert et al. (2008)......................................................... 120

Table 2.13 Methodology and research design in the empirical studies................... 121

Table $3.1 \quad$ Phases and actions of data collection................................... 139

Table 3.2 Theoretical clustering process............................................. 144 




\title{
Introduction
}

"Acuisost has opened up a wide range of innovation opportunities. It was challenging, especially at the beginning, because a lot of companies and research centers arrived together at our home and we needed to coordinate all of them"

\author{
José Luis Tejedor del Real \\ Dibaq's R\&D Manager and \\ Acuisost Consortium's Coordinator
}

\section{Motivation and aim of the dissertation}

Multi-partner R\&D (MR\&D) alliances constitute powerful strategic devices to deal with competitive challenges, allowing firms to explore and exploit innovation opportunities, by creating multilateral discussion forums and combinations of diverse resources (Doz, Olk, \& Ring, 2000; Mothe \& Quelin, 2001; Lavie, Lechner, \& Singh, 2007). A MR\&D alliance can be defined as 'a collective voluntary inter-organizational agreement that interactively engages multiple partners in multilateral R\&D activities' (Lavie et al., 2007). Given the potential for innovation afforded by MR\&D alliances, governments throughout the world are implementing policy programs encouraging their creation, placing an indisputable emphasis on a particular kind of MR\&D alliances: $R \& D$ consortia. $A R \& D$ consortium is 'a collaborative contractual agreement between a group of organizations to conduct a $R \& D$ project together, sharing its costs and results, and in which specific groups of partners are usually responsible for specific parts of the R\&D project vis-à -vis the entire project' (Sakakibara, 1997; Mothe \& Quelin, 2001). In this line are, for example, those programmes under the spirit of the 'Lisbon Strategy' in European Union (EU) countries, such as the 'Multidisciplinar Research Consortia' programme in United Kingdom, the 'Programme on Strategic Growth Technologies' in Denmark, or the 'National Strategic Consortia for Technical Research Programme (CENIT Programme)' in Spain ${ }^{1}$. As a result, MR\&D alliances are becoming increasingly commonplace in business practice.

However, emphasizing only the important potential advantages of MR\&D alliances does not yield a complete picture: huge complexity in alliance management is at the other side of the coin (Das \& Teng, 2002; Garcia-Canal, Valdés-Llaneza, \& Ariño, 2003; Zeng \& Chen, 2003; Valdés-Llaneza \& García-Canal, 2006). In MR\&D alliances, two different kind of collaborative $R \& D$ relationships take place simultaneously, each of them with different patterns of exchange

\footnotetext{
1 For detailed information of these and other funding programmes in the EU area see http://cordis.europa.eu/erawatch/index.cfm?fuseaction=ri.home (last access: December 2011).
} 
and reciprocity (Das \& Teng, 2002; Thorgren, Wincent, \& Eriksson, 2010). MR\&D alliances entail bilateral exchanges between pairs of partners to accomplish specific parts of the R\&D project, in which one partner's contributions revert to the other partner and vice versa (i.e., partners are expected to reciprocate each other directly). In addition, MR\&D alliances entail generalized multilateral exchanges in which one partner's contributions revert to 'the alliance' and that partner expects a quid pro quo relationship within 'the alliance' (but not necessarily with any specific partner). Therefore, complexity caused by the very nature of $R \& D$ activities is enhanced in multi-partner settings (Sampson, 2005; Mahnke \& Overby, 2008). The existence of multiple and diverse partners that group together and form a collection of dyadic R\&D relationships generates an intricate scenario for interaction (Parkhe, 1991; Lavie et al., 2007). Furthermore, MR\&D alliances are also threatened by the likelihood of disequilibrium in partners' contributions, being often difficult to infer the level of effort made by each individual partner and to detect timely unintended leakages of valuable resources (Das \& Teng, 2002; Sampson, 2005). Therefore, partners in MR\&D alliances make contributions without knowing exactly whether, and if so, how and who will reciprocate such contributions and, what is worse, whether they will be betrayed by any opportunistic partner (Zeng \& Chen, 2003). A straightforward conclusion is that the trade-off between the high value-creation potential that strategic alliances offer and the significant management challenges they impose for the realization of such value (Madhok \& Tallman, 1998) is enhanced in the context of MR\&D alliances.

In this collaborative context, effective realization of value depends on (1) the capability of individual partners to collaborate with other organizations, and (2) the collective capability of partners to collaborate together (Dyer \& Singh, 1998; Madhok \& Tallman, 1998; Anand \& Khanna, 2000). Both kinds of capabilities represent collections of collaborative routines (Zollo, Reuer, \& Singh, 2002) or stable patterns of behavior and interaction in the collaborative context developed out of alliance's experience accumulation, the former at the level of an individual partner and the latter at the inter-organizational level (Simonin, 1997; Dyer \& Nobeoka, 2000).

Given these antecedents, this doctoral dissertation aims to contribute to a more comprehensive view of the collaboration and value-creation dynamics of MR\&D alliances. To accomplish this general research objective, the empirical part of this dissertation focuses on the Acuisost Consortium as its research setting and addresses the creation and evolution of collaborative routines at two different levels of analysis: collaboration among the multiple partner firms of the Acuisost Consortium and dyadic collaboration between firms and research organizations in the consortium. 
The Acuisost Consortium is a real-life R\&D consortium which covered the four-year period from 2007 to 2010 and was formed under a public funding programme (the Spanish CENIT Programme), with the aim of achieving innovation to foster sustainable aquaculture. In addition to Grupo Dibaq, which acted as the lead firm of the consortium, a number of partners firms got involved in the Acuisost Consortium. All these partners were Spanish firms and lacked prior significant alliance experience, although varied in terms of their organizational (e.g., size, age, industry) and membership characteristics, such as financial, managerial, and technical involvement in the consortium, alliance objectives (e.g., exploitation of existing capabilities or exploration of new opportunities) and length of participation (fourteen from the seventeen founder partners keep involved during the whole lifecycle of the consortium; one partner from the three later entrants depart from the consortium before its termination). These firms held the status of partners of the Acuisost Consortium and were thus contractually linked to each other through a consortium agreement. According to the requisites of the CENIT Programme, each partner firm conducted a specific part of the whole R\&D project through contractual links with one or more research organizations (i.e., private and public technological centers and university research groups). Therefore, the two above mentioned kinds of collaborative relationships that characterize MR\&D alliances coexisted in the Acuisost Consortium: (1) multilateral relationships between firms holding the status of partners and providing private funding to the Acuisost Consortium, and (2) dyadic R\&D agreements between those partner firms and research organizations responsible for specific tasks of the $R \& D$ project. In this regard, research organizations acted as technological partners of the consortium firms, even though not holding the status of partners of the Acuisost Consortium as a whole.

Combining in-depth review of existing literature and longitudinal data collection and analysis on the Acuisost Consortium allowed the identification of some real-life phenomena for which proper academic answers are still lacking. These unresolved questions underlay the definition of two more specific research objectives, guiding thus the case-study research efforts of this dissertation (Yin, 2003). The accomplishment of these objectives together is expected to yield a more comprehensive view on the dynamics of collaboration and value-creation of MR\&D alliances, contributing thus to academic research and managerial practice.

The first specific research objective is to improve existing understanding on the creation of organizational collaborative routines when partners lack significant alliance experience. In the pursuit of competitive dynamic economies, public policies are increasingly bringing the innovation opportunities afforded by MR\&D alliances to firms with little alliance experience (e.g., small firms and firms active in industries other than high-tech). As a result, the landscape of MR\&D alliances, traditionally dominated by well-endowed high-tech firms with strong alliance experience, has started to change. As Doz et al. (2000) point out, an important reason of 
this change is the increasingly important role that triggering entities (i.e., government agencies or private consulting firms) are playing in the distribution of these public funds. As occurred in the Acuisost Consortium, triggering entities search a combination of partners that fits the priority conditions established by policy makers to become granted, subsequently engineering the formation of the 'ad-hoc' alliance. Given the increasing emphasis placed by policies on small firms and low-technological industries, this engineered process might result in a group of partners with little or no experience in dyadic alliances and none in multi-partner alliances. A complex collaborative situation thus may emerge: Inexperienced firms join a MR\&D alliance seeking to seize the underlying innovation opportunities, whilst having to learn to collaborate in such a multi-partner setting.

As in any collaborative context, effective realization of value in MR\&D alliances is enabled when partner's actions convey the relational norm of cooperation ${ }^{2}$ (Anderson \& Narus, 1990), implementing a longitudinal adjustment of partners' behaviors to the ongoing needs of each other and of the alliance (Ariño \& De La Torre, 1998; Kumar \& Nti, 1998). Therefore, cooperation is key to achieving success in alliance formation, a critical lifecycle stage in alliances in general (Doz, 1996; Ariño \& De La Torre, 1998) that proves even more complex in the case of MR\&D alliances (Doz et al., 2000). At the partner-level, cooperative behavior can be viewed as a purposefully built collaborative routine (Zollo et al., 2002) which, exercised during the formation stage, positions the firm in the short-term to capture long-term innovation opportunities (Kogut \& Kulatilaka, 2001). However, it could be inferred from received wisdom that inexperienced partners may find difficult to cooperate during the MR\&D alliance formation stage, because they do not know how to deal with tasks like contributing R\&D resources and exchanging knowledge with the multiple partners (Zeng \& Chen, 2003; Sampson, 2005). Interestingly, some inexperienced partners behave more cooperatively than others under the same challenging conditions, as we observed in the Acuisost Consortium. Since existing research has not fully explained the causes of such disequilibrium, the first empirical study of this dissertation is devoted to the in-depth examination of this question. The main conclusion is that whether an inexperienced firm overcomes the suspicious from generalized reciprocity and engages in cooperative behavior in multi-partner settings is mainly a matter of value-creation expectations. These expectations are forged by the interplay of factors at different levels (partner, relationship, and environmental levels), following a dynamic logic. From these

\footnotetext{
${ }^{2}$ Throughout this dissertation, the term cooperation refers to a relational norm governing the alliance, defined as "complementary coordinated actions taken by partners in a collaborative relationship to achieve mutual outcomes or private outcomes with expected reciprocity over time (Anderson \& Narus, 1990: 45). By contrast, collaboration is used as a broader term describing 'the act of being involved to work together in a strategic alliance' (with or without cooperation). Therefore, cooperation entails a positive nuance from a relational standpoint, whereas collaboration has a more neutral meaning in this regard.
} 
findings, a recommendation for inexperienced firms' managers may be to evaluate the possibility of creating strong rules of reciprocity in the MR\&D alliance, before ruling out the building of valuable collaborative routines.

The second specific research objective of the dissertation is to improve existing understanding on the value-creating dynamics of $R \& D$ alliances by focusing on the creation and evolution of inter-organizational collaborative routines. In this regard, existing literature provides an interesting but still unresolved debate about the keys to success in R\&D alliances. Traditionally, two kinds of predictions about success and failure have been put forward by connecting two features of these R\&D alliances: the innovation-seeking orientation of the alliance (exploitation of existing innovation opportunities versus exploration of new ones) and the existence of prior relationships between the partners (unfamiliar versus familiar partners). Some scholars have predicted that unfamiliar partners, especially in explorative domains, are more likely to success than familiar partners in R\&D collaboration: only unfamiliar partners may bring to the alliance novel knowledge resources furnishing thus likelihood of synergies and innovation (Uzzi, 1997; Beckman, Haunschild, \& Phillips, 2004; Goerzen, 2007). Other scholars have predicted that $R \& D$ collaboration is more likely to success when occurs between familiar partners than between unfamiliar partners: only familiar partners may have built, through repeated interactions, the required inter-organizational routines to make the most of the collaboration (Dyer \& Singh, 1998; Rothaermel \& Deeds, 2006; Tiwana, 2008). In this context, some other scholars have tried to bring together both postures (e.g., Hoang \& Rothaermel, 2005; Gulati, Lavie, \& Singh, 2009), recognizing that there is a gap between the value potential afforded by R\&D alliances and the realization of such value, being the latter dependent on the partners' capability to collaborate together (Madhok \& Tallman, 1998). However, empirical evidence provided by these studies is rather ambiguous (e.g., Tiwana, 2008; Phelps, 2010).

The Acuisost Consortium brought the opportunity to observe in practice these collaborative phenomena and thus to make important contributions: many of the agreements between firms and research organizations of the consortium represented explorative $R \& D$ alliances between unfamiliar partners, many others represented either explorative or exploitative $R \& D$ alliances between familiar partners and, as a whole, these alliances showed varying rates of success. Furthermore, such varying rates of success did seem to have to do more with how the partners collaborate than with other alliance conditions (e.g., innovation-seeking orientation and partners' familiarity). Two situations in particular attracted our attention, motivating their empirical examination in this dissertation. First, the explorative alliances between firms and research organizations lacking a prior history of mutual collaboration showed the two extremes: some proved really successful, whereas other dramatically failed. By contrast, those agreements between firms and research organizations with long histories of join collaboration usually 
proved successful, regardless the nature of their technical objectives. Interpreting these real-life observations in light of existent literature (e.g., Dyer \& Singh, 1998; Zollo et al., 2002) we arrived at an important conclusion: existing research has not properly explained the valuecreation dynamics of $\mathrm{R} \& \mathrm{D}$ alliances mainly because it has not looked at the processes of collaboration - i.e., dynamics of alliance evolution understood in terms of inter-partner interaction patterns- (Ring \& Van de Ven, 1994; Salk, 2005). As a consequence, it is still unknown how unfamiliar partners may realize joint value by creating effective routines and how familiar partners, which have effective inter-organizational routines in place, may realize joint value by redeploying such routines in a new collaborative scenario.

The second empirical study of this dissertation (in turn divided into two more specific studies) is devoted to the in-depth examination of these questions. A main conclusion here is that whether unfamiliar partners are able to build adequate routines (and thus realize joint value) in explorative alliances has to do with the tensions between their respective beliefs about the reciprocal obligations in the collaboration. Furthermore, familiar partners assuming their whole collaborative relationship (instead of the focal $R \& D$ alliance) as the locus of collaboration are able to successfully redeploy their routines in both contexts of exploitation and exploration. From these findings, a recommendation for managers may be staring collaboration with new partners by resetting 'the psychological clock'. Assuming that my beliefs about how and why to collaborate are probably not the beliefs of my partner may represent a first step towards alliance success. Moreover, managers may be encouraged to explicitly structure the collaborative relationships of their organizations as long-term portfolios of collective opportunities, promoting the creation of ambidextrous routines. These recommendations may be useful for managing both independent $\mathrm{R} \& \mathrm{D}$ alliances and those included in macro-projects like the Acuisost Consortium, in which the degree of success of the different dyadic R\&D alliances determine the technological success of the MR\&D alliance as a whole.

\section{Structure of the dissertation}

This doctoral dissertation consists of five chapters, as displayed in Figure I. Chapter 1 presents the review of the literatures on strategic alliances and dynamic capabilities, and of the particular field of alliance capabilities and routines, all relevant conceptual bases for this dissertation. In this chapter, research objectives of the dissertation are also explained, in light of some important identified research gaps and the idiosyncrasy of the research setting (i.e., the Acuisost Consortium). Therefore, the final section of Chapter 1 serves simultaneously as a conclusion of the literature review previously presented and as an introduction to the empirical studies of the dissertation. Chapter 2 is devoted to present the research methodology and design of this dissertation and thus, amongst other, contains a detailed description of the Acuisost Consortium. The two following chapters (Chapter 3 and Chapter 4) present the empirical studies through 
which the specific research objectives of the dissertation are addressed. In particular, Chapter 3 and Chapter 4 present, respectively, the first empirical study of the dissertation (Study I) and the second empirical study of the dissertation (Study II, which in turn comprises two more specific studies: Study II.1. and Study II.2.). Finally, Chapter 5 provides concluding remarks, highlighting the main limitations, and implications- for research and managerial and policy practice- of the three empirical studies of the dissertation, as well as some interesting avenues for further work.

Figure I. Overview of this doctoral dissertation

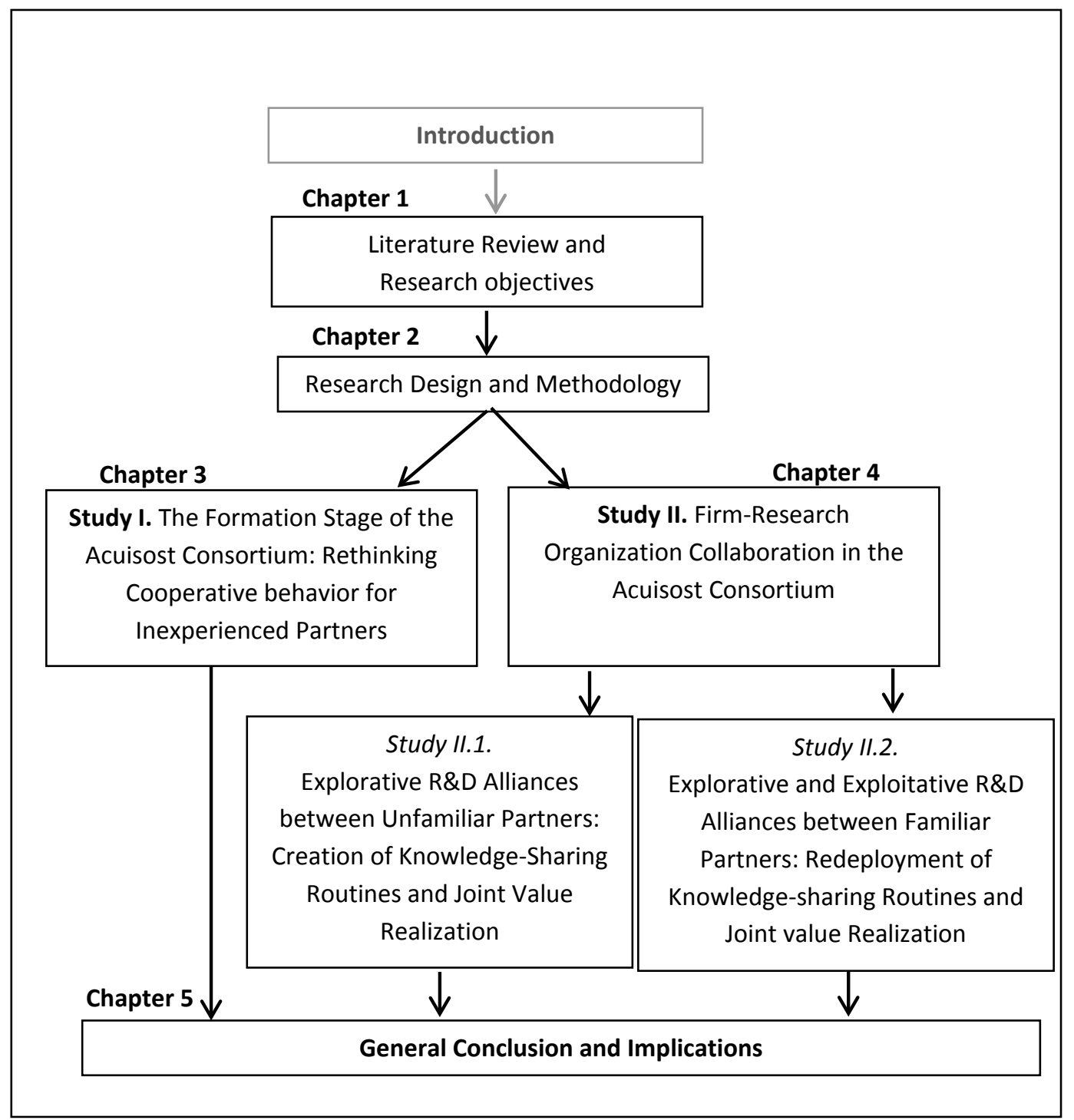



CHAPTER 1. 


\section{Chapter structure}

1.1. Literature Review.................................................. 13

1.1.1. The literature on strategic alliances........................................... 14

1.1.1.1. Theoretical frameworks in alliance research......................... 15

1.1.1.2. Topics in alliance research...................................... 24

1.1.1.3. Perspectives in alliance research.................................... 29

1.1.1.4. Levels of analysis in alliance research.............................. 33

1.1.1.5. Types of strategic alliances........................................ 35

1.1.1.6. Research on multi-partner R\&D alliances............................ 36

1.1.2. The literature on dynamic capabilities..................................... 43

1.1.2.1. Origins and conceptual development of the dynamic capabilities view........ 43

1.1.2.1.1. About the concept of routines: Sources of inertia or flexibility?............. 46

1.1.2.1.2. Creation and evolution of dynamic capabilities: The capability 47 lifecycle and some complementary insights.....................

1.1.2.2. Empirical research into dynamic capabilities............................ 49

1.1.2.3. Main shortcomings in the dynamic capabilities field....................... 52

1.1.3. Linking dynamic capabilities and strategic alliances.............................. 54

1.1.3.1. Alliance capabilities: An overview of existing research.................. 55

1.1.3.2. Research on alliance capabilities: Main contributions and shortcomings...... 57

1.1.3.3. Alliance capabilities as dynamic capabilities: A focus on collaborative

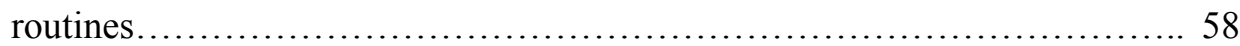

1.1.3.3.1. Collaborative routines: Two levels of analysis.................... 61

1.2. Research objectives of the dissertation............................... 63

1.2.1. Defining research objectives...................................................................6 63

1.2.2. Research gaps, research objectives, and introduction to empirical studies.... 64 
"Each field of inquiry has a forum in which the work of scholars in that field should be presented, and if a candidate's work is accepted in that forum then such work should be deemed scholarly" (Macmillan, 1989: 391).

“... Every one of my research projects started the same way: recognizing that the established theory did not explain a certain phenomenon"

\section{C.K. Prahalad}

The Life's Work of

a Thought Leader (2009) ${ }^{1}$

The first section of this chapter is devoted to present the review of those streams of academic literature which are considered as the most relevant for the development of this dissertation. This literature review allows the identification of relevant gaps in existing research which in combination with some real-life observations from the research setting of this dissertation (i.e., the Acuisost Consortium), motivate the research objectives to be addressed. These research objectives are presented in the second section of the chapter.

\subsection{Literature review}

As previously stated, this dissertation aims to study the collaboration and value-creation dynamics of multi-partner R\&D (MR\&D) alliances by focusing on the creation and evolution of collaborative routines. Collaborative routines in turn are the constituent elements of a particular type of dynamic capabilities: alliance capabilities. Therefore, this dissertation builds on the literatures of strategic alliances and dynamic capabilities, as illustrated in Figure 1.1.

Figure 1.1. Relevant literatures for this doctoral dissertation

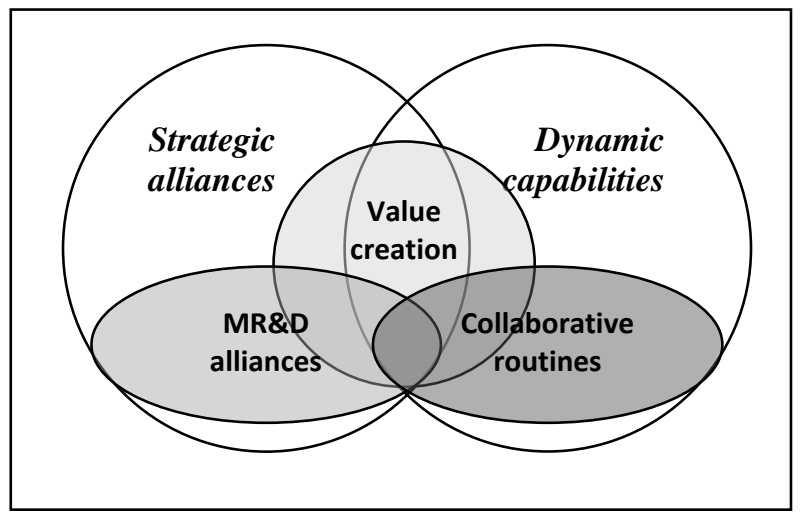

Source: Own elaboration

\footnotetext{
${ }^{1}$ Interview to C.K. Prahalad, available at http://www.strategy-business.com/article/00043 (last access: December 2011).
} 
Accordingly, an overview of existing research into strategic alliances is first provided, making an explicit reference to MR\&D alliances. Subsequently, the dynamic capabilities literature is reviewed, emphasizing the role of routines as their constituent elements and their processes of development. Finally, the field of research into alliance capabilities and collaborative routines is reviewed, justifying the dynamic nature of alliance capabilities.

\subsubsection{The literature on strategic alliances}

Strategic alliances can be broadly defined as "voluntary arrangements between organizations involving exchange, sharing or co-development of products, technologies, or services' (Gulati, 1998: 293) [Appendix I.1 displays other representative definitions]. Strategic alliances represent a ubiquitous phenomenon in the current business landscape and may afford important advantages concerning relevant aspects of organizations' competitive strategy, such as innovation, market entry or the achievement of scope and scale economies (Fuller \& Porter, 1986; Saxton, 1997; Das \& Kumar, 2011). At the same time, strategic alliances entail complex inter-organizational processes (e.g., cooperation and coordination) (Das \& Teng, 1998; Gulati \& Singh, 1998) and, consequently, alliance failure rates remain in high levels (Das \& Kumar, 2011). Their proliferation, together with their important potential advantages and inherent complexity, has led to a growing scholarly interest in alliances, particularly from the 1990s.

The strategic alliances literature can be mapped out according to five non-exclusive criteria (Barringer \& Harrison, 2000; Salk, 2005; Culpan, 2009; Nielsen, 2010), as displayed in Figure 1.2 .

Figure 1.2. Mapping out the literature on strategic alliances

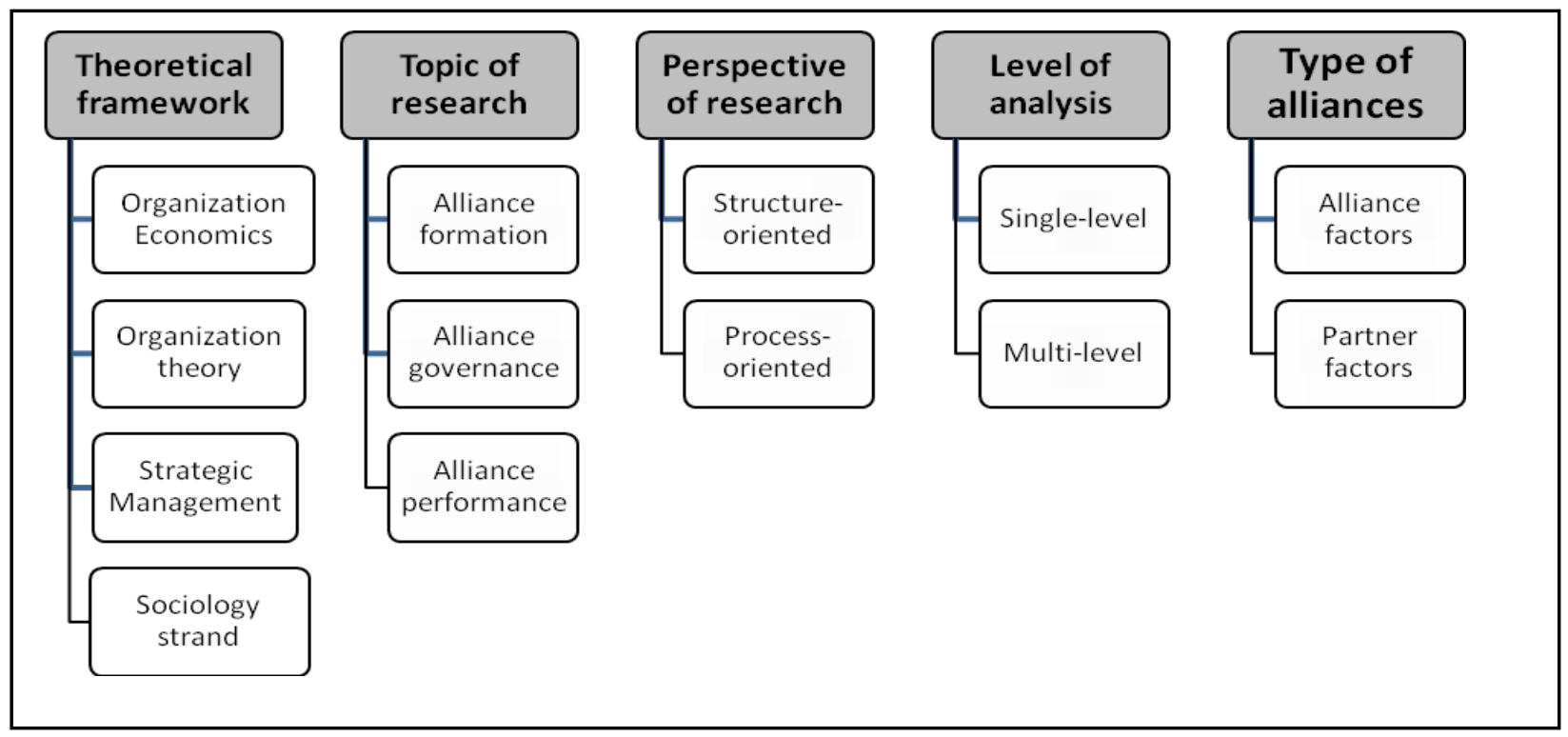

Source: Own elaboration 
In the following, we first review alliance literature ${ }^{2}$ according to these five criteria [(1) by theoretical framework, (2) by topic of research, (3) by perspective of research, (4) by level of analysis, (5) and by type of alliances studied], and then provide a more focused review on multi-partner R\&D alliances ${ }^{3}$.

\subsubsection{Theoretical frameworks in alliance research}

Alliance research has been inspired by a number of theoretical frameworks, which in turn can be grouped into the broader strands of organization economics, organizational theory, strategic management, and sociology ${ }^{4}$ (Kogut, 1988; Das \& Teng, 2000a; Hagedoorn et al., 2000). In the following, we concentrate on those theoretical frameworks that can be considered as the most relevant underpinnings of this dissertation (i.e., transaction cost economics, resource-based view, the relational view, social network theory, social exchange theory, real options reasoning), due to either their prominence in the literature of strategic alliances in general and/or their direct conceptual contribution [See Appendix I.2 for a summary of the contributions of these and other theoretical frameworks to the strategic alliances field].

As stated by some scholars (Das \& Teng, 2000b; Madhok, 2002), the two most prominent theoretical frameworks in alliance research are transaction costs economics (Williamson, 1985) and the resource-based view (Barney, 1991). Within the strand of organization economics, transaction costs economics (TCE) is primarily concerned with the management of transactions in an efficient manner through the form of governance that minimizes transaction costs, under the assumption of opportunism-'self-interest seeking with guile'(Williamson, 1985). The central question that sets the agenda for TCE (i.e., 'why firms exist') translates into the more applied question of 'why alliances exist' in the field of strategic alliances (Madhok, 2002). TCE conceives strategic alliances as hybrid forms lying between the polar forms of market (i.e., arm's-length transactions) and hierarchy (i.e., the firm boundaries) (Williamson, 1991). Under this view, the traditional make-or-buy decision may be understood in terms of the make-ally-buy trichotomy (Villalonga \& McGahan, 2005). Since alliances, by

\footnotetext{
${ }^{2}$ For simplification purposes, we confine our literature review to what Koza and Lewin (1998) label as 'modern research on strategic alliances', dated by these authors to the publication of the Contractor and Lorange's (1988) influential volume.

${ }^{3}$ As Hagedoorn, Link and Vonortas (2000: 570) stress "any literature taxonomy is partially an arbitrary exercise" and the five-criterion taxonomy presented here is no exception.

${ }^{4}$ For different literature reviews on strategic alliances according to the theoretical framework adopted, see, for example, Kogut (1988), Gray and Wood (1991), Das and Teng (2000a), García and Medina (1998), Barringer and Harrison (2000), Hagedoorn, Link and Vonortas (2000), or Culpan (2009). For example, Hagedoorn et al. (2000) identify three broad categories for literature of research partnerships: transaction costs economics, strategic management, and industrial organizational theory. Other like García and Medina (1998) also consider the category of marketing literature (e.g., Camarero-Izquierdo \& Gutiérrez-Cillán, 2004).
} 
definition, combine elements of the two poles of the market-hierarchy continuum, firms would engage in alliances when the transaction costs associated with the exchange are intermediate (i.e., discourage arm's-length transactions) but are not high enough to justify vertical integration (Williamson, 1985; Gulati, 1995). Hennart (1988) and Kogut (Kogut, 1988) state that alliances minimize transaction costs under two basic circumstances: (a) integration of the activity implies the sacrifice of scale economies and (b) the transaction involves inter-organizational transfer of tacit knowledge.

TCE has shown explanatory power concerning important alliance-related questions such as formation, governance and make-ally-or-buy decisions (Barringer \& Harrison, 2000; 2000b; Das \& Teng, 2000a). However, Madhok (1996) argues that a complete theory of economic organization must address the dynamic side of costs and benefits associated to organizational forms, while TCE-based analysis remains static. Therefore, TCE fails to capture the dynamics of collaboration over time (Gulati, 1998: 86): it ignores the possibility of repeated alliances [...] This omission is significant because experience can engender trust ${ }^{5}$, and trust can limit the transaction costs associated with their future alliances". Indeed, assuming that transactions are not always discrete events, TCE alliance scholars have revisited the traditional transaction costs arguments by incorporating the trust-opportunism binomial (González-Benito, SuárezGonzalez, \& Spring, 2000; Goerzen, 2007). For Barringer and Harrison (2000) and Das and Teng (2000a), another criticism is that the cost-minimizing and efficiency alliance rationale offered by TCE may not be so important for actual decision makers. After all, given the availability of correction mechanisms, problems of opportunism in alliances may not be as problematic as suggested (Madhok, 1996).

Within the strand of strategic management, the resource-based view $(\mathbf{R B V})^{6}$ lies in two basic assumptions about heterogeneity of resources (and capabilities) ${ }^{7}$ controlled by firms

\footnotetext{
${ }^{5}$ Madhok (1995) defines trust in alliances as the perceived likelihood of the other partner not behaving in a self-interested manner. He identifies two interrelated components of trust: the structural component (which concerns complementarity of partners' resources) and the social component (which concerns the quality of the relationship and long-term equity perceptions)(Madhok, 1995).

${ }^{6}$ Notice that, following other management scholars (e.g., Makadok, 2001; Helfat \& Peteraf, 2003) the label RBV is used as an umbrella term for the different strands of this framework, including thus the dynamic capabilities (Teece et al., 1997) and the knowledge-based views (Grant, 1996). Due to its importance for this doctoral dissertation, section 1.1.2 of this chapter reviews in detail the dynamic capabilities view.

${ }^{7}$ Barney (1991: 101), in line with Wernefelt (1984), defines broadly resources as "all assets, capabilities, organizational processes, firm attributes, information, knowledge, etc. controlled by a firm that enable the firm to conceive of and implement strategies that improve its efficiency and effectiveness". Thereafter, Amit and Schoemaker (1993) make a clear distinction between resources and capabilities that has been widely adopted in the literature since. In this line, Winter (2003: 991) define an organizational capability as " a high-level routine (or collection of routines) that, together with its implementing input flows,
} 
(Wernerfelt, 1984; Barney, 1991): (1) resources are heterogeneously distributed across firms within an industry (i.e., heterogeneity exists), and (2) these resources are firm specific or imperfectly mobile (i.e., heterogeneity persists over time). These assumptions underpin a particularly powerful rationale for entering into strategic alliances (Eisenhardt \& Schoonhoven, 1996; Das \& Teng, 2000b): alliances are conceived as strategic instruments used by organizations to create value by means of the synergies that emerge when partners' bundles of complementary resources are suitably merged. After all, "firms attempt to find the optimal resource boundary through which the value of their resources is better realized than through other resource combinations" (Das \& Teng, 2000b: 36). In the collaborative context, value refers to the earning of rents over and above what could have been achieved in the absence of the collaboration (Madhok \& Tallman, 1998). From the above general theoretical insights, RBV alliance scholars have made more explicitly or implicitly a conceptual distinction between two different kinds of alliance-related sources of competitive advantages (Ireland, Hitt, \& Vaidyanath, 2002).

First, alliances are considered themselves sources of competitive advantage insofar they may provide (access to) ${ }^{8}$ VRIN resources the organization lacks and probably cannot develop in isolation (Ireland et al., 2002). Barney (1991) argues that those resources which are controlled by the firm and fulfill the so-called VRIN conditions (i.e., valuable, rare, imperfectly imitable, and non-substitutable) can be source of sustained competitive advantage. Valuable resources enable firms to improve efficiency and effectiveness by exploiting opportunities and/or neutralizing threats; rareness, inimitability and non-substitutability ensure the uniqueness of resources, providing thus a foundation for competitive advantage. More specifically, Das and Teng (2000b) point out two different resource-related motives for entering strategic alliances: (a) gaining access to additional resources possessed by others (which has to do with creating competitive advantage), and (b) retaining one's own resources (which has more to do with preserving competitive advantage). Furthermore, RBV alliance scholars have emphasized the role of organizational resources as sources of alliance opportunities. According to this line of reasoning, Eisenhardt and Schoonhoven (1996: 137) view alliances as "cooperative relationships driven by logic of strategic resource needs and social resource opportunities". The

confers upon an organization's management a set of decision options for producing significant outputs of a particular type".

${ }^{8}$ Grant and Baden-Fuller (2004) argue that knowledge-based view of alliance formation has been inhibited by a simplistic view of alliances as vehicles for organizational learning (i.e., it is assumed that strategic alliances are motivated by firms' desire to acquire knowledge from one another), proposing that the primary advantage of alliances is in accessing rather than acquiring knowledge. See also EscribáEsteve and Urra-Urbieta (2002) for a conceptual knowledge-based analysis of strategic alliances. 
logic here is that the number of alliance opportunities available for an organization increases with the strength of its resource endowment, either directly by enhancing its attractiveness as a 'partner of choice' (i.e., resources themselves are attractive) or indirectly (e.g., organizations with broader networks of contacts have more information about alliance opportunities) (Ahuja, 2000).

Second, RBV alliance scholars akin the primary RBV theoretical question of 'why firms differ' (Madhok, 2002) to the notion of alliance capabilities ${ }^{9}$ (e.g., Kale \& Singh, 2007). Research widely recognizes that only a few alliances prove really successful, since alliances are riddle with risk and complexity (Das \& Teng, 1998). From a RBV, success heterogeneity across alliances have been attributed to the fact that firms systematically differ in their ability to face such alliance challenges (Anand \& Khanna, 2000). More successful firms at forming and managing alliances (and thus at extracting value from them) are presumed to have alliance capabilities. Alliance capability represents therefore the second source of alliance-related competitive advantage (Ireland et al., 2002): (a) only a few firms hold such kind of capabilities and (b) these capabilities allow them to take advantage of the value-creation opportunities afforded by alliances (Simonin, 1997; Dyer \& Singh, 1998; De Man et al., 2010).

Although the RBV is considered one of the most influential frameworks in the field of strategic alliances (Das \& Teng, 2000b), Lavie (2006) provides a particularly powerful criticism structured around two main points. First, the fundamental proprietary assumption of the RBV (i.e., resources that confer competitive advantage must be confined by the organizational boundaries) is inconsistent with the nature of the phenomenon of inter-organizational collaboration. Empirical evidence strongly supports the importance of network resources (Gulati, 1999) transferred via inter-organizational interactions for firm's competitive strategy and performance. For example, Saxton (1997) finds that firms benefited from their alliance partners' reputation. RBV alliance scholars have been forced to implicitly relax the traditional RBV proprietary assumption to explain the value-creation properties of alliances, which is not consistent with the RBV itself. Second, RBV alliance scholars usually retain the RBV level of analysis (i.e., individual organization as alliance partner), overlooking the part of the collaborative process associated to strategic alliances that take place between the individual partners, thus at the inter-organizational level of analysis.

Building upon TCE and the RVB, the relational view (RV) of alliances (Dyer \& Singh, 1998), elaborates on issues of joint value creation, placing the locus of competitive advantage at the inter-organizational level (Lavie, 2006). The core premises of the RV are (a) alliances generate

\footnotetext{
${ }^{9}$ Section 1.1.2 elaborates further on the concept of alliance capabilities and related research.
} 
competitive advantage only as the relationship move away from the attributes of pure market transactions, and (b) critical resources may span firm boundaries, and may be embedded in inter-organizational routines and processes (Dyer \& Singh, 1998; Mesquita, Anand, \& Brush, 2008). Central in the RV is the notion of relational rents, defined as 'supernormal profits jointly generated in an exchange relationship that cannot be generated by either firm in isolation and can only be created through the joint idiosyncratic contributions of the specific alliance partners' (Dyer \& Singh, 1998: 662). According to these authors, there are four potential sources of relational rents: (1) long-term relationship-specific investments ('facilitate interpartner cooperation, coordination, and commitment and by analogy to the situation that 'firms must do something specialized or unique to gain competitive advantage'), (2) knowledgesharing routines ('regular patterns of inter-organizational interactions that permit the transfer, recombination and/or creation of specialized knowledge') (e.g., Dyer \& Hatch, 2006), (3) complementary resources ('alliance partners' distinctive resources that collectively generate greater rents than the sum of those obtained from the individual endowments of each partner'), and (4) effective governance of the relationship (specially self-enforcing or trust-based modes that reduce transaction costs and increase partners' willingness to engage in value-creation initiatives).

Although Dyer and Singh (1998) are who formally developed the RV, important antecedents are the works of Zajac and Olsen (1993), Dyer (1997) and Madhok and Tallman (1998). Zajac and Olsen (1993) propose a transactional value, rather than transaction cost, perspective for examining inter-organizational relationships, relying on the principle of joint value maximization (instead of transaction cost minimization) and emphasizing the processes by which exchange partners create and claim value (instead of structural features of interorganizational exchange). Dyer's (1997) in-depth study of the automotive industry concludes that (a) reciprocal investments in relationship-specific assets transform contractual-oriented interaction between automakers and suppliers into more committed and mutually oriented relationships and (b) this shift in the nature of the relationship between partners enhance the value achieved in the automaker-suppliers relationships, by enhancing resource synergies and mitigating transaction costs. Finally, Madhok and Tallman (1998) developed a 'perspective of value' for inter-organizational collaborative relationships integrating arguments from both the RBV and the TCE. Alliances are formed under the expectations of resource synergies, yet alliance partners often fail to identify the transaction-specific investments required to actually attain these synergies. From these arguments, these authors introduce an important conceptual distinction (Madhok \& Tallman, 1998: 328) between "the potential value attainable through an alliance and the realization of such value": the former aspect concerns the "theoretical synergies 
arising from the ideal combination of complementary resources", whereas the latter aspect "reflects the realities on the ground and has more to do with the effectiveness of the actual management of the alliance".

The RV of alliances represents "an excellent attempt to cover an area of strategic research previously neglected: a focus on inter-organizational relations in the study of the competitive factors of firms" (Molina, 1999). However, Molina (1999) concerns about the possibilities of applying the RV to the realities of business beyond networks formed in a 'natural' way by firms sharing the same geographic context. Moreover, he argues that the shift from the individual firm to inter-organizational relationship proposed by the RV is indeed an extension of the RBV principles [in this regard, see the extension of the RBV for inter-connected firms developed by Lavie (2006)]. Dyer and Singh reject this argument (see debate in Molina, 1999): the RV offers an independent explanation for how firms earn (relational) rents. Mesquita et al. (2008) offer empirical proofs of the distinction between the two frameworks: RBV explains how strategic alliances may enhance organizational redeployable performance, whereas the RV informs about how strategic alliances enhance relational performance ${ }^{10}$.

Rooted in sociology, social network theory (Granovetter, 1973) and social exchange theory (Blau, 1964), are other two important theoretical frameworks for studying strategic alliances. Pivotal in social network theory (SNT) is the notion of social embeddedness: economic action in embedded in social context, hence, economic actors are embedded in networks of interconnected social relationships (Granovetter, 1985). Consequently, social context shapes economic actors' behaviors and their results, acting a source of both opportunities and constraints (Gulati, 1998). Networks (or collection of ties between economic actors) represent resource access (including social capital ${ }^{11}$ and inter-organizational trust) as well as sources of

\footnotetext{
${ }^{10}$ Mesquita et al. (2008) identify two basic components of value realization in alliances at the firm-level: the redeployable performance (average performance that a firm achieves by redeploying its collaborative routines across its alliance portfolio) and the relational performance (performance achieved by a firm with a specific partner). Concerning this distinction a clarification should be made. As defined by Mesquita et al. (2008), the redeployable component refers to the firm-level of analysis. Broadly speaking, redeployment is the process by which a firm transfers its existing resources and capabilities to a new strategic scenario (Anand \& Singh, 1997; Helfat \& Peteraf, 2003). Notice that in Study II.2 this concept will be extended to the inter-organizational level (Capron \& Mitchell, 1998), defining redeployment of familiar partners' routines as the process by which they jointly transfer their existing joint routines into a new focal alliance.

${ }^{11}$ Nahapiet and Ghosal (1998: 243) define social capital as "the sum of the actual and potential resources embedded within, available through, and derived from the network of relationships possessed by an individual or social unit. Social capital thus comprises both the network and the assets that may be mobilized through that network". Therefore, social capital may take the form of social status or reputation (Ahuja, 2000). Martín-de-Castro, Navas-López, and López-Sáez (2006: 362) define corporate reputation "as the collective representation of actions and outcomes of the past and present of the organization that
} 
control and power (Tsai \& Ghoshal, 1998; Gulati et al., 2000). Therefore, SNT makes three considerations: (a) strategic alliances are collections of ties, (b) alliance formation is a consequence of firms' social embeddedness, and (c) social context is an important determinant of partners' behaviors in alliances. In this regard, it is important the notion of network resources or external resources embedded in the firm's alliance network that provide strategic opportunities and affect firm behavior and value (Gulati, 1999; Lavie, 2006).

Building on the center-stage notion of embeddedness (Granovetter, 1985), two perspectives have been applied in SNT research into strategic alliances: the structural embeddedness perspective and relational embeddedness perspective (Nahapiet \& Ghoshal, 1998; Moran, 2005; Zaheer, Gözübüyük, \& Milanov, 2010). Structural embeddedness refers to the 'impersonal' configuration of network ties between firms (Nahapiet \& Ghoshal, 1998). Accordingly, scholars in this tradition have focused on configuration properties like network centrality, density, and closure (i.e., structural holes), characterizing ties between partners in accordance (e.g., direct, indirect, bridge ties). Relational embeddedness refers to the 'personal' relationships firms have developed with each other through a history of prior interactions (Nahapiet \& Ghoshal, 1998). The basic distinction here is between weak and strong ties, and salient is the associated notion of tie strength (Lavie, 2006). Both research streams on embeddedness have offered important insights, advancing our understanding of the strategic alliances phenomenon. According to Gulati (1998), adopting a network philosophy can benefit not only the examination of alliance formation phenomenon but also other important aspects like the choice of alliance governance structure, the dynamic evolution of alliances, the performance of alliances, as well as the performance implications for alliance partner firms. More specifically, Lavie (2006) argues that the tie strength notion paves the way to study other relational properties of alliance networks like cooperation, conflict, trust, and communication. In addition to socially contextualize strategic alliances, SNT offers a great potential for integration with other theoretical frameworks, hence enabling a more comprehensive understanding of collaborative endeavours (Gulati, 1998; Lavie, 2006). As Zaheer et al. (2010) stress, much of the work developed in the strategic alliances field under SNT lens borrows elements from other theoretical frameworks (e.g., RBV).

Despite the above virtues of SNT for studying alliances, Moran (2005) points that a basic shortcoming of SNT research into strategic alliances is that the structural and the relational embeddedness perspectives remain unconnected. Furthermore, Zaheer et al. (2010) highlight

describe its capability to obtain valuable outcomes for different stakeholders" and that is "the result of the process of 'social legitimization' of the organization". 
that the integrative trend in the field has result in lack of coherence and parsimony: contributors borrowing elements from other frameworks have often overlooked the core SNT assumptions.

For its part, social exchange theory (SET) originates to study social behavior at the individual level, defining social exchanges as "voluntary actions of individuals that are motivated by the returns they are expected to bring and typically in fact bring from others" (Blau, 1964: 91), highlighting their differences respect to economic exchanges (Das \& Teng, 2002; Cropanzano \& Mitchell, 2005). Unlike economic exchanges, (a) social exchanges may or may not involve extrinsic benefits with objective economic value, and (b) these benefits are often not contracted explicitly but assumed in the psychological contract ${ }^{12}$ of each exchange party. Therefore, social exchange relationships involve a series of interdependent interactions that generate obligations between the parties, these interactions entailing "an ongoing reciprocal process" in which actions are "contingent on rewarding reactions from others" (Blau, 1964: 6). SET has been extended into the study of strategic alliances (Young-Ybarra \& Wiersema, 1999; Das \& Teng, 2002; Muthusamy \& White, 2005). Under this view, alliances are conceived as voluntary social exchange relationships motivated by the returns they are expected to bring over time on the basis of reciprocity (Das \& Teng, 2002). SET alliance scholars recognize a dual link between the nature of the exchange relationship (characterized mainly in the form of relational norms) and the process of social exchange between partners (characterized mainly in the form of 'relational outputs'). On the one hand, relational norms (e.g., reciprocity, cooperation, solidarity, flexibility, information exchange) affect the process of exchange between partners by generating a normative definition of partners' interactions (or 'behavioral guidelines') that govern the relationship (Anderson \& Narus, 1990; Heide \& John, 1992)()()(). On the other, interdependent exchange interactions between partners evolve over time into collaborative relationships characterized by mutual trust and commitment (Muthusamy \& White, 2005).

SET provides important insights by recognizing the importance of partners' expectations about reciprocity and non-economic benefits for alliance formation, the importance of the relational side of the collaborative process for alliance management and performance, as well as the necessity to take into account partners' psychological contracts in addition to formal alliance contracts (Ring \& Van de Ven, 1994). However, research into strategic alliances from a SET suffers from several criticisms. From a theoretical standpoint, it has been criticized for (a) holding an oversocialized (overenthusiastic) view of human action prescribing cooperative and trustworthy partners' behaviors and (b) emphasizing the ongoing relational processes' quality as

\footnotetext{
${ }^{12}$ Broadly defined, a psychological contract is an individual's belief in mutual obligations between that person and another party such an employer, arising out of the interpretation of promises (Rousseau \& Tijoriwala, 1998: 679-681).
} 
the driver of alliance performance (overlooking other structural determinants) (Faems, Janssens, Madhok, \& Van Looy, 2008). From an empirical standpoint, "very few studies directly examine exchange processes- or the 'black box' of social exchange" taking place in collaborative interorganizational relationships (Cropanzano \& Mitchell, 2005).

Drawing upon the option theory, real options reasoning (ROR) is a conceptual approach that exploits the analogy between financial options and real options ${ }^{13}$ for valuating corporate investments and strategies in uncertain contexts (Myers, 1984; McGrath \& Nerkar, 2004). ROR holds two main assumptions. First, the rent-creating potential of a firm is akin not only to the rents that are expected to be generated over time by already deployed resources but also to any subsequent redeployment the firm might make, which in turn derived from prior resource investments (Bowman \& Hurry, 1993; De Andrés-Alonso, Azofra-Palenzuela, \& De la FuenteHerrero, 2006). Second, the optimal investment strategy allows the firm to maximize the value of its portfolio of present and future opportunities. Accordingly, this approach conceive alliances as real options or investment platforms which confer upon the partner firms the potential to take advantage of future strategic opportunities, without involving one-step commitments of resources (Kogut, 1991; Kogut \& Kulatilaka, 2001a). Thus, ROR prescribes that alliances are particularly valuable tools to maintain flexibility in highly uncertain contexts (Kogut \& Kulatilaka, 1994).

A number of papers have applied ROR in the field of strategic alliances, with an indisputable emphasis on joint ventures (Kogut, 1991; Tong, Reuer, \& Peng, 2008; Kumar, 2010). The alliance formation phenomenon has been framed in terms of real options acquisition. Some studies have examined under which industry- and firm-level conditions alliances are formed (Estrada, de la Fuente-Herrero, \& Martín-Cruz, 2010), whereas other studies have adopted a strategic choice perspective (i.e., alliances vs. other organizational forms). For instance, Folta (1998) finds, amongst other, that equity alliances are preferred to acquisitions in uncertainty technological fields which offer extensive growth opportunities, arguing that the cost of commitment compensate for the benefits of hierarchical governance. Applying ROR, scholars have examined the alliance termination decision in terms of option exercise/abandoning (Kumar, 2010). A particular situation extensively studied is the buyout of the partner stake in joint ventures (e.g., Reuer \& Tong, 2005). Also, some recent empirical developments have applied ROR in the study of alliance portfolios (e.g., Vassolo, Anand, \& Folta, 2004) and to

\footnotetext{
${ }^{13}$ In the words of Kogut and Kulatilaka (2001: 745) "a real option is the investment in physical assets, human competence, and organizational capabilities that provide the opportunity to respond to future contingent events".
} 
empirically test the ROR's central premise that alliances provide firms valuable growth options (Tong et al., 2008).

In addition to the plausible conceptualization of alliances as investment platforms in opportunities, the appeal of this approach lies in its dynamic perspective (McGrath \& Nerkar, 2004). Therefore, ROR offers conceptual foundations for alliance process-oriented research, supporting the study of the whole alliance process. However, existing ROR research in alliances is dominated by the structural perspective, and thus tends to ignore the collaboration processes mediating between alliance formation and termination (Faems \& Madhok, 2009). As Vassolo et al. (2004) state, ROR represents an emerging strand of thinking in the strategic alliances field.

Once reviewed the most relevant theoretical frameworks, it is important to mention two characteristics of alliance research identified by reviewing the literature. First, a large portion of studies rely on multi-theoretical frameworks to address specific alliance-related questions, either explicitly combining several frameworks (e.g., Parkhe, 1993; Young-Ybarra \& Wiersema, 1999) or testing the predictive power of different theories -usually in the form of competing hypotheses- (e.g., Colombo, 2003; Yasuda, 2005; Goerzen, 2007). Second, alliance research often combines insights from multiple frameworks without explicitly pointing them out. Studies in this trend may provide a more comprehensive understanding of the particular collaborative phenomenon under study but may raise concerns about the conceptual solidness of their contributions (besides making complex their classification according to the theoretical framework criterion).

\subsubsection{Topics in alliance research}

According to this criterion, three main streams of research can be identified in alliance literature, each of them covering different research questions (see Table 1.1.): the stream on alliance formation, the stream on alliance governance, and the stream on alliance performance (Kale, 1999; Das \& Teng, 2000b; Ireland et al., 2002). In the following, these streams of research are reviewed.

Alliance formation constitutes a prolific research stream covering two broad kinds of research questions: 'Why alliances are formed?' and 'How alliances are formed?' A large number of studies, usually from a structure-oriented perspective (see section 1.1.1.3.), have focused on explaining why strategic alliances are formed and/or under which circumstances alliance formation occurs. This research has provided a well-developed understating into the phenomenon of alliance formation. Empirical studies in this tradition tend to have a marked link with a particular theoretical framework and, accordingly, closely follow a particular alliance 
rationale and thus testing the predictive power of the chosen framework [See, for example, Hennart (Hennart, 1988) for a TCE analysis of joint venture formation and Eisenhardt and Schoonhoven (1996) for a RBV of alliance formation]. There are also in this tradition other empirical studies combining/comparing alliance rationale aspects of different frameworks (e.g., Ahuja, 2000). These broad 'why' research questions have given way to other more specific research questions addressing under which conditions certain alliance formation decisions are taken (see, for example, Geringer, 1991; Beckman et al., 2004; Li et al., 2008 for partner selection), analysing the propensity of certain organizations/organizations in certain contexts to form strategic alliances (see, for example, Bayona et al., 2001; Fritsch \& Lukas, 2001; or Sánchez-González, González-Álvarez, \& Nieto, 2009 for rationale of R\&D collaboration with different agents) or examining under which conditions strategic alliances are preferred over other organizational forms like in-house development or acquisition (Villalonga \& McGahan, 2005; Wang \& Zajac, 2007).

Table 1.1. Topics in alliance research

\begin{tabular}{|c|c|c|}
\hline Topic & Typical research questions & Illustrative studies \\
\hline \multirow{2}{*}{$\begin{array}{l}\text { Alliance } \\
\text { formation }\end{array}$} & Why are alliances formed? & $\begin{array}{l}\text { (Hennart, 1988; Eisenhardt \& Schoonhoven, } \\
\text { 1996; Ahuja, 2000; Fritsch \& Lukas, 2001; } \\
\text { Villalonga \& McGahan, 2005; Sánchez- } \\
\text { González, González-Álvarez, \& Nieto, 2009) }\end{array}$ \\
\hline & How are alliances formed? & $\begin{array}{l}\text { (Doz et al., 2000; Hagedoorn, 2006; Eisner et } \\
\text { al., 2009; Stephens, Fulk, \& Monge, 2009; } \\
\text { Ariño \& Ring, 2010; Loohuis \& Groen, 2011) }\end{array}$ \\
\hline \multirow{2}{*}{$\begin{array}{l}\text { Alliance } \\
\text { governance }\end{array}$} & $\begin{array}{l}\text { Which factors explain the choice } \\
\text { of alliance governance form? }\end{array}$ & $\begin{array}{l}\text { (Gulati, 1995; Colombo, 2003; Comino, } \\
\text { Mariel, \& Sandonis, 2007; García-Canal, } \\
\text { Valdés-LLaneza, \& Sánchez-Llordá, 2008) }\end{array}$ \\
\hline & $\begin{array}{l}\text { How is the relationship } \\
\text { governed/managed? }\end{array}$ & $\begin{array}{l}\text { (Oxley, 1997; Kumar \& Nti, 1998; Young- } \\
\text { Ybarra \& Wiersema, 1999; Ariño, 2001; } \\
\text { Poppo \& Zenger, 2002; Faems et al., 2008) }\end{array}$ \\
\hline \multirow{3}{*}{$\begin{array}{l}\text { Alliance } \\
\text { performance }\end{array}$} & $\begin{array}{l}\text { How could alliance performance } \\
\text { be conceptualized and measured? }\end{array}$ & $\begin{array}{l}\text { (Geringer \& Hebert, 1991; Glaister \& } \\
\text { Buckley, 1998; Ariño, 2003; Lunnan \& } \\
\text { Haugland, 2008) }\end{array}$ \\
\hline & $\begin{array}{l}\text { Which factors determine } \\
\text { success/failure of alliances? }\end{array}$ & $\begin{array}{l}\text { (Saxton, 1997; Ariño \& De La Torre, 1998; } \\
\text { Madhok \& Tallman, 1998; Park \& Ungson, } \\
\text { 2001; García-Canal et al., 2003; Mora- } \\
\text { Valentín et al., 2004; Lunnan \& Haugland, } \\
\text { 2008; Mahnke \& Overby, 2008; Schreiner, } \\
\text { Kale, \& Corsten, 2009) }\end{array}$ \\
\hline & $\begin{array}{l}\text { Which are the performance } \\
\text { implications of alliances? }\end{array}$ & $\begin{array}{l}\text { (Anand \& Khanna, 2000; Kale \& Singh, } \\
\text { 2007; Lavie, 2007; Lavie et al., 2007; } \\
\text { Sampson, 2007; Schreiner et al., 2009) }\end{array}$ \\
\hline
\end{tabular}

Source: own elaboration 
Empirical studies addressing how alliances are formed, usually adopting case-study designs (see Doz et al. (2000) for an exception) have developed a more fine-grained understanding of the alliance formation processes and decisions (i.e., adopting a process-oriented, see section 1.1.1.3). Their detailed narratives often provide insights into the 'why' side of alliance formation. For example, the case study of Ariño and Ring (2010) describes in the detail a failed attempt to form an international joint venture, focusing on the role of perceived fairness as the driver of the partners' assessments which in turn determine their decision on whether or not to form it. In the context of R\&D consortia, for example (see also section 1.1.1.6.), Stephens et al. (2009) study a three-partner 'cupid alliances' (i.e., formed between 'target' firms at the behest of a third 'cupid' organization on which target firms are resource dependent). These authors find that lack of inter-partner trust and some constraints from the cupid organization may affect partners' motivation to build a successful relationship, making collaboration complex and uncertain.

Within the stream of research into alliance governance and management two broad groups of studies in turn can be identified (Faems, 2006): (1) studies examining the governance of alliances in terms of the choice for a specific governance structure, and (2) studies looking at the governance of alliances in terms of how the inter-organizational relationship between partners is managed. Research into alliance governance choice is mainly inspired by $\mathrm{TCE}^{14}$, extending the so-called make-or-by decision into the equity-or-nonequity alliance decision (Colombo, 2003; Villalonga \& McGahan, 2005; García-Canal et al., 2008). In particular, the choice between contractual agreements and equity joint ventures has attracted a lot of scholarly attention. The main conclusion here is that the greater the risk of partner opportunism and uncertainty the more likely is the alliance to be structured as an equity joint venture. For example, Garcia-Canal et al. (2008) found that Spanish firms tend to adopt the form of joint venture for the agreement when it involves unilateral technology transfer or co-development in order to prevent partners' opportunism. Colombo (2003: 1214) argues that "the need to cope with greater appropriability hazards makes the use of low-flexibility forms more likely". Past research has traditionally associated previous collaborations between partners to the choice of non-equity alliances, assuming that prior ties foster trust, thus, reduce perceived opportunism (e.g., Gulati, 1995).

Within research into how the inter-organizational relationship among partners is governed, two different perspectives in turn have been identified (Faems et al., 2008): (a) the contractual perspective and (b) the relational perspective. The contractual perspective on alliance governance takes the formal alliance contract as the key governance instrument in alliances

${ }^{14}$ See Das and Teng (2000b) for a conceptual discussion of alliance governance choice from a RBV and Comino, Mariel and Sandonis (2007) for an empirical application of TCE, ROR and RBV. 
(Oxley, 1997). Closely to TCE arguments, studies in this tradition maintain that complex alliance contracts mitigate the perceived risk of opportunistic behaviors and facilitated coordination in alliances, for different reasons. Complex contracts facilitate detection and curbing of opportunistic behaviors by defining what is allowed and what is out-limits, establishing the associated formal sanctions, as well as structures and standards for joint action [see Reuer and Ariño (2007) for a discussion of alliance contract complexity]. Alliance contract determines also alliance scope, which is viewed as an additional mechanism to control the threat of opportunism (Oxley \& Sampson, 2004). Within the relational perspective on alliance governance some studies have clearly reacting to the previous contractual perspective (Poppo \& Zenger, 2002), relying mainly on arguments from both the RV of alliances (Dyer \& Singh, 1998) and SET (Blau, 1964). These studies focus on relational processes within on-going interorganizational relationships and emphasize the role of trust and commitment ['the soft side of alliance management' (Cullen, Jhonson \& Sakano, 2000)] in safeguarding and coordinating alliance activity. For example, Faems et al. (Faems et al., 2008) adopt a process-oriented perspective to explain how structural and relational aspects of alliance governance (i.e., contracts and trust) interact over time, both within and between transactions. Cullen, Johnson and Sakano (1995) examine antecedents of partners' commitment in international joint ventures. Ariño (2001) examines how a firm's perception of non-cooperative behavior exerted by its partner impacts its own cooperative behavior, finding that negative perceptions have greater impact in the case of perceived partners' omission of obligations. From a broader perspective and a variety of frameworks, other studies have pointed out numerous factors as relevant for managing the collaborative relationships. For example, Kumar and Seth (1998) study how strategic interdependence between partners and the joint venture, influences control and structure. Young-Ybarra and Wiersema (1999) test TCE and SET arguments about the two main forms of strategic flexibility in alliances (a key factor in alliance management): flexibility to change the alliance and flexibility to exit the alliance. Tsai (2002) examines several coordination tools on knowledge-sharing flows in networks comprising both cooperative and competitive ties. Guerras-Martín and Montoro-Sánchez (2004) also focus on alliance coordination mechanisms, finding that informal mechanisms like trust and communication play a relatively more significant role, but their effects may be inhibited by incompatibility in partners' goals. Given the interest of this dissertation in relational aspects of collaboration, Appendix I.4 summarizes a review of this literature.

Within the research stream into alliance performance, three broad kinds of research questions have been addressed: (1) How could alliance performance be conceptualized and measured? (2) Which are the factors determining success/failure of strategic alliances, and (3) Which are the 
performance implications of strategic alliances for its partner firms? Studies addressing how alliance performance could be conceptualized and measured emphasize that alliance performance definition and measures require further scholarly efforts (e.g., Glaister \& Buckley, 1998; Ariño, 2003; Lunnan \& Haugland, 2008). From the in-depth review of this literature, two main conclusions have been extracted. First, alliance performance is a multi-dimensional construct (Ariño, 2003), embracing different kinds of results at different levels (partner- and alliance-level $^{15}$ (Khanna, Gulati, \& Nohria, 1998) that can be properly capture through subjective measures (Geringer \& Hebert, 1991; Glaister \& Buckley, 1998) like partners' satisfaction and perceived degree of fulfillment of both formal alliance goals (e.g., innovation in R\&D alliances) and other (non-formal) goals (e.g., learning, social capital) (Parkhe, 1993; Mohr \& Spekman, 1994; Ariño, 2003; Lunnan \& Haugland, 2008). Second, alliance performance and alliance stability are not interchangeable concepts. On the one hand, alliances are inherently instable and such instability is not necessary a reflection of alliance success/failure (Doz, 1996; Ariño \& De La Torre, 1998; Das \& Teng, 2000a). On the other hand, alliance stability is much more than alliance survival/continuity/duration (Kumar \& Nti, 1998; Das \& Teng, 2000a; Reuer $\&$ Zollo, 2005). Along this vein, Gulati (1998: 307) states that "not all ongoing alliances are necessarily successful, and some may be continuing more out of inertia or the high exist costs associated with dismantling it than because of the inherent success of the partnership".

Within the vast research examining which factors determine alliance success/failure of strategic, alliance performance has been associated with a variety of factors that can be grouped, according to Saxton (1997) and Mohr and Spekman (1994), into two broad groups: (a) factors related to partners' characteristics (e.g., organizational values like learning orientation and commitment, partner's cooperative behavior; alliance capabilities, and collaborative routines), and (b) and factors related to the alliance/the relationship between the partners (e.g., inter-organizational trust, strategic and organizational partners' compatibility, knowledge exchange and communication, adaptive governance, conflict resolution mechanisms; coordination, inter-organizational collaborative routines) (e.g., Parkhe, 1993; Mohr \& Spekman, 1994; Park \& Russo, 1996; Inkpen \& Beamish, 1997; Saxton, 1997; Khanna et al., 1998; Kumar \& Nti, 1998; Madhok \& Tallman, 1998; Dyer \& Nobeoka, 2000; Kale, Singh, \& Perlmutter, 2000; Park \& Ungson, 2001; Shenkar \& Yan, 2002; Mora-Valentín et al., 2004; Mahnke \& Overby, 2008; Das \& Kumar, 2010). This is tantamount to saying the same factors addressed by

\footnotetext{
${ }^{15}$ Two types of goals can be identified in alliances: common and private goals. Common goals represent interests shared by the partners and from whose accomplishment all partners may profit (common benefits). By contrast, the interests each partner holds in the alliance constitute its private goals, whose accomplishment will benefit exclusively that partner (private benefits). Furthermore, common benefits may not benefit equally all the partners (Khanna et al., 1998).
} 
scholars in the alliance formation and management streams have been also examined as antecedents of alliance success and failure. As occurs in the stream on alliance formation, some studies have developed a more fine-grained understanding of how certain factors affect alliance success or failure. (i.e., adopting a process-oriented, see section 1.1.1.3). The detailed narratives of these studies usually cover the whole lifecycle stage (from formation to termination). For example, Mankhe and Overby (2008) study a failed six-partner R\&D consortium whose objective is to develop advanced mobile services, finding that different strategic prioritisation and lack of shared vision of alliance partners may negatively affect the ongoing evolution and performance of the alliance. For another example of this kind of research, see the case study of Ariño and de la Torre (1998) on a failed joint venture (described in section 1.1.1.3.).

Finally, a large number of studies have also examined which are the performance implications of strategic alliances for its partner firms, as a whole confirming the positive link between alliances and firm's performance enhancement (De Man \& Duysters, 2005; Lavie, 2007). Some scholars have focused on the financial or economic implications of alliances for firm performance (e.g., Simonin, 1997; Goerzen, 2007). In this line, several studies have used the event study methodology, concluding that firms typically enjoy significant positive abnormal stock market returns following alliance announcements (e.g., Anand \& Khanna, 2000; Kale, Dyer, \& Singh, 2002). The performance implications of alliances have also been studied in terms of other factors, basically learning and innovation (e.g., Simonin, 1997; Kale et al., 2000; Sampson, 2005) and social and market capital (e.g., Sarkar, Echambadi, \& Harrison, 2001a; Lavie, 2007; Sarkar, Aulakh, \& Madhok, 2009). Finally, it is important to remark that some contributors have relied on overall managerial assessments of alliance implications, giving rise to constructs like 'perceived net alliance's spillover effects for the firm' (Parkhe, 1993) or 'perceived benefits in terms of profitability, market growth' (Cullen et al., 1995).

\subsubsection{Perspectives in alliance research}

Relying on the distinction between structure and process in strategy research (Van de Ven, 1992), alliance research can be grouped in two categories: the structure- oriented and the process-oriented perspectives (Contractor, 2005; Kaulio \& Uppvall, 2009) (See Figure 1.3.).

The structure-oriented perspective is concerned with the static analysis of structural conditions ${ }^{16}$ as antecedents of strategic alliances decisions and outcomes. Thus, scholars in this perspective, usually relying on cross-sectional data, have examined which factors underlying

\footnotetext{
${ }^{16}$ Following Hennart (2006), structural conditions include the type of alliance (scale vs. link), its scope, its contractual stipulations (ex-ante vs. residual-sharing contracts), the relationship between the strategies of the alliance and its partners, the goals of the partners and the extent to which they are potential or actual competitors.
} 
alliance formation (e.g., Hennart, 1988; Eisenhardt \& Schoonhoven, 1996) or other alliance decisions like partner selection, governance mode or scope (e.g., Hennart \& Reddy, 1997; Beckman et al., 2004; Oxley \& Sampson, 2004; Li, Eden, Hitt, \& Ireland, 2008). Also, structure-oriented research has dealt with the performance implications of these structural conditions at both the alliance-level and the firm level (e.g., Saxton, 1997; García-Canal et al., 2003; Hoang \& Rothaermel, 2005; Lunnan \& Haugland, 2008).

Figure 1.3. Perspectives in alliance research

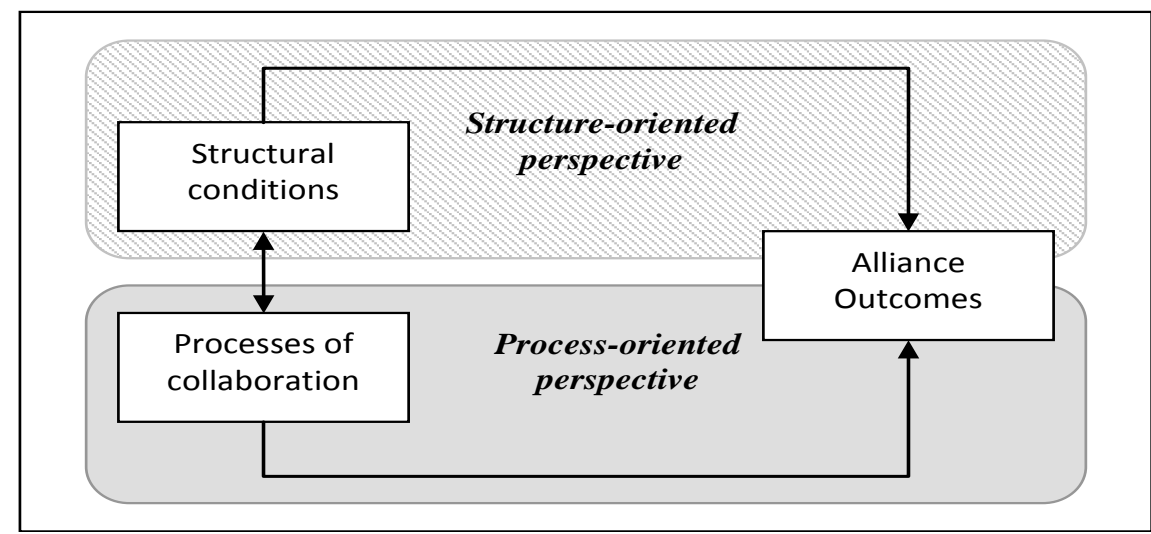

Source: own elaboration

As stated in the previous section, research conducted under this perspective has already created a well-consolidated framework. However, the structure-oriented perspective is unable to fully capture the complexity of the collaborative phenomenon (Contractor, 2005; Salk, 2005). Alliances entail much more than structural factors: alliances are basically "socially contrived mechanisms for collective action, which are continually shaped and restructured by actions and symbolic interpretations of the parties involved" (Ring \& Van de Ven, 1994: 96).

The process-oriented perspective, a much less common approach, covers the study of the processes of collaboration (dynamics of alliance evolution understood in terms of partners' interaction), addressing their interconnections over time and impact on alliance outcomes. Thus, alliance process-oriented research, when empirical, tends to rely on longitudinal data, prevailing in-depth case studies. De Rond and Bouchikhi (2004) identify four different (but not exclusive) approaches within the process-oriented perspective: the life-cycle (e.g., Reuer, 2000), the teleological (e.g., Ring \& Van de Ven, 1994; Doz, 1996; Ariño \& De La Torre, 1998) the evolutionary (e.g., Koza \& Lewin, 1998; Gulati \& Gargiulo, 1999), and the dialectical approach 
(e.g., Das \& Teng, 2000a) ${ }^{17}$. In the following, these four approaches are described, emphasizing the two first, because they are relatively more relevant for this dissertation.

Early attempts to capture the process aspects of alliances were made within the life-cycle approach. Alliances are framed in terms of processes encompassing a linear, and predictable, sequence of lifecycle stages in which every successive stage is a logical progression from the previous one (Forrest \& Martin, 1992; Murray \& Mahon, 1993; Reuer, 2000). A key contribution of this approach is that it circumscribes alliance characteristics over time, identifying particular management challenges for each alliance stage (De Rond \& Bouchikhi, 2004). For example, partner selection and contract formulation at the formation stage and distribution of benefits at the latest stage deserve special managerial attention. However, there is a lack of consensus on which stages comprise alliance lifecycle: stages of alliance lifecycle have been studied in fine-grained or more aggregated terms, depending upon the specific research purposes (Reuer, 2000) [See Appendix I.3 for different conceptualizations of alliance lifecycle]. Indeed, the main criticisms of this approach resides in that alliance life-cycle models may be not generalized because lifecycle stages may not follow a linear sequential path and also are idiosyncratic (Kaulio \& Uppvall, 2009). Therefore, the subjective lifecycle perceptions of alliance actors should not be ignored in defining alliance stages (Mosakowski \& Earley, 2000).

More important attempts to 'open the black box' of collaboration have been conducted within the teleological approach (De Rond \& Bouchikhi, 2004). This process-oriented approach relies on two main assumptions. First, collaboration entails dynamic processes of inter-partner interaction with iterative cycles of evaluation and adjustment. Second, alliance outcomes depend not only on structural variables but also on these processes, concerning interaction between partners and their perceptions on the relationship. Ring and Van de Ven (1994), Doz (1996) and Ariño and de la Torre (1998) are seminal works in this approach ${ }^{18}$. Ring and Van de Ven (1994) offer a conceptual framework on how collaborative relationships emerge, evolve, and dissolve through a developmental process, characterized by cyclical sequences of negotiation (development of joint expectations about the relationship), commitment (agreement on partners' obligations and rules for future action), and execution (of commitments and rules). In each of these stages, partners assess the status of the alliance in terms of efficiency and

\footnotetext{
${ }^{17}$ Bell, den Ouden, and Ziggers (2006) state that the simplicity of this typology overlooks the complexity of the process-oriented perspective. These authors however applaud the effort to structure this so fragmented stream of research, encouraging the use of this typology in this dissertation.

18 Other particularly good examples of process-oriented alliance research are Larsson, Bengtsson, Henriksson, and Sparks (1998), Kumar and Nti (1998), and Faems et al., (2008).
} 
equity ${ }^{19}$. Partners gradually expand their commitment unless they perceive significant imbalances, which increase the likelihood of dissolution. Doz (1996) draws on a multi-case approach to explain the processes interceding between alliance initial conditions ${ }^{20}$ and outcomes. In successful alliances, initial conditions and interaction among partners lead to subsequent learning cycles, enabling continuous evaluation of the alliance (efficiency, equity, and adaptability $)^{21}$ and improving of initial conditions. The step from (re-)evaluation to (re-) adjustment is in turn affected by the quality of the relationship, which determines partners' willingness to strengthen their commitments to the collaboration. Ariño and de la Torre (1998) study the emergence, evolution and dissolution of a failed international joint venture. The collaborative process is governed by learning-action-reaction loops, which are driven by initial conditions, influenced by external events, and mediated by the quality of the relationship. According to Kaulio and Uppvall (2009), the teleological approach is well positioned to capture the complexity of the collaborative phenomenon by addressing the interplay between structure, people and processes. However, it is still in a very immature stage of development (De Rond \& Bouchikhi, 2004).

The evolutionary approach emphasizes the environment as the main motor of change, to which alliances need to adapt in order to survive and succeed. The main contribution here is provided by Koza and Lewin (1998), who develop a conceptual framework based on the coevolution between internal dynamics and the institutional, organizational, and competitive context of alliances. Although alliance research has widely assumed such a co-evolutionary philosophy at different levels (e.g., Gulati \& Gargiulo, 1999; Reuer et al., 2002) few empirical studies has addressed it from a markedly process-oriented perspective [see Ariño and de la Torre (1998) and Inkpen and Curral (2004) for two exceptions]. Finally, the dialectical approach assumes collision of coexisting contradictory social forces. The main contribution here is provided by Das and Teng (2000a), who propose three kinds of internal tensions in alliances: (a) cooperation- competition, (b) rigidity- flexibility, and (c) short-term - long-term orientation. When significant imbalance exists concerning any one of these tensions (e.g., too

\footnotetext{
${ }^{19}$ Ring and Van de Ven (1994) define efficiency in terms of "the less costly governance structure for undertaking a transaction" (p. 93) and equity as 'fair dealing' (i.e., equality is not necessary, reciprocity is sufficient).

${ }^{20}$ Initial conditions include "a definition of the task to be performed, a set of action routines borrowed from the organizational contexts of each partner, a design for the interface between the partners, and a series of expectations about the performance of the alliance (and the behavior of one's partner) towards and within it" (Doz, 1996: 64).

${ }^{21}$ For these authors, efficiency refers to the likelihood of the alliance to create value; equity refers to partner's behavior in terms of trustworthiness and forthrightness, and adaptability refers to partner's adjustment capabilities.
} 
much inter-partner competition and insufficient cooperation), alliances experience instability, which in turn leads to alliance adjustments or termination [see Gogan, Gelinas and Rao (2007) for a life-cycle development]. De Rond and Bouchikhi (2004) argue that this approach is underdeveloped and extend with other kinds of tensions (e.g., trust-vigilance, controlautonomy) [see also Kumar and Nti (1998) for the tension between expectations and actual outcomes (i.e., discrepancies)].

As a whole, process alliance research accommodates the value creation dynamics in the collaborative context. Since the partners' capability to collaborate together only can developed, if so, over time (Zollo et al., 2002; Helfat \& Peteraf, 2003), value will be created (or dissipated) cumulatively as partners interact with each other along the life stages of the collaboration, from formation to termination (Zajac \& Olsen, 1993; Madhok \& Tallman, 1998; Shenkar \& Yan, 2002). In this regard, alliance lifecycle stages are interdependent (Reuer, 2000) and particularly critical is interaction at the formation stage, which will influence largely the ongoing evolution of the collaboration (Doz, 1996; Doz et al., 2000) ${ }^{22}$.

\subsubsection{Levels of analysis in alliance research}

According to this criterion, existing literature on strategic alliances can be split into two main streams of research, as illustrated in Figure 1.4.: studies focusing on the partner-level of analysis and studies focusing on the inter-organizational level of analysis (Faems, 2006; Nielsen, 2010).

Although studies in both streams have addressed the above mentioned topics of research (i.e., alliance formation, governance and management, and performance), studies adopting a partnerlevel of analysis are more common. This stream has provided important insights as regards to individual alliance strategies and their implications for partner organizations. For example, Ahuja (2000) studies motivations and opportunities of individual firms to form R\&D alliances and Lavie et al. (Lavie et al., 2007) study the performance implications of multi-partner alliances for individual partner firms. Yet, it provides only a partial view of the collaborative phenomenon: alliances entails by definition interaction between two or more independent organizations (Ring \& Van de Ven, 1994; Gulati, 1998).

\footnotetext{
${ }^{22}$ Without assuming that a successful formation process leads necessarily to lack of complexity, in subsequent stages, it could be emphasized that otherwise the alliance is likely to fail. In fact, some alliances fall ill at their inception and never recover (e.g., Ariño \& De La Torre, 1998; Shenkar \& Yan, 2002)
} 
Figure 1.4. Levels of analysis in alliance research

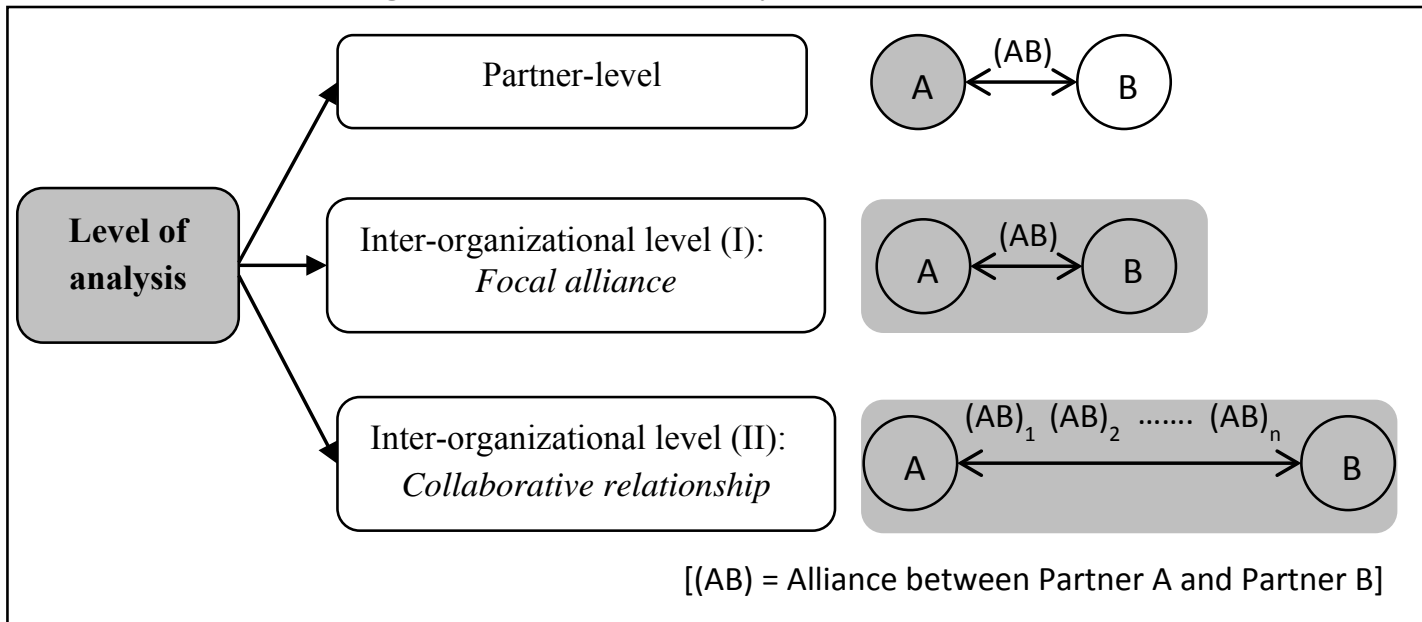

Source: Own elaboration

In this regard, adopting an inter-organizational level of analysis could provide a more comprehensive picture (Salk, 2005). Within this stream of research, an important distinction can be made (see above Figure 1.5). Most studies concentrate on a particular alliance between a specific set of partners (and the term focal alliance is thus adopted to refer to such alliance under study). By contrast, other studies examine the whole collaborative relationship between the same two or more partners and thus comprising several collaborative agreements established between them over time ${ }^{23}$. The process-oriented perspective is better positioned to examine alliances at the level of the collaborative relationship and thus this research usually relies on indepth longitudinal case studies (e.g., Ariño \& De La Torre, 1998; Faems et al., 2008).

It is important to note that the election of the level of analysis is viewed as contingent on the theoretical framework of the study, since each framework has its particular conceptual level of analysis [see Nielsen (2010) for an in-depth discussion]. Thus, the RBV traditionally focuses on the firm-level [see Lavie (2006) for an extension of the RBV to the inter-organizational level of analysis], whereas TCE, the RV, SET and SNT support a more inter-organizational optic, either focusing on the focal alliance (or the transaction in the language of TCE) and/or the collaborative relationship (RV, SET, and SNT) ${ }^{24}$. However, Nielsen (2010) suggests that a main

\footnotetext{
${ }^{23}$ Comparing the two following studies could illustrate the differences between these two interorganizational levels of analysis. Mora-Valentín et al. (2004) study success factors of R\&D alliances between firms and research organizations, drawing on a sample of 800 focal alliances and survey-data from the two partners of each alliance. Faems et al. (2008) conduct a case study on two sequential alliances between the same firms. Drawing mainly on interview data, the authors explain how structural and relational aspects of alliance governance (i.e., contracts and trust) interact over time, both within and between transactions.

${ }^{24}$ One may argue that this is a simplified view of alliance research and other different units of analysis can be found in studies inspired by these theoretical frameworks. For example, Zaheer et al. (2010) identify three main levels of analysis in SNT research: ego-level (from the perspective of a focal firm or
} 
deficiency of the literature on strategic alliances is that the conceptual level of theories and their constructs are rarely identified explicitly, often underlying inconsistencies between the theoretical framework and the empirical design of alliance studies. For example, Oxley (1997) stresses that TCE conceptually focuses on the transaction as the unit of analysis, whereas empirical alliance research inspired by TCE usually uses partner-level measures. Another deficiency of alliance research in this regard is the prevalence of single levels of analysis whereas alliances entail multi-level phenomena by definition (Hagedoorn, 2006; Nielsen, 2010; Loohuis \& Groen, 2011).

\subsubsection{Types of strategic alliances}

Concerning the type of alliances that have been studied, the main alliance typologies are defined in terms of two broad group of factors giving rise to more specific criteria: (1) alliance characteristics (area of collaboration, geographic scope, alliance form) and (2) alliance partners characteristics (number of partners, type of partners, partners contributions, partners position in the value chain). This literature taxonomy, displayed in Table 1.2, is of pragmatic nature insofar it aggregates partial typologies found in different specialised literatures.

Scholars in each specialised literature have used different specific criteria providing (more or less explicitly) different alliance typologies, in order to justify the need of their works and contextualize their contributions within existing literature. For example, and given the focus of this dissertation, Oxley and Sampson (2004) and Thorgren et al. (2010) emphasize the relatively more complexity of, respectively, research and development (R\&D) alliances and multi-partner alliances respect to alliances involving other areas of collaboration and only two partners. Furthermore, scholars in each stream have addressed the topics of research above mentioned (i.e., alliance formation, alliance governance and management, and alliance performance) either from a structure-oriented and a process-oriented perspective.

'ego' in the network), dyadic level (viewing networks as collections of bilateral linkages between two partners), and network-level (focusing on the network as a whole). 
Table 1.2. Typologies of strategic alliances

\begin{tabular}{|c|c|c|c|}
\hline \multicolumn{2}{|c|}{ Criteria } & Types of alliances & Illustrative references \\
\hline \multirow{4}{*}{ 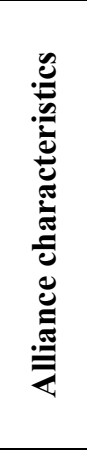 } & Area & $\begin{array}{l}\text { - R\&D [Explorative and } \\
\text { exploitative] } \\
\text { - Manufacturing } \\
\text { - Marketing } \\
\end{array}$ & $\begin{array}{l}\text { (Fuller \& Porter, 1986; Mohr \& Spekman, } \\
\text { 1994; Koza \& Lewin, 1998; Anand \& } \\
\text { Khanna, 2000; Sampson, 2007) }\end{array}$ \\
\hline & $\begin{array}{l}\text { Geographic } \\
\text { scope }\end{array}$ & $\begin{array}{l}\text { - Domestic } \\
\text { - International }\end{array}$ & $\begin{array}{l}\text { (Fuller \& Porter, 1986; García-Canal, 1996; } \\
\text { Oxley \& Sampson, 2004; Kim \& Inkpen, } \\
\text { 2005) }\end{array}$ \\
\hline & \multirow{2}{*}{$\begin{array}{l}\text { Alliance } \\
\text { form }^{25}\end{array}$} & $\begin{array}{l}\text { - Equity vs. non-equity } \\
\text { (commitment) }\end{array}$ & \multirow{2}{*}{$\begin{array}{l}\text { (García-Canal, 1996; Colombo, 2003; } \\
\text { García-Canal et al., 2008; Culpan, 2009) }\end{array}$} \\
\hline & & $\begin{array}{l}\text { - New venture creation: Joint } \\
\text { ventures vs. contractual alliances }\end{array}$ & \\
\hline \multirow{3}{*}{ 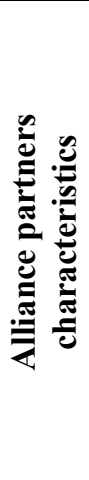 } & $\begin{array}{l}\text { No. of } \\
\text { partners }\end{array}$ & $\begin{array}{l}\text { - Dyadic } \\
\text { - Multi-partner }\end{array}$ & $\begin{array}{l}\text { (García-Canal et al., 2003; Valdés-Llaneza } \\
\text { \& García-Canal, 2006; Gong et al., 2007; } \\
\text { Lavie et al., 2007) }\end{array}$ \\
\hline & $\begin{array}{l}\text { Type of } \\
\text { partners }\end{array}$ & $\begin{array}{l}\text { - Inter-firm collaboration (e.g., } \\
\text { competitors, clients) } \\
\text { - Firm- research organization } \\
\text { collaboration } \\
\text { - Firm-government collaboration }\end{array}$ & $\begin{array}{l}\text { (Fritsch \& Lukas, 2001; Mora-Valentín et } \\
\text { al., 2004; Montoro-Sánchez et al., 2006; } \\
\text { Bercovitz \& Feldman, 2007; Sánchez- } \\
\text { González et al., 2009) }\end{array}$ \\
\hline & $\begin{array}{l}\text { Partners' } \\
\text { position in } \\
\text { the value } \\
\text { chain }\end{array}$ & $\begin{array}{l}\text { - Horizontal (competitors) } \\
\text { - Vertical (buyer-supplier) }\end{array}$ & (García-Canal, 1996; Mesquita et al., 2008) \\
\hline
\end{tabular}

Source: Own elaboration

\subsubsection{Research on multi-partner $R \& D$ alliances}

Once reviewed the general alliance literature, this section elaborates further on the kind of collaborative setting addressed in this dissertation: multi-partner R\&D alliances. Multi-partner

R\&D (MR\&D) alliances are 'collective voluntary inter-organizational agreements that interactively engages its multiple partners in multilateral R\&D activities' (Lavie et al., 2007). They combine characteristics from two collaborative phenomena by definition: R\&D alliances and multi-partner alliances. In order to gain deeper understanding of MR\&D alliances, existing research on these two kinds of alliances is reviewed.

R\&D alliances are 'innovation-seeking agreements that involve, at least partly, a significant collaborative effort in $\mathrm{R} \& \mathrm{D}^{26}$, engaging two or more companies, research organizations and/or

\footnotetext{
${ }^{25}$ Several perspectives coexist concerning alliance governance choice. A well-accepted view is to identify two broad categories: (a) equity alliances (joint ventures) and (b) non-equity alliances (contractual alliances). However, some scholars talk about 'equity joint ventures' as different from other possible forms of joint ventures (e.g., Hennart, 1988).

${ }^{26}$ According to Hagedoorn (2002: 447), R\&D refers to "the standard research and development activity devoted to increasing scientific or technical knowledge and the application of that knowledge to the creation of new and improved products and processes". According to Galende-del-Canto and SuárezGonzález (1999: 888) research is an "original and planned investigation pursuing the acquisition of new knowledge and higher understanding in the scientific or technical area" and development refers to "the concrete application of the achievements obtained in the research up to the point when commercial production is begun".
} 
government agencies' (Hagedoorn, 2002: 447). In the past two decades, a prolific stream of research on R\&D alliances has been developed, reflecting the notable importance of this kind of collaborative activities in current business practice. Concerning R\&D alliance formation, although RBV has empirically shown more predictive power than TCE (Yasuda, 2005) the combination of both perspectives offers a more comprehensive 'inducements-opportunitiesconvenience' framework for explaining the phenomenon. On the one hand, RBV scholars highlight a dual role of resources (Eisenhardt \& Schoonhoven, 1996; Ahuja, 2000). First, advantages in the form of combination of complementary resources- not only technical capital but also commercial and social capital (Teece, 1986)- potentially afforded by R\&D alliances act as inducements for organizations to engage in this kind of collaboration. Second, these resource endowments also determine organizations' opportunities for R\&D alliance formation (e.g., the stronger resource endowments of a firm, the stronger its attractiveness as a partner). In this line, Fritsch and Lukas (2001) identify a set of factors (e.g., high number of R\&D employees) that distinguish firms that cooperate on R\&D from firms that do not using a sample of German manufacturing firms. Similarly, Bayona, García-Marco and Huerta (2001) find that those Spanish manufacturing firms which conduct innovative internal efforts in a systematic manner and are involved in high-technology industries have also a greater propensity to form $R \& D$ alliances. Bercovitz and Feldman (2007) find that Canadian R\&D intensive firms are highly active in forming university-based research alliances. Likewise, Martín-de-Castro, NavasLópez, López-Sáez, and Delgado-Verde (2009) account for the 'inducements and opportunities' logic in the context of emergent industries. On the other hand, TCE scholars emphasize the potential advantages of $R \& D$ alliances in the form of reduction of uncertainty and costs of $R \& D$ activities, suggesting conditions under which it is more convenient (a) allying than undertaking make-or- buy R\&D strategies (Hennart \& Reddy, 1997) and (b) forming hierarchical R\&D alliances than contractual R\&D alliances (García-Canal et al., 2008). Extending this reasoning, Oxley and Sampson (2004) and Li et al. (2008) study respectively alliance scope and partner selection as mechanisms to control the threat of knowledge leakage and protect core proprietary assets in R\&D alliances. Amongst other, these studies find that opportunism is mitigated by defining narrow scope of alliance activities and, in alliances seeking radical innovation, following an intransitive logic of partner selection (i.e., friends are preferred to strangers and strangers are preferred to acquaintances).

Existing empirical research has widely supported the positive impact of $R \& D$ alliances on firms' innovation ${ }^{27}$ performance (Stuart, 2000; De Man \& Duysters, 2005; Sampson, 2005;

\footnotetext{
${ }^{27}$ Innovation could be broadly defined as "certain technical knowledge about how to do things better than the existing state of the art either in the firm and/or in the world (Teece, 1986: 288; Pérez-Luño, Valle-
} 
Sampson, 2007; Sánchez-González, González-Álvarez \& Nieto, Sánchez-González et al., 2008). For example, Sánchez-González et al. (2008), using longitudinal data on Spanish firms, find that R\&D collaboration with firm's customers fosters the development of both process and product innovation. For the purposes of this dissertation, it is particularly important the distinction of R\&D alliances depending on its innovation-seeking orientation ${ }^{28}$ (Tiwana, 2008). Thus, explorative $R \& D$ alliances are those formed with the aim of discovering new technological opportunities, whereas exploitative $R \& D$ alliances are those formed with the aim of capturing already available technological opportunities (Koza \& Lewin, 1998; Lavie \& Rosenkopf, 2006). In this regard, an important conclusion of existing research is that $R \& D$ alliances have become essential strategic tools for firms to develop innovation, by enabling either the leverage of existing capabilities (exploitative R\&D alliances) or the creation of new capabilities (explorative $R \& D$ alliances) and thus the capture or discovery of technological opportunities (Koza \& Lewin, 1998; Lavie \& Rosenkopf, 2006).

Despite these potential value-creating properties, existing research on the governance of R\&D alliances highlights their great complexity. According to the alliance risk-based view proposed by Das and Teng (1998), R\&D alliances are characterized by high levels of both performance and relational risks ${ }^{29}$. First, due to the nature of R\&D activities, objectives pursued in $R \& D$ alliances entail uncertain developmental trajectories and results (Koza \& Lewin, 1998), thus entail conditions of high performance risk. Second, fulfilment of objectives in R\&D alliances is surrounded by relational risk, given the required exchange and combination of partners' technological resources (Sampson, 2005; 2007), the value of this kind of resources for competition, and the risk of opportunistic behavior inherent in alliances (Gulati \& Singh, 1998; Ariño, 2001). A key management challenge thus $\operatorname{arises}^{30}$ : partners in R\&D alliances must balance open exchange of knowledge and protection from unintended leakage of valuable technology (e.g., Oxley \& Sampson, 2004). Indeed, research in R\&D alliances usually

Cabrera, \& Wiklund, 2009: 98). According to Nieto (2004: 315) technological innovation is "a learning process through which a flow of new knowledge competencies and capabilities is generated".

${ }^{28}$ We in turn define innovation-seeking orientation in terms of the traditional distinction between two kinds of learning: exploration and exploitation. (1991: 71) states that exploration "includes things captured by terms such as search, variation, risk taking, experimentation, play, flexibility, discovery" whereas exploitation "includes such things as refinement, choice, production, efficiency, selection, implementation, execution". Levinthal and March (1993: 105) added that exploration involves "a pursuit of new knowledge," whereas exploitation involves "the use and development of things already known".

${ }^{29}$ According to the alliance risk-based view of Das and Teng (1998), two kind of risk may be identified in alliances: relational and performance risk. Relational risk refers to the probability that partners behave not complying with the spirit of cooperation. Performance risk, to which we will refer soon, concerns the probability that intended alliances goals may not be achieved.

${ }^{30}$ See Kaulio and Uppval (2009) for a fine-grained discussion of critical incidents in R\&D alliances. 
structures around these two points, suggesting a variety of factors (e.g., alliance scope, partners' general and specific alliance experience, technological distance/complementarity among partners' resources) that may contribute to mitigate risk either in its performance or relational dimensions (Lane \& Lubatkin, 1998; Oxley \& Sampson, 2004; Sampson, 2005; 2007; Li et al., 2008; Tiwana, 2008). In this regard, an intriguing scholarly debate exists on how the interplay between the existence of prior ties between partners (familiar vs. unfamiliar partners) and the innovation-seeking orientation of $R \& D$ alliances (exploration vs. exploitation) impact $R \& D$ alliance performance (e.g., Hoang \& Rothaermel, 2005; Gulati et al., 2009). [This debate motivates Study II of this dissertation and thus will be further discussed in Chapter 4].

Multi-partner alliances are 'collective voluntary inter-organizational agreements that interactively engages its multiple -three or more- partners in multilateral value chain activities, such as research, development, sourcing, production, or marketing of technologies, products or services' [Appendix I.5 displays other definitions]. Multi-partner alliances are an increasingly important collaborative phenomenon in the competitive landscape. However, research into multi-partner alliances remains scarce (Das \& Teng, 2002; Zeng \& Chen, 2003; Lavie et al., 2007; Thorgren et al., 2010). Alliance scholars have tended to confine their conceptual and, particularly, empirical contributions to the context of dyadic alliances ${ }^{31}$, either arguing lower relative importance of multi-partner alliances or for simplification purposes (e.g., Dyer \& Singh, 1998; McCarter, Mahoney, \& Northcraft, 2011).

Das and Teng (2002) argue that not all theoretical frameworks are well positioned to examine the special collaborative dynamics of multi-partner alliances. Important theoretical contributions have been framed within the RBV (Barney, 1991; Eisenhardt \& Schoonhoven, 1996), SNT (Granovetter, 1973; Gulati, 1998) and $\mathrm{SET}^{32}$ (Blau, 1964; Muthusamy \& White, 2005). The RBV offers a meaningful rationale for multi-partner alliances. For example, Sakakibara (1997) reports that skill-sharing motives encourage Japanese firms to form R\&D consortia with

\footnotetext{
${ }^{31}$ In this regard, it is important to mention a specific stream of research with relatively higher extent of empirical development that usually coins the term of 'alliance constellations' (i.e., alliances among multiple firms that compete against each other (Lazzarini, 2007)] and focuses on the dynamics of competition among multi-partner alliances in specific settings like the airline industry [see Lazzarini (2007) and Gomez-Casseres (2003) for a discussion]. According to Das and Teng (2002), this stream of research, however, has not emphasized the development of theoretical foundations for multi-partner alliances. Furthermore, without denying that this stream of research has provided some important insights, the research contribution of this dissertation does not particularly build upon them, due to differences in foci of analysis.

${ }^{32}$ Although less relevant for the development of this dissertation, multi-partner alliances have also been studied from a game theory perspective. Hwang and Burgers (1997) argue that traditional game theory developments that focus on dyadic alliances cannot explain the dynamics of multi-partner alliances, which are unique in terms of their payoff structure and the way they are played out, and where mutual cooperation is complex to achieve.
} 
partners possessing heterogeneous capabilities. Mothe and Quelin (2001) conclude that firms may create both tangible and intangible resources through their participation in R\&D consortia under certain conditions like alignment between the agreed area of collaboration and its own strategy, as well as frequent knowledge exchange with other partners.

For its part, SET captures the complexity of collaboration in multi-partner settings by explicitly identifying two different kind of collaborative relationships that take place simultaneously when alliances have three or more partners (see Figure 1.5.). In this regard, Das and Teng (2002) argue that the main difference in the value creation logic of multi-partner and dyadic alliances resides in the patterns of exchange between partners (and the associated kinds of reciprocity).

Figure 1.5. Illustration of two kinds of relationships in multi-partner alliances

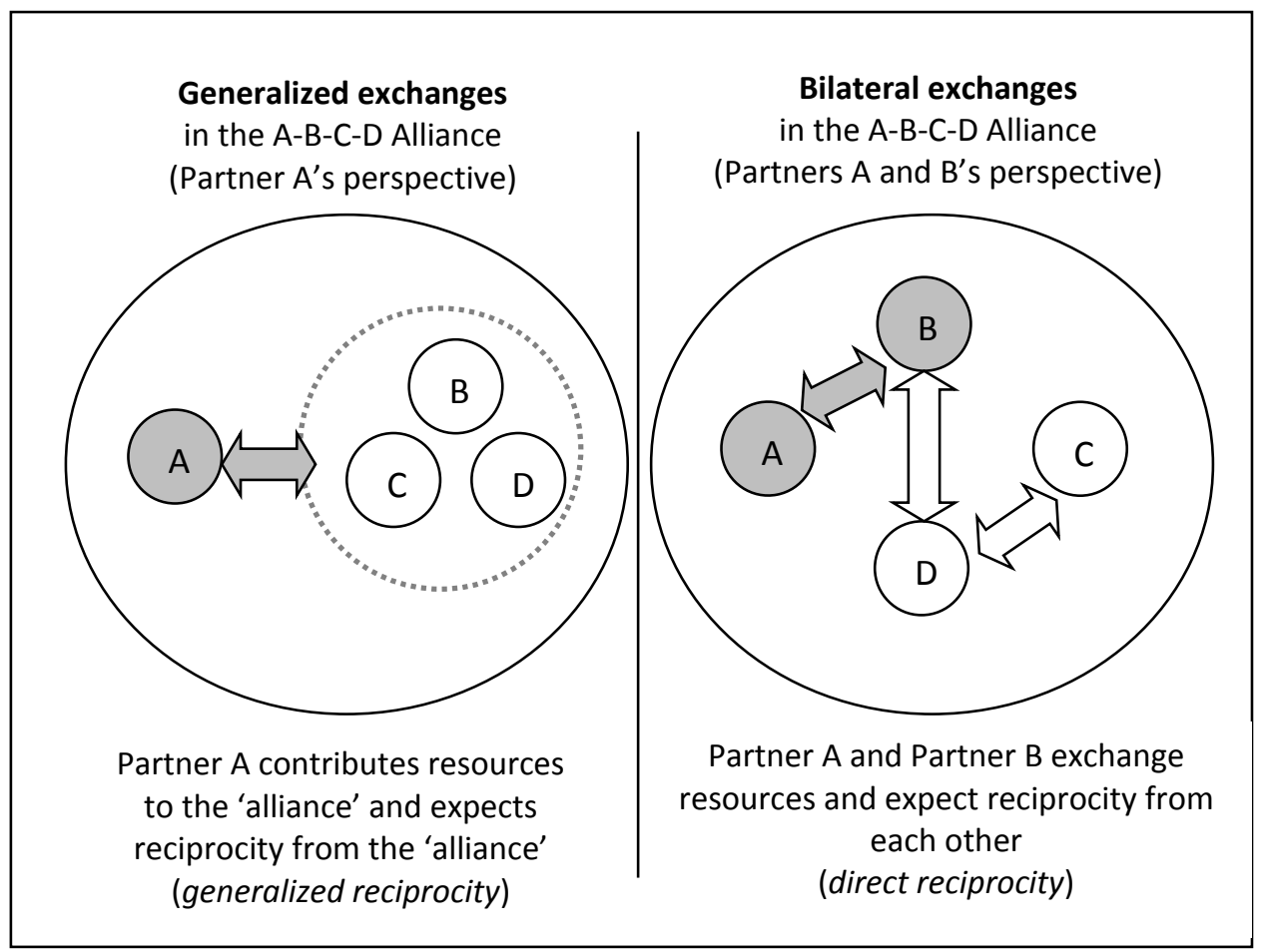

Source: Own elaboration based on Das and Teng (2002) and Thorgren et al. (2010)

Dyadic alliances entail direct/bilateral exchanges in which one partner's contributions revert to the other partner and vice versa, hence, partners reciprocate each other directly (direct reciprocity). By contrast, multi-partner alliances entail not only bilateral exchanges but also generalized multilateral exchanges in which one partner's contributions revert to 'the alliance' (i.e., one or more partners could benefit from them), hence, partners expect a quid pro quo relationship within 'the alliance' (as an entity itself) but not necessarily with any specific partner (generalized reciprocity). The coexistence of these two kinds of relationships, and particularly the existence of generalized exchanges, explains the great level of complexity associated to multi-partner alliances (Hwang \& Burgers, 1997; Lavie et al., 2007; Thorgren et al., 2010). In 
this line, the empirical evidence found by Thorgren et al. (2010) suggests that individual cooperative behaviors of partners facilitate the development of generalized exchanges and trustbuilding in multi-partner alliances.

Based on the former arguments, scholars studying multi-partner alliances have emphasized that these alliances entail more than a simple collection of dyadic alliances (Lavie et al., 2007). However, there are some resemblances -beyond the number of partners- that allow considering multi-partner alliances as a kind of network (Grandori \& Soda, 1995; Gulati, 1998). For example, many multi-partner alliances adopt the form of ego-networks (Lavie, 2006), in which an organization acts as the central node orchestrating the alliance (Doz et al., 2000; Dhanaraj \& Parkhe, 2006). Likewise the notion of network resources (Gulati, 1999) resonates closely to the logic of generalized exchanges: organizations can benefit from contributions of other partners of the multi-partner alliances in which they are involved, by a similar logic through which organizations accrue network resources from the networks they are located (Lavie, 2006). Therefore, SNT may provide important insights into the study of multi-partner alliances. For example, insights from network formation may inform the phenomenon of multi-partner alliances formation (e.g., Doz et al., 2000; Ring et al., 2005), evidence about the implications of network position may shed light into the value-creation implications of multi-partner alliances (e.g., Lavie et al., 2007), and notions like 'concurrent and prior ties between network actors' can explain why firms join, stay or leave multi-partner alliances (e.g., Olk \& Young, 1997; Doz et al., 2000).

In the context of multi-partner R\&D (MR\&D) alliances, conditions of both performance and relational risk above explained intensify. Performance risk, inherently high in $R \& D$ alliances due to the type of objectives and resources involved (Das \& Teng, 1998; Sampson, 2007) is intensified in multi-partner contexts. The great partners diversity (Parkhe, 1991) in terms of both their characteristics (e.g., age, size, sector affiliation, culture) and alliance strategies (e.g., alliance horizon, timing of entry, private goals), leads per se to an intricate scenario for interaction (Hwang \& Burgers, 1997; Das \& Teng, 2002), hampering key alliance activities like the establishment of domain consensus (Doz et al., 2000; Ring, Doz, \& Olk, 2005), alignment of interests and cognition (Mahnke \& Overby, 2008), and integration of partners' R\&D resources (Tiwana, 2008; Kaulio \& Uppvall, 2009). Without overcoming these obstacles, the foundation for value creation cannot be established, and the alliance will probably be doomed to failure (Ariño \& De La Torre, 1998; Shenkar \& Yan, 2002). Likewise, conditions of relational risk are intensified in MR\&D alliances. In multi-partner settings, partners need to combine their R\&D resources but simultaneously protect them against unintended leakages that may occur through multiple potential points (Bresser, 1988; Hwang \& Burgers, 1997; Oxley \& Sampson, 2004). 
Furthermore, given the generalized nature of reciprocity (Das \& Teng, 2002; Thorgren et al., 2010), partners may felt less guilty when no cooperating (Mahnke \& Overby, 2008) and it is difficult to infer the level of effort made by each partner and to detect non-cooperative individual behaviors (Ariño, 2001; Ryall \& Sampson, 2009). In the face of such a social dilemma, incentives to behave cooperatively may be diluted and, while non-cooperative acts seem individually rational, may undermine the foundation of cooperation and joint value creation (Zeng \& Chen, 2003). Integrating these observations with previous insights presented throughout this chapter, three interconnected conclusions may be drawn: (1) the formation stage, critical in strategic alliances in general (Doz, 1996; Ariño \& De La Torre, 1998), is particularly complex in the setting of MR\&D alliances (Doz et al., 2000), (2) cooperation, critical in strategic alliances in general (Anderson \& Narus, 1990; Luo, 2008), is even more needed and, at the same time, even more complex to achieve in the setting of MR\&D alliances (Zeng \& Chen, 2003), and (3) the two former assertions are particularly true when alliance partners lack significant prior experience in multi-partner settings (Doz et al., 2000; Zollo et al., 2002). Study I of this dissertation relies on and elaborates further on these premises (see Chapter 3).

From the multiple forms that fall under the label of 'multi-partner alliances' [e.g., R\&D consortia, official and de facto standard-setting or -promoting associations, multi-party joint ventures, supplier networks, co-marketing arrangements, and industry constellations, Lavie (2007)] R\&D consortia are highlighted, given their relevance in academic research and the particular research setting of this dissertation (i.e., the Acuisost Consortium). An R\&D consortium is 'a collaborative contractual agreement between a group of organizations to conduct a R\&D project together, sharing its costs and results' (Sakakibara, 1997; Mothe \& Quelin, 2001) in which partners usually are responsible for specific parts of the R\&D project vis-à -vis the entire project (Eisner et al., 2009) [See Appendix I.6 for other representative definitions and a description of the distinctive properties of R\&D consortia]. Within existing research into multi-partner R\&D alliances, studies focusing on $R \& D$ consortia prevail, examining a variety of factors concerning their formation, governance and management, and performance.

For the purposes of this dissertation, and given the importance of the formation stage in MR\&D alliances, it is particularly relevant the typology of $\mathbf{R} \& \mathbf{D}$ consortia formation pathways developed by Doz and colleagues [See Appendix I.6 for a more detailed description of this typology and for a selection of case studies focusing on R\&D consortia formation]. Doz et al. (2000) identify two basic formation pathways (emergent and engineering processes) and Ring et al. (2005) add a new formation pathway (embedded process). In emergent process, partners 
recognize the opportunity to form together a $R \& D$ consortium, motivated by the existence of prior ties and strong senses of environmental interdependence and interest similarity. By contrast, engineered process is characterized by lack of partners' prior ties and spontaneous recognition of interest similarity and environmental interdependence. In this case, a 'triggering entity' perceives the opportunity to form the consortium and takes the initiative to do it. Embedded process refers to $\mathrm{R} \& \mathrm{D}$ consortia created between partners already belonging to a well-established network (i.e., the consortium just represent a further step in the partners' collaborative trajectory).

Particularly important for this dissertation are those $R \& D$ consortia that are created with the support of public institutions or government-sponsored R\&D consortia (Sakakibara, 1997; Mothe \& Quelin, 2001; Montoro-Sánchez, 2005). As mentioned, in the pursuit of competitive dynamic economies, governments throughout the world are increasingly supporting the creation of R\&D consortia (e.g., policies of EU countries under the spirit of the Lisbon Strategy). Public support characterizing government-sponsored R\&D consortia may refer to the initiative to form the consortium (i.e., public agencies acting as triggering entities) and/or to some kind of financial support from public funding programmes (e.g., subsidies and grants). For example, see the analysis of Moth and Quelin (2001) and Montoro-Sánchez (2005) for R\&D alliances under the EU Eureka Programme and, for other policies, the case-based studies of Mathews (2002), Nakamura, Nelson, and Vertinsky (2003), and Stephens et al. (2009). As advanced (and further discussed in Chapter 2), the consortium under study in this dissertation (i.e., the Acuisost Consortium) was included in a Spanish funding programme, thus illustrating the second type of public support.

\subsubsection{The literature on dynamic capabilities}

The dynamic capabilities view (DCV) of strategic management (Teece, Pisano, \& Shuen, 1997; Eisenhardt \& Martin, 2000; Zollo \& Winter, 2002) seeks to explain why some organizations are more successful than others in creating economic value within dynamic contexts on the basis of dynamic capabilities or, as first defined, "the firm's ability to integrate, build, and reconfigure internal and external competences to address rapidly changing environments" (Teece et al., 1997: 516) [See Appendix I.7 for a selection of dynamic capabilities definitions]. In the following, the main conceptual and empirical developments and shortcomings of the dynamic capabilities field are described.

\subsubsection{Origins and conceptual developments of the DCV}

DCV is frequently conceived as an extension of the resource-based view (RBV) (Barney, 1991; Peteraf, 1993), which has become one of the most influential theoretical frameworks in the 
strategic management literature (Madhok, 2002). However, RBV has been described as an inherently static framework that fails to explain how firms may build and sustain competitive advantage in situations of rapid and unpredictable change (Priem \& Butler, 2001) ${ }^{33}$. In this context, the DCV emerges to enhance the RBV, by drawing more explicitly upon evolutionary economics (Nelson \& Winter, 1982) ${ }^{34}$. In the words of Teece et al. (1997: 509) ${ }^{35}$, "strategic theory is replete with analyses of firm-level strategies for sustaining and safeguarding extant competitive advantage, but has performed less well with respect to $[\ldots]$ how and why certain firms build competitive advantage in regimes of rapid change". Thereafter, other two influential contributions shape the conceptual development of the DCV: Eisenhardt and Martin (2000) and Zollo and Winter (2002). These three contributions are usually considered the 'intellectual core' of the dynamic capabilities field. Indeed, Screyögg and Kliesch-Eberl (2007) identify three different schools of thought within the DCV, each of them headed, respectively, by each of the mentioned key contributions: the integrative approach (Teece et al., 1997), the dynamization approach (Eisenhardt \& Martin, 2000), and the innovation routines approach (Zollo \& Winter, 2002) [See Appendix 1.7 for a summary of each approach]. Although each of these approaches has idiosyncratic contributions, three points of consensus can be identified (Zahra, Sapienza, \& Davidsson, 2006; Ambrosini \& Bowman, 2009; Easterby-Smith, Lyles, \& Peteraf, EasterbySmith et al., 2009), illustrated in Figure 1.6. and briefly described in the following.

Figure 1.6. Main points of consensus on dynamic capabilities literature

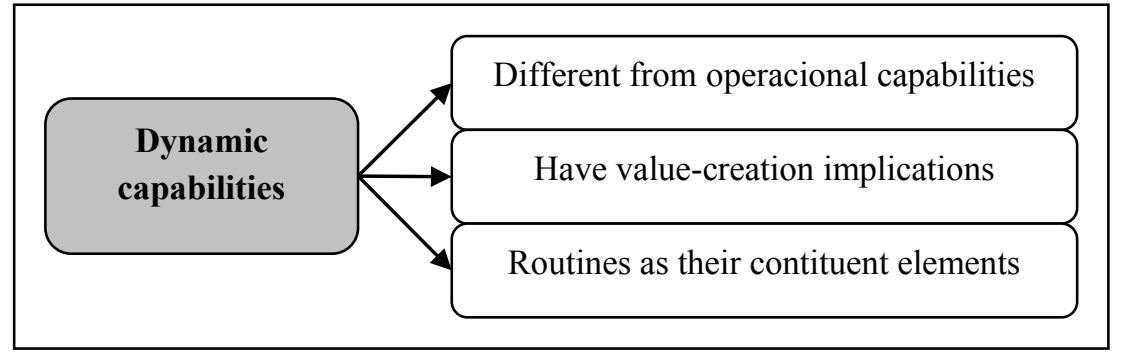

Source: Own elaboration

\footnotetext{
${ }^{33}$ Other common criticisms to the RBV are that its concepts are ambiguous and inconsistent, it is tautological, and fails to explain how resources transform into competitive advantage (e.g., Priem \& Butler, 2001).

${ }^{34}$ According to Priem and Butler (2001) and Lavie (2006), the DCV invigorates the idea of evolutionary economics, already pointed out by early proponents of the RBV (e.g., Penrose, 1959), that while resources are undoubtedly important, there are by themselves insufficient: firms need to coordinate and deploy resources by applying routines over time.

35 The formal origins of the DCV are traditionally attributed to the publication of the seminal work of Teece et al. (1997). As an important antecedent, a journal article (Teece \& Pisano, 1994) should be mentioned.
} 
Dynamic capabilities are different from operational (ordinary) capabilities. 'Dynamic' connotes change and evolution (Teece \& Pisano, 1994). Easterby-Smith and Prieto (2008) stress that dynamic capabilities are the potential to do things, not the things that are done. In particular, changes in ordinary capabilities are the visible outcome of dynamic capabilities (Winter, 2003) ${ }^{36}$. Moreover, dynamic capabilities are themselves dynamic (i.e, they build on a dynamic fashion and evolve over time) (Zollo \& Winter, 2002; Helfat \& Peteraf, 2003).

Dynamic capabilities contribute to explain value-creation differences across firms. Despite some differences in nuance between the three approaches in the dynamic capabilities field (Teece et al., 1997; Eisenhardt \& Martin, 2000; Zollo \& Winter, 2002)- See Appendix I.7-, the conclusion here is that dynamic capabilities may explain the differential rate of success that firms achieve in contexts characterized by some degree of dynamism (Zahra et al., 2006; Ambrosini \& Bowman, 2009; Easterby-Smith et al., 2009).

Dynamic capabilities are founded on organizational routines. Teece et al. (1997) explain that routines represent organizational or managerial processes that are firm-specific (i.e., the way things are done in the firm) and allow the fulfilment of three roles of different nature (static versus dynamic and transformational). Zollo and Winter (2002) define routines as 'stable patterns of behavior that characterize organizational reactions to a variegated, internal, or external stimuli'. They also identify two broad types of organizational routines: operating routines (those related to operational functioning of the firm) and search (or innovation) routines (those that seek to bring about desirable changes in existing operating routines and are the founding dimensions of dynamic capabilities). In a similar vein, Eisenhardt and Martin (2000) are explicit in stating that dynamic capabilities consist of specific identifiable organizational processes (e.g., alliancing, decision making, and product development) ${ }^{37}$. From these insights, it is well accepted in the dynamic capabilities field that routines are the main building blocks of dynamic capabilities (Zahra et al., 2006; Ambrosini \& Bowman, 2009; Easterby-Smith et al., $2009)^{38}$.

\footnotetext{
${ }^{36}$ Recently, scholars have begun to develop the notion of capability hierarchy (Collis, 1994; Winter, 2003; Danneels, 2008), invigorating the peculiarities of dynamic capabilities. In this line, Winter (2003) defines ordinary or "zero- level" capabilities as those that permit a firm to "make a living" in the short term, and dynamic capabilities as those that operate to extend, modify or create ordinary capabilities.

${ }^{37}$ Notice that Eisenhardt and Martin (2000) introduce a nuance that has been subject to important criticism: the nature of such processes varies with the degree of market dynamism, ranging from detailed analytic routines in moderately dynamic markets to fragile experiential processes (i.e., simple rules of thumb) in high-velocity environments. Winter (2003) rejects this view by arguing that "brilliant improvisation is not a routine" (Winter, 2003: 991).

${ }^{38}$ In this regard, Dosi, Nelson, and Winter (2000) stress that "routines are the building blocks of capabilities, although routines are not the only building blocks of capabilities. A marketing capability
} 


\subsubsection{1. About the concept of routines: Sources of inertia or flexibility?}

Scholars have debated about many of the characteristics that conceptualize the notion of routines and have offered different conceptualizations of routines [See Appendix I.8 for a summary of main characteristics and conceptualizations]. Particularly salient is the debate about whether routines are stable patterns of interaction in the form of automatic responses to stimuli (leading thus to organizational inertia) or effortful accomplishments making possible organizational change ${ }^{39}$. This latter conceptualization therefore matches the spirit of dynamic capabilities (as collections of routines that integrate, reconfigure, gain, and release resources to match or even create market change (Eisenhardt \& Martin, 2000). In particular, this perspective is compatible with the framework developed by Zollo and Winter (2002), in which a conceptual distinction is made between operating and search routines (i.e., the building blocks of dynamic capabilities).

According to Feldman (2000) the conceptualization of routines in evolutionary economics (Nelson \& Winter, 1982) emphasizes the values of stability and lack of change, viewing routines as essentially automatic responses to stimuli that are executed without explicit deliberation of choice. This leads to the recognition of routines as sources of inertia (Feldman, 2000). Stability is needed in order to make a pattern of behavior reliable and identifiable as a distinct unit (Schreyögg \& Kliesch-Eberl, 2007). But, paradoxically, as routines are stable patterns of behavior stored in organizational memory and executed automatically (Cohen \& Bacdayan, 1994), changes in environment leads to maladaptation ${ }^{40}$.

By contrast, other scholars have conceptualized routines as effortful accomplishments that are executed as a result of explicit deliberation (Pentland \& Rueter, 1994). This view suggests that it could be possible to choose the most adequate pattern of behavior according to the contingencies and thus achieve adaptation. The assumption here is that a repertoire of alternative patterns of behaviors is available for the organization (Feldman, 2000; Becker, 2004). In this context arises the conceptualization of routines as 'grammars of action' (Pentland \& Rueter, 1994). Routines, as 'grammars of (collaborative) action' define a set of possible patterns of behavior, rather than prescribing a single pattern. Feldman (2000) extends this framework arguing that change and flexibility in routines concerns more than choosing from

might require a customer database, for example, which is neither a routine itself nor does it resemble a routine in the way that the working of complex equipment sometimes does. The database is, instead, a contextual requisite of some of the organizational routines supporting the capability" (Dosi, Nelson, \& Winter, 2000: 4).

${ }^{39}$ See Pentland and Rueter (1994) for an in-depth discussion of this question.

${ }^{40}$ See also Van Driel and Dolfsma (2009) for a discussion of the relation between routines and pathdependence. 
among a repertoire of responses, and that the repertoire itself and the rules that govern choice within a repertoire can also change. Therefore, she recognizes that routines can be considered as sources continuous flexibility and change. Feldman and Pentland (2003) also recognize flexibility of routines by emphasizing that execution of routines is not an invariant reflection of the expectations which have motivated their creation: routine actors may react to the outcomes of prior routine iterations and thus rebuild their initial cognitive structure.

\subsection{Creation and evolution of dynamic capabilities: The capability lifecycle and some complementary insights}

Different interpretations on how dynamic capabilities emerge, develop, and change over time have been made. For the integrative (Teece et al., 1997) and the innovation routines approaches (Zollo \& Winter, 2002), learning from accumulated experience and path-dependency play a key role in dynamic capability creation and development. By contrast, Eisenhard and Martin (2000) propose that role of experience and learning is contingent on the degree of environmental dynamism. As a whole, considering routines as the main constituent element of dynamic capabilities involves the recognition of learning and experience accumulation as key aspects of their creation and evolution (Zollo \& Winter, 2002; Helfat \& Peteraf, 2003). As stressed by Pisano (Pisano, 2000: 129) "Without learning, it is difficult to imagine from where a firm's unique skills and competencies would come, and thus how it might create a competitive advantage".

The innovation routines approach (Zollo \& Winter, 2002) is the one offering a deeper view of the phenomenon. According to these authors, routines (and hence dynamic capabilities) arise from purposeful learning investments, rather than from ad hoc problem solving in response to changing environmental demands. In particular, these authors combine two complementary learning approaches. On the one hand, they view experience accumulation (behavioral learning) as the necessary basis on which routines (hence, dynamic capabilities) built and evolve. On the other, Zollo and Winter (2002) emphasize a more deliberate process involving articulation and codification of the knowledge generated from accumulating experience (cognitive learning). These systematic learning mechanisms represent the actual routine-building (capabilitybuilding) mechanisms. From this optic, dynamic capabilities are conceived as collections of search routines ${ }^{41}$ that modify operating ones, therefore, the evolution of dynamic capabilities relates to the exploration-exploitation dilemma (Danneels, 2002): firms need to have learnt (and routinized) how to do specific things in superior ways but, simultaneously, in order to remain

\footnotetext{
${ }^{41}$ In this line, some scholars coin the term 'meta-routines' or high-order routines that modify existing ones and guide the search and selection of new routines [see Van Driel and Dolfsma (2009) for an indepth discussion].
} 
successful over time, they need to have learnt (and routinized) how to change the way specific things are usually done.

Scholars have provided other complementary insights into the creation and evolution of dynamic capabilities. First, creating capabilities corresponds not only to the opportunity to change existing firm routines but also to managerial expectations concerning the valuecreation implications of undertaking such changes (Adner \& Helfat, 2003; Ambrosini \& Bowman, 2009). Thus, it is key the managerial comparison between expected costs and benefits associated with such decisions (Winter, 2003). Managerial decisions regarding the development and redeployment of dynamic capabilities operate on the firm's resource base (Adner \& Helfat, 2003), differences in resource endowments (i.e., positions and paths) thus leading to possible differences in capability-building (and capability-redeployment) incentives across firms (Ambrosini \& Bowman, 2009). As stated by Zúñiga-Vicente, de la Fuente-Sabaté and SuárezGonzález (2005: 239), "it is impossible to explain strategy without considering certain managerial characteristics of the decision-maker". This perspective resonates closely with the notion of capabilities as real options (Kogut \& Kulatilaka, 2001a). Strategy is view as an option chain, where prior investment and the resulting organizational learning is a required precondition to make new ongoing related investments (Bowman \& Hurry, 1993). As Kogut and Kulatilaka (2001a) stress, managers cannot easily adjust existing organizational capabilities to emergent market opportunities because of inertia. Amongst other factors, managerial commitment to current strategy is one of the cited causes of such inertia (e.g., Sánchez-Peinado, Sánchez-Peinado, Escribá-Esteve, 2010). Consequently, only managers that have made preliminary investments in the appropriate capabilities are able to react to opportunities in a timely manner. Therefore, capabilities can be considered as real options because they build up gradually, representing strategic investment platforms which confer upon firms the potential to exploit future strategic opportunities.

Resonating closely with such real options reasoning, Helfat and Peteraf (2003) provide a capability lifecycle model ${ }^{42}$. The underlying premise is that an organization has a capability when the building process has reached a minimum threshold that permits reliable performance of an activity. These authors identify three main developmental paths or lifecycle stages that unfold sequentially: the founding stage (which lays the basis for subsequent development of the

\footnotetext{
${ }^{42}$ Although we use it to explain how dynamic capabilities emerge and develop over time, Helfat and Peteraf (2003) are explicit in making their capability lifecycle model adaptable to any kind of capability, whether dynamic or ordinary. In fact, they conceive their contribution as an attempt to explain how firms' heterogeneity arises and, therefore, to offer a 'dynamic resource based view' that links together the various strands of the RBV (including thus, the DCV). Furthermore, given that capabilities are collection of routines (Winter, 2003), insights from this capability lifecycle model can be useful in explaining the evolutionary dynamics of routines themselves.
} 
capability and do not necessarily involve a blank slate), the development stage (during which capability is gradually built combining purposeful investments and experience accumulation), and the maturity stage (in which capability building ceases and, if regularly exercised, become deeply embedded in organizational memory). Additionally, Helfat and Peteraf (2003) identify six lifecycle branches [retirement (death), retrenchment, renewal, replication, redeployment, and recombination] or potential trajectories that capabilities may follow as a consequence of internal/external selection events once it has reached a minimum level of functionality (i.e., at the development or maturity stages). Selection events may be identified by managers either as 'capability opportunities' leading to further investments or replications of the capability (i.e., renewal, replication, redeployment, and recombination) or as 'capability threats' often leading to the full or gradual abandon of the capability (i.e., retirement and retrenchment). Selection events may refer to both endogenous and exogenous factors. After all, dynamic capabilities are complex entities in this regard (García-Muina, Martín-de-Castro, López-Sáez, \& Navas-López, 2006).

\subsubsection{Empirical research into dynamic capabilities}

As a whole, important scholarly efforts have been made to empirically apply the conceptual foundations of dynamic capabilities within several fields of research. By doing so, dynamic capabilities have been brought close to practice, which is a clear symptom of progress of the field (Easterby-Smith et al., 2009; Di Stefano, Peteraf, \& Verona, 2010). In the following, an overview of existing empirical research on dynamic capabilities is provided [See Appendix I.9 for a summary], first following the structure proposed by Di Steffano et al. (2010) as displayed in Figure 1.7, and then describing the research design employed by studies in the field.

Figure 1.7. Empirical research into dynamic capabilities

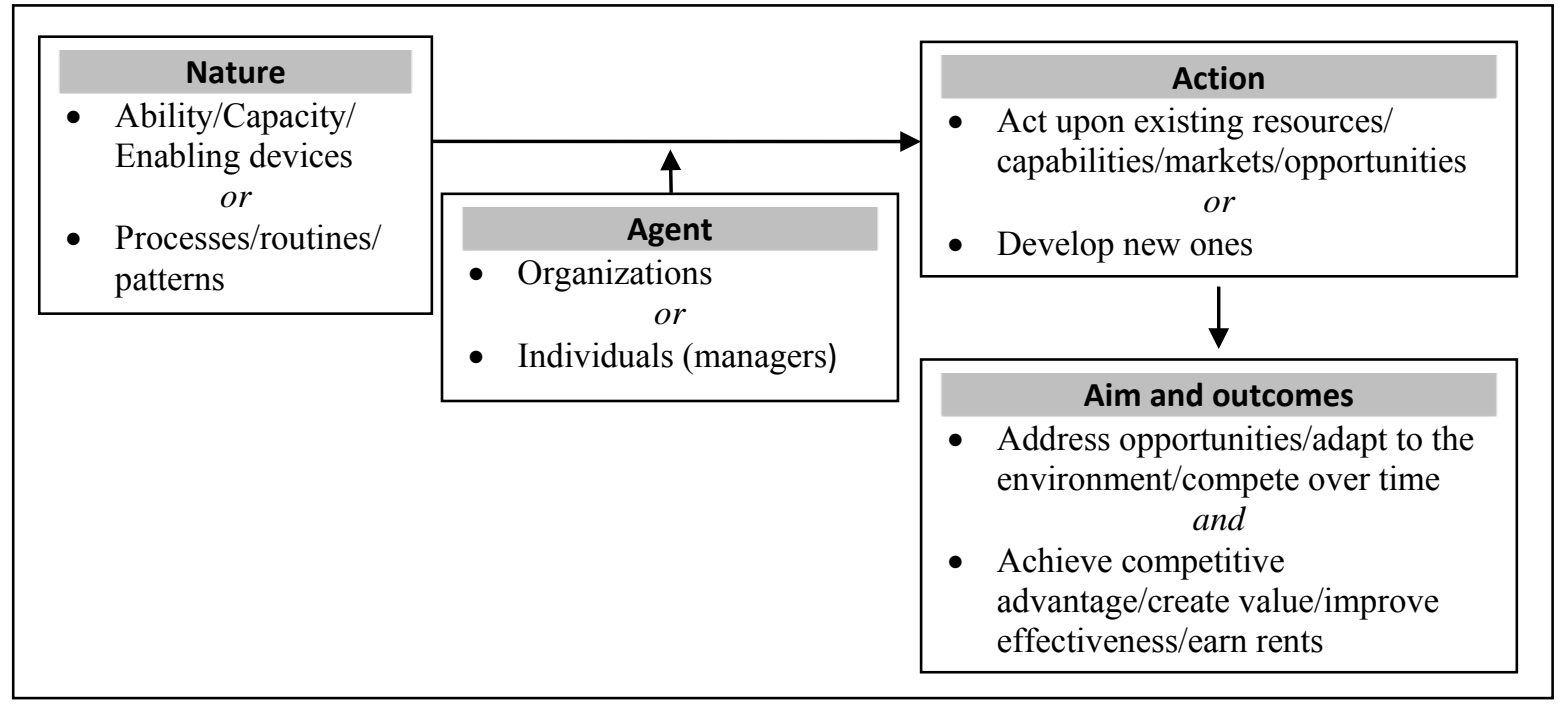

Source: Adapted from Di Stefano et al. (2010) 
The nature of dynamic capabilities (i.e., 'what' are dynamic capabilities). Two broad interpretations can be found in existing empirical research (Easterby-Smith \& Prieto, 2008; Di Stefano et al., 2010): Dynamic capabilities as latent actions (i.e., in terms of abilities, capacity, or enabling devices) or as processes, routines or behavioral patterns (i.e., in terms of their constituent elements). Examples for the former can be found in Helfat (1997), Deeds, Decarolis and Coombs (2000), King and Tucci (2002), and Adner and Helfat (2003). Thus, King and Tucci (2002: 171) stress that "the ability to respond to a new market is part of organizational capabilities called 'dynamic capabilities'. The alternative view (i.e., dynamic capabilities in terms of their constituent routines), less common in empirical research, is illustrated by works like Petroni (1998), Zollo, Reuer and Singh (2002) (2002), Prieto, Revilla, and Rodríguez-Prado (2009), and Wiklund and Shepherd (2009). For example, Prieto et al. (2009) concentrate on the processes of knowledge generation, integration, and reconfiguration as the core of dynamic capabilities in the field of new product development.

The agent of dynamic capabilities (i.e., 'who' possess and executes the dynamic capability). Most studies take the organization as the unit of analysis. Accordingly, they concentrate on general organizational capabilities [e.g., capabilities in the context of organizational change (e.g., Rindova \& Kotha, 2001)] or capabilities to pursue particular strategies [e.g., innovation: R\&D capabilities, new product development capabilities (e.g., Petroni, 1998), and absorptive capacity (e.g., Lane \& Lubatkin, 1998); new market entry (King \& Tucci, 2002); alliances and acquisitions (e.g., Wiklund \& Shepherd, 2009)] ${ }^{43}$. A less common perspective taken in empirical research is the individual level of analysis ${ }^{44}$. Studies like Adner and Helfat (2003) and Newert, (2005) link decision-making processes to dynamic capabilities, mainly focusing on managers as the agents of dynamic capabilities. Managerial capabilities are thus viewed as those with which managers built, integrate, and reconfigure resources and competences (Adner \& Helfat, 2003; Newbert, 2005). From such managerial perspective, several strategic situations have been studied. For example, Adner and Helfat (2003) analyze downsizing decisions in the petroleum industry and Newbert (2005) views the dynamic capability of new firm formation as a process executed at the individual level.

\footnotetext{
43 These capabilities have not always been explicitly treated as dynamic capabilities. Clear examples are absorptive capacity [see Zahra and George (2002)] and alliance capabilities [we return to this point later].

${ }^{44}$ Obviously, managers are always responsible for decision-making and, broadly speaking, individuals who form organizations are the actors of such processes. Empirical research into dynamic capabilities relies explicitly or implicitly on this assumption, which is pointed out by Teece et al. (1997) and Eisenhartd and Martin (2000). The basic difference with this group of studies, therefore, is that they explicitly view individuals (and particularly, managers) as the agents of dynamic capabilities.
} 
The action, aim, and outcomes of dynamic capabilities. Empirical studies in the dynamic capabilities field also vary concerning the action of dynamic capabilities (i.e., whether they act upon existing resources/capabilities/markets or developed new ones), the aim of such actions (i.e., whether they are aimed to deal with environmental changes, or simply to successfully compete over time or to address new opportunities) and, consequently, concerning the outcomes of dynamic capabilities (i.e., whether they provide competitive advantage, create value, improve effectiveness or simply allow the firm to earn rents). For example, studies like Tripsas (1997) and Rosembloom (2000) study the role of dynamic capabilities in retaining firm's market position in the face of radical technological change, the two first focusing on the creation of new technological capabilities, whereas the latter focusing on change in existing dynamic capabilities. Rindova and Kotha (2001) focus on achievement/maintenance of competitive advantage through dynamic capabilities in contexts subject to high degrees of technological dynamism where continuous change is required to compete successfully over time. Studies like Deeds, Decarolis and Combs (2000) and Bruni and Verona (2009) examine how either improvement in existing firm's dynamic capabilities or creation of new ones can yield value creation or improvement of firm's performance. As a summary, it can be mentioned the line of reasoning linking dynamic capabilities to the discover and capture of new technological opportunities (e.g., Nieto \& Quevedo, 2005).

Research design adopted within empirical research into dynamic capabilities. In this regard, two broad types of studies can be identified: qualitative case-based studies and quantitative large-sample studies ${ }^{45}$. According to Easterby-Smith et al. (2009), both methodologies possess strengths and weakness, summarized in Table 1.3.

An important conclusion from the above discussion is that measuring adequately dynamic capabilities remains as an important challenge (Ambrosini \& Bowman, 2009; Arend \& Bromiley, 2009) ${ }^{46} 47$. This point is retaken below.

\footnotetext{
${ }^{45}$ Note that case studies can rely on both quantitative and qualitative methods of analysis - we return to methodological questions in next chapter. Thus, the terms 'qualitative study' and 'case study' are not interchangeable in general (Yin, 2003) but in empirical dynamic capabilities research such correspondence clearly exists (i.e., case studies have tended to use qualitative approaches). An exception is the early work of Camuffo and Volpato (1996).

${ }^{46}$ This difficulty in measurement is part of a larger problem of organizational capabilities and lies in their inherent inobservability. Deeping down, it is fully coherent with the theoretical assumptions of the field. As Dutta, Natrasimhan and Rajiv (2005) reason, if dynamic capabilities are indeed hard to observe, they would be hard to imitate or buy, as the DCV and, more broadly, the RBV suggest.

${ }^{47}$ Dutta et al. (2005) have recently developed a parametric approach that non-tautologically estimates organizational capabilities. However, the method is not already adapted to estimate dynamic capabilities.
} 
Table 1.3. Case study vs. Large-sample studies: Relative strengths and weaknesses

\begin{tabular}{|c|c|c|}
\hline Research design & Strengths & Weaknesses \\
\hline $\begin{array}{l}\text { Case studies } \\
\text { (e.g., Petroni, 1998; Galunic \& } \\
\text { Eisenhardt, 2001; Rindova \& Kotha, } \\
\text { 2001; Verona \& Ravasi, 2003) }\end{array}$ & $\begin{array}{l}\text { Qualitative longitudinal designs } \\
\text { - Enrich and refine existing } \\
\text { understanding of DCs, by } \\
\text { means of detailed narratives, } \\
\text { (e.g., descriptions of routines } \\
\text { and of their creation and } \\
\text { evolution) }\end{array}$ & $\begin{array}{l}\text { - Abstraction in relevant } \\
\text { constructs and relationships } \\
\text { - Lack of formal } \\
\text { operationalization of DCs }\end{array}$ \\
\hline $\begin{array}{l}\text { Large-sample studies } \\
\text { (e.g., Helfat, 1997; King \& Tucci, } \\
\text { 2002; Prieto et al., 2009; Wiklund \& } \\
\text { Shepherd, 2009) }\end{array}$ & $\begin{array}{l}\text { Quantitative methods provide: } \\
\text { - More precise definitions and } \\
\text { formal measures } \\
\text { - More explicit identification } \\
\text { of interactions between } \\
\text { relevant factors (e.g., } \\
\text { managerial and } \\
\text { environmental factors) }\end{array}$ & $\begin{array}{l}\text { - Mismatch between research } \\
\text { design (static, cross- } \\
\text { sectional) and the dynamic } \\
\text { nature of DCs } \\
\text { - Inadequate operationalization }\end{array}$ \\
\hline
\end{tabular}

Source: Own elaboration

\subsubsection{Main shortcomings in the dynamic capabilities field}

Although the DCV has become an influential framework in strategic management research and academic conversation on dynamic capabilities has experienced notable success over the last decade, it is still in its infancy (Zahra et al., 2006; Di Stefano et al., 2010). Indeed, titles of recent contributions like "What are dynamic capabilities and are they a useful construct in strategic management?" (Ambrosini \& Bowman, 2009) suggest that the concept, nature and consequences of dynamic capabilities remain open for debate. Based on prior reviews of the framework (Zahra et al., 2006; Ambrosini \& Bowman, 2009; Arend \& Bromiley, 2009; Easterby-Smith et al., 2009), a key shortcoming of the dynamic capabilities field is the existence of logical inconsistencies that become noticeable when the notion of dynamic capabilities is applied in empirical research. In particular, Teece et al. (1997), stress that the three elements of dynamic capabilities (processes, position, and paths) must be the units of analysis of the framework. More recently, Teece (2007) discusses the need to adopt a micro-level perspective, using the term 'microfoundations of dynamic capabilities' to refer to distinct skills, processes, procedures, organizational structures, decision rules, and disciplines which undergird the sensing, seizing, and reconfiguring dimensions of dynamic capabilities (Teece, 2007: 1321). By conceptualizing dynamic capabilities as collections of routines, Zollo and Winter (2000) and Winter (2003) emphasize the need to focus on routines as the main building blocks (or microfoundations) of dynamic capabilities (Dosi, Nelson, \& Winter, 2000). 
However, existing empirical research has usually studies dynamic capabilities from a more macro-level perspective, treating thus dynamic capabilities as 'black boxes'. Some empirical studies infer the existence of dynamic capabilities from performance, investments or experience (e.g., Tripsas, 1997; Wiklund \& Shepherd, 2009; Anand et al., 2010) overlooking that dynamic capabilities consist of routines. In this regard, it can be said that prior research has paid attention to position and paths but has overlooked the most important element of dynamic capabilities: processes (Teece et al., 1997; Eisenhardt \& Martin, 2000; Zollo \& Winter, 2002). Furthermore, contributors who discuss methodology in the dynamic capabilities field (e.g., Verona \& Ravasi, 2003; Ambrosini \& Bowman, 2009) highlight the need for conducting longitudinal studies, whether qualitative or quantitative, in order to provide relevant insights into the practice of dynamic capabilities by actually capturing their dynamic essence (Teece \& Pisano, 1994). Within the less and more recently developed stream of research directly addressing routines as the constituent elements of dynamic capabilities (McKelvie \& Davidsson, 2009; e.g., Prieto et al., 2009), large-sample quantitative studies have tended to adopted static cross-sectional designs thus overlooking the processual nature of routines, whereas qualitative studies and case studies often do not provide formal operationalization (e.g., Galunic \& Eisenhardt, 2001; Verona \& Ravasi, 2003).

These logical inconsistencies give rise to the second shortcoming of the dynamic capabilities field: dynamics of dynamic capabilities are still not well understood (Zahra et al., 2006; Ambrosini \& Bowman, 2009; Easterby-Smith et al., 2009). Although research supports the key role played by experience and learning, lack of focus on routines as units of analysis (or by doing so from a static macro-level perspective), leaves unresolved the important questions of how and through which developmental paths dynamic capabilities are built over time (Helfat \& Peteraf, 2003). According to Wolfgang and Stefan (2010), these inconsistencies of the dynamic capabilities field are not surprising, insofar the notion of dynamic capabilities builds on the notion of routines and research on routines itself suffers from inconsistency (Becker, 2004). In this regard, Pentland and Feldman (2005) identify two broad approaches for studying routines as units of analysis. The first and most common approach is treating routines themselves as 'black boxes', which is simple, may provide important insights about antecedents and consequences of routines, but it is indeed not accurate and provides a narrow understanding of the constituent elements of dynamic capabilities. The second and much less common approach pointed out by these authors involves opening the 'black box' and studying the internal structure of routines, which is more complex but may provide a more fine-grained understanding of the constituent elements of dynamic capabilities by either focusing on one some of the elements of 
routines (see section 1.1.2.1. and Appendix I.8 for more details about routines) or on the interactions among these elements.

Opening the 'black boxes' of both dynamic capabilities and routines may allow research to provide compelling answers to questions concerning the dynamics of dynamic capabilities (Helfat \& Peteraf, 2003; Pentland \& Feldman, 2005; Teece, 2007). First, opening the 'black box' of dynamic capabilities may enable the study of how learning and experience relates to the creation and evolution of capabilities, by emphasizing dynamic capabilities as collection of routines which in turn are built upon purposeful learning investments (Zollo \& Winter, 2002). Second, opening the 'black box' of routines themselves may enable understanding of the internal dynamics of routines and thus shedding light on how these purposeful learning investments emerge, develop and evolve over time (Pentland \& Feldman, 2005).

\subsubsection{Linking dynamic capabilities and strategic alliances}

The notions of dynamic capabilities and strategic alliances can be linked to each other using two distinct but closely related lines of reasoning. These two lines of reasoning in turn reflected the two kinds of alliance-related sources of competitive advantage considered by RBV scholars (Ireland et al., 2002) and previously described in this chapter (see section 1.1.1.1). as shown in Figure 1.8.

Figure 1.8. Linking dynamic capabilities and strategic alliances

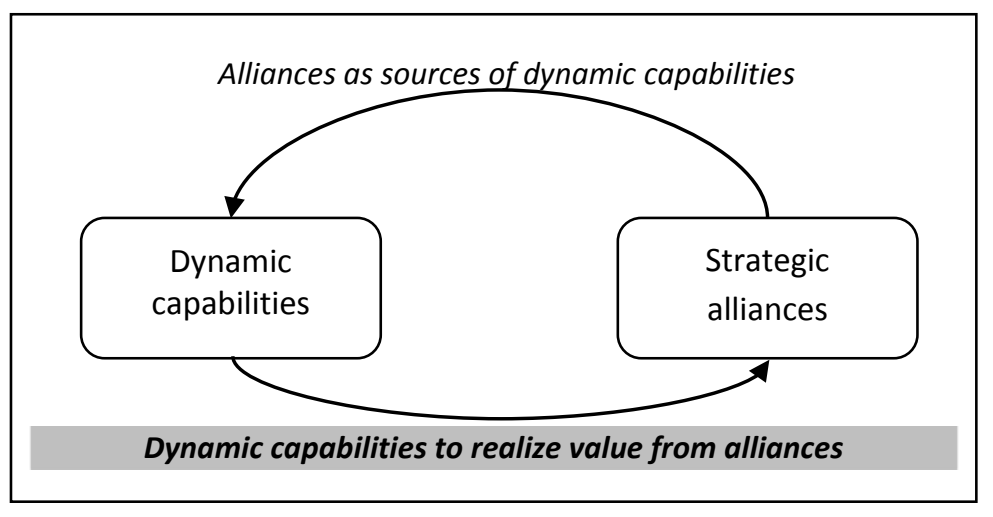

Source: Own elaboration

On the one hand, strategic alliances are explicitly cited in the dynamic capabilities literature as important external sources of knowledge [see, for example, Teece et al. (1997: 518-520) or Eisenhardt and Martin (2000: 1109)]. A first type of 'alliance-related competitive advantage' thus resides in the alliance potential to change and enhance existing resource and ordinary capabilities and, in particular, to create new dynamic capabilities (Teece et al., 1997; Eisenhardt \& Martin, 2000). On the other, potential for value creation offered by alliances- and this is central to this dissertation- is different from the effective realization of such value (Madhok \& 
Tallman, 1998). Therefore, the firm requires specific dynamic capabilities to take advantage of such potential. As discussed, some alliance scholars have also advocated for this logic (e.g., Anand \& Khanna, 2000; Kale et al., 2002; Kale \& Singh, 2007): some firms are systematically successful in extracting value from their strategic alliances (or at least they achieve relatively superior alliance performance) whereas others systematically fail to do so (or at least they achieve relatively inferior alliance performance). Thus, the notion of alliance capabilities as the second type of 'alliance-related competitive advantage' emerges.

Alliance scholars have recently started to systematically study those alliance capabilities, which have been broadly defined as 'abilities to create value through alliances by anticipating alliance contingencies occurring during all phases of the collaborative lifecycle and responding to them in an effective manner' (Simonin, 1997; Anand \& Khanna, 2000) [See Appendix I.10 for other definitions]. In the following, an overview of existing research on alliance capabilities is presented, highlighting then its main contributions and limitations. Subsequently, alliance capabilities are conceptualized as a particular type of dynamic capabilities. The section concludes with a statement about the adequacy of the dynamic capabilities view as a key underpinning of this dissertation.

\subsubsection{Alliance capabilities: An overview of existing research}

From an in-depth review of this literature, three different foci of analysis can be identified, as represented in Figure 1.9.: (1) the antecedents of alliance capabilities, (2) alliance capabilities in terms of either their underlying mechanisms or their dimensions), and (3) the consequences of alliance capabilities [See Appendix I.10 also for a summary of this literature review and see De Man et al., (2010) and Kale and Singh (2009) for other reviews].

Figure 1.9. Foci of analysis in alliance capabilities research

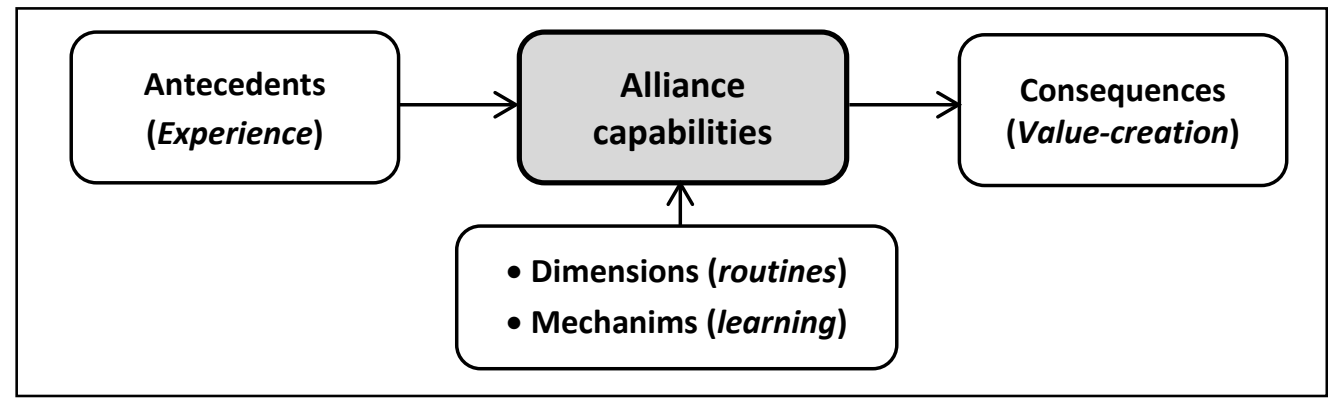

Source: Own elaboration

Antecedents refer to factors underlying the creation of alliance capabilities. By analogy with notion of capabilities in general (e.g., Winter, 2003), scholars have identified alliance experience as the main antecedent of alliance capabilities. For example, Simonin (1997) 
distinguishes between structural and functional alliance experience and finds that collaborative know-how is cumulatively built upon them. Similarly, Anand and Khanna (2000) report that firms learn to create value from alliances and thus develop alliance capability particularly as they accumulate R\&D joint ventures experiences. From a different but related perspective, the research by Rothaermel and Deeds (2006) emphasizes the path-dependence nature of the alliance management capability and find that alliance experience moderates the relationship between formation of R\&D alliances and biotechnological firms' performance in terms of new product development. The research by Kim and Inkpen (2005) reveals that alliance-experienced firms are more likely to benefit in terms of technology learning in alliances. As a whole, this research supports the role of accumulative alliance experience in building alliance capabilities. Put differently, firm's alliances outcomes are interdependent and application of lessons learned in a focal alliance may have spillover effects on other concurrent and subsequent firm's alliances (Heimeriks \& Duysters, 2007).

A basic premise of this literature is that alliance experience accumulation is not a sufficient condition and that alliance capabilities only can be built "if the lessons of this (alliance) experience are internalized by the firm and drawn into specific know-how that can be used to guide future actions" (Simonin, 1997: 1167). This is what Kale and Singh (2007) refers to as 'alliance learning process', which in turn gives rise to the study of underlying learning mechanisms. These mechanisms are defined as managerial tools that support an organization's alliance activity and the processes of articulation, codification, sharing, and internalization of alliance management know-how generated from alliance experiences (Kale et al., 2002). Existing research has provided relevant insights in this regard, supporting that firms need to count on managerial and coordinative mechanisms in order to effective capitalize on past alliance experiences (Draulans et al., 2003; De Man \& Duysters, 2005). Although other hard alliance mechanisms have been studies, research emphasizes the key role play by a dedicated alliance function (e.g., Kale et al., 2002; Kale \& Singh, 2007) defined as "a structural mechanism, in the form of a separate organizational unit or team of managers, responsible for managing and coordinating a firm's alliance activity" (Kale and Singh, 2007: 983). Draulans et al. (2003) suggest other three main alliance management tools (alliance evaluation, alliance training, and alliance specialist) and confirm their contribution to alliance success introducing contingent effects of alliance experience.

Some studies have reacted to existing overemphasis on alliance experience and alliance mechanisms, arguing that this research "does not directly conceptualize or measure alliance capability; it simply implies its existence by showing how factors that underlie its development lead to greater alliance success" (Schreiner et al., 2009: 1398). This research stream thus 
concentrates on dimensions of alliance capabilities as their constituent elements, representing thus what alliance capabilities actually are (Simonin, 1997; Walter et al., 2006; Sarkar et al., 2009; Schreiner et al., 2009). Scholars have offered different perspectives on which are the dimensions of alliance capabilities [See Appendix I.10 for a detailed description] at different levels (e.g., firm-level, network level, and alliance portfolio level). However, all these perspectives seem to support Simonin's (1997) notion of collaborative know-how, defined as a multifaceted construct that concerns the main alliance lifecycles stages, including thus skills for alliance formation (e.g., identifying and selecting potential partners and negotiating the structure of the alliance) and post-formation (e.g., monitoring, managing, and terminating the collaboration).

Within the emergent body of research into alliance capabilities, scholars have also look at the consequences or value-creation implications of these capabilities. At the firm-level, empirical evidence supports the argument that alliance capabilities bring firms alliance tangible benefits, like economic profits (e.g., Simonin, 1997; Walter et al., 2006) or stock market gains (e.g., Anand \& Khanna, 2000; Kale et al., 2002), as well as more intangible benefits such as interfirm learning (e.g., Simonin, 1997; Kale \& Singh, 2007), satisfaction (e.g., Zollo et al., 2002), or the enhancement of firm's reputation as a partner of choice (e.g., Sarkar et al., 2009). At the alliance-level, for example, Sarkar et al., (2009) find that alliance portfolio management capability leads to competitiveness and strength of relationships within the portfolio. Focusing on post-formation dynamics of alliances, Schreiner et al. (2009) report that the firm's alliance management capability promotes joint action between partners, and thus the fulfillment of alliance goals as well.

\subsubsection{Research on alliance capabilities: Main contributions and shortcomings}

The literature review presented in the above section yields the conclusion that research on alliance capabilities has provided valuable insights by clearly supporting the existence of specific capabilities to form, manage, and terminate alliances and thus confirming its core tenet: alliance capabilities may represent sources of competitive advantage since they explain heterogeneity in firms' realization of value from alliances (Kale \& Singh, 2009; De Man et al., 2010).

However, some shortcomings may also be identified in the field of alliance capabilities. These shortcomings in the alliance capabilities field, which is also considered to be an emerging field (De Man et al., 2010), resemble those already discussed for the dynamic capabilities field (see section 1.1.2.3. in this chapter). Therefore, alliance capabilities have usually been studied rather from a more macro-level ('black box') perspective than from a micro-level perspective (Teece, 
2007). By analogy with the notion of capabilities in general (Winter, 2003), the notion of 'dimensions of alliance capabilities as their constituent elements' represent by definition collaborative routines (Zollo et al., 2002) [The notion of collaborative routines is discussed in next section]. However, dimensions of alliance capabilities, when directly studied, have not been systematically treated from a routine perspective (i.e., the 'black box' of collaborative routines remain unexplored), and research has often adopted non-longitudinal designs (e.g., Sarkar et al., 2009; Schreiner et al., 2009). Overlooking that alliance capabilities' dimensions are collaborative routines (and overlooking their longitudinal nature) has impeded existing research to unveil the dynamics of alliance capabilities. In this regard, it is clear from received wisdom that alliance capabilities consist of collaborative routines built upon accumulation of collaborative experience (e.g., Simonin, 1997; Anand \& Khanna, 2000). However, the developmental processes along which collaborative routines, thus alliance capabilities, create and evolve remain unknown (De Man et al., 2010). In particular, the conducted literature review allows us to recognize that existing research has left unresolved the questions of (1) how the alliance capability-building process commences (i.e., in the presence of lack of alliance experience), and (2) how the capability-redeployment process takes place (i.e., how already built alliance capabilities are transferred into subsequent collaborations). The three empirical studies of this dissertation represent attempts to contribute in these two directions.

\subsubsection{Alliance capabilities as dynamic capabilities: Focus on collaborative routines}

Existing literature on alliance capabilities rarely informs about the nature of such capabilities (i.e., whether they are ordinary and thus just allow firms to 'make a living' though alliances or they are dynamic capabilities by definition) [See Schilke and Goerzen (2010) and Wiklund and Shepherd (2009) for two exceptions]. This dissertation takes the position that alliance capabilities are a particular type of dynamic capabilities (Wiklund \& Shepherd, 2009; Schilke \& Goerzen, 2010). To justify the dynamic nature of alliance capabilities, alliance capabilities may be linked to the three points of consensus in the dynamic capabilities field identified previously in this chapter (i.e., dynamic capabilities are different from ordinary capabilities, lead to value creation in contexts of some degree of dynamism, and routines are the building blocks of dynamic capabilities).

Alliance capabilities are dynamic capabilities (and not ordinary capabilities). Alliance capabilities represent a particular kind of dynamic capabilities, since they allow integration, building, and reconfiguration of internal and external resources from alliances (Ireland et al., 2002; Rothaermel \& Deeds, 2006; Heimeriks \& Duysters, 2007; Teece, 2007; Schreiner et al., 
2009; Schilke \& Goerzen, 2010). Furthermore, changes in resources and low-order capabilities are the visible outcomes of these dynamic alliance capabilities (Simonin, 1997; Kale et al., 2002; Winter, 2003; Anand et al., 2010). In this line, Heimeriks and Duysters (2007) define alliance capability as a higher-order resource that is difficult to obtain and imitate and has the potential to enhance the performance of the firm's alliance portfolio. Integrating the proposals of Teece (2007), and Schilke and Goerzen $(2010)^{48}$ and other alliance scholars (e.g., Simonin, 1997; Sarkar et al., 2009; Schreiner et al., 2009) alliance capabilities could be conceptualized as displayed in Table 1.4.

Table 1.4. 'Dynamic' alliance capabilities and collaborative routines

\begin{tabular}{|c|c|c|c|}
\hline $\begin{array}{l}\text { Dimensions } \\
\text { of dynamic } \\
\text { capabilities }\end{array}$ & \multicolumn{2}{|c|}{$\begin{array}{l}\text { Dimensions of alliance capabilities } \\
\text { (collaborative routines) }\end{array}$} & References \\
\hline $\begin{array}{l}\text { Sensing } \\
\text { opportunities }\end{array}$ & $\begin{array}{l}\text { Sensing alliance opportunities: } \\
\text { Discovering and promoting new } \\
\text { alliance opportunities } \\
\text { (formation stage) }\end{array}$ & $\begin{array}{l}\text { - } \text { Identifying and } \\
\text { selecting new areas for } \\
\text { collaboration } \\
\text { - } \text { Identifying and } \\
\text { selecting potential } \\
\text { partners }\end{array}$ & $\begin{array}{l}\text { (Simonin, 1997; } \\
\text { Sarkar et al., 2001b; } \\
\text { Sarkar et al., 2009; } \\
\text { Schilke \& Goerzen, } \\
\text { 2010) }\end{array}$ \\
\hline $\begin{array}{l}\text { Seizing } \\
\text { opportunities }\end{array}$ & $\begin{array}{l}\text { Seizing alliance opportunities: } \\
\text { Addressing alliance management } \\
\text { challenges (formation and post- } \\
\text { formation stages) }\end{array}$ & $\begin{array}{l}\text { - } \text { Coordination } \\
\text { - Joint work } \\
\text { - Problem-solving } \\
\text { - Knowledge-sharing }\end{array}$ & $\begin{array}{l}\text { (Mohr \& Spekman, } \\
\text { 1994; Walter et al., } \\
\text { 2006; Sarkar et al., } \\
\text { 2009; Schreiner et al., } \\
\text { 2009; Schilke \& } \\
\text { Goerzen, 2010) }\end{array}$ \\
\hline
\end{tabular}

Source: Own elaboration

Alliance capabilities contribute to explain value creation in alliances. In the DCV, dynamic capabilities are at the center-stage to explain value creation in contexts characterized by certain degree of dynamism (Teece et al., 1997; Eisenhardt \& Martin, 2000; Zollo \& Winter, 2002; Teece, 2007). In order to justify why alliance capabilities can contribute to explain value creation in alliances, the value-creation properties attributed to dynamic capabilities in genera ${ }^{49}$ can be translated into the alliance context. Indeed, the literature on strategic alliances is riddle

\footnotetext{
${ }^{48}$ In a recent contribution, Teece (2007) refines and extends his initial framework reacting to received criticisms [See Appendix I.7]. He proposes that dynamic capabilities can be disaggregated into capabilities of sensing (and shaping) opportunities and threats, capabilities of seizing opportunities, and capabilities of managing threats and reconfiguration. In order to integrate such new ideas with those exposed in the initial work, he asserts that the processes of coordination/integration, learning, and reconfiguration "are a subset of the processes that support sensing, seizing, and managing threats" (Teece, 2007: 1341). The proposal of Schilken and Goerzen (2010) for alliance dynamic capabilities follows Teece's (2007).

${ }^{49}$ According to Drnevich and Kriauciunas (2011), the value-creation contribution of dynamic capabilities can occur in at least three ways: dynamic capabilities can allow the firm to (1) identify and respond to new opportunities, (2) improve the effectiveness and efficiency with which a firm responds to environmental challenges, and (3) offer previously unavailable sets of decision options for the firm.
} 
with similar statements about such value-creation properties in which the term dynamic capabilities is replaced with the term strategic alliance. However, dynamic capabilities are the potential to do things in a particular way, not the things that are done (Easterby-Smith \& Prieto, 2008). Consequently, alliance capabilities, alliance activity (e.g., number and type of alliances in the firm's alliance portfolio or the firm's cumulative alliance experience), and alliance performance are different things ${ }^{50}$. Alliance capabilities act as the missing link between the potential for value creation offered by strategic alliances and the actual realization of such value (Madhok \& Tallman, 1998). As can be deduced from the previous review of the alliance capabilities field (see also above Table 1.4.), alliance capabilities can allow the firm to (1) identify and respond to new alliance opportunities (e.g., Simonin, 1997; Sarkar et al., 2001b; Sarkar et al., 2009), (2) improve the effectiveness and efficiency with which a firm operates and responds to alliance challenges(e.g., Simonin, 1997; Walter et al., 2006; Sarkar et al., 2009; Schreiner et al., 2009), and (3) offer previously unavailable sets of collaborative options for the firm (e.g., Ahuja, 2000; Kale \& Singh, 2007; Sarkar et al., 2009) ${ }^{51}$. In support of the two first arguments, Simonin (1997) finds that collaborative know-how comprises a wide range of skills required to make the most along the whole alliance lifecycle: skills in identifying and selecting potential partners; skills in negotiating the structure of the alliance, and skills in monitoring, managing, and terminating the collaboration. Likewise, alliance capabilities may enhance the range of future collaborative opportunities available to the firm (Ahuja, 2000), amongst other, by creating strong relationships with partners, reinforcing the reputation of the firm as a partner of choice, and broadening its network of contacts with, partners of partners, and so on (Kale \& Singh, 2007; Sarkar et al., 2009; Schreiner et al., 2009).

Collaborative routines as the main constituent elements of alliance capabilities. Alliance capabilities are not 'black boxes' (Zollo et al., 2002; Pentland \& Feldman, 2005). Rather they are composed of collaborative routines or patterns of interaction in the collaborative context (Zollo et al., 2002). In fact, a fine-grained criticism of existing research linking alliance experience and alliance performance is that collaborative routines act as the missing link in this research (Simonin, 1997; Schilke, 2007). Therefore, alliance capabilities encompass collaborative routines that determine how the firm takes its alliance-related decisions and, consequently, how the firm carries out its alliance activity. In this line, Wiklund and Shepherd

\footnotetext{
${ }^{50}$ In fact, a basic criticism of existing research into alliance capabilities is that, by focusing on indicators of firm's alliance activity like the number and type of alliances or indicators of firm- and alliance-level performance (e.g., Anand \& Khanna, 2000; Anand, Oriani, \& Vassolo, 2010), alliance capabilities are not actually captured (Schreiner et al., 2009; De Man et al., 2010).

${ }^{51}$ For simplification purposes, we limit the set of decision options to collaborative options, although other kind of opportunities could be also included (e.g., new business opportunities).
} 
(2009: 196) state that "firm's routines that bring in and integrate newly accessed resources from alliances (and acquisitions) constitute an important dynamic capability". The following section provides further insights on collaborative routines.

\subsection{Collaborative routines: Two levels of analysis}

Relying on the same arguments discussed for the case of dynamic capabilities in general (see section 1.1.2.3.), the position in this dissertation is that alliance capabilities (and in particular its developmental dynamics) can be better understood from a 'microfoundation' perspective (Teece, 2007). In particular, focusing on collaborative routines as the main constituent elements of alliance capabilities (Zollo et al., 2002; Teece, 2007) may enable a more comprehensive study of their creation and evolution dynamics (Pentland \& Feldman, 2005).

Considering the two main levels of analysis existing in alliance research (see section 1.1.1.4), it is possible to make a conceptual distinction between collaborative routines at the organizational level (partner-level) and collaborative routines at the inter-organizational level, as displayed in Figure 1.10. In support of these arguments, Ziggers and Tjemkes (Ziggers \& Tjemkes, 2010) find that the link between alliance performance and individual alliance capabilities are mediated by alliance management and relational quality between the partners, factors related to their capability to collaborate together.

Figure 1.10. Levels of alliance capabilities (and routines)

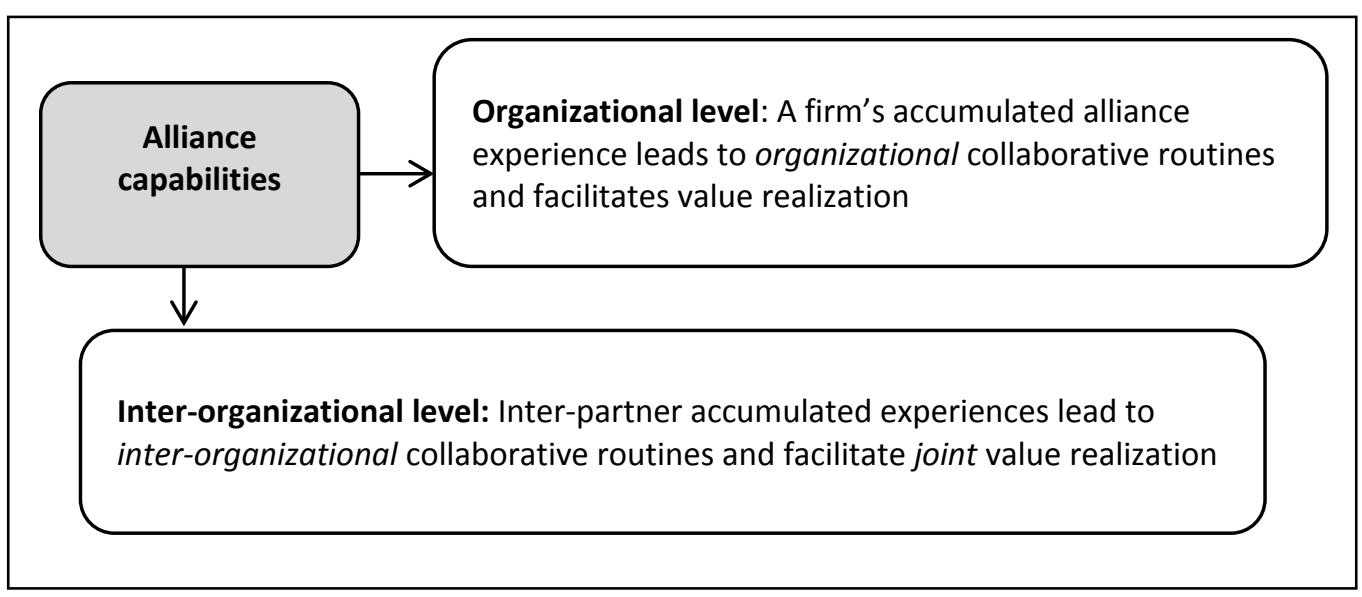

Source: Own elaboration

Organizational collaborative routines are partner-level routines that (a) have to do with a firm's individual alliance capability, (b) represent purposeful learning investments made by that individual firm through accumulation of alliance experiences with diverse alliance partners and in diverse collaborative contexts (Simonin, 1997; Zollo \& Winter, 2002), and (c) can allow that firm to create value from its alliance activity (Anand \& Khanna, 2000; Anand et al., 2010). In 
this regard, existing research (see above Table 1.4.) allows the identification of several key collaborative routines like those related to sensing new alliance opportunities, selecting adequate alliance partners, and exchanging knowledge, coordinating, jointly working, and solving problems with them. Collaborative routines, for example, determine how the firm identifies alliancing opportunities, how the firm manages and governs its ongoing alliances and, more specifically, how the firm exchanges knowledge with its alliance partners, what methods adopts for solving problems, how it coordinates its own alliance tasks with those of partners in the alliance arena (e.g., Simonin, 1997; Sarkar et al., 2009; Schreiner et al., 2009), and so on. Interestingly, De Man, Duysters, \& Saebi (2010) introduce the notion of the soft side of alliance capabilities, highlighting it deserves further investigation. In alliance research, the soft side of alliance management refers to 'intangible' attributes of trust and commitment characterizing the collaborative relationship (Cullen et al., 2000). Therefore collaborative routines located at the soft side of alliance capabilities are linked to relational norms in alliances, describing the pattern of partners' cooperative actions and behaviors (De Man et al., 2010). Since routines are behavioral regularities (Becker, 2004), a conceptual analogy can be traced between cooperative behavior and such soft collaborative routines. Building on these premises, Study I of this dissertation aims to extend understanding on the creation of these collaborative routines.

As discussed, the partner-level of analysis is the prevailing perspective in the strategic alliances field, and research on alliance capabilities is not an exception in this regard (e.g., Simonin, 1997; Sarkar et al., 2009; Schreiner et al., 2009). However, some alliance scholars (e.g., Dyer \& Nobeoka, 2000; Zollo et al., 2002) have moved from the organizational to the interorganizational level of analysis, focusing on inter-organizational collaborative routines. These routines are defined as stable patterns of interaction among several specific organizations developed and refined in the course of repeated collaborations (Dyer \& Singh, 1998; Zollo \& Winter, 2002). From these works, it can be concluded that inter-organizational routines (a) have to do with the capability of two (or more) partners to collaborate together, (b) represent purposeful learning investments made by those partners in a coordinated fashion through accumulation of mutual alliance experiences over time, and (c) can allow those partners to realize joint value from their mutual alliance activity. In this regard, the key collaborative routines identified above at the organizational level could be framed into the interorganizational level as collaborative routines of two (or more) specific partners to sense new opportunities to collaborate together, exchange knowledge, coordinate, jointly work, and solve problems with each other. For example, Zollo et al. (2002) highlight the role played by interfirm cooperation and coordination routines, finding that partner-specific experience positively impacts alliance performance, particularly in nonequity-based alliances. In this regard, other 
studies focusing on partner-specific experience also contribute to indirectly support the role played by inter-organizational routines in the collaborative context (e.g., Reuer et al., 2002; Hoang \& Rothaermel, 2005; Gulati et al., 2009).

Furthermore, scholars in this tradition have placed emphasis on a particular type of interorganizational routines: knowledge-sharing routines or recurrent patterns of inter-partner interactions that, when effective, permit the mutual transfer, recombination and/or creation of specialized knowledge in the alliance (Dyer \& Singh, 1998; Dyer \& Nobeoka, 2000). Such an emphasis is largely influenced by the relational view (RV) of alliances which describes knowledge-sharing routines as important sources of relational rents (Dyer \& Singh, 1998). Relying on this premise, Dyer and Nobeoka (2000) explain the creation of knowledge-sharing routines in the Toyota's network, showing that the company provides its suppliers with strong incentives to engage in network-level exchange activities by incorporating a relational philosophy into its actions (e.g. banishing the concept of proprietary knowledge from the network, promoting bilateral and multilateral interactions within it, and providing intense technical support to its suppliers). Dyer and Hatch (2006) demonstrate that those routines contribute to explain Toyota's competitive advantage vis-à-vis its rivals. Study II of this dissertation represents another attempt to understand the creation, evolution, and value-creation impact of these knowledge-sharing routines. Van Driel and Dolfsma (2009) reexamine the Toyota production routines in light of the notions of path-dependence and meta-routines and concluded that although competitors have imitated many features of the Toyota's system, the continuous application of underlying meta-routines has given Toyota's way of producing a unique dynamic nature.

\subsection{Research objectives of the dissertation}

\subsubsection{Defining research objectives}

As advanced, the definition of research objectives in this dissertation (See Figure 1.11) has been conducted by iteratively reviewing existing literature and collecting and analyzing data on the Acuisost Consortium. This dual process, characteristic of case-study methodology (Yin, 2003), allowed the definition of a general research objective, motivated by a general gap identified in the strategic alliances literature ${ }^{52}$. Subsequent theoretical and empirical efforts of the dissertation are structured around this general research objective, which is specified in two more

\footnotetext{
${ }^{52}$ Indeed the doctoral education of the PhD candidate has been linked from the very beginning to the field of strategic alliances. In this regard, the review of the strategic alliances literature conducted during the two first years of the doctoral period (2006-2008) yielded the conclusion that research on multi-partner alliances was scarce. Known this, the Acuisost Consortium was selected as the research setting of this dissertation.
} 
narrow objectives. They in turn comprise several research questions, reflecting both other more specific research gaps and the idiosyncrasy of the research setting of this dissertation.

Figure 1.11. Research objectives and research questions in this dissertation

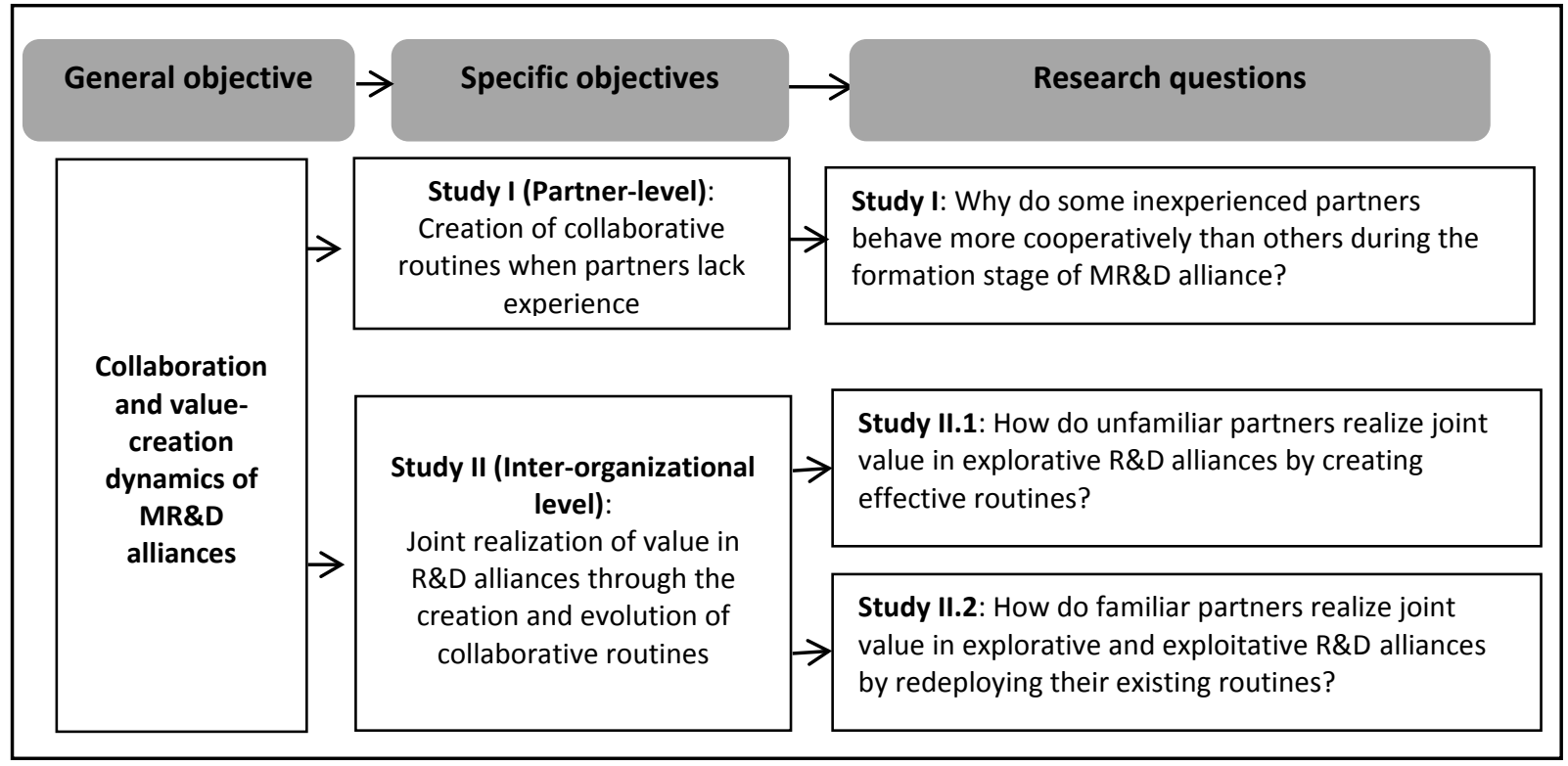

\subsubsection{Research gaps, research objectives, and introduction to empirical studies}

Multi-partner $R \& D(M R \& D)$ alliances, and $R \& D$ consortia in particular, are becoming an increasingly important phenomenon in the business landscape, more and more encouraged by public policies through the world. These alliances constitute valuable strategies to deal with the competitive challenge of continuously explore and exploit innovation opportunities, by creating multilateral discussion forums and combinations of dissimilar resources (Sakakibara, 1997; Doz et al., 2000; Mothe \& Quelin, 2001). At the same time, however, MR\&D alliances entail highly complex scenarios for inter-partner interaction and dual relationships (Das \& Teng, 2002; Lavie et al., 2007; Thorgren et al., 2010); MR\&D alliances thus impose significant challenges for cooperation and value realization (García-Canal et al., 2003; Zeng \& Chen, 2003; Gong et al., 2007).

Existing literature offers some important insights about the intriguing collaboration and valuecreation dynamics of MR\&D alliances (e.g., Olk \& Young, 1997; Lavie et al., 2007; Mahnke \& Overby, 2008). However, research in MR\&D alliances is relatively scarce, reflecting the imbalance between dyadic and multi-partner settings in the strategic alliance fields (Das \& Teng, 2002). Furthermore, research in MR\&D alliances have tended to concentrated on partial aspects of the phenomenon, such as partners' decision to stay or leave the alliance (Olk \& Young, 1997) or partners' commitment and resource creation in R\&D consortia (Mothe \& Quelin, 2001). As a result, several important questions remain underexplored and a 
comprehensive view on the collaboration and value-creation dynamics of these complex alliances is still lacking. Without providing such a comprehensive view, research will remain unable to provide useful guides for managing MR\&D alliances in practice. This general gap in research (and the consequences of inattention for business practice) gives meaning to this dissertation as a whole, motivating its general research objective:

\section{General research objective}

This doctoral dissertation aims to contribute to a more comprehensive view of the collaboration and value-creation dynamics of MR\&D alliances.

To accomplish this general research objective, as mentioned, this dissertation relies on case study methodology and focuses on a real-life MR\&D alliance as its research setting: The Acuisost Consortium ${ }^{53}$. The Acuisost Consortium is a domestic contractual MR\&D alliance formed for the period 2007-2010, seeking to foster sustainable development of aquaculture in Spain by innovating in key areas to ensure the industry's competitiveness and survival. In addition to Grupo Dibaq, which acted as the lead firm of the consortium, two kinds of participants got involved in the Acuisost Consortium: firms (holding the status of partners of the consortium) and research organizations (not holding the status of consortium's partners but of technological partners of the consortium firms).

Furthermore, this dissertation tries to overcome two common limitations of existing strategic alliances research. The first one concerns the imbalance between structure- and process-oriented perspective in alliance research: the processes of collaboration are 'often called but rarely studied' (Salk, 2005). Therefore, the collaboration and value-creation dynamics of MR\&D alliances are addressed in this dissertation from a markedly process-oriented perspective (Ring \& Van de Ven, 1994; Doz, 1996; Salk, 2005). In particular, the processes of collaboration are framed in this dissertation in terms of creation and evolution of collaborative routines [or stable patterns of behavior and interaction in the collaborative context developed out of alliance's experience accumulation (Zollo et al., 2002)]. Existing research states that there is an important gap between the value potential offered by strategic alliances and the effective realization of such value, the latter depending on the partners' capabilities to collaborate (i.e., alliance capabilities) (Madhok \& Tallman, 1998). Alliance capabilities represent a particular kind of dynamic capabilities, since they allow integration, building, and reconfiguration of internal and external resources from alliances (Teece, 2007; Schilke \& Goerzen, 2010). Collaborative routines in turn represent the constituent elements of those capabilities (Winter, 2003). Existing research on alliance capabilities, though providing some important insights, have not paid

\footnotetext{
${ }^{53}$ The Acuisost Consortium will be further described in Chapter 2.
} 
enough attention to collaborative routines and thus have failed to properly explain the dynamics of alliance capabilities.

The second limitation commonly present in the strategic alliances field refers to the tendency of conducting single-level studies instead of multi-level studies, whilst alliances represent multilevel phenomena by definition (Hagedoorn, 2006; Nielsen, 2010). In this dissertation, the two kind of collaborative relationships that coexist in MR\&D alliances (i.e., generalized and bilateral exchanges) leads to the identification of two important levels of analysis: (1) collaboration among the multiple partners to conduct the R\&D consortium's project as a whole, and (2) dyadic collaboration between specific pairs of partners to conduct specific parts of that R\&D project. Likewise, alliance capabilities (and thus collaborative routines) could be referred to two conceptual levels: the partner- and the inter-organizational level (Simonin, 1997; Dyer \& Singh, 1998; Zollo et al., 2002; Lavie, 2006). At the partner-level (i.e., a partner's capability to collaborate), collaborative routines represent organizational patterns of interaction and behavior in the collaborative context, which are built as that partner accumulates individual alliance experience. At the inter-organizational level (i.e., two or more partners' capabilities to collaborate together), collaborative routines represent inter-partner patterns of interaction and behavior in a joint collaborative context, which are built as those partners accumulate mutual alliance experience. Therefore, this dissertation examines the creation and evolution of collaborative routines at both levels, referring to the two kinds of relationships coexisting in MR\&D alliances. Following this multi-level reasoning, the general aim of this dissertation is defined as a two-fold objective comprising two more specific objectives. Each of them will be addressed in the different empirical studies of the dissertation, as explained in the following.

\section{Study I. The formation stage of the Acuisost Consortium}

Firms with little or none alliance experience (e.g., small firms and firms active in industries other than high-tech) are more and more getting involved in MR\&D alliances, often encouraged by public policies, seeking to profit from the great innovation opportunities afforded by this kind of alliances. This phenomenon entails a complex collaborative situation: Inexperienced firms, lacking the adequate routines, join a MR\&D alliance and have to learn to cooperate in such a multi-partner setting (Anand \& Khanna, 2000; Doz et al., 2000; Sampson, 2005). Existing research ventures the difficulty inexperienced firms may find in creating collaborative routines in MR\&D alliances but has not explored the phenomenon to an extent enough to provide useful managerial recommendations. This specific gap in research (and the consequences of inattention for business practice) gives meaning to the first empirical study of the dissertation, motivating its specific research objective: 


\section{Specific research objective (I)}

In the context of MR\&D alliances, Study I of this doctoral dissertation aims to improve existing understanding of the creation of organizational collaborative routines when partners lack significant alliance experience.

In the setting of MR\&D alliances, the formation stage is particularly critical (Doz et al., 2000). During this stage, achieving cooperation among the multiple partners ${ }^{54}$ is simultaneously essential and challenging (Anderson \& Narus, 1990; Zeng \& Chen, 2003). Cooperative behavior (the analogous concept of cooperation at the partner level) could be understood as a collaborative routine located at the soft side of alliance capabilities (Ariño, 2001; De Man et al., 2010). In this context, existing literature suggests that inexperienced partners may feel particularly vulnerable in multi-partner settings (Zollo et al., 2002). However, the reality is that, under the same unfavorable conditions, some inexperienced partners do make the leap to cooperation, whereas others do not. Indeed, we observed varying levels of partner's cooperative behavior during the formation stage of the Acuisost Consortium: weak (ten partners), medium (three partners), and strong (five partners). Existing research, so far, has not fully explained the causes of such disequilibrium. Therefore, Study I, relying on insights from several frameworks (i.e., social exchange and social network theories, resource-based and dynamic capabilities views), addresses the following question:

\section{Research question Study I:}

Why do some inexperienced partners behave more cooperatively than others during the formation stage of MR\&D alliances?

\section{Study II. Firm-Research organization collaboration in the Acuisost Consortium}

A prolific stream of research on R\&D alliances has been recently developed, reflecting the notable importance of this kind of collaborative activities in current business practice (e.g., Oxley \& Sampson, 2004; Sampson, 2005; Sampson, 2007). In particular, an intriguing scholarly debate exists on how the interplay between the existence of prior ties between partners (familiar vs. unfamiliar partners) and the innovation-seeking orientation of $R \& D$ alliances (exploration vs. exploitation) impact R\&D alliance performance (e.g., Hoang \& Rothaermel, 2005; Tiwana, 2008; Gulati et al., 2009). This open debate in research, together with the importance of mutual experience among partners in R\&D consortia (Doz et al., 2000), motivate the specific research objective that will be addressed in the second empirical study of the dissertation:

\footnotetext{
${ }^{54}$ The relational norm of cooperation entails complementary coordinated actions taken by partners to achieve mutual outcomes or private outcomes with expected reciprocity over time (Anderson \& Narus, 1990: 45).
} 


\section{Specific research objective (II)}

In the context of MR\&D alliances, Study II of this doctoral dissertation aims to improve existing understanding of the value-creation dynamics of $R \& D$ alliances by focusing on the creation and evolution of inter-organizational collaborative routines.

The portfolio of dyadic R\&D alliances between firms and research organizations embedded in the Acuisost Consortium may provide interesting insights to this debate. In the Acuisost Consortium, some explorative alliances between firms and research organizations lacking a prior history of collaboration proved really successful, whereas other dramatically failed. By contrast, those agreements between firms and research organizations with long histories of join collaboration usually proved successful, regardless the explorative or exploitative nature of their technical objectives. Accordingly, empirical efforts to accomplish this research objective are structured in two specific studies addressing different but complementary parts of the debate on R\&D alliances: Explorative R\&D alliances formed by unfamiliar partners (Study II.1.) and $R \& D$ alliances (explorative and exploitative) formed by familiar partners (Study II.2.). Both empirical studies focus on a particular kind of routines, which has been pointed out by the literature as particularly important in the R\&D context (Mowery, Oxley, \& Silverman, 1996; Dyer \& Singh, 1998; Dyer \& Nobeoka, 2000; Dyer \& Hatch, 2006): knowledge-sharing routines or those that, when effective, permit the mutual transfer, recombination and/or creation of specialized knowledge in the alliance (Dyer \& Singh, 1998; Dyer \& Nobeoka, 2000).

\section{Study II.1. Unfamiliar partners and value-creation dynamics in explorative alliances}

Concerning this debate, two conflicting postures coexist: some scholars argue that unfamiliar partners are likely to succeed at exploration because they bring to each other novel knowledge resources(Parkhe, 1991; Uzzi, 1997; Goerzen, 2007), whereas other scholars predict failure of these alliances arguing that unfamiliar partners lack inter-organizational routines (Parkhe, 1991; Madhok \& Tallman, 1998; Zollo et al., 2002). Despite some attempts to reconcile both postures (e.g., Hoang \& Rothaermel, 2005; Gulati et al., 2009), prior research has provided contradictory and ambiguous evidence, mainly because it has not directly looked at the processes of collaboration (Ring \& Van de Ven, 1994; Salk, 2005). In particular, existing research has not sufficiently examined whether and how unfamiliar partners could be able to build effective inter-organizational knowledge-sharing routines, and how technological complementarities and relational dissimilarities influence such a process. As a result, value-creation dynamics in explorative $R \& D$ alliances formed by unfamiliar partners remain as a 'black box'. Without properly disentangling these processes, useful managerial recommendations could not be provided on how to manage successfully collaboration with unfamiliar partners. Given these antecedents, Study II.1 addresses the following research question, integrating insights from the 
literatures on routines (dynamic capabilities and relational views) and psychological contracts (e.g., Rousseau \& Tijoriwala, 1998):

\section{Research question Study II.1:}

How do unfamiliar partners can realize joint value in explorative $R \& D$ alliances by creating effective knowledge-sharing routines?

Study II.1. Familiar partners and value-creation in explorative and exploitative alliances

Recent research has started to challenge the traditional 'paradox of embeddedness' (Uzzi, 1997), which predicts that familiar partners are likely to succeed at exploitation and to fail at exploration. Emphasis is place on how inter-organizational collaborative routines (Dyer and Singh, 1998; Zollo et al., 2002) may allow familiar partners to succeed at both exploration and exploitation (e.g., Tiwana, 2008). However, empirical research has not always provided conclusive evidence in this regard (e.g., Hoang \& Rothaermel, 2005; Gulati et al., 2009; Phelps, 2010). The main reason is that it has not directly looked at the processes of collaboration (Ring \& Van de Ven, 1994; Salk, 2005): prior research has usually concentrated on a focal alliance, overlooking that it is embedded in a broader collaborative relationship. Moreover, existing research has not unveiled how familiar partners jointly transfer their inter-organizational routines into a new joint collaborative scenario (i.e., the process of routines redeployment). Without properly studying these aspects, useful managerial recommendations could not be provided on how to manage successfully collaboration with familiar partners. Combining insights from the literatures on routines (dynamic capabilities and relational views) and real options (e.g., Kogut \& Kulatilaka, 2001b), Study II.2 addresses the following question:

\section{Research question Study II.2:}

How do familiar partners can realize joint value in explorative and exploitative $R \& D$ alliances by redeploying their existing knowledge-sharing routines? 

CHAPTER 2.

'METHODOLOGY AND RESEARCH DESIGN: DATA COLLECTION AND ANALYSIS' 


\section{Chapter structure}

2.1. Case study methodology and research design 73

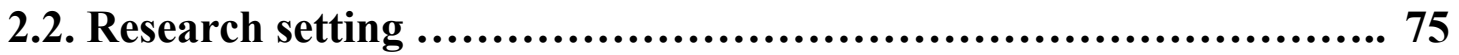

2.2.1. Selection and description of the Acuisost Consortium................ 76

2.2.1.1. Overview of the Acuisost Consortium.............................. 76

2.2.1.2. Selection of the Acuisost Consortium.............................. 77

2.2.1.3. Description of the Acuisost Consortium...................... 80

2.2.1.3.1. Institutional framework: The CENIT Programme............. 80

2.2.1.3.2. Industrial context: The field of aquaculture in Spain........... 82

2.2.1.3.3. Objectives and technical and organizational structure............ 84

2.2.1.3.4. Participants of the Acuisost Consortium........................ 88

2.2.1.4. A longitudinal description of the Acuisost Consortium............. 95

2.2.1.4.1. The formation stage...................................... 96

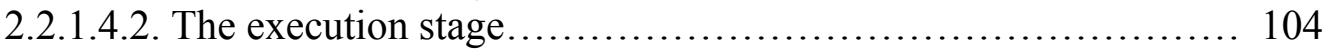

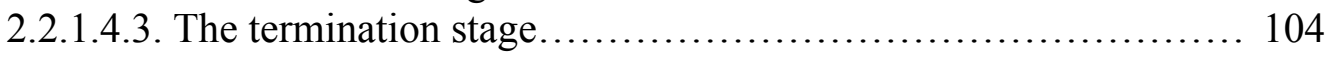

2.2.2. Selection of multi-cases for particular studies...................... 105

2.3. Data collection and analysis: Quality of the research................ 106

2.3.1. Data collection: principles and process.............................. 106

2.3.1.1. Data collection principles.................................... 106

2.3.1.2. Process of data collection ...................................... 109

2.3.2. Data analysis: Process, levels and methods of analysis ................ 114

2.3.2.1. Selection of diverse levels of analysis: multi-level research.......... 115

2.3.2.2. Selection of diverse methods of analysis: multi-method research.... 116

2.3.3. Tests of quality research......................................... 118

2.4. Outline of methodology ................................................ 121 
"...If you look historically at the strategy literature [...] the most powerful ideas did not come out of multiple examples. They came out of single-industry studies and case studies".

C.K. Prahalad

The Life's Work of a Thought Leader $(2009)^{1}$

The preceding chapter has presented the conceptual basis and research objectives of this dissertation. This chapter is devoted, first, to justify the use of case study methodology to address those research objectives, describing its research design. Next section addresses the selection of the Acuisost Consortium as the research setting of this dissertation and of the specific cases studied in the empirical chapters. Subsequently, the processes of data collection and analysis are explained, presenting the measures adopted to ensure the quality of the research As a summary, the main characteristics of the research design of the empirical studies are finally presented.

\subsection{Case study methodology and research design}

This dissertation conducts an in-depth longitudinal study of a real-life R\&D consortium (i.e., the Acuisost Consortium), investigating different but complementary phenomena at different levels of analysis. Therefore, this dissertation employs a case study methodology ${ }^{2}$. Although there are multiple definitions and understandings of case study methodology, Yin (2003: 13-14) offers a comprehensive and well-accepted definition: "A case study is an empirical inquiry that investigates a contemporary phenomenon within its real-life context, especially when the boundaries of phenomenon and context are not clearly evident".

Broadly speaking, case study research offers some advantages respect to other research strategies. For example, a major strength of case study research lies in its capacity to examine a phenomenon within its real context: large-scale research may intend to deal with phenomenon and context but often fails to reveal complex social processes in which the phenomenon is embedded (Yin, 2003). Compared to conceptual studies, "one can offer a purely theoretical motivation, but one that is grounded in real-life situation is usually much more appealing (Siggelkow, 2007: 21-23). Importantly, case study theorists have emphasized the distinctions between qualitative research and case study. Thus, Eisenhardt (1989: 534-535) explains that "case studies typically combine data collection methods such as archives,

\footnotetext{
${ }^{1}$ Interview to C.K. Prahalad, available at http://www.strategy-business.com/article/00043 (last access: December 2011).

${ }^{2}$ As Bonache (1999) notes, there are some scholarly debate about the denomination of the case study research as a method or as a methodology. The term 'methodology' will be used to refer to a general strategy to investigate a research question (or a set of research questions), whereas the term 'method' will refer to a specific technique used to analyse data.
} 
interviews, questionnaires, and observations. The evidence may be qualitative (e.g., words), quantitative (e.g., numbers) or both". In this regard, Yin (2003: 14) emphasizes the nature of case study as a research strategy that "comprises an all-encompassing method (covering the logic of design, data collection techniques, and specific to data analysis)" and not "a data collection tactic or merely a design feature alone". Furthermore, case study theorists have emphasized an important difference between case study and large sample research: the analytical power of case study research resides in the principle of analytical generalization or its capacity to build, expand, and generalize theories (instead of statistical generalization of findings as occurs in large-sample research) (Eisenhardt, 1989; Yin, 2003). Yin (2003) points out that the traditional criticism of 'lack of rigor' of case study research is rooted in the confusion between these two kinds of generalization (together with the fact that case study researchers sometimes fail to explain the systematic nature of their inquiry). See, for example, Nieto and Pérez (2000) for a discussion of these aspects applied in the field of management.

As explained, the general research objective of this dissertation is to improve understanding into the collaboration and value-creation dynamics of MR\&D alliances by focusing on the creation and evolution of collaborative routines. This general research objective gives rises to two more specific research objectives and several research questions guiding the research efforts in this dissertation. In line with the first specific objective, Study I. addresses the question of 'Why do some inexperienced partners behave more cooperatively than others during the formation stage of MR\&D alliances?' In line with the second specific objective of this dissertation, Study II addresses the questions of 'How do unfamiliar partners realize joint value in explorative R\&D alliances by creating effective routines?' and 'How do familiar partners realize joint value in explorative and exploitative R\&D alliances by redeploying their existing routines?'

In light of these objectives, the choice of case study methodology in this dissertation is justified by the following three reasons. First, case study research is particularly appropriate to investigate 'how' and 'why' questions which refer to a contemporary set of events on which the investigators has little or no control (Yin, 2003). Therefore, case study research fits the nature of the research questions of this dissertation, formulated on the basis that internal dynamics of alliances do not emerge and evolve in isolated bubbles but in close connection with the context in which they are embedded (Ariño \& de la Torre, 1998; Koza \& Lewin, 1998). Second, case study research is particularly appropriate to deal with links among variables that mobilize multiple observations needing to be traced longitudinally over time (Pettigrew, 1990; Yin, 2003; Eisenhardt \& Graebner, 2007). In this regard, case study research has been described as a sort of 'gold standard' for process-oriented research in strategic alliances (Salk, 2005). Third, case study research is particularly appropriate to examine phenomena on which the state of the art leaves open several fundamental questions yielding the necessity of rethink existing theory and/or to build new conceptual insights (Eisenhardt, 1989; Yin, 2003; Eisenhardt \& Graebner, 2007). Concerning the two last reasons, case study methodology in this dissertation is 
justified because, as explained, in-depth process research is needed to capture the complexities of inter-organizational collaboration (Smith, Carroll, \& Ashford, 1995; Madhok \& Tallman, 1998). More specifically, it is need to rethink and extend existing theory (a) to further explain the processes of collaboration and value-creation in MR\&D alliances (Doz et al., 2000; Das \& Teng, 2002) and (b) to clarify the developmental processes of collaborative routines adopting research designs which are consistent with their processes' nature (Dyer \& Nobeoka, 2000; Rerup \& Feldman, 2011).

According to the main existing typologies of case study research (See Appendix II.1), it could be said that this dissertation, as a whole, adopts an embedded design, aiming at both theory-testing and theorybuilding $^{3}$ (Yin, 2003; Eisenhardt, 1989) on different aspects of the processes of collaboration and value-creation in MR\&D alliances. However, the designs of the particular Studies of this dissertation nuanced this description. In particular, Study I adopts a multi-case design and Study II.1 and Study II.2 adopt comparative designs of two different pair of cases, both associated to rigor and replication logic in case study research (Eisenhardt, 1989; Yin, 2003). This dual design, taking the Acuisiost Consortium as the research setting, has generated an embedded case-study on the Acuisost Consortium, which allows a more fine-grained understanding on the phenomenon under study than holistic designs (Leonard-Barton, 1990; Yin, 2003) and thus fits better the multi-level nature of collaboration and value-creation dynamics of MR\&D alliances than single-level research (Nielsen, 2010).

Following Yin (2003), a complete description of the research design should contain descriptions of four more specific and interconnected elements: (1) research questions of the study, (2) theoretical 'a priori' propositions (if any), (3) level/s of analysis, (4) analytic strategy followed to link data to propositions (if any) and/or interpret case study findings. The corresponding description of these elements, some of which have been already advanced in this section, will be provided through the next sections of this chapter.

\subsection{Research setting}

This section is devoted to present the research setting and the particular cases on which this dissertation focuses, as well as to justify their selection. Accordingly, an overview of the research setting (i.e., the Acuisost Consortium) is first presented, in order to put the rest of subsequent sections in context. Next, the reasons underlying the selection of the Acuisost Consortium as the research setting are explained. A detailed description of this research setting follows, specifying the structure of the Acuisost Consortium in both technical and organizational terms, and presenting the different consortium participants. This picture of the Acuisost Consortium is completed with a description of its

\footnotetext{
${ }^{3}$ According to Colquitt and Zapata-Phelan (2007), theory-testing is the empirical process by which existing theory is applied as a means of grounding a specific test of a priori propositions, while theory-building is the empirical process that clarifies or supplements existing theory or introduces relationships and constructs that serve as the foundations for new theory.
} 
evolution from a lifecycle perspective. The section concludes by presenting the selection of particular cases within the Acuisost Consortium for in-depth examination in each of the empirical Studies of the dissertation.

\subsubsection{Selection and description of the Acuisost Consortium}

In this section, the reasons justifying the selection of the Acuisost Consortium as a research setting of this dissertation are displayed, providing first an overview and then a detailed description of its main characteristics and participants. Finally, emphasis is placed on the longitudinal nature of the Acuisost Consortium case.

\subsubsection{Overview of the ACUISOST Consortium}

The Acuisost Consortium represents a domestic multi-partner R\&D alliance, organised as a formal contractual R\&D consortium (not involving the creation of a new venture, like a joint venture or an Economic Interest Grouping). Table 2.1. summarizes its main characteristics.

Table 2.1. Characterization of the Acuisost Consortium

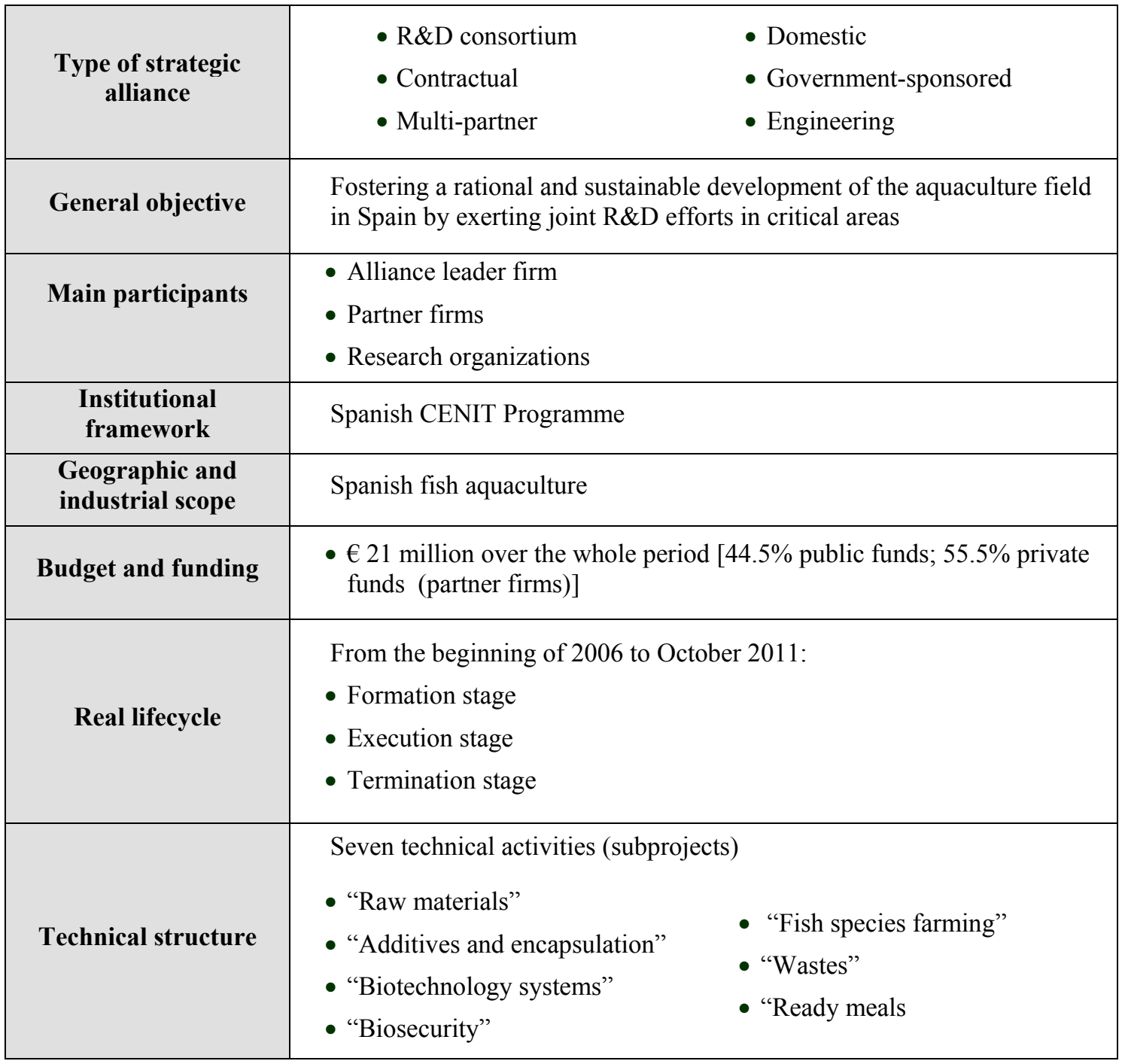

Source: Own elaboration based on Acuisost Consortium's private documents. 
The general objective of the Acuisost Consortium was to foster rational and sustainable development of the Spanish fish aquaculture by developing innovation in critical areas (improvement of fish nutrition, biosecurity, waste management, and enhancement of the added value of fish aquaculture products). To accomplish this general research objective, other seven more specific objectives were defined, supporting the structuration of the consortium along seven technical activities (or subprojects).

According to the typology of Doz et al. (2000) the formation of the Acuisost Consortium followed engineering pathway (i.e., was induced by a triggering entity). Furthermore, the Acuisost Consortium was government-sponsored under the Spanish CENIT Programme (National Strategic Consortia for Technical Research Programme), an instrument of the Spanish National Plan for Scientific Research, Development and Technological Innovation (2008-2011). Therefore, the consortium project was cofinanced between public and private actors (from the total budget of 21 million euros, the grant from the CENIT Programme covers the $44.5 \%$ ).

In line with the stipulations of the CENIT programme, two main categories of alliance participants can be recognised in the Acuisost Consortium: partner firms (from which a specific partner acts as the consortium lead firm) and research organizations. The main difference among them lies in their participation conditions: firms held the status of partners of the Acuisost Consortium, whereas research organizations were in charge of the research processes but do not hold the status of formal partners of the consortium. Rather, they are linked to the partner firms through private R\&D contracts (acting thus as the 'technological partners of the consortium firms'). Therefore, two kinds of collaborative relationships can be identified in the Acuisost Consortium: collaboration between the partner firms of the consortium (which signed together the 'consortium agreement') and dyadic collaboration between partner firms and research organizations (which signed private bilateral R\&D contracts).

Collaboration in CENIT Consortia should take place during a four-year period (from 2007 to 2010 in the case of the Acuisost Consortium), comprising four technical annuities. However, as we will explain later, the real alliance lifecycle of the Acuisost Consortium covered a longer period comprising three stages: (1) formation stage (from 2006 to January 2008), (2) execution stage (from January 2008 to December 2010), and (3) termination stage (from December 2010 to October 2011).

\subsubsection{Selection of the Acuisost Consortium}

As a general rationale, Yin (2003) states that single-case designs are appropriated when the case represents the critical, unique, representative, revelatory, and/or longitudinal case. Without denying the superior analytical power of multi-case designs due to replication logic (Eisenhardt 1989; Nieto \& Pérez, 2000), it is important to note that analytical generalization is also possible from a single case 
(Dyer \& Wilkins, 1991; Yin, 2003). Regardless the number of cases, "research involving case data can usually get much closer to theoretical constructs and provide a much more persuasive argument about causal forces that broad empirical research can" (Siggelkow, 2007: 22-23). The choice of the singlecase (or, more precisely the single 'research setting') in this dissertation, however, deserves more specific justification (Yin, 2003).

As summarized in Table 2.2 and explained below, the Acuisost Consortium was selected as the research setting of this dissertation following three main criteria, commonly employed in case study research (e.g., Eisenhardt, 1989; Yin, 2003): representativeness, attractiveness, and opportunity.

Table 2.2. Reasons for selection of the Acuisost Consortium as the research setting

\begin{tabular}{|l|l|}
\hline \multirow{2}{*}{ Representativeness } & $\begin{array}{l}\text { The Acuisost Consortium is a multi-partner R\&D alliance which seeks to create } \\
\text { value through collaboration among multiple participants by developing } \\
\text { innovation in critical areas }\end{array}$ \\
\hline \multirow{2}{*}{ Attractiveness } & $\begin{array}{l}\text { - Longitudinal, contemporaneous case } \\
\text { - Clear definition of lifecycle stages } \\
\text { - Complex formation stage: engineering, government-sponsored, crisis } \\
\text { - Interesting industrial context (aquaculture) }\end{array}$ \\
\hline - Inexperienced partner firms \\
- Explorative and exploitative dyadic R\&D alliances
\end{tabular}

First of all, the Acuisost Consortium fulfils the criterion of representativeness for the research purposes of this dissertation (Eisenhardt, 1989; Yin, 2003). The specification of the population of reference is crucial in both case study and large-scale research, determining case selection and the limits for analytical generalization (Eisenhardt, 1989). However, in case study research, case selection relies on theoretical sampling (i.e., cases should be chosen for theoretical, not statistical, reasons) unlike what occurs in large-scale research (Nieto \& Pérez, 2000; Eisenhardt \& Graebner, 2007). In this regard, the population of reference in this dissertation consists of 'multi-partner R\&D (MR\&D) alliances' (or, as previously defined, those 'inter-organizational agreements, like R\&D consortia, that interactively engages multiple partners in multilateral R\&D activities'). The Acuisost Consortium is a $\mathrm{R} \& \mathrm{D}$ consortium and thus is representative of the phenomenon under study. Furthermore, in order to extend existing theory or build new one, the research setting needs to either replicate the major characteristics of the population of reference or to be a polar type (Eisenhardt, 1989). In this regard, the Acuisost Consortium fits the former criteria: it brings together (a) multilateral collaboration among multiple partner firms and (b) dyadic collaboration between partner firms and research organizations, 
reflecting the coexistence of two kind of relationships characteristic of MR\&D alliances (Das \& Teng, 2002; Thorgren et al., 2010).

The Acuisost Consortium also fulfils the criterion of attractiveness (Yin, 2003). Some of its idiosyncratic characteristics enhance its attractiveness as a research setting, enabling the formulation of interesting specific research objectives and questions in combination with existing literature. First, the attractiveness of the Acuisost Consortium lies in the possibility to deal longitudinally with ongoing value-creation and collaboration processes, from the beginning to the end of the alliance ${ }^{4}$ (Nieto \& Pérez, 2000). Likewise, its temporal structure helps the systematic identification of different stages of its alliance lifecycle. These two conditions positioned the Acuisost Consortium as an interesting setting to address the general aim of this dissertation Second, the formation stage of the Acuisost Consortium was characterized by a set of complex conditions: (a) it was about an 'ad hoc' consortium whose formation was induced by an external triggering entity instead of being recognized as an opportunity directly by its partner firms, (b) it was government-sponsored under a public funding programme which imposed certain constrains for the consortium's initial development, and (c) an economic (global and industrial) crisis unfolded concurrently to the first phase of the consortium. These conditions made more complex the emergence of cooperation among the multiple partner firms of the consortium, especially because of their lack of prior significant alliance experience. Therefore, the Acuisost Consortium represented an interesting setting to study the creation of collaborative routines at the organizational level. Third, different kinds of alliances could be identified within the portfolio of dyadic R\&D relationships taken place under the Acuisost Consortium, mainly: exploration-oriented alliances between unfamiliar partners (some successful and other failed) and exploration- and exploitation-oriented alliances between familiar partners (often successful). These circumstances made the Acuisost Consortium to be an interesting setting to study the links between value realization with (a) the creation of new inter-organizational routines, and (b) the evolution of already existing inter-organizational routines.

Finally, the Acuisost Consortium fulfils the criterion of opportunity. As Yin (2003) states, getting access to interesting case studies (and all the required information to their examination) is not always a simple task, such that the willingness of case study actors to collaborate in the research represents an important advantage. Without the willingness of the actors, access to critical sources of information may be hampered and some critical aspects of the case may remain hidden for the researcher. Many case-study researchers make explicitly such a circumstance. For example, Gilbert (2006)explicitly states that the managerial willingness to provide the required level of access was a determining factor to select the newspaper firm in which his study about organizational change is based. Similarly, Boon (2008) recognises that the existence of prior university-firm contacts largely influenced the selection

\footnotetext{
${ }^{4}$ Most part of the Acuisost Consortium (2006-2011) unfolds contemporaneously to this research (2008-2011).
} 
of three firms on which her explorative study of human resource management fit focuses. In this dissertation, both the existence of prior contacts with the lead firm and its willingness and support for the research proved determinant in the selection of the Acuisost Consortium. Indeed, the existence of prior contacts with the lead firm guided the attention focus of the researchers to the Acuisost Consortium as an interesting setting for this dissertation. Once research started, the lead firm's managers became key informants for the dissertation (especially the R\&D Manager, responsible for the Acuisost Consortium), giving full access to a wide range of confidential documents and information, and providing valuable periodical feedback. Moreover, the lead firm R\&D manager acted as an intermediary with the rest of alliance participants, providing the research team the opportunity to conduct relevant interviews and direct observation, thus to get fully immersed and know all the ins and outs of the consortium.

\subsubsection{Description of the Acuisost Consortium}

This section describes with more detail the main characteristics of the Acuisost Consortium. First, two important aspects of its context are presented (i.e., institutional and industrial contexts). Subsequently, the objectives, structure, and participants of the Acuisost Consortium are explained.

\subsection{Institutional framework ${ }^{5}$}

As previously stated, the Spanish CENIT Programme represents the institutional framework of the Acuisost Consortium. Understanding the institutional framework in which a government-sponsored alliance is created is required to understand its internal dynamics of cooperation and value-creation (Koza \& Lewin, 1998). Accordingly, a brief description of the main characteristics of the CENIT Programme is presented in this section.

With the ambitious objective of making the European Union (EU) the most competitive economy in the world, the EU Council launches the 'Lisbon Strategy' in March 2000. The EU leaders re-launch the Lisbon Strategy in the 2005 EU Spring Council. In response, the Spanish government presents in June 2005 the INGENIO 2010 initiative to support the Spanish National Science and Technology Strategy. INGENIO 2010 aims to align EU and Spain strategies, seeking full convergence in 2010 (in terms of per capita income, employment, knowledge society indicators). In particular, INGENIO 2010 seeks to achieve the $3 \%$ of GDP to be spent on R\&D activities by 2010 , involving in a concerted effort all the players of the research and innovation system (the State, the business sector, and public and private research entities). The Spanish National Plan for Scientific Research, Development and Technological Innovation (2008-2011) represents the policy instrument for the management of the R\&D system, in line with such a convergence spirit, and includes several instrumental working lines.

\footnotetext{
${ }^{5}$ This section is based on information provided by the Spanish Ministry of Science and Innovation [available at http://www.micinn.es/portal/site/MICINN (last access: December 2011)] and the EU Community Research and Development Information Service (CORDIS) [available at http://cordis.europa.eu/spain/home en.html (last access: December, 2011)]
} 
In particular, the instrumental working line labelled as 'Articulation and Internalisation of the system' includes several instruments to strengthen the Spanish R\&D and innovation system by improving its efficiency and competitiveness. Within this instrumental working line, the National Programme of Public-Private Collaboration stands out due to its importance, aiming to foster stable innovationseeking collaboration between public and private organizations by providing funding for different kinds of R\&D initiatives through different subprogrammes, among them, The CENIT Programme.

The CENIT Program, whose initials stand for "National Strategic Consortia for Technical Research" (in Spanish, "Consorcios Estratégicos Nacionales de Investigación Técnica") provides funding for industrial projects of strategic, large-scale research in high-potential areas (for technology development and international projection). The programme aims to develop new products, processes or services, and/or to integrate technologies in order to improve technological Spanish position. To that end, collaboration between the private and public sectors (firms and public and private research organisations) is promoted, providing funds to support the creation of R\&D consortia (see Table 2.3.).

\section{Table 2.3. The CENIT Programme}

\begin{tabular}{|c|c|}
\hline 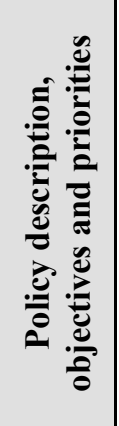 & $\begin{array}{l}\text { a) Objective and priorities: } \\
\text { - Improvement of technological capabilities within a framework of sustainable development } \\
\text { - Minimum temporal horizon of projects: four years } \\
\text { - Minimum annual budgets of five million euros where i) a minimum of } 50 \% \text { funded by the private } \\
\begin{array}{ll}\text { sector, and ii) at least } 50 \% \text { of the public funds going to public research organizations } \\
\text { b) Priority research areas (not confined to): } & \text { c) Type of research: } \\
\text { - Health science, food and nanotechnologies } & \text { - Basic research } \\
\text { - Information, production, and design technologies } & \text { - Applied research } \\
\text { - Environment-friendly technologies } & \end{array}\end{array}$ \\
\hline 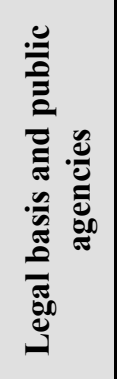 & $\begin{array}{l}\text { a) Legal basis (Official Spanish Gazette): } \\
\text { - General rules: Sept, 1, } 2005 \text { (ITC/2759/2005); Jul. 4, } 2006 \text { (ITC/2143/2006) } \\
\text { - Annual calls: Feb. 9, } 2007 \text { (ITC/2815/2007); Feb. 15, } 2008 \text { (ITC/2780/2008) } \\
\text { b)Funding and managing agency: Centre for the Development of Industrial Technology (CDTI), } \\
\text { Spanish Ministry of Science and Innovation (MICINN) } \\
\text { c) Budget and funding: } \\
\text { - Overall budget : 1,159,999,600 € (2005-2011); Mode of funding: Ex-post grants } \\
\text { - Eligible costs: labour costs; equipment; training; external expertise (e.g. consultancy and R\&D) }\end{array}$ \\
\hline 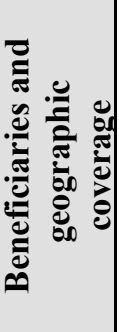 & $\begin{array}{l}\text { a) Beneficiaries: } \\
\text { Spanish firms/non-profit service providers and public/private research organizations } \\
\text { b) Eligible groups: } \\
\text { - Large groups of firms (or Economic Interest Grouping), one acting as the consortium lead firm } \\
\text { - Inclusion of at least two large private firms and an equal number of SMEs } \\
\text { - Inclusion of at least two research organizations subcontracted by the partner firms } \\
\text { - R\&D efforts carried out inside national boundaries }\end{array}$ \\
\hline 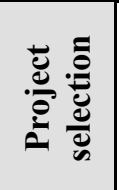 & $\begin{array}{l}\text { a) Selection criteria (competitive basis): } \\
\text { - Ambition and multidisciplinary in project objectives and participants } \\
\text { - Technical and economic quality and feasibility, and social impact of the proposal } \\
\text { - Representativeness of the Spanish region and industrial systems }\end{array}$ \\
\hline
\end{tabular}

Source: Own elaboration based on information provided by the Community Research and Development Information Service (CORDIS) and the Spanish Ministry of Science and Innovation (MICINN) 
Some aspects of the CENIT Programme, because of their interest for the study of the Acuisost Consortium, should be highlighted. First, the CENIT Programme emphasizes (1) ambition and multidisciplinary in consortium goals, (2) representation of different regions of Spain, and (3) collaboration between large, medium-size and small firms in both high-tech and non-high-tech fields. Such stipulations involved high diversity in membership conditions in the Acuisost Consortium, making complex collaboration, especially during the first years of the consortium. Second, CENIT consortia need to maintain a minimum budget of 20 million euros during the overall 4-year period of collaboration. Otherwise, projects will be excluded from the CENIT Programme. As the overall budget of the Acuisost Consortium was of 21 million euros, such stipulation imposed a continuous threat for its survival, especially during the first years of the consortium. Third, CENIT Programme grants are provided annually and ex-post, that is, once R\&D expenses and investments are carried out and justified by the consortium partners. Justification procedures include individual actions of each partner (presentation of invoices and audit) and collective actions (overall audit conducted by the public agency). After this, public funds are received by the consortium lead firm, who distributes the funds among the rest of the partner firms, according to their proportional involvement in the consortium budget. Such stipulations of the CENIT Programme involved serious internal problems during the formation stage of the Acuisost Consortium. Finally, eligible costs of the CENIT Programme include labour costs, equipment, and external services. Only investments in research equipment (and not in productive equipment) will be considered under this category. Moreover, at least $25 \%$ of the overall budget should be used to pay the R\&D services provided by research organizations. Such stipulations represented an important source of dissatisfaction for partner firms during the formation stage of the Acuisost Consortium.

\subsection{Industrial context: The field of aquaculture in Spain ${ }^{6}$}

Once understood the institutional framework, it is also necessary to present the industry context on which the Acuisost Consortium focused: the field of aquaculture ${ }^{7}$ in Spain.

In recent years, the contribution of aquaculture to global supplies of fish has significantly grown. At the Rome Summit of June 2008, the FAO sent a clear message: aquaculture can play a key role in future food production worldwide but if faces the significant challenge of how to fulfil these expectations without causing environmental damages. As long as a sustainable development is

6 This section is mainly based on secondary sources like FAO_Fisheries and Aquaculture [http://www.fao.org/fishery/en, last access: December 2011], APROMAR annual reports (Business association of Spanish Marine Producers) [http://www.apromar.es/informes.asp, last access: December 2011], and information provided by Fundación OESA (Fundation of the Spanish Observatory of Aquaculture) [http://www.fundacionoesa.es, last access: December 2011]

\footnotetext{
${ }^{7}$ According to the FAO, aquaculture is the economic farming of aquatic organisms, including mainly fish, molluscs and crustaceans, and aquatic plants (accounting, respectively for $50 \%, 25 \%$ and $25 \%$ of global aquaculture activity). In line with the Acuisost Consortium scope, we will focus on fish aquaculture.
} 
promoted, aquaculture can offer important advantages over traditional capture fisheries: more efficient use of natural resources, reduced environmental impact, better food safety control, and higher regularity in products availability. Spain, holding important positions in the EU ranking of aquaculture production, could play a key global role given (1) the long tradition of aquaculture as an economic activity in Spain, and (2) its privileged geographic characteristics and water resources. Indeed, Spanish fish aquaculture, particularly in its marine domain ${ }^{8}$, significantly grown during 2000s. However, such growth was irrational and explosive, influenced by an aggressive growth of the international competition. As a result, the effects of a severe crisis of overproduction began to appear at the end of 2007. Other factors contributed to increase the complexity of the situation. First, the prices of raw materials for fish feed, which represents the largest cost of the productive process, had been systematically increasing in precedent years, concerning both traditional raw materials of animal origin (such as oil and fish meal) raw materials of vegetal origin (such as soybean meal), until now, considered as alternatives. Second, the effects of the aquaculture crisis were exacerbated by the overall economic and financial crisis. As a consequence, the credit access to aquaculture firms, which have long production cycles and higher capital requirements, was hampered. The effects have been especially dramatic for marine aquaculture (in an earlier lifecycle stage than continental aquaculture), and for the smallest aquaculture producers which have been forced even to accept prices below costs.

To guarantee the survival of the Spain aquaculture, it is required to overcome some endemic problems which, without having directly caused the crisis, have contributed to enhance its damaging effects. Experts point out to three main innovation challenges (see APROMAR Reports 2009, 2010). First, significant research efforts should be made concerning fish feed, quality and food safety, by searching for new raw materials in order to alleviate the pressure from production costs, improve fish quality, and guarantee food safety. In fact, quality and food safety should be the basis for the Spanish aquaculture competitive advantage. Second, Spanish aquaculture should seek a more efficient use of the natural resources and achieve environmental sustainability. To that end, it is necessary to investigate superior ways of managing fish farming's wastes, looking at alternative uses and byproducts revaluation (e.g., energy uses). Finally, Spanish aquaculture needs diversification. Aquaculture producers need to diversify its activity in terms of number and type of species. Traditionally, aquaculture in Spain has concentrated on a reduced number of species, which are in the maturity lifecycle stage (mainly, sea bass and sea bream in marine aquaculture and trout in continental aquaculture). Also, it is required to take the leap into higher value added products (e.g., filleted and gutted fish, fish prepared meals). The creation of the Acuisost Consortium should be understood within this framework and spirit. As shown in Table 2.4., the technical activities (i.e., subprojects) of

\footnotetext{
${ }^{8}$ There are two basic types of fish farming environments: continental aquaculture (farming of freshwater species like salmon, and trout) and marine aquaculture (farming of saltwater fish species like sea bream and sea bass).
} 
the Acuisost Consortium correspond closely to the main innovation challenges suggested by aquaculture experts.

Table 2.4. Correspondence between technical activities and aquaculture challenges

\begin{tabular}{|l|l|l|}
\hline \multicolumn{1}{|c|}{ Aquaculture challenges } & \multicolumn{2}{|c|}{ Technical activities of the Acuisost Consortium } \\
\hline \multirow{2}{*}{ Fish feed, quality and food safety } & $\begin{array}{l}\text { Act. 1. "Raw materials" } \\
\text { Act. 2. "Additives and } \\
\text { encapsulation" } \\
\text { Act. 3. "Biotechnology } \\
\text { systems" }\end{array}$ & $\begin{array}{l}\text { Act. 4. "Biosecurity" } \\
\text { Act. 5. "Fish species } \\
\text { farming" }\end{array}$ \\
\hline \multirow{2}{*}{ Environmental sustainability } & $\begin{array}{l}\text { Act. 4. "Biosecurity" } \\
\text { Act. 6. "Wastes" }\end{array}$ \\
\hline \multirow{2}{*}{ Diversification } & $\begin{array}{l}\text { Act. 6. "Wastes" } \\
\text { Act. 7. "Ready Meals" }\end{array}$ \\
\hline
\end{tabular}

Source: Own elaboration based on Acuisost Consortium's documents

\subsection{Objectives and technical and organizational structure}

The general objective of the Acuisost Consortium was to foster a rational and sustainable development of the Spanish fish aquaculture by seeking innovation in critical areas through collaborative R\&D efforts areas among its partner firms, as illustrated in Figure 2.1.

Figure 2.1. The Acuisost Consortium: Towards a sustainable aquaculture

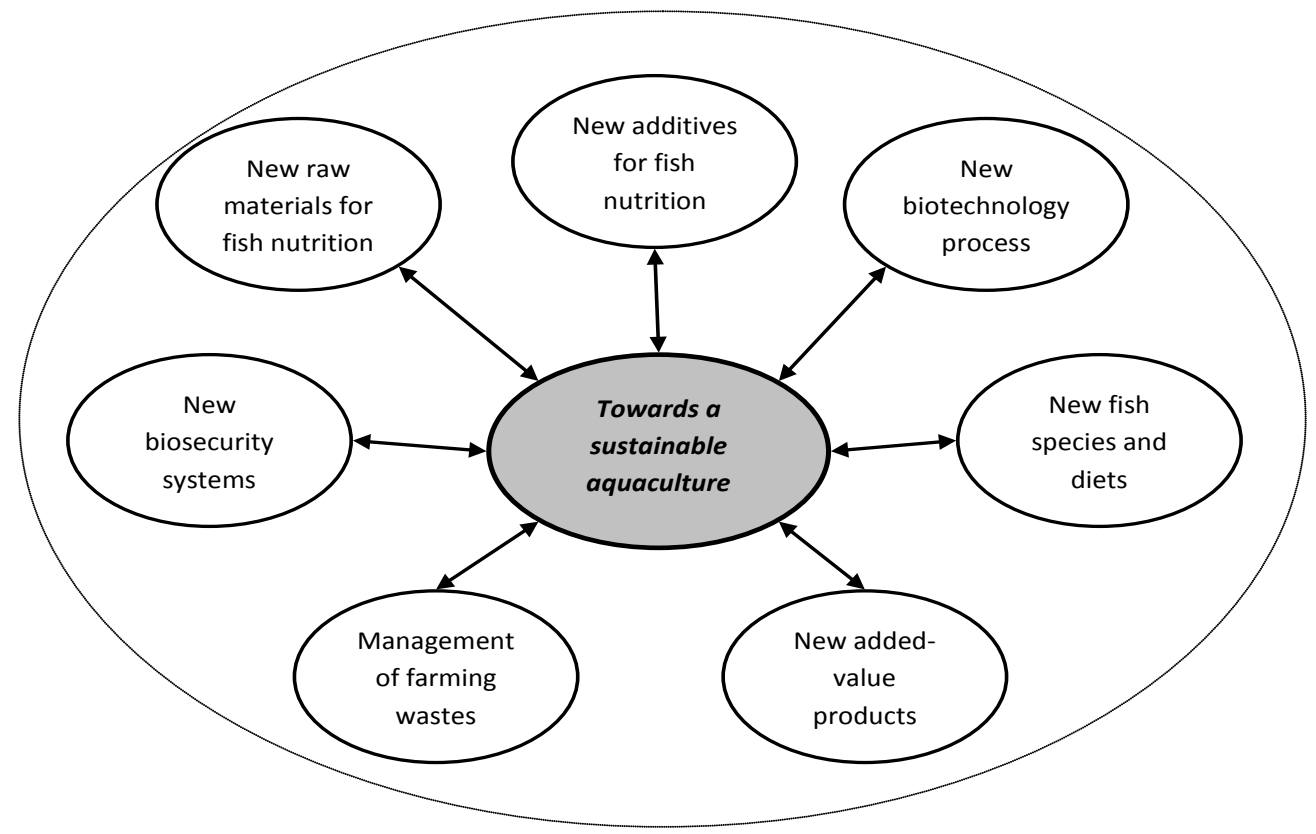

Source: Own elaboration based on Acuisost Consortium's documents

To accomplish this general objective, seven more specific technical objectives were defined, giving rise to the seven technical activities (or subprojects) in which the technical structure of the consortium specifies. Each technical activity comprised in turn several research tasks, for whose 
accomplishment dyadic collaboration between partner firms and research organizations took place. Each technical task was allocated to a specific partner firm, which contracted one or more research organizations to conduct the associated R\&D activities. Therefore, technical tasks represented partners' technical objectives within the consortium. These technical tasks were partner-specific: When a partner firm joined the consortium (either as a founder partner or as a later entrant), it defined its specific task/s, reflecting its contributions to the consortium. It is important to note that not all partners firms and research organizations of the Acuisost Consortium collaborated in all activities and that some of them were simultaneously involved in several technical activities. Furthermore, for each technical activity, a representative of one the partner firms involved in the activity was designated as the 'technical activity coordinator'. Activity coordinators were in charge of orchestrating and monitoring the technical development within the activity, as well as of channelling relevant information to the lead firm of the consortium.

In the following, we described the initial technical structure of the Acuisost Consortium, summarized in Table 2.5.

Table 2.5. Initial technical structure of the Acuisost Consortium

\begin{tabular}{|c|c|c|c|c|c|}
\hline $\begin{array}{c}\text { Technical } \\
\text { activity }\end{array}$ & Objective & $\begin{array}{l}\text { No. } \\
\text { tasks }\end{array}$ & $\begin{array}{l}\text { No. } \\
\text { firms }\end{array}$ & $\begin{array}{l}\text { No. } \\
\text { RO }\end{array}$ & $\begin{array}{c}\text { Membership } \\
\text { changes }\end{array}$ \\
\hline $\begin{array}{l}\text { 1. Raw } \\
\text { Materials }\end{array}$ & $\begin{array}{l}\text { Nutritional, technical, economic, and } \\
\text { environmental evaluation of new raw } \\
\text { materials (alternative to fish meal and oil) } \\
\text { for fish nutrition }\end{array}$ & 13 & 5 & 6 & Yes \\
\hline $\begin{array}{l}\text { 2. Additives } \\
\text { and } \\
\text { encapsulation }\end{array}$ & $\begin{array}{l}\text { Additives and encapsulation systems for } \\
\text { nutrition-controlled release }\end{array}$ & 5 & 3 & 3 & Yes \\
\hline $\begin{array}{l}3 . \\
\text { Biotechnology } \\
\text { systems }\end{array}$ & $\begin{array}{l}\text { Application of technical and } \\
\text { biotechnological systems for the } \\
\text { improvement of fish diets }\end{array}$ & 5 & 3 & 3 & Yes \\
\hline 4. Biosecurity & $\begin{array}{l}\text { Development of new production } \\
\text { technologies and biosecurity systems }\end{array}$ & 9 & 7 & 4 & Yes \\
\hline $\begin{array}{l}\text { 5. Fish species } \\
\text { farming }\end{array}$ & $\begin{array}{l}\text { Fish species development and culture, } \\
\text { evaluation of new fish diets }\end{array}$ & 8 & 6 & 5 & Yes \\
\hline 6. Wastes & Wastes management and transformation & 4 & 4 & 3 & Yes \\
\hline $\begin{array}{l}\text { 7. Ready } \\
\text { meals }\end{array}$ & $\begin{array}{l}\text { Ready meals from aquaculture products } \\
\text { for human consumption }\end{array}$ & 5 & 4 & 4 & No \\
\hline
\end{tabular}

Source: Own elaboration based on Acuisost Consortium's documents and interview-data

The three first technical activities concerned innovation challenges in the field of aquaculture nutrition. In particular, the first technical activity ("Raw materials") sought to develop new fish feeds based on new raw materials (alternative to the traditional ones: fish meal and oil). Initially, this 
activity consisted of thirteen technical tasks, and entailed the participation of five partner firms and six research organizations. The second technical activity of the consortium ("Additives and encapsulation") 9 aimed to search for additives (attractants and pigments) from natural sources and with lower costs, thus alternative to the traditionally used ones. In addition, it seeks to adapt the encapsulation systems employed in cosmetics and human nutrition for nutrients administration in aquaculture. Initially, three firms and three research organizations collaborate within this activity in the pursuit of five technical tasks. Concerning the third technical activity ("Biotechnology systems"), it initially involved three partner firms and three research organizations, and it was structured along five tasks. The general objective here was to develop functional fish feed based on biotechnological systems (prebiotics and probiotics) which improve fish digestive processes and strengthen fish immune systems ${ }^{10}$.

The fourth activity of the consortium ("Biosecurity") concerned the reduction of the environmental impact of the aquaculture activity and the improvement of aquaculture fish safety for consumers. The activity's objectives were to minimize water consumption in fish farms, develop biocidal and virucidal products for fish farming, and enhance quality control of fish pathogens. Its initial design included the participation of seven partners and four research organizations and nine tasks to be accomplished.

The six partner firms and five research organizations initially involved in the fifth technical activity of the Acuisost Consortium ("Fish species farming") sought to accomplish eight technical tasks with a twofold purpose: farming of new fish species and monitoring of new diets for commercial species (traditional marine species, ornamental fish and eels) developed in the first technical activity. These actions had to do with the need of diversification of aquaculture activity and, simultaneously, completed the actions carried out within the consortium for the improvement in fish nutrition. With regard to the sixth technical activity ("Wastes"), the focus was on the management and revalorization of wastes generated in aquaculture facilities towards the generation of biofuels. Initially, four partner firms and three research organizations were involved in the development of its four technical tasks. Thus, this activity addresses the need of improving environmental sustainability and exploring ways of diversification. Finally, the seven technical activity of consortium ("Ready meals") aimed to enhance

\footnotetext{
${ }^{9}$ Pigments and attractants are key additives in fish nutrition. Colouring, a highly appreciated attribute of the aquaculture fish, is achieved by including pigments in fish diets. For example, for salmon trouts, a series of red pigments are required. Attractants are elements included in fish feed to allow fish to identify it as food. Encapsulation allows controlled-release of nutrients.

${ }^{10}$ In its biotechnology glossary, FAO defines functional foods as those which provide a health benefit beyond basic nutrition, including the prevention and treatment of disease [available at http://www.fao.org/biotech/findformalpha-n.asp, last access: December, 2011)]. According to the International Scientific Association of Prebiotics and Probiotics (ISAPP), prebiotics are non-digestible substances that when consumed provide a beneficial physiological effect on the host by selectively stimulating the favourable growth or activity of a limited number of indigenous bacteria. Probiotics are live microorganisms which when administered in adequate amounts confer a health benefit on the host (available at http:/www.isapp.net/pp intro.asp,last access: December, 2011)].
} 
the added value of aquaculture products, by developing new products (e.g., filleted and semi-cooked fish). Initially, four partner firms and four research organizations participated to develop five technical tasks.

Above Table 2.5 also displays whether membership changes occurred within each technical activity. Given the partner-specific nature of technical tasks, the above-described initial technical structure of the Acuisost Consortium changed over time, as its membership configuration did (although the seven technical activities remained). Thus, each partner firm's departure from the Acuisost Consortium involved the removal of the associated specific tasks. Given the bilateral nature of the contracts with research organizations, each partner firm's departure from the consortium also meant the departure of its research organizations (as long as they had no additional contractual links with other partner firms). Likewise, new partner firms implied new technical tasks (and often new research organizations). Membership changes should be described later (see section 2.2.1.3.4 of this chapter).

Concerning the initial organizational structure of the Acuisost Consortium, in addition to partner firm's representatives, seven different organizational figures were defined: the lead firm of the consortium, the consortium coordinator (triggering entity), the consortium committees (Steering, Scientific-Technical Committee, Permanent, and Results Diffusion and Protection Committees), and technical activity coordinators. Table 2.6. details information about this organizational structure.

Table 2.6. Organizational structure of the Acuisost Consortium: Figure and roles

\begin{tabular}{|l|l|}
\hline \multicolumn{1}{|c|}{ Figure } & \multicolumn{1}{c|}{ Description and main roles } \\
\hline Lead Firm & $\begin{array}{l}\text { - Ensuring a proper development of the consortium, monitoring decisions and } \\
\text { agreements, receiving public funds and distributing them among partners }\end{array}$ \\
\hline $\begin{array}{l}\text { Consortium } \\
\text { (triggering entity) }\end{array}$ & $\begin{array}{l}\text { - Spokesperson for the consortium, assisting the partners in the administrative } \\
\text { - Vork and, if necessary, mediating in conflicts }\end{array}$ \\
\hline Steering Committee & $\begin{array}{l}\text { - Highest decision-making body } \\
\text { - Composition: the leader (chair), a representative of each partner whose } \\
\text { holding exceeds 5\% of the total budget and a common representative }\end{array}$ \\
\hline $\begin{array}{l}\text { Permanent } \\
\text { Committee }\end{array}$ & $\begin{array}{l}\text { - Support body for the consortium coordinator } \\
\text { - Composition: the leader, an individual on behalf of the Steering Committee, } \\
\text { and the Coordinator Consortium (chair) }\end{array}$ \\
\hline $\begin{array}{l}\text { Scientific-Technical } \\
\text { Committee }\end{array}$ & $\begin{array}{l}\text { - Body in charge of the proper technical development of the Consortium } \\
\text { - Composition: the leader (chair), and consortium and activity coordinators }\end{array}$ \\
\hline $\begin{array}{l}\text { Results Protection } \\
\text { Committee }\end{array}$ & $\begin{array}{l}\text { - Body in charge of protecting alliance knowledge (property rights) } \\
\text { - Composition: Leader and consortium coordinator (chair) }\end{array}$ \\
\hline coordinators & $\begin{array}{l}\text { - Individuals elected by partner firms collaborating in each technical activity } \\
\text { Coordinating and monitoring the technical development within the activity }\end{array}$ \\
\hline
\end{tabular}

Source: Own elaboration based on Acuisost Consortium's documents 


\subsection{Participants of the Acuisost Consortium ${ }^{11}$}

This section provides information about the participants of the Acuisost Consortium. According to the two mention collaborative relationships that coexisted in the Acuisost Consortium, two main categories of consortium participants could be distinguished: partner firms and research organizations $^{12}$. Within the first category of participants, one partner firm stands out because it played the role of 'lead firm' of the Acuisost Consortium, according to the stipulations of the CENIT Programme. Although partner firms and research organizations are the protagonist of the Acuisost Consortium, another category of participants could be recognized, basically due to the engineering and government-sponsored nature of the consortium: the triggering entity inducing the creation of the Acuisost Consortium, and the public agency managing the CENIT Programme.

The lead firm of the consortium is Dibaq, the parent company of Dibaq Group. Dibaq Group is a strong multinational corporation active in the field of animal nutrition. In particular, the mission of Dibaq Group concerns 'animal nutrition, welfare and health', which specifies in the vision of 'innovation to the service of animal nutrition, welfare and a health keeping leading competitive position'. The philosophy of Dibaq Group lies on values like high quality, continuous improvement, environmental sustainability, social responsibility, human resources as strategic assets, close collaboration with clients and suppliers, and innovation (in 2008, the firm invested 4 million Euros in R\&D expenses, which accounted for more than $2 \%$ of its whole budget). Its more than twenty subsidiaries comprising the corporation are grouped into four business units. The core business of Dibaq Group are represented by the units of 'Aquaculture' (aquaculture nutrition: production of fish feed, where it occupies a high position in the competitive ranking in Spain) and 'Pet Care' (pet nutrition), accounting jointly for $90 \%$ of its annual turnover. Dibaq Group's business portfolio is completed with the unit of 'Fish farming' (i.e., vertical integration: aquaculture fish production ) and other business unit which encompasses several activities and is internally labelled as 'Support Activities' (e.g., pet specialized stores, technology services, software design, production of minerals and vitamins, functional products, shipping). Dibaq Group is a family-owned enterprise, whose origins date back to the fifties: its activity evolved from poultry and pig production in 1956 to fish feed production in 1988, when Dibaq was formally founded. From the outset, Dibaq conveyed large international vocation: first movements towards international expansion were taken in 1988. As a result of this proactive international strategy, Dibaq has achieved an important global presence: in 2010, Dibaq's products were present in fifty countries in Europe, Asia, America, and Africa, with

\footnotetext{
${ }^{11}$ Description of participants is based on both primary sources of information (interviews) and secondary sources of information (consortium's documents and organizations' private documents like annual reports, and Websites).

${ }^{12}$ For confidentiality reasons, the names of the consortium participants (except the lead firm) have been replaced by pseudonyms.
} 
production centers in Spain, Czech Republic, and México and logistics centres and trade delegations in many other countries.

In the Acuisost Consortium, Dibaq, as the lead firm, was in charge of ensuring a proper development of the consortium, monitoring decisions and agreements, chairing the Steering Committee, receiving public funds and distributing them among partners. As the consortium leader, Dibaq played a key role in the creation and evolution of the Acuisost Consortium: it can be considered to be the central node of the network. Therefore, the lead firm's representatives represented the most important informants for this dissertation. Individually considered as a partner of the Acuisost Consortium, Dibaq participated directly in six of the seven technical activities of the consortium, collaborating with nine different research organizations. However, it is important to describe the overall alliance strategy followed by the Dibaq Group: three subsidiaries of Dibaq Group also took part in the Acuisost Consortium as partner firms (as a whole, holding 30\% of the consortium's budget and having presence in all the technical activities of the consortium). Moreover, the lead firm ensured the presence in the consortium of other five firms belonging to its network of contacts. With such an alliance strategy, the lead firm intended to ensure (a) higher probability of realizing value from the consortium (e.g., by facilitating better coordination) and (b) enhanced ability to capture rents realized in the consortium.

Concerning the rest of partner firms of the Acuisost Consortium, (i.e., those firms that signed the consortium agreement and represented the beneficiaries of the CENIT Programme), there were twenty of them participating over time in the consortium [Appendix II.2 provides a description of all partner firms involved in the Acuisost Consortium over time]. In this regard, it is important to make explicit two considerations about partner firms. First, several partner firms are owned by the same business group. In particular, three companies belong to 'Mediterranean Aquaculture', and five firms belong to 'The Biscuits Company'. In this dissertation, they have been grouped together, respectively, under the common labels of 'Mediterranean Aquaculture' and 'The Biscuits Company'. In doing so, suggestions of the own firms' managers were followed: they explained that those grouped firms had a unique overall alliance strategy. For example, 'The Biscuits Company' sought the transformation and revalorization of various types of food wastes as raw materials for fish nutrition; each of those companies, affiliated to the same business group, experimented with a different type of food waste, according to the their industrial activity (e.g., biscuits, snacks, bread, pasta). This strategy yielded the identification of seventeen firms as founder partner firms of the Acuisost Consortium for research in this dissertation (instead of twenty, the 'real' number of firms signing the consortium agreement in 2007). Second, as typically occurs in R\&D consortia, the Acuisost Consortium was founded by seventeen partner firms (in addition to the lead firm) but this number changed over time: only the lead firm and fourteen of these seventeen founder partners kept involved during the whole lifecycle of the consortium. This information is summarized in Table 2.7. 
During the formation stage (January 2006-March 2009) eighteen partner firms got involved in the consortium: the seventeen founder partners and a new partner firm that joined the consortium after its formalization. However, two of the founder partners (i.e., BioNaval and BioNutrition) and the new partner joining the consortium i (i.e., Cantabrian Seafood) departed from the consortium in this period. During the execution stage (December 2008-December 2010) seventeen partner firms participate in the consortium: the fifteen remaining founder partners and two new entrants (i.e., BigFish and Rhodium). However, one of the founder partners (i.e., Northern Trouts Co.) left the consortium in this period. Finally, during the termination stage (December 2010-October 2011), the remaining sixteen partners kept involved in the consortium.

Table 2.7. Evolution of membership in the Acuisost Consortium

\begin{tabular}{|c|c|c|c|}
\hline & $\begin{array}{c}\text { Formation stage } \\
\text { (Jan. 2006-Mar. 2009) }\end{array}$ & $\begin{array}{c}\text { Execution stage } \\
\text { (Mar. 2009-Dec.2010) }\end{array}$ & $\begin{array}{c}\text { Termination stage } \\
\text { (Dec. 2010- Oct. 2011) }\end{array}$ \\
\hline Founder partner firms & $\begin{array}{l}\text { Lead firm } \\
17 \text { firms }\end{array}$ & $\begin{array}{l}\text { Lead firm } \\
15 \text { firms }\end{array}$ & $\begin{array}{l}\text { Lead firm } \\
14 \text { firms }\end{array}$ \\
\hline New entrants & $\begin{array}{l}1 \text { firm [Cantabrian } \\
\text { Seafood, March 2008] }\end{array}$ & $\begin{array}{l}2 \text { firms [BigFish and } \\
\text { Rhodium, Dec. 2009] }\end{array}$ & ---- \\
\hline Early departures & $\begin{array}{l}3 \text { firms [BioNaval, Jan. } \\
\text { 2008;BioNutrition, Dec. } \\
\text { 2008; Cantabrian } \\
\text { Seafood, March 2009 ] }\end{array}$ & $\begin{array}{l}1 \text { firm [Northern Trouts } \\
\text { Co., Dec. 2009] }\end{array}$ & ---- \\
\hline $\begin{array}{l}\text { Total no. of partner } \\
\text { firms participating in } \\
\text { this period }\end{array}$ & 18 firms (+ lead firm) & 17 firms (+ lead firm) & 16 firms (+ lead firm) \\
\hline
\end{tabular}

Source: Own elaboration based Acuisost Consortium's documents and interview data.

Partner firms of the Acuisost Consortium are all Spanish firms, but vary in terms of its organizational characteristics (e.g., size, age, industry affiliation, geographic location) and alliance strategies, holding varying alliance objectives and degrees of involvement- in terms of managerial (i.e., responsibility in the governance bodies of the consortium), financial (i.e., participation in the consortium's budget), and technical involvement in the Acuisost Consortium (i.e., participation in technical activities)-, besides its length of participation (as explained, founder partners, new entrants, early departures). For example, most of the partner firms belong to the aquaculture sector (eight partner firms, in addition to the lead firm). The next most represented fields are the agri-food, biotechnology, and chemical industries (three partner firms in each of them), given the potential synergies between fish and human nutrition. Finally, two other industries can be identified: waste management (one partner firm) and packaging (one partner firm). Partners in different industries usually held different individual alliance objectives. In general terms, it can be said that aquaculture partners sought market penetration by participating in the Acuisost Consortium, whereas firms 
belonging to other industries often viewed the Acuisost Consortium as a platform to entry (or at least to explore) a new field of activity: aquaculture. This observation could be explained with the analysis of the relationships between the different industries to which partner firms belong to, and their contributions to the aquaculture value system in the Acuisost Consortium (Figure 2.2.).

Figure 2.2. Contributions to the fish aquaculture value system in the Acuisost Consortium

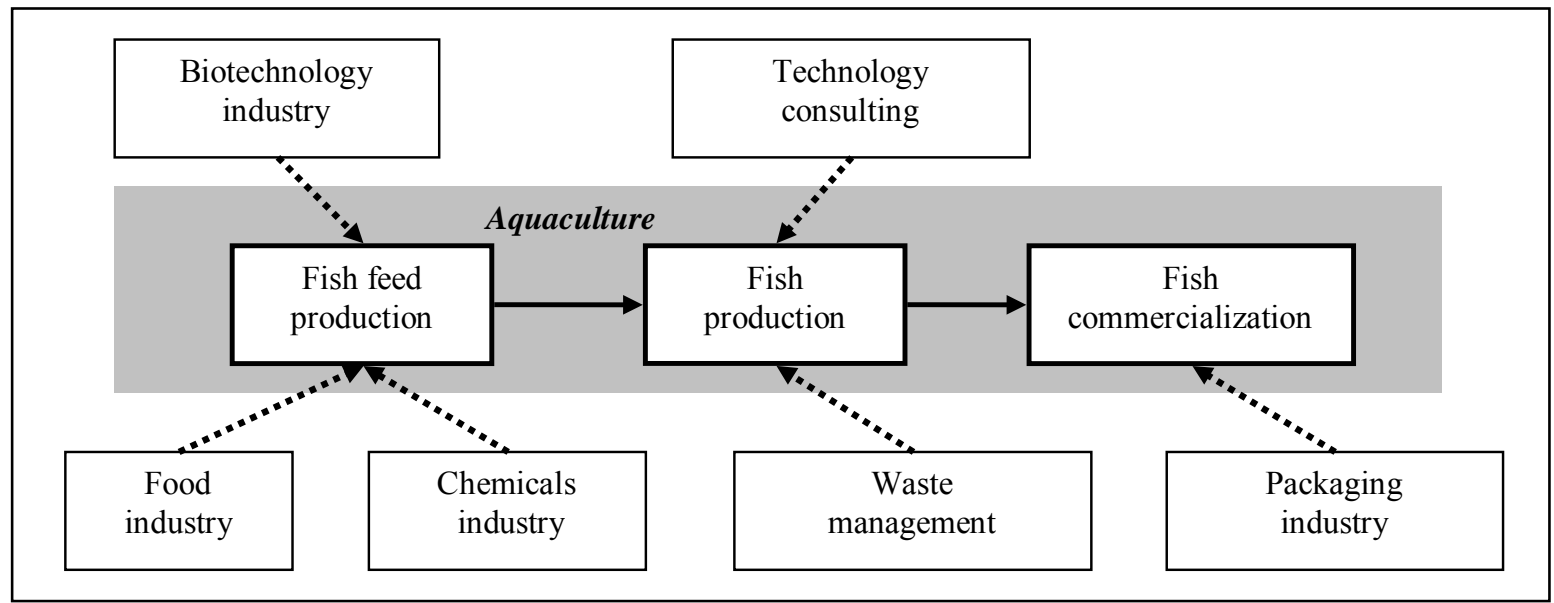

Source: Own elaboration based on Acuisost Consortium's documents

As mentioned, partner firms of the Acuisost Consortium also vary in terms of its main organizational characteristics like size (fourteen SMEs and six large firms) and age (five start-ups and fifteen established firms). However, it is important to take into account a common organizational characteristic, central to the development of this dissertation: partner firms did not have significant alliance experience before the Acuisost Consortium [See Appendix II.2 for some data illustrating this observation]. Furthermore, most of their low prior experience had been forged in dyadic R\&D relationships with research organizations, whereas collaborative experience in multi-partner settings was practically inexistent.

The second category of main participants of the Acuisost Consortium are the research organizations, which played the role of technological partners of the consortium firms (through bilateral $R \& D$ contracts), although not holding the status of partners of the Acuisost Consortium as a whole (as established in the CENIT Programme). As explained, that means that the number of research organizations participating in the consortium was also time-variant and depends on the changes in membership (i.e., partner firm's departure from the consortium meant the departure of its research organizations, as long as they had no additional contractual links with other partner firms, and each entry of a new partner firm often implied new research organizations). Furthermore, some research organizations collaborated with several partner firms in the development of different technical tasks of the Acuisost Consortium. 
Given these observations, it is more precisely to talk about a portfolio of forty dyadic relationships among twenty partner firms and nineteen research organizations which took place within the context of the Acuisost Consortium. Appendix II.3 provides information about the main characteristics of these research organizations (type, geographic location, involved organizational areas, and main research fields of the research).

As their main descriptive characteristics, the type of research organization and its main area of research could be highlighted. Within the research organizations involved in the Acuisost Consortium, three major types have been identified according to the Spanish legal framework: eleven university research groups (research teams within the academic context, belonging to some of the Spanish public universities), three public research agencies (public research institutions with national scope, which represent, together with universities, the core of the public scientific system in Spain) and five technological centres (private non-profit organizations with a strong regional involvement whose mission is to encourage competitiveness of the business system by supporting technological development). Most of these research organizations specialize in aquaculture, although a wide number of organizations focus also on other segments of animal science and on food technologies and process as their main fields of research.

As a summary, Table 2.8 presents an overview of the dyadic $R \& D$ alliances between partner firms and research organizations of the Acuisost Consortium. 
Table 2.8. The Acuisost Consortium as a portfolio of dyadic R\&D alliances

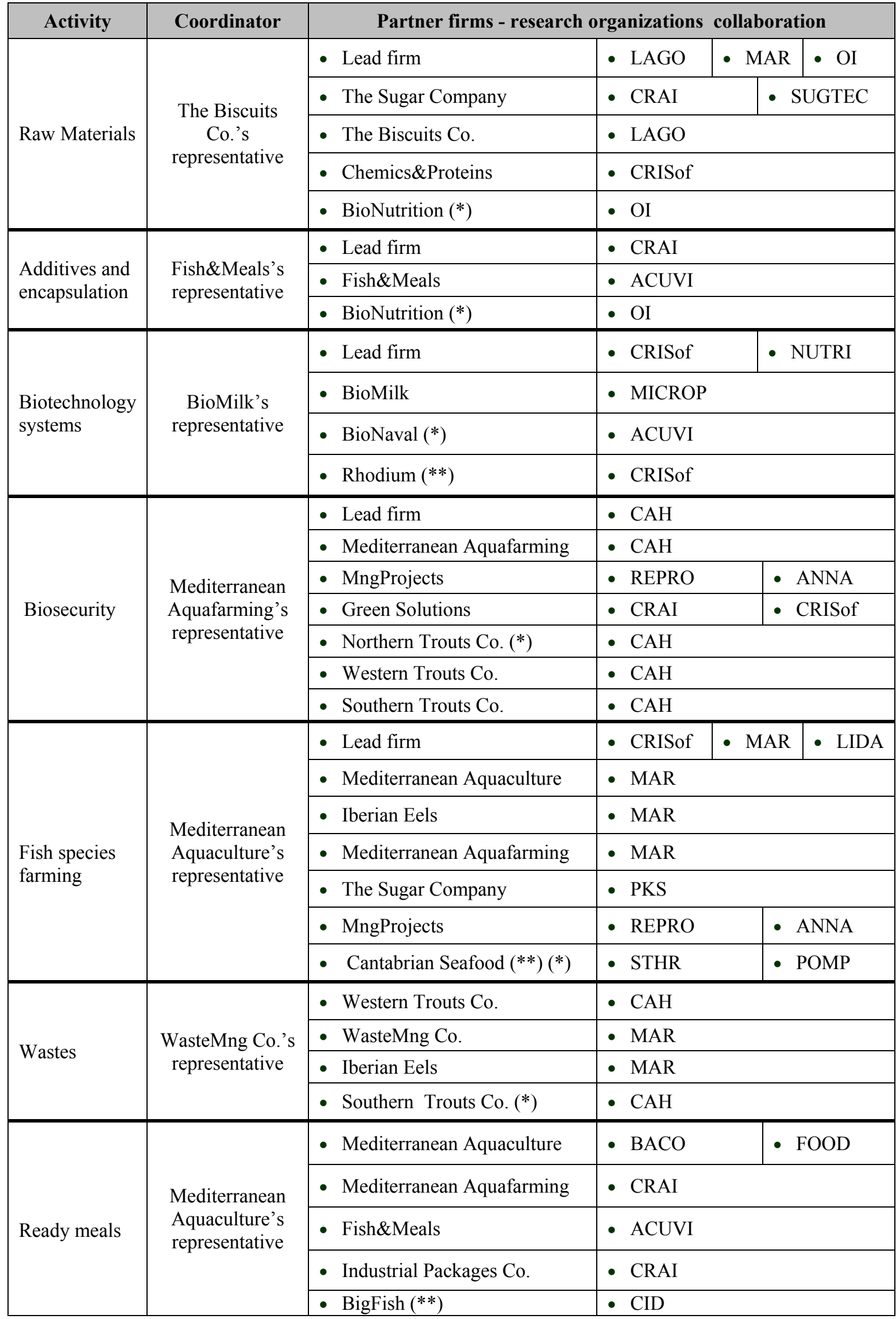

Source: Own elaboration based on Acuisost Consortium's documents and interview data 
Once described the main participants of the Acuisost Consortium, a brief reference should be made to other entities taking part somehow in the Acuisost Consortium, as thus representing sources of information for this dissertation, but which cannot be considered to be included in none of the above categories. We label them as other participants of the Acuisost Consortium.

First, given the engineering nature of the Acuisost Consortium, it is important to mention AquaEnviron Consulting, the triggering entity perceiving the opportunity and subsequently inducing the formation of the Acuisost Consortium and organizing the application for funding from the CENIT Programme. Aqua-Environ Consulting provides consultancy services for firms in the agri-food, maritime, forestry, and environmental sectors regarding national and international R\&D public policies. Basically, it focuses on the identification and assessment of opportunities, project viability evaluation, and search for funds from regional, state and international research programmes. As stated earlier, Aqua-Environ Consulting held the status of coordinator of the Acuisost.

Second, another firm conducting administrative tasks within the Acuisost Consortium should be mentioned: MngInvest. MngInvest is also a consultancy firm, focusing on the integrated management of industrial investment projects and investment tools, covering the whole process: ex-ante analysis of the project potential, subsequent search of public funding (European, national, regional, and local funding programmes), and management of public funding processes (documents, technical reports, etc.). Unlike the triggering entity, MngInvest did not occupy a coordination position in the consortium. However, it provided administrative support to many partner firms of the Acuisost Consortium through private bilateral contracts. In particular, before the consortium, MngInvest had provided consultancy services to the lead firm and another partner firm (i.e., the Biscuit Company) for a long time, and continued helping these two firms in managing the Acuisost Consortium. Moreover, once the consortium started, given the hard administrative requirements imposed by the CENIT Programme, the firm begun to provide services to many other partners of the consortium. As a result, MngInvest played an important supporting role during the formation and evolution of the alliance, being their representatives considered as useful informants for this dissertation.

Finally, due to the government-sponsored nature of the Acuisost Consortium, it is also important to mention the public agency responsible for the CENIT Programme, namely CDTI (Centre for the Development of Industrial Technology (CDTI), under the Spanish Ministry of Science and Innovation (MICINN), the CDTI's general objective is to help Spanish firms to increase their technological capabilities, through three action lines: evaluating and funding technological development and innovation initiatives (collaborative and non-collaborative projects), providing technical, strategic, legal, and financial support for the participation of Spanish firms in international programmes of technological collaboration (e.g., EU Framework Programmes), and fostering the generation and 
development of new technology-based firms. In the Acuisost Consortium, CDTI monitored the fulfilment of objectives and provided partial funding for its development.

\subsubsection{A longitudinal description of the Acuisost Consortium ${ }^{13}$}

As previously explained (see Chapter 1, section 1.1.1.3), the alliance lifecycle approach allows researchers to circumscribe alliance characteristics over time, smoothing thus the progress of longitudinal studies (De Rond \& Bouchikhi, 2004). Therefore, a lifecycle approach is adopted here to support a longitudinal systematic description of the Acuisost Consortium. To that end, it is required to consider not only the stages identified in prior studies but also the specificities of the Acuisost Consortium. Moreover, as argued by Mosakowski and Early (2000) dynamic strategy research often fails to capture the subjective temporal perceptions of actors thus failing to bring theoretical models to practice. Following these premises, key informants in the interviews were explicitly asked to set the beginning and termination of the consortium. Also, the temporal limits between the stages were also identified based on interview data, deducing whether participants perceived that the consortium stayed in the same stage or it had moved into a new one. Thus, taking insights from prior literature as reference (Murray \& Mahon, 1993; Reuer, 2000; Shenkar \& Yan, 2002) and combining them with the idiosyncrasy of Acuisost Consortium and the subjective perceptions of its participants, allowed the retrospective identification of three lifecycle stages through which the Acuisost Consortium unfolded: formation, execution and termination.

Within the CENIT Programme, collaboration should last for four calendar years, in particular, starting from January 2007 and finishing at December 2010 in the case of the Acuisost Consortium. In principle, within the CENIT Programme and according to the annual distribution of the public grant, each of these calendar years represents a technical annuity of the consortium. However, due to a bureaucratic delay, as will be explained later, CDTI allowed a different technical schedule for the Acuisost Consortium, extending the first annuity for three months (overtime) and shortening the subsequent ones (duration of eleven months instead of twelve). As a result, the first technical annuity covered the period from $1^{\text {st }}$ January 2007 to $31^{\text {st }}$ March 2008; the second one extended from $1^{\text {st }}$ April 2008 to $28^{\text {th }}$ February 2009; the period from $1^{\text {st }}$ March 2009 to $31^{\text {st }}$ January 2010 represented the third annuity and, finally, the fourth technical annuity corresponded to the period from $1^{\text {st }}$ February 2010 to December 2010. At the end of each technical annuity, the Consortium had to provide feedback to CDTI regarding the technical advances carried out and the justification of costs to be covered by the grant. Such a formal timeline undoubtedly conditioned the evolution of the Acuisost Consortium. The technical timeline of the CENIT Programme is based strictly on when the technical collaboration starts and finishes. However, strategic alliances do not commence in a vacuum (Kanter, 1994; Doz, 1996;

\footnotetext{
${ }^{13}$ Notice that the lifecycle of the Acuisost Consortium as a whole and the periods of collaboration between research organizations and partner firms are not exactly the same (January 2008-December 2010). The reader is referred to Study II.1 for more details about this issue.
} 
Shenkar \& Yan, 2002) and collaboration may not finish automatically at the pre-established ending date (Murray \& Mahon, 1993; Reuer \& Zollo, 2005). As a result, this technical timeline did not correspond exactly to the 'real' lifecycle of the Acuisost Consortium. Figure 2.3. compares the real life cycle of the Acuisost Consortium with such official technical timeline.

Figure 2.3. The technical timeline versus the real lifecycle of the Acuisost Consortium

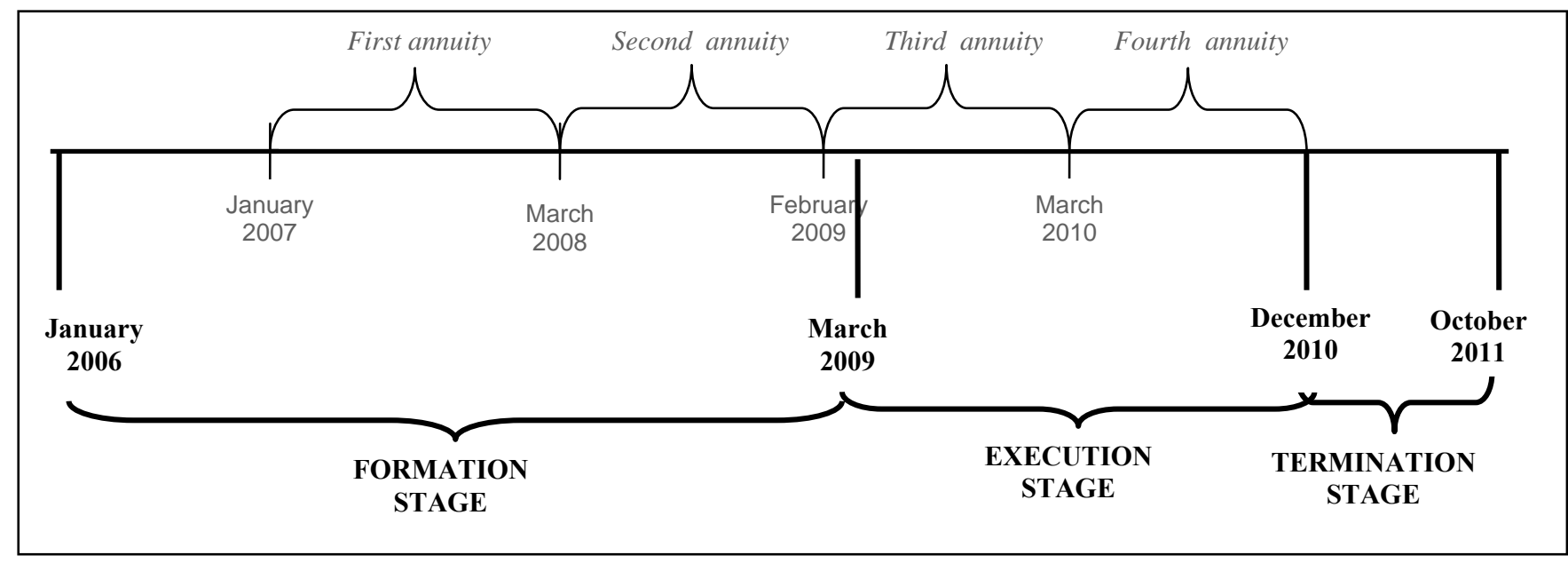

Source: Own elaboration based on Acuisost Consortium's documents and interview data

Formation represents the first lifecycle stage covering the period from January 2006 to March 2009, including three substages which we label background, structuring stage, and start-up stage. During the formation stage, the opportunity to form the Consortium is recognised (Shenkar \& Yan, 2002) and several actions are taken, like 'courtship' and partner selection (e.g. Kanter, 1994) and negotiations (e.g. Reuer, 2000). The execution stage of the Acuisost Consortium, the second one in the alliance lifecycle, unfolded from March 2009 to December 2010, representing the central period of the multipartner collaboration (Parkhe, 1993). During this stage, the R\&D tasks were performed, partners implementing the contractually binding commitments made in the previous phase (Das \& Teng, 2002). The termination stage represents the 'home stretch' of the project, where alliance outcomes became concrete. This last stage covered the period from December 2010 to October 2011.

The following sections provide a longitudinal description of the Acuisost Consortium evolution according to these three lifecycle stages.

\subsection{The formation stage (January 2006-March 2009)}

As stated earlier, the formation stage of the Acuisost Consortium unfolds along three interconnected substages. The opportunity to form the alliance is perceived at the first substage (Shenkar \& Yan, 2002), which we label 'Background'. During this substage, a breeding ground for the formal creation of the alliance was generated and the alliance design and its objectives started to be defined (Mahnke $\&$ Overby, 2008). The second formation sub-stage, which we label 'Structuring stage' according to Das and Teng (2000) and Gogan et al. (2007), covers the search of potential partners, negotiations and 
the establishment of the initial conditions of the alliance (Murray \& Mahon, 1993; Kanter, 1994; Reuer, 2000). Finally, partners started implementing the agreement entering into the 'Start-up' stage (Murray \& Mahon, 1993), experiencing a 'trial period' (Zajac \& Olsen, 1993). Derived retrospectively from the analysis, Figure 2.4, summarizes the lifecycle process along which the formation stage of the Acuisost Consortium developed.

\section{Background: recognition of the opportunity (January 2006- November 2006)}

In a context of Spanish aquaculture expansion and keeping in mind the innovation challenges pointed out by experts in the field, at the beginning of 2006, Aqua-Environ Consulting, (henceforth, the triggering entity), perceived the opportunity to form the Acuisost Consortium: a collaborative R\&D project addressing aquaculture innovation challenges was likely to receive public financial support. In particular, the triggering entity identified a clear match between the sustainable development of the Spanish aquaculture and the priorities of the CENIT Programme. The Acuisost Consortium was born in this way (i.e., following an engineering pathway ${ }^{14}$ ). The triggering entity started to shape what the consortium could be according to the CENIT programme spirit established in its 2006 call. Between middles and November of 2006, it was decided that the alliance would aim to develop innovation in the pursuit of a rational and sustainable aquaculture development. Since allocation of funds from the CENIT Programme takes place on a competitive basis, all subsequent actions were clearly aimed to enhancing the possibilities of the consortium to become one of the beneficiary projects.

\footnotetext{
${ }^{14}$ Such a strategy is usually followed to create new opportunities by some consulting firms which are known in the business context as "grant-achiever". First, they identify opportunities to create projects, usually collaborative ones, which are likely to receive public financial support, by means of technology watch. Then, the idea is proposed to potential partners and, if they agree, the consulting firm engineers the project, usually assuming its coordination in the subsequent development of the alliance. This is a service for which they charge a fee.
} 
Figure 2.4. A longitudinal view on the formation stage of the Acuisost Consortium

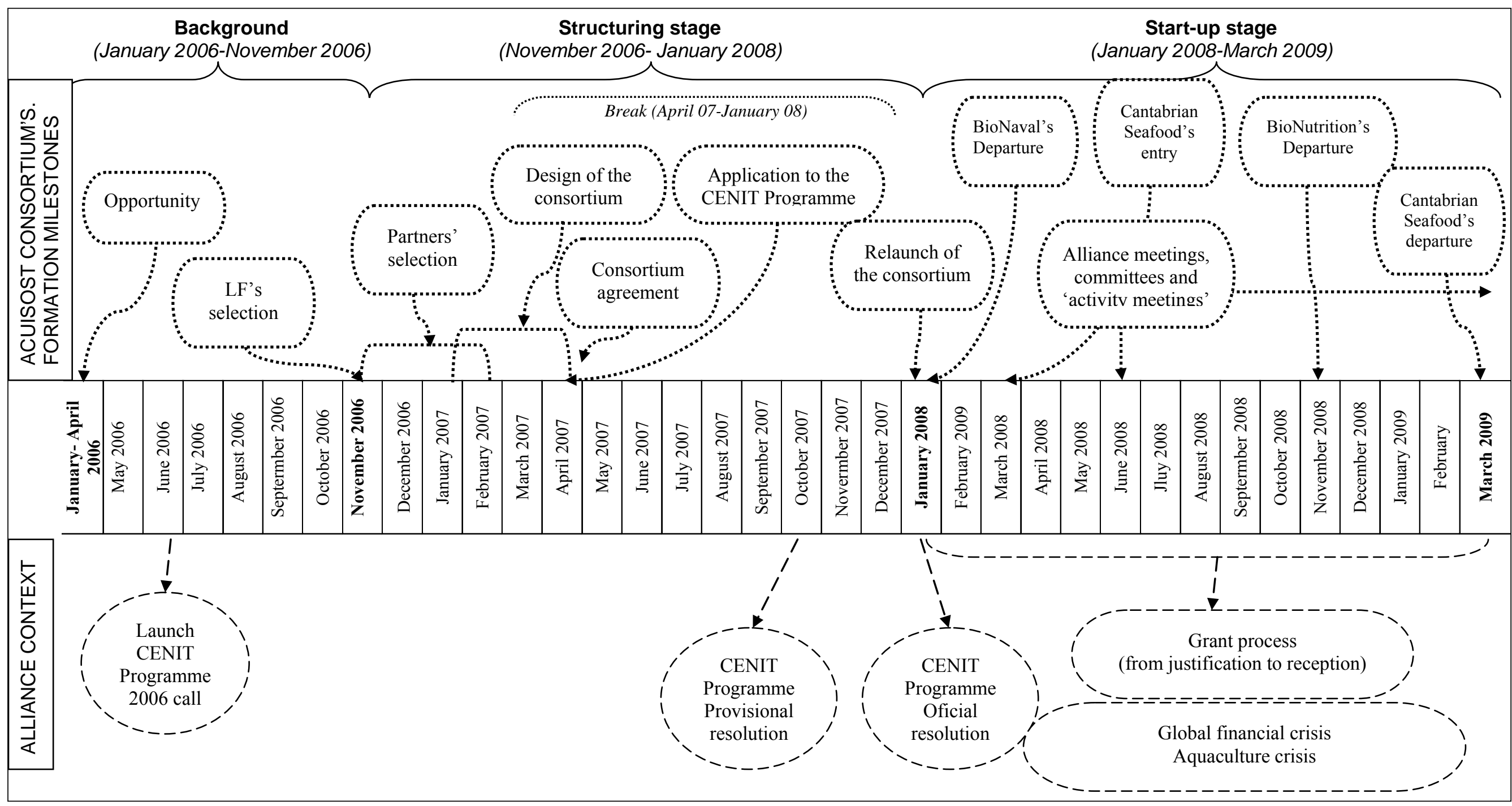

Source: Own elaboration based on Acuisost Consortium's documents and interview data 


\section{Structuring stage: Establishment of initial conditions (November 2006-January 2008)}

Selection of the lead firm and the partners. Once the basis of the Acuisost Consortium was established, the next step was to search potential partners. Interestingly, according to the typology proposed by Doz and colleagues (Doz et al., 2000; Ring et al., 2005), three approaches for selection was employed in the Acuisost Consortium: intra-community, hub and spoke, and open solicitation.

According to CENIT Programme stipulations, the triggering entity developed a 'map of potential industries' (searching for synergies between them and aquaculture) and identified several interesting firms within each of them. Dibaq (hencerfoth, the lead firm) was identified as a firm with high potential as a leader, because of (a) its dimension, (b) its R\&D and financial capacity, (c) its multinational involvement, and, particularly, (d) it is the only fully Spanishownership firm in the aquaculture nutrition field. Moreover, experts point that the innovation challenges of Spanish aquaculture need to be conducted in a coordinated manner among all industry actors but led by the 'core' of the value chain (i.e., fish feed producers). This is because fish feed represents the main cost of the aquaculture productive process and, accordingly, one of the main concerns of the necessary innovative actions.

In November 2006, the triggering entity established contact with the managers of lead firm to present them an overview of the consortium and to convince them about the advantages of leading it. Once the lead firm assessed and accepted the proposal, it searched among its own network of contacts potential partners for the consortium (intra-community approach). Following a corporative group-level strategy, three subsidiaries of lead firm's group (WasteMng Co., Mediterranean Aquaculture, and Iberian Eels) and other five firms belonging to the leader's network joined the consortium. With four of them, the LF had longstanding supplier-buyer relationships- three aquaculture continental producers (Southern Trouts Co., Wetern Trouts Co., and Northen Trouts Co.) and a marine fish farmer (Mediterranean Aquafarming). With the other partner firm, an important company of the Spanish food industry (The Biscuits Company), the LF shared membership in a business association which created the opportunity for personal friendship at the CEO level.

Simultaneously, the triggering entity went on approaching other target firms according to the previously mentioned map of sectors (hub and spoke approach) and finally, the triggering entity and the LF jointly organized two meetings (held respectively in November 2006 and February 2007) summoning all the potentially interested audience (open solicitation approach) and thus completing the search of initial potential partners (BioMilk, Fish\&Meals, The Sugar Company, BioNaval, Industrial Packages Co., Green Solutions, Chemics\&Proteins, MngProjects, and BioNutrition). After presentations, some bilateral meetings took place informally between 
partner firm and research organizations that had perceived potential synergies if working together ${ }^{15}$.

Definition of the structure of the alliance. Once it was considered that a sufficient number of potential partners were gathered, next formation steps should cover the development of the consortium's report and the consortium agreement to apply for CENIT Programme funding. These two documents were developed between January 2007 and April 2007, and were finally submitted to apply for the CENIT Programme by middles of April 2007, proposing an overall alliance budget close to 30 million euros. An interesting peculiarity of the Acuisost Consortium is the lack of overall negotiations during its formation stage neither on its structure (technical, financial, organizational) nor about its contractual conditions.

The consortium agreement was finally signed by the lead firm and the founder partner firms on the $4^{\text {th }}$ April 2007. According to the CENIT Programme ${ }^{16}$ a simply contractual relationship was chosen for the Acuisost Consortium, due to its high flexibility in the face of possible membership changes. Furthermore, also in accordance with the 2006 call of the funding programme $^{17}$, the established horizon of collaboration was the period from January 2007 to December 2010, comprising four technical annuities (each of them covering a calendar year, that is, the period from $1^{\text {st }}$ January to $31^{\text {rd }}$ December $)^{18}$. However, a suspensive clause was included in the consortium agreement: if finally the Acuisost Consortium would not become granted by the CENIT Programme, the consortium agreement would be automatically rescinded.

Detailed descriptions of the alliance's technical, financial, and organizational structure (distribution of R\&D tasks and timeline of contributions; budget's allocation; interface and governance mechanisms) represented the main contents of the consortium's report. Potential partners had autonomy to decide what they want to contribute to the alliance (i.e., R\&D tasks to be performed), as well as the timing and resources for these contributions. During the two

\footnotetext{
${ }^{15}$ The triggering entity asked each potential partner to sign a confidentially agreement, which was nonbinding with regard to the involvement in the alliance (since it was not yet formally created).

16 Two different contractual relationships are allowed for CENIT projects: Economic Interest Grouping or, a contractual relationship involving the signing of a consortium agreement between the partners (instead of the creation of a new legal entity).

${ }^{17}$ In public funding programmes as the CENIT, grants are usually given to research projects initiated previously to the official announcement of the call. With such a procedure, policy makers seek to favour the financing of ongoing 'real' projects rather than of projects ad hoc created. As a result, every project applying for a grant from the 2006 CENIT Programme's call was supposed having started at January 2007.

${ }^{18}$ This division in four technical annuities is what CDTI uses for periodically evaluating the progress of the funded projects and, according to this evaluation, to pay the corresponding part of the assigned public financing support.
} 
previously mentioned initial meetings (held in November 2006 and February 2007 respectively) each potential partner made a brief presentation on what it can potentially contribute to the aquaculture field.

As potential partners showed their willingness to continue committed to the alliance, the triggering entity asked them to formalize their potential contributions by developing an individual report, for which certain format and contents standards were defined. Then, the triggering entity shaped the technical structure of the alliance, based on these individual reports, and some subjective criteria to enhance the attractiveness of the proposal. Thus, seven subprojects or, as internally labelled, technical activities, were included in the consortium, representing its specific technical objectives.

Waiting for CENIT Programme resolution. The start-up of collaboration in the Acuisost Consortium did not unfold automatically after partners signed the consortium agreement, for two connected reasons: (a) the previously mentioned suspensive clause, and (b) the delay in assignment of CENIT Programme ${ }^{19}$ grants corresponding to its 2006 call (it took six months since the application deadline). As a result, the formation processes of the alliance suffered a break between April 2007 and January 2008. The unique movement that deserves to be mentioned during this period is that the LF hired in 2007 a professional with a $\mathrm{PhD}$. in the aquaculture field to be the maximum responsible for the consortium (currently, he holds the position of lead firm's R\&D Manager).

In October 2007, CDTI announced to the LF that the Acuisost Consortium had been chosen as one of the beneficiary projects of the CENIT Programme 2006 call. However, the public financial support provisionally assigned to the Acuisost Consortium significantly differed from the expected one, both quantitatively and qualitatively: Several investments in equipment, viewed as critical by partners, were excluded from the set of eligible costs. CDTI, arguing that these equipments were productive instead of research equipments, denied all partners' appeals. Therefore, the official resolution of the CENIT Programme of January 2008 (published in the Spanish Official Gazette on $15^{\text {th }}$ February 2008) confirmed the provisional one, that is, with an approved budget of 21 million euros (almost 11 million lower than applied).

\footnotetext{
${ }^{19}$ Resolution procedures of the CENIT Programme's calls are as follows. After carefully evaluating all the proposals, CDTI first launches a provisional resolution, which is announced to the leaders of the applicants projects and details the provisionally approved budget (in our case, it happened in October 2007). Then, there is period within applicants may file appeals to the CDTI. After considering them, CDTI establishes the definitive resolution, which is made officially published in the Spanish Official Gazette (in our case, it happened in January 2008).
} 


\section{Start-up stage: ready, steady, go? (January 2008-March 2009)}

Relaunching the Acuisost Consortium. Once the official resolution of the CENIT Programme was definitively available, partner firms wondered whether the Acuisost Consortium would be able to work under such budget constraints, re-assessing the convenience to keep their commitment to the alliance. It is important to note that the landscape of the Acuisost Consortium in the start-up stage had abruptly changed with respect to the economic conditions prevailing during the structuring stage: in January 2008, the effects of the global financial crisis started to seriously damage the economy of the country and a crisis of overproduction burst out in the aquaculture field in Spain. The LF and most of the founder partners of the Acuisost Consortium, however, agreed to continue the alliance. In January 2008, the picture of membership in the Acuisost Consortium started to change with the departure of BioNaval, which argued that both technical and financial conditions did not match its expectations. Given that the budget of the Acuisost Consortium (21 mill Euros) was in the limit respect to the minimum budget established for CENIT Consortia (20 mill Euros), the LF perceived the need to relaunch the consortium, encouraging partners' sense of belonging to definitively overcome scepticism on the possibilities of the consortium. With that in mind, a relaunch meeting, summoning all the partners, was hold in Valencia on the $16^{\text {th }}$ January 2008.

Ending the first technical annuity (without having started). As a result of the suffered break in the consortium and the changes in its initial schedule, the consortium started justifying the first technical annuity, which was supposed to have started at January 2007. Thus, justification of the first technical annuity, in the form of preparing and sending all the required documentation to the public agency, was conducted in the period from January 2008 to March $2008^{20}$.

In the launching meeting, the triggering entity insisted that the consortium should start by making a significant joint effort to justify the costs and expenditures as closely as possible to what had been initially planned for the first annuity, in order to preserve the corresponding part of the grant and thus allowed the consortium to survive, since the departure of BioNaval imposed per se a reduction in the funding to be received. As can be deduced, the problem was that most partners had to justify costs associated to R\&D tasks that almost had not been started. Moreover, the Website implemented to deal with administrative tasks in practice lacked functionality, making the process of uploading files very time-consuming. Moreover, some partners were not very familiar with the use of new technologies. This situation involved significant tensions in the consortium which, after the LF had proposed alternative procedures

${ }^{20}$ CENIT Programme established a long process of justification to the ex-post reception of grants in each technical annuity. Thus, after submitting all the required of documentation justifying investments and expenses under rigid format requirements and they are revised by the public agency, several audits take place. Then, the lead firm receives the public funds and distribute them among the partners according to their relative participation in the budget. 
for dealing with the administrative tasks, they were fulfilled and the first part of the justification of the first technical annuity was completed in March 2008.

The second technical annuity. Partners begun to concentrate on the project itself once the administrative hustle and bustle finished. At this point, the second technical annuity of the project started, and would cover the period from March 2008 to March 2009. Once completed the first technical annuity, in March 2008, a new partner, Cantabrian Seafood, joined the consortium, having being invited by the triggering entity to preserve the overall budget of the consortium. However, just a year later, it departed from the consortium, probably due to its external involvement in another private project.

During this period, in parallel with the development of partners' R\&D projects, several alliance meetings and committees were celebrated. As time progressed, the LF's R\&D Manager realized that there was not a real mechanism which allowed multilateral interaction between alliance participants (among partners, on the one hand, and among partners and research organizations, on the other). After all, the Website has failed as the virtual interface of the consortium. The lead firm's R\&D Manager felt that such interaction could bring important potential benefits, particularly for the technical development of the project. Thus, in a annual alliance meeting held in June 2008, a new organizational mechanism was established, labelled 'activity meetings'. Within each technical activity of the consortium, at least an activity meeting per year should take place. Activity coordinators should be responsible for summoning them, enhancing the participation of all partners and research organizations participating in the activity. The representatives of the leader insisted on the need to implement such a mechanism, offering their personal support for making the most of these meetings. However, the success of this initiative, which had been created outside the contract, varied widely across activities. During the rest of the start-up stage of the Acuisost Consortium, activity meetings were successfully organized in the 'Raw materials' activity. In other activities like 'Biosecurity' or 'Wastes', activity meetings were organized but without the intended frequency and intensity, and there were no activity meetings in the 'Biotechnology' and 'Fish farming activities'.

The subsidy issue. The CENIT Programme entails long processes of justification to the ex-post reception of grants. As a result, at the end of the start-up stage of the Acuisost Consortium (March 2009), most partners had not already received any financial support from the public agency (indeed, funding corresponding to the first technical annuity would not arrive until April 2009). This should be understood in a context of economic crisis and liquidity difficulties for partner firms. In November 2008, BioNutrition, due to its fragile economic situation, left the consortium. 


\subsection{The execution stage (March 2009-December 2010)}

During the formation stage, as explained, the Acuisost Consortium was characterized by collaboration between multiple partner firms searching to organize the macro-structure of the consortium, as well as to define their respective positions and collaborative strategies within it. The role played by research organizations during the formation stage confined to the definition of the specific technical objectives of the partner firms with the Acuisost Consortium. Once the formation stage finished, however, the Acuisost Consortium transformed into a phenomenon of dyadic collaboration between multiple partner firms and research organizations taking place in the context of a larger consortium. Therefore, what may be labeled the locus of technological collaboration in the Acuisost Consortium shifted from the inter-firm level to the firm-research organization level, remaining during the whole period of execution.

Indeed, multilateral interaction among partner firms during this stage confined to four annual meetings and committees of the consortium (held respectively in June 2009, September 2009, June 2010, and October 2010). The initiative of 'activity meetings', did not consolidate (with the notable exceptions of the "Raw Materials" and "Biotechnology systems" Activities), most partner firms showing decreased willingness to continue engaging on multilateral knowledge exchange.

As a result of the severe economic crisis, Northen Trouts Co. departed from the consortium in December 2009. The threat of 'minimum budget in CENIT Consortia' (20 mill. Euros) resurfaced: the departure of this partner firm put the Acuisost Consortium at risk of being excluded from the CENIT Programme. In this context, the triggering entity arranged the entry of two new partner firms in December 2009: BigFish and Rhodium. Furthermore, partner firms continued feeling struggled by administrative requirements of and delays in funding reception remained.

\subsection{The termination stage (December 2010-October 2011)}

Although the contractual relationship between partners of the consortium expired in December 2010 (when the technological collaboration with research organizations also finished), the partners continued linked until October 2011. Then, the final closing meeting consortium was held, with the presence of the public agency that manages the CENIT. The purpose of this meeting was to discuss the overall results of the consortium and assess whether it has achieved an acceptable degree of accomplishment. Final assessment was positive.

In public presentations, the CDTI's representatives highlighted three main results of the Acuisost Consortium as a whole: (1) establishing the basis for collaboration between multiple firms and research organizations (39 new research projects had been agreed, and the prospect is 
to create other 27 projects) (2) driving effect on SMEs (i.e., opportunity to explore and exploit innovation opportunities), and (3) learning how to manage property rights of intangible results (innovation). In subsequent presentations, the coordinators of the technical activities and the representatives of some other partner firms and research centers reviewed the specific results achieved in the relations mentioned by the CDTI in the first place. Such emphasis confirmed the idea that the Acuisost Consortium represented a portfolio of dyadic relations between research centers and partner firms. In some of these collaborations, important technical results had been achieved in the form of five patents already registered or in the process (e.g., a new vaccine, a new microorganism with immune-stimulant properties, a new process for obtaining proteins for fish feed) or new developed products (e. g., new high-value added fish-based products for human consumption). Most of the results corresponded to industrial prototypes, the 'opening up of new interesting vies for further exploration', or the identification of 'technically viable processes that still required up-scaling and cost-reducing efforts'.

The lead firm's R\&D Manager emphasized the strengths and weakness of the Acuisost Consortium, arguing that, despite the overall satisfaction gained and the important results achieved between firms and research organizations, "in R\&D projects, it is also necessary to recognize the non-results" and that the consortium would have multiplied such positive results if stronger overall cooperation had existed.

\subsubsection{Selection of multi-cases for particular studies}

As mentioned, within the framework of the Acuisost Consortium, different cases have been selected to address the different research objectives and questions of each empirical study. In doing so, research design moves from a single-case research in the dissertation as a whole to multi-case research in the empirical studies (at different levels of analysis). After all, research questions define the level of analysis of the study and 'what' the case is (Yin, 2003).

In particular, five cases (i.e., five partner firms of the Acuisost Consortium) were selected for in-depth examination of creation of collaborative routines at the partner-level in Study I. Thus, Study I follows a 'nested' multi-case approach (Gibbert, Ruigrok, \& Wicki, 2008): multiple cases within a single setting. For each of the studies included in Study II, two different cases (i.e., firm-research organization relationships within the Acuisost Consortium) were selected for in-depth examination and comparison of the creation and evolution of collaborative routines at the inter-organizational level: the OI-LF and the CRAI-LF alliances in Study II.1 and the MARLF and the CAH-LF alliances in Study II.2. All these cases were selected following theoretical sampling criteria (Eisenhardt, 1989; Pettigrew, 1990; Eisenhardt \& Graebner, 2007): selected cases are representative of the particular phenomenon of interest of the empirical study (i.e., inexperienced partners in Study I, unfamiliar partners in Study II.1. and familiar partners in 
Study II.2) and the processes to be analyzed within each of them was transparently observable. For more details about each of these cases and the particular reasons supporting their selection, the reader is referred to the methodology sections of the empirical studies.

\subsection{Data collection and analysis: Quality of the research}

This section is devoted first to describe the processes, principles, and methods of data collection and analysis followed in this dissertation. Subsequently, information to judge the quality of the research is presented- according to the basic criteria of validity and reliability. Finally, this section concludes with an outline of the research design and methods adopted in each empirical study of this dissertation.

It is important to remark that, in case study research, the processes of data collection and analysis, often develop concurrently to literature review tasks, and go hand in hand one with each other -'circularity of the research'- (Nieto \& Pérez, 2000; Yin, 2003). For simplification purposes, however, this section provides two separate chronologies for data collection and analysis.

\subsubsection{Data collection: principles and process}

In structuring the data collection efforts in this dissertation, it has been followed: (1) what Yin (2003) labels 'the three principles of data collection in case study research' (i.e., use of multiple sources of evidence, maintenance of a chain of evidence, and feedback from key informants), and (2) the recommendations of Pettigrew (1990) and Pentland (1999) to go from surface to deeper levels of data collection. In the following, principles and process of data collection in this dissertation are explained.

\subsubsection{Data collection principles}

The first principle of data collection was addressed by resorting to multiple sources of evidence, containing both primary and secondary information: exploratory and semi-structured interviews following different scripts according to the data to be collected in each phase), questionnaire (to deal with data reduction dilemmas), alliance documents (e.g., the consortium's report ${ }^{21}$, the consortium agreement signed by partner firms, private agreements between firms and research organizations, minutes of meetings, technical reports ${ }^{22}$, press releases and other publicly available information (e.g., annual reports of firms and research organizations, Websites), and

\footnotetext{
${ }^{21}$ The consortium's report is a 456-page document, prepared at the beginning of the consortium to apply funding from the CENIT program. Among others, the report contains the consortium objectives, the justification of the project's relevance, description of the initial partner firms and research organizations involved, description of the covered research areas and technical activities, the overall and itemized budget, a description of the organizational structure of the consortium, expected results and their exploitation strategy. See Appendix II.4 for an outline of the consortium's report.
} 
direct observation in four annual consortium committees and meetings, during which extensive notes were taken.

Although other sources provided very useful insights (particularly, the consortium's report and the contractual agreements, see Appendix II.4), interviews represented the main source of information (and data collection technique) for the research in this dissertation. As reflected in Table 2.9., forty-five interviews with different informants were conducted during the whole research period, with an average length of an hour and a half (minimum length of fifty minutes, maximum length of six hours).

Table 2.9. Summary of interviewing actions

\begin{tabular}{|l|c|}
\hline Lead firm & 16 interviews \\
\hline Partner firms & 14 interviews \\
\hline Research organizations & 12 interviews \\
\hline Other participants & 3 interviews \\
\hline Total No. interviews & $\mathbf{4 5}$ interviews \\
\hline
\end{tabular}

Before conducting each interview, the research team spent significant time in preparing a 'customized interviewer script ${ }^{, 23}$, which was headed by the general data of the interview (main objective of the interview, the interviewers name of the research team, name of the respondents of the consortium, expected duration, place and date) and listed the basic contents of the interview. At the beginning of each interview, this script was given to the interviewee for her/his personal records with a two-fold purpose: (1) 'breaking the ice' by showing transparency and focusing the attention of the interviewee on the data points of interest, and (2) facilitate the redirection of the interview if necessary. Furthermore, these scripts provide a useful schema for subsequent transcription of the interviews, their classification and subsequent retrieval from the case study database. Therefore, all interviews conducted were semi-structured interviews (except the first one conducted with the lead firm's CEO which adopted a more unstructured style), some of them aiming to collect exploratory data (more general data on the Acuisost Consortium or more specific data on the different phenomena addressed in the empirical studies) and others aiming to collect more focus data (i.e., in-depth interviews). Regardless their orientation, most interviews were conducted by at least two researchers, which were conducted

${ }^{23}$ Similar scripts were also prepared for conducting direct observation in annual meetings of the consortium. 
by at least two researchers and recorded whenever possible ${ }^{24}$, then transcribed and checked by all the researchers involved.

These different sources of evidence allowed fulfilling the second principle of data collection: a dynamic chain of evidence was maintained. The different sources of evidence provided longitudinal information on different levels of the Acuisost Consortium, generating thus a picture of the whole research period which captured how data evolves over time (Yin, 2003). For example, the consortium's report provides information about the initial conditions of the alliance (e.g., who were the founder partner firms), which was completed and updated through subsequent interviews with different informants (e.g., which founder partner firms remained over time in the consortium and which new partner firms joined it). According to Yin (2003) and other case-study researchers (e.g., Pentland, 1999; Faems et al., 2008), longitudinal narratives (or case study reports developed at the first step of the analysis process), illustrated such a chain of evidence by containing extensive references to the different sources of data.

In line with the third principle of data collection, key informants provided periodical feedback in order to guarantee accuracy and to preserve confidentiality. To that end, before obtaining research results themselves (subsequently materialized in the empirical studies), the research team developed two reports (labelled as 'Preliminary report, June 2009' and 'Intermediary report, December 2009'). These two reports were presented to the lead firm, which made them available to the consortium partners through the private area of the Acuisost Consortium Website. Subsequently, as data were analysed and empirical studies of this dissertation were developed (January 2010 to December 2011), drafts were periodically email to the lead firm's R\&D Manager, who reviewed them in order to give consent to their diffusion in academic forums. This process also allowed the identification and correction of erroneous and imprecise interpretations of data. For example, based on first collected information, The Biscuit Company was classified as a non-friend partner firm of the lead firm. However, the lead firm's R\&D Manager remarked that, despite having no prior collaborative or commercial relationships, these two firms could not be described as unfamiliar: a long-standing personal friendship existed between the CEOs of both companies, forged through shared membership in the regional business association of family enterprise. Furthermore, during the whole research period, interviews with the lead firm's R\&D Manager always serve as feedback interviews. Each interview started by asking him 'the main Acuisost Consortium news from the last interview' and comprised a section devoted to 'clarify doubts', often referring to technical aspects of aquaculture processes relevant to understand the technological collaboration in the consortium. As a proof of their commitment with the research, it is important to note that the lead firm's

\footnotetext{
${ }^{24}$ Interviewees almost always agreed on being recorded, except on two occasions (also, the two phone interviews were unrecorded).
} 
R\&D Manager provided by his own initiative information 'potentially of interest for the research'. In addition, once the two broad levels of analysis of research in the dissertation were decided, a 'closing interview' for Study I (partner firms of the Acuisost Consortium) and a 'starting interview' for Study II (firm-research organization relationships in the consortium) were conducted with the lead firm's R\&D Manager. During the period of development of the empirical studies, we also maintained follow-up contact with other informants to deal with discrepancies among data sources and emerging needs of information.

\subsubsection{Process of data collection}

In this section, the process of data collection followed in this dissertation is described. An overview is displayed in Figure 2.5.

Before describing the different phases through which these data collection efforts unfolded, it is important to advance the general strategy of data collection followed in this dissertation. In line with the process vocation of this research, data was collected longitudinally. In this regard, case study theorists suggest two main approaches: ongoing and retrospective data collection (Leonard-Barton, 1990; Pettigrew, 1990; Faems et al., 2008). Ongoing data collection provides a much more accurate view on the phenomenon under study, yet it is usually less efficient than the retrospective approach, involving the risk of collecting much unnecessary data and falling into 'data asphyxiation'. A retrospective strategy allows a much more focused data collection fitting better the purposes of the research. After all, 'looking back' is a necessary condition for sensemaking (Gioia \& Chittipeddi, 1991). However, retrospective data collection involves risk of respondent cognitive biases (e.g., overemphasis on certain events, misleading time sequences). Data triangulation and the use of semi-structure interviews may mitigate such biases (Faems et al., 2008). Both approaches were combined in this dissertation [data were ongoing collected given the partial overlap between the research period (June 2008-December 2011) and the Acuisost Consortium (January 2006-October 2011)].

As stated, the structure of the data collection efforts for this dissertation followed the recommendations of Pettigrew (1990) and Pentland (1999), collecting data first on a more exploratory level and then on a deeper level along four main phases (explained in the following). However, it is important to remark that exploratory and in-depth data collection efforts for the different empirical studies of this dissertation developed concurrently over time. For example, interviews conducted to collect information for Study I provides also collateral data for Study II. Therefore, these four main phases of data collection refer to the dissertation as a whole and present some nuances when applied in each empirical study. In this regard, the reader is referred to the methodology sections of each empirical study. 
The 'zero' phase of data collection covered the period from January 2008 (getting access to the Acuisost Consortium case) to June 2008 (actual start-up of the research), paving the way for subsequent actions in the dissertation. In January 2008, a meeting was arranged with the CEO of the lead firm with the aim of getting access to the Acuisost Consortium case. A press announcement (December 2008) guided the attention of the research team towards the Acuisost Consortium as an interesting setting for this dissertation: studying such a complex R\&D consortium may resulted in important research contributions. Two circumstances should be mentioned to understand this decision: (a) prior contacts existed with the lead firm, which sounded as a potential advantage to get access to the case, and (b) the $\mathrm{PhD}$ candidate had already started to focus on the field of strategic alliances during the first phase her doctoral education, ongoing at that time, (as a result, the need of further scholarly efforts on multipartner settings had already been discovered). In this meeting, a first outline of the research project was presented to the $\mathrm{CEO}$, emphasizing the commitment of the research team to preserve confidentiality, provide periodical feedback, study the whole period of the consortium, and strive to generate useful research not only for academy but also for practice. Moreover, the research team proposed a preliminary chronology for the research project, in connexion with the status of the doctoral education of the $\mathrm{PhD}$ candidate (i.e., the research would actually started after the first doctoral period concluded, by June 2008).

In this initial meeting, the lead firm's CEO also provided some preliminary information about the Acuisost Consortium, its background, participants, and objectives. Two weeks later, the approval of the proposal to study the Acuisost Consortium was confirmed to the research team, which also received contact information about the individuals most directly involved in the management of the Acuisost Consortium within the lead firm: the Aquaculture Division Manager and the coordinator of the Acuisost Consortium (currently, the R\&D Manager).

In subsequent months, they were contacted and a meeting was arranged with both of them in April 2008. During this semi-structured exploratory interview, the research team explained with the detail its research proposal (more mature but still in a very preliminary stage), emphasizing the previously commitments arranged with the CEO. Both managers provided a lot of information about the Acuisost Consortium (e.g., origin, structure, participants, emerging problems, expected benefits). 
Figure 2.5. Progress of the research (data collection efforts)

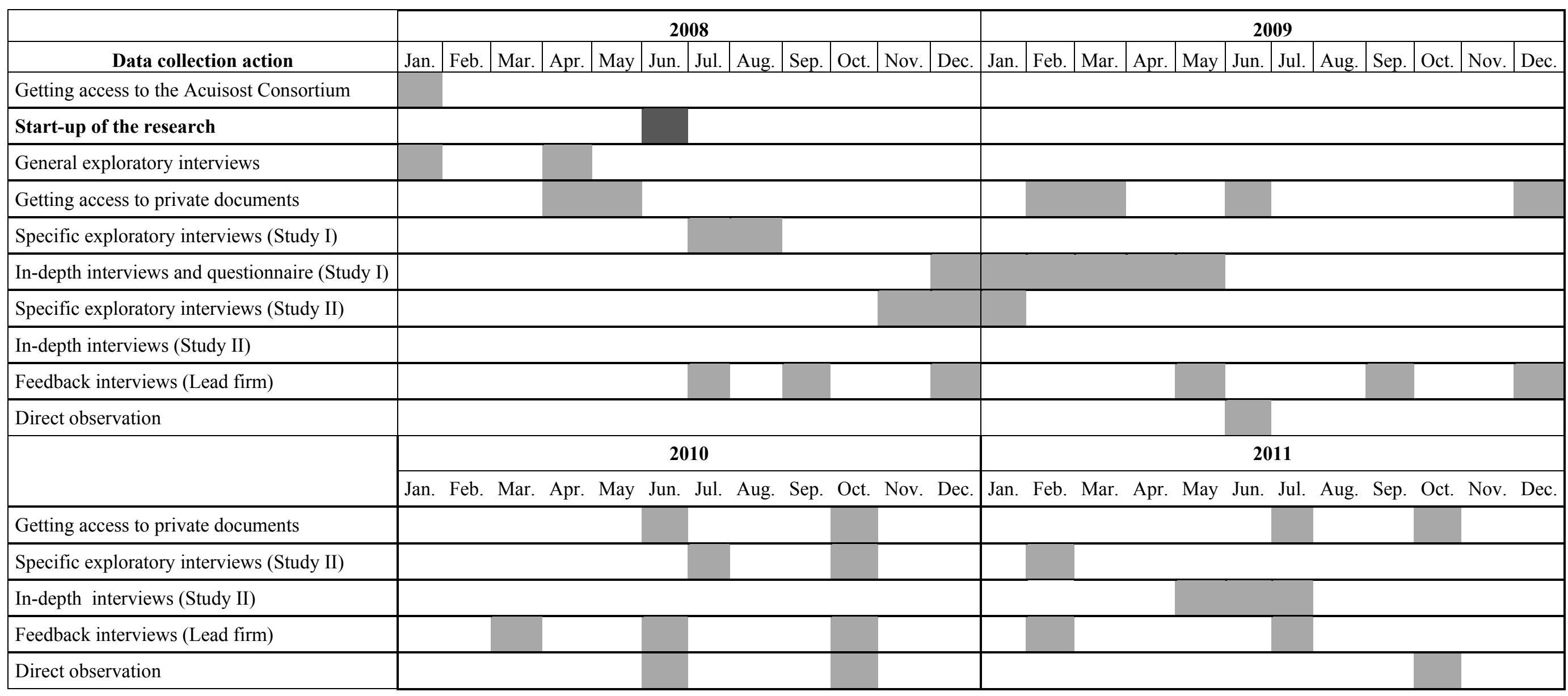


In a subsequent semi-structured interview with the lead firm's R\&D Manager (April 2008), the research team got access to relevant private documents of the Acuisost Consortium (e.g., the consortium's report and contractual agreement) and other personal files containing codified information (e.g., contact details of some consortium participants, distribution of consortium's budget among partner firms) which resulted very useful to draw a picture of the complex alliance and to undertake subsequent contacts with case study actors by complementing publicly available information. Other documents were longitudinally collected (e.g., press releases or private documents like minutes of meetings) and revised during the whole research period. Also in April 2008, an additional general exploratory interview was conducted (by phone) with the representative of the triggering entity with the main purposes of starting to understand the formation process of the Acuisost Consortium, establishing contact, and probing its acceptance about our research proposal. At that moment, the research team was asked to sign a "nondisclosure agreement' to preserve an adequate development of the consortium.

The first phase of data collection in the dissertation as a whole unfolded during the period from June 2008 to December 2008. This phase started with a semi-structured interview with the lead firm's R\&D Manager and a technician providing him assistance (July 2008), and followed with two semi-structured interviews with the R\&D Managers of two partner firms (October 2008) and the head researchers of two research organizations (November 2008), which served as exploratory interviews, respectively, of Study I and Study II. In parallel, the questionnaire for Study I was designed. The questionnaire was pre-tested with three key informants: the representatives of the lead firm and of other two partners, identified by the former as 'strategic partners'. Once the process design was completed, the questionnaire was mailed to all partners' representatives (also identified with the help of the LF), accompanied with a letter of introduction (co-signed by the research team and the leader's representative) and a return envelope. Reception of questionnaires for Study I was unfolding slower than expected, so we contacted by telephone with firms that had not yet collaborated and offered them some alternatives (re-sending by post or e-mail the survey, filling it through a face-to-face interview or, as a last resort, by telephone). This follow-up procedure finally resulted in a total of 14 partner firms completing the questionnaire (response rate close to $78 \%$ ) in December $2008^{25}$.

The second phase of data collection in the dissertation as a whole went through the period from December 2008 to December 2009. Here, the first data collection action concerned indepth semi-structured interviews, conducted to collect specific data for Study I. In particular, meetings were arranged with the representatives of eight partner firms, five of them holding the position of activity coordinators, and those five and another one being members of the

\footnotetext{
${ }^{25}$ As some of the informants showed preference for the option 'filling the survey through a face-to-face interview', collection of questionnaire data indeed finished during the subsequent phase.
} 
Technical and Scientific Committee of the consortium. In parallel, the representatives of four research organizations were interviewed (December 2008 and January 2009). These interviews provided explanatory information for Study II. In some of these interviews, some private documents were provided to the research team.

Data collection actions were completed with (a) an interview with the two managers of MngInvestment -a consulting firm significantly involved in the consortium- (March 2009) ${ }^{26}$, (b) an interview with the representative of the triggering entity (April 2009), (c) three additional interviews with the lead firm's R\&D Manager (May, September, and December 2009), and (d) direct observation in an annual meeting of the consortium (June 2009). These data collection actions allowed solving discrepancies among data sources and confirming some impressions, reconstructing the story, and gaining multi-perspective insights into the formation dynamics of the Acuisost Consortium to a sufficient extent to understand and then explain it in Study I.

The third, and last, phase of data collection in the dissertation as a whole covered the period from December 2009 to October 2011. As will be explained later, some periods within this phase of data collection developed concurrently to the processes of data analysis and manuscript writing [general data on the Acuisost Consortium and specific data on Study I (December 2009December 2010); specific data on Study II (July 2011-October 2011)]. The most important data collection actions conducted during this phase concerned Study II. In this regard, two exploratory interviews were conducted with the lead firm's R\&D Manager (July 2010 and February 2011) and other four, respectively, with the representatives of two partner firms a two research organizations (October 2010). After this, eight in-depth semi-structured interviews were conducted with the lead firm's R\&D Manager (four interviews between May and July 2011) and the head researchers of the four selected research organizations (four interviews between May 2011 and June 2011). These data collection actions allowed solving discrepancies among data sources and confirming some impressions, reconstructing the story, and gaining dual insights into the four selected dyadic R\&D relationships under the Acuisost Consortium to a sufficient extent to understand and explain them in Study II.

To maintain a dynamic chain of evidence, other complementary actions of data collection were conducted. In particular, the lead firm's R\&D Manager provided once again information about news in the Acuisost Consortium (he was formally interviewed in March 2010, February 2011 and July 2011). Furthermore, direct observation was conducted in several annual meetings and

\footnotetext{
${ }^{26}$ As mentioned, this firm maintains private concurrent contracts (for consulting services) with several partners. In particular, this firm has provided consultancy services to the LF and another partner firm for years, thus it provides them consultancy services not only in the context of the Acuisost Consortium but also in other areas. Moreover, once the alliance started, it began to provide consultancy services to many other partners, supporting them in managing alliance-related issues.
} 
committees of the consortium (June 2010, October 2010, and October 2011). Information officially presented in the meetings provided relevant insights about the progress of the consortium as a whole and of the different alliances between firms and research organizations. Furthermore, the attendance of the research team to these meetings gave rise to insightful conversations with a variety of case informants (e.g., the lead firm's Aquaculture Division and R\&D Managers, the members of the Steering and Technical and Scientific committees of the consortium, or the representative of the triggering entity). These conversations, though informal fashion, often sustained in a broader script prepared in advance by the research team, which detailed information gaps to be covered during the meetings. Table 2.10 provides a summary of the phases and actions of data collection.

Table 2.10. Phases and actions of data collection in the dissertation as a whole

\begin{tabular}{|c|c|c|}
\hline $\begin{array}{c}\text { 'Zero' phase } \\
\text { (January -June 2008) }\end{array}$ & $\begin{array}{c}\text { First phase } \\
\text { (June -December 2008) }\end{array}$ & $\begin{array}{c}\text { Second phase } \\
\text { (Dec. 2008-Dec. 2009) }\end{array}$ \\
\hline $\begin{array}{l}\text { - Getting access to the case } \\
\text { (interview with the lead } \\
\text { firm's CEO) } \\
\text { - General exploratory } \\
\text { interviews (CEO, } \\
\text { Aquaculture Division } \\
\text { Manager and R\&D Manager } \\
\text { of the lead firm and } \\
\text { representative of the } \\
\text { triggering entity) } \\
\text { - Private documents and other } \\
\text { publicly available } \\
\text { information } \\
\text { - Actually start-up of the } \\
\text { research }\end{array}$ & $\begin{array}{l}\text { - Semi-structured interview } \\
\text { (lead firm's representatives) } \\
\text { - Exploratory interviews for } \\
\text { Study I (R\&D managers of } \\
\text { two partner firms) } \\
\text { - Exploratory interviews of } \\
\text { Study II (Head researchers of } \\
\text { two research organizations) } \\
\text { - Design, pre-test, mailing and } \\
\text { reception of questionnaire for } \\
\text { Study I }\end{array}$ & $\begin{array}{l}\text { - Exploratory interviews for } \\
\text { Study II (lead firm's R\&D } \\
\text { Manager and representatives } \\
\text { of two research organizations } \\
\text { and two partner firms) } \\
\text { - In-depth semi-structured } \\
\text { interviews for Study II (lead } \\
\text { firm's R\&D Manager and } \\
\text { head researchers of four } \\
\text { research organizations) } \\
\text { - Direct observation in three } \\
\text { annual consortium meetings }\end{array}$ \\
\hline
\end{tabular}

\subsubsection{Data analysis: Processes, levels and methods in particular studies}

As stated, the structure of the data analysis efforts of this dissertation followed the recommendations of Pettigrew (1990) and Pentland (1999), analyzing data first on a more exploratory level and then on a deeper level. Broadly speaking, it can be said that data analysis started with the reconstruction of the stories at hand and the development of longitudinal narratives, which laid the basis for subsequent in-depth analysis The processes of analysis, including narrative and manuscript writing, is detailed in Table 2.11.

As the Table 2.10 reflects, it is useful to distinguish between two broad (and interrelated) types of collected data: general data on the Acuisost Consortium and more specific data for conducting the empirical studies of the dissertation. 
Table 2.11. Processes of analysis in this dissertation

\begin{tabular}{|l|c|}
\hline & Research period: June 2008 to December 2011 \\
\hline $\begin{array}{l}\text { Analysis of general data on the Acuisost } \\
\text { Consortium and longitudinal description }\end{array}$ & June 2008- December 2010 \\
\hline $\begin{array}{l}\text { Data analysis for Study I and manuscript } \\
\text { writing }\end{array}$ & June 2009- December 2010 \\
\hline $\begin{array}{l}\text { Data analysis data for Study II and } \\
\text { manuscript writing }\end{array}$ & \multicolumn{2}{|c|}{ October 2010-Dec. 2011} \\
\hline
\end{tabular}

The former kind of data was reflected in the longitudinal description of the Acuisost Consortium (see section 2.2.1.4. of this Chapter), mainly developed between June 2008 and December 2010 (although update until the end of the research). As previously explained, analysis of general data allowed the definition of the specific objectives addressed in the empirical studies. By analyzing information provided in the first exploratory interviews, the following circumstances were perceived, motivating Study I: (a) the formation stage of the Acuisost Consortium had been particularly complex, and (b) the Acuisost Consortium had been founded by a group of partner firms without significant experience in multi-partner settings. Likewise, subsequent analysis of general data on the consortium revealed that, from the execution stage, the Acuisost Consortium has transformed into a portfolio of dyadic R\&D relationships between firms and research organizations, thus giving rise to Study II. Furthermore, analysis of general data provided also some specific impressions and observations for the empirical studies. For example, when Study II started it was already known that for some firm and research organizations collaborating together the Acuisost Consortium represented the first alliance, whereas other linkages were close friends.

\subsubsection{Selection of diverse level analysis: multi-level research}

In case study research, research questions define the unit of analysis which, in turn, defines 'what' the case is (Yin, 2003). According to the two specific research objectives of this dissertation, Study I and Study II address different levels of analysis. As explained, alliances entail multi-level phenomena by definition (Hagedoorn, 2006; Nielsen, 2010). We address two different levels of analysis, allowing a more comprehensive understanding on the Acuisost Consortium dynamics.

Study I is designed at the partner-level of analysis, such that the partner firms of the Acuisost Consortium represent the cases (and the Acuisost Consortium constitutes the research setting in which such cases developed). Following theoretical sampling (Eisenhardt, 1989), five cases were selected for in-depth study. The reader is referred to the methodological section of Study I for more details. 
Both Study II.1 and Study II.2. focus on the inter-organizational level of analysis, such that the relationships of dyadic R\&D collaboration between partner firms and research organizations represent the cases (and the Acuisost Consortium constitutes the research setting in which such cases developed). Study II.1 unfolds at the level of the focal R\&D alliance, studying and comparing the collaboration between two different pairs of unfamiliar partners collaborating for explorative purposes: one alliance was successful whereas the other failed. Study II also takes account the whole collaborative relationship existing between other two pairs of familiar partners: one alliance was oriented at exploitation and the other at exploration, and both of them proved successful. The reader is referred to the methodological section of Study II.1 and Study II.2 for more details.

\subsubsection{Selection of diverse method analysis: multi-method research}

According to Yin (2003: 109), data analysis in case study research "consists of examining, categorizing, tabulating, testing, or otherwise recombining both quantitative and qualitative evidence" to address the initial research objectives of the study. Furthermore, different methods of analysis or analytical strategies could be used, depending on the nature of the case study. Therefore, different analytical strategies were applied in Study I and Study II, generating multimethod case study research in the dissertation as a whole (Eisenhardt, 1989; Yin, 2003; Patton, 2002). However, approaches used in both studies could be considered as variants of the technique of 'pattern-matching' which, broadly defined, "compares an empirically based pattern with a predicted one (or with several alternative patterns)" (Yin, 2003: 116). For more finegrained details about the analysis the reader is referred to the methodological sections of the empirical studies.

Study I represents a multi-case exercise of theory-testing and theory-building, and follows an iterative analytic strategy labeled by Yin (2003: 120-121) as 'explanation-building': "a special type of pattern matching [...] (with) the goal of analyze the case study data by building an explanation about the case $[\ldots]$ the case study evidence is examined, theoretical propositions are revised, and the evidence is examined once again from a new perspective, in this iterative mode". In Study I, this pattern-matching process started with some initial propositions built upon existing theory, and follows by comparing case study evidence with these propositions. This part of the study should be considered as a 'case-based' theory-testing exercise: propositions are compared with case patterns (i.e., pattern matching) gaining a fine-grained longitudinal testing of existing theory which in turn flowed towards the building of theory (Yin, 2003). In doing so, research efforts first devoted to coding all available information (qualitative and quantitative) to generate fully quantitative variables (Larsson, 1993), and then moved from within-case to cross-case analysis (Galunic \& Eisenhardt, 2001) using two complementary 
methods of analysis: narrative and statistical methods. Research methodology theorists suggest that using together these two sensemaking strategies allows us to gain both theoretical parsimony by abstracting from original data (quantification strategy) and empirical accuracy by providing 'thick descriptions' (narrative strategy). In particular, quantification strategy will be much more convincing if it used in combination with qualitative approaches that allow contextualization, adding nuances of interpretation and incorporating the longitudinal element, confirming or challenging suggestions from statistic analysis with direct evidence (Langley, 1999). As quantitative techniques, we resort to Partial Least Squares (PLS) and partition analysis, respectively using SmartPLS 2.0 (Ringle, Wende, \& Will, 2005) and JMP software. Bearing in mind the purpose of analytical rather than statistical generalization inherent to case study research (Eisenhardt, 1989; Yin, 2003), case study findings cannot be statistically generalized (regardless the number of data points on which statistical analysis is based).

Study II.1 and Study II.2 both aimed at inductive theory-building by means of a comparative study of two cases, such that the analytical strategy they followed resembles a different variant of 'pattern-matching'. Broadly speaking, the strategy followed in Study II could be considered as an inductive variant of pattern-matching: instead of stating a priori propositions, patterns are induced from the narratives of each case, then compared to each other and interpreted in light of existing concepts (moving from first-order to second-order constructs). Therefore, Study II.1 and Study II.2 aimed at exploration of patterns in the collected data (Strauss \& Corbin, 1998). To that end, iterative discussions between the researchers involved were held, building a more complete image on the phenomenon under study (Eisenhardt, 1989). Moreover, although these two studies could be described as 'qualitative case studies', it is important to note that the process of narrative construction and analysis was supported by the operationalization of constructs as Likert-scale variables (obtained thorough face-to-face surveys), which involved advantages in terms of data reduction dilemmas (Langley, 1999).

In Study II.1, two explorative alliances between unfamiliar partners were selected and comparatively studied: one successful alliance and the other unsuccessful. In Study II.2., two successful alliances between familiar partners were selected and compared: the variable of differentiation here was the innovation-seeking orientation of the alliance (one alliance oriented at exploitation and the other at exploration). Contrary to Yin (2003) proposals for more 'deductive' case studies (i.e., development of a priori rival theoretical propositions and subsequent analysis of the matching with those predicted patterns), discussion of findings in Study II.1 and Study II.2 arrived at explanatory frameworks yielding several induced propositions. In Study II.1 most of these propositions are mutually exclusive, reflecting the 
differences between the cases, whereas in Study II.2 these propositions emphasize the commonalities between the cases.

\subsubsection{Test of quality research}

First of all, it is important to note that it is necessary to provide some proofs about the quality of the research conducted, and case study research is no an exception in this regard (Yin, 2003). Indeed, addressing explicitly the quality of the research may help to demystify the common criticism of lack of rigor in case study research. Following Yin (2003) and Gilbert et al. (2008), four different but complementary tests can be used to judge the quality of case study research: construct validity, internal validity, external validity, and reliability. As a whole, this dissertation aims at both theory-testing and building, it is thus necessary to cover the four tests $^{27}$. In the following, each quality test and the main actions taken to address them are described. See Table 2.12 for a summary of these parameters [See Ariño and Ringh (2010) for a good description of quality tests in case study research].

The first quality test refers to construct validity which means defining accurate operational measures for the concepts being studied and avoiding subjective judgements in collecting the data (Yin, 2003). As explained, this dissertation meets the principle of construct validity thorough the following actions: data and researcher triangulation, chain of evidence, and feedback from key informants. The second quality test concerns the extent to which nonspurious causal relationships between the outcome variables and the explanatory ones have been established, labelled as internal validity. To enhance internal validity, empirical studies of this dissertation have applied analytical approaches that entail replication logic (i.e., explanation building with multiple cases and exploration of patterns by means of two-case comparison), as well as researcher and methodological triangulation (Eisenhardt, 1989; Patton, 2002). Interestingly, Eisenhardt (1989: 544) states that "if researches ignore conflicting findings, then confidence in the findings is reduced. For example, readers may assume that the results are incorrect (a challenge to internal validity) or if correct, are idiosyncratic to the specific cases of the study (a challenge to generalization)".

Concerning these two quality tests, this dissertation has mainly addressed triangulation in a multilevel sense (Patton, 2002; Yin, 2003). Information has been provided by multiple sources of evidence (data triangulation), both primary (interviews, questionnaires) as well as secondary sources (e.g., reports and Websites), at different levels. Furthermore, as explained, these multiple sources of evidence allowed the maintenance of a chain of evidence, reflected in the studies by means of explanation of data collection and analysis procedures and extensive

\footnotetext{
${ }^{27}$ Following Yin (2003), internal validity only concerns explanatory case studies, where the objective is to determine causal relationships between variables.
} 
citations to data sources in case narratives. All the interviews were conducted by at least two researchers, then transcribed and checked by all the researchers involved (researcher triangulation). Likewise, researchers involved in each study engaged in iterative discussions to analyse and interpret data. Eisenhardt (1989: 538) emphasises two advantages of multiple researchers: "First, they enhance the creative potential of the study [...] Second, the convergence of observations from multiple investigators enhances confidence in the findings". In addition, different types of data have been collected (i.e., qualitative and quantitative data), allowing the gain of data synergies (Eisenhardt, 1989; Patton, 2002). The use of several sensemaking strategies facilitates theorizing from process-data: quantification strategy provides simplicity by dealing with data reduction dilemmas (Langley, 1999), whereas narrative provides accuracy by providing details and 'thick descriptions' (Dyer \& Wilks, 1991), allowing contextualization and incorporating the longitudinal element (Leonard-Barton, 1990; Langley, 1999).

The third quality test about which case study researchers should concern refers to whether the case study's findings can be generalized beyond the immediate case or external validity (Yin, 2003). In this regard, the main measure adopted in this dissertation concerns the representativeness of the selected research setting and cases, relying on theoretical sampling criteria (Eisenhardt, 1989): The Acuisost Consortium and the other selected cases are representative of the respective 'population of reference' of the empirical studies (e.g.,. multipartner R\&D alliances).

The final quality test proposed by Yin (2003) and Gilbert et al. (2008) has to do with the potential of case study procedures to be replicated with the same results or reliability. In this regard, the main measures adopted in this dissertation concern the use of case study protocols for guiding the ongoing research (Nieto \& Pérez, 2000) [see above about the 'interviewers script'] and the compilation of all collected data in case study databases, referenced in the empirical studies. 
Table 2.12. Quality of the research in this dissertation, according to Yin (2003) and Gibbert et al. (2008)

\begin{tabular}{|c|c|c|c|}
\hline Quality test & Main measures & & Adopted measures and implementation \\
\hline \multirow{4}{*}{$\begin{array}{l}\text { Construct validity: } \\
\text { Correct conceptualization and } \\
\text { operationalization of key } \\
\text { concepts, avoiding subjective } \\
\text { judgments }\end{array}$} & Data triangulation & $\checkmark$ & - Multiple sources of evidence (interviews, questionnaire, documents) \\
\hline & Researcher triangulation & $\checkmark$ & $\begin{array}{l}\text { - Approach used in interviews } \\
\text { - Multiple coding process (three raters in Study I) }\end{array}$ \\
\hline & Feedback from key informants & $\checkmark$ & - Confirmation of some findings and correction of erroneous impressions \\
\hline & Chain of evidence & $\checkmark$ & $\begin{array}{l}\text { - Explanation of data collection and analysis procedures } \\
\text { - Extensive citations to data sources in case analysis }\end{array}$ \\
\hline \multirow{4}{*}{$\begin{array}{l}\text { Internal validity: } \\
\text { Establishing non-spurious } \\
\text { causal relationships }\end{array}$} & $\begin{array}{l}\text { Research framework explicitly } \\
\text { derived from the literature }\end{array}$ & $\checkmark$ & $\begin{array}{l}\text { - Cooperative behavior and cooperation in multi-partner alliances (Study I) } \\
\text { - Research on R\&D alliances (Study II) }\end{array}$ \\
\hline & $\begin{array}{l}\text { Pattern matching and exploration } \\
\text { of patterns (replication) }\end{array}$ & $\checkmark$ & $\begin{array}{l}\text { - Initially proposed patterns and empirical ones are confronted (Study I) } \\
\text { - Case-by-case explanation building (multi-case conclusions extracted) (Study I) } \\
\text { - Comparison of emergent patterns across cases (Study II) }\end{array}$ \\
\hline & Methodology triangulation & $\checkmark$ & - Combination of qualitative and quantitative evidence \\
\hline & Researcher triangulation & & - Iterative discussions among researchers to interpret evidence \\
\hline \multirow{3}{*}{$\begin{array}{l}\text { External validity: } \\
\text { Potential of case study } \\
\text { findings to be analytically } \\
\text { generalized }\end{array}$} & Replication logic & $\checkmark$ & $\begin{array}{l}\text { - 'Nested' approach (18 partners of a MR\&D alliance, Study I) } \\
\text { - Comparative case study (two cases in Study II) }\end{array}$ \\
\hline & Rationale for case study selection & $\checkmark$ & - Theoretical sampling and other complementary criteria (e.g., opportunity) \\
\hline & Details on case study context & $\checkmark$ & - 'Thick description' of the collaborative dynamics and most relevant events \\
\hline \multirow{3}{*}{$\begin{array}{l}\text { Reliability: } \\
\text { Potential of case study } \\
\text { procedures to be replicated } \\
\text { with the same results }\end{array}$} & $\begin{array}{l}\text { Case study protocol } \\
\text { ('interviewer scripts') }\end{array}$ & $\checkmark$ & \multirow[t]{2}{*}{ Portions of case study protocol and database are reflected in the studies } \\
\hline & Case study 'database' & $\checkmark$ & \\
\hline & Non-anonymity & --- & $\begin{array}{l}\text { Actual names of partner firms (other than the lead firm) cannot be provided } \\
\text { (confidenciality reasons) }\end{array}$ \\
\hline
\end{tabular}




\subsection{Outline of the methodology}

As a summary of the contents of this chapter, this section outlines of the main methodological characteristics of the three empirical studies developed under this doctoral dissertation (see Table 2.13).

Table 2.13. Methodology and research design in the empirical studies

\begin{tabular}{|c|c|c|c|}
\hline & Study I & Study II.1 & Study II.2 \\
\hline $\begin{array}{l}\text { Case study } \\
\text { design }\end{array}$ & $\begin{array}{l}\text { Multi-case study } \\
\text { ('nested' approach) }\end{array}$ & $\begin{array}{c}\text { Comparative study: } \\
\text { two cases }\end{array}$ & $\begin{array}{c}\text { Comparative study: } \\
\text { two cases }\end{array}$ \\
\hline $\begin{array}{l}\text { Research } \\
\text { question }\end{array}$ & $\begin{array}{l}\text { Why do some inexperienced } \\
\text { partners behave more } \\
\text { cooperatively than others } \\
\text { during the formation stage } \\
\text { of MR\&D alliances? }\end{array}$ & $\begin{array}{l}\text { How do unfamiliar partners } \\
\text { realize joint value in } \\
\text { explorative R\&D alliances } \\
\text { by creating effective } \\
\text { routines? }\end{array}$ & $\begin{array}{l}\text { How do familiar partners } \\
\text { realize joint value in } \\
\text { explorative and exploitative } \\
\text { R\&D alliances by } \\
\text { redeploying their existing } \\
\text { routines? }\end{array}$ \\
\hline $\begin{array}{l}\text { Level of } \\
\text { analysis }\end{array}$ & Partner-level & $\begin{array}{l}\text { Inter-organizational } \\
\text { (Focal Alliance) }\end{array}$ & $\begin{array}{l}\text { Inter-organizational } \\
\text { (Collaborative relationship } \\
\text { and focal alliance) }\end{array}$ \\
\hline Lifecycle & $\begin{array}{l}\text { Formation stage of the } \\
\text { Acuisost Consortium }\end{array}$ & $\begin{array}{l}\text { Formation, execution, and } \\
\text { termination of dyadic } \\
\text { collaboration under the } \\
\text { Acuisost Consortium }\end{array}$ & $\begin{array}{l}\text { Formation, execution, and } \\
\text { termination of dyadic } \\
\text { collaboration under the } \\
\text { Acuisost Consortium }\end{array}$ \\
\hline $\begin{array}{c}\text { Data } \\
\text { sources }\end{array}$ & $\begin{array}{l}\text { - Interviews } \\
\text { - Questionnaire } \\
\text { - Documents }\end{array}$ & $\begin{array}{l}\text { - Interviews } \\
\text { - Face-to-face survey } \\
\text { - Documents }\end{array}$ & $\begin{array}{l}\text { - Interviews } \\
\text { - Face-to-face survey } \\
\text { - Documents }\end{array}$ \\
\hline $\begin{array}{l}\text { Analytical } \\
\text { approach }\end{array}$ & $\begin{array}{l}\text { 'Explanation building', } \\
\text { theory-testing and theory- } \\
\text { building }\end{array}$ & $\begin{array}{l}\text { 'Exploration of patterns', } \\
\text { inductive, theory-building } \\
\text { approach }\end{array}$ & $\begin{array}{l}\text { 'Exploration of patterns', } \\
\text { inductive, theory-building } \\
\text { approach }\end{array}$ \\
\hline $\begin{array}{l}\text { Selected } \\
\text { cases for in- } \\
\text { depth study }\end{array}$ & $\begin{array}{l}\text { - Mediterranean } \\
\text { Aquaculture } \\
\text { - Fish\&Meals } \\
\text { - Cantabrian Seafood } \\
\text { - Iberian Eels } \\
\text { - BioMilk }\end{array}$ & $\begin{array}{l}\text { - The OI-LF alliance } \\
\text { - The CRAI-LF alliance }\end{array}$ & $\begin{array}{l}\text { - The CAH-LF alliance } \\
\text { - The MAR-LF alliance }\end{array}$ \\
\hline
\end{tabular}



CHAPTER 3.

STUDY I. 'THE FORMATION STAGE OF THE ACUISOST CONSORTIUM' 


\section{Chapter structure}

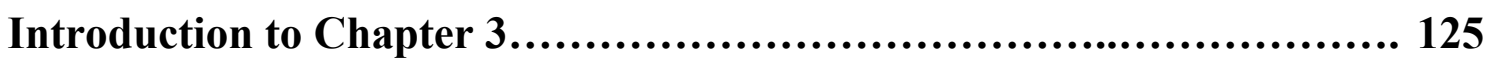

Study I. Rethinking Cooperative Behavior for Inexperienced Firms in the Formation Stage of MR\&D Alliances...................................... 127

3.1. Introduction............................................................. 127

3.2. Conceptual background and propositions.............................. 129

3.2.1. Direct competition and cooperative behavior.......................................... 133

3.2.2. Learning orientation and cooperative behavior............................. 134

3.2.3. Strategic importance and cooperative behavior............................. 135

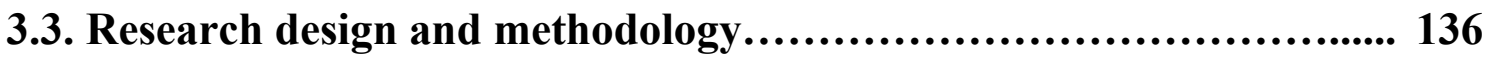

3.3.1. Research setting and cases........................................... 137

3.3.2. Data collection and analysis....................................... 138

3.3.3. Operationalization of variables...................................... 140

3.4. Analysis of the cases.................................................. 143

3.4.1. Within-case analysis................................................. 143

3.4.2. Cross-case analysis................................................. 156

3.5. Discussion and conclusion......................................... 160

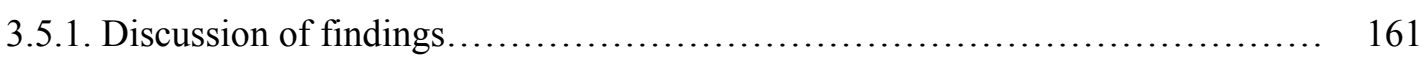

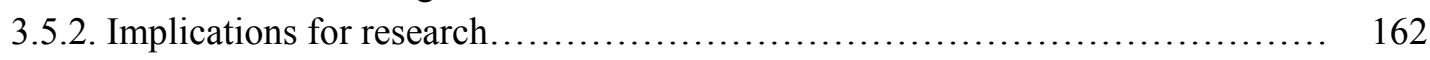

3.5.3. Implications for practice .......................................... 164

3.5.4. Limitations and future research.................................... 164 


\section{Introduction to Chapter 3}

During the formation stage, as explained, the Acuisost Consortium was characterized by collaboration between multiple partner firms searching to organize the macro-structure of the consortium, as well as to define their respective positions and collaborative strategies within it. Therefore, multilateral collaboration among partner firms seemed to be more salient than dyadic collaboration between firms and research organizations. During the first phase of research (Study I) the collaboration dynamics among partner firms of the Acuisost Consortium grabbed our attention. As the Acuisost Consortium evolved and we conducted ongoing data collection and analysis, we arrived at three important observations:

(1) The formation stage of the Acuisost Consortium unfolded under a set of environmental conditions seriously challenging the emergence of cooperation ${ }^{1}$ among partners, basically (a) it was created 'ad-hoc' by an external triggering entity (instead of partners self-recognition of their need to ally), (b) the resolution of the public funding programme under which the Acuisost Consortium sought to be sponsored took much more time than expected, delaying the starting-up of collaboration, (c) once the Acuisost Consortium became operational, the economic and industrial conditions under which it had been formulated changed (i.e.,. global and aquaculture crisis).

(2) Partner firms of the Acuisost Consortium held varying organizational characteristics and alliance expectations, but shared an important feature: all of them lack significant prior collaborative experience. Indeed, the Acuisost Consortium was the first experience in a multi-partner setting for almost all of them.

(3) Under the same challenging conditions, however, some of the partners behave more cooperatively than others during the formation stage of the Acuisost Consortium, raising disequilibrium in cooperation.

The formation stage of the Acuisost Consortium was thus considered as an interesting setting for Study I, focusing on such disequilibrium in partners' cooperative behaviors during first phase of MR\&D alliances.

\footnotetext{
${ }^{1}$ The term cooperation refers to a relational norm governing the alliance, defined as 'complementary coordinated actions taken by partners in a collaborative relationship to achieve mutual outcomes or private outcomes with expected reciprocity over time (Anderson \& Narus, 1990: 45). By contrast, collaboration is used as a broader term describing 'the act of being involved to work together in a strategic alliance' (with or without cooperation). Therefore, cooperation entails a positive nuance from a relational standpoint, whereas collaboration has a more neutral meaning in this regard.
} 
This chapter presents Study I. As advanced, Study I addresses the first specific objective of the dissertation (see Figure 3.1.).

Figure 3.1. Position of Study $I$ in this dissertation

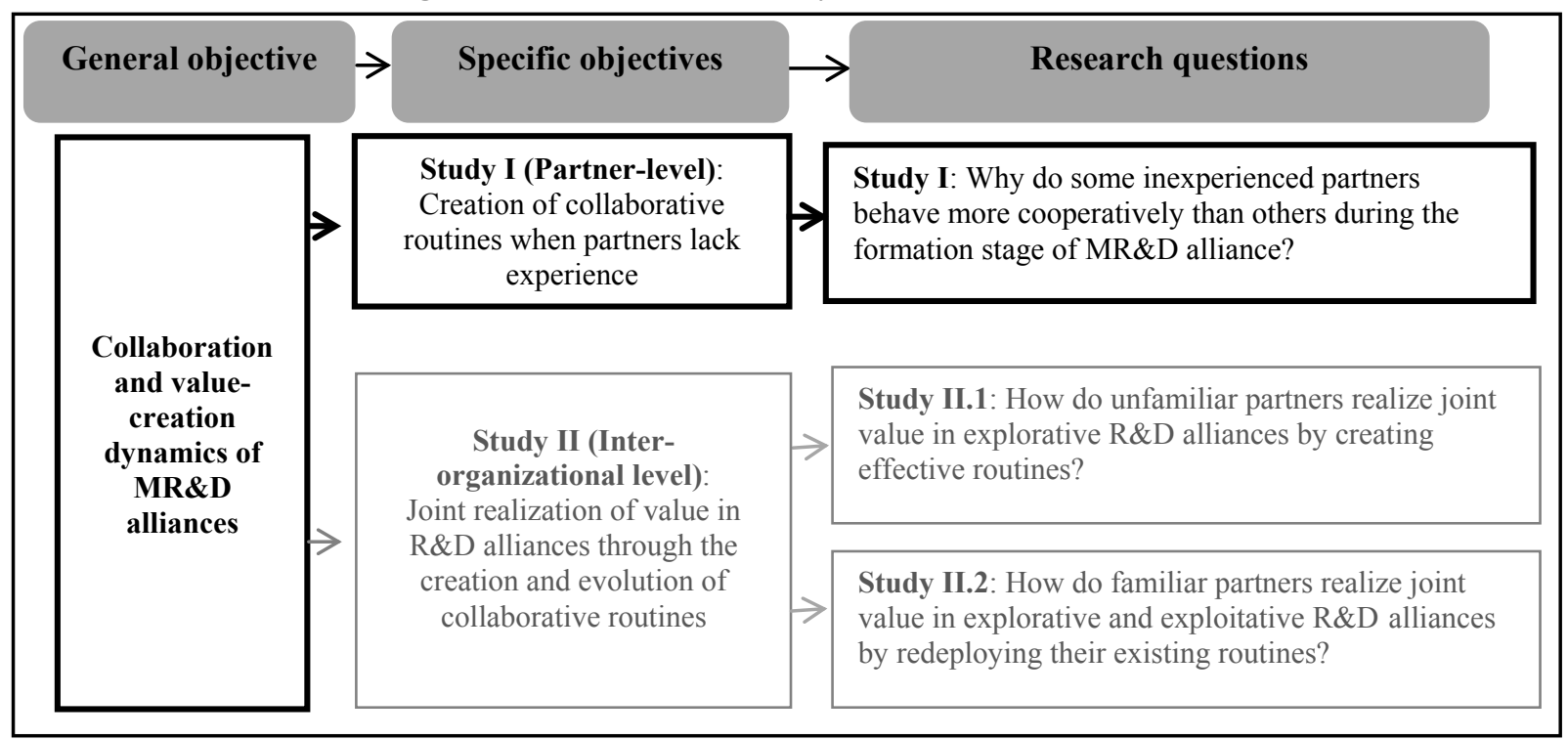




\section{Rethinking Cooperative Behavior for Inexperienced Firms in the Formation Stage of MR\&D Alliances ${ }^{1}$}

\subsection{Introduction}

Multi-partner R\&D (MR\&D) alliances constitute powerful strategic devices to explore and exploit innovation opportunities by creating multilateral discussion forums and combinations of diverse resources (Doz et al., 2000; Lavie et al., 2007; Montoro-Sánchez, Ortiz-de-UrbinaCriado, \& Romero-Martínez, 2009). In the pursuit of competitive dynamic economies, governments throughout the world are implementing funding programs to foster the creation of such MR\&D alliances, especially R\&D consortia (e.g., those in EU countries under the spirit of the Lisbon Strategy). Public policies are increasingly bringing these innovation opportunities to firms with little alliance experience (like SMEs and firms active in industries other than hightech). As a result, the landscape of MR\&D alliances, traditionally dominated by well-endowed high-tech firms with broad alliance experience, has started to change. Broadly speaking, there is the trade-off between the high value-creation potential offered by alliances and the significant management challenges they impose for the realization of such value (Madhok \& Tallman, 1998). In the context of MR\&D alliances, such a trade-off intensifies (Doz et al., 2000; Das \& Teng, 2002). Unlike dyadic alliances, multi-partner involve generalized exchange settings (Thorgren et al., 2010) within per se intricate scenarios of interaction (Lavie et al., 2007), in which partners need to contribute their R\&D resources whilst protecting themselves from unintended leakages, the reciprocity obligations of the remaining partners not being clearly defined (Das \& Teng, 2002). A complex collaborative situation thus may emerge during the formation stage of these alliances: Inexperienced firms engage in MR\&D alliances in an effort to seize the innovation opportunities they bring whilst having to learn to collaborate in such a multi-partner setting in order to create long-term value.

Cooperation is key to achieving success in alliance formation, a critical lifecycle stage for collaborative settings in general (Doz, 1996; Ariño \& Doz, 2000; Ariño \& Ring, 2010). Given their idiosyncrasy, the formation stage proves even more complex in the case of MR\&D alliances (Doz et al., 2000), making cooperation amongst partners even more essential (Zeng \& Chen, 2003). Cooperative behavior is the appropriate rent-seeking behavior to profit from partners' complementary resources and can be viewed as a purposefully built collaborative routine which, exercised during the formation stage, positions the firm in the short-term to capture long-term innovation opportunities (Kogut \& Kulatilaka, 2001). At the same time, a partner's decision to comply with what cooperative behavior entails -i.e., to longitudinally

\footnotetext{
${ }^{1}$ Useful comments and suggestions have been provided by Javier Rodríguez Pinto and Horacio Miranda, Vargas, as well as by the participants of several academic forums (see Scientific Diffusion section at the end of the dissertation).
} 
adjust its behavior to the needs of the alliance and its partners, (Ariño, 2001)- is rife with uncertainty in MR\&D alliances (Das \& Teng, 2002; Zeng \& Chen, 2003). By this dynamic logic, lack of experience may hinder adoption of cooperative behavior during the formation stage of MR\&D alliances: inexperienced partners may feel particularly vulnerable since they lack collaborative know-how to deal with the challenges posed by MR\&D alliances (Zollo et al., 2002; Sampson, 2005). However, in practice some inexperienced partners behave more cooperatively than others under the same challenging conditions (as we observed in the Acuisost Consortium).

Existing research, whilst providing some important insights (e.g., Doz et al., 2000; Mothe \& Quelin, 2001; Valdés-Llaneza \& García-Canal, 2006; Thorgren et al., 2010), has yet to fully unearth the specificities of this cooperative phenomenon. First, most research has focused on dyadic contexts (e.g., Parkhe, 1993; Ariño, 2001; Escribá-Esteve, 2002; Luo, 2008), while research into multi-partner alliances is far more scarce (e.g., Gong et al., 2007; Lavie et al., 2007; Thorgren et al., 2010). Second, the structure-oriented perspective usually adopted generates an important mismatch between the static treatment given to cooperative behavior and its actual longitudinal nature (Smith et al., 1995). Third, empirical studies focusing on multipartner contexts have usually examined partial aspects related to cooperation, such as trust or commitment (Olk \& Young, 1997; Mothe \& Quelin, 2001; Lavie et al., 2007; Thorgren et al., 2010), without paying enough attention to the formation of these alliances (with the notable exception of Doz et al., 2000). Finally, and more important for our study, existing research has not explored the case of inexperienced partners to the best of the authors' knowledge. As a result, little is known about why only some partners who lack significant alliance experience engage longitudinally in cooperative behavior during the formation stage of MR\&D alliances. Understanding the reasons underlying the partners' choice of behavior may provide a guide for consortium managers on how to encourage multilateral cooperation in MR\&D alliances formed by inexperienced partners.

The purpose of this study is to fill such a gap in research against the backdrop of alliance process-oriented research (Ring \& Van de Ven, 1994; Doz, 1996; Ariño \& De La Torre, 1998). Focusing on partners lacking significant alliance experience and on the formation stage of MR\&D alliances, we address the following research question: Why do some partners behave more cooperatively than others? In order to do so, we conduct a simultaneous theory-testing and theory-building exercise. Theory-testing is justified because existing research allows us to derive a set of initial propositions on the antecedents of cooperative behavior in the formation stage of MR\&D alliances but provides few clues about the case of inexperienced partners. By using a research setting that uncovers these specificities, we will gain a longitudinal testing of 
existing theory, flowing naturally towards theory-building (Yin, 2003). In particular, we conduct a multiple case study on the formation stage of a Spanish R\&D consortium - The Acuisost Consortium- which was government-sponsored through a public funding program, and in which eighteen inexperienced partner firms, active in different industries, took part.

Combining qualitative and quantitative evidence, our longitudinal analysis reveals that the interactions of the considered variables go beyond the simple linear relations suggested by prior literature. In particular, partner firms in the Acuisost Consortium devoted more significant cooperative efforts when the following circumstances occurred simultaneously: (a) they expected important learning benefits, (b) perceived that such benefits could substantially favor their core business areas, and (c) faced no direct competition in the consortium and other contextual factors did not cancel out such incentives.

This study contributes to several research dialogues. Firstly, it contributes to the strategic alliances field, dominated by studies on dyadic contexts, by examining a multi-partner alliance (Lavie et al., 2007), shedding light on the critical formation stage of these alliances (Doz et al., 2000). Second, this study addresses calls for more longitudinal case studies on the phenomenon of cooperation (Smith et al., 1995) and contributes to clarifying why inexperienced partners engage (or not) in multilateral cooperation. Third, by identifying interplay effects between the considered variables and combining alliance and capability lifecycle insights, this study contributes to explaining how value-creation expectations may (or may not) encourage inexperienced firms to start building collaborative routines. In doing so, the dynamic capabilities view (Teece et al., 1997; Zollo \& Winter, 2002) is supported as a suitable framework for explaining cooperation dynamics during the formation stage of MR\&D alliances.

The remainder of the study is organized as follows. First, we provide our conceptual background and introduce a set of initial propositions ${ }^{2}$. After explaining the methodological issues, we present evidence from the analysis. The study concludes with a discussion of findings, highlighting its main implications and limitations, and offering avenues for further research.

\subsection{Conceptual background and propositions}

In the collaborative context, value is created (or dissipated) cumulatively as partners interact with each other along the life stages of the alliance (Madhok \& Tallman, 1998; Reuer, 2000). In this process, the alliance formation stage is critical, significantly influencing the ongoing

\footnotetext{
${ }^{2}$ To understand this structure, we advanced that this study follows what Yin (2003) terms 'explanationbuilding' as our general analytic strategy (i.e., an iterative process which in this study commences by stating some initial propositions built upon existing research. We then compare our case study evidence with these propositions, and conclude by conducting a review thereof).
} 
evolution of the collaboration: initial conditions are then established and partners experience a trial period of interaction (Zajac \& Olsen, 1993; Ring \& Van de Ven, 1994; Doz, 1996; Doz et al., 2000). Broadly speaking, important challenges may emerge during the alliance formation stage (Kaulio \& Uppvall, 2009), which, if not overcome, will probably doom the alliance to failure (Doz, 1996; Ariño \& De La Torre, 1998; Ariño \& Doz, 2000). In this context, cooperative behavior can be regarded as a key factor to achieving success in the alliance formation stage.

Cooperative behavior reflects the extent to which a partner's actions in the alliance convey the relational norm of cooperation (Anderson \& Narus, 1990). More specifically, it can be defined as the longitudinal adjustment of a firm's behavior to the actual or anticipated needs of its partners and the alliance (Kumar \& Nti, 1998; Ariño, 2001). Following Ariño (2001), cooperative behavior represents a multidimensional construct, encompassing two main dimensions: veracity and commitment. Veracity refers to a partner's attitudinal behavior of being truthful (Das \& Teng, 1998; Ariño, 2001), thus reflecting the extent to which the partner is willing to comply with agreements and to share timely, detailed and accurate information. Commitment refers to a partner's attitudinal behavior of focusing on mutual benefit, hence reflecting the extent to which the partner is willing to devote efforts to make the alliance work in such a direction (Das \& Teng, 1998; Ariño, 2001).

From a social exchange theory viewpoint, alliances are social exchange relationships between partners motivated by the benefits which collaboration is expected to bring over time on the basis of reciprocity (Blau, 1964; Das \& Teng, 2002). Thus, cooperative behavior conveys partners' willingness to overcome the obstacles that may appear during the formation stage, to give priority to common goals over private ones (Kumar \& Nti, 1998; Cullen et al., 2000), and make intangible contributions beyond the contract and short-term sacrifices in the pursuit of joint long-term reciprocal value (Doz et al., 2000; Mahnke \& Overby, 2008). Complementarily, social network theory emphasizes the network of relationships in which the firms' economic action is embedded (Granovetter, 1973; Gulati, 1998), perceiving cooperative behavior as a way of socially characterizing ties between partners (Lavie, 2006). Scholars in this tradition postulate

\footnotetext{
${ }^{3}$ Similar to Madhok (1995), Cullen, Jhonson, and Sakano (2000) identify two basic dimensions of trust: credibility trust (which refers to the confidence in partners' ability to meet obligations and make the promised contributions to the alliance) and benevolent trust (which represents the emotional or affective dimension and concerns the belief that partners will behave with goodwill toward the alliance and the partner). Accordingly, veracity reflects the affective dimension of trust. Similarly, these authors identify two interlinked dimensions of partner commitment; calculative commitment (which concerns the economic benefit/cost analysis for the partners) and attitudinal commitment (which reflects the emotional side and involves striving harder to make the alliance work beyond mere contractual obligations). Therefore, this attitudinal or emotional commitment is what we refer to as dimension of cooperative behavior.
} 
that mutual cooperation is key to initiating network formation which, in turn, largely determines network evolution and maintenance (Gulati, 1998). From a resource-based view (Barney, 1991; Eisenhardt \& Schoonhoven, 1996), the value creation potential of MR\&D alliances resides in the opportunity they afford to combine a wide range of complementary resources and capabilities (Mothe \& Quelin, 2001). Firms' resource endowments influence their strategic behavior, which in turn is shaped by their resource needs (Barney, 1991; Teece et al., 1997). Viewed thus, cooperative behavior can be understood as rent-seeking behavior in MR\&D alliances in which firms need to engage in order to profit from partner resources (Lado, Boyd, \& Hanlon, 1997). Within the same research tradition, proponents of the dynamic capabilities view (Teece et al., 1997; Zollo \& Winter, 2002) provide arguments to interpret cooperative behavior not just as a rent-seeking behavior but, following the longitudinal nature of the phenomenon, as a collaborative routine purposely built to extract value from collaboration (Zollo et al., 2002). This view also adds the nuance that exercising such a collaborative routine during the formation stage of the alliance might serve as a strategic investment platform to capture future valuecreation opportunities (Kogut \& Kulatilaka, 2001).

Building more implicitly or explicitly upon these conceptual arguments, existing research has empirically examined the phenomenon of cooperation, most contributions focusing on dyadic alliances (e.g., Anderson \& Narus, 1990; Ariño, 2001; Escribá-Esteve, 2002). As a whole, this research stream has supported the cooperation-reciprocity link, reciprocity between two partners ensuring that, once underway, cooperative relationships will be sustained, mutual cooperation evidencing the capacity to perpetuate itself (Lado et al., 1997). By contrast, in multi-partner contexts, scholars have not empirically applied and developed existing theoretical ideas to such an extent (Das \& Teng, 2002; Thorgren et al., 2010). Our discussion about the key role that cooperative behavior may play during the formation stage of alliances in general may be extended to the particular case of MR\&D alliances, all the more so, given that the formation dynamics of MR\&D alliances may prove particularly complex (Doz et al., 2000). As a result, cooperative behavior can smooth key formation activities (Kaulio \& Uppvall, 2009), which are complex and uncertain in MR\&D alliances, such as the establishment of domain consensus (Doz et al., 2000), alignment of interests and cognition (Mahnke \& Overby, 2008), and the design of procedures for integration of partners' R\&D resources (Gong et al., 2007). However, the above-mentioned empirical insights from research into dyadic alliances are not directly applicable to multi-partner-contexts (Doz et al., 2000; Das \& Teng, 2002; Thorgren et al., 2010). This is because, unlike dyadic alliances MR\&D alliances involve not only direct exchanges between two partners (i.e., based on bilateral reciprocity), but also generalized social exchanges amongst the multiple partners resulting in generalized reciprocity (Das \& Teng, 
2002; Thorgren et al., 2010). Hence, MR\&D alliances are said to impose a social dilemma ${ }^{4}$, in the face of which non-cooperative acts may seem individually rational and incentives to adopt cooperative patterns may be diluted (Zeng \& Chen, 2003). Extending the general learning logic embodied in the dynamic capabilities view (Teece, Pisano and Shuen, 1997; Zollo and Winter, 2002), lack of alliance experience might be expected to also impose significant challenges for cooperation in multi-partner alliances ${ }^{5}$. Therefore, inexperienced partners may be expected to feel vulnerable in the formation stage of $M R \& D$ alliances, finding it difficult to contribute whilst simultaneously protecting their R\&D resources in such a context (Das \& Teng, 2002; Zollo et al., 2002; Sampson, 2005).

As a whole, the scant empirical research addressing multi-partner alliances, whilst providing some important insights, has not yet fully explained why partners who lack significant alliance experience and engage in an MR\&D alliance decide to cooperate (or to not cooperate). Prior research has shed some light on what may be the important antecedents of cooperative behavior in multi-partner alliances, highlighting three main factors: (a) the existence of direct competition between partners, a commonplace situation in MR\&D alliances (Browning et al., 1995; ValdésLlaneza \& García-Canal, 2006), (b) the learning orientation of the firm with the MR\&D alliance (Olk \& Young, 1997; Mothe \& Quelin, 2001), and (c) the degree of strategic importance that firms attach to the alliance (Olk \& Young, 1997; Mothe \& Quelin, 2001). However, this field suffers from some important limitations.

First, empirical studies in MR\&D alliances have failed to pay sufficient specific attention to the formation stage of these alliances (with the notable exception of Doz et al., 2000), and have overlooked the case of inexperienced partner firms. Second, they have tended to adopt a narrow view, focusing on a specific part of the cooperation phenomenon, such as trust (e.g., Mahnke \& Overby, 2008; Thorgen et al., 2010) or commitment (e.g., Mothe \& Quelin, 20001; Lavie et al.,

\footnotetext{
${ }^{4}$ Partners need to contribute resources to make alliances work, whether dyadic or multi-partner, such contributions creating obligations of reciprocity among the remaining partners. In dyadic alliances, reciprocity is of a direct nature, that is, it is obvious that a partner's contributions to the alliance should be reciprocated somehow over time by the other partner (Das \& Teng, 2002). By contrast, in multi-partner alliances, partners expect a quid pro quo relationship within the 'group', but not necessarily with any specific partner. Thus, a partner may contribute resources to the 'group', although the same partner(s) profiting from such a contribution may not necessarily be the one(s) to fulfill the particular obligation of 'giving in return' what has been created (Thorgren et al., 2010). In this context, partners can take advantage of other partners' contributions without reciprocating (Das and Teng, 2002) and may feel less guilty when failing to cooperate (Mahnke \&Overby, 2008), since it is also more difficult to detect noncooperative individual behavior (Ariño, 2001; Ryall \& Sampson, 2009).

${ }^{5}$ Existing research has demonstrated that firms learn to successfully manage and create value from alliances as they accumulate alliance experiences (e.g., Anand \& Khanna, 2000), by extracting lessons and transforming them into collaborative routines (Simonin, 1997). However, this capability-building process remains a 'black box' and, in particular, little is known about how it commences (De Man et al., 2010)
} 
2007). For example, Lavie et al. (2007), focusing on technology-driven industries, find that a partner who is highly committed to a multi-partner alliance (i.e., engages in alliance activities like information sharing to a high extent) can occupy privileged positions, providing it with greater access to alliance resources and taking better alliance decisions. Focusing on innovationseeking multi-partner alliances, Thorgen et al. (2010) recently found that the curvilinear relationship between a partner's size and the degree of trust it has in its partners is moderated by what is termed 'the effort of partners to establish generalized exchanges'. Third, existing research has usually adopted cross-sectional designs, rather than being based on longitudinal case studies -see Mankhe and Overvy (2008) for an exception. This kind of designs in turn entails three major limitations. Large-sample cross-sectional designs are less able than longitudinal case studies to account for how partners' cooperative behavior dynamically evolves (Smith et al., 1995). Likewise, case study research is, by definition, better position to study a phenomenon within its real-life context (Yin, 2003), which is important in the case of alliances: Factors from the alliance context can also contribute to explaining cooperation (Ariño \& De La Torre, 1998; Koza \& Lewin, 1998). Furthermore, the econometric techniques usually employed by these studies constrain analysis by assuming linear relationships between antecedents and cooperative behavior and overlooking possible cross-effects (Langley, 1999; Fiss, 2007).

Such a state of the art allows us to derive a set of initial propositions (focusing on direct competition, learning orientation and strategic importance) about the antecedents of cooperative behavior in the formation stage of MR\&D alliances (Langley, 1999; Fiss, 2007). However, to the best of our knowledge, there is no empirical or theoretical evidence allowing us to elucidate a priori how one particular antecedent may impact the cooperative behavior of one partner differently due to the latter's lack of alliance experience. Accordingly, our initial propositions, presented in the following sections, refer to "cooperative behavior in the formation stage of MR\&D alliances' (instead of 'cooperative behavior of partners lacking alliance experience in the formation stage of MR\&D alliances'). Testing these propositions grounded on existing theory will only partially cover our research question, thus motivating our subsequent theorybuilding exercise. As mentioned, factors from the alliance context can also contribute to explaining cooperation (e.g., Koza \& Lewin, 1998). Since context is idiosyncratic, rather than proposing specific relationships a priori, we will explore its impact in connexion with our case analysis.

\subsubsection{Direct competition and cooperative behavior}

Direct competition refers to the situation in which firms participate together in an MR\&D alliance and share the same industry and segment as their primary business area (Oxley \& Sampson, 2004). Such a situation, commonplace in MR\&D alliances (Browning et al., 1995; Valdés-Llaneza \& García-Canal, 2006; Lavie et al., 2007), has been widely considered a source 
of complexity, instability and failure (e.g., Park \& Russo, 1996; García-Canal et al., 2003; Valdés-Llaneza \& García-Canal, 2006). Firms involved in R\&D alliances need to interact and cooperate, whilst simultaneously guarding "against leakage of technological assets outside the scope of the collaboration to its partners" (Kumar \& Nti, 1998: 359), particularly if they compete outside the alliance (Oxley \& Sampson, 2004). Competing partners have incentives and skills to absorb valuable knowledge from the counterpart (Cohen \& Levinthal, 1990). Marketplace confrontation can be thus transferred to the alliance arena (Das \& Teng, 2002), giving rise to conflicts of interests (Kogut, 1988) and mistrust amongst partners (ValdésLlaneza \& García-Canal, 2006). Critical cooperative activities during the alliance formation stage, like close interaction or active information sharing, may thus be perceived by partner firms as high-risk actions when direct competitors converge in alliances (Das \& Teng, 2002). Such internal tension between cooperation and competition is exacerbated in multi-firm situations (Zeng \& Chen, 2003), where, as a consequence of the generalized nature of reciprocity, the 'risk of uncontrolled information disclosure' increases (Thorgren et al., 2010). In MR\&D alliances, one competing partner may well take advantage of the knowledge transferred by another, even without direct bilateral sharing, since leakage may occur through multiple potential points (Kumar \& Nti, 1998; Oxley \& Sampson, 2004). The threat from direct competitors automatically reduces the firm's 'transparency' (Hamel, 1991), making it more concerned with protecting its own knowledge (if not with appropriating valuable partner knowledge) than with accomplishing the common goals of the alliance (Park \& Russo, 1996). Thus, direct competition reduces the length of the 'shadow of the future', discouraging cooperation from the outset of the alliance (Parkhe, 1993; García-Canal et al., 2003). For example, García-Canal et al. (2003)argue that competitors in multi-party joint ventures have little incentive to invest in relational assets, preferring to participate in areas other than core ones. Interestingly, Jacobsen and Tschoegl (1999) conducted a qualitative study of the cooperative trends for international expansion in the Norwegian banking industry and explain that banks did not cooperate with their domestic competitors, only with their international competitors. The demise of some of these established consortia was influenced by deregulation, allowing international co-opetitors to enter each other's domestic banking market. Accordingly, we offer the following proposition:

Proposition 1. The presence of a firm's direct competitors in an MR\&D alliance discourages that firm from behaving cooperatively during the alliance formation stage

\subsubsection{Learning orientation and cooperative behavior}

Learning orientation refers to the extent to which the firm's decision to join the alliance is motivated by learning-related expectations (Hamel, 1991; Wu \& Cavusgil, 2006). MR\&D alliances offer a wide range of learning opportunities, which are closely related to innovation 
(Powell et al., 1996) and thus represent a core motivation for firms to enter into such agreements (Mothe \& Quelin, 2001; Montoro-Sánchez et al., 2009). In MR\&D alliances, firms may expect to acquire valuable new technological, marketing, production, and managerial knowledge from their counterparts, not only in areas directly related to the focus of innovation but also in others (Hamel, 1991; Sakakibara, 1997). Learning in alliances requires a long-term vision, which is linked to cooperative behaviors (Anderson \& Narus, 1990; Kumar \& Nti, 1998), as well as close interaction of partners' knowledge resources and intense information sharing to create common language and understanding (Kogut, 1988; Lubatkin et al., 2001). Thus, the more learning oriented the firm is, the greater its propensity to behave cooperatively since the need to cooperate with partners to achieve its private goals is higher (Hamel, 1991; Kale et al., 2000). Furthermore, a firm engaging in the MR\&D alliance may reflect a proactive attempt to improve its alliance capabilities (Simonin, 1997). In this regard, learning orientation may promote cooperative experiences, which provide a guide for new alliances, through replication of alliance practices that have worked and avoidance of those that have proved damaging (Simonin, 1997; Sampson, 2005). However, not all firms are equally concerned with these learning opportunities and, as a result, learning orientation with the alliance may vary widely across partners (Hamel, 1991). A firm's decision to join an MR\&D alliance may simply be motivated by the chance to take advantage of some partner's knowledge resources that the firm itself may be lacking without internalizing such knowledge. In support of these arguments, for example, $\mathrm{Wu}$ and Cavusgil (2006) report that the stronger the learning orientation of a firm, the higher its dedication to the alliance and the priority given by that firm to mutual alliance benefits. Similarly, Emden, Yaprak and Cavusgil (2005) find that strong learning orientation in technology alliances leads to the adoption of the behavioral routines required for learning. The convergence of these arguments leads us to offer the following proposition:

Proposition 2. The more the learning orientation of a firm with the MR\&D alliance, the stronger the cooperative behavior of that firm during the alliance formation stage.

\subsubsection{Strategic importance and cooperative behavior}

Strategic importance means the extent to which the participation of a firm in the alliance is perceived to be important for the current or future development of the firm's core business areas (Pfeffer \& Salancik, 1978; Lunnan \& Haugland, 2008). Strategic importance has been evidenced as an important antecedent of membership continuity (Olk \& Young, 1997), as well as of alliance survival and performance (e.g., Mothe \& Quelin, 2001; Lunnan \& Haugland, 2008). Alliance partners must allocate resources and efforts and make short-term sacrifices for alliances to work and create long-term value (Kumar \& Seth, 1998; Reuer et al., 2002). Their willingness to act in such a way is directly affected by the strategic importance attached to the alliance (Kumar \& Seth, 1998; Mothe \& Quelin, 2001). The logic here is that as strategic 
importance increases, the distance between private and common benefits diminishes, since overall alliance success would support the development of the firm's strategic areas (Reuer et al., 2002; Lunnan \& Haugland, 2008). Thus, a firm that attaches a high degree of strategic importance to the alliance is likely to behave cooperatively during the formation stage of the agreement, for example, by contributing resources (Mothe \& Quelin, 2001; Reuer et al., 2002), complying with agreements (Cullen et al., 1995), and actively engaging in information-sharing activities (Kumar \& Seth, 1998). Reuer et al. (2002), for example, link strategic importance and ex-post contractual changes in biotechnology alliances, arguing that the more central the alliance for the partner firms, the greater the perceived opportunity costs of alliance failure, and thus the greater the involvement of managerial attention and resources. Therefore, alliance partners for whom a focal MR\&D alliance constitutes a matter of strategic importance have a major incentive to devote efforts to make the alliance work from the very outset, and thus to behave cooperatively during the alliance formation stage. Accordingly, we propose the following:

Proposition 3. The more the strategic importance a firm attaches to the MR\&D alliance, the stronger the cooperative behavior of that firm during the alliance formation stage

\subsection{Research design and methodology}

We conduct a longitudinal multi-case study aimed at both theory-testing and theory-building (Eisenhardt, 1989; Yin, 2003) on the cooperation dynamics of MR\&D alliances formed by inexperienced partners. In particular, our multi-case design follows what Gibbert et al. (2008) term a 'nested' approach (i.e., multiple case studies-18 partner firms- within one research setting- The Acuisost Consortium). This research design may be considered appropriate for addressing our research question for at least three reasons. First, the scarcity of specific evidence makes it necessary to rethink existing theory on cooperative behavior for the case of inexperienced firms (Eisenhardt, 1989). Secondly, we address a 'why' research question, focusing on the phenomenon and its context (Langley, 1999; Yin, 2003) since alliances coevolve with the institutional, organizational, and competitive environment in which they are embedded (Koza \& Lewin, 1998). Thirdly, adopting such a process-oriented perspective matches the longitudinal nature of cooperative behavior (Smith et al., 1995).

Our research setting was selected following theoretical sampling criteria (Eisenhardt, 1989): The Acuisost Consortium is a MR\&D alliance formed by partner firms which lack significant alliance experience, thus, being representative of the phenomenon under consideration. Furthermore, the formation process of the alliance dynamically provides insights into the concepts of interest for a sufficient period of time so that issues surrounding cooperative behavior could be expected to have surfaced. Finally, we also selected the Acuisost Consortium 
because the lead firm (henceforth, the LF) of the consortium brought us the opportunity to adopt high-quality research criteria, providing the required level of access to relevant information and key informants, as well as insightful feedback (Gilbert, 2006).

\subsubsection{Research setting and cases: The Acuisost Consortium and its partner firms}

The Acuisost Consortium is a domestic contractual MR\&D alliance seeking to foster rational and sustainable development of fish aquaculture in Spain by innovating in key areas. The formation process of the alliance covers the period from early 2006 until March $2009^{6}$. Retrospectively, and combining prior alliance lifecycle literature (e.g., Reuer, 2000; Shenkar \& Yan, 2002) with temporal perceptions of the alliance actors (Mosakowski \& Earley, 2000), we identified three sub-stages within the alliance formation period: background, structuring stage, and start-up stage [see Chapter 2, section 2.2.1.4 for a more detailed longitudinal description of the formation stage].

At the first stage (Background: January 2006-November 2006), the opportunity to form the consortium is perceived by a start-up consulting firm active in the environment and agrifood fields (henceforth, Aqua-Environ Consulting ${ }^{7}$ ). Thus, following the taxonomy of Doz et al. (2000), such a process corresponds to an engineered pathway. These consortia are characterized by the existence of a triggering entity that engineers their formation, rather than by spontaneous recognition of the opportunity by the partners. In a context of expansion in aquaculture production in Spain and innovation needs, specifically in its marine domain, around April 2006, Aqua-Environ Consulting perceived that a cooperative R\&D project addressing such challenges was likely to receive public financial support, in particular from the CENIT Program in Spain (National Strategic Consortia for Technical Research Programme), an instrument of the National Plan for Scientific Research, Development and Technological Innovation (2008-2011). Thus, the consortium was government-sponsored, $44.19 \%$ of the overall consortium budget (21 million euros) being provided by public funds. Around mid-November 2006, it was decided that the scope of the alliance would explore potential innovative paths towards rational and sustainable aquaculture development.

At the second stage, (Structuring stage: November 2006-January 2008), subsequent steps to form the consortium were taken. Since public funding is allocated on a competitive basis, the initial conditions of the alliance were gradually established with the stipulations of the CENIT Programme in mind. By November 2006, Aqua-Environ consulting approached the LF

\footnotetext{
${ }^{6}$ Although the period 2007-2010 represents the formal horizon of the alliance as expressed by the contractual agreement, the origins of the Acuisost Consortium date back to the beginning of 2006, the partners not commencing work together until January 2008.

${ }^{7}$ For confidentiality reasons, we use pseudonyms for all the companies cited in the paper.
} 
(henceforth, the LF), a strong multinational family-owned corporation active in the animal nutrition sector (the business unit of aquaculture fish feed production accounting for approximately $45 \%$ of the corporation's annual turnover) that plays the role of fish feed producer in the consortium. When the LF accepted the proposal, other potential partners were selected. To that end, two approaches were followed. Firstly, the LF designed a corporative group-level alliance strategy, such that several firms in its own network were invited (and agreed) to join the consortium. Simultaneously, according to the CENIT Programme stipulations, Aqua-Environ Consulting developed a 'map of potential sectors' that might evidence synergies with aquaculture, identifying in each several 'attractive firms' to be approached and offered membership of the consortium. As a result of this two-fold process, eighteen partners were involved in the formation of the consortium, apart from the LF- See Appendix II.2 of Chapter 2 for a detailed description of partner firms. Partners are all Spanish firms involved in different industries and vary in terms of size and age, although all lacked significant prior alliance experience (and any whatsoever in multi-partner collaborative settings). As often occurs in R\&D consortia (Doz et al., 2000; Lavie, et al., 2007), the timing of entry, and the length and extent of involvement also vary across partners in the case. At this second stage, the structure of the consortium was also defined (distribution of R\&D tasks and timeline of contributions; budget allocation; interface and governance mechanisms) - See Chapter 2, section 2.2.1.3.3 for more information about the initial technical structure of the alliance. The consortium's report to apply to the CENIT Programme and the contractual consortium agreement were also drawn up. The consortium agreement was finally signed by the partners on 4 April 2007, and the consortium's report was simultaneously sent for application. In accordance with the funding program, the established horizon of the consortium was January 2007-December 2010. However, the consortium agreement included a suspensive clause: if the alliance were to fail in its effort to obtain a CENIT grant, the contract would automatically be rescinded.

During the final stage (Start-up stage: January 2008-March 2009), once the official decision concerning the CENIT Programme was finally available (January 2008), which took longer than expected and ultimately led to less public financial support being awarded than was initially envisaged, partners wondered whether the consortium would work. Indeed, they reappraised whether to remain committed to the alliance. However, partners did finally commence working together.

\subsubsection{Data collection and analysis}

In order to enhance validity and reliability, we follow a multilevel triangulation criterion (Patton, 2002; Yin, 2003): data, researcher, and methodological triangulation. We first address 
data triangulation by resorting to multiple sources of evidence: interviews, questionnaire, alliance documents (e.g., the consortium's report, the consortium agreement, minutes of meetings), press releases, and direct observation. Secondly, researcher triangulation is used in interviews (30 in total, averaging an hour and a half), which were conducted by at least two researchers and recorded, then transcribed and checked by all the researchers involved. Furthermore, as we explain later, data was coded on a multiple coding process (Larsson, 1993). Finally, for methodological triangulation we employed different methods of analysis (Barley, Meyerson and Grodal, 2011), gaining data synergies and cross-data validity checks (Patton, 2002).

Following our research purpose, data was collected longitudinally ${ }^{8}$ over three phases ranging from surface level to deeper levels (Pettigrew, 1990; Faems et al., 2008). Table 3.1 provides a summary ${ }^{9}$.

Table 3.1. Phases and actions of data collection (Study I)

\begin{tabular}{|c|c|}
\hline $\mathbf{P h}$ & Ac \\
\hline $\begin{array}{l}\text { First phase } \\
\text { (January -April 2008) }\end{array}$ & $\begin{array}{l}\text { - Exploratory interviews (CEO, Aquaculture Division Manager and R\&D } \\
\text { Manager of the LF) } \\
\text { - Private documents and other publicly available information }\end{array}$ \\
\hline $\begin{array}{l}\text { Second phase } \\
\text { (May -December 2008) }\end{array}$ & $\begin{array}{l}\text { - Semi-structured interviews (LF and the 'triggering entity') } \\
\text { - Design and pre-test of the questionnaire (LF and two partners) } \\
\text { - Mail of questionnaires (subsequent phone contact) } \\
\text { - Reception of questionnaires (14 partners) }\end{array}$ \\
\hline $\begin{array}{l}\text { Third phase } \\
\text { (January -June 2009) }\end{array}$ & $\begin{array}{l}\text { - In-depth interviews with several key informants (LF, the 'triggering entity', } \\
\text { some partners and research organizations, as well as representatives in the } \\
\text { Technical and Scientific Committee of the alliance) } \\
\text { - Direct observation in an overall alliance meeting }\end{array}$ \\
\hline
\end{tabular}

In line with our research question, our unit of analysis is the partner firm. We build our casebase explanation by conducting analysis at two levels: within-case analysis and cross-case analysis (Eisenhartd, 1989; Yin, 2003). Within-case analysis allows us to examine firms' cooperative behavior in depth, moving from description to explanation (Pentland, 1999). To enhance accuracy, this narrative analysis is extensively illustrated with citations from interviews and documents (Galunic \& Eisenhardt, 2001; Faems et al., 2008). Cross-case analysis, combining quantitative and qualitative evidence, allows us to comply with replication logic, strengthening the validity of our findings (Eisenhardt, 1989). Quantitative techniques - Partial

\footnotetext{
${ }^{8}$ Data were contemporaneously collected from the beginning of the research (January 2008), although information concerning the preceding period (from early 2006) was collected retrospectively, allowing for a more focused process but entailing the risk of respondent cognitive biases (Leonard-Barton, 1990). Data triangulation and the use of structured interviews allow us to reduce such biases (Faems et al., 2008).

${ }^{9}$ The reader is referred to Chapter 2, section 2.3.1 for more details about data collection processes.
} 
Least Squares (PLS) and partitioning analysis, respectively using SmartPLS (Ringle et al. 2005) and JMP software - enhance accuracy on the rationale behind findings (Eisenhardt, 1989).

\subsubsection{Operationalization of variables}

Variables were operationalized at the partner-level and from a process-oriented perspective, following a multiple coded process and using data from multiples sources. We first design a coding scheme for systematic conversion of the qualitative and quantitative information into fully quantified variables. For each of these variables, information from multiple sources was put together in a data matrix, and then coded by three raters (namely, the three researchers involved in this study (Yin, 1981). Following the recommendations of Larsson (1993) for multiple coding processes, once data was coded independently by each researcher, results were merged and discussed until agreement was reached (sometimes involving several rounds and reformulations in the coding scheme). Moreover, the LF's representative helped us to validate certain coding results. This approach allows us to maintain a dynamic chain of evidence, thus capturing the evolving nature of variables in our measures ${ }^{10}$. [See Appendix III.1 for more details about data sources, Appendix III.2 for a summary of operationalization process, and Appendix III.3 for descriptive information on the variables].

Cooperative behavior. In our study, this variable represents the longitudinal adjustment of a partner's behavior to the actual or anticipated needs of its partners and the consortium (Kumar \& Nti, 1998; Ariño, 2001) during the formation stage. As discussed, cooperative behavior encompasses two main dimensions or behaviors: veracity (e.g., being truthful) and commitment (e.g., focusing on mutual benefit). Moreover, a partner may behave cooperatively in some domains/moments and non-cooperatively in others (Heide \& John, 1992). Accordingly, we create two three-point Likert measures -weak (1), medium (2), and strong (3), respectively, capturing the degree of veracity and commitment conveyed through partners' actions. To avoid bias from self-reported data (Ariño, 2001; Podsakoff et al., 2003), we combine information from (a) interviews with each partner and with other alliance participants (e.g., the LF and some alliance activity coordinators), and (b) other secondary sources (e.g., the consortium's report, minutes of meetings). We observed that, in accordance with theoretical discussions, cooperative behavior is an evolving multidimensional concept whose two behavioral dimensions may be manifested through a wide range of actions and attitudes. Thus, following prior research (e.g., Mohr \& Spekman, 1994; Ariño, 2001; Escribá-Esteve, 2002) we first identify which specific

\footnotetext{
${ }^{10}$ That is extremely important not only for measuring cooperative behavior adequately, which has a longitudinal nature by definition, but also for other variables such as strategic importance or learning orientation. These other variables, in principle, are defined at a certain point in time (i.e., when the partner takes the decision to join the alliance), but are also susceptible to change as the alliance and its context evolves.
} 
actions and attitudes may reflect each of these dimensions. Simultaneously, we identify specific situations or events within the evolution of the formation stage of the Acuisost Consortium in which cooperative partners' behavior may have been manifested, thus conducting a longitudinal follow-up for each partner (see Figure 3.2).

Figure 3.2. A longitudinal follow-up of partners' cooperative behavior

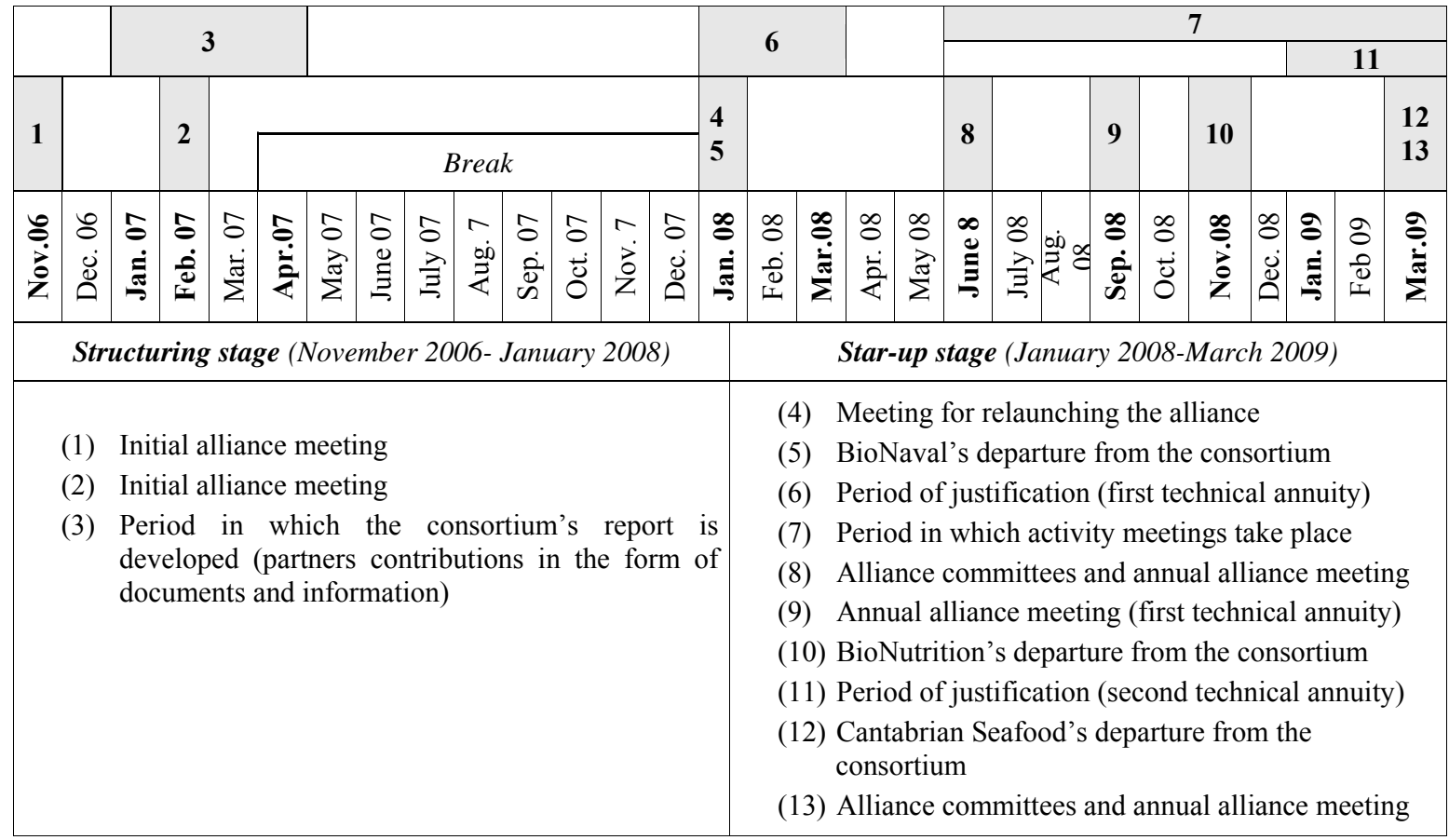

In particular, to reflect veracity (Ariño, 2001; Escribá-Esteve, 2002), we centre on how much the partner complies with agreements (e.g., handing in documents and reports, performing initial R\&D tasks, attending general alliance meetings and meetings of the particular technical activity/ies in which the partner participated) and the partner's manifested willingness to share detailed, accurate, and timely information (e.g., level of detail provided by the partner concerning its alliance strategy to draw up the consortium's report, level of technical details provided by the partner in its periodical technical reports and during the alliance meetings, extent of bilateral communication with the LF). To reflect commitment, we analyze the priority that partners attach to mutual benefit over private interests as conveyed through the partner's statements (e.g., Mohr \& Spekman, 1994; Ariño, 2001; Escribá-Esteve, 2002), as well as increase in their involvement in the alliance along the formation stage (Lunnan \& Haugland, $2008)^{11}$.

\footnotetext{
${ }^{11}$ As discussed, the commitment dimension of cooperative behavior reflects the attitudinal or affective component of commitment rather than the instrumental one (Cullen et al., 2000). We refer to the latter dimension as 'organizational involvement' to avoid confusion. As stated by Lunan and Haughland (2008), we observed in the Acuisost Consortium that increases in involvement of the partner over time as a response of another partner's departure may be interpreted as a proactive effort to make the alliance
} 
Direct competition. To reflect direct competition (whether partner firms participate together in the consortium sharing the same industry and segment as their primary business area) we define a dummy variable (direct competition) distinguishing two categories - competition (1) and noncompetition (2) - in line with the measure of product market competition used by (Park \& Russo, 1996; Oxley \& Sampson, 2004). As these authors argue, measuring competition between diversified firms proves problematic and since there is no universally accepted method, adopting a straightforward approach focusing on primary business is the best solution. Accordingly, our basis was information provided by (a) the consortium's report and (b) interviews. First, the consortium's report informs us about the firm's primary business area (when such information was missing, we resorted to the Net). Second, interviews allow us to confirm the existence of direct competition and to specify such relationships. In this regard, our measurement is also inspired by García-Canal et al. (2003) who ask respondents directly through the questionnaire to state which partners are considered direct competitors of the focal firm. These procedures allow us, for example, to realize that not all partners involved in the aquaculture field directly compete among them. In fact, two of the partners (Iberian Eels and Cantabrian Seafood), despite being active in aquaculture, have no competitors in the alliance (i.e., their core business activities concern highly specific species).

Learning orientation. To measure partner's learning orientation, we use Hamel's (1991) conceptual notion of learning intent and adapt the proposals of Emden, Wu \& Cavusgil (2005) and $\mathrm{Wu}$ and Cavusgil (2006). We build a 3-point Likert scale (learning orientation) -low (1), medium (2), and high (3) - by combining information from (a) a questionnaire, (b) the consortium's report, and (c) interviews. Firstly, respondents were asked in the questionnaire to assess the importance of a list of possible initial expectations based on prior research (Parkhe, 1993; Mothe \& Quelin, 2001; Ariño, 2003), which includes the following learning-related expectations: innovation development; learning valuable new market, technological, management, or manufacturing knowledge, and improving a firm's capabilities to manage complex alliances. Second, information provided by interviews and the consortium's report allows us to build the variable with a deeper understanding of the extent to which partners are learning oriented.

Strategic importance. Strategic importance is operationalized based on Cullen et al. (1995), Mothe and Quelin, (2001), Reuer et al. (2002), and Lunan and Haugland (2008). Accordingly, we combine (a) questionnaire-data and (b) information available in the consortium's report, in

work. By contrast, managerial involvement of partners (as members in the consortium committees or as activity coordinators) could not be attributed to their cooperative behavior, since it did not correspond to a proactive decision of partners. 
order to build a 3-point Likert scale (strategic importance): marginal (1), important (2), and critical (3). Firstly, in the questionnaire, partners were asked to rate two items concerning the extent to which the firm's alliance strategy is aligned to the overall alliance strategy, and the extent to which the firm's overall strategy is reinforced by its participation in the alliance. Second, the scope and objectives of the consortium were compared with information provided by the firm about its core business areas and its alliance goals, available in the consortium's report.

\subsection{Analysis of the cases}

As mentioned, analysis starts by within-case analysis and is then followed by cross-case analysis. These two steps are presented separately below.

\subsubsection{Within-case analysis}

In order to conduct within-case analysis, we selected five partner firms, according to the unit of analysis in the study, from the eighteen that were involved in the formation of the Acuisost Consortium. We drew on inductively derived theoretical clustering (Fiss, 2007) ${ }^{12}$, combined with common criteria for theoretical sampling used in multi-case study research (Eisenhartd, 1989; Galunick \& Eisenhartd, 2001). First, we group partners into three categories according to the three levels of cooperative behavior identified (weak, medium, and strong). Second, in line with our research question and following the criterion of 'polar cases' (Eisenhartd, 1989), we concentrate on the two extremes categories of cooperation (weak and strong). We then set cooperative behavior against the other variables considered (direct competition, learning orientation, strategic importance, and factors from the alliance context) and identify four patterns (or similar combinations of variables). Table 3.2 summarizes this process.

Once patterns were identified, cases were selected for in-depth analysis according to the following specific criteria (Eisenhardt, 1989; Galunic \& Eisenhartd, 2001): (1) in each selected case, the process of interest (i.e., cooperative behavior and impact of the studied variables therein) is transparently observable; (2) each case is representative of a pattern within its category, and (3) selected cases account for different ways to join the Acuisost Consortium (i.e., via prior relationships with the LF or through being approached by Aqua-Environ Consulting) and for different industry affiliation (i.e., aquaculture versus other industries).

\footnotetext{
12 Our theoretical clustering is inspired by the philosophy of set-theoretic methods (Fiss, 2007), which explicitly conceptualize cases according to the patterns (or combinations of attributes) they follow, thus allowing identification of potential interactions between the variables.
} 
Table 3.2. Theoretical clustering process

\begin{tabular}{|c|c|c|c|c|c|c|}
\hline $\begin{array}{c}\text { Cooperative } \\
\text { behavior }\end{array}$ & Partner firms & $\begin{array}{c}\text { Direct } \\
\text { competition }\end{array}$ & $\begin{array}{c}\text { Learning } \\
\text { orientation }\end{array}$ & $\begin{array}{c}\text { Strategic } \\
\text { importance }\end{array}$ & $\begin{array}{l}\text { Alliance } \\
\text { context factors }\end{array}$ & Patterns \\
\hline \multirow{10}{*}{$\begin{array}{l}\text { Weak cooperative } \\
\text { behavior (1) }\end{array}$} & Mediterranean Aquaculture & Yes (1) & High (3) & High (3) & No & \multirow{3}{*}{ Direct competition discouraged cooperative behavior } \\
\hline & Northern Trouts Co. & Yes (1) & High (3) & High (3) & No & \\
\hline & Southern Trouts Co. & Yes (1) & Medium (2) & $\operatorname{High}(3)$ & No & \\
\hline & Fish\&Meals & No $(0)$ & Low (1) & Medium (2) & No & \multirow{5}{*}{$\begin{array}{l}\text { Low learning orientation/low strategic importance } \\
\text { discouraged cooperative behavior }\end{array}$} \\
\hline & BioNaval & No $(0)$ & Low (1) & Medium (2) & No & \\
\hline & Industrial Packages Co. & No $(0)$ & Low (1) & Medium (2) & No & \\
\hline & Green Solutions & No $(0)$ & Medium (2) & Low (1) & No & \\
\hline & MngProjects & No $(0)$ & Low (1) & Medium (2) & No & \\
\hline & Cantabrian Seafood & No $(0)$ & Medium (2) & $\operatorname{High}(3)$ & Yes & \multirow{2}{*}{ External events discouraged cooperative behavior } \\
\hline & BioNutrition & No $(0)$ & High (3) & Medium (2) & Yes & \\
\hline \multirow{5}{*}{$\begin{array}{c}\text { Strong } \\
\text { cooperative } \\
\text { behavior } \\
\text { (3) }\end{array}$} & Iberian Eels & No $(0)$ & $\operatorname{High}(3)$ & $\operatorname{High}(3)$ & No & \multirow{5}{*}{$\begin{array}{l}\text { In the absence of direct competition, high/medium } \\
\text { strategic importance and high learning orientation } \\
\text { (for exploitation or exploitation purposes) } \\
\text { encouraged cooperative behavior }\end{array}$} \\
\hline & WasteMng Co. & No $(0)$ & High (3) & High (3) & No & \\
\hline & BioMilk & No $(0)$ & High (3) & Medium (2) & No & \\
\hline & The Biscuits Co. & No $(0)$ & High (3) & Medium (2) & No & \\
\hline & Chemics\&Proteins & No $(0)$ & High (3) & Medium (2) & No & \\
\hline
\end{tabular}

Note: Values of the measured variables appear in parentheses; selected cases within each category are highlighted in light grey. 
In the following, we first briefly explain the identified patterns within each category (shown in Figure 3.3), and then carry out within-case analysis of the selected firms.

Figure 3.3. Identified patterns in the extremes categories of cooperation

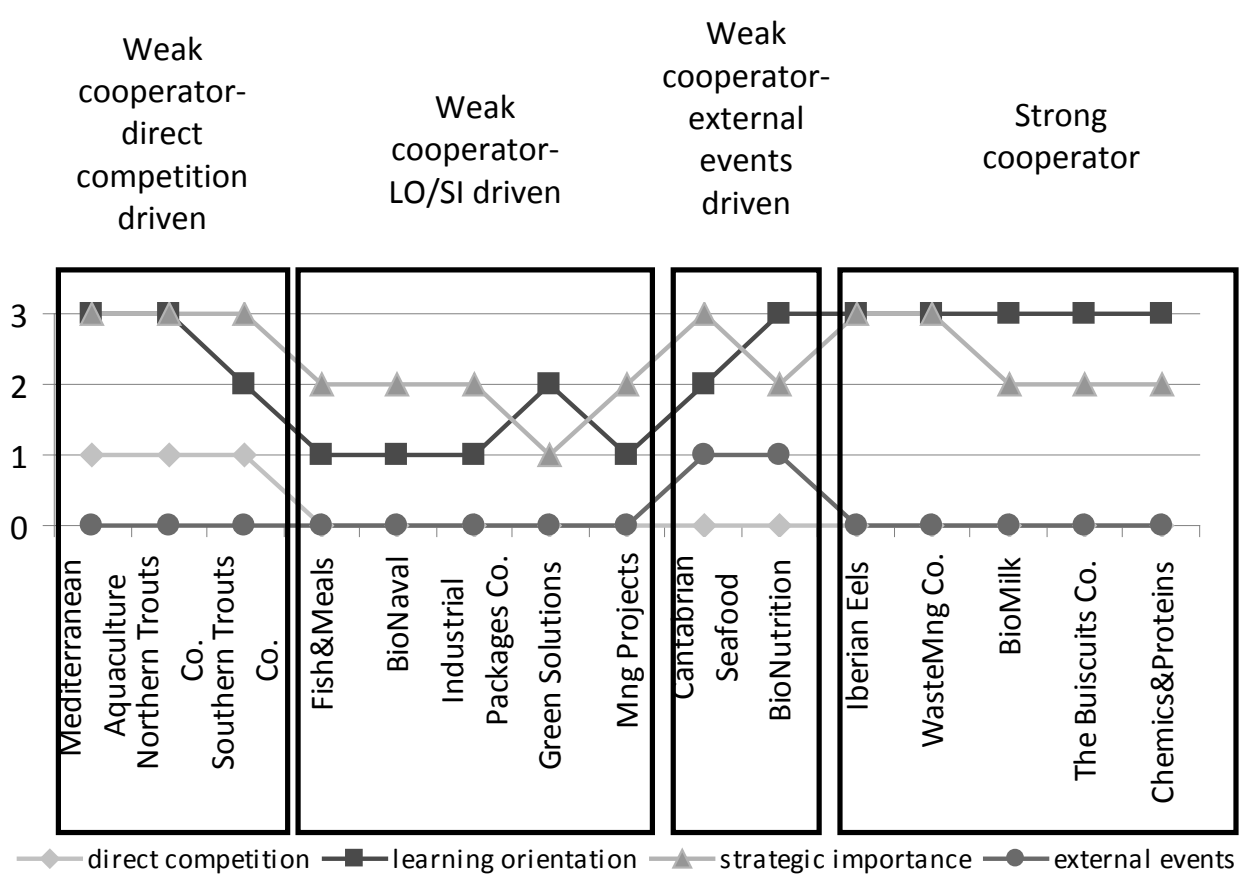

Why did some partners show weak cooperative behavior during the formation stage of the Acuisost Consortium?

Amongst the ten partners included in this category of non-cooperative partners (cooperative behavior $=1$ ) we found three distinct patterns, accounting for three different kinds of conditions surrounding partner participation in the consortium. In the first pattern, all the three partners included (Mediterranean Aquaculture, Northern Trouts Co., and Southern Trouts Co.) were active in the aquaculture sector, thus, collaborating with direct competitors, considering the consortium to be highly strategically important and possessing important learning expectations. In the second pattern, partners (Fish\&Meals, BioNaval, Industrial Packages Co., Green Solutions, and MngProjects) lack strong incentives either in terms of perceived strategic importance of the Acuisost Consortium or expected learning benefits to derive from it. In the third pattern, the two partners included (Cantabrian Seafood and BioNutrition) were faced with external events. In the following, we provide an in-depth analysis of one representative firm for each pattern, respectively, Mediterranean Aquaculture, Fish\&Meals, and Cantabrian Seafood.

\section{Mediterranean Aquaculture: Direct competition discouraged cooperative behavior}

Mediterranean Aquaculture is a large, well-established fish-farming firm which focuses its activities on the two main species in the marine field of aquaculture in Spain: sea bass and 
gilthead bream. Mediterranean Aquaculture is one of the three subsidiaries of the LF's group that joined the consortium through the LF, becoming involved in two technical activities of the Acuisost Consortium: 'Fish species farming' and 'Ready meals'. These two activities addressed two of the main concerns that experts stated for the future of the aquaculture field in Spain: improving fish nutrition and diversifying (e.g., by extending the range of products offered and venturing into higher added value products like filleted and gutted fish).

Therefore, given the full alignment between the objectives of the Acuisost Consortium and the needs of the aquaculture industry, the Acuisost Consortium was considered to be 'critical' for the development of the core business areas of Mediterranean Aquaculture (strategic importance =3). In particular, the overall objective of the 'Fish species farming' activity was to assess the new fish diets developed in the consortium, in particular in the 'Raw materials activity', under real-life conditions. The 'Ready meals' activity sought to develop pre-prepared fish-based meals (based on gilthead bream and sea bass). Indeed, the section of the consortium's report devoted to describing the alliance strategy of Mediterranean Aquaculture described the firm's objectives with the consortium in line with the competitive state of the aquaculture industry:

" ...in recent years, the mass entrance of imported low-cost fish and the reduction in the growth rates of the domestic market are challenging the survival of aquaculture in our country $[\ldots]$ there are only two viable alternatives: reducing production costs and offering differentiated products [...] Only firms that follow this path will survive in future $[\ldots]$ the firm seeks to take advantage of such opportunities (offered by the Acuisost Consortium) to improve its current competitive position vis-à-vis rivals "

When Mediterranean Aquaculture joined the Acuisost Consortium, it already had a high production capacity but its accumulated $R \& D$ experience was scarce and, consequently, its technological capabilities were underdeveloped. This combination of high production capacity and low technological skills of Mediterranean Aquaculture was common throughout the marine field of aquaculture in Spain. The prior expansion of the market, where the extensive offer of fresh fish was fully absorbed did not force firms to innovate. By contrast, when this traditional market began to become saturated, innovation became a must to survive. Accordingly, Mediterranean Aquaculture conceived its participation in the Acuisost Consortium as an opportunity to develop new technological knowledge, especially in the 'Ready Meals' activity ${ }^{13}$,

${ }^{13}$ To understand this, a distinction between the two activities mentioned may be made. The activity of 'Fish species farming' did not particularly demand cooperative effort between the partners involved: partners would only have to coordinate with the LF, which would have previously developed the test feeds and then sent a different test feed to each aquaculture producer. Therefore, the key role in addressing this innovation challenge was played by fish feed producers (not by fish producers). By contrast, firm diversification towards the kind of high added-value products considered in the 'Ready meals' activity might be one key to face up to the threat from low-cost international competition, and thus ensure the long-term survival of marine aquaculture in Spain that fish producers needed to carry out 
that would allow them to maintain their competitive position (learning orientation $=3$ ). The following quote, taken from the section of Mediterranean Aquaculture in the consortium's report illustrates these arguments:

“...the firm lacks technological specialized staff and own lab facilities [...] the Acuisost Consortium could provide the firm with the technological infrastructure required to optimize production of sea bass and gilthead bream"

Contrary to what might be expected in light of these high levels of both strategic importance of the consortium for this partner and its learning orientation, Mediterranean Aquaculture did not allocate cooperative efforts and resources to make the consortium work. In this regard, it is important to note that in both activities, 'Fish species farming' and 'Ready meals', due to the technical objectives they sought, several firms active in the aquaculture industry were involved. One of these firms, Mediterranean Aquafarming, was a direct competitor of Mediterranean Aquaculture, since both focused on the same fish species (gilthead bream and sea bass). The presence of a direct competitor in the consortium (direct competition $=1$ ) led Mediterranean Aquaculture to be more concerned with protecting its core knowledge resources than with actual collaboration itself, thus preventing the emergence of mutual cooperation between these two partners. The was due to its need to protect core knowledge resources from uncontrolled information disclosure, even if it meant renouncing certain benefits that might emerge from interaction and active knowledge sharing with other partners (e.g., not only collective benefits for the industry but also other private learning benefits). In support of these arguments, Mediterranean Aquaculture's representative, who acted as coordinator of the 'Ready meals' activity and was thus responsible for organizing activity meetings, stressed during an interview that meetings were not held because "it is better this way". The unwillingness of partners involved in the 'Ready meals' activity to exchange information was also reflected in the technical reports they had to draw up periodically and that the activity coordinator had to compile. In the words of the representative of Mediterranean Aquaculture:

"....notice that in this activity there is one firm that is a competitor of ours. We are highly cautious in disseminating relevant information [...] I think this is a mutual feeling. In this activity we have had no meetings to date and none of the partners seem interested in holding such periodical meetings, since nobody complained about it [...] there is no personal contact in the activity. I just contacted them by email when required [...] My tasks as coordinator are confined to compiling the technical reports that firms need to produce periodically and that tend to be generic without specifying important technical details"

directly. Therefore, collaboration among partners in the 'Ready meals' activity involved greater potential for knowledge synergies. 
According to its global vision of the consortium, the representative of the LF also stated that Mediterranean Aquaculture and Mediterranean Aquafarming were reluctant to interact with one another actively and to exchange knowledge concerning technical aspects such as the progress they had made, what obstacles they had encountered and whether and how they had overcome them. As he illustratively explained to us during an interview:

“...two fish farmers were sitting opposite each other and were unwilling to clearly say what they were getting from the alliance, fearing that the other firm might take advantage of their progress, thus wasting a year of research. Although it is a common project, some partners tend to believe that excessive transfer of information might prove harmful"

\section{Fish\&Meals: Low learning orientation discourages cooperative behavior}

Fish\&Meals is an SME founded in 2001, specializing in producing fish-based prepared meals using high-potential pasteurization technology (i.e., a thermal process that allows microbial decontamination of food without significantly altering its properties, such that it can be conserved for long periods). At the beginning of the structuring stage of the Acuisost Consortium, Fish\&Meals was identified by Aqua-Environ Consulting as a potential partner. When Aqua-Environ Consulting approached the R\&D Manager of Fish\&Meals, she accepted the proposal, identifying the opportunity to achieve a two-fold objective:

“... on the one hand, exploring the possibilities of revaluing a high-protein by-product of our production process by using it in the release of nutrients in fish farming [...] on the other, examining new fifth-range ready-to-eat products made from aquaculture fish" (Fish\&Meals section in the consortium's report)

Accordingly, the participation of Fish\&Meals in the Acuisost Consortium involved two technical activities: 'Additives and encapsulation' (where the general objective was to develop new feed additives and encapsulation systems for nutrition-controlled in fish-farming) and 'Ready Meals' (which, as mentioned, aimed to develop high-added value aquaculture products). The firm's project in the first activity represented an exploration of the opportunities to enter the fish nutrition field, while the project in the second was fully aligned with the core business of Fish\&Meals. Therefore, participation in the Acuisost Consortium as a whole appeared to be strategically important for Fish\&Meals (strategic importance $=2$ ). Moreover, there was no threat from direct competition (direct competition $=0$ ) for this firm in the Acuisost Consortium, since it was one of the few firms applying the same pasteurization technology in Spain for this kind of ready fish-based meals. Hence, no other partner in the consortium shared the same core business and segment area.

However, in contrast to what might be expected in light of the previous arguments, Fish\&Meals was one of the least cooperative partners of the Acuisost Consortium during the period studied. 
For example, in terms of veracity, Fish\&Meals' initial individual report as well as the subsequent periodical technical reports, were highly generic and plain, and failed to provide detailed information concerning the firm's alliance strategy or the technical state of its projects in the consortium. Similarly, during our data collection and observation process, there was no proof of commitment showing the willingness of Fish\&Meals to make the consortium work. In this regard, it is important to remember that Fish\&Meals' decision to join the Acuisost Consortium was not motivated by important learning expectations (learning orientation $=1$ ), or any anticipation of acquiring new technological knowledge or learning about a new market. Indeed, case analysis shows that such a low learning orientation is key to explaining Fish\&Meals' lack of incentive to cooperate. In support of these arguments, it should be noted that Fish\&Meals' R\&D manager was in charge of coordinating the 'Additives and encapsulation' activity and thus, was a member of the consortium's Technical and Scientific Committee. However, in line with the above-mentioned non-cooperative attitudes that this partner had shown from the very beginning, Fish\&Meals' R\&D manager did not organize any activity meeting, and did not attend other general alliance meetings and committees held during the period studied. When asked during an interview about her perceptions concerning potential benefits that interaction with the LF and other partners might bring, the R\&D Manager of Fish\&Meals surprisingly stated that:

“....activity meetings are not needed here, because there are only two partners in the activity and if we wanted to coordinate with each other we could do so by email or phone $[\ldots]$ we do not expect to learn from other alliance members since our firm already has wide market and R\&D experience"

Since Fish\&Meals did not perceive any potential benefit from interacting with other partners in the Acuisost Consortium, the firm was not motivated to devote any effort in terms of knowledge sharing and continuous contact with other partners. Indeed, it appeared that Fish\&Meals did not consider its participation in the Acuisost Consortium to be an exercise of close collaboration, rather a common setting where each partner firm could individually develop its research project in pursuit of its own objectives (without necessarily taking into account the objectives and needs of other partners). For example, as a part of the project in the "Additives and encapsulation activity', Fish\&Meals sent the LF a sample of a co-product obtained from cooking a certain mollusk. Previously, Fish\&Meals had conducted an analysis of its properties, discovering that, in the words of its R\&D Manager, "it has high protein content, it is pure collagen, ideal for fish nutrition". When the LF received the sample and analyzed the report in which the composition properties of the material were detailed, it realized that this kind of co-product from mollusk cooking might indeed have potential not only for inclusion as fish feed attractant (elements included in fish diets to make them recognized by fish as edible), as initially considered, but for 
the field of animal nutrition in general. However, there was a mismatch between the current status of the sample sent by Fish\&Meals (liquid state) and the technology production of the LF, such that, for the LF to be able to produce a test diet that included it, the co-product needed to be presented in dry matter. The LF representative proposed that the Fish\&Meals' R\&D manager should continue this line of research within the consortium. Yet, the R\&D manager felt that such research efforts were the responsibility of the LF, and that, if both firms finally did reach a commercial agreement, the role of Fish\&Meals would simply be to supply such raw material (as it came out of its production process). The representative of the LF argued that his firm could not make the important investment required to incorporate the co-product in a liquid state without being certain of the feasibility (in both technical and economic terms) of using it in fish feed production. As a result the collaborative project ground to a halt.

We therefore observe that, even when strategic importance is high, the lack of direct competition is insufficient to spur cooperative behavior if the partner evidences no learning orientation.

\section{Cantabrian Seafood: external events discouraged cooperative behavior}

Cantabrian Seafood is a small technology-based firm founded in 2004 with the aim of attaining, as stated in a press release, "a leading position in intensive farming of abalone in the European marketplace" in the long-term. Abalone (also known as 'sea ear') is a high-value mollusk, traditionally considered a delicacy, especially in southern and eastern Asia. Over-fishing has dramatically reduced the wild population, and increasing global demand has spurred the farming of this mollusk in recent decades, although this activity still remains underdeveloped in Europe.

As a result of the premature departure of a founder partner in January 2008, in order to preserve the initial budget and dimensions of the consortium the triggering entity approached Cantabrian Seafood as a new potential partner. Cantabrian Seafood thus joined the Acuisost Consortium in March 2008, seeking to develop new artificial diets for abalone within the 'Fish species farming' activity. Cantabrian Seafood, however, left the consortium just a year later (in March 2009).

Cantabrian Seafood's objective in the Acuisost Consortium, as stated by the managers of the firm in the questionnaire, was fully aligned with its core business and, consequently, they felt that the firm's overall strategy would be significantly reinforced by the firm's participation in the alliance (strategic importance $=3$ ). Despite being active in the marine field of aquaculture, Cantabrian Seafood had no direct competitors in the consortium (direct competition $=0$ ) since, as mentioned, its core business was concerned specifically with abalone, farming of which was scarce in Europe and, accordingly, no other partner in the consortium focused on it (in fact, no other firm in Spain did). Moreover, in line with this, although the managers of Cantabrian 
Seafood did not expect to acquire significant market or production knowledge from other alliance participants, they took the decision to join the consortium expecting significant learning benefits in terms of technological knowledge (learning orientation $=2$ ).

In line with the previously stated arguments, Cantabrian Seafood might have been expected to show strong cooperation during its period of involvement in the Acuisost Consortium. In particular, close interaction accompanied by intense exchange of technical information between Cantabrian Seafood and the LF, given the expertise of the latter in aquaculture nutrition, might have significantly favored fulfillment of Cantabrian Seafood's objectives and expectations within the consortium. Moreover, there was no reason for Cantabrian Seafood to protect its knowledge resources from unintended leakages to competitors inside the consortium. However, in practice, it proved to be one of the least cooperative partners. During the short period this partner was involved in the consortium, its managers neither attended alliance meetings nor maintained any contact with other alliance participants (they did not even meet the leader's representative). As the specialized press revealed, the non-cooperative behavior shown by Cantabrian Seafood might be explained in light of external events. Since 2007 (and therefore, when the firm joined the Acuisost Consortium in March 2008), Cantabrian Seafood had been awaiting approval of one of its business projects by the regional authorities, which in turn was pending approval of the New Regional Aquaculture Plan. Regional authorities gave the company the go ahead in March 2009, coinciding with the departure of Cantabrian Seafood from the Acuisost Consortium. The specialized press echoed this news:

“.... the initiative, already included in the Regional Aquaculture Plan, seeks to implement integrative farming systems of abalone, for which a facility of 47,533 m2 will be created [...] (Cantabrian Seafood) will pioneer generation of this product in the country"

It thus seems that when the managers of Cantabrian Seafood took the decision to join the Acuisost Consortium, it was intended as a short-term project or, to be more precise, as a temporary solution until the firm's long-term business project could start. Indeed, the most efficient solution for intensive abalone farming is to develop integrative systems, that is, as Cantabrian seafood attempted to do, simultaneously farming the mollusk and algae to feed it. To implement this farming model for abalone, developing an adequate diet is a key step. Abalone have specific nutritional needs that change during the long growth period required to reach market size (during the early stages of its life-cycle, from two to five years, abalone feed on microalgae, and later feed on macroalgae). Thus, the Acuisost Consortium provided Cantabrian Seafood with the opportunity to advance its private business project by developing algae-based diets for the subsequent farming of abalone, whilst at the same time receiving public financial support to that end. In fact, a few weeks after the departure of Cantabrian Seafood from the 
Acuisost Consortium, another press release announced that Cantabrian Seafood's project had "obtained a subsidy of 3.5 million euros from the regional government". The short-term orientation with the Acuisost Consortium and the final approval of its private business project by the regional authorities may thus account not only for the early departure of Cantabrian Seafood, but also its lack of incentive to commit to any active cooperation during its involvement.

Why did some partners show strong cooperative behavior during the formation stage of the Acuisost Consortium? The category comprising most cooperative partners (cooperative behavior $=3$ ) contained just five partner firms. Collected evidence leads us to identify a single pattern. For the most cooperative partners, there was a noticeable absence of direct competition (direct competition $=0$ ), high partner learning orientation (learning orientation $=3$ ), and medium/high levels of strategic importance attached to the consortium. To ensure variability, we selected two cases (Iberian Eels and BioMilk). Whilst Iberian Eels was active in the aquaculture field, BioMilk was involved in the biotech industry. The nature of the expected learning benefits thus varied (learning for exploitation versus learning for exploration, respectively). Furthermore, whilst Iberian Eels joined the consortium via prior relationships with the LF, BioMilk was approached by Aqua-Environ Consulting. The following sections provide an in-depth analysis of these two cases.

\section{Iberian Eels: in the absence of direct competition, high strategic importance and learning orientation (for exploitation purposes) encouraged cooperative behavior}

Iberian Eels is a medium-size established firm that holds a leading position in the niche market of eel production in Spain and is affiliated to the LF's group. Accordingly, the participation of Iberian Eels in the Acuisost Consortium reflected the LF's alliance strategy and concerned the activities of 'Fish species farming' and 'Wastes'.

As previously discussed, these two activities addressed important aspects for improvement in the field of aquaculture, several aquaculture partners subsequently being involved in development thereof. However, due to its market positioning in the eel niche, Iberian Eels had no direct competitors in the consortium (direct competition $=0$ ). Moreover, in line with this firm's industry affiliation, Iberian Eels considered its membership in the Acuisost Consortium to be critical for developing its core business areas (strategic importance $=3$ ). The section of the consortium's report devoted to presenting Iberian Eel's alliance strategy illustrates this idea, describing the firm's main technical objectives with the consortium, and making explicit reference to the advantages that fulfillment thereof might imply for the firm's core business activity: 
“...the firm has made a strong commitment to research, development, and innovation. [...] the strategy of the firm with the consortium entails the development process of a new diet for its main product, the eel, that could allow high-quality and more sustainable nutrition and, at the same time, could provide a distinctive sign in the marketplace [...] Also, the firms seek to develop an integrative system for managing and revaluing organic wastes generated in the day-to-day production process, to selfproduction of energy, improving environmental sustainability standards of our plant"

However, as the General Manager of Iberian Eels explained during an interview, the firm's project in the "Wastes' activity could offer "higher future potential" and was "more technologically challenging" for the firm than the one to be carried out in the "Fish species farming activity', since "testing new diets is a day-to-day task for fish farmers". Closely related to this, the high learning benefits Iberian Eels expected to gain from the Acuisost Consortium (learning orientation $=3$ ) related particularly to the firm's project in the 'Wastes' activity, which would be developed in close interaction with the LF. In particular, Iberian Eels' project in the 'Wastes' activity consisted of feeding a freshwater fish specie with eel production wastes (to be carried out by Iberian Eels), and subsequently extracting molecules from fish to assess their properties for use in generating biofuel (to be carried out by the LF).

Iberian Eels proved to be one of the most cooperative partners in the Acuisost Consortium during the period studied, as regards both veracity and commitment. In this line, for example, the General Manager of WasteMng Co., who was the coordinator of the 'Wastes' activity, explicitly recognized the strong cooperative efforts that Iberian Eels was making to help the Acuisost Consortium succeed, attitudes that contrasted strongly with those of other participants in the activity:

"....while other firms involved in this activity are showing their lack of commitment, Iberian Eels is playing its role properly [...] its General Manager is taking the research project really seriously, which is reflected in the comprehensive technical reports the firm provides"

Such expressions of Iberian Eels' willingness to cooperate were not only evident in the 'Wastes' activity, as mentioned, considered by the firm to be more strategically important and with more potential in terms of learning. The firm's commitment to the aquaculture industry, and thus, to the spirit of the Acuisost Consortium, extended to the domains of the consortium as a whole. Indeed, the General Manager of Iberian Eels was explicit in stating the firm's commitment and its focus on mutual benefit, despite the difference in the attached levels of strategic importance and expected benefits between the two activities, as the following interview quote reflects:

"....we create relationships and strive to maintain them [...] for us the project in the 'Wastes' activity is more strategically important and technologically challenging than the project in the 'Fish species farming' one [...] (but) there is one and only one 
objective in the Acuisost Consortium: reinventing aquaculture [...] we are willing to collaborate with the LF in this regard: if our project is technically viable and the lead firm is interested in going on with it, we will".

Interestingly, the high learning expectations held by Iberian Eels when it joined the Acuisost Consortium, and the consequent incentives for cooperation, remained throughout the whole of the period studied, despite the firm realizing after the first year of research that one of the initially pursued lines needed to be reformulated. During an interview, the General Manager of Iberian Eels explained the situation as follows:

"We have to reformulate some goals that we initially sought with the project. Tests carried out during the previous months have shown that one of the proposed lines lacks feasibility, although maybe after ten years of research we will be able to find a proper solution, for example, by combining additional factors [...] the most important thing is that the way has been paved [...] we are not here to earn money (referring to the public grant) but to accomplish research objectives that are really important for us".

These words reflect the fact that Iberian Eels felt that behaving in such a cooperative way, characterized by close interaction and knowledge sharing with other consortium participants, was the way to achieve the learning-related benefits the firm sought through its membership of the Acuisost Consortium, whether they could be achieved in the medium or in the long-term.

\section{BioMilk: in the absence of direct competition, medium strategic importance and high learning orientation (for exploration) encouraged cooperative behavior}

BioMilk is an established micro-enterprise active in biotechnology and specializing in the development of ferments, enzymes, and lactic acid bacteria. Since its foundation over 70 years ago, the firm's products have targeted the dairy industry, and in particular cheese production. BioMilk was approached by Aqua-Environ Consulting as an attractive potential partner for the Acuisost Consortium, for the same reason that encouraged BioMilk to accept the proposal: there were important synergies between biotechnology (and, particularly, the production of probiotics from acid lactic bacteria) and the aquaculture nutrition field. As stated in the consortium's report, "probiotics are live micro-organisms usually supplemented in feed, which beneficially affect the host animal by improving its intestinal microbial balance". Accordingly, probiotics can be used in aquaculture to control disease, since they are "effective in inhibiting the growth of fish pathogens", making it possible to reduce the (often questioned) use of antibiotics in fish farming. Moreover, probiotics may "stimulate fish appetite and improve nutrition by generating vitamins and facilitating ingest of indigestible elements", factors that all together may entail enhanced fish growth patterns. At the same time, the Acuisost Consortium provided BioMilk with an important opportunity to explore possible diversification by linking its core business 
areas and the aquaculture nutrition field. Therefore, the Acuisost Consortium was considered an important strategic device for BioMilk (strategic importance $=2$ ). Based on these expectations, BioMilk's participation in the consortium thus concerned the 'Biotechnology systems' activity, seeking to develop new techniques for producing probiotics to be applied in aquaculture functional nutrition:

"Undertaking this project would be important for our firm, since, if successful, it will contribute to optimizing the firm's production capacity, diversifying its lines of production, thus providing new market expectations for the firm, which so far focuses on the dairy industry" (quote taken from BioMilk's section of the consortium's report)

Since the background of the firm concerning the development of probiotics concentrated on functional dairy products for human consumption (e.g., 'bio-yoghurt with lactobacillus'), exploring the field of probiotics for fish nutrition involved developing new technology (e.g., learning how to apply probiotics in fish diets, which strains of probiotic microorganisms might prove appropriate for fish nutrition), as well as learning about the market properties of aquaculture nutrition (learning orientation $=3$ ). The following quote taken from the description of the alliance strategy of Biomilk in the consortium's report illustrates these arguments:

“.... Establishing a new production process requires new technologies and new knowledge [...] day-to-day contact and close collaboration with industry agents may enable the firm to know the details of the new production process and to find the most appropriate solutions to apply our products [...] Based upon the wide experience and knowledge the firm has accumulated in the sector, [...] the main advantages the firm expects to obtain by developing a technique for producing probiotic microorganisms to be applied in aquaculture are: a) new market opportunities [...] (and) b) diversification of the firm's production lines".

Furthermore, when the R\&D Manager of BioMilk was asked in an interview about the learning benefits a firm might obtain from a multi-partner alliance like the Acuisost Consortium, she explicitly pointed out that it meant improving the firm's understanding of the ins and outs of multi-partner collaborative settings. Making an explicit comparison with those in-house individual R\&D projects partially funded by regional authorities in which the firm had accumulated wide experience, she stated that:

"... After two years of experience (in the Acuisost Consortium) the lesson we can draw is that consortia can be highly enriching for firms but also entail risks [...] CENIT projects are created, by definition, to generate synergies among partners [...] (however) partners have not made equal contributions and that can sometimes prevent collective success"

BioMilk was one of the most cooperative partners of the Acuisost Consortium during the period studied. For example, from the very beginning, this firm showed its willingness to actively 
exchange knowledge with other partners and the LF, as well as to maintain close, frequent, and multilateral interaction. One clear indication of BioMilk's commitment to mutual benefit was its increased participation in the consortium's budget, maintaining the overall financial structure in the face of the premature departure of BioNaval, including new (related but different) lines of research to its project and, in the words of the R\&D Manager, "because the lead firm asked us to do so”. Further, BioMilk's R\&D manager fulfilled her role as coordinator of the 'Biotechnology systems' activity showing the same spirit of cooperation, in the words of the LF contributing to generating "a mini-consortium within the consortium". Such strong cooperative behavior by BioMilk could be understood as a proactive win-win strategy enabling the firm to achieve superior performance by developing the knowledge required to explore an important diversification business opportunity. Indeed, this idea is reflected in some assertions conveyed in the previously presented quotes like "day-to-day contact and close collaboration" with other partners in the Consortium as a way to achieve its alliance objectives and its R\&D manager's description of consortia as mechanisms "to generate synergies among partners". More specifically, the R\&D Manager stated during an interview that:

".... (the Acuisost Consortium) is like a train: the leader represents the engine, and there are other cars (partners) that support it to gather speed and others that do the opposite [...] the level of contribution to the consortium closely corresponds with the extent to which a firm demands itself rigor in its day-to-day activities [...] we are very proud of the way we act in the Consortium [...] our firm is up to scratch"

\subsubsection{Cross-case analysis}

As the last step in the analysis, we conduct cross-case analysis, introducing quantitative evidence, at two levels: within-pattern comparison (i.e., comparing findings from the selected cases for in-depth analysis with other cases following the same pattern), and between-pattern comparison (i.e., comparing firms with weak and strong cooperative behavior).

\section{Why did some partners behave more cooperatively than others during the formation stage of}

the Acuisost Consortium? Following on from our explanation-building analytic strategy (Yin, 2003), we here review our initial propositions by first offering overall quantitative evidence referring to all partner firms in the Acuisost Consortium.

In interpreting our PLS analysis, we follow the traditional two-stage approach (Rodríguez-Pinto et al., 2008): assessing the measurement model (detailed in Appendix III.3), and testing the structural model. However, we here concentrate on the structural model, since we have already established 'confidence' in our measures by using the principles of data and researcher triangulation (i.e., multiple coding process) as corresponds to our case-study methodology 
(Larsson, 1993; Yin, 2003). The structural model tested shown in Figure 3.4, although to be taken with caution due to the low number of data points, indicates acceptable goodness-of fit ${ }^{14}$.

Figure 3.4. PLS analysis: Structural tested model

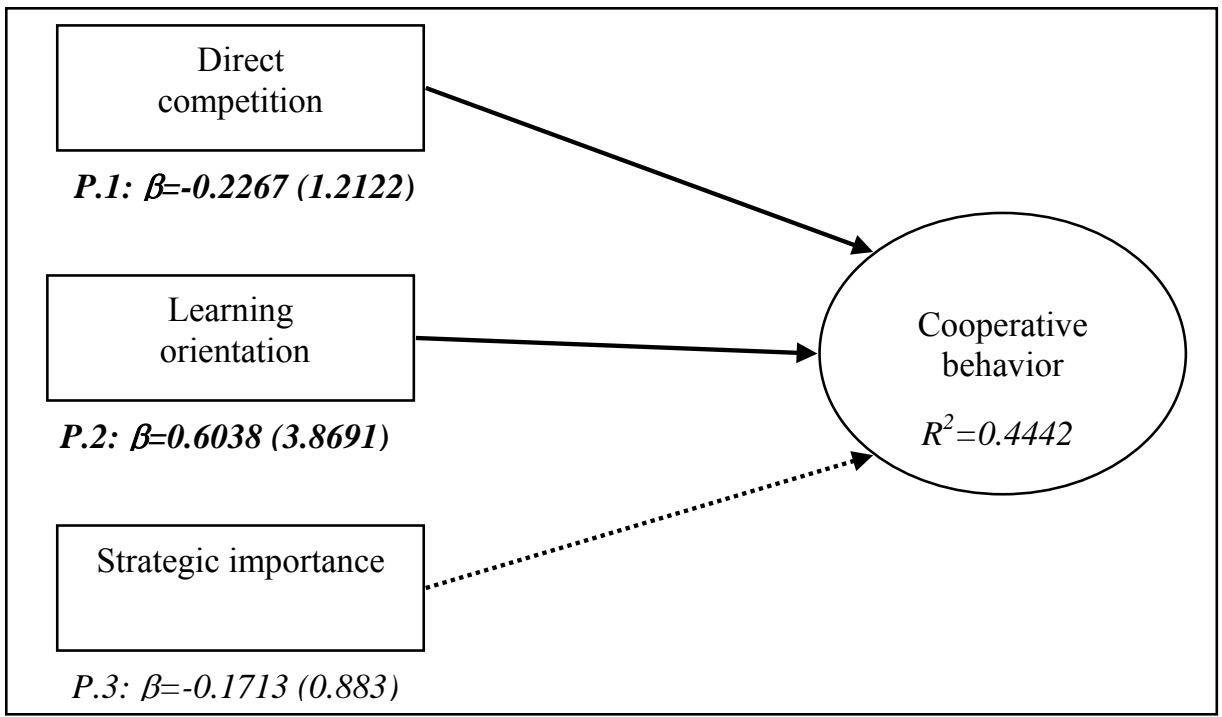

Note: Bootstrap re-sampling procedure (200 subsamples randomly generated); the standardized coefficients $(\beta)$ appear after the propositions and $t$ statistics appear in parentheses. Significant relationships appear in bold and with continuous paths.

In particular, the three variables considered (direct competition, learning orientation, and strategic importance), jointly considered, seem to account for $44.42 \%$ of the cooperative behavior construct ( $R 2=0.4442$ ). Nevertheless, the picture shown by PLS leaves room for other findings that arise from our in-depth qualitative analysis (e.g., factors from the alliance context may be also important).

First, we proposed that direct competition for a firm in the MR\&D alliance discourages this firm from behaving cooperatively (Proposition 1). As expected, PLS analysis shows a direct negative relationship between direct competition $(\beta=-0.227 ; p$-value $<0.05)$ and cooperative behavior of partners during the formation stage of the Acuisost Consortium. In line with this, partition analysis, as detailed in Figure 3.5, shows that no partner making strong cooperative efforts faced the threat imposed by direct competition. In this regard, quantitative evidence supports previously presented qualitative evidence, which also enriches our understanding by showing that direct competition might exert a negative moderating effect, eliminating the potential positive impact of other variables (i.e. strategic importance and learning orientation) on the firm's incentives to cooperate.

\footnotetext{
${ }^{14}$ Because of this reason, we complement PLS and partitioning analysis with cross-tabulation analysis (summarized in Appendix III.3).
} 


\section{Figure 3.5. Partitioning analysis (direct competition)}

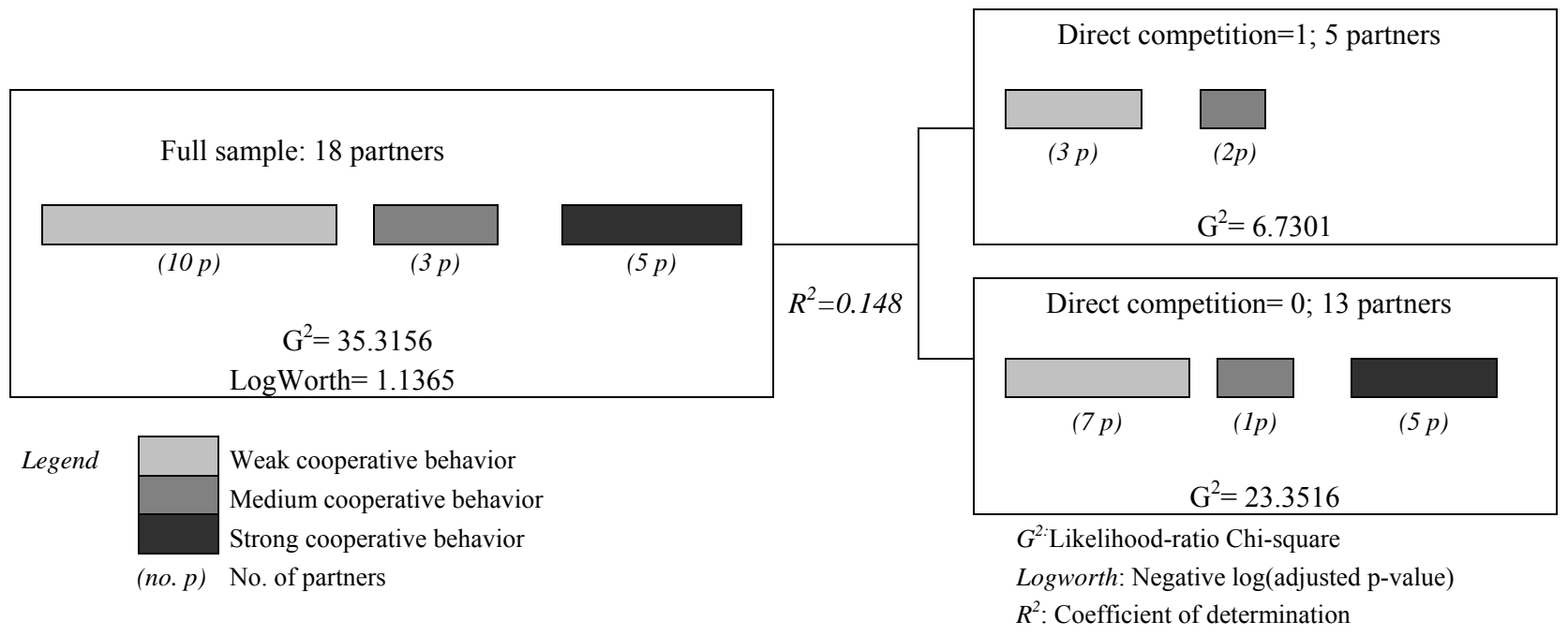

The case of Mediterranean Aquaculture (Pattern: Direct competition discouraged cooperative behavior), which faced the threat of cooperating directly with Mediterranean Aquafarming, its direct competitor in the marine field of aquaculture, illustrates these arguments. This finding may be strengthened by looking at other firms, competitors in the continental field of aquaculture (Northern Trouts Co., Western Trouts Co., and Southern Trouts Co.) who collaborate together in several consortium activities and did not engage in any cooperative effort at all, as a means of safeguarding against mutual unintended leakages of relevant knowledge.

Secondly, we proposed that the greater a firm's learning expectations with the MR\&D alliance, the stronger that firm's cooperative behavior (Proposition 2). Accordingly, PLS indicates that learning orientation $(\beta=0.604 ; p$-value $<0.05)$ may have encouraged partners to invest in their cooperative capabilities during the formation stage of the consortium.

Figure 3.6. Partitioning analysis (learning orientation)

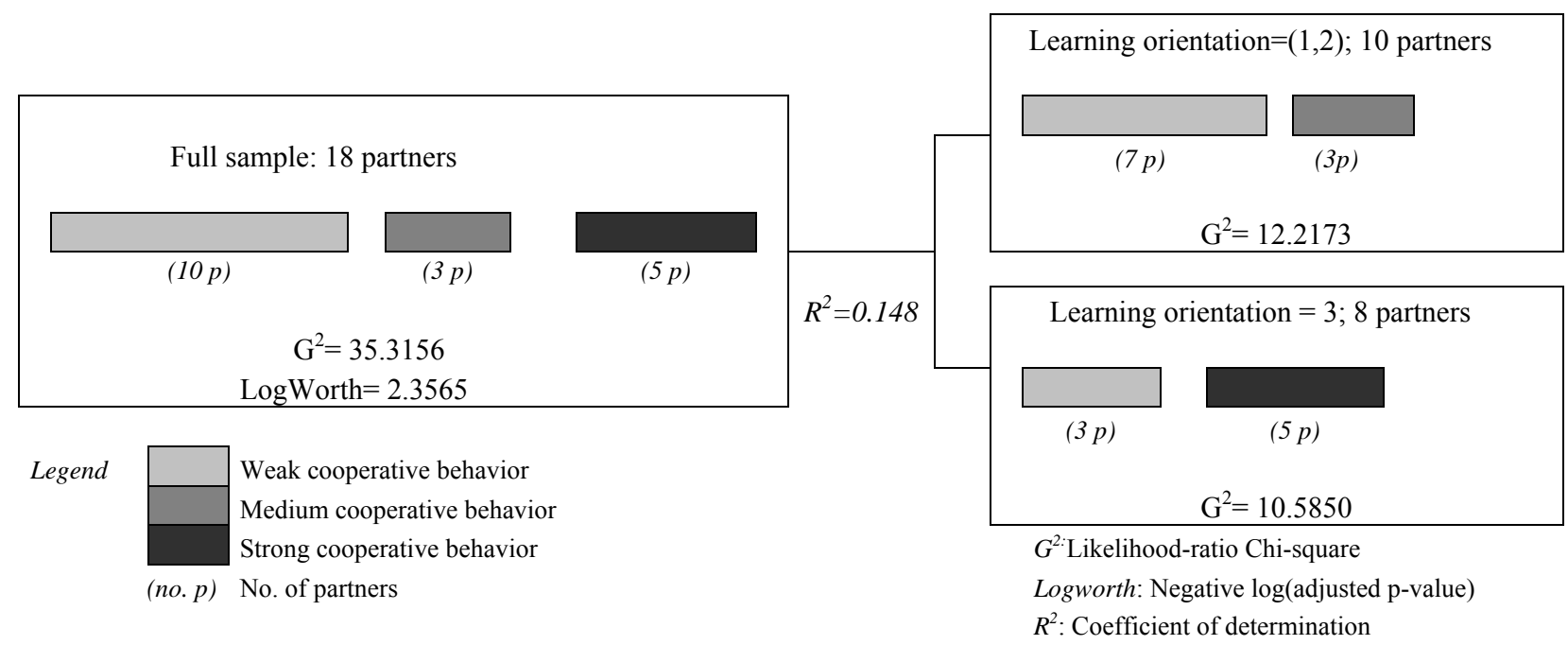


In fact, as shown by partition analysis (Figure 3.6), all the partners who evidenced strong cooperative behavior also expected significant learning benefits from participation in the consortium. However, the opposite assertion cannot be made, since there were several partners with a significant learning orientation (medium or even high) who displayed no cooperative efforts at all during the formation period.

Finally, we proposed that the more strategic importance a firm attaches to the MR\&D alliance the stronger that firm's cooperative behavior (Proposition 3). Contrary to our proposition, PLS analysis indicates that, although not statistically significant, strategic importance $(\beta=-0.171 ; p$ value $>0.05$ ) might have discouraged partners from behaving cooperatively during the formation stage of the Acuisost Consortium. Although it may seem surprising, this finding is not so incoherent in light of the other insights to emerge from the case study. In this line, partitioning analysis (Figure 3.7) reveals that the Acuisost Consortium represents just one important strategic endeavor for the most cooperative partners, with the exception of two (for whom the alliance is critical). Qualitative evidence yields important insights to understand these findings.

Figure 3.7. Partitioning analysis (strategic importance)

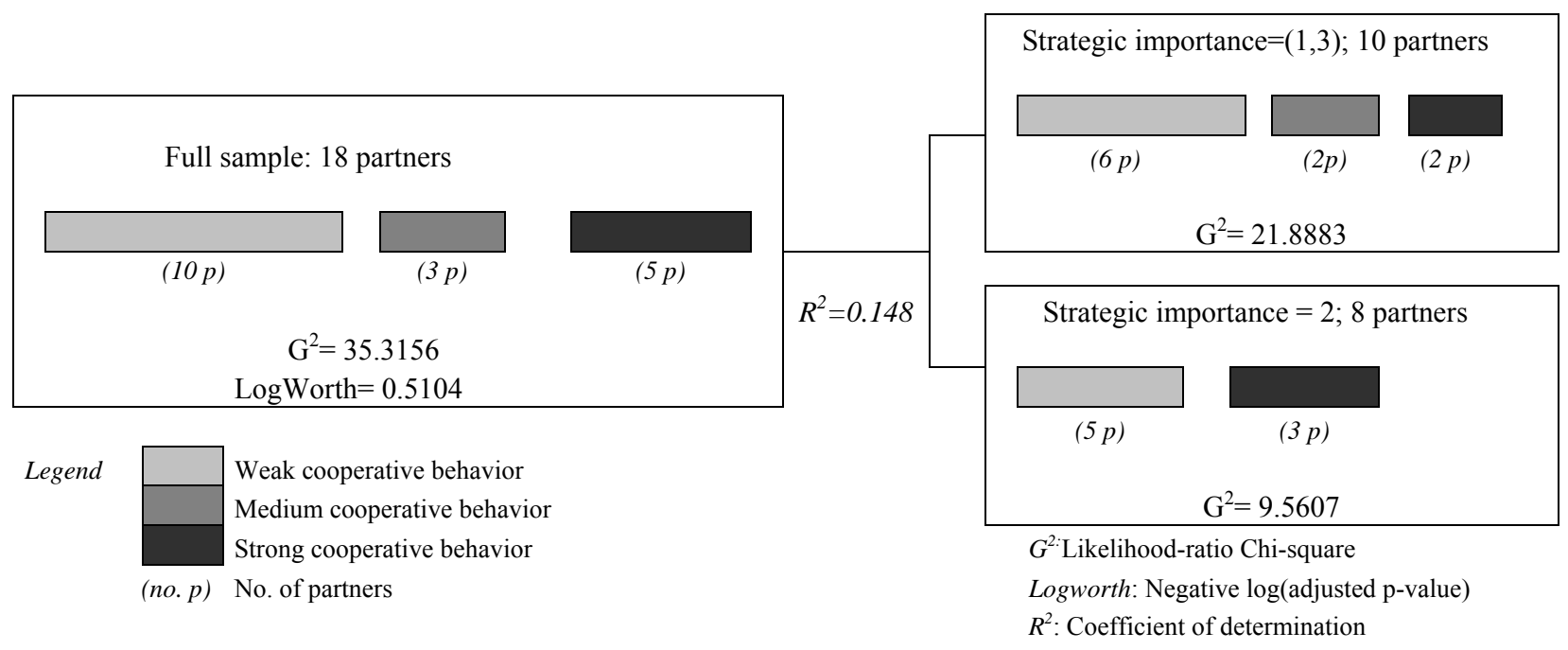

In-depth analysis of the selected cases supports the idea that these two factors interplayed in generating incentives for cooperation. Looking at the category of non-cooperative partners, the in-depth case analysis of Fish\&Meals (pattern: low learning orientation/low strategic importance discouraged cooperative behavior) revealed that, in the absence of direct competition, when the firm lacked important learning expectations with the consortium (although it was considered to be strategically important) no significant benefits are expected from close interaction and knowledge sharing with other partners, the firm thus having no motivation to engage in cooperative behavior. 
A similar conclusion may be drawn, for example, from the cases of BioNaval or Green Solutions, two of the other least cooperative partners who, respectively, held unimportant learning expectations and perceived the consortium to be non-strategically important ${ }^{15}$. Furthermore, in-depth analysis of Cantabrian Seafood (pattern: external events discouraged cooperative behavior) shows that the firm's involvement in external projects explains why it did not cooperate despite having important learning expectations and despite considering the consortium to be critical in strategic terms. The case of BioNutrition provides a similar example, although focused on another kind of external event, the global crisis, the onset of which coincided with the initial lifecycle phases of the Acuisost Consortium and, in the case of BioNutrition involved a fragile economic situation resulting not only in lack of incentives to cooperate but also in its decision to leave the consortium prematurely.

In-depth analysis of Iberian Eels and BioMilk (pattern: in the absence of direct competition, high strategic importance and high learning orientation encouraged cooperative behavior) shows that major cooperative efforts were devoted by partners in the absence of direct competition and other negative alliance context factors. In particular, that occurred when two additional circumstances concurred: they expected important learning-related benefits from the alliance (either for exploitation or for exploration purposes) and, simultaneously, perceived that such learning could be a matter of strategic importance (at least the consortium is considered 'important') for its core business development.

The findings obtained from the analysis of Iberian Eels and BioMilk, respectively, can be replicated looking at the cases of WasteMng Co., on the one hand, and The Biscuits Company and Chemics\&Proteins on the other. All these partners showed their willingness to actively exchange knowledge with other partners and maintain close, frequent, and multilateral interaction in the consortium. Behaving cooperatively in the Acuisost Consortium afforded them the opportunity to extend their existing know-how either to advance current business projects or to explore new market opportunities provided by the aquaculture nutrition field, as well as learning to cooperate in multi-partner settings (Doz et al., 2000; Lavie et al., 2007; Montoro-Sánchez et al., 2009)

\subsection{Discussion and conclusions}

Understanding why partners who lack prior experience behave cooperatively during the formation stage of MR\&D alliances is a key research question which, if properly addressed,

15 Notice that our study led us to extend the explanation of weak cooperative behavior based on low learning orientation (although there was medium strategic importance) found in the Fish\&Meals case, to the case of Green Solutions, a chemical company for whom the Acuisost Consortium represented a marginal strategic endeavor (although it seemed to have learning expectations). 
may generate useful practical recommendations to overcome obstacles that could emerge during said process. However, little scholarly attention has been paid in this direction even though R\&D consortia could be viewed as entrepreneurial strategies that offer high potential for inexperienced firms to innovate (Montoro-Sánchez et al., 2009). In order to fill this gap in the literature, we have explored longitudinally the formation stage of an MR\&D alliance within its real-life context: the Acuisost Consortium. To conclude, we first discuss our findings in connection with existing literature, which leads to the implications of the study (for research and for practice), the main limitations, and some avenues for further work.

\subsubsection{Discussion of findings}

Conducting both within-case (of some representative selected cases) and cross-case analysis, and combining qualitative and quantitative evidence, we have simultaneously rethought existing theory and brought new insights into cooperation, allowing analytical generalization of results (Eisenhardt, 1991).

We find first that the interplay of learning orientation and strategic importance can generate incentives for cooperation. This finding concurs with and expands prior related literature in several ways. For example, Mothe and Quelin (2001) and Olk and Young (1997), point to strategic importance and learning orientation as two key antecedents, respectively, for resource creation and membership continuity in $R \& D$ consortia. The common assumption is that when strategic importance and/or learning orientation are high, partners are more committed to the consortium. In this regard, our study focuses explicitly on examining the influence of these two factors on cooperative behavior (and not only on their commitment) when partners lack significant alliance experience, and also shows that they are intrinsically linked concepts. In particular, partners in the Acuisost Consortium who showed the strongest cooperative efforts during the period studied expected important learning-related benefits from the consortium, and perceived that such learning was a matter of strategic importance, either for exploitation (improvement of their current market position) or for exploration (discovery of new market opportunities). Thus, strategic importance of the MR\&D alliance may induce efforts to make the alliance mutually beneficial when combined with important learning-related expectations, besides encouraging the adoption of learning behaviors (Emden et al., 2005), creation of new resources (Mothe \& Quelin, 2001), and changes in the alliance structure (Reuer et al., 2002).

The above conclusions, however, must be taken with caution. Our case study evidence suggests that they are only true under the premise of 'absence of direct completion and negative contextual events'. We find first that, paraphrasing Park and Russo (1996), direct competition eclipsed cooperation between aquaculture partners during the formation stage of the Acuisost Consortium. This finding concurs closely with existing research linking direct competition and 
alliance complexity, instability, and failure (Park \& Russo, 1996; García-Canal et al., 2003; Oxley \& Sampson, 2004; Valdés-Llaneza \& García-Canal, 2006), challenging the predictions of 'collusive behavior' between similar firms (Fuentelsaz \& Gómez, 2006). Moreover, our research refines existing theory by showing that when firms lacking significant alliance experience interacted with direct competitors in the MR\&D alliance, the risk of unintended knowledge leakages may dilute learning and strategy-related incentives, discouraging them from behaving cooperatively. We thus introduce this negative moderating effect of direct competition, explicitly sustaining an idea implicitly assumed in the field. For example, Heidl (2010) argue that intensity of competition deters knowledge sharing in multi-partner alliances set up primarily for new technology development (wherein therefore learning is supposed to be a key initial motivation for partners). Moreover, our study provides additional evidence on the co-evolution between cooperation and the institutional, organizational, and competitive alliance environment (Ariño \& De La Torre, 1998; Koza \& Lewin, 1998). We find that certain external factors from the alliance context also might shape partners' value-creation expectations in such a way as to discourage cooperative behavior. This evidence supports the argument that "the repertoire of strategies that are available to alliance partners may be constrained by the institutional ... environment within which the partner firms are embedded" (Kumar \& Nti, 1998: 367).

Finally, concerning the initial relationship between the partners and the LF of the Acuisost Consortium (taken as qualitative controls in our selection of cases), our case analysis reveals that it could be relevant to explain why some partners joined the consortium, but not to explain the mode of behavior they subsequently adopted. This finding, thus, contradicts the social sanctions logic, at least during the formation stage (Gulati, 1998), but are in accordance with the recent case study by Stephens et al. (2009). These authors discuss how two dependent partners that were induced to ally together by a dominant firm ('cupid alliances') failed to recognize their common interests.

\subsubsection{Implications for research}

By means of theory-testing, this study contributes to the strategic alliance field, largely dominated by studies conducted in dyadic contexts, by (a) examining a multi-partner alliance (Lavie et al., 2007), (b) shedding light on the critical formation stage of these alliances (Doz et al., 2000), and (c) addressing calls for more longitudinal case studies on the phenomenon of cooperation (Smith et al., 1995). In particular, it explains the dynamics of cooperative behavior in the formation stage of an MR\&D alliance, contributing to clarifying why inexperienced partners engage (or not) in cooperative behavior. 
In light of our findings, we argue that cooperative behavior might be better understood as a collaborative routine ${ }^{16}$ purposefully and longitudinally built during the alliance formation stage. There is a dynamic process in which collaborative routines are shaped by continuous interactions with value-creation expectations (e.g., from the strategic importance and learning orientation of each partner), that in turn evolve in close connection with the alliance context. Thus, the effect of any change in variables like strategic importance and learning orientation (and thus in the associated value-creation expectations) may be overwhelming ${ }^{17}$. Furthermore, because inexperienced firms do not have initial collaborative routines in this kind of complex alliances, direct competition might prove a greater 'enemy' than in another co-opetion setting in which partner firms, well-endowed with alliance experience, know how to interact with competitors without losing their competitive advantage (i.e., simultaneously contributing and protecting R\&D resources). During the formation stage of the Acuisost Consortium, we observed that none of the firms who faced a competitor within the alliance was willing to cooperate, even though their managers might have been expected to have been willing to invest in building alliance dynamic capabilities (given their learning intentions and desire to maintain competitive advantage). Therefore, competition among partners created an adverse situation in the consortium, to which partners reacted by behaving non-cooperatively (Tjemkes \& Furrer, 2010).

Given these conclusions, our study supports the dynamic capabilities view as a suitable framework for explaining such a cooperative phenomenon. Firstly, the dynamic capabilities view accommodates the dynamic nature of cooperative behavior (Ariño, 2001). Second, and central to our arguments, it accounts for the creation of new capabilities, assuming the existence of a capability lifecycle (Helfat \& Peteraf, 2003): when inexperienced partners join an MR\&D alliance and invest cooperative capability-building efforts, the founding stage of their alliance capabilities takes place, at least in part, during the initial life-cycle stage of the alliance. Moreover, this view allows us to interpreted factors pointed out by other theories (e.g., social network and exchanges theories) as sources of value-creation expectations that determine the creation of new routines (Winter, 2003), rather than rejecting them. Whether new collaborative

\footnotetext{
${ }^{16}$ Taking into account that routines are defined as behavioral regularities (Becker, 2004), a conceptual analogy can be traced between the two dimensions of cooperative behavior (veracity and commitment) and the routines forming the soft side of alliance capabilities (De Man et al., 2010). The soft side of alliance management refers to 'intangible' attributes of trust and commitment characterizing the collaborative relationship (Cullen et al., 2000).

${ }^{17}$ Two cases (i.e., The Sugar Company and Western Trouts Co.) included in the category of 'medium cooperative behavior' showed that abrupt collapses in initial expectations caused by external events (e.g., legislation and strategic changes) were not immediately absorbed. Rather, the cooperative behavior of the affected partner gradually adapted to the new situation, shifting from strong to weak cooperative behavior). Therefore, these findings accommodate capability-inertia arguments (Schreyögg \& KlieschEberl, 2007).
} 
routines are created or not depends on the managerial comparison between expected costs and benefits (related to the combination of direct competition, strategic importance, learning orientation) associated not only with building but, particularly, with implementing such routines (Winter, 2003). Therefore, by interpreting our case study evidence from the dynamic capabilities view, this study also contributes to conceptually clarifying how the building process of dynamic alliance capabilities may commence (De Man et al., 2010).

\subsubsection{Implications for practice}

We have endeavored to generate a 'good story with good constructs' and to build a rigorous case study (Eisenhardt, 1991), thereby creating relevant managerial knowledge (Gibbert et al., 2008). We have illustrated that inexperienced firms may find it difficult to behave cooperatively when direct competitors are also involved in the MR\&D alliance. First, entrepreneurial managers entering an MR\&D alliance for the first time should meditate what benefits they expect to gain, whether the venture would lead to a substantial improvement in strategy, and what effort they are willing to make. Only when the expected benefits are strategically significant will their efforts be rewarded. When this happens and there are direct competitors, firms must assess whether it is possible to create a reciprocity-based atmosphere, rather than a priori giving up the opportunity to engage in valuable rent-seeking cooperative behavior. Closely related to this, our findings may prove useful for managing the formation process of engineered MR\&D alliances. When seeking potential partners for these complex alliances, triggering entities should pay specific attention not only to the theoretical resources, synergies or economies of scope that may emerge among the multiple partners, but also to their valuecreation expectations. Moreover, maintaining such value-creation expectations throughout the whole formation stage is critical if collaborative routines are to be developed and thus enable the alliance to survive its initial lifecycle stage and create value.

\subsubsection{Limitations and future research}

Our 'nested' multi-case design (Gibbert et al., 2008), focusing on the Acuisost Consortium, has allowed us to extend the landscape offered by prior research to the aquaculture field, which has to date received far less attention from scholars than other high-tech areas (Sankaran \& Mouly, 2006). However, the findings are clearly contextualized, preventing us from offering extensive replication logic (Eisenhardt, 1989; Yin, 2003). Moreover, we acknowledge that some researcher bias and subjectivity may have affected our multiple coding processes. In this regard, future research may explore how and why cooperative behavior is built in diverse industrial and institutional frameworks, and refine the process of transforming rich qualitative data into fully quantified variables. 
We hope to encourage further work beyond the multi-case or large-sample test of our model. Examining other determinants of cooperation (or sources of value-creation expectations associated with such collaborative rent-seeking behavior) is a promising line for further research. In this regard, it sounds particularly interesting the in-depth examination of how internal dynamics of cooperation in MR\&D alliances coevolve with the alliance context. Another important line for further work could be to examine how cooperative behavior affects value creation for the partners during the formation stage of MR\&D alliances. After all, success at the formation stage is thought to involve the foundation for long-term success in alliances (Doz, 1996; Doz et al., 2000). Indeed, this was a central premise for the development of our arguments (although its empirical examination was beyond the scope of this study). In the same vein, it might be interesting to study the building of alliance capabilities across the whole capability lifecycle, considering how changes in value-creation expectations may affect this process. In addressing the two later lines, extending the entrepreneurship perspective to the collaborative context seems to be soundly warranted (e.g., Montoro-Sánchez et al., 2009). 

CHAPTER 4.

STUDY II. 'FIRM-RESEARCH ORGANIZATION COLLABORATION IN THE ACUISOST CONSORTIUM' 


\section{Chapter structure}

Introduction to Chapter 4

4.1. Study II.1.How do unfamiliar partners succeed in explorative R\&D alliances? Psychological Contracts and Creation of knowledgesharing routines................................................................ 172

4.1.1. Introduction. 172

4.1.2. Conceptual background.

4.1.2.1. The two streams of research into ER\&D alliances: The need to focus on processes.

4.1.2.2. Psychological contracts in E\&D alliances formed by unfamiliar partners.

4.1.2.3. Inter-organizational knowledge-sharing routines and psychological contracts

4.1.3. Methodology

4.1.3.1. Research setting and the cases......................................... 179

4.1.3.2. Data collection and analysis........................................ 182

4.1.4. Analysis of the cases: The OI-LF and CRAI-LF alliances.............................. 183

4.1.4.1. Initiation of the OI-LF and CRAI-LF alliances............................. 183

4.1.4.2. The OI-LF alliance................................................. 184

4.1.4.3. The CRAI-LF alliance ............................................ 189

4.1.5. Discussion: The OI-LF and CRAI-LF alliances as marriages........................... 194

4.1.5.1. Starting the alliance: The honeymoon period................................ 195

4.1.5.2. Facing the first problems: Marriage restoration vs. crisis.................... 197

4.1.5.3. Ending the alliance: marriage consolidation versus divorce................ 200

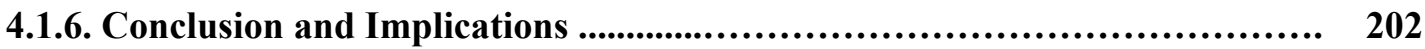

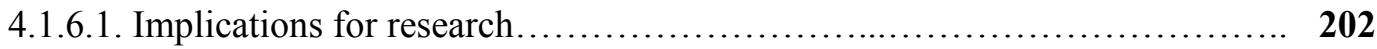

4.1.6.2. Implications for practice.................................................... 203

4.1.6.3. Limitations................................................................ 203

4.1.6.4. Future research............................................................. 204 
4.2. Study II.2. How do familiar partners succeed in explorative and exploitative $R \& D$ alliances? Real options reasoning and redeployment of knowledge-sharing routines...........................

4.2.1. Introduction.

4.2.2. Conceptual background.................................................. 208

4.2.2.1. R\&D alliances from real options reasoning..................................... 208

4.2.2.2. R\&D alliances between familiar partners and real options reasoning........ 210

4.2.2.3. Real options reasoning and redeployment of inter-organizational routines... 210

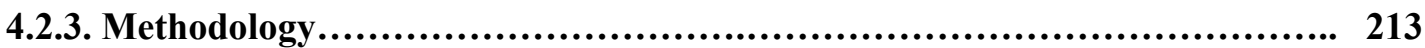

4.2.3.1. Research setting and the cases.................................... 213

4.2.3.2. Data collection and analysis...................................... 214

4.2.4. Analysis of the cases: The CAH-LF and MAR-LF alliances............................. 216

4.2.4.1. The CAH-LF case .............................................. 216

4.2.4.2. The MAR-LF alliance.......................................... 221

4.2.5. Discussion: Real options reasoning in the CAH-LF and MAR-LF alliances.... 226

4.2.5.1. Redeployment: A process of exploring and exploiting collective real options 226

4.2.5.2. Managerial cognition and the identification of collective real options....... 228

4.2.5.3. Redeployment and joint value realization: Managing uncertainty through

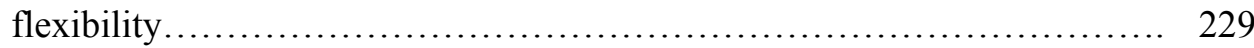

4.2.6. Conclusion and Implications ..................................................... 231

4.2.6.1. Implications for research.................................... 232

4.2.6.2. Implications for practice...................................... 233

4.2.6.3. Limitations................................................. 234

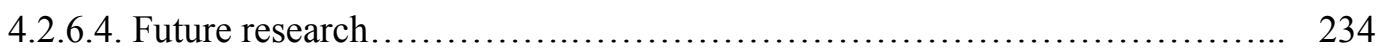




\section{Introduction to Chapter 4}

As the Acuisost Consortium evolved and we conducted ongoing data collection and analysis, we observed that the research focus should shift from the partner firms to the relationships between firms and research organizations (ROs) of the consortium. During the formation stage, the role played by ROs in the Acuisost Consortium confined to the definition of the specific technical objectives of the consortium firms. Once the formation stage finished, however, the case at hand transformed into a phenomenon of dyadic collaboration between firms and ROs taking place in the context of a larger consortium. Therefore, we observed that what may be labeled the locus of technological collaboration in the Acuisost Consortium shifted from the inter-firm level to the firm-RO relationships. Consequently, we started thinking on the Acuisost Consortium as a network of dyadic R\&D alliances entailing firm-RO collaboration and decided to concentrate subsequent research efforts on this level of analysis ${ }^{1}$.

As we continued collecting and analyzing data, we arrived at the three following observations that concern relevant factors to explain value-creation dynamics of $R \& D$ alliances:

(1) The Acuisost Consortium represented the first alliance for some firms and ROs collaborating together (i.e., R\&D alliances formed by unfamiliar partners), whereas the Acuisost Consortium represented for other dyads just another milestone of their long history of interactions (i.e., R\&D alliances formed by familiar partners).

(2) Some of the firm-RO alliances of the Acuisost Consortium were oriented at exploration (i.e., explorative R\&D alliances), whereas others were oriented at exploitation (i.e., exploitative R\&D alliances). Moreover, we did not identify a clear pattern between the formal innovation-seeking orientation of the alliances (exploration vs. exploitation) and the existence of prior relationships between firms and ROs (unfamiliar partners vs. familiar partners).

(3) Firm-RO alliances of the Acuisost Consortium ended up in varying rates of success (i.e. successful $R \& D$ alliances and failed $R \& D$ alliances) seeming the pattern of knowledge sharing a key factor in explaining alliance success/failure. Furthermore, the relevance of knowledge sharing seemed to be true regardless the two former conditions of the alliances (unfamiliar partners vs. familiar partners; exploration vs. exploitation).

\footnotetext{
${ }^{1}$ According to the shift in the level of analysis, by 'the alliance(s)' we will refer in Study II to 'the dyadic firm-RO alliance(s)' created under the Acuisost Consortium and by 'the partners' to the firms and ROs collaborating together in those alliances. By contrast, by the term 'alliance' we referred in Study I to the Acuisost Consortium as a whole and by the term 'partner' we referred to the '(partner) firms' which have signed the contractual agreement of the consortium.
} 
Along these lines of reasoning, this chapter presents the second empirical study of this doctoral dissertation, which addresses its second objective and is split in turn into two specific studies (see Figure 4.1.).

Figure 4.1. Position of Study II in this dissertation

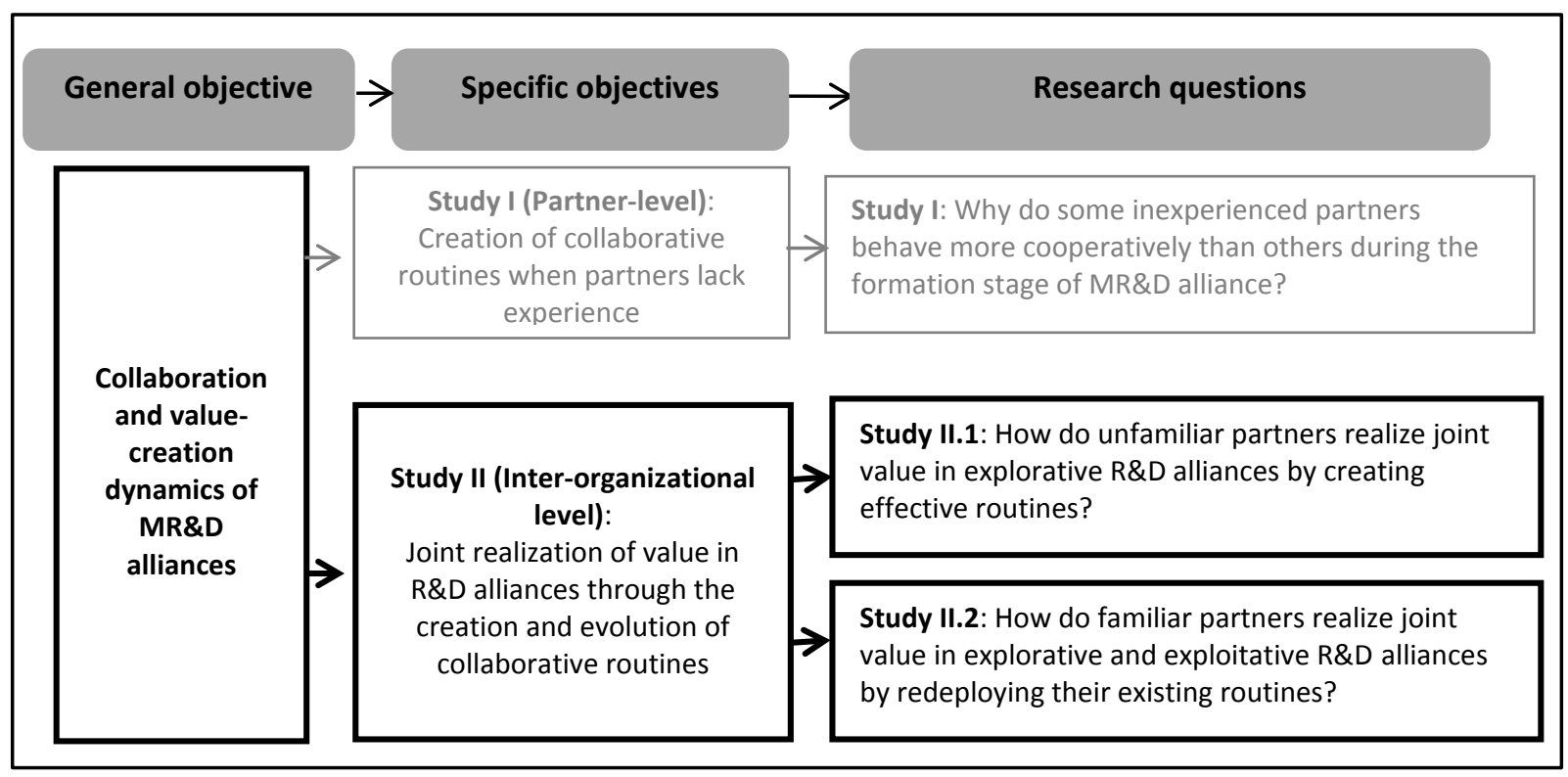

In Study II.1, we explore how unfamiliar partners may successfully realize joint value in explorative $\mathrm{R} \& \mathrm{D}$ alliances by creating effective inter-organizational knowledge-sharing routines. In Study II.2, we explore how familiar partners may successfully realize joint value by redeploying their inter-organizational knowledge-sharing routines in both exploitative and explorative $R \& D$ alliances. 


\subsection{Study II.1. : How Do Unfamiliar Partners Succeed in Explorative R\&D alliances? Psychological Contracts and Creation of Knowledge-Sharing Routines ${ }^{1}$}

\subsubsection{Introduction}

Exploration R\&D (ER\&D) alliances are motivated by the desire to discover new technological opportunities (Koza \& Lewin, 1998; Faems, Janssens, \& van Looy, 2007). They have become a noteworthy strategic tool (Lavie \& Rosenkopf, 2006) used by organizations as today investment platforms for future exploitation of technological opportunities (Vassolo et al., 2004). ER\&D alliances involve complex and unpredictable trajectories and results (Koza \& Lewin, 1998), their value-creation dynamics thus have attracted important scholarly attention (Hoang \& Rothaermel, 2005; 2010). In this research tradition, two main streams can be distinguished.

On the one hand, alliance formation scholars, mainly inspired by the resource-based view (Barney, 1991) and social network theory (Granovetter, 1973), have emphasized the value potential offered by ER\&D alliances formed by unfamiliar partners (e.g., Beckman et al., 2004; Goerzen, 2007). Unfamiliar partners bring technological complementarities to the alliance which, stemming from their diverse and unconnected technological endowments, furnish the flow of new ideas and perspectives and thus likelihood of synergies and novel, non-redundant technological knowledge (Parkhe, 1991; Tiwana, 2008; Phelps, 2010). If exploration has to do with "search, variation, risk taking, experimentation, play, flexibility, discovery, innovation" (March, 1991: 71) and involves "a pursuit of new knowledge" (Levinthal \& March, 1993: 105), then the higher the complementarity of partners' technological resources the higher the value potential of the ER\&D alliance.

On the other hand, alliance management scholars, drawing on the dynamic capabilities (Zollo \& Winter, 2002) and the relational views (Dyer \& Singh, 1998), have emphasized the difficulties associated to the effective realization of value in ER\&D alliances formed by unfamiliar partners (e.g., Rothaermel \& Deeds, 2006; Li et al., 2008). Unfamiliar partners bring relational dissimilarities to the alliance which, stemming from their diverse and unconnected backgrounds and organizational schemata (e.g., different cultures) may seriously hinder building inter-organizational knowledge-sharing routines ${ }^{2}$ (Parkhe, 1991).

\footnotetext{
${ }^{1}$ First version of this manuscript was developed during visiting scholar in the University of Groningen. Subsequent versions are thus co-authored with Dries Faems, and expected to be presented in several academic forums (see Scientific Diffusion section at the end of the dissertation).

${ }^{2}$ These routines can be defined as recurrent patterns of inter-partner interactions that, when effective, permit the mutual transfer, recombination and/or creation of specialized knowledge in the alliance (Dyer \& Singh, 1998; Dyer \& Nobeoka, 2000).
} 
These routines, developed out of accumulative interaction, allow effective integration of resources, joint work, coordination, and problem solving (Dyer \& Nobeoka, 2000; Zollo et al., 2002; Tiwana, 2008). If exploration of new technological opportunities in alliances requires continuous exchange, confrontation, and integration of partners' knowledge resources (March, 1991; Koza \& Lewin, 1998), then the higher the relational dissimilarities among partners the lower the likelihood of value realization in the ER\&D alliance.

Arguments for and against forming E\&RD alliances with unfamiliar partners seem to be equally compelling (Hoang \& Rothaermel, 2005; Gulati et al., 2009; Phelps, 2010). Indeed, each stream addresses different value-creation domains that are considered to work in tandem (Madhok \&Tallman, 1998; Parkhe, 1991). However, each stream has placed emphasis on one single value-creation domain, often disregarding the other side of the coin, insights they provide thus remain contradictory to each other. The first stream suggests that ER\&D alliances with unfamiliar partners are likely to trigger success because they maximize technological complementarities, whilst the second stream holds that ER\&D alliances with unfamiliar partners are likely to fail because they maximize relational dissimilarities. Because they are viewed as inversely related, benefits from technological complementarities must come at the expense of benefits from relational similarities, and vice versa.

We argue that prior research into ER\&D with unfamiliar partners has provided contradictory and ambiguous evidence mainly because it has not directly looked at the processes of collaboration, even though process-related arguments often support the motivation of hypotheses and the discussion of findings. As a result, value-creation dynamics in ER\&D formed by unfamiliar partners remain as a black box. Without properly disentangling the processes underlying value creation, useful managerial recommendations could not be provided on how succeed in ER\&D alliances with unfamiliar partners.

We seek to elucidate the value-creation dynamics of ER\&D alliances between unfamiliar partners, from value potential to effective realization of value by exploring some important collaborative processes. In particular, we address the research question of How unfamiliar partners can realize joint value in ER\&D alliances by creating effective knowledge-sharing routines? In order to do so, we study the relationship over time between knowledge-sharing routines and psychological contracts, one aspect of relational dissimilarities particularly important in this kind of alliances (Ring \& Van de Ven, 1994) through a comparative case study on two ER\&D alliances- one successful and other failed- formed by unfamiliar partners. In particular, we study longitudinally two four-year alliances formed by the same firm with two different research organizations (ROs) in the context of the Acuisost Consortium. Firm-RO alliances offer an adequate setting for our research purpose, since their different institutional missions potentially 
maximize both technological complementarities (e.g., applied technological capabilities vs. basic science capabilities) as well as relational similarities (e.g., property intellectual protection vs. open science philosophy, short-term problem-solving vs. long-term curiosity-driven research) (Lacetera, 2009).

Our study concludes that inter-organizational knowledge-sharing routines and psychological contracts are interactively 'co-constituted' (Rerup \& Feldman, 2011) through the actions taken by the partners' representatives to adjust the alliance to their respective expectations. In doing this, we not only show that psychological contracts can influence the building of routines over time but also that this routine-building process can influence the process of convergence experienced by the partners' psychological contracts, and that this co-evolution in turn determines joint realization of value.

The study is organized as follows. First, we present our conceptual background. After explaining the methodological issues and describing the study alliances, we present evidence from the analysis. Next, we discuss the findings, linking them to our research question and to existing literature. The study concludes by highlighting the main contributions and limitations, as well as some avenues for further research.

\subsubsection{Conceptual background}

\subsubsection{The two streams of research into ER\&D alliances: The need to focus on processes}

Reviewing alliance literature, we identify two main streams of research into value creation in ER\&D alliances formed by unfamiliar partners: the stream on alliance formation (e.g., Beckman et al., 2004; Laursen \& Salter, 2006) and the stream on alliance management (e.g., Darr \& Kurtzberg, 2000; Li et al., 2008). These two streams have focused on different domains of value creation, drawing on different theoretical frameworks and assumptions. They consequently envisage different value-creation trajectories these alliances and can be criticized for different reasons. Table 4.1.1 displays the comparison between the two streams of research.

Focusing on value potential and relying on the resource-based view (Barney, 1991; Eisenhardt \& Schoonhoven, 1996) and social network theory (Granovetter, 1973; Gulati, 1998), the stream on alliance formation rests on the assumptions that technological complementarities triggers discovering new technological opportunities and that unfamiliar partners bring technological complementarities to the ER\&D alliance. From a resource-based view, the raison d'être of ER\&D alliances is the combination of the partners' diverse technological that, by complementing each other, allows the discovery of new technological opportunities (Mowery et al., 1996). Alliance partners are conceived as bundles of distinctive resources and the technological endowments of unfamiliar partners remain unconnected until the first alliance, furnishing then likelihood of synergies and new technological knowledge. In a similar 
vein, social network scholars argue that resources that are needed by the organization to discover new technological opportunities are often not located within its existing network of relationships (Goerzen, 2007). Over time, knowledge of existing network partners become redundant, limiting the room for exploration. By contrast, unfamiliar partners involve the flow of new ideas and perspectives into the network, furnishing then likelihood of novel, non-redundant technological knowledge (Tiwana, 2008; Phelps, 2010). Therefore, the stream on alliance formation predicts that ER\&D alliances formed by unfamiliar partners are likely to experience success.

Table 4.1.1. The two research streams: ER\&D alliances between unfamiliar partners

\begin{tabular}{|c|c|c|}
\hline & Stream on alliance formation & Stream on alliance management \\
\hline $\begin{array}{l}\text { Value creation } \\
\text { domain }\end{array}$ & Value potential & Value realization \\
\hline $\begin{array}{l}\text { Theoretical } \\
\text { frameworks }\end{array}$ & $\begin{array}{l}\text { - Resource-based view } \\
\text { - Social network theory }\end{array}$ & $\begin{array}{l}\text { - Dynamic capabilities view } \\
\text { - Relational view }\end{array}$ \\
\hline $\begin{array}{l}\text { Main } \\
\text { assumptions }\end{array}$ & $\begin{array}{l}\text { Technological complementarities } \\
\text { trigger the discover of new } \\
\text { technological opportunities } \\
\text { - Unfamiliar partners bring } \\
\text { technological complementarities to } \\
\text { the alliance }\end{array}$ & $\begin{array}{l}\text { - Relational dissimilarities hamper the } \\
\text { discover of new technological } \\
\text { opportunities } \\
\text { - Unfamiliar partners bring relational } \\
\text { similarities to the alliance }\end{array}$ \\
\hline $\begin{array}{l}\text { Predicted value- } \\
\text { creation } \\
\text { trajectory }\end{array}$ & Success & Failure \\
\hline Main criticism & $\begin{array}{l}\text { - Overemphasis on technological } \\
\text { complementarities } \\
\text { - Overlook of the role of processes }\end{array}$ & $\begin{array}{l}\text { - Overemphasis on relational } \\
\text { dissimilarities } \\
\text { - Overlook of the role of processes }\end{array}$ \\
\hline $\begin{array}{l}\text { Relevant } \\
\text { references }\end{array}$ & $\begin{array}{l}\text { Granovetter (1973) } \\
\text { Eisenhardt and Schoonhoven (1996) } \\
\text { Ahuja (2000) } \\
\text { Beckman, Haunschild and Phillips } \\
\text { (2004) } \\
\text { Laursen and Salter (2006) } \\
\text { Goerzen (2007) }\end{array}$ & $\begin{array}{l}\text { Zollo and Winter (2002) } \\
\text { Dyer and Singh (1998) } \\
\text { Anand and Khanna (2000) } \\
\text { Darr and Kurtzberg (2000) } \\
\text { Rothaermel and Deeds (2006) } \\
\text { Li, Eden, Hitt and Ireland (2008) }\end{array}$ \\
\hline
\end{tabular}

By contrast, the stream on alliance management focuses on value realization. Relying on the dynamic capabilities (Zollo \& Winter, 2002) and relational views (Dyer \& Singh, 1998), this stream rests on the assumptions that relational dissimilarities hampers discovering new technological opportunities and that unfamiliar partners bring relational dissimilarities to the ER\&D alliance. From a dynamic capabilities view, alliance partners, which likely possess dissimilar schemata, background and experiences, have to 
jointly deploy their technological resources by applying inter-organizational knowledge-sharing routines or regular patterns of inter-partner interactions that, when effective, permit the mutual transfer, recombination and/or creation of specialized knowledge in the alliance $e^{3}$ (Dyer \& Singh, 1998; Dyer \& Nobeoka, 2000). These routines, develop out of accumulative interaction, are viewed are one of the most important constituent elements of the capability of partners to collaborate together, thus as an important driver of alliance success, allowing effective exchange of knowledge, joint work, coordination, and problem solving (Zollo et al., 2002). Over time, partners may iteratively implement and refine a set of shared routines, dissimilarities in organizational processes are thus progressively eroded, enabling the discovery of new technological opportunities (Anand \& Khanna, 2000; Tiwana, 2008). Conversely, due to the lack of prior mutual experiences, unfamiliar partners have not developed inter-organizational routines and thus they likely remain relationally dissimilar. Relational view scholars deepen these ideas, adding that ability of partners to generate relational rents through knowledge-sharing requires significant time to be developed, not only due to the idiosyncrasy of routines (Dyer \& Nobeoka, 1998), but also because it is dependent on informal self-enforcing safeguards that align partners' incentives and encourage transparency, which in turn requires a history of prior interactions (Dyer \& Singh, 1998; Mesquita et al., 2008). Therefore, the stream on alliance management foresees that ER\&D alliances formed by unfamiliar partners are unlikely to experience success.

Although both streams have provided important insights, they can be criticized for different (but related) reasons. Each stream places emphasis on a different domain of value, disregarding the other side of the coin. The stream on alliance formation overemphasizes the positive effects of technological complementarities among the unfamiliar partner, assuming that value will come automatically from them. By contrast, the stream on alliance management overemphasizes the negative effects of their relational dissimilarities, assuming that value will unlikely be realized during the subsequent development of the collaboration due to relational dissimilarities. Technological complementarities and relational dissimilarities are therefore viewed as inversely related, the benefits from one coming at the expense of the other. Consequently, existing evidence, if interpreted as a whole, falls into ambiguity and contradiction: ER\&D alliances formed by unfamiliar partners are simultaneously thought to likely succeed and fail.

\footnotetext{
${ }^{3}$ We define knowledge broadly as comprising both implicit (know-how) and explicit elements (information) (Nonaka \& Takeuchi, 1995; Kogut \& Zander, 1996; Bueno, Rodríguez, \& Salvador, 2008). Accordingly, when we state that knowledge-sharing routines can yield "creation of specialized knowledge in the alliance" we implicitly refer to two kinds of alliance learning (Doz, 1996): technological learning and learning to collaborate with that specific partner.
} 
We argue that a common criticism of both streams is behind such contradictory and ambiguous evidence: existing research into ER\&D alliances has not directly focus on the processes of collaboration. As a result, the question of how unfamiliar partners can successfully realized value in ER\&D alliances remains uncontested. The stream on alliance formation ignores the role that collaborative processes may play in moving from value potential to realization. More specifically, it overlooks the process by which knowledge-sharing routines emerge and evolve and the role they can play in transforming technological complementarities into new technological opportunities. Empirical studies in the stream on alliance management, even though conceptually grounded in process-related arguments, have not directly looked at the processes of collaboration. Consequently, it has been neglected the role that knowledge-sharing processes may play in solving relational dissimilarities of unfamiliar partners. The first knowledgesharing interactions between (relationally dissimilar) unfamiliar partners, as they built a history of mutual interactions, may end up in the establishment of knowledge-sharing routines that allow them to effectively realize joint collaborative value (Doz, 1996).

The adoption of an alliance process-oriented perspective (Ring \& Van de Ven, 1994; Doz, 1996) is necessary to explain how unfamiliar partners could develop effective knowledge-sharing routines in turn allowing success or joint value creation ${ }^{4}$ in ER\&D alliances. In particular, we invoke the concept of psychological contracts in alliances (Ring \& Van de Ven, 1994; Rousseau, 1995) and explore its coevolutionary dynamics with knowledge-sharing routines. Broadly defined, a psychological contract is an individual's belief in mutual obligations between that person and another party such an employer, arising out of the interpretation of promises (Rousseau \& Tijoriwala, 1998: 679-681). In the inter-organizational context, a psychological contract is the representative of one partner's belief in reciprocal obligations between that the two partners (i.e., between that person's organization and the other partner).

\subsubsection{Psychological contracts in ER\&D alliances formed by unfamiliar partners}

Beliefs forming the psychological contract are of subjective and implicit nature (Rousseau \& Tijoriwala, 1998). Therefore, psychological contracts of each partners' representatives are likely to differ not only from the formal contract but also from each other (Ring \& Van de Ven, 1994; Rousseau, 1995; Hill, Eckerd, Wilson \& Greer, 2009). In particular, the level of congruence ${ }^{5}$ between each partners'

\footnotetext{
${ }^{4}$ Following Madhok and Tallman (1998), we define alliance success as entailing joint value creation which occurs when both partners perceived that rents have been earned over and above what could have been achieved in the absence of collaboration.

${ }^{5}$ The level of congruence can be defined as the extent to which the two individuals involved in an exchange relationship share the same beliefs in reciprocal obligations between their respective organizations (Morrison \& Robinson, 1997).
} 
psychological contracts depends on two main contributing factors: (a) complexity or ambiguity of the exchange relationship itself (b) differing cognitive schemata (or interpretive frameworks) of the exchange parties (Morrison \& Robinson, 1997). In the case of ER\&D alliances formed by unfamiliar partners, therefore, the likelihood of incongruence is magnified. First, ER\&D alliances involve per se complex and unpredictable trajectories, displaying therefore ambiguous information (Koza \& Lewin, 1998) that, even when it is perceived by all the exchange parties, likely elicits different representations of reality (Morrison \& Robinson, 1997). Second, cognitive schemata form mainly thorough experiences (Rousseau \& Tijoriwalla, 1998). Since unfamiliar partners lack a history of mutual interactions and usually possess varied backgrounds and prior experiences, they are more likely to have different schemata (Morrison \& Robinson, 1997). As a result of this psychological contracts incongruence, unfamiliar partners may experience unfavorable discrepancies between the expected and the actual state of the alliance (Kumar \& Nti, 1998). Such discrepancies may generate conflicts between the partners which, if not properly managed, may elicit negative spirals likely destroying the possibility of realizing value in the newly created collaboration (Kumar \& Nti, 2004).

\subsubsection{Inter-organizational knowledge-sharing routines and psychological contracts}

Psychological contracts incongruence may challenge the creation of inter-organizational knowledgesharing routines in ER\&D alliances formed by unfamiliar partners. Recent literature linking dynamic capabilities and cognition (Tripsas \& Gavetti, 2000; Adner \& Helfat, 2003; Gavetti, 2005) and, more specifically, organizational schemata and routines (Edmondson, Boomer, \& Pisano, 2001; Feldman \& Pentland, 2003; Rerup \& Feldman, 2011) supports this argument. The overall conclusion is that organizational capabilities, and therefore routines as they constituent elements (Zollo \& Winter, 2002), "are sustained by the cognitive structures of individual organizational members" (Pentland \& Rueter, 1994: 486) and routines therefore "are carried out against a background of rules and expectations" (Feldman \& Pentland, 2003: 102). The theorization of routines as both cognitive and behavioral phenomena is central to this reasoning (Feldman, 2000; Feldman \& Pentland, 2003). The specific actions taken by the specific actors involved in the execution of the routine incorporate the subjective understandings of the routine actors about what is the routine (Feldman \& Pentland, 2003). Such an abstract conceptualization of the routine in turn serves as a guide both for ongoing behavior and for retrospective sensemaking ${ }^{6}$ on the prior development of the routine (Becker, 2004). Extending these ideas to the inter-organizational context, we argue that incongruence in the psychological contracts held by unfamiliar partners may constraint the development of knowledge-sharing routines by creating a gap

\footnotetext{
${ }^{6}$ Sensemaking can be defined as "an ongoing retrospective development of plausible images that rationalize what people are doing"(Weick, Suctcliffe, \& Obstfeld, 2005: 409).
} 
between the abstract conceptualizations of the routine each of them hold. After all, inter-organizational routines are built cumulatively upon purposeful coordinated investments between the partners and thus require a baseline level of mutual understanding to be successfully created (Zollo \& Winter, 2002; Zollo, Reuer \& Singh, 2002).

The relationship between inter-organizational knowledge-sharing routines and psychological contracts goes beyond the above exposed. Indeed, developing knowledge-sharing routines may enable the creation of a shared psychological contract between the partners (i.e., psychological contract congruence), by gradually engaging in joint sensemaking (i.e., joint problem definition and solving, Faems et al., 2008) and building mutual understanding about what specific actions should be carried out and how they relate to a larger organizational picture. In this regard, routines have been defined as 'sources of connections and understandings' (Feldman \& Rafaeli, 2002). As Feldman and Pentland (2003) argue, the performative aspect of routines is not always a static reflection of the underlying ostensive aspect. As a result of the implementation process of the routine itself, routine actors may both maintain and deviate from the initial abstract conceptualization thus iteratively building and rebuilding it (Feldman, 2000; Feldman \& Pentland, 2003). These ideas are in line with the psychological contracts literature, which attributes two roles to communication: Communication allows exchange parties first to identify sources of incongruence, and then to engage in joint sensemaking, their psychological contracts experience a process of convergence - i.e., their differing interpretive schemes are gradually shaped towards congruence(Nicholson \& Johns, 1985; Morrison \& Robinson, 1997). Extending these arguments to the interorganizational context, we argue that as unfamiliar partners engage and refine their knowledge-sharing routines, the gap between their psychological contracts can be reduced. After all, inter-organizational routines develop iteratively out of accumulative interactions between the partners and, when successful, lead to common ground, shared understanding, and effectiveness (Dyer \& Nobeoka, 2000; Zolloet al., 2002)

In sum, there are strong theoretical reasons to expect that knowledge-sharing routines and psychological contracts entail co-evolving processes, which likely affect realization of collaborative value. However, we still ignore how such co-evolution is and under which circumstances it allows value realization in ER\&D alliances formed by unfamiliar partners, motivating our theory-building comparative case study.

\subsubsection{Methodology}

\subsubsection{Research design and cases}

This study aims at inductive theory-building. To that end, we study longitudinally and comparatively two real-life ER\&D alliances developed in the course of a larger R\&D consortium (i.e., The Acuisost 
Consortium, 2007-2010), formed between its lead firm (LF) and two different ROs [the Oil Institute (OI) and the Center for Research in the Agri-food Industry (CRAI)], labeled the OI-LF and the LF and CRAILF alliances (see Table 4.1.2).

Table 4.1.2. Main characteristics of the OI-LF and CRAI-LF alliances

\begin{tabular}{|c|c|c|}
\hline & OI-LF Alliance & CRAI-LF Alliance \\
\hline Written contract & & \\
\hline $\begin{array}{l}\text { Research orientation } \\
\text { and field (technical } \\
\text { activity of the } \\
\text { consortium) }\end{array}$ & $\begin{array}{l}\text { Exploration; fish nutrition ('Raw } \\
\text { Materials') }\end{array}$ & $\begin{array}{l}\text { - Exploration; fish nutrition ('Additives } \\
\text { and Encapsulation') }\end{array}$ \\
\hline $\begin{array}{l}\text { Technical objectives } \\
\text { Horizon, Budget }\end{array}$ & $\begin{array}{l}\text { - Obtaining, analysing and } \\
\text { encapsulating vegetable protein, } \\
\text { obtained from rapeseed (Obj.1), } \\
\text { chickpea (Obj.2), and lupine (Obj.3), } \\
\text { for aquaculture nutrition } \\
\text { - } 4 \text { years, } 432.000 €\end{array}$ & $\begin{array}{l}\text { - Identifying and collecting natural } \\
\text { pigments adapted to aquaculture } \\
\text { nutrition (Obj. 1); encapsulating these } \\
\text { pigments (Obj. 2), and developing a } \\
\text { micro-algae additive for aquaculture } \\
\text { nutrition (Obj. } 3 \text { ) } \\
\text { - } 4 \text { years, 590.000€ }\end{array}$ \\
\hline $\begin{array}{l}\text { Expected relational } \\
\text { dissimilarities }\end{array}$ & High [Unfamiliar partners; firm-RO ] & High [Unfamiliar partners; firm-RO] \\
\hline $\begin{array}{c}\text { Expected } \\
\text { technological } \\
\text { complementarities }\end{array}$ & $\begin{array}{l}\text { High }^{7} \text { [OI: Vegetable proteins (human } \\
\text { nutrition); LF: aquaculture nutrition } \\
\text { (animal proteins)] }\end{array}$ & $\begin{array}{l}\text { High }^{8}:[\text { CRAI: Natural additives and } \\
\text { pigments (human nutrition); LF: } \\
\text { aquaculture nutrition (artificial additives } \\
\text { and pigments)] }\end{array}$ \\
\hline Joint value & - Success (e.g., co-patent) & - Failure (e.g., objectives unmet) \\
\hline Technological & & \\
\hline Relational & $\begin{array}{l}\text { - Success (e.g., continuation of the } \\
\text { collaboration) }\end{array}$ & $\begin{array}{l}\text { - Failure (e.g., discontinuation of the } \\
\text { collaboration) }\end{array}$ \\
\hline Key informants & $\begin{array}{l}\text { - LF's R\&D Manager, } \\
\text { - OI's Head researcher }\end{array}$ & $\begin{array}{l}\text { - LF's R\&D Manager } \\
\text { - Head Engineer of the project at CRAI }\end{array}$ \\
\hline
\end{tabular}

${ }^{7}$ As explained by informants in the interviews and in the consortium's report, proteins are a key element in aquaculture nutrition and, in particular, vegetable proteins (like those from chickpea, lupine and rapeseed) may represent a viable alternative for fish-based proteins, which are the traditionally used and involved higher costs both in economic and environmental terms.

${ }^{8}$ Additives and pigments are key elements in aquaculture nutrition (e.g., to shape fish colour and reinforce fish health) and, in particular, natural additives (e.g., from food wastes) may represent a viable alternative for artificial additives, which are the traditionally used and involved higher costs. 
This research design can be considered appropriate for two main reasons. First, existing evidence is contradictory and ambiguous (Eisenhartd, 1989) and we do not know how knowledge-sharing routines and psychological contracts coevolve and how this process impact joint realization of value in E\&RD alliances formed by unfamiliar partners. Second, case study matches the nature of our 'how' research question, which deals with links between collaborative processes and its context (Yin, 2003), mobilizing multiple observations on complex relational processes which need to be traced longitudinally over time (Langley, 1999).

The two studied alliances were selected as our research setting following theoretical sampling criteria (Eisenhartd, 1989; Yin, 2003). First, both of them are ER\&D alliances formed by unfamiliar partners ${ }^{9}$, thus they are representative of the phenomenon under consideration. In particular, they involved firm-RO collaboration, which maximize both technological complementarities (e.g., applied technological capabilities vs. basic science capabilities) as well as relational similarities (e.g., property intellectual protection vs. open science philosophy, short-term problem-solving vs. long-term curiosity-driven research) (Lacetera, 2009). Second, both studied alliances were formed within the same larger context (i.e., The Acuisost Consortium) by the same firm (i.e., the lead firm -LF- of the consortium) and two different ROs. That allows reliability in comparison, minimizing the risk of extraneous variation (Eisenhartd, 1989; Yin, 2003). For example, the formal contracts in the two alliances were highly similar ${ }^{10}$ and the fact that both alliances shared a common partner (i.e., the $\mathrm{LF}^{11}$ ) allowed us to focused on the relational side of knowledge-sharing routines, whilst qualitatively control for the redeployable side of at least one of the partners (Mesquita et al., 2008). To ensure rich variability in the phenomenon of interest, we followed the criterion of 'polar cases' (Eisenhardt, 1989). The LF's R\&D Manager described the OI-LF and the CRAI-LF alliances as the two poles of the success continuum, respectively, " $a$ white blackbird" (success) and "a pig in a poke" (failure).

${ }^{9}$ Before the Acuisost Consortium, the OI had no prior ties with the LF and with other partner firms of the consortium either. By contrast, prior to the consortium, the CRAI and other partner firm (i.e., Mediterranean Aquafarming) were linked via both institutional ties (i.e., Mediterranean Aquafarming was member of CRAI) and several past R\&D contracts. In turn, Mediterranean Aquafarming belonged to the LF's existing network of contacts (i.e., established client-supplier relationship). We explored through the interviews whether the existence of such indirect ties between the LF and CRAI could have affect the subsequent development of the relationship (e.g., whether Mediterranean Aquafarming acted as an intermediary in conflict resolution), concluding that the existence of indirect ties did not mark a relevant difference.

${ }^{10}$ First, both contracts complied with specific requirements of the CENIT Program (i.e., 4-year horizon) and, second, because both were developed by InvestMng, a firm providing consulting services to the LF. The main differences between both contracts resided in the technical objectives.

${ }^{11}$ Moreover, we concentrate on these two alliances formed by the LF of the Acuisost Consortium following theoretical sampling (Eisenhardt, 1989) and opportunity criteria (Gilbert, 2006): it guarantees enough commitment to both alliances (inherent to the leadership condition of the firm) and the LF brought us the opportunity to adopt high-quality research criteria, providing access to relevant information and insightful feedback. 


\subsubsection{Data collection and analysis}

We follow the recommendations of Pettigrew (1990) and Pentland (1999), structuring our research efforts on two subsequent phases that went from surface to deeper levels of data collection and analysis.

During the first phase (April 2008- October 2010), we collected overall information. This study emerged from a larger ongoing research project on the Acuisost Consortium. Although the first phase of data collection was not aimed specifically to compare the dynamics of value creation in the OI-LF and CRAILF alliances, it provided large corpora of relevant data to that end. For example, in this phase we obtained access to both primary and secondary data sources, which provided information about objectives and actors involved in the firm-RO alliances of the consortium. Similarly, interviews with the LF and direct observation in some consortium committees, informed us about the ongoing evolution of these alliances. All this information led us to consider inter-organizational knowledge sharing as an important explanatory factor of the rate of success of the firm-RO alliances of the consortium.

During the second phase (October 2010-September 2011), to confirm our first impressions, we started with exploratory interviews with the LF's R\&D Manager, as well as with several partner firms and ROs involved in the consortium (October 2010). On the basis of this information, we selected the OI-LF and CRAI-LF alliances, following criteria above explained. At the same time, we reviewed relevant literature to decide the theory-driven variables on which the study would focus (i.e., inter-organizational knowledge-sharing routines and joint realization of value, whose operationalization is explained below). After one more exploratory interview with the LF's R\&D Manager (February 2011), we started collecting specific information about the OI-LF and CRAI-LF alliances. In particular, data was collected retrospectively through semi-structured interviews in the form of face-to-face surveys (Yin, 2003), conducted between May and July of 2011 with key informants of both partners in each alliance (i.e., the LF's R\&D Manager, the OI's Head researcher, and Head Engineer of the project at CRAI). Interviews (which had an average length of 1.5 hours, were recorded and then transcribed by the two interviewers involved) were not conducted under a rigid question-answer format. Informants were also asked to provide information about the longitudinal evolution of the alliance (e.g., details, anecdotes, examples, milestones) as well as to justify their responses. This data collection strategy allowed us to deal with data- 
reduction dilemmas, generate 'customized' items, collect process data and avoid self-respondent biases by fulfilling the principle of triangulation ${ }^{12}$ (Langley, 1999; Yin, 2003).

Data analysis started with the reconstruction of the history of the two studied alliances, combining information from interviews - See Appendix IV.1 for more details about operationalization of theorydriven variables (i.e., knowledge-sharing routines and joint value realization)- and other data sources (e.g., consortium's report, R\&D contract between firms and ROs, see Appendix II.4 of Chapter 2 for these data sources). Next, an extensive case study report for each alliance was wrote, containing a lot of citations from interviews and documents to stay very close to the original data and thus achieve accuracy (Langley, 1999). Subsequently, we analyzed data through an inductive approach (e.g., Rerup \& Feldman, 2011), involving iterative, first two-by-two and then overall discussions between the four researchers of the study. During this process, we realized that the partners in each studied alliance had brought to the collaboration different interpretations of their reciprocal obligations and that they thus could be comprehensively explained in light of the psychological contracts literature. Based on the case study reports, we moved from raw data to first-order constructs (see narratives in next section) and subsequently from them to second-order constructs, linking data with theoretical concepts, identifying thus data-driven variables (i.e., psychological contracts whose operationalization is explained in Appendix IV.2) and arriving at an explanatory framework for addressing the research question of the study (see discussion of findings).

\subsubsection{Analysis of the cases: The OI-LF and CRAI-LF alliances}

In this section, we first describe jointly the initiation of both alliances. Then, we provide a longitudinal description on the emergence and evolution of collaboration in each of them, structured along three lifecycle stages identified retrospectively: Start-up (January-December 2008), Execution (December 2008-December 2009) and Termination (December 2009-December 2010). Appendix IV. 2 summarizes quantitative and qualitative evidence.

\subsubsection{Initiation of the OI-LF and CRAI-LF alliances (November 2006-January 2008)}

The first indirect contact between the lead firm (LF) and, respectively, the Oil Institute (OI) and the Center for Research in Agrifood Industry (CRAI) took place in the open solicitation meeting of the

\footnotetext{
${ }^{12}$ Interviewing emerged as the necessary data collection technique, since information about knowledge sharing among partners was not available in reports of other secondary sources of information. In this context, we triangulate the information by resorting to two key informants in each alliance.
} 
Acuisost Consortium ${ }^{13}$ (November 2006). The LF's Managers perceived that the research proposals presented by the OI and the CRAI were highly promising and thus the OI-LF and CRAI-LF alliances were born. Subsequently, the partners held their first direct contacts in two initial meetings of the 'Raw Materials' and the 'Additives and Encapsulation' activities of the consortium, in which the OI-LF and CRAI-LF alliances respectively were framed (January 2007). Although both the OI-LF and CRAI-LF alliances were signed in April 2007, actual collaboration did not started until January 2008, as a consequence of a break suffered by consortium as a whole ${ }^{14}$.

\subsubsection{The OI-LF alliance}

Both the LF and the OI started the alliance perceiving important technological complementarities between their respective areas of expertise (aquaculture nutrition and vegetable proteins) and thus holding important value-creation expectations with the collaboration (see above Table 4.1.2 for objectives' description). Furthermore, both of them envisaged a shift to exploitation. In particular, the OI's head researcher perceived the opportunity to apply his extensive experience in plant proteins developed in the human nutrition field into "a new industrial field" (i.e., the aquaculture nutrition field). In turn, the presentation of the OI in the open solicitation meeting, lead the LF's Managers to perceive that "competitive advantage" can be achieved:

"We were impressed by the presentation because it advanced what could be the final outcome of the research. We realized that it could be applicable for our industrial ends" (The LF's R\&D Manager)

\section{Start-up stage (January 2008- December 2008)}

In January 2008, technical efforts of the project started. In parallel, the LF and the OI started to exchange technological knowledge not particularly frequently (e.g., partners met twice during the whole period, maintaining some email communication meanwhile). Out of these inter-partner interactions, the first visits to the facilities of the partners stand out due to their consequences for the subsequent development of the project.

${ }^{13}$ The formation of the Acuisost Consortium was induced by a triggering entity, which organized this meeting to help partner firms to select research organizations for their consortium projects. As many other research organizations, the OI and the CRAI addressed the call for this meeting, making a presentation of their research proposals.

${ }^{14}$ Given its government-sponsored nature, a delay in the assignment of the public funds involved a break in the Acuisost Consortium between April 2007 (application to the public funding program) and January 2008 (official resolution of the public funding program). 
In March 2008, the R\&D and the Aquaculture Division Managers of the LF were invited to visit the OI. During the visit, they could know more about the OI's technological facilities (e.g., they were showed how the pilot plant worked). During the visit, the LF's managers found out that the technological capabilities of the OI were "much stronger than expected", which reinforced their expectations about the potential of the project. After the visit, the first technological meeting between the partners was held. In this meeting, the OI people explained to the LF's managers that initial tests deterred further work on one of the raw materials (i.e., rapeseed) and they thus proposed to change the initial technical objectives of the project, admitting failed expectations with the initial research proposal:

"...we early realized that rapeseed would not yield the desired outcomes. [...] we proposed ruling it out and concentrate on the other two objectives". (OI's head researcher)

As the OI, the LF perceived that this initial technical failure was not a lack-of- feasibility indicator, but stemmed from the risk inherent in "long-term R\&D projects". They thus implemented the first change in the project's objectives, agreeing that the project needed to "evolve according to the ongoing circumstances". The reaction of the LF affected positively the OI's expectations with the collaboration. Making explicit comparisons with other firms, the OI's head researcher realized that (a) the LF really understood "what research is" and (b) the LF appreciated the OI's technical expertise:

"We had never worked with a firm that understood research as the LF does [...] Firms tend to be less flexible and less willing to rely on our technical experience (OI's head researcher)

In June 2008, the OI's research team was invited by the LF to visit its main production facilities. As the LF's R\&D Manager explained in an interview, they considered this visit as "essential" due to the lack of experience of the OI in the aquaculture field. As a result, the OI learnt more about the firm's production technologies and processes. Furthermore, the OI highly appreciated the detailed information provided by the LF, interpreting it as an important sign of transparency:

"...we started from scratch in aquaculture [...] (the LF) has shown us even its formulae program $[\ldots]$ (which has) allowed us to better conduct the research [...] firms tend to be reluctant to share confidential information" (OI's head researcher)

By the end of the period, the two first objectives of the alliance had been successfully accomplished.

\section{Execution stage (December 2008-December 2009)}

In December 2008, partners met to discuss the achievements of the project during its first year of collaboration. The OI's head researcher was convinced about the value of these achievements (because scientific quality standards had been exceeded), whereas the LF's R\&D Manager were seriously 
concerned about their industrial viability (because industrial quality standards had been exceeded). From the LF's perspective, this disagreement was a clear indicator that the OI did not understand what the firm really needed. The LF's R\&D Manager perceived that, even though the underlying reason was the lack of experience of the $\mathrm{OI}$ in the aquaculture field, the pattern of interaction was preventing them from overcoming the inexperience barrier. The OI people tended to work autonomously without providing feedback as frequently as required to conduct an ongoing follow-up of the project:

"...the problem was that, at the beginning, they worked a lot on their own and when they showed us the results we had to tell them that they were not viable for us" (LF's R\&D Manager)

In this context, the LF's managers explained "with detail" to the OI team that particular attention has to be paid to costs when taking production-related decisions (i.e., describing the production costs and the profit margin of the firm per kilo), urging them to estimate costs and to provide continuous feedback. For the OI, the LF's concerns about the lack of industrial viability clearly conveyed its willingness to bring the project results to life. They realized that following the LF's advice would allow better understanding of the industrial necessities, the possibilities of doing applied research thus enhanced:

“... we have learnt a lot from (the LF's) criticisms [...] the quality standards in the scientific and business contexts differ [...] a protein richness level lower than $90 \%$ used to mean failure for us but the LF explained us that a $75-80 \%$ level exceeds common industrial standards [...] what we had offered them was too costly to be industrially implemented" (OI's head researcher)

Henceforth, knowledge exchange between the partners became gradually more frequent and intense. In parallel, the research team started optimizing the processes to obtain less costly products with similar properties (e.g., the OI searched new suppliers, because its habitual suppliers specialized in high-quality products, "ideals for the lab but too costly for business"). Within the first months of 2009, these optimization efforts successfully concluded. However, partners realized that there was a mismatch between their respective production capacities: the OI's pilot plant (15 kg every 3 months) could not satisfy the amount of protein products required by the LF to produce the experimental feed in its own facilities $(300 \mathrm{~kg})$. Both partners believed that such an unexpected technical problem had been caused by an exogenous factor (i.e., insufficient funds provided by the public funding program to acquire the required production equipment). In this context, they agreed that the OI would accumulate the production of protein products until the threshold amount was reached, then providing it to the LF and the OI started making additional efforts to extend the production capacity of its pilot plant.

Along this period, the LF perceived a significant increase in the OI's proactiveness, strongly appreciating its willingness to adapt and to provide technological solutions. The partners, perceiving a reciprocal focus 
on "mutual benefit", were already convinced that "the collaboration would continue in future". They started to consider alternatives to deal with the mismatch between their production capacities, since it would involve a serious obstacle for up-scaling. In particular, the co-creation of a spin-off involving an intermediate semi-industrial production plant emerged as one possible solution.

In such an encouraging context, the LF's R\&D Manager sensed the opportunity to extend the collaboration, by experimenting with new raw materials. Holding increasing expectations about the possibility of doing real applied research, the OI agreed on extending the project, new experiments starting in March 2009. For the OI, the new objectives, even though involving changes respect to the (written) contract, were inside the scope of the ongoing alliance. The LF's R\&D Manager in turn highly appreciated the OI's flexibility:

“... it was out of contract, but it was part of the project. After all, we seek to develop a product useful for the LF" (OI's head researcher)

“...the OI has striven to adapt to our necessities" (LF's R\&D Manager)

Although a wide range of unexpected technological opportunities opened up, the OI's head researcher perceived a certain risk of chaos (i.e., partners would decide "on the fly" which new raw materials analyze, according to their evolving prices), highlighting the necessity of a new working methodology that enabled better inter-partner coordination. In April 2009, both partners agreed on holding bilateral meetings after each meeting of the 'Raw Materials' activity of the consortium. The frequency of the activity meetings covered the face-to-face knowledge-sharing necessities of the project (every three months from October 2008 to November 2010) and their location was of mutual convenience, smoothing the problem of geographic distance (i.e., $646 \mathrm{~km}$ ).

Inter-partner interactions during the rest of the period thus became stronger, in terms of both frequency and knowledge exchange intensity, and mutual understanding between the partners developed. Their distinctive knowledge resources (i.e., aquaculture nutrition and proteins expertise) were smoothly integrated, new technological knowledge were built and progressively applied. As a result, the new objectives were successfully accomplished, ending up with a positive evaluation of patentability in December 2009. The OI's head researcher illustratively explained the situation as "a nice symbiosis" entailing "mutual learning" between the two partners. The LF's R\&D Manager explained us that he felt "proud of working with the OI people" and that the project would be "really profitable" for the firm. Furthermore, both informants stressed in the interviews that, after the technological meetings, informal conversations took place in a relaxed atmosphere (i.e., "while we lunch together or having a beer"), strengthening the relationship also at the personal level: 
“... we have developed a really good relationship with the LF [...] friendship has emerged between the LF's R\&D Manager and me [...] we even share personal information, for example, about our holiday" (OI's head researcher)

\section{Termination (December 2009-December 2010)}

In February 2010, the partners met to discuss the overall projects' development and to evaluate alternative paths for the remaining months. Both partners considered that the collaboration had been successful (in both technological and relational terms), showing their willingness to moving towards the industrial application of the achieved results, by co-creating a spin-off. However, the ongoing economic crisis discouraged the investment required to that end and up-scaling thus was postponed. In this context, they perceived that patenting the results would preserve the opportunity for future. The patenting process (e.g., selection and optimization of the most promising results) concluded in August 2010 with the register of the co- patent (Spanish Office of Patents and Trademarks):

"We decided to keep the idea 'in a drawer' and wait for the right moment [...] we have just made an initial part of this investment, by patenting the most promising results" (LF's R\&D Manager)

The OI-LF alliance was supposed to finish in December 2010. By initiative of the OI, however, the partners agreed a one-year free extension of the contract in November 2010 (i.e., not involving additional service fees for the LF). Such a costless contract extension was viewed by the OI as a self-obligation of reciprocity respect to the $\mathrm{LF}$, since the protein products developed had not been industrially applied:

“...We feel indebted to the LF and we want to find out a raw material to reinforce the LF's competitive position in the field of aquaculture". (OI's Head research)

From a relational standpoint, the LF's highly appreciated the extension of the contract, which in turn would bring a new set of unexpected possibilities for mutual collaboration ${ }^{15}$. Both the LF and the OI's informants confirmed that they had already known how to effectively work together and that the relationship had proved to be (still was and probably would be) mutually beneficial:

"The human team plays an essential role: you may find research centers with high-level technological capabilities, as the OI, but probably they lack the willingness to collaborate that the OI has" (LF's R\&D Manager)

\footnotetext{
${ }^{15}$ In June 2011, when we collected the main part of the data, this phase of collaboration was still ongoing (JanuaryDecember 2011). During this period, the OI provided technological support to the LF in its day-to-day activities and also carried out 'technological watch' concerning its area of expertise.
} 
"We have worked with other firms with which we do not expect to collaborate again in future, because unlike the LF, they have not been enough transparent or they simply lack innovation capacities" (OI's Head researcher)

During the last interviews we conducted, the LF and the OI's informants described each other's organization as "the new (technological/industrial) partner", pointing out that the formalization of new joint projects was only "a matter of time". Indeed, through subsequent feedback contacts, the LF's R\&D Manager confirmed us that new collaborative projects had been agreed in June 2011 and the OI's head researcher stressed that they would be undertook by both partners "with great enthusiasm". Still waiting for the right moment to invest in the up-scaling of the new co-developed products, the partners would collaborate in new lines of research related to the two main business units of the LF (i.e., aquaculture nutrition and pet nutrition).

\subsubsection{The CRAI-LF alliance}

Both the LF and the CRAI started the alliance perceiving important technological complementarities between their respective areas of expertise (aquaculture nutrition and natural additives) and thus holding important value-creation expectations with the collaboration (see above Table 4.1.2 for objectives' description). However, the LF envisaged the industrial application of results, whereas the research proposal of CRAI focused on discovering new technological opportunities ${ }^{16}$ :

"...they offered us an opportunity that we could not reject [...] directly related to competitive advantage, in terms of significant reduction of costs and environment-friendly technology" (LF's R\&D Manager, emphasis added)

"...research is recently looking at the benefits of some natural pigments [...] microalgae are sources of a variety of valuable substances [...] It would be interesting to investigate their properties for fish nutrition" (Source: consortium's report, emphasis added)

\section{Start-up stage (January 2008- December 2008)}

In January 2008, the CRAI started to address the three objectives of the project included in the written contract. From the beginning and during the whole period, highly frequent and intense knowledge exchange took place between the LF and CRAI (e.g., technological meetings every three months, continuous email and phone communication).

The important expectations with the project triggered the LF's motivation. Once the project started, all the signs received by the LF seemed to confirm its perceptions (i.e., CRAI was a "leading center"). For

\footnotetext{
${ }^{16}$ In the list of research services offered to firms in the CRAI's Website, a clear distinction is made between exploration-oriented contracts ("Research projects") and exploitation-oriented contracts ("Technological solutions"). Through the interviews, we confirmed that the alliance with the LF was included in the former category.
} 
example, in January 2008, after visiting the CRAI's headquarters, the LF became really interested in an innovative environment-friendly technology (i.e., SF technology) that CRAI had in place and that would be used in the development of the project:

“...it was the 'exciting phase' of the project [...] we were really convinced that the project was promising, and thus we were really motivated to invest time and efforts in its development" (LF's R\&D Manager)

Moreover, the head engineer at CRAI explained that their 'working philosophy' was characterized by close interaction and intensive exchange of knowledge with firms contracting its R\&D services:

"Values of fluid communication, 'the open door', total transparency, are in the DNA of the CRAI" (Head engineer of the project at CRAI)

By the middle of 2008, the project yielded satisfactory preliminary results on the initial tasks of the three objectives ${ }^{17}$. Henceforth, efforts concentrated on the first and third objectives which represented the two priority fronts for the LF. After several months working, attempts on the first objective resulted unsuccessful, whereas concerning the third objective, it was found out that a particular micro-algae could serve as a natural pigments' source (the same pigments on which the first objective focused). In a meeting held in July 2008, CRAI people openly shared with the LF its failed experiences in experimenting with natural pigments, recognizing the immaturity of the process. In this context, the head engineer of the project at CRAI proposed continuing experimenting with natural pigments before addressing the second objective (encapsulation of these pigments). The LF's R\&D Manager also believed that the initial failure stemmed from the risk inherent in R\&D projects ("R\&D projects stand by research"). However, he perceived a risk of getting stuck on the extraction of natural pigments without advancing in the encapsulation of these pigments ("an equally important part of the industrial process"). Hence, he proposed started experimenting in the encapsulation process using artificial pigments (the ones used in the commercial products of the LF), until natural pigments were obtained.

CRAI accepted this minor (and temporary) alteration of the objectives of the written contract, following the premises of its 'working philosophy':

\footnotetext{
${ }^{17}$ According to the contract, each of the three technical objectives of the project split into several tasks. In particular, each objective started with 'initial tasks' (review of scientific literature), continued with 'development tasks' (development of the research processes themselves), and finished with 'concluding tasks (evaluation of industrial viability)'. In turn, a sequential link interceded between the 'development tasks' of the first and the second objective. During the first months, the 'initial tasks' of these two objectives developed in parallel. Henceforward, it was no longer possible: if natural pigments were not obtained, there would be nothing to encapsulate.
} 
"...we take off the lab coat to put on the uniform of the firm that has contracted our services" (CRAI's head engineer of the project)

The first attempts to encapsulate artificial pigments failed, the CRAI people arguing "emerging needs of knowledge". The LF's R\&D Manager understood it was a "reasonable" request, inviting the CRAI team to see the production process in-situ. Subsequent technical efforts, however, remained unsuccessful.

\section{Execution stage (December 2008-December 2009)}

Technical efforts so far had not yielded successful results (except the identification of a promising species of micro-algae). Consequently, the alliance experienced successive reformulations of its objectives in this period and the relationship between the partners gradually deteriorated, even though technological meetings continued being held frequently and intensively.

As established in the contract, CRAI developed an annuity technical report in December 2008, which meant a turning point in the alliance eliciting inter-partner conflicts and disagreements. By thoroughly reading that report, the LF's R\&D Manager assessed the first year of the collaboration, comparing it with other research projects of the consortium. As a result, the expectations of the LF's R\&D Manager with the project itself and with the CRAI crashed down:

“...we started to realized that the CRAI had not provide us any useful result and that their efforts had diluted [...] other centers had achieved results in the same time [...] CRAI's report was superior in terms of presentation but its scientific content was weaker, basically theoretical knowledge" (LF's R\&D Manager)

In this context, the first change in the project was implemented. In a meeting held in January 2009, the LF's R\&D Manager proposed to reframe the project's objectives, concentrating all efforts on the only front on which some results had been obtained (i.e., micro-algae):

"...we realized that we would waste our time and our money unless we changed completely the course of the project" (LF's R\&D Manager)

The necessity of reframing the project was not so obvious to the CRAI. As its head engineer explained in an interview, they perceived that the project had provided important insights not in the form of "which path to take' but in the form of 'which path not to take', according to the high innovativeness of the research proposal:

"Long-term research projects are inherently complex and uncertain [...] failure can be viewed as success, since it allows firms to ruled out unviable processes that are not viable" (CRAI's head engineer of the project) 
However, CRAI accepted the change, following its 'working philosophy' (e.g., "we are in service to our customers"). Shortly after experiments with micro-algae started, the LF's R\&D Manager lost his "confidence in the micro-algae idea", feeling that CRAI people were "fishing in the dark", not providing "proper feedback" and that they would not be able to succeed due to "lack of the required capabilities". In this context, in a meeting held in April 2009, the LF's R\&D Manager proposed another major change. The new LF's proposal entailed more than simply reframing the objectives (i.e., providing the LF with a new micro-algae pigment) and thus its internal approval in CRAI took significant time. For LF's R\&D Manager, the reaction of CRAI to this new adjustment proposal conveyed its lack of flexibility in the face of alterations of the (written) contract. The LF did not received new feedback from CRAI until six months later and the experimental tests (conducted between October and December 2009) finally confirmed the lack of feasibility of the new idea. In this context, the LF's R\&D Manager reproached the CRAI for its lack of efforts and initiative to make the project 'get out of the trap' in the face of the last failure:

"(CRAI) is a rigid center $[\ldots]$ it has not always showed itself willing to comply with our requests when they entailed departing from the script [...]there is an important difference between failed R\&D projects developed with and without effort" (LF's R\&D Manager)

By contrast, when we asked the head engineer of the project at CRAI about these questions, she highlighted the limits imposed by the formal contract and the LF's responsibility in decision-making:

“...in long-term projects, it is not all 'a bed of roses' [..] we have tried to adapt the project to the firm's needs, moving within the framework of the contract [..] the firm is who decides what to do" (CRAI's head engineer of the project)

In such an atmosphere of extreme tensions, it was surprising that the partners continued having frequent and continuous contact (e.g., they met every three months). In the interviews, informants offered us conflicting explanations. The LF's R\&D Manager described this second year of collaboration as the "the failed re-planning phase" and the meetings held between partners as 'tense'. In this context, frequent exchange of knowledge was the consequence of the urgent need to change the course of the collaboration, inter-partner interactions confirming over time the deterioration of the relationship. By contrast, for the head engineer at CRAI, this pattern of interaction with the LF reflected that collaboration had developed smoothly and had resulted gradually in mutual understanding, describing their technological meetings as 'easy':

"Our collaboration has been very close [...] we have followed the logical evolution of R\&D projects. As the project progresses, the parties start get to know each other and to assimilate and applied new knowledge. Progressively, parties build a bridge to overcome the precipice (i.e., technological uncertainty)" (CRAI's head engineer of the project) 
"...we continued having frequent contact with the CRAI because it was like to see how a ship is sinking and desperately try to refloat it [...] Lack of understanding has been frustrating [...] they did not realize that we had not obtained anything useful [...] In the last meetings, our positions were clearly opposed" (LF's R\&D Manager)

\section{Termination stage (December 2009-December 2010)}

In January 2010, the last meeting between the LF and the CRAI was held. Disagreements between the partners resurfaced. CRAI people continued perceiving the initial lines of research as interesting, highlighting the results so far obtained, whilst the LF people emphasized their lack of industrial usefulness. However, the LF's R\&D Manager agreed on retaking the initial objectives of the project, admitting that he "had run out of ideas to find an alternative solution".

Henceforth, face-to-face meetings were no longer held, inter-partner interactions confined to exchange of "administrative information" through "occasional emails and phone calls", in the words of the LF's R\&D Manager, just to fulfill the formal obligations of the consortium. Although the head engineer of the project at the CRAI stated in an interview that the frequency of contact had varied according to "the ongoing necessities", the LF's R\&D Manager recognized that he had proactively finished interaction with the CRAI people. He referred to this last year as the 'disappointment phase' and perceived that 'the ship had already sunk':

“...there was no longer point in investing time and effort because the project would not provide us valuable results". (LF's R\&D Manager)

The alliance terminated in December 2010 with technical failure concerning its initial objectives and discontinuation of the relationship. Interviewees offered us conflicting overall assessments of the collaboration:

“...initial goals have been fulfilled to an acceptable degree [...] Our team has achieved quite interesting results, even patentable [...] if the LF needs our services in future, we will collaborate together (CRAI's head engineer of the project)

“...research organizations must provide technological solutions to firms. However, the CRAI has not proposed anything [...] We will not collaborate with them again" (LF's R\&D Manager)

By comparing the description of objectives of the consortium's report with the presentation made by the CRAI in a consortium Scientific and Technical Committee (July 2010), we obtained objective information confirming that the initial objectives of the CRAI-LF alliance had been unfulfilled. 


\subsubsection{Discussion: The OI-LF and CRAI-LF alliances as marriages}

In this section, we link our findings to relevant theoretical concepts and to our research question. We develop a process model for each studied ER\&D alliance, presented in Figure 4.1.1. Since metaphors are useful theory-building instruments (Weick, 1989) we elaborate on the so-called metaphor between alliances and marriages (e.g., Kanter, 1994) for the case of ER\&D alliances formed by unfamiliar partners. To that end, we endow the three lifecycle stages previously identified with sensemaking labels ('Honeymoon', 'Marriage restoration vs. crisis', and 'Marriage consolidation vs. divorce").

Figure 4.1.1. Co-evolution of psychological contracts and knowledge-sharing routines in ER\&D alliances formed by unfamiliar partners

\begin{tabular}{|c|c|c|c|}
\hline & Starting the alliance & Facing the first problems & Ending the alliance \\
\hline \multicolumn{2}{|l|}{ OI-LF alliance } & Marriage restoration & Marriage consolidation \\
\hline \multirow[t]{2}{*}{ Value } & $\begin{array}{l}\text { Perceived technological } \\
\text { complementarities }\end{array}$ & $\begin{array}{l}\text { Successful intermediate } \\
\text { outcomes }\end{array}$ & Alliance success \\
\hline & Value expectations & Value indicators & Joint realization of value \\
\hline \multirow{2}{*}{$\begin{array}{l}\text { Psychological } \\
\text { contracts }\end{array}$} & $\begin{array}{l}\text { 'Initial' Operational- } \\
\quad \text { incongruence }\end{array}$ & \multirow[t]{2}{*}{ Convergence } & 'Final' congruence \\
\hline & False consensus effect & & Shared psy. contract \\
\hline \multirow{2}{*}{$\begin{array}{l}\text { Knowledge- } \\
\text { sharing } \\
\text { routines }\end{array}$} & $\begin{array}{l}\text { First knowledge-sharing } \\
\text { interactions }\end{array}$ & $\begin{array}{l}\text { Effective knowledge- } \\
\text { sharing interactions }\end{array}$ & $\begin{array}{l}\text { Effective knowledge-sharing } \\
\text { interactions }\end{array}$ \\
\hline & First routine iterations & Routines are created & Routines are consolidated \\
\hline \multicolumn{2}{|c|}{ CRAI-LF alliance } & Marriage crisis & Divorce \\
\hline \multirow{2}{*}{ Value } & $\begin{array}{l}\text { Perceived technological } \\
\text { complementarities }\end{array}$ & $\begin{array}{l}\text { Failed intermediate } \\
\text { outcomes }\end{array}$ & Alliance failure \\
\hline & $\begin{array}{l}\text { Value-creation } \\
\text { expectations }\end{array}$ & No indicators of value & No joint value realizatio ph \\
\hline \multirow[t]{2}{*}{$\begin{array}{l}\text { Psychological } \\
\text { contracts }\end{array}$} & $\begin{array}{c}\text { 'Initial' strategic } \\
\text { incongruence }\end{array}$ & Divergence & 'Final' incongruence \\
\hline & $\checkmark$ 'False consensus effect' & 'False jqint sensemaking' & Non-shared psy. Contrałt \\
\hline \multirow{2}{*}{$\begin{array}{l}\text { Knowledge- } \\
\text { sharing } \\
\text { routines }\end{array}$} & $\begin{array}{l}\text { First knowledge-sharing } \\
\text { interactions }\end{array}$ & $\begin{array}{l}\text { Ineffective knowledge- } \\
\text { sharing interactions }\end{array}$ & $\begin{array}{c}\text { No knowledge-sharing } \\
\text { interactions }\end{array}$ \\
\hline & First routine iterations & Routines are created & Routines are retired \\
\hline
\end{tabular}




\subsubsection{Starting the alliance: The honeymoon period}

('Start-up’ stage, January-December 2008)

Existing literature suggests that the beginning of collaboration between unfamiliar partners is likely complex due to relational dissimilarities (e.g., Parkhe, 1991). Our empirical evidence tells a different story, closest to the Fichman and Levinthal's (1991) perspective that relationships start with favorable expectations resulting in a honeymoon period.

In both the OI-LF and CRAI-LF, we observed that partners were willing to share knowledge relatively frequently and intensively. This observation challenges Inkpen's (1998: 225) arguments that unfamiliar partners "will be hesitant to share knowledge" until the "alliance survives the critical 'honeymoon' period" (Emphasis added). The partners of the studied alliances experienced a 'love at first glance' in the open solicitation meeting of the consortium, which triggered a rapid 'commitment to marriage'. Partners' positive perceptions about their mutual technological complementarities triggered great value-creation expectations with the collaboration, on the basis of which they subsequently started to get known each other. In this regard, our data show that the first knowledge-sharing interactions emerge as proactive routine-building efforts (Winter, 2003): The first knowledge-sharing interactions were the result of purposeful learning investments made by the two partners in each studied alliance and motivated by perceived technological complementarities. However, we observed that the routines had not been already created during the first year of collaboration, for two interconnected reasons: this initial exchange of knowledge had not reached a minimum level of functionality [i.e., a stable pattern of inter-partner interactions cannot be identified (Helfat \& Peteraf, 2003)] and knowledge exchange did not prove effective, although perceived as satisfactory by the partners (Zollo et al., 2002). In this regard, we observed that these first knowledge-sharing interactions corresponded to 'the first routine iterations' (Feldman, 2000) and that the founding stage of the routines lifecycle took place during the first year of collaboration, paving the way for further development (Helfat \& Peteraf, 2003) ${ }^{18}$.

Moreover, although first routine-building efforts developed smoothly in both studied alliances, we retrospectively observed that partners brought to the collaboration divergent beliefs about their reciprocal obligations. As discussed, previous research has stated that psychological contracts incongruence is likely an initial condition of alliances formed by unfamiliar partners. Our data on the OI-LF and CRAI-LF

\footnotetext{
${ }^{18}$ Helfat and Peteraf (2003) develop a lifecycle approach that explains the developmental paths of capabilities across three stages: founding (basis for further capability-building), development (gradual building of the capability), and maturity (capability-building ceases). We apply here this lifecycle approach to the case of routines, relying in the conceptualizations of capabilities as 'collections of routines' and routines as the 'constituent elements of capabilities' (e.g., Winter, 2003).
} 
alliances allows us to provide a more comprehensive view of the phenomenon. At the beginning of the OI-LF and CRAI-LF alliances, we observed that the LF's R\&D Manager sought to achieve industrially applicable results (respectively, protein products and natural pigments for fish nutrition), in the pursuit of competitive advantage. Accordingly, he displayed a flexible contract application behavior during the collaboration (i.e., moving from exploration to exploitation and taking each alliance's formal objectives as starting references). To that end, he perceived that frequent and intense knowledge-sharing with continuous feedback was required. The OI's head researcher sought to apply his technological expertise in commercial products to help the LF improve its competitive position, thinking that providing periodical feedback was sufficient to that end. By contrast, the CRAI's head engineer of the project sought to apply her technological expertise in experimenting with high innovative processes, taking the formal objectives as the route to follow. Following the philosophy of her center (e.g., 'open door'), she considered that providing continuous feedback was necessary to help the LF to discover new technological opportunities.

Given these observations, we adapt the proposal of Sarkar at al. (2001) to make a conceptual distinction between two kinds of 'initial' psychological contract incongruence: operational and strategic. This distinction represents an important theory-building contribution since, as discussed later on, it allows us to explain under which circumstances initial tensions between the unfamiliar partners' psychological contracts may prevent realization of value in ER\&D alliances. As occurred in the OI-LF alliance, operational psychological contract incongruence originates when partners envisage the pattern of interaction in the alliance in different ways (i.e., how to collaborate) and, consequently, their initial beliefs about their reciprocal obligations differ (e.g., continuous vs. periodical feedback). As showed by the CRAI-LF alliance, strategic psychological contract incongruence is rooted in different interpretations of the purpose of the alliance (i.e., why to collaborate), which generates a situation in which partners' initial beliefs about their reciprocal obligations in the alliance differ (e.g., moving-to-exploitation vs. exploration).

Interestingly, we observed in the two studied alliances 'initial' psychological contract incongruence, whether operational or strategic existed but remained in a 'latent' state (i.e., was not perceptible for the partners) within the honeymoon period. For example, in the CRAI-LF alliance, the LF proposed a 'moving-to-exploitation' solution to deal with initial failure (i.e., starting experiments with artificial pigments), whereas the CRAI proposed an 'exploration-oriented' solution (i.e., continuing with natural pigments). Consequently, our study reveals that 'initial' psychological contract incongruence did not involve a barrier for the first knowledge-sharing interactions between the unfamiliar partners. The notion of 'false consensus effect' (i.e., tendency of individuals to overestimate the degree to which other believe as they do) from the psychological contracts literature (Morrison \& Robinson 1997; 2004) provides a 
compelling explanation for this question. Our data on the OI-LF and CRAI-LF alliance shows that partners were subjected to a 'false consensus effect' insofar they overlooked the possibility of divergent beliefs about either the operational or strategic aspects of the collaboration. The psychological contracts literature points to 'excitement' as one possible root of the 'false consensus effect' (e.g., Morrison \& Robinson, 1997). Accordingly, signals that emerged from the initial knowledge-sharing interactions between the partners, as usually corresponds to any 'couple in love', were received by each partner as confirmations of the initially perceived technological complementarities (Doz, 1996). The positive impressions of the LF after visiting the ROs' facilities for the first time are illustrations of these arguments (i.e., the LF became impressed by the cutting-edge technology of the OI's pilot plant and the CRAI's environment-friendly SF technology). Therefore, we observed that in the presence of high perceived technological complementarities, partners' judgments about the ongoing collaboration could be clouded and indicators of initial tensions between their psychological contracts thus could be overlooked.

The above discussion gives rise to the following proposition:

Proposition 1. In ER\&D alliances formed by unfamiliar partners, perceived technological complementarities trigger first knowledge-sharing interactions, even in the presence 'initial' psychological contract incongruence (and either it is of operational or strategic nature).

\subsubsection{Facing the first problems: Marriage restoration vs. crisis}

('Execution' stage, January-December 2008)

As prior literature suggests (Fichman \& Levinthal, 1991; Gioia \& Chittipeddi, 1991; Deeds \& Rothaermel, 2003), the first marital problems emerged after a year of collaboration in both alliances under study, experiencing therefore the end of the honeymoon period. In particular, we observed that knowledge-sharing interactions provided a guide to retrospectively evaluate the relationship by comparing early indicators of value creation with initial expectations. We also observed that the OI-LF alliance was successfully restored, whereas the CRAI-LF alliance went irreversibly in crisis. We explain these differences relying in the notions of sensemaking (e.g., Gioia \& Chittipeddi, 1991) and breach/violation of the psychological contract ${ }^{19}$ (e.g., Morrison \& Robinson, 1997).

In the OI-LF alliance, we observed that knowledge-sharing interactions first allowed individual sensemaking at the LF and subsequently successful joint sensemaking, eliciting two parallel and

\footnotetext{
${ }^{19}$ Following Morrison and Robinson (1997), breach of the contract refers to the cognition that one's partner has failed to meet one or more obligations within one's psychological contract, whereas violation of the contract involves a negative affective state that follows a perceived breach and emanates from the feeling that one has been betrayed or mistreated (encompassing negative feelings like disappointment, frustration, anger and indignation).
} 
interrelated processes: convergence in partners' psychological contracts and gradual development of effective knowledge-sharing routines. From a meeting in which partners discussed the achievements of the first year of collaboration, the LF's R\&D Manager perceived that the pattern of interaction the OI had been showing differed from the required to achieve industrially applicable results. Put differently, his psychological contract experienced a breach (Morrison \& Robinson, 1997; Hill et al., 2009), the LF's R\&D Manager realized that both partners held conflicting perceptions about their mutual knowledgesharing obligations and thus the 'false consensus effect' ceased. Through subsequent knowledge-sharing interactions, both partners engaged in successful joint sensemaking: the OI's Head researcher realized that providing the LF with more frequent feedback was a sine qua non condition to attain the shared objective (i.e., doing real applied research). Consequently, tensions between each partner's psychological contracts gradually disappear. An indicator of this process of psychological contracts convergence was the fact that the OI's head research highlighted the necessity of more frequent inter-partner discussions (although at first he showed less proactive for knowledge sharing) when LF proposed extending the contract with new technical objectives. The behavior and proofs of commitment showed by the OI in turn restored the perceived breach, and the implemented adjustments subsequently produced the desired effects, triggering positive reinforcing cycles. In parallel, knowledge-sharing interactions became increasingly more frequent and intense, mutual understanding developing at both organizational and individual levels as a result. Early conflicts thus proved to be "the best thing that happened in the alliance" (Das \& Kumar, 2010: 22).

By contrast, in the CRAI-LF, we observed that knowledge-sharing interactions triggered individual sensemaking at the LF, which however ended up in unsuccessful joint sensemaking, in turn eliciting increasing divergence in partners' psychological contracts and ineffectiveness of knowledge-sharing routines. Assessing the achievements of the first year of collaboration described in the report, the LF's R\&D Manager concluded that CRAI had not been making the required level of effort to attain the desired results. He still thus assumed that CRAI shared the same beliefs about their mutual technological obligations in the alliance (instead of considering if the CRAI people were making pure explorative efforts). Therefore, knowledge sharing had not dispelled the 'false consensus effect'. In this context, subsequent knowledge-sharing interactions triggered a false joint sensemaking effect: partners discussed and applied adjustments, and continued exchanging knowledge in a frequent, intense, and willing manner, but the underlying logics of these processes were different for each of them. As a result, attempts to adjust the alliance successively failed creating a negative spiral of conflicts in the relationship (Kumar \& Nti, 2004). Put differently, the LF's R\&D Manager psychological contract experienced successive perceived breaches, ending up in a violation feeling. Consequently, tensions between the partners' psychological 
contracts became increasingly stronger, since sustained conflicts "may exacerbate the already existing interpretive contradictions" (Das \& Kumar, 2010: 28). Indicators of this divergence process between the partners' psychological contracts were complaints of the LF's R\&D Manager about the last meetings organized by the CRAI, arguing that their format does not accommodate the 'discussion necessities of the project $^{20}$.

In both alliances under study we observed that routine-building efforts continued, resulting in frequent, intense, and willing knowledge-sharing interactions that reached a threshold level of functionality, characteristic of the development stage of the routines lifecycle (Helfat \& Peteraf, 2003). We can affirm, therefore, that knowledge-sharing routines were created during the second year of collaboration in both alliances. Our data on OI-LF alliance clearly shows that this routine-building process proved to be effective insofar partners gradually assimilated and apply new knowledge, yielding some early indicators of joint realization of value (e.g., technical success, extension of the collaboration beyond the focal agreement). These findings support the arguments that routines may change as a result of routine actors' reflections and reactions to outcomes of previous iterations of the routine (Feldman \& Pentland, 2003). As predicted by these authors, we observed that partners in the OI-LF alliance first repaired their routines (i.e., increasing frequency) to obtain the desired outcomes and subsequently extend the routines (i.e., increasing intensity) to take advantage of emergent opportunities. The CRAI-LF alliance, however, reveals that high levels of knowledge-sharing frequency, intensity and willingness may not be an indicator of the effectiveness of the created routines. Rather the opposite, we identified no indicators of joint value creation in this alliance during this period. This pattern of knowledge-sharing interactions can also reflect, paraphrasing the LF's R\&D Manager, the process of 'refloating a ship that is sinking' during which 'frustrating misunderstanding' between partners may be the norm. Therefore, purposeful learning investments in the form of knowledge-sharing interactions can also be motivated by decreases in valuecreation expectations. Furthermore, although the psychological contracts literature argues that knowledgesharing "is important for reducing incongruence because [...] it can help to dispel the false consensus effect" (Morrison \& Robinson, 2004: 176), the studied alliances show that this role of knowledge-sharing is contingent on the type of 'initial' incongruence.

Based on the above discussion, we propose:

\footnotetext{
${ }^{20}$ We did not observe, however, negative behaviors of the CRAI. Violation me be rooted in either incongruence or reneging (i.e., knowingly failing to fulfill an obligation) but even when the former is the real cause, a party may assume that the other purposefully reneged on a promise (Morrison \& Robinson, 1997). In retrospect, we observed that these last meetings could not accommodate the idiosyncrasy of the project as understood by the LF but could be adequate according to the CRAI's interpretative framework (i.e., taking the leap into exploitation would have required more intense discussions than a pure explorative research).
} 
Proposition 2. In ER\&D alliances formed by unfamiliar partners, effective knowledge-sharing routines are created and partners' psychological contracts converge if 'initial' psychological contract incongruence is of operational nature.

Proposition 3. In ER\&D alliances formed by unfamiliar partners, ineffective knowledge-sharing routines are created and partners' psychological contracts diverge if 'initial' psychological contract incongruence is of strategic nature.

\subsubsection{Ending the alliance: Marriage consolidation vs. divorce}

('Termination’ stage, December 2009-December 2010)

After two years of collaboration, we observed marriage consolidation in the OI-LF alliance, whereas the CRAI-LF alliance ended up in divorce. The studied alliances show that partners assess the convenience of continuation based on the previous course of the marriage and that "it would take a number of unsatisfying experiences to motivate a decision to divorce" (Fichman \& Levinthal, 1991: 450).

The story of the CRAI-LF alliance shows that continued dissatisfaction lead to "lessened commitment and to the alliance withering away over time" (Ariño \& Doz, 2000: 173-174). We observed that partners experienced a separation period during the last year of collaboration, before getting divorced. Although prior research predicts premature alliance dissolution for such kind of collaborative trajectories (e.g., Olk \& Young, 1997; Kumar \& Nti, 2004), the LF and CRAI continued linked to each other until the formal contract expired. In this regard, our study confirms that completion of the agreed period is not a good indicator of alliance success (e.g., Gulati, 1998; Reuer \& Zollo, 2005) ${ }^{21}$. Furthermore, this separation period entailed a a divestiture process, directly affecting the further development of the knowledgesharing routines. Frequent and intense knowledge-sharing interactions no longer existed during the last year of the CRAI-LF alliance, confining to occasional exchange of administrative information. As the LF's R\&D Manager stressed, it was the result of a proactive decision: the LF was no longer willing to maintain the previous pattern of interaction with CRAI. Our data clearly shows that, when the last year of collaboration started, the LF's perceived that the possibility of realize value from partners' technological complementarities had already fall under the minimum threshold. Such a value-creation expectations collapse discouraged the LF from committing resources to the alliance, as predicted by the literatures in alliance processes (e.g., Doz, 1996), and inter-organizational routines (e.g., Dyer \& Nobeoka, 2000)). From a routine-building perspective, these findings support the arguments that the internal dynamics of

${ }^{21}$ Indeed, the LF's R\&D Manager explained that the alliance with CRAI had not been terminated prematurely beacuse of 'inertia' and 'opportunity costs', corroborating that an alliance "may be continuing more out of inertia or the high exit costs associated with dismantling it" (Gulati, 1998: 307). 
routines are themselves sources of change (Feldman \& Pentland, 2003) and that, in particular, changes in underlying expectations may elicit the gradual retirement (or retrenchment) of the created routines (Helfat $\&$ Peteraf, 2003 ${ }^{22}$. As predicted by prior research, the significant reduction of knowledge exchange between the CRAI and the LF in turn impeded definitively joint realization of value and positioned the partners' psychological contracts in a permanent state of incongruence. Clear indicators of this 'final' psychological contract incongruence were the conflicting beliefs that the interviewees from each organization manifested about the status of the relationship and the degree of alliance success. For example, the LF's R\&D Manager described the alliance as 'an absolute failure' that had not provided useful results. By contrast, the CRAI's engineer referred to it as 'a non-failed project' that had explored a very innovative line of research obtaining thus interesting (even patentable) results, since viability of some avenues for further work had been clarified.

Conversely, in the OI-LF alliance, the favorable experiences accumulated during the previous course of the collaboration enhanced perceived technological complementarities, encouraging both partners to continue committing resources to the collaboration (even beyond the focal alliance) and, in particular, to the development of their knowledge-sharing routines. These 'purposeful learning investments' (Zollo \& Winter, 2002) allowed partners to consolidate their effective inter-organizational routines ${ }^{23}$, resulting in joint value creation (e.g., co-patent) and, simultaneously securing their psychological contracts in a state of congruence. The extension of the (written) contract itself illustrates such a state of congruence. On the one hand, the partners signed a formal extension of the existing contract but they informally agreed on that collaboration in the subsequent period would involve tasks other than those involved in the consortium project (i.e., technical support for the LF's day-to-day activities, technology watch). On the other hand, this contract extension would not involve additional fees for the LF since it represented, in practice, the continuation of the psychological contract in place, and thus developing industrial applicable results remained as the 'real' (implicit) objective of the collaboration. Moreover, according to Helfat and Peteraf (2003), we observed that partners respond to the opportunity to extend the collaboration beyond the focal alliance by transferring and adapting their knowledge-sharing routines to the new collaborative context. The above discussion supports the following propositions:

\footnotetext{
${ }^{22}$ According to the Helfat and Peteraf's (2003) lifecycle model, during the development stage or once maturity is reached, routines may branch into different developmental pathways, which involve further investment (renewal, replication, redeployment), gradual divestiture (retrenchment), or even the death of the routines (whole retirement).

${ }^{23} \mathrm{We}$ do not assume that the routine-building process ceased (which occurs in the maturity stage). A routine may have reached a threshold level of functionality but not its highest possible development level (Helfat \& Peteraf, 2003).
} 
Proposition 4. In ER\&D alliances formed by unfamiliar partners, psychological contract congruence leads to consolidation of knowledge-sharing routines that in turn triggers joint realization of value.

Proposition 5. In ER\&D alliances formed by unfamiliar partners, psychological contract incongruence leads to retirement of knowledge-sharing routines that in turn hampers joint realization of value.

\subsubsection{Conclusion and implications}

This study provides a marked process-oriented perspective on the value-creation dynamics of ER\&D alliances formed by unfamiliar partners, exploring how the creation of inter-organizational knowledgesharing routines and partners' psychological contracts co-evolve over time. By comparing two alliances (one successful and other failed), our study concludes that (1) that perceived technological complementarities trigger the first iterations of the knowledge-sharing routines, (2) the development of effective knowledge-sharing routines is contingent on the nature of the initial tension between each partner's psychological contracts and (3) when psychological contracts experience a process of convergence, knowledge-sharing routines allow joint realization of value at both technological and relational levels. Consequently, this study yields some important implications.

\subsubsection{Implications for research}

This study makes several research contributions. First, this study reconciles the postures of the two main streams of research in the literature of ER\&D alliances formed by unfamiliar partners. As argued by alliance formation scholars (e.g., Beckman et al., 2004; Goerzen, 2007), we find that technological complementarities between unfamiliar partners proved highly relevant in explaining success in ER\&D alliances. However, our findings are also in line with alliance management scholars, (e.g., Rothaermel \& Deeds, 2006; Li et al., 2008). We find that relational dissimilarities between unfamiliar partners may impede value realization in ER\&D alliances, by constraining the establishment of the adequate patterns of interaction. Therefore, our findings complements those from other integrative studies like Gulati et al. (2009), revealing that knowledge-sharing processes themselves can alleviate relational dissimilarities (in the particular form of psychological contracts incongruence), when unfamiliar partners hold, from the beginning of the collaboration, shared beliefs about their reciprocal obligations concerning the strategic aspects of the alliance.

Second, this study extends the literature linking the fields of psychological contracts and strategic alliances (e.g., Ring \& Van de Ven, 1994) mainly developed in the context of buyer-supplier relationships (e.g., Hill et al., 2009), into the field of ER\&D alliances formed by unfamiliar partners. On the basis of our findings, we have offered a conceptual categorization of incongruence between partners' psychological contracts (operational vs. strategic) that echoes the dual ontology of collaborative 
phenomena and may be useful to explain how initial tensions between the unfamiliar partners may prevent them from building effective routines and thus from realizing value in ER\&D alliances.

Third, this study contributes to explain how inter-organizational knowledge-sharing routines are created and how this routine-building process evolves across the founding and development lifecycles stages (Helfat \& Peteraf, 2003). Our evidence concludes that first routine-building efforts are motivated by perceived technological complementarities and that the subsequent creation of effective interorganizational knowledge-sharing routines provides to partners collective platforms to exploit future technological opportunities (Kogut \& Kulatilaka, 1991; McCarter et al., 2011). However, effectiveness is not an automatic occurrence from frequent, intense, and willing knowledge-sharing interactions between the unfamiliar partners but a much more complex unfolding story in which tensions between partners' psychological contracts play a key role. Therefore, this study addresses calls for clarifying the building process of alliance capabilities (De Man et al., 2010), since knowledge-sharing routines are one of the most important constituent elements of the partners' capability to collaborate together. In doing so, our study suggest to rethink the conceptualization of alliance capabilities (e.g., Simonin, 1997; Sarkar et al., 2009), by including skills directly related to the identification and management of tensions between partners' psychological contracts.

\subsubsection{Implications for practice}

Based on the above discussion, we offer some recommendations for managers involved in the formation and management of ER\&D alliances formed by unfamiliar partners. In the failed CRAI-LF alliance, we have observed that if managers had restarted the 'psychological contracts clock' (Ring \& Van de ven, 1994), they probably would have been able to avoid the false consensus effect and the subsequent false joint sensemaking, which in turn seriously deteriorated their opportunity to extract value from the collaboration. Therefore, managers need to be aware of the notion of psychological contracts and of its influence on the creation of adequate patterns of interaction, considering that (a) the psychological contracts of each partners' representatives are likely to differ not only from the formal contract but also from each other, and (b) psychological contract incongruence may render knowledge-sharing interactions useless. Unlike what we observed in the failed CRAI-LF alliance, these managerial actions could represent the first step in the ability to manage the tensions between partners' psychological contracts, to effectively share knowledge, and thus to discover new technological opportunities.

\subsubsection{Limitations}

Our findings are based on an in-depth longitudinal study of two ER\&D alliances formed by the same firm and two different ROs within the context of a larger R\&D consortium (i.e., the Acuisost Consortium). 
Although this research design has allowed us to minimize the risk of extraneous variation (e.g., formal contracts were very similar in both cases) and thus to make a reliable comparison of the two alliances, our findings are clearly contextualized. Thus, we deduced from our data that when the tension between partners' psychological contract is located on the strategic aspects of the collaboration, it may remain invisible eventually eliciting a negative spiral. However, we cannot assume this to happen in other collaborative settings. For example, divergent beliefs may emerge during negotiations that take place before formalizing alliances. However, the partners of the studied alliances did not engage in such a process of bilateral negotiation, due to the idiosyncrasy of the Acuisost Consortium.

\subsubsection{Future research}

Based on the above discussion, we identify some interesting avenues for further research, beyond the large-sample test of our induced model. In line with the limitations of the study, it could be interesting to compare the co-evolution of knowledge-sharing routines and psychological contracts in ER\&D alliances formed by different kinds of unfamiliar partners (e.g., firm-firm vs. firm-RO alliances), as well as between different collaborative settings (e.g., ER\&D alliances within a larger consortium vs. 'independent' alliances). Another promising avenue for further research could be assessing the tensions between unfamiliar partners' psychological contracts and formal contracts in ER\&D alliances, extending thus the work initiated by Lumineau and Fréchet (2008). 


\subsection{Study II.1.: How do Exploitative and Explorative R\&D Alliances between Familiar Partners Succeed? Real Options Reasoning and Knowledge-Sharing Routines Redeployment ${ }^{1}$}

\subsubsection{Introduction}

R\&D alliances have become essential strategic tools for firms to bring about innovation in uncertain and complex environments, by providing opportunities either to leverage existing capabilities (exploitative R\&D alliances) or to discover new technological opportunities (explorative R\&D alliances) (Koza \& Lewin, 1998; Lavie \& Rosenkopf, 2006). By their very nature, however, $R \& D$ alliances entail high level of risk, not only concerning performance but also in relational terms (Das \& Teng, 1998). This situation magnifies the gap between the value potential offered by $R \& D$ alliances and the effective realization of value, being the latter in turn contingent upon the capability of the partners to collaborate together (Madhok \& Tallman, 1998). Therefore, R\&D alliances between familiar partners- those counting on a history of mutual interactions (Granovetter, 1973; Beckman et al., 2004)- seems to offer some potential advantages. In this context, many firms resort to familiar partners for $R \& D$ collaboration, as observed in empirical literature (Hoang \& Rothaermel, 2005; Gulati et al., 2009; Hoang \& Rothaermel, 2010).

Recent research has started to challenge the traditional 'paradox of embeddedness' (Uzzi, 1997), which predicts that familiar partners are likely to succeed at exploitation and to fail at exploration, emphasizing the notion of collaborative routines as the founding dimensions of the partners' capability to collaborate together (Dyer \& Singh, 1998; Zollo et al., 2002). The underlying logic is that familiar partners develop patterns of interaction out of accumulative mutual experiences which, when iteratively implemented and refined, may end up in a set of inter-organizational routines that allow effective resources exchange, joint work, coordination, and problem solving (Zollo et al., 2002). Therefore, adequate inter-organizational routines, especially those related to knowledge-sharing ${ }^{2}$, may increase the likelihood of success of familiar partners at both exploration and exploitation. Compelling evidence in this regard is provided by recent studies like Zollo et al. (2002), who show that prior partner-specific experience increased the performance of subsequent alliances with the same partner, and

\footnotetext{
${ }^{1}$ Useful comments and suggestions have been provided by Gabriel de la Fuente, Dries Faems, as well as by the participants of the PhD Seminar 'Business Econimics' (University of Valladolid) (see Scientific Diffusion section at the end of the dissertation).

${ }^{2}$ These routines can be defined as recurrent patterns of inter-partner interactions that, when effective, permit the mutual transfer, recombination and/or creation of specialized knowledge in the alliance (Dyer \& Singh, 1998; Dyer \& Nobeoka, 2000).
} 
Tiwana (2008), who shows that strong ties among partners facilitate knowledge integration which in turn furnishes likelihood of successful alliance ambidexterity (i.e., concurrence of exploration and exploitation). However, empirical research has not always provided conclusive evidence in the regard. On a broad context, studies like Goerzen (2007) remain finding that repeated alliances with the same partner decrease firm's economic performance. In the context of $R \& D$ alliances, some studies conclude that explorative $R \& D$ alliances between familiar partners are likely to succeed only when partners are able to provide each other novel knowledge (e.g., Gulati et al., 2009), whereas the findings of other studies suggest that routines arising from prior experience between alliance partners simply are not relevant in explaining innovation success (Hoang \& Rothaermel, 2005; Phelps, 2010).

From our point of view, prior research into $R \& D$ alliances between familiar partners has provided such ambiguous evidence mainly because it has adopted structure-oriented static designs, thus has not directly looked at the processes of collaboration (Ring \& Van de Ven, 1994; Salk, 2005) on two levels. First, prior research has tended to focus on a specific R\&D agreement between a pair of familiar partners, overlooking that this focal alliance is embedded in a broader collaborative relationship. In doing so, it has neglected relevant interactions among the shadow of the past- partners' history of prior interactions- (Poppo, Zhou, \& Ryu, 2008), the shadow of the future- expected future join alliances- (Parkhe, 1993), and the shadow of the present-concurrent relationships between the partners- (Gulati, 1998). Second, existing research has not unveiled how familiar partners, having already created the capability to collaborate together, leverage their mutual collaborative experience when they form a new R\&D alliance. More specifically, it is still unknown the process by which familiar partners jointly transfer the inter-organizational knowledge-sharing routines they have created through their accumulated mutual experiences into a new joint collaborative scenario. We refer to this process as redeployment of knowledge-sharing routines, adapting the concepts of bilateral resource redeployment (Capron \& Mitchell, 1998) and capability redeployment (Helfat \& Peteraf, 2003) to our research context.

In the setting of R\&D collaboration, knowledge-sharing routines are one of the most important constituent elements of the partners' mutual collaborative capability (Zollo et al., 2002). Therefore, if exploitation involves "using currently available information to improve present returns" (March, 1991: 71-72) and exploration requires "gaining new information about alternatives and thus improving future returns" (March, 1991: 71-72), the stronger the routinization of inter-partner interactions, the higher the likelihood to succeed. Seeking to elucidate the value dynamics of $R \& D$ alliances between familiar partners, this study adopts a markedly process-oriented perspective to address the research question of How do familiar 
partners can realize joint value in explorative of exploitative $R \& D$ alliances by redeploying their existing knowledge-sharing routines?

To address this research question, we conduct a longitudinal comparative case study on two successful R\&D alliances (one exploitation-oriented and the other exploration-oriented) formed by two pairs of familiar partners with long histories of interactions. Rather than conceiving these two R\&D alliances as independent collaborative endeavors, we take the collaborative relationship of each pair of familiar partners as the unit of analysis, and analyze the interactions between the processes of redeployment and value realization in each focal R\&D alliance and the broader collaborative relationship of each pair of familiar partners.

Adopting an inductive theory-building approach (Eisenhardt, 1989), we interpret our findings by bridging the literatures on inter-organizational routines (Dyer \& Singh, 1998; Zollo et al., 2002) and real options (Myers, 1984; Kogut \& Kulatilaka, 2001). The conceptualization of firm strategy as a chain of real options (Bowman \& Hurry, 1993) offers an adequate dynamic perspective to study the process of routines redeployment. Under this optic, R\&D alliances between familiar partners are viewed as rather integrated in broader platforms of embedded collective real options (Kogut, 1991; McCarter et al., 2011) than as independent collaborative settings. Furthermore, as Kogut and Kulatilaka (2001) stress, framing capabilities (and thus routines) as real options, guides the interpretation of the learning balance between exploitation and exploration. In this regard, the conceptual analogy between the exploration-exploitation of collaborative opportunities and the acquisition-exercise of collective real options guides the study of redeployment of familiar partners' routines and its implications for value realization.

In this line, our study shows that familiar partners may realize joint value in both exploiting and exploring technological opportunities by abstractly conceptualizing (and thus redeploying) their routines as ambidextrous mechanisms, allowing them to deal with the flexibility-uncertainty trade-off over time. Furthermore, our study shows that managerial cognition is more relevant in explaining heterogeneity in both routines redeployment and realization of joint value across alliances than the formal seeking-orientation of a focal $R \& D$ alliance between familiar partners.

The remainder of the study is organized as follows. Next section presents the conceptual background. After describing the research design and methodology of the study, we move on to data analysis. Subsequently, we elaborate further on this evidence and discuss the theorybuilding contributions of the study. Finally, we present the main conclusions, implications and limitations of the study, as well as some avenues for further research. 


\subsubsection{Conceptual background}

\subsubsection{R\&D alliances from real options reasoning}

Real options reasoning (ROR) "is a conceptual approach to strategic investment that takes into account the value of preserving the right to make future choices under uncertain conditions" (McGarth \& Nerkar, 2004: 1), by exploiting the analogy between financial and real options. A real option "is the investment in physical assets, human competence, and organizational capabilities that provide the opportunity to respond to future contingent events" (Kogut \& Kulatilaka, 2001: 745). The logic of ROR lies in two main assumptions. First, the rent-creating potential of a firm is akin not only to the rents that are expected to be generated over time by already deployed resources but also to any subsequent redeployment the firm might make, which in turn derived from prior resource investments (Bowman \& Hurry, 1993; De AndrésAlonso, et al., 2006). Second, the optimal investment strategy allows the firm to maximize the value of its portfolio of present and future opportunities.

In this regard, ROR is a powerful tool for explaining strategic decision-making in response to uncertainty (Bowman \& Hurry, 1993). In particular, R\&D strategies have been characterized as real options because they furnish a proprietary right for the investing firm to make later decisions (such as to further exploit or to exit a particular technological area) either by involving initial foray into a new technological area (explorative R\&D) or deepening into a previously explored technology (exploitative R\&D) (McGrath, 1997) ${ }^{3}$. Likewise, alliances "are created as real options to expand in response to future technological and market developments" and thus "serve as platforms" (Kogut, 1991: 19; 32). Therefore, R\&D alliances belong to the category of strategic investments susceptible to be evaluated applying ROR (McGrath, Ferrier \& Mendelow, 2004). Existing research have provided important contributions in this regard (e.g., Folta, 1998; Vassolo et al., 2004).

From ROR, R\&D alliances are analogous to financial call options ${ }^{4}$ in the sense that they endow the firm with the right (not the obligation) to expand on the underlying technology at or before the expiration of the agreement. Therefore, the option embedded in R\&D alliances is of dual nature (Vassolo et al., 2004): R\&D alliances provide simultaneously a growth option to expand

\footnotetext{
${ }^{3}$ In this regard, works like McGrath and Nerkar (2004), Cassimon, Engelen, Thomassen and Wouwe (2004) and Hartmann and Hassan (2006) demonstrate that investments in R\&D of pharmaceutical firms are consistent with the logic of ROR. Similarly, Baldwin, Hienerth, and Hippel (2006) explore the product innovation process, from creation of new designs to their application in commercial products, arguing that "every new design is an option" and that technological uncertainty "justifies investment in multiple design searches" (p. 1296-1297).

${ }^{4}$ A call option conveys on the holder the right, but not the obligation, to buy an underlying asset (e.g., a stock, an index, another derivative) at a given price (strike price) and at some point in the future (expiration date).
} 
on future technological opportunities ${ }^{5}$ and a option to defer full commitment of resources to the underlying technology. Since technology investments are irreversible and risky, delaying the decision to full commitment represents a source of flexibility (Folta, 1998; Folta \& Miller, 2002). Flexibility derives from the incremental nature of the investment process in R\&D alliances, represented by the four-step option chain (Bowman \& Hurry, 1993) displayed in Figure 4.2.1.

The process starts in Step 1 with the recognition of shadow options or latent opportunities for technological collaboration. In Step 2, the firm acquires the option through R\&D alliance formation and thus ensure access to new technological opportunities at some point in the future, while committing a relatively small amount of resources (i.e., the cost of R\&D alliance formation is lower than the cost of directly purchasing/developing the technology).

Figure 4.2.1. The option chain for R\&D alliances from a dynamic perspective ${ }^{6}$

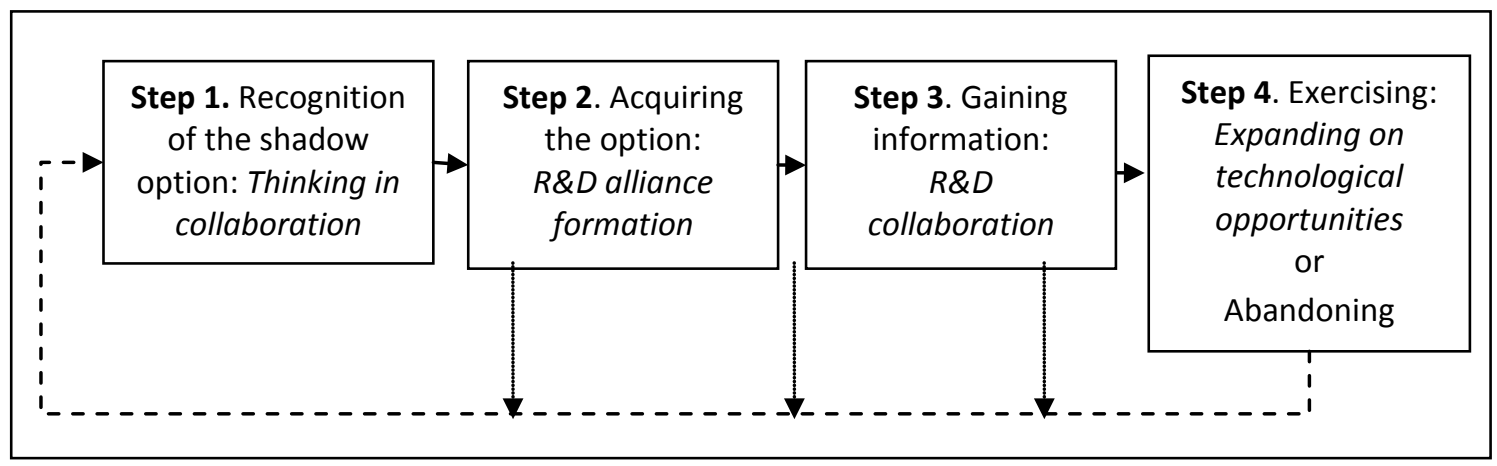

Source: Adapted from Bowman and Hurry (1993) and Estrada et al.(2010)

In Step 3, as collaboration evolves, the firm keeps the option 'open' seeking to gain more information about the convenience of expanding by making a larger commitment on the underlying technology. Holding the right to exercise the option the firm preserves all the potential upside rents by maintaining flexibility, while limiting potential losses to the initial investment. The firm undertakes the final decision concerning the option embedded in the R\&D alliance in Step 4: either exercise (if positive signals have emerged from the environment

\footnotetext{
${ }^{5}$ The nature of both the underlying technology and the associated growth option in turn varies between according to the innovation-seeking orientation of the alliance. In exploration-oriented $R \& D$ alliances the underlying technology represents a bundle of technological resources previously unavailable and the growth option main refers to discover new technological opportunities through collaboration. In exploitation-oriented R\&D alliances, the underlying technology represents a bundle of technological capabilities previously available but not fully developed, and the growth option refers to exploiting associated future technological opportunities.

${ }^{6}$ Notice that we offer a simplified view of strategy as an option chain. ROR suggests, as we will explain further regarding R\&D collaboration between familiar partners, the existence of a portfolio of real options interconnected to each other over time, each of these options possibly following such an option chain simultaneously.
} 
encouraging making a larger investment) or abandonment (if the signals from the environment discourage full commitment) (Kogut, 1991; Vassolo et al., 2004; Kumar, 2010).

Whatever this final decision, the firm has gained shared experiences with the partner of the $R \& D$ alliance, enhancing their capability to collaborate together and thus encouraging future collaborative agreements (i.e., new shadow collective options). Following McCarter et al. (2011), a collective real option is an action undertaken jointly by alliance partners when they agree to make a small initial investment of resources to uncover additional information about the possible success of a subsequent larger-scale alliance initiative.

\subsubsection{2. $R \& D$ alliances between familiar partners from real options reasoning}

Managers of familiar partners, when engaging into a new join $R \& D$ alliance, usually have in mind a larger inter-organizational picture, bringing together (a) the shadow of the past or their history of prior interactions (Poppo et al., 2008), (b) the shadow of the future or expected future alliances (Parkhe, 1993), and (c) the shadow of the present or other concurrent relationships (Gulati, 1998). In this regard, the 'scenario' in which collaboration with familiar partners is perceived to take place [i.e., the locus of collaboration (Powell et al., 1996)] does not confine to a specific focal $R \& D$ alliance but relates to an inter-temporal and multi-fold scenario, resembling the long-term and composite vision of strategy through the option lens (Bowman \& Hurry, 1993). Therefore, focal $R \& D$ alliances between familiar partners should be contextualized within a long-term chain (or portfolio) of embedded collective real options. As stressed by Vassolo et al. (2004), an emphasis on synergistic interactions across real options is needed to fully understand the configuration of options portfolios. In this regard, familiar partners can be said to have constructed a join incremental strategy of nested R\&D investments along their continuum of collaboration. In doing so, familiar partners usually have built a collaborative relationship of ambidextrous nature (Tiwana, 2008), balancing the tension between exploitation and exploration over time (March, 1991; Koza \& Lewin, 1998; Lavie \& Rosenkopf, 2006). Familiar partners can start, for instance, collaborating in exploitationoriented projects, and, once a join technological infrastructure is built, continue by searching new technological alternatives through exploration-oriented alliances.

\subsubsection{Real options reasoning and redeployment of inter-organizational routines}

From the above discussion, we argue that real options approach offers an adequate dynamic perspective to explain routines redeployment in the setting of $R \& D$ collaboration between familiar partners. At its core, ROR explains resource (re)deployment investments under uncertainty (Bowman \& Hurry, 1993; Adner, 2007). Routines represent thus sources of collective real options or joint investments in interaction patterns already undertaken by the 
familiar partners, whereas redeployment has to do with their choice made among the alternative opportunities (in turn afforded by the creation of such routines). Furthermore, ROR allows taking the inter-organizational level of analysis, conceiving $R \& D$ alliances between familiar partners as integrated in broader platforms of collective real options (Kogut, 1991; McCarter et al., 2011). In this regard, it is important to take into account that existing literature suggests that the process of routines redeployment may vary according to the innovation-seeking orientation: "The mindsets and organizational routines needed for exploration are radically different from those needed for exploitation" (Gupata, Simth, \& Shalley, 2006). Given these reasons, we identify three main points of integration of the real options and routines, useful for studying routines redeployment. Redeployment of routines thus refers to nested join decisions of acquiring, valuating and exercising collective real options on technological opportunities. Therefore, framing routines in terms of real options guides the interpretation of the learning balance between exploitation and exploration over time (Kogut \&Kulatilaka, 2001). Given these reasons, we identify three main points of integration of the real options and routines, useful for studying routines redeployment.

First, both literatures emphasize the importance of the collaborative relationship as the framework for the focal alliance, at different levels. Following Feldman and Pentland (2003) ${ }^{7}$, familiar partners' interpretation of what their routines are and what stand for is expected to influence the specific redeployment investments (i.e., executions of the routines) undertaken by the familiar partners in a focal alliance. Routines are context-dependent (Becker, 2004) thus the conceptualization of the inter-organizational routines is akin to the locus of collaboration hold by the familiar partners and thus contains the envisioned platform of collective real options. It thus follows that the redeployment undertaken by familiar partners in R\&D alliances is expected to be imbued with a real options reasoning. However, we do not know how exactly it occurs and how this redeployment process differs in exploration-oriented and exploitation-oriented R\&D alliances. Given the above discussion, this study aims to provide a richer understanding of the contribution of familiar partners' routines redeployment to joint value realization by exploring the first specific research question: How does the collaborative relationship influence redeployment of familiar partners' routines into a new focal $R \& D$ alliance?

\footnotetext{
${ }^{7}$ According to their framework, organizational routines consist of two interrelated aspects: the ostensive and the performative. Broadly speaking, "the ostensive aspect is the idea; the performative aspect is the enactment" (Feldman \& Pentland, 2003: 102). More specifically, the ostensive aspect is the abstract schematic conceptualization of a routine, whereas the performative aspect concerns the specific actions taken by the specific actors involved in the routine (See also Becker, 2004).
} 
Second, both literatures recognize that managerial cognition acts as a driver of strategic action. ROR envisions an active role for management over time: managers scan, map and track the environment on an ongoing basis, deciding what options should be acquired and continuously rethinking strategic implications of such decisions in terms of exercise (further commitment), waiting for more information (delay of further commitment) or abandonment (Bowman \& Hurry, 1993). From a dynamic capabilities view, cognition drives opportunity sensing and seizing, enabling some developmental trajectories and constraining others (Tripsas \& Gavetti, 2000; Teece, 2007; Rerup \& Feldman, 2011). In particular, redeployment of already created routines represents a reaction to a new perceived opportunity (Helfay \& Peteraf, 2003). This brings us to the critical role that managerial cognition plays in the routine-redeployment process: managerial cognitive schemata frame the portfolio of collective options envisioned by familiar partners and thus contain answers to questions such as 'what are the potential future allocations of our existing routines?' Therefore, it can be argued that managerial cognition is an important factor in explaining redeployment of routines, but we do not know exactly how it occurs and how this process differs in exploration-oriented and exploitation-oriented R\&D alliances. Given the above discussion, our second specific research question is: How does managerial cognition influences redeployment of familiar partners' routines into a new focal $R \& D$ alliance?

Finally, both literatures address the flexibility-uncertainty relationship, offering complementary perspectives on the phenomenon (e.g., Kogut, 1991; Pentland \& Rueter, 1994; Feldman \& Rafaeli, 2002; McCarter et al., 2011). A distinction can be made between two broad types of uncertainty in inter-organizational contexts [that echoes the alliance risk-based view (Das \& Teng, 1998)]: (a) social uncertainty (endogenous to the collaborative relationship), and (b) environmental uncertainty (exogenous to the collaborative relationship). Concerning social uncertainty, inter-organizational routines act as sources of connections and understandings between the partners, providing a guide on how to develop their patterns of interaction (Feldman \& Rafaeli, 2002). By a similar logic, partners can manage the social dilemma inherent to alliances by acquiring collective real options, and thus increasing simultaneously mutual trust, cooperation, and exposure (Faems \& Madhok, 2009; Faems \& Madhok, 2009; McCarter et al., 2011; McCarter et al., 2011). Concerning environmental uncertainty, scholars in the learning routines literature have emphasized the necessity of balancing the tension between exploration and exploration over time as way to achieve flexibility in uncertain contexts (e.g., March, 1991; Lavie \& Rosenkopf, 2006). In the real options literature, this ambidextrous flexibility has been framed in terms of acquisition of new real options and exercise of previously acquired real options (e.g., Kogut, 1991; McGrath \& Nerkar, 2004; Vassolo et al., 2004). 
Therefore, both literatures converge in the importance of balancing exploration and exploitation (put differently, the importance of following a real options strategic reasoning) to create value in uncertain environments. At the theoretical level, therefore, the conclusion is that redeployment of routines may yield such a necessary flexibility to deal with uncertainty and thus realize joint value. However, we do not know how this process occurs and how it differs in explorationoriented and exploitation-oriented R\&D alliances. Given the above discussion, our third specific research question is: How does redeployment of familiar partners' routines into a new focal $R \& D$ alliance contributes to managing uncertainty through flexibility and thus yields joint realization of value?

\subsubsection{Methodology}

\subsubsection{Research design and cases}

This study aims at theory-building to explain how familiar partners can successfully realize joint value in both exploitative and explorative R\&D alliances between familiar partners. To that end, we study longitudinally the redeployment processes occurring into two real-life R\&D alliances developed in the course of a larger R\&D consortium (i.e., The Acuisost Consortium), labeled CAH-LF and MAR-LF alliances (see Table 4.2.1).

Table 4.2.1. Main characteristics of the CAH-LF and MAR-LF alliances

\begin{tabular}{|c|c|c|}
\hline & CAH-LF Alliance & MAR-LF Alliance \\
\hline $\begin{array}{l}\text { Familiar } \\
\text { partners }\end{array}$ & $\begin{array}{l}\text { - } \text { Center for Animal Health (CAH) } \\
\text { - } \quad \text { Lead firm of the A.Consortium (LF) } \\
\text { - } \quad \text { Collaboration from } 1990\end{array}$ & $\begin{array}{ll}\text { - } & \text { Research group on Marine } \\
& \text { Resources (MAR) } \\
\text { - } & \text { Lead firm of the A.Consortium (LF) } \\
\text { - } & \text { Collaboration from } 2000\end{array}$ \\
\hline $\begin{array}{l}\text { Innovation- } \\
\text { seeking } \\
\text { orientation } \\
\text { (formal contract) }\end{array}$ & - Exploitation & - Exploration \\
\hline $\begin{array}{l}\text { Technical } \\
\text { objectives }\end{array}$ & $\begin{array}{l}\text { Developing on an industrial scale a } \\
\text { (previously explored) new pathogen- } \\
\text { detection methodology }\end{array}$ & $\begin{array}{l}\text { Obtaining vegetable proteins from } \\
\text { macro-algae and analyzing their } \\
\text { applicability for fish feed production } \\
\text { (new research line for the partners) }\end{array}$ \\
\hline $\begin{array}{l}\text { Horizon, } \\
\text { Budget }\end{array}$ & - 4 years, $220.000 €$ & - 4 years, $159.236 €$ \\
\hline $\begin{array}{l}\text { Key informants } \\
\text { (partners' } \\
\text { representatives) }\end{array}$ & $\begin{array}{l}\text { - CAH's Head (Head researcher of the } \\
\text { alliance) } \\
\text { - LF's R\&D Manager ( responsible } \\
\text { for the alliance) }\end{array}$ & $\begin{array}{l}\text { - MAR's Head (Head researcher of } \\
\text { the alliance) } \\
\text { - LF's R\&D Manager (responsible for } \\
\text { the alliance) }\end{array}$ \\
\hline
\end{tabular}

This research design can be considered appropriate for two main reasons (Eisenhardt, 1989). First, existing evidence is contradictory and ambiguous and, in particular, it is still unknown how familiar partners can successfully redeploy their knowledge-sharing routines in the context 
of innovation-seeking collaboration. Second, case study matches the nature of our 'how' research question, which deals with links between collaborative processes and its context, mobilizing multiple observations on complex relational processes which need to be traced longitudinally over time (Langley, 1999).

The two studied alliances were selected as our research setting following theoretical sampling criteria (Eisenhardt, 1989; Yin, 2003). First, both of them are R\&D alliances formed by familiar partners, thus they are representative of the phenomenon under consideration. As explained by LF's R\&D Manager in several interviews, the CAH (Center for Animal Health) and the MAR (the Research group on Marine Resources) were, at the inception of the Acuisost Consortium, the main "lifelong technological partners" of the LF. Second, both studied alliances were formed within the same larger context (i.e., The Acuisost Consortium) by the same firm- the lead firm of the consortium ${ }^{8}$ (LF) - and two different research organizations (ROs) -the CAH and MAR. That allows reliability in comparison, minimizing the risk of extraneous variation (Eisenhardt, 1989; Yin, 2003). For example, the formal contracts in the two alliances were highly similar. Furthermore, firm-RO alliances between familiar partners offer an adequate setting for studying not only exploitation but also exploration (i.e., applied technological capabilities vs. basic science capabilities, property intellectual protection vs. open science philosophy, and short-term problem-solving vs. long-term curiosity-driven research) (Bercovitz \& Feldman, 2007; Lacetera, 2009). To ensure rich variability in the phenomenon of interest, we followed the criterion of 'polar cases' (Eisenhardt, 1989) concerning the formal (contractual) innovation-seeking orientation of the alliances (exploitation in the CAH-LF alliance and exploration in the MAR-LF alliance). After all, existing literature suggests that the process of knowledge-sharing routines redeployment may vary according to the innovation-seeking orientation (Gupta et al., 2006).

\subsubsection{Data collection and analysis}

We follow the recommendations of Pettigrew (1990) and Pentland (1999), structuring our research efforts on two subsequent phases that went from surface to deeper levels of data collection and analysis. During the first phase (April 2008- October 2010), we collected overall information. This study emerged from a larger ongoing research project on the Acuisost Consortium. Although the first phase of data collection was not aimed specifically to compare

\footnotetext{
${ }^{8}$ Moreover, we concentrate on these two alliances formed by the lead firm of the Acuisost Consortium following theoretical sampling (Eisenhardt, 1989) and opportunity criteria (Gilbert, 2006): it guarantees enough commitment to both alliances (inherent to the leadership condition of the firm) and the lead firm brought us the opportunity to adopt high-quality research criteria, providing access to relevant information and insightful feedback.
} 
the CAH-LF and MAR-LF alliances, it provided large corpora of relevant data to that end. For example, in this phase we obtained access to both primary and secondary data sources, which provided information about objectives and actors involved in all the firm-RO alliances of the consortium (e.g., consortium's report, consortium agreement). Similarly, interviews with the LF and direct observation in some consortium committees, informed us about the ongoing evolution of these alliances. All this information led us to consider inter-organizational knowledge sharing as an important explanatory factor of the rate of success of the firm-RO alliances of the consortium.

During the second phase (October 2010-September 2011), to confirm our first impressions, we started with exploratory interviews with the LF's R\&D Manager, as well as with several partner firms and ROs involved in the consortium (October 2010). On the basis of this information, we selected the CAH-LF and MAR-LF alliances, following criteria above explained. At the same time, we reviewed relevant literature to decide the theory-driven variables on which the study would focus (i.e., inter-organizational knowledge-sharing routines and joint realization of value, whose operationalization is explained in Appendix IV. 1). After one more exploratory interview with the LF's R\&D Manager (February 2011), we started collecting specific information about the CAH-LF and MAR-LF alliances. In particular, data was collected retrospectively through semi-structured interviews in the form of face-to-face surveys (Yin, 2003), conducted between May and July of 2011 with key informants of both partners in each alliance (i.e., two interviews with the LF's R\&D Manager, one interview with the CAH's Head and one interview with the MAR's Head). Interviews had an average length of 1.5 hours, were recorded and then transcribed by the two interviewers involved, and were not conducted under a rigid questionanswer format. Informants were also asked to provide information about the longitudinal evolution of their collaborative relationships and the focal R\&D alliances (e.g., details, anecdotes, milestones, and examples) as well as to justify their responses. This retrospective data collection strategy allowed us to deal with data-reduction dilemmas, generate 'customized' items, collect process data and avoid self-respondent biases by fulfilling the principle of triangulation ${ }^{9}$ (Langley, 1999; Yin, 2003).

Data analysis started with the reconstruction of the history of the two cases under study, combining information from interviews and other data sources ${ }^{10}$. Next, an extensive case study

\footnotetext{
${ }^{9}$ Interviewing emerged as the necessary data collection technique, since information about knowledge sharing among partners was not available in reports of other secondary sources of information. In this context, we triangulate the information by resorting to two key informants in each alliance.

${ }^{10}$ When discrepancies among data sources emerged, we contacted informants to solve them.
} 
report for each collaborative relationship was wrote, containing a lot of citations from interviews and documents to stay very close to the original data and thus achieve accuracy (Langley, 1999). Subsequently, we analyzed data through an inductive approach (Rerup \& Feldman, 2011), involving iterative discussions between the three researchers of the study. Based on the case study reports, we moved from raw data to first-order constructs and subsequently from them to second-order constructs, linking data with theoretical concepts, arriving at comprehensive explanatory framework for addressing the research question of the study.

\subsubsection{Analysis of the cases: The CAH-LF and MAR-LF cases}

In this section, we provide a detailed description of the two cases under study. For each of them, we first describe the history of the relationship between the two familiar partners (represented in Figure 4.2.2 and Figure 4.2.3, respectively) in which each focal R\&D alliance is embedded. Subsequently, we present their collaboration under the Acuisost Consortium from a ROR (see Figure 4.2.4 and Figure 4.2.5) and describe the processes of redeployment of their knowledgesharing routines and joint realization of value. Appendix IV.3 summarizes quantitative and qualitative evidence.

\subsubsection{The CAH-LF case}

\section{The history of the CAH-LF relationship}

The relationship dates back to late 80 's, when the LF was still a start-up (it was formally founded in 1987) and the CAH did not exist as such (it was formally founded in 2005). Contact started on a personal level between the current Head of the CAH (who had been appointed full professor in 1988 and was leading the research group germ of the center) and two current executives and founders of the LF, who had obtained their degree in veterinary medicine in the school to which CAH is affiliated:

“...the firm had recently been brewed, they needed basic technical support and started looking for it in our School [...] Empathy emerged between us and we start collaborating together, at first in a very modest way" (CAH's Head)

In the 90's, an epidemic arose devastating the trout production of the country (the main aquaculture species at that time), becoming endemic from them. At that time, the LF did not possess its own microbiological laboratory yet, $\mathrm{CAH}$ conducting all microbiological analysis of the LF and providing support and after-sales services to the LF's clients. This working methodology paved the way to co-develop a strong vaccine, which the LF successfully sold to their clients during subsequent years, involving important financial flows for both partners and the institutionalization of their collaborative relationship. 
Since then, the partners continued collaborating together, tying different kind of projects over time and gradually increasing the complexity of their collaborative initiatives. In the words of the LF's R\&D Manager "CAH played the role of R\&D unit" of the LF during those years. As the LF's technological infrastructure consolidated, the services provided by CAH became "more sophisticated". For example, once the LF built its own microbiological analysis in 2004, CAH started providing technical support to the LF's Department of Microbiology and Illness Diagnosis in all those themes which the firm was not able to do by itself, as explained by the CAH's Head, due to "technological complexity or excessive costs".

Figure 4.2.2. Main milestones in the CAH-LF relationship

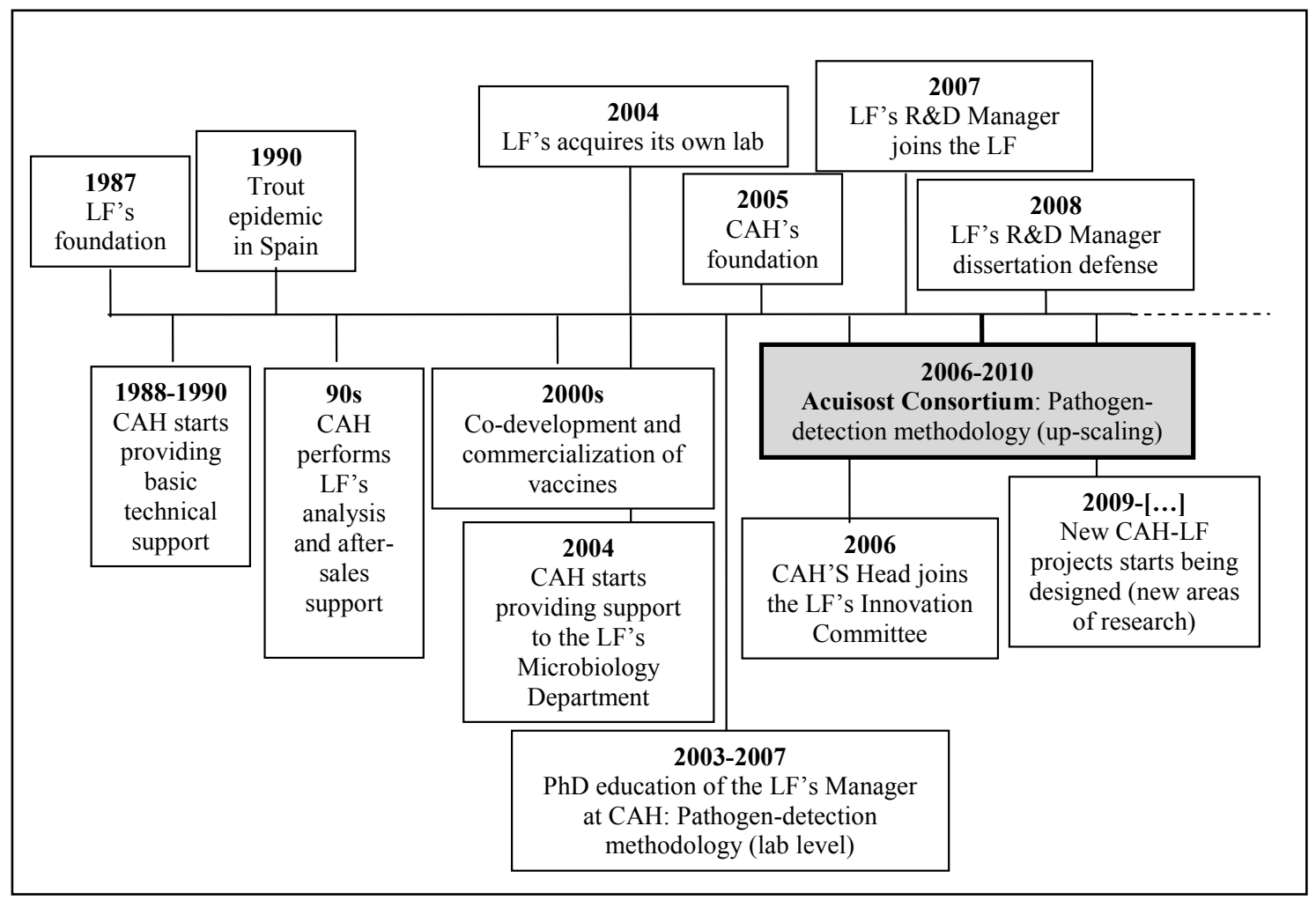

In explaining the CAH-LF collaborative relationship the PhD education of the LF's Manager should be mentioned. Having obtained his degree in the School of Veterinary Medicine to which CAH is affiliated, the current LF's R\&D Manager occupied a PhD position in the CAH (period 2003-2007) under the supervision of the CAH's Head (dissertation defense in 2008). From the interviews we identify to reasons underlying the importance of this milestone. First, the doctoral dissertation is directly related with the CAH-LF collaboration under the Acuisost Consortium. When the opportunity to lead the consortium came to the LF (November 2006) it offered CAH to collaborate, and both partners agreed extending the research undertaken in the doctoral dissertation of LF's R\&D Manager into the industrial level. Second, the LF is a familyowned enterprise and the LF's R\&D Manager, as a family member, always wanted to work in 
the LF. His $\mathrm{PhD}$ education thus was understood as a "training period prior to joining the firm" 11 (starting in 2007 as manager of the Acuisost Consortium and getting promoted to R\&D Manager in 2009). In particular, the doctoral dissertation of the LF's R\&D Manager focused on developing, based on the knowledge created in reaction to the above mentioned epidemic, a new pathogen-detection methodology at the lab level. Indeed, as can be read in the dissertation acknowledgment writings of LF's R\&D Manager, arguing that aquaculture would be the LF's business area of strongest development:

“... (the CAH's Head) changed my vocation and convinced me to specialize in the exciting field of aquaculture"

In parallel to other specific research projects, including thus the collaboration under the Acuisost Consortium, the CAH's Head played the role of external technical advisor in the LF's Innovation Committees which, implemented in 2006 as a part of the technological sophistication process in the LF, were held yearly to design the firm's innovation strategy for next year. Furthermore, concurrently to the Acuisost Consortium, the partners started to design new joint projects extending their collaboration, which had focused on aquaculture biosecurity so far, into the areas of aquaculture nutrition and pet biosecurity.

Both the CAH's Head and the LF's R\&D Manager stress during the interviews that the CAH and the LF had developed along their collaborative trajectory a strong value-creating relationship characterized by the values of mutual benefit, trust and long-term orientation. Likewise, these values extended to the relationship between the CAH's Head and the LF's R\&D Manager on a personal level ${ }^{12}$ :

"The relationship is strategic [...] it has allowed us to link our scientific area of expertise with the aquaculture field in the academic arena [...] CAH became a center of reference in research [...] the LF has become an important multinational company, CAH has had to do in this process [...] I directly supervised all the projects with the LF, they have priority $[\ldots]$ we strive to preserve the relationship $[\ldots]$ my personal relationship with the LF's R\&D Manager is simply excellent $[\ldots]$ he is an important asset of the LF (CAH's Head)

"The CAH is and will remain our star research center [...] the CAH and the LF have grown together $[\ldots]$ The CAH's Head is a leading scientific in Spain, he was appointed

\footnotetext{
${ }^{11}$ The LF's CEO confirmed these arguments during a visit to the LF's facilities, organized at the very beginning of our research on the Acuisost Consortium (as a teaching activity within the course of Strategic Management of the Business Management Degree). He explained that the 'family member condition' was not enough to collaborate in the management of the LF. In this regard, he referred to a third-generation family member was finishing his $\mathrm{PhD}$ education, as a requisite to join the company.

${ }^{12}$ We directly observed some conversations between the CAH's Head and the LF's R\&D Manager, finding clear indicators of their good relationship (e.g., relaxed tone, jokes, questions about personal life).
} 
professor at his $29 ![\ldots]$ he is a friend of the LF in general and of mine in particular" (LF's R\&D Manager, interview) “....I would like to thank the CAH's Head for his encouraging friendly orientation [...] I hope our collaboration continue in this new stage, it is not easy to find people like you" (Acknowledge writings, LF's R\&D Management Doctoral Dissertation)

\section{The focal CAH-LF alliance: ROR, redeployment and value realization}

The CAH-LF alliance in the Acuisost Consortium extended an existing research line in aquaculture biosecurity by "developing on an industrial scale a new pathogen-detection methodology" (Source: consortium's report). The CAH-LF alliance thus was markedly exploitation-oriented. From the interviews we know that, in parallel with this project, partners started preliminary experiments in other areas, which ended up in two new joint projects. In this regard, the CAH-LF alliance under the Acuisost Consortium can be clearly contextualized into the larger portfolio of collective real options of the CAH-LF relationship.

Figure 4.2.3. The CAH-LF alliance within the chain of collective real options

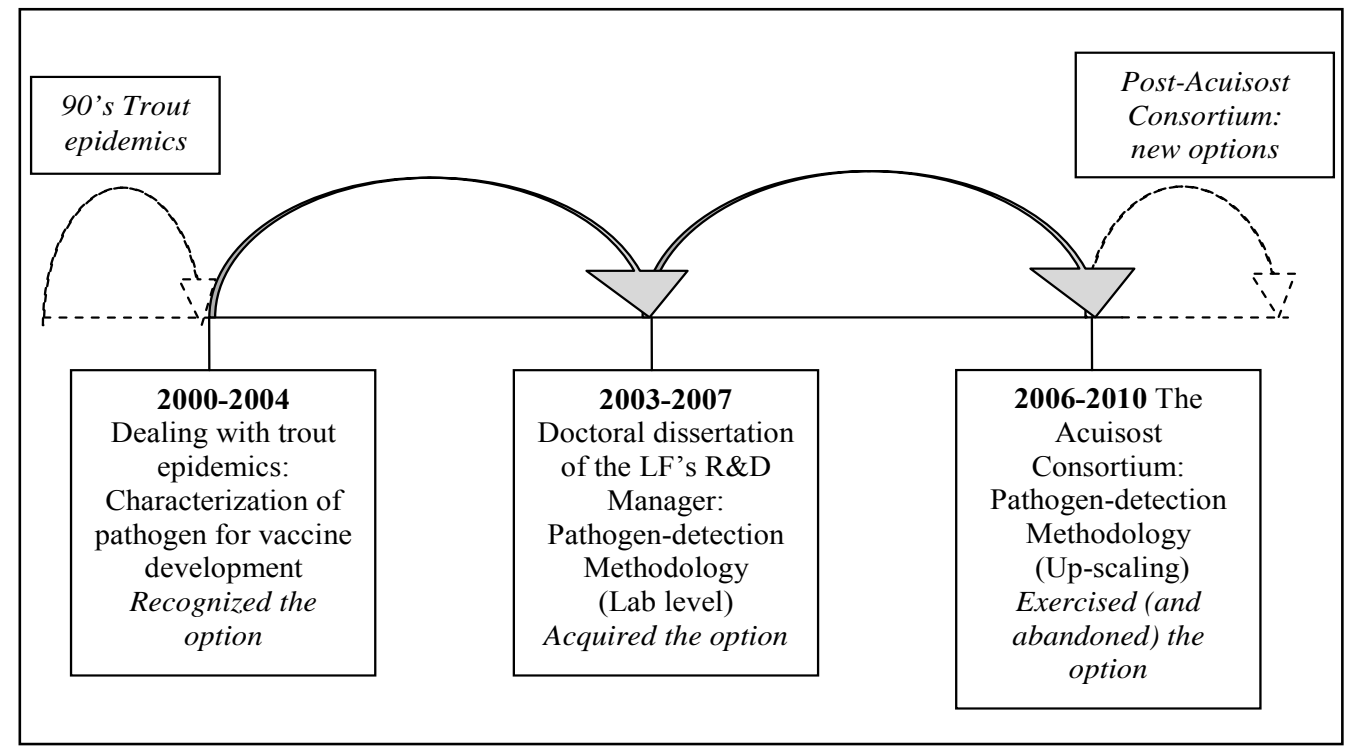

As Figure 4.2.3 shows, this focal alliance sought to exploit a pathogen-detection methodology (through up-scaling) which partners had previously explored together (by means of a doctoral dissertation developed by the LF's R\&D Manager and supervised by the CAH's Head) and which in turn was related to a previous collaborative initiatives (i.e., when dealing with a trout epidemic). At the same time, partners started exploring new future opportunities (acquiring new collective options), and collaboration continued after the Acuisost Consortium with new agreed joint R\&D projects addressing new research lines (e.g., biosecurity in the pet nutrition field).

Our data on the CAH-LF alliance indicate that the redeployment of the familiar partners' knowledge-sharing routines [see Appendix IV.3 for a summary of quantitative and qualitative 
evidence] during the Acuisost Consortium was characterized by frequent and intense knowledge exchange interactions between the partners, where technological knowledge flows were particularly important. Moreover, both partners perceived mutual flexibility and willingness to both transfer to and received knowledge from each other.

Also both partners described their knowledge exchange interactions as 'effective', by confirming that they were able to recognize, assimilate and apply new knowledge:

“...we use the same language [...] mutual understanding allows us to arrive at important achievements [...] research at the CAH reflects into our activities" (LF's R\&D Manager)

"...We are a tool of the LF. We acquire knowledge from the LF to find out its necessities, then we assimilate and apply this knowledge into our research [...] (the LF) finally applies it in its products and processes [...]" (CAH's Head)

Indeed, our data on joint realization of value in the CAH-LF alliance [see Appendix IV.3 for a summary of quantitative and qualitative evidence] confirm such effectiveness. For example, both partners stated high levels of satisfaction despite 'it was not worth patenting the results achieved' and decided 'to not commit further resources' to the methodology object of research, taken for granted the continuation of their collaborative relationship.

From this evidence, two factors stand out in light of our research purpose. First, when we asked informants about their knowledge-sharing interactions in the focal $R \& D$ alliance, their answers were usually accompanied by taglines like 'as usual' or 'not only in the Acuisost Consortium but in general'. Therefore, informants suggested no differences between their patterns of interaction in the focal exploitative alliance and other previous/concurrent relationships with different orientations. Second, comparing objective information about initial technical objectives of the CAH-LF alliance (i.e., description available in the consortium's report) with descriptions of results provided by the LF's R\&D Manager, we first arrived at the conclusion that the familiar partners had failed at fulfilling the objectives of the alliance. Interview data then revealed that partners were actually mixing the results (and objectives) of their project in the Acuisost Consortium and of their collaboration as a whole. For example, explaining results obtained in terms of academic publications, the CAH's Head stressed that:

“... we have developed important academic results, some publications are co-authored by the LF's R\&D Manager, but it is difficult to say that they came strictly from the Acuisost Consortium, maybe they come from our relationship with the LF in general" (CAH's Head) 
Similarly, when we asked the LF's R\&D Manager about the realization of value in the CAH-LF alliance, they provided us answers from a generalized standpoint not exclusively referring to the period of the Acuisost Consortium:

“...our relationship with $\mathrm{CAH}$ is key to us because its multidisciplinary activity [...] CAH have provided us many new opportunities overtime, and I am sure CAH will remain providing them to us" (LF's R\&D Manager)

Therefore, statements like 'initial objectives have been met to an $80 \%$ degree' contained the ongoing reformulation of expectations carried out by the partners. In this regard, these factors make clear the point that the locus of collaboration between the CAH and the LF was not the focal alliance under the Acuisost Consortium but their collaborative relationship as a whole. ROR allows us to interpret it as an indicator of interaction within the portfolio of collective real options: "because options interact [...] subsequent option investments in $R \& D$ arenas can increase the value of options opened earlier" (McGarth \&Nerkar, (2004: 4).

\subsubsection{The MAR-LF case}

\section{The history of the MAR-LF relationship}

Although the MAR and the LF started collaborating together in $2000 \mathrm{~s}$, the origins of the relationship date back to late 80 's, when the MAR's Head held the position of Production Manager at an aquaculture company.

As a result of their respective professional activities (e.g., business associations meetings, trade fairs, the Annual National Conference on Aquaculture), he entered into personal relationships with several current LF's actors (i.e., the General Managers of Iberian Eels and Mediterranean Aquaculture- two fish producer firms affiliated to the LF's corporate group-, as well as with the of the LF themselves). Indeed, the Iberian Eels' General Manager and the MAR's Head described each other in the interviews as his "best (personal) friend" ${ }^{13}$. Subsequently, the MAR's Head changed its career towards the academic world, founding the MAR research group. Shortly after, MAR started collaborating with Iberian Eels and Mediterranean Aquaculture, providing them technical support to extend their production facilities and to achieve official environmental accreditations.

In 2000, direct collaboration between the MAR and the LF started in the area of quality control. At that time, the LF did not possess yet its own quality control equipment and thus MAR performed the related analysis. Such a collaborative scope remained like that until 2004 when, following the advice of the MAR's Head, the LF invested in its own quality control equipment:

\footnotetext{
${ }^{13}$ We interviewed the Iberian Eels' General Manager in other data collection stages of this doctoral dissertation.
} 
“... a firm like the LF, at that time in process of technological growth, needed its own quality control equipment $[\ldots]$ one may think that it would damage the MAR's interests in the short term but the fact is that the long-term effects would be rather the opposite: it opened us the opportunity to address together many other areas" (the MAR's Head)

Figure 4.2.4. Main milestones in the MAR-LF relationship

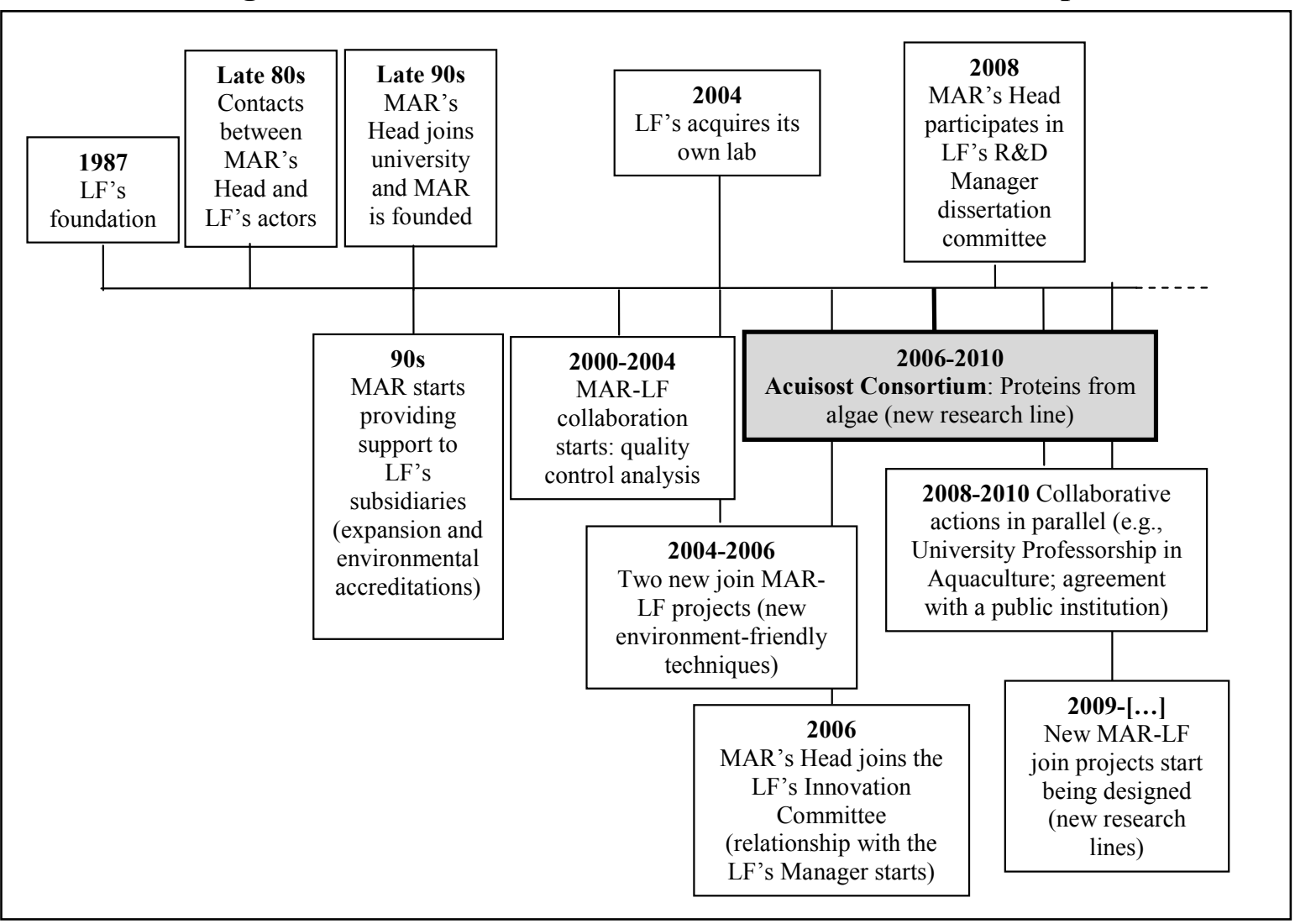

Indeed, our data confirm the reasoning of the MAR's Head. In the following two years (20042006), the MAR and the LF undertook two new research projects to experiment with new environmental-friendly techniques, denoting increasing sophistication in the collaboration. In addition, the MAR's Head started acting as external technical advisor in the LF's Innovation Committees in 2006. Furthermore, when the opportunity to lead the Acuisost Consortium came to the LF (November 2006) and it offered MAR to collaborate, MAR proposed taking the leap in aquaculture nutrition, experimenting with algae that represented potential sources of proteins new for both organizations. Sounding appealing to the LF, the two organizations jointly elaborated further on this idea until arrive at the definitive research proposal:

“....proteins from algae may represent a nutritionally viable less costly and sustainable alternative for fish-based proteins [...] There are a lot of scientific studies and there are also some established commercial products [...] the most innovative aspect (of the MAR-LF project in the Acuisost Consortium) is its focus on macro-algae available in 
the domestic market (farmed in Spain, instead of imported)" (Source: consortium's report)

In parallel with the development of the Acuisost Consortium, the MAR and the LF engaged in some other collaborative actions. In December 2009, both organizations launched a University Professorship in Aquaculture, managed by the MAR's Head and sponsored by the LF. Also in 2009, both organizations signed a collaboration agreement with the Spanish Ministry of Environment and Rural and Marine Affairs to develop a guide for aquaculture practices (published by the public institution in 2010).

Similar to the CAH- LF case, both the MAR's Head and the LF's R\&D Manager stress during the interviews that both organizations had developed along their collaborative trajectory a strong value-creating relationship characterized by the values of mutual benefit, trust and long-term orientation:

“... they know we will not cheat and vice versa [...] Perhaps I am not an Einstein but the LF's R\&D Manager knows that I will make all effort to provide them useful results $[\ldots]$ derived benefits are reciprocal $[\ldots]$ all of this keeps up together $[\ldots]$ the LF's R\&D Manager possess important technical capacities [...] it is easy for both of us to collaborate together" (MAR's Head)

“... he is a good technician and a better strategist, simply a business man [...] we really get on well with each other MAR provided us interesting business opportunities [...] the MAR's Head have launched many initiatives with an important impact on the image of the firm" (LF's R\&D Manager)

Unlike what occurred in the CAH-LF case, the professional collaboration between the MAR's Head and the LF's R\&D Manager started with the Acuisost Consortium. However, the first contacts between them took place in 2006. The LF's R\&D Manager, still holding a PhD position in the CAH, was also invited to the 2006 LF's Innovation Committee as external advisor (in view of his forthcoming incorporation in 2007). Subsequently, the MAR's Head was also invited to participate as external examiner to the defense of the LF's R\&D Manager doctoral dissertation (July 2008). When we asked informants about their personal relationship, they confirmed that the strong bonds existing between their organizations acted as an important starting point to gradually build a harmonious, empathy- and trust-based relationship on a personal level ${ }^{14}$.

\footnotetext{
${ }^{14}$ Indeed, we identified some indicators of this good personal relationship (e.g., a relaxed tone, jokes, questions about personal life) in personal conversations between the LF's R\&D Manager and the MAR's Head by means of direct observation.
} 


\section{The focal MAR-LF alliance: ROR, redeployment and value realization}

As advanced, the MAR-LF alliance in the Acuisost Consortium addressed a research line totally new for both organizations related to the improvement of aquaculture nutrition. In particular, it aimed at "obtaining vegetable proteins from macro-algae and analyzing their applicability for fish feed production" (Source: consortium's report). Therefore, it can be said that the MAR-LF collaboration under the Acuisost Consortium clearly was exploration-oriented. However, the LF's R\&D Manager explained in an interview that a shift towards exploitation was envisaged by both partners:

"... it was not about to discover new knowledge for the sake of discovering, but for extending it into the industrial front someday" (LF's R\&D Manager)

The incremental strategy of investment in collective real options could also be illustrated with the MAR-LF alliance, as shown in Figure 4.2.5.

Figure 4.2.5. The MAR-LF alliance within the chain of collective real options

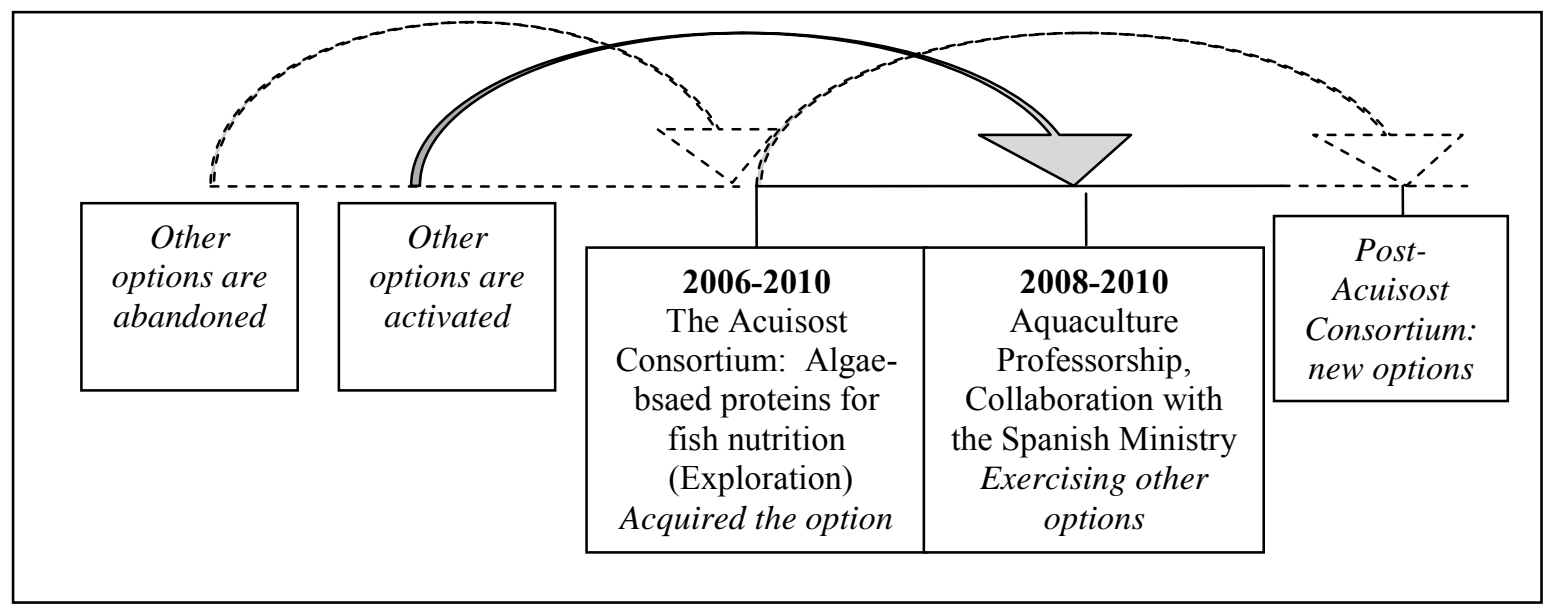

Under the Acuisost Consortium, partners sought to explore new technological alternatives, on which none of the partners had prior experience (i.e., analyzing algae-based proteins for fish nutrition as a new acquire collective option). They confirmed that the idea was technically viable, yet they decided to delay full investment of resources in the algae project, waiting until the financial uncertainty (i.e., global crisis) was resolved. Simultaneously, partners exploited other opportunities in the form of collective options (e.g., the University Professorship on Aquaculture managed by MAR and sponsored by the LF; ) though previously activated mainly through the MAR's network of institutional contacts, and continued their collaboration beyond the Acuisost Consortium exploring new non-related lines of research (acquiring new collective options). 
Highly similar to what we observed in the previous case, our data on the MAR-LF alliance indicate that the redeployment of the familiar partners' knowledge-sharing routines [see Appendix IV. 3. for a summary of quantitative and qualitative evidence] was characterized by frequent and intense knowledge exchange interactions between the partners. Moreover, both partners perceived mutual flexibility and willingness to both transfer to and received knowledge from each other. Also as in the previous case, knowledge exchange interactions between partners were perceived as 'effective' by both informants, who emphasizes their mutual abilities to recognize, assimilate and apply new knowledge. Such effective pattern of interaction ended up in a wide range of results, in addition to 'acceptable degrees of objectives' fulfillment' and 'high levels of satisfaction', informants described as reflections of joint realization of value [See appendix IV.3 for a summary of quantitative and qualitative evidence].

From this evidence, three factors stand out for research purpose. First, as in the previous case, informants of the MAR and LF stressed repeatedly in the interviews that their collaborative interactions were 'always' characterized by values like willingness and flexibility, and not only in the Acuisost Consortium. Therefore, confirming that their redeployment patterns were not particularly different when they try to explore or exploit technological opportunities together. Second, despite the MAR-LF alliance under the Acuisost Consortium formally embraced a R\&D exploration project, market knowledge flows were described by informants as more important than technological knowledge flows in the development of the project. Similarly, informants stressed their mutual emphasis on obtaining tangible results, more associated to exploitation-oriented research:

“...the LF resort to us because it needs solutions [...] we understand it and do real applied research $[\ldots]$ if the LF do not develop new products from the consortium, it will make no sense " (MAR's Head)

Finally, by comparing the results described by informants with objective information available in documents about the objectives and content of the project in the Acuisost Consortium, we could conclude that. However, informants emphasized those results that, even though achieved during the period of the Acuisost Consortium, cannot be strictly attributed to this focal alliance. For example, the MAR's Head highlighted the creation of a laboratory with cutting-edge environment-friendly technology, owned by its university but that would support subsequent collaborative initiatives with the LF. Similarly, the LF'R\&D Manager stressed that:

“... the MAR's Head has launched several initiatives like the professorship or the new lab enhancing the image of our firm [...] the LF profits from the important network of institutional contacts of the MAR's Head [...] (he) put me in contact with 
an Egyptian firm with which we have signed a collaboration agreement" (LF's R\&D Manager)

As a whole, this evidence highlights that the locus of collaboration between the MAR and the LF was rather their broader collaborative relationship than the focal alliance under the Acuisost Consortium, confirming the arguments of Vassolo et al. (2004: 1046) that "in the presence of interactions, the valuation of a portfolio of related options is not straightforward. Failure to consider the effect of interactions [...] would lead to misleading explanations".

\subsubsection{Discussion: Real options reasoning in the CAH-LF and MAR-LF alliances}

From the in-depth analysis and comparison of the CAH-FL and the MAR-LF cases, we first derived an important conclusion for our research purpose: the innovation-seeking orientation of the focal R\&D alliance (exploitation-oriented or exploration oriented) does not provides a complete explanation into how familiar partners redeploy their existing knowledge-sharing routines. This conclusion thus challenges the idea that "the mindsets and organizational routines needed for exploration are radically different from those needed for exploitation" (Gupta et al., 2006) and in turn is rooted in the following two broad observations. First, we did not observe differences between the two focal $R \& D$ alliances that can be clearly attributed to their different innovation-seeking orientation (exploitation vs. exploration) ${ }^{15}$. Second, in both alliances under study it is difficult to discern between the part of the processes of value realization that corresponded to the collaboration in the Acuisost Consortium from the part that corresponded to the overall collaboration between the familiar partners. In fact, informants themselves stressed repeatedly during the interviews ideas like "it is difficult to isolate what happens in the Acuisost Consortium from our relationship in general" or "the Acuisost Consortium has not created a before and after in our relationship" (CAH's Head).

To further elaborate on these ideas, we address the three specific research questions in the following in light of the two cases under study.

\subsubsection{Redeployment: A process of exploring and exploiting collective real options.}

Based on the above narratives and the prior theoretical discussion, we claim that the redeployment investments made by the familiar partners in both alliances under the Acuisost

\footnotetext{
${ }^{15}$ The redeployment processes of both studied alliances were not particularly different from each other in terms of frequency of contact, knowledge-sharing willingness and effectiveness (See comparatively tables in Appendix IV.3). The most notably differences resided in the dimension of intensity. For example, the intensity of market knowledge flows was more important in the MAR-LF alliance (exploration-oriented) than in the CAH-LF alliance (exploitation-oriented).
} 
Consortium incorporated the abstract conceptualizations of the knowledge-sharing routines and thus were inexorably imbued with a real options spirit. Given the collaborative trajectories of each pair of familiar partners, we could consider that each of them by accumulating explorative and exploitative experiences (i.e., following ROR reasoning) over time had developed ambidextrous knowledge-sharing routines (Filippini, Gütel, \& Nosella, 2011). This reasoning is in line with the above- mentioned conceptualizations of routines: 'grammars of action' (Pentland \& Rueter, 1994) ${ }^{16}$. These routines, as 'grammars of (collaborative) action', define a set of possible patterns of interaction between the partners, rather than prescribing a single pattern (Pentland \& Rueter, 1994; Zollo et al., 2002). Importantly, we did not observed that partners retrieved from their inter-organizational memory only a specific part of their knowledge-sharing routines (Cohen \& Bacdayan, 1994) and thus redeployed them in a pure exploitation or exploration mode (Gupta et al., 2006), according to the formal orientation of the focal alliance. Rather, our data on the CAH-LF and the MAR-LF alliances suggest that each pair of familiar partners simultaneously explored and exploited collective options by redeploying their knowledge-sharing routines in the focall alliance regardless the formal orientation of that focal alliance. Our evidence thus challenges inertia arguments usually associated to collaboration between familiar partners (Kogut \& Kulatilaka, 2001; Schreyögg \& Kliesch-Eberl, 2007). The redeployment stories of the CAH-LF and MAR-LF alliances show how familiar partners can possess well-established patterns of interaction which are, however, of flexible nature.

The above reasoning has allowed us to explain how the collaborative relationship as a whole affected redeployment of knowledge-sharing routines into the CAH-LF and MAR-LF alliances. Hence, it provides an explanation of why we found no differences in redeployment and value realization between the two studied R\&D alliances that can be clearly attributed to their innovation-seeking orientation (exploitation vs. exploration). On a broader level, these findings represent an important theory-building contribution since they provide a compelling explanation to some existing contradictory evidence on the role that partner-specific experience may play in alliance exploration success: familiar partners may redeploy ambidextrous knowledge-sharing routines and thus explore and exploit technological opportunities in a simultaneous fashion even if the alliance formally aims at exploration. The above discussion gives rise to the following proposition:

\footnotetext{
${ }^{16}$ Pentland and Feldman (1994) develop the framework of routines as 'grammars' in an attempt to integrate flexibility in the conceptualization of patterned activity. In this regard, Feldman and Pentland (2003) also recognize flexibility of routines by emphasizing that the performative aspect is not an invariant reflection of the ostensive aspect: routine actors may react to the outcomes of prior routine iterations and thus rebuild the initial abstract conceptualization [See also Feldman (2000)].
} 
Proposition 1. In $R \& D$ collaboration between familiar partners which have developed ambidextrous routines, redeployment entails exploring and exploiting collective real options, regardless the formal seeking-orientation of the focal alliance (exploitation vs. exploration).

\subsubsection{Managerial cognition and the identification of collective real options}

Our data on the CAH-LF and the MAR-LF alliances allow us to identify some distinctive features of the professional backgrounds and profiles of the partners' representatives. As can be deduced from the previous narratives, the CAH's Head profile was more academic oriented than the MAR's Head and the LF's held a more profiles, which integrated managerial and academic experiences. Given these observations, and considering that cognitive schema form mainly through experiences (Tripsas \& Gavetti, 2000), we argue that combination of different professional profiles resulted in a different cognitive infrastructures sustaining the redeployment processes of knowledge-sharing routines in each studied alliance. Furthermore, such heterogeneity in cognition led the partners of both studied alliances to envision idiosyncratic collaborative scenarios, containing thus different portfolios of collective real options. Therefore, the collaborative efforts of each pair of familiar partners or, put differently, their redeployment investments, aimed at exploring and exploiting different bundles of opportunities. We observed that the redeployment strategies undertaken by each pair of familiar partners possessed general commonalities (i.e., managing uncertainty through flexibility) but were idiosyncratic in details(Eisenhardt \& Martin, 2000), since the envisioned targets of collective real options giving meaning to the strategies were idiosyncratic. Put differently, although in both alliances under study partners held an options-based locus of collaboration, we observed different attention focus of collaboration. As a result, the different subjective representations of each pair of familiar partners led them to establish different collaborative agendas (Nadkarni \& Barr, 2008) and, thus, they realize joint value in different ways. As Bowman and Hurry (1993) argue, opportunities for strategic action (or real options) come into being only when managers recognized them through retrospective sensemaking, remaining until that in the form of shadow options. Indeed, the LF's R\&D Manager explained that the CAH and the MAR provided two different kinds of opportunities for innovative strategic action to the firm, emphasizing different kind of shadow options derived from the CAH's network of scientific contacts versus the MAR's network of institutional contacts ${ }^{17}$.

The above reasoning has allowed us to explain the differences we identified between the two studied alliances (and that, as we argued, were not attributable to the alliance innovationseeking orientation). In doing so, we explain how managerial cognition influenced

\footnotetext{
${ }^{17}$ See comparatively tables displayed in Appendix IV.3 to find out more indicators of these arguments (e.g., results in terms of publications).
} 
redeployment of familiar partners' routines (and thus joint realization of value) in the CAH-LF and MAR-LF alliances. On a broader level, these findings represent an important theorybuilding contribution, extending prior literature linking cognition and routines, into the particular context of redeployment. In doing so, our study shows the important role that heterogeneity in managerial cognition can play in explaining heterogeneity in alliance success, by affecting the redeployment of inter-organizational knowledge-sharing routines and not only the creation and change of organizational capabilities (Tripsas \& Gavetti, 2000; Rerup \& Feldman, 2011). The above discussion supports the following proposition:

Proposition 2. In $R \& D$ collaboration between familiar partners, heterogeneity in managerial cognition leads to heterogeneous envisioned portfolios of collective real options across alliances.

\subsubsection{Redeployment and joint value realization: Managing uncertainty through flexibility.}

Our data on the CAH-LF and MAR-LF alliances confirm that each pair of familiar partners were able to realize joint value because they (1) had already overcome social uncertainty when they initiated their collaboration under the Acuisost Consortium and (2) managed collectively environmental uncertainty over time by applying a flexible redeployment strategy. We elaborate further on these two points below.

Social uncertainty already overcome. Our study shows that partners were able to concentrate their routine-redeployment investments on the management of one unique source of uncertainty (i.e., environmental uncertainty). The reason here is that social uncertainty between them had been already been overcome when they engaged in the alliances under the Acuisost Consortium. These arguments are corroborated by some statements, arising recurrently in the interviews, such as "the LF knows that we will not cheat and vice versa" and "we know how to do things well when collaborating with each other" (MAR's Head). Therefore, likelihood of knowledgesharing effectiveness was no longer a volatility variable in the collaborative equation, but a kind of intercept for which it was thus no needed to consider different possible scenarios and that gave meaning to the continuity of the CAH-LF and MAR-LF relationships. Lack of social uncertainty and trust thus rendered the collaborative scenarios in a state of stability, in turn reducing complexity and thus enhancing likelihood of joint realization of value (Kumar \& Nti, 1998). In this regard, our data on the CAH-LF and the MAR-LF alliances study extends the framework developed by McMacter et al. (2011) for partners lacking a long history of prior 
interactions ${ }^{18}$ into the context of familiar partners. Collective real options resulting from the redeployment of familiar partners' routines represent an otherwise inconceivable portfolio of value-creating opportunities, rather than provide them "the opportunity to first try and then trust each other" (McCarter et al., 2011: 635)".

Environmental uncertainty and flexibility. Previously, we have comprehensively argued that the two studied pairs of familiar partners had developed and then redeployed ambidextrous knowledge-sharing routines along their collaboration. Partners of the CAH-LF and MAR-LF alliances therefore faced environmental uncertainty by flexible redeploying of their knowledgesharing routines, and thus were able to realize joint value. Inter-organizational routines, understood as 'grammars of actions', allow partners to choose the most adequate pattern of interaction from all the possible ones to deal with exogenous contingencies (Pentland \& Rueter, 1994; Teece et al., 1997; Zollo et al., 2002). More specifically, strategic alliance scholars (e.g., Kogut, 1991; Estrada et al., 2010) have emphasized that ROR allows partners to maintain flexibility in uncertain environments. Alliance partners can explore simultaneously a wide range of technological alternatives by forming multiple alliances concurrently and over time (i.e., portfolio of embedded collective options), deterring full commitment of resources until corroborating which one/ones is/are the most favorable. We observed precisely this strategic behavior in the alliances under study. For example, in the CAH-LF alliance, partners decided not to continue with that line of research (considering it to be 'exhausted') and started exploring new technological opportunities. In the MAR-LF alliance, partners explored a new technological opportunity. Potential was confirmed so, instead of totally abandon the idea, partners decided to wait before committing more resources due to the global economic crisis, starting exploration of new technological opportunities. In this regard, our study extends to the inter-organizational context the argument that real option reasoning in strategic decision-making allows firms not only to protect from environmental uncertainty but to profit from it (Kogut, 1991; Kogut \& Kulatilaka, 2001).

The above reasoning has allowed us to explain how redeployment of familiar partners' routines into the CAH-LF and the MAR-LF alliance contributed to managing uncertainty through flexibility and thus yielded joint realization of value. On a broader level, these findings represent a major theory-building contribution, challenging prior research that, relying on the

\footnotetext{
${ }^{18}$ In fact, our data on the CAH-LF and the MAR-LF alliances suggest that the 'testing the waters' strategy emphasized by these authors can perhaps take place during the capability-building process (i.e., as partners develop their capabilities to collaborate together they acquire collective real options to deal with social uncertainty). The examination of this question goes beyond our interest, since the present study focuses on the capability-redeployment process that comes once the partners' capabilities are already in place, yet it sounds as an interesting avenue for further work.
} 
'paradox of embeddedness' arguments (Uzzi, 1997), argues that explorative alliances between familiar partners are not likely to succeed. Conversely, we find that both pairs of familiar partners under study were able to realize joint value by redeploying their knowledge-sharing routines, regardless the different innovation-seeking orientation of the alliances (exploitation vs. exploration). Emphasizing that knowledge of familiar partners become redundant over time (e.g., Goerzen, 2007), these studies have denied two important realities showed in this study: (1) familiar partners may follow a real options reasoning and thus develop inter-organizational routines of flexible nature that allows them to simultaneously explore and exploit technological opportunities [or ambidextrous inter-organizational routines in the words of Filippini et al., (2011)], and (2) under these circumstances, familiar partners together can not only apply existing knowledge but also generate new one by redeploying their existing knowledge-sharing routines. Based on the above discussion, we propose:

Proposition 3. In $R \& D$ collaboration between familiar partners which have overcome social uncertainty, redeployment triggers realization of joint value by allowing management of environmental uncertainty through flexibility.

\subsubsection{Conclusion and implications}

This study provides a process-oriented perspective on the value-creation dynamics of $R \& D$ alliances formed by familiar partners, studying how they are able to realize joint value in both exploring and exploiting technological opportunities by redeploying their inter-organizational knowledge-sharing routines. By focusing on the collaborative relationship as the unit of analysis and comparing two successful focal R\&D alliances (one oriented at exploitation and the other oriented at exploration) our study concludes that (1) familiar partners with long history of prior interactions define the locus of their collaboration as a multi-fold longitudinal collaborative scenario that entails a portfolio of embedded collective real options over time, thus resembling ROR $^{19}$ (2) familiar partners may have already overcome social uncertainty and created ambidextrous knowledge-sharing routines whose redeployment allows them to realize joint value by managing environmental uncertainty through flexibility, and (3) heterogeneity in managerial cognition is a more relevant factor in explaining heterogeneity in value realization rates in $R \& D$ alliances formed by familiar partners, than the innovation-seeking orientation included in the formal alliance contracts. Consequently, this study yields some important implications.

\footnotetext{
${ }^{19}$ As Adner (2007) argues, in assessing the applicability of real options reasoning to strategy, it is important to separate arguments about the possibility that decision-making processes fit the real options logic from the probability that decision makers in real organizations explicitly hold (or are aware of being following) such a real options logic.
} 


\subsubsection{Implications for research}

This study extends prior scholarly efforts to bridge the literatures of strategic management and real options (Myers, 1984; Bowman \& Hurry, 1993; McGrath \& Nerkar, 2004; Vassolo et al., 2004). Broadly speaking, this study adds important insights to the research tradition explaining strategic alliances phenomena through the option lens (Kogut, 1991; Vassolo et al., 2004; Estrada et al., 2010). More specifically, this study extends the conceptual literature linking the fields of capabilities and real options (Kogut \& Kulatilaka, 2001), focusing on one important constituent element of the dynamic capability to collaborate (i.e., inter-organizational knowledge-sharing routines (Zollo et al., 2002) and opening the black box of redeployment. In doing so, this study contributes to existing literature in several important ways.

In light of our data, we have conceptualized collaboration between familiar partners in terms of portfolios of embedded collective real options that are explored and exploited iteratively in a multi-fold longitudinal scenario. Thus, our study extends through the option lens well-ground alliance research arguments that past interactions, concurrent relationships between partners, as well as mutual expectations about future together cast a shadow upon the present (Parkhe, 1993; Gulati, 1998; Poppo et al., 2008), explaining how it may affect current redeployment behavior. As argued by Kogut and Kulatilaka (2001), studying capabilities as real options allows a more comprehensively interpretation of the learning balance between exploitation and exploration. In this regard, integration of literatures on routines and real options has elicited a comprehensively conceptualization of inter-organizational knowledge-sharing routines, bridging together the perspectives of routines as 'grammars of action' (Pentland \& Rueter, 1994), 'dual phenomena' (Feldman \& Pentland, 2003), and 'ambidextrous' mechanisms (Filippini et al., 2011). Our study thus endows the notion inter-organizational knowledge-sharing routines with deep theoretical underpinnings, broadening existing understanding (Dyer \& Nobeoka, 2000; Zollo et al., 2002; Dyer \& Hatch, 2006). Similarly, relying on the dynamic perspective offered by ROR, our conclusions enrich the broader field of research into resources and capabilities redeployment, which has traditionally focused on acquisitions instead of alliances and has usually adopted a structure-oriented approach (Anand \& Singh, 1997; Capron \& Mitchell, 1998; Capron et al., 1998). In this regard, our study extends the bilateral perspective proposed by Capron and Mitchell (1998) by shifting attention focus on redeployment from resources individually developed by targets and acquirers to knowledge-sharing routines jointly developed by familiar partners. Taking into account that routines are the constituent elements of capabilities (Zollo \& Winter, 2002), ROR also provides a compelling empirical illustration of how the capability lifecycle evolves across the maturity stage when the trajectory branches into redeployment (Helfat \& Peteraf, 2003) 
As a whole, ROR allows a more fine-grained perspective to addresses the value-creation dynamics of R\&D alliances formed by familiar partners, contributing thus to resolve existing ambiguous evidence. We find that familiar partners may be able to successfully balance the tension between exploration and exploitation over time as long as they have developed ambidextrous routines, in line with Tiwana (2008) and Filippini et al. (2011). Therefore, our conclusions provide an interesting counterpoint to the predictions, inspired by "paradox of embeddedness' (Uzzi, 1997), that explorative R\&D alliances formed by familiar partners are likely to fail. Furthermore, our data on the CAH-LF and the MAR-LF alliances reveals that whether an alliance between familiar partners is formally oriented to exploration or exploitation may be not as relevant as presumed. As long as familiar partners frame their collaboration in terms of collective real options, differences in the interpretive schemata of managers may lead them to consider different opportunities (in the form of collective real options), thus explaining heterogeneous rates of alliance success and joint realization of value. All these arguments may comprehensively complement discussion of findings of studies like Hoang and Rothaermel (2005) or Phelps (2005) concluding that partner-specific alliance experience is not always a relevant determinant of innovation success in alliances.

\subsubsection{Implications for practice}

Real options approach applied to strategic management may allow scholars to "develop ideas that are relevant to the problems facing decision-makers" (Adner \& Levinthal, 2004). Indeed, the routines and learning literatures proved much more convincing to address the two real-life alliances under study when combined with real options arguments. Accordingly, we offer some recommendations for managers involved in the management of $R \& D$ alliances with familiar partners.

Our study shows that redeployment of inter-organizational routines may be consistently analyzed from a ROR (Adner \& Levinthal, 2004; McGrath et al., 2004) and that following an option-based philosophy could be a successful strategy for alliance ambidexterity. We thus strongly recommend managers to explicitly organize the collaborative behaviors of their organizations around such a real options philosophy. Looking at alliances through the option lens may promote (1) development of ambidextrous knowledge-sharing routines, (2) reduction of uncertainty and complexity in collaboration, and (3) likelihood of innovation success. Furthermore, given the importance of managerial cognition, we recommend to search for an adequate cognitive structure by placing special attention to the professional backgrounds of the individuals managing the alliances. This strategic decision could be particularly useful for firms-research organization collaboration, due to differences in institutional missions and perspectives (Lacetera, 2009). 


\subsubsection{Limitations}

Our findings are based on an in-depth longitudinal study of two R\&D alliances formed by the same firm and two different ROs within the context of a larger R\&D consortium (i.e., the Acuisost Consortium). This research design has allowed us to minimize the risk of extraneous variation and thus to make a reliable comparison of the two alliances (e.g., formal contracts were very similar in both cases and both pairs of partners had a long history of prior interactions). However, our findings are clearly contextualized, and consequently they need to be taken with caution in other research settings. For example, our data on the CAH-LF and MAR-LF alliances reveal that both pairs of partners over time had successfully overcome social uncertainty, have balanced the exploitation-exploration tension, and have developed ambidextrous knowledge-sharing routines. However, inheritance from history of interactions may be different. Partners may have not build such harmonious relationship -and continue collaborating together out of inertia (Gulati, 1998) - or simply they have only accumulated experiences in either exploitation or exploration. Under any of these circumstances, familiar partners may not have in place effective knowledge-sharing routines that allow them to successfully exploit and explore technological opportunities.

\subsubsection{Future research}

Based on the above discussion, we identify some interesting avenues for further research, beyond the large-sample test of our theoretical conclusions. In line with the limitations of the study, it could be interesting to compare the processes of redeployment of knowledge-sharing routines and joint value realization in R\&D alliances formed by different kinds of familiar partners (e.g., firm-firm vs. firm-research organization alliances; familiar partners with and without harmonious histories of interactions), as well as between different collaborative settings (e.g., R\&D alliances within a larger consortium vs. an 'independent' alliances).

Furthermore, our data suggest several conclusions that may inspire some other lines of further work. First, our data suggest that familiar partners may have already overcome social uncertainty when they engage in a new joint alliance. In this regard, it could be interesting to frame 'the testing the waters' strategy proposed by McCarter et al. (2011) in terms of 'building process of the capability of partners to collaborate together' and thus studying the creation of alliance capabilities as real options. Second, our data reflects debate around the 'paradox of embeddedness' at the network level (Uzzi, 1997; Phelps, 2010). On the one hand, embeddedness may constraint network opportunities [“... our relationship with the LF is strategic and the aquaculture sector knows it ... we collaborate with most of the LF's client firms but none of the LF's competitors has asked us our services" (CAH's Head)]. At the same 
time, an advantageous balance may be achieved in network composition [“...the LF profits from the important network of institutional contacts of the MAR's Head ... if they (CAH) cannot provide us a solution, they search among its network of contacts and remit us to another research center (LF's $R \& D$ Manager)]. Therefore, our data suggest that revisiting the concept of alliance portfolio capabilities (Hoffmann, 2007; Sarkar et al., 2009) using real options thinking may be an interesting line for further work. 

CHAPTER 5.

CONCLUSION, IMPLICATIONS, LIMITATIONS, AND FUTURE RESEARCH 


\section{Chapter structure}

5.1. Summary of findings and implications for research.

5.1.1. Study I.: Understanding the creation of organizational collaborative routines.

5.1.1.1. Why some inexperienced partners are more cooperatively than others during the formation stage of multi-partner R\&D alliances

5.1.1.2. Contributions to research objective (I ).

5.1.2. Study II.: Understanding the value-creation dynamics of R\&D alliances:

Creation and evolution of inter-organizational collaborative routines.

5.1.2.1. Study II.1: How unfamiliar partners succeed in explorative alliances: Creating knowledge-sharing routines.

5.1.2.2. Study II.2: How familiar partners succeed in exploitative and explorative alliances: Redeploying knowledge-sharing routines

5.1.2.3. Contributions to research objective (II)

5.1.3. Methodological contributions

5.1.4. Overall conclusion: Towards a more comprehensive view on the collaboration and value-creation dynamics of MR\&D alliances.

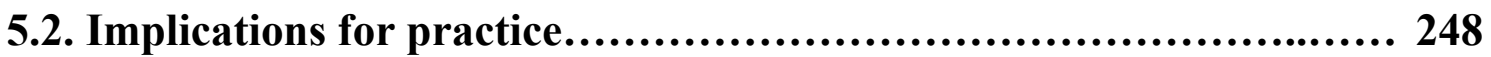

5.2.1. Managerial recommendations............................................................. 248

5.2.2. Policy recommendations............................................... 251

5.3. Limitations....................................................... 252

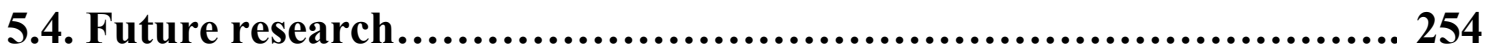


...Where is that process of reasoning which, from one instance, draws a conclusion, so different from that which it infers from a hundred instances that are nowise different from that single one? ... But if you insist that the inference is made by a chain of reasoning, I desire you to produce that reasoning.

David Hume

An Enquiry Concerning Human Understanding (1748)

This dissertation aims to contribute to a more comprehensive view on the dynamics of collaboration and value-creation in multi-partner R\&D alliances (MR\&D alliances). To accomplish this general research objective, empirical efforts have focused on in-depth longitudinal study of a real-life MR\&D alliance: The Acuisost Consortium. By iteratively reviewing existing literature and collecting and analyzing data on different levels of the Acuisost Consortium, the general research objective of the dissertation has been specified in two specific research objectives. These objectives in turn have been addressed in the empirical studies through different research questions. In order to show the contributions of this dissertation, this chapter follows a 'from the particular to the general' approach (see Figure 5.1), according to the principle of analytical generalization in case study research (Yin, 2003).

Figure 5.1. Analytic generalization of findings in this dissertation

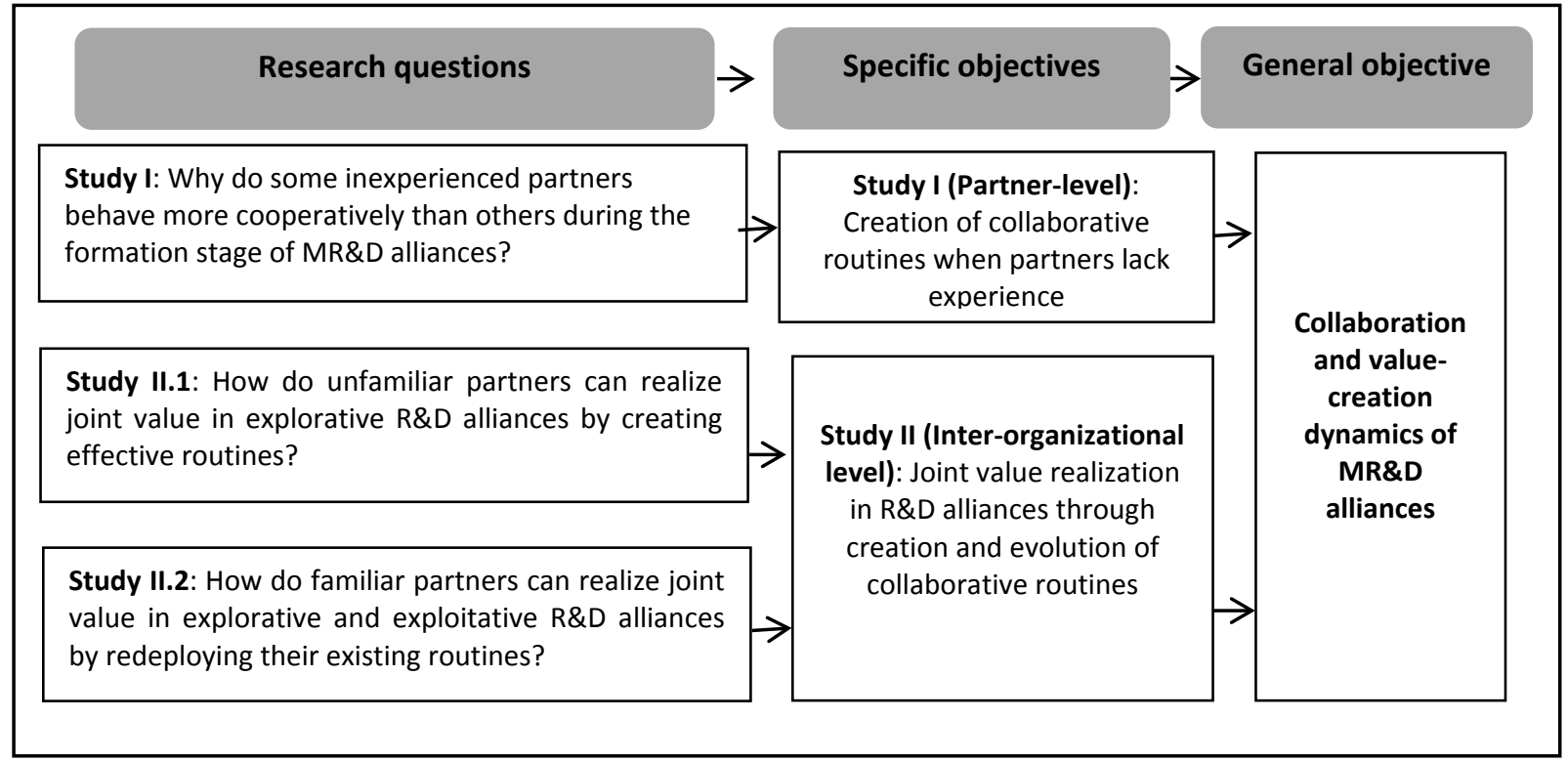

First, the main implications for research are presented through this process: after discussing how findings of each study contribute to cover the specific objectives of the dissertation, an overall conclusion is drawn. To understand the scope of these contributions, the main methodological implications are also highlighted. Next, academic conclusions are extended to the practical level, deriving some recommendations for managerial and policy practice. Once discussed the main limitations, some interesting avenues for further work are presented. 


\subsection{Summary of findings and implications for research}

\subsubsection{Study I. Understanding the creation of organizational collaborative routines}

\subsubsection{Why some inexperienced partners are more cooperatively than others during the formation stage of multi-partner $R \& D$ alliances}

Study I examines why some partner firms of the Acuisost Consortium behaved more cooperatively than others during the formation stage, taking into account that the situation proved to be highly challenging for all them: partners firms of the Acuisost Consortium lacked significant alliance experience and the MR\&D alliance entailed a social dilemma for cooperation (Das \& Teng, 2002; Zeng \& Chen, 2003). To that end, we followed the analytic strategy of 'explanation building' (Yin, 2003), which allows simultaneously theory-testing and theory-building. We first launched three theoretical propositions, focusing on three variables highlighted by prior research -direct competition among partners (e.g., Valdés-Llaneza \& García-Canal, 2006), learning orientation of the partner firm with the consortium (e.g., Mothe \& Quelin, 2001), and its strategic importance for the partner firm's business development (e.g., Olk \& Young, 1997). We then moved to case analysis, conducting first within-case analysis of five selected cases or partner firms of the Acuisost Consortium (i.e., Mediterranean Aquaculture, Fish\&Meals, Cantabrian Seafood, Iberian Eels, and BioMilk) and subsequently cross-case analysis (combining qualitative evidence from those five cases and quantitative data on all the consortium partner firms).

This first study shows that perceived risk of unintended knowledge leakages from the presence of direct competitors in the MR\&D alliance discouraged inexperienced partners to behave cooperatively directly and indirectly: direct competition weakened the effects of other learning and strategy-related motivations. Likewise, evidence on the Acuisost Consortium shows that certain external events (e.g., partner firms' financial problems or concurrent involvement in other projects) discouraged some partner firms from behaving cooperatively. Furthermore, Study I concludes that, in the absence of direct competition and other negative external events, most cooperative partners of the Acuisost Consortium were strongly learning-oriented and perceived that such learning was strategically important, either for improving their current market position (exploitation learning) or for profiting from new market opportunities in future (exploration learning).

\subsubsection{Contributions to research objective (I)}

Study I improves existing understanding on the creation of organizational collaborative routines when partners lack significant alliance experience, by showing that cooperative behavior could be better understood as a purposefully built routine which concerns the soft side of alliance capabilities (Simonin, 1997; Zollo et al., 2002; De Man et al., 2010). Combining lifecycle 
approaches of alliances (e.g., Reuer, 2000) and capabilities (Helfat \& Peteraf, 2003), we argue that the founding stage of organizational collaborative routines takes place, at least in part, during the formation stage of the MR\&D alliance. In this regard, this study concludes that the partner decision to start building collaborative routines (1) is a matter of value-creation expectations the partner holds with such a decision (Adner \& Helfat, 2003; Ambrosini \& Bowman, 2009), and (2) involves the managerial comparison between potential benefits and costs (Winter, 2003). Thus, Study I supports the conclusions of prior studies suggesting that direct competition among partners in alliances likely eclipses cooperation (Park \& Russo, 1996; García-Canal et al., 2003; Oxley \& Sampson, 2004; Valdés-Llaneza \& García-Canal, 2006), that learning orientation and strategic importance may foster cooperation (Hamel, 1991; Parkhe, 1993; Cullen et al., 1995; Olk \& Young, 1997; Mothe \& Quelin, 2001; Wu \& Cavusgil, 2006), and that internal dynamics of cooperation in alliances co-evolve with external factors located at the alliance context (Ariño \& De La Torre, 1998; Koza \& Lewin, 1998).

However, contributions of Study I do not confine to replicate existing evidence for the case of inexperienced partners. Study I shows that the roots of value-creation expectations underlying the creation of collaborative routines are of intricate and dynamic nature. First, value-creation expectations are forged by the interplay among factors like direct competition, learning orientation, and strategic importance. In particular, learning orientation and strategic importance jointly generate strong value-creation expectations with the building of collaborative routines (important potential benefits in the form of exploitation or exploration of strategic opportunities), whereas the existence of direct competitors in the MR\&D alliance provokes the opposite effect (important costs in the form of unintended knowledge leakages). As we observed in the Acuisost Consortium, inexperienced partners facing the threats of direct competition in the alliance may understand that costs of exercising collaborative routines (erosion of firm's competitive position) outweigh benefits (improvement of firm's competitive position), thus deciding not to invest in the building of such routines. Second, the building process of collaborative routines is a dynamic process, as long as the value-creation expectations underlying such investment decisions may change over time and evolve in close connection with the environment. Partners iteratively assess and reassess their value-creation expectations (Ring \& Van de Ven, 1994; Doz, 1996; Ariño \& De La Torre, 1998). As a result, updates of the benefits-costs comparison may induce partners to abandon the building of collaborative routines. In doing so, Study I enriches the lifecycle understanding of the capabilities to collaborate, shedding some light on how the organizational processes of alliance experience accumulation and alliance capability building may commence (Helfat \& Peteraf, 2003; Rothaermel \& Deeds, 2006; De Man et al., 2010). Furthermore, Study I contributes to the 'microfoundations perspective of alliance capabilities' (Teece, 2007; Schilke \& Goerzen, 2010) 
by focusing on those collaborative routines located at the underexplored soft side of alliance capabilities (De Man et al., 2010).

\subsubsection{Study II. Understanding the value-creation dynamics of $R \& D$ alliances: Creation and evolution of inter-organizational collaborative routines}

\subsubsection{How unfamiliar partners succeed in explorative alliances: Creating knowledge-sharing routines}

Study II.1 examines how unfamiliar partners may or may not realize joint value in explorative $\mathrm{R} \& \mathrm{D}$ alliances by conducting a comparative longitudinal study on two firm-research organization alliances of the Acuisost Consortium, one successful (the OI-LF alliance) and other failed (the CRAI-LF alliance). This comparative case study has focused on the creation of knowledge-sharing routines at the inter-organizational level of analysis (Dyer \& Singh, 1998; Helfat \& Peteraf, 2003). Aiming to inductive theory-building (Eisenhardt, 1989) and relying on insights from the psychological contracts literature (e.g., Rousseau, 1995), it has yielded three main conclusions.

First, perceived technological complementarities at the inception of the alliance smooth the initiation of collaboration by encouraging partners to actively exchange knowledge and reducing the negative impact of relational dissimilarities (honeymoon period). Second, the quality of subsequent of interactions (once the honeymoon period phases out) is contingent on the nature of relational dissimilarities; divergence in partners' beliefs is reparable when concerns the operational aspects of the alliance (i.e., how to collaborate), whereas it may be difficult to overcome divergences about the strategic aspects of the alliance (i.e., why to collaborate). Third, only if relational dissimilarities are progressively eroded as collaboration evolves, perceived technological complementarities hold in levels high enough to motivate further collaborative commitments, in turn allowing joint realization of value.

\subsubsection{How familiar partners succeed in exploitative and explorative alliances: Redeploying knowledge-sharing routines}

Study II.2 examines how familiar partners may realize joint value in explorative and exploitative R\&D alliances by conducting a comparative longitudinal study on two successful firm-research organization alliances of the Acuisost Consortium, one exploitation-oriented (the CAH-LF alliance) and other exploration-oriented (the MAR-LF alliance). This comparative case study have focused on the redeployment of existing knowledge-sharing routines (Dyer \& Singh, 1998; Helfat \& Peteraf, 2003) of familiar partners in a focal alliance (i.e., the alliance under the Acuisost Consortium) but taking into account the whole collaborative relationship between them. Aiming at inductive theory-building (Eisenhardt, 1989) and relying on real 
options reasoning (Myers, 1984; McGrath \& Nerkar, 2004), Study II.2 has yielded three main conclusions.

First, familiar partners may have developed ambidextrous routines along their history of mutual collaboration, and redeployment of those routines in a new focal $R \& D$ alliance (regardless its formal orientation) may entail both exploring and exploiting technological opportunities. Second, managerial cognition is more relevant in explaining heterogeneity in redeployment than the formal seeking-orientation of the focal alliance. Third, familiar partners are able to realize joint value in both explorative and exploitative alliances when they apply a flexible redeployment strategy which allows them to manage environmental uncertainty over time, having already overcome social uncertainty.

\subsubsection{Contributions to research objective (II)}

Study II contributes to research in strategic alliances by showing that notions like 'psychological contracts incongruence', 'false consensus effect' or 'breach/violation of the psychological contract' (e.g., Morrison \& Robinson, 1997) could offer important intuitions to understand the dynamics of 'type II partner diversity' (Parkhe, 1991) and its connections with the processes of collaboration and value realization in R\&D alliances. Likewise, Study II shows that the conceptualization of collaborative relationships as 'portfolios of embedded collective real options' (Vassolo et al., 2004; McCarter et al., 2011) could provide valuable insights into how histories of inter-organizational collaboration are built and evolve over time. In this regard, Study II extends the literatures linking the phenomena of strategic alliances with the fields of psychological contracts (Rousseau, 1995; Rousseau \& Tijoriwala, 1998) and real options (Kogut, 1991; McGrath \& Nerkar, 2004). More specifically, Study II.1 and Study II.2 jointly contribute to existing understanding on the value-creating dynamics of $R \& D$ alliances by explaining (1) how unfamiliar partners can succeed at exploration by creating effective interorganizational collaborative routines, and (2) how familiar partners can succeed at either exploration or exploitation by effectively redeploying their existing collaborative routines. In doing so, Study II sheds some light on the developmental processes of the capability of two partners to collaborate together (Madhok \& Tallman, 1998; Helfat \& Peteraf, 2003) studying how accumulation of mutual experience shapes its constituent elements (Zollo et al., 2002; Hoang \& Rothaermel, 2005). Therefore, Study II contributes to extend the 'microfoundation perspective of dynamic capabilities' (Teece, 2007) into the field of alliance capabilities (Kale \& Singh, 2009; Schreiner et al., 2009; De Man et al., 2010).

Concerning existing research into explorative $\mathbf{R} \& D$ alliances between unfamiliar partners, Study II.1, adopting a markedly process-oriented perspective, extends insights provided by existing research. First, Study II.1 shows the role that collaborative processes may play in 
moving from value potential to value realization (Doz, 1996; Madhok \& Tallman, 1998), largely ignored by studies in the stream on alliance formation(e.g., Goerzen, 2007; Phelps, 2010). In this regard, the CRAI-LF alliance showed that realization of value from technological complementarities does not occurs automatically from knowledge exchange between the unfamiliar partners but reflects a much more complex unfolding story in which relational dissimilarities play a key role. Second, Study II.1 shows the role that inter-partner interaction may play in solving relational dissimilarities among unfamiliar partners, largely ignored by studies in the stream on alliance management (e.g., Zollo et al., 2002; Tiwana, 2008). Effective routines for knowledge exchange are more likely to be created if partners' divergence concerns the operational aspects of collaboration than if it concerns the strategic aspects of the alliance. The OI-LF alliance showed that first interactions between unfamiliar partners which were able to overcome their relational dissimilarities encourage the building of a subsequent collaborative story (Doz, 1996; Dyer \& Singh, 1998). Third, Study II.1 shows the links between technological complementarities and relational dissimilarities taking place along the collaborative processes, usually overlooked by studies in the integrative tradition (Sarkar et al., 2001; Hoang \& Rothaermel, 2005; Gulati et al., 2009). In this regard, both the OI-LF and the CRAI-LF alliances showed that technological complementarities and relational dissimilarities exert different but interdependent effects on alliance success.

Concerning existing research into exploitative and explorative R\&D alliances between familiar partners, Study II.2 provides interesting counterpoints to studies in the stream on alliance formation, which suggest failure of exploration-oriented collaboration between familiar partners due to 'the paradox of embeddedness' (Uzzi, 1997). At the same time, Study II.2 extends insights provided by studies in the stream on alliance management (Zollo et al., 2002; Tiwana, 2008). In concurrence with predictions of the later stream of research, the CAH-LF and MAR-LF alliances demonstrated that $R \& D$ alliances between familiar partners, either exploitation or exploration-oriented, are likely to success when adequate inter-organizational routines exist and are applied. Furthermore, Study II.2 overcomes two important limitations of existing research by shedding light on the process by which familiar partners jointly transfer their routines into a new focal alliance, explicitly considering it as embedded in a broader collaborative relationship. In doing so, it enriches the field of research on 'capabilities and resources redeployment', which has traditionally focused on acquisitions instead of alliances (Anand \& Singh, 1997; Capron \& Mitchell, 1998; Capron et al., 1998).

\subsubsection{Methodological contributions}

This dissertation has addressed calls for longitudinal case studies that are capable of capturing the complexities of collaboration (Smith, Carroll, \& Ashford, 1995; Madhok \& Tallman, 1998) and the dynamics of dynamic capabilities (Rosenbloom, 2000; Verona \& Ravasi, 2003). More 
specifically, longitudinal case study research is ideally suited to capture the collaboration and value-creation dynamics of MR\&D alliances (Doz et al., 2000; Das \& Teng, 2002) and is consistent with the process nature of collaborative routines, being able to clarify their developmental processes (Dyer \& Nobeoka, 2000; Rerup \& Feldman, 2011). In doing so, this dissertation makes two important methodological contributions.

The first contribution concerns the overall research design and setting of this dissertation. Empirical efforts have focused on the Acuisost Consortium as the research setting, addressing the creation and evolution of collaborative routines at two different levels of analysis: (1) collaboration among the multiple partner firms of the Acuisost Consortium (partner-level) and (2) dyadic collaboration between firms and research organizations in the Acuisost Consortium (inter-organizational level). In particular, Study I adopts a multi-case design and Study II.1 and Study II.2 adopt comparative designs of two different pair of cases, both associated to rigor and replication logic in case study research (Eisenhardt, 1989; Yin, 2003) As a whole, this dual design has generated an embedded case-study on the Acuisost Consortium, which allows a more fine-grained understanding on the phenomenon under study than holistic designs (Yin, 2003) and thus fits better the multi-level nature of collaboration and value-creation dynamics of MR\&D alliances than single-level research (Nielsen, 2010).

The second contribution has to do with the specific processes of data collection and analysis followed in this dissertation. Data on the different levels of the Acuisost Consortium have been obtained on a longitudinal fashion, both retrospectively and ongoing, covering the whole life cycle of the consortium and allowing thus a markedly process-oriented perspective on the phenomena under study (Pettigrew, 1990; Langley, 1999; Salk, 2005). Moreover, the adoption of multilevel triangulation criteria- data, researcher, and methodological triangulation- ensure validity and rigor of research (Patton, 2002; Yin, 2003). In this line, research methodology theorists (Langley, 1999; Gibbert et al., 2008) suggest that using together the two sensemaking strategies of narrative and quantification enables both theoretical parsimony by abstracting from original data (quantification strategy) and empirical accuracy by providing 'thick descriptions' (narrative strategy). Furthermore, explicit operationalization of constructs has allowed the generation of relatively 'good stories with good constructs', building a rigorous case-study research (Eisenhardt, 1991) thereby offering relevant academic and managerial knowledge (Gibbert et al., 2008).

\subsubsection{Overall conclusion: Towards a more comprehensive view on the collaboration and value-creation dynamics of multi-partner $R \& D$ alliances}

MR\&D alliances constitute valuable strategies to deal with the challenge of continuously explore and exploit innovation opportunities, and thus are becoming increasingly commonplace 
in business practice. At the same time, MR\&D alliances impose significant challenges for cooperation and value realization (Das \& Teng, 2002; Mahnke \& Overby, 2008). Despite some important insights provided by prior research (Olk \& Young, 1997; Sakakibara, 1997; Mothe \& Quelin, 2001), the intriguing collaboration and value-creation dynamics of MR\&D alliances are still not well understood (Doz et al., 2000; Das \& Teng, 2002). This dissertation aims to contribute to a more comprehensive view on these dynamics, taking into account that collaborative routines (1) may play a key role in reducing the gap between value potential and value realization in MR\&D alliances (Dyer \& Singh, 1998; Madhok \& Tallman, 1998), and (2) could exist at the partner- and inter-organizational levels (Simonin, 1997; Zollo et al., 2002), fitting the coexistence of two kind of relationships in MR\&D alliances (Das \& Teng, 2002; Thorgren et al., 2010).

Although a different approach has been followed in each empirical study of this dissertation, the notions of 'collaborative routines', 'value-creation expectations', 'technological complementarities', and 'relational (dis)similarities' provide the guiding thread to draw these two overall conclusions: (1) Investments, in both creation of new collaborative routines and redeployment of existing ones, are contingent on value-creation expectations, in turn determined by the interactions between technological complementarities and relational (dis)similarities and, (2) such interactions are particularly complex in MR\&D alliances, likely provoking failure in the cost-benefit calculus of collaborative investments.

Building and redeployment investments in collaborative routines are contingent on valuecreation expectations (Helfat \& Peteraf, 2003; Winter, 2003), at both the organizational and the inter-organizational levels. Value-creation expectations are, in turn, forged through managerial comparison between costs and benefits associated with technological complementarities and relational (dis)similarities among partners (Madhok \& Tallman, 1998). Therefore, the processes of investments in collaborative routines may be "continually shaped and restructured by actions and symbolic interpretations of the parties involved" (Ring and Van de Ven, 1994: 96).

Technological complementarities not only give meaning to the partners' decision to join a MR\&D alliance (Doz et al., 2000; Mothe \& Quelin, 2001), but also may drive their decision to undertake purposeful investments in collaborative routines. Perceived complementarities between the partner's own resource endowment and either the MR\&D alliance as whole or other specific partners, determine the strategic importance of the potentially attainable benefits (Parkhe, 1991). As observed in the Acuisost Consortium, if partners start collaboration with strong expectations of accessing complementary knowledge and gain significant innovation and learning benefits from the MR\&D alliance, they will be motivated to adopt individual cooperative strategies during the alliance formation stage and to invest in the creation and 
maintenance of interaction patterns with other specific partners (Fichman \& Levinthal, 1991; Doz, 1996).

Concerning relational similarities, however, the experience of Acuisost Consortium does not yield an unequivocal rule on their effects on collaborative routines and value realization in MR\&D alliances, as previous literature usually suggests (Parkhe, 1991; Zollo et al., 2002). Indeed, the Acuisost Consortium teaches that relational dissimilarities may be not so bad, and relational similarities may be not so good. To provide a complete explanation of their effects, it is necessary to consider their interconnections with technological complementarities (Sarkar et al., 2001). On the one hand, the existence of relational dissimilarities between the partners is not always negative, depending on its nature. If partners' divergences affect the operational aspects of the collaboration (and not the strategic aspects), the process of interaction itself may feedback initial value-creation expectations from technological complementarities, motivating further relation-specific investments in the creation of collaborative routines, furnishing thus likelihood of value creation. On the other hand, relational similarities do not always facilitate the process of interaction among partners and support investments in collaboration routines in MR\&D alliances. For this to happen, the Acuisost Consortium experience points to two conditions that must be simultaneously in place: relational similarities among partners are not at the expense of their capacity to provide each other complementary resources and generate new knowledge (Lavie \& Rosenkopf, 2006; Tiwana, 2008), and such new knowledge generates mutual benefits that do not erode the competitive position of one of the partners vis-à-vis its rivals (Park \& Russo, 1996; Valdés-Llaneza \& García-Canal, 2006).

Although existing literature has paid significant attention to elucidate the connections between the gains from alliances and the nature of alliance experience (Hoang \& Rothaermel, 2005; Sampson, 2005; Gulati et al., 2009), it has not highlighted the key role played by alliance experience in the cost-benefit calculus of collaborative investments (Madhok \& Tallman, 1998). In MR\&D alliances, interconnections between technological complementarities and relational (dis)similarities are highly complex basically because they occur at two different levels simultaneously (i.e., between a partner and the MR\&D alliance and between two specific partners of the MR\&D alliance). As a result, lack of alliance experience may produce imprecise cost-benefit comparisons, partners may thus fail to choose the most promising option from available collaborative investments, incurring in opportunity costs.

At the partner-level, inexperienced partners may overemphasize the risk of unintended leakages of knowledge, misvaluing other potential benefits (i.e., social capital and learning) that could only be accrued by building organizational routines for multi-partner cooperation. Furthermore, when lack of alliance experience in multi-partner alliances is combined with some experience in 
dyadic R\&D collaboration, overpessimistic calculus and organizational inertia (Tripsas \& Gavetti, 2000; Winter, 2003) may provoke a kind of 'crowding out effect', biasing partners' investment decisions towards narrow areas of dyadic instead of multilateral collaboration within the MR\&D alliance. As we observed in the Acuisost Consortium, this situation is accentuated when partners realize that they could achieve their technological objectives without facing the risks inherent in multi-partner collaboration ${ }^{1}$. At the inter-organizational level, the managerial cost-benefit comparison of redeploying inter-organizational routines that have been created through long histories of interaction with other partners is easier. Familiar partners operate together in stable collaborative scenarios, where the values of reciprocity and mutuality yield additional benefits and foster the creation of collaborative value (Dyer \& Singh, 1998; Tiwana, 2008). By contrast, unfamiliar partners may overvalue the innovation opportunities potentially attainable by pooling their resource endowments, costs of resources integration remaining undiscounted. Such overenthusiastic calculus may lead partners to undertake relational-specific investments in inter-organizational routines without previously checking the feasibility of joint collaboration with the new partners. The challenge here resides in that unfamiliar partners have to abstract from potential advantages and strive for discovering insuperable relational barriers before it is too late: these relational barriers may remain latent otherwise (Morrison \& Robinson, 1997), rendering investments undertaken so far in inter-organizational routines unproductive.

\subsection{Implications for practice}

Based on the in-depth investigation of the Acuisost Consortium, some recommendations for forming and managing MR\&D alliances in practice are offered below. Given the governmentsponsored nature of the Acuisost Consortium, these recommendations concern both managerial action in MR\&D alliances and public funding of these collaborative initiatives.

\subsubsection{Managerial recommendations}

The in-depth study on the Acuisost Consortium has allowed the identification of factors both promoting and hindering multilateral cooperation and value-creation. In the following, we integrate these observations and translate them into managerial recommendations, concerning both the formation and post-formation of MR\&D alliances, especially those engineered by a triggering entity.

\footnotetext{
${ }^{1}$ Although beyond the scope of this dissertation, collected data allowed a preliminary exploration of the value-creation implications of cooperative behavior during the formation stage. Partner firms making strong cooperative efforts seemed to profited more from social capital and learning opportunities afforded by the consortium than their non-cooperative counterparts. A priori no significant differences, however, were observed concerning progress towards innovation and overall satisfaction achieved by partner firms during the formation stage.
} 
Selecting potential partners. Triggering entities thinking of engineering a MR\&D alliance must be the first assuming that (1) multilateral cooperation among the multiple partners is a necessary condition to realize the potential value offered by these alliances, and (2) specific strategic measures must be adopted if such multilateral cooperation is to be created. Under this spirit, maps of potential partners should contain organizations with and without prior mutual experiences because, as we observed in the Acuisost Consortium and Capaldo (2007) concludes, such kind of dual networks maximize the innovation potential. However, two important aspects should be taken into account during the partner selection process: (1) whether familiar partners working together would be able to create new knowledge (or would fall in redundancies and inertia) and (2) whether unfamiliar partners would be able to effectively work together. Therefore, specific attention should be paid not only to the theoretical synergies and technological complementarities that can emerge among the multiple partners, but also to the compatibility of their respective value-creation expectations. After all, value-creation expectations guide the collaborative strategies and behaviors that these potential partners would adopt during the alliance. Furthermore, when approaching potential partners, triggering entities must convey such spirit of multilateral cooperation and emphasize the potential benefits it affords, making clear the kind of commitments that partners will be expected to undertake and that their acceptation is an essential prerequisite to hold the status of 'potential partner'.

Deciding whether to be a potential partner. As observed in the Acuisost Consortium and argued by Madhok and Tallman (1998), firms lacking alliance experience may be much more willing to invest in tangible technological resources, where the cost-benefit calculus is easier to evaluate, than undertaking 'long-term investments in relationships'. Hence, entrepreneurial managers assessing whether to join or not the MR\&D alliance should meditate what benefits they may expect beyond the pure technological ones, being aware that (1) social capital and learning benefits are important antecedents of long-term innovation, and (2) the building of 'collaborative routines' would be required to attain them. When joining a MR\&D alliance seems to be significantly advantageous for the firm but there are direct competitors in the alliance, firms must assess whether it is possible to create a reciprocity-based atmosphere, rather than giving up, a priori, the opportunity to build valuable collaborative routines. As stated by Fuentelsaz and Gómez (2006) reciprocity in contacts between direct competitors may lead to mutual forbearance.

Negotiating written and unwritten contracts. Although triggering entities should provide a starting structure and guidance for the design of the alliance, they should not monopolize the process by deciding unilaterally. Intense negotiations on the terms of the alliance are required, giving all potential partners voice and vote. Although time-consuming, this process could (1) bring to the fore each partner's expectations about what the alliance is and how it should 
operate, and (2) ensure that partners that make contractual commitment with the MR\&D alliance are those who share the spirit of multi-partner cooperation. Therefore, negotiations should not be limited to the written contract, but include the unwritten contracts. In fact, the formal contract should reflect the 'psychological contract' of the alliance as a whole, explicitly describing participation in multilateral dialogue and interaction as a reciprocal obligation of the partners.

Structuring the MR\&D alliance. As observed in the consortium and concluded by Dyer and Nobeoka (2000) for the Toyota case, establishing several subprojects may improve efficiency and coordination in MR\&D alliances. However, this structure should not be confused with the creation of a collection of dyadic relationships that are grouped into different subprojects. Thus, it should be avoided that members could fully accomplish their (formal) private objectives without engaging in multilateral cooperation. In this regard, structuring explicitly the consortium as a portfolio of interconnected collaborative opportunities, and explaining the power of such interconnections to the participating firms, may facilitate the emergence of a spirit of multi-partner cooperation. On a more practice level, the creation of bridge teams entailing close interaction between individuals of multiple alliance partners (Lunnan \& Barth, 2003) sounds very useful to promote synergies and coordination.

Promoting and monitoring multi-partner cooperation. In addition to design a favorable structure, it should be continuously promoted the multilateral interaction within and between each subproject, establishing adequate interfaces to that end. In this regard, as we observed in the Acuisost Consortium, two practices may be especially valuable: (1) holding multilateral technological meetings in each subproject, and (2) appointing a coordinator for each subproject who, in close coordination with the leader of the MR\&D alliance, promotes interaction and collaboration within and between subprojects. To make these measures more effective, especially when the partners do not have experience, it may be useful to establish associated contractual commitments and incentives. As observed in the Acuisost Consortium and explained by Dyer and Nobeoka (2000) for the Toyota case, the lead firm of the MR\&D alliance may play a key motivating role. However, in MR\&D alliances in which two coordinating entities coexist, both of them should share the same governance style, such that, for example, non-relational actions of the triggering entity cannot annul the capacity of a relational-oriented leader to socially sanctioning partners' undesirable behaviors.

Maintaining expectations and managing tensions between partners. Although a spirit of multilateral cooperation had been achieved in the MR\&D alliance, it is possible that over time (1) value-creation expectations of partners change, and (2) tensions arise between the partners, especially between those who work directly with each other to achieve a specific objective. 
Thus, it is important to monitor the evolution of partners' expectations, and triggering entities and leader firms need to preserve the adequate conditions for their realization. In this regard, managers are recommended to structure collaboration with valuable partners as long-term chains of mutual opportunities: partners, thinking in their joint future (Parkhe, 1993), may be motivated to invest in polyvalent interaction mechanisms and to generate mutual benefits. Similarly, it is important to actively manage ongoing tensions. In this regard, managers should be aware that successful collaboration requires active investments in both relationship-building and maintenance. In the case of partners that have not collaborated together before, managers are encouraged to reset 'the psychological contract clock' and strive to bring the hidden expectations of each partner to the fore. As observed in the Acuisost Consortium and argued by Ariño and Doz (2010) assuming that my beliefs about how and, particularly, why collaborate are probably not the beliefs of my partner, may allow solving these tensions 'before it is too late'.

\subsubsection{Policy recommendations}

Governments throughout the world are investing more and more funds in the creation of R\&D consortia. For example, the Spanish CENIT Programme has invested 1072 million Euros in the period 2006-2010, supporting 91 consortia in which 1253 firms (60\% SMEs) and 1589 research organizations have participated. Ii is therefore important to assess the efficiency and returns of these millionaire R\&D investments of public money. Government evaluations usually conclude that these policy programmes yield important technological outcomes. Thus, the CENIT Programme in the period 2006-2010 yields 211 patents, 1867 industrial prototypes, 565 scientific publications, and the creation of 52 new multi-partner R\&D alliances funded by the VII European Union Framework Programme (2007-2013). However, scholarly studies in the field of innovation management usually offer complementary assessments (Herrera \& Nieto, 2008; Silva, Leitao, \& Raposo, 2008). For example, Herrera and Nieto (2008) emphasize the need to consider the geographic location of firms in order to assess correctly the effect of national innovation policies. In this regard, the in-depth study on the Acuisost Consortium, government-sponsored by the CENIT Programme, has allowed the identification of the following recommendations- especially for policy programmes similar to the CENIT Programme.

Beyond public financial support. Public funds may bring otherwise unattainable R\&D opportunities to inexperienced firms, often SMEs in non-high-tech industries. Many representatives of the partner firms of the Acuisost Consortium emphasized this point during interviews. However, public support should not confine to the financial aspects if inexperienced firms are to take advantage of social capital and learning opportunities afforded by multi-partner cooperation. Public policies should help those firms to learn how collaborate in such settings. For example, government agencies may act as triggering entities of mini-constellations formed 
by competitors in industries like Spanish aquaculture facing global competitive challenges. As learning is a matter of experience accumulation, this kind of initiatives may favour, in the longterm, the performance of macro consortia.

Research organizations as consortium partners. In CENIT consortia, research organizations do not hold the status of consortium partners but of technological partners of the consortium firms. This situation contributed to reduce the possibilities of multilateral cooperation in the Acuisost Consortium. First, partner firms in the Acuisost Consortium, unknowing to deal with unintended leakages and being much more accustomed to work bilaterally with research organizations, concentrated their efforts on their bilateral R\&D contracts. Second, the configuration of the Acuisost Consortium as a collection of dyads allowed the accomplishment of R\&D objectives without multilateral cooperation. Furthermore, if research organizations had been consortium partners, they probably would have transferred their spirit of cooperation (accustomed to work in networks and open disclose information in the scientific community) to the Acuisost Consortium. Policy makers are thus encouraged to revisit these membership conditions.

Too much complexity, too less cooperation. Funding programmes like CENIT usually favour the creation of complex consortia (e.g., large number of participants, multidisciplinary, interregional participation), often overlooking the relational potential of the consortium. Furthermore, rigid bureaucratic procedures are usually imposed for these consortia (e.g., complex and time-consuming procedures of funding justification and reception). As many informants of the Acuisost Consortium stated during interviews, inexperienced partners may find particularly difficult to collaborate in such complex settings. Given these observations, policy makers are encouraged to foster the creation of less potential (complex) but more feasible consortia. Therefore, in deciding whether accept or reject a project, public agencies may take into account relational aspects. For example, whether direct competition could be a drawback or whether the implementation of mechanisms promoting multilateral interaction in the consortium is considered. Furthermore, policy agencies are encouraged to significantly simplify the administrative system surrounding these consortia and, particularly, to speed up the progress of funding, letting partners to concentrate on collaboration.

\subsection{Limitations}

Despite the above-discussed implications, this dissertation has some important limitations. As a whole, focusing on the Acuisost Consortium as a research setting involves a clear contextualization of findings, hindering analytical generalization of results into other industrial and institutional contexts. More specifically, the idiosyncrasy of the Acuisost Consortium, whilst bringing the opportunity to study highly interesting phenomena, leads to some shortcomings. 
First, in the formation stage of the Acuisost Consortium, given its engineered nature, there were no overall multi-partner negotiations on its structural and contractual conditions. This peculiarity has impeded Study I to offer insights on cooperation dynamics during negotiations, a crucial aspect in alliance formation (Ariño \& Ring, 2010). Second, our data on firm-research organization relationships of the Acuisost Consortium did not allow the identification of failed alliances between familiar partners. By comparing successful and unsuccessful alliances (rather than two successful alliances) Study II.2 could have yielded more revelatory conclusions (Eisenhardt, 1989). Third, and maybe more important, the idiosyncrasy of the Acuisost Consortium has not allowed the in-depth study of the partner- and the inter-organizational level in interaction (i.e., interactions between the two kinds of relationships that coexisted in MR\&D alliances and have been analysed separately in Study I and Study II). As the lifecycle of the Acuisost Consortium evolved, the locus of collaboration shifted from the inter-firm level to the firm-research organization level, without experiencing significant interactions between them. Indeed, some firms behaving non-cooperatively during the formation stage developed successful collaboration with their research organizations (and vice versa). Therefore, ongoing data collection and analysis indicated that the research focus of this dissertation should also shift from collaboration among the multiple partner firms to the firm-research organization relationships of the consortium. Insights on interactions between the partner- and the interorganizational levels may have yielded a more comprehensive view on the dynamics of MR\&D alliances (Nielsen, 2010). This limitation reflects what Yin (2003) refers to as 'failing to return to the larger unit of analysis in embedded case-study designs'.

On a more pure methodological level, this dissertation suffers also some limitations. Concerning Study I, research design follows Yin (2003)'s recommendations ('explanation building' with explicit a priori propositions), according to the state of the art (justifying a simultaneous theorytesting and building exercise). However, it must be admitted that an important challenge in positivist case-study research is "to articulate rules or bases for 'deciding associations' and for determining how results and findings fit with preliminary propositions" since this kind of research "lacks the explicit coefficients and criteria for evaluating and falsifying (propositions) that (large-sample) quantitative research has developed" (Gephart, 2004: 456). In this regard, the analysis emerging from the two quantitative techniques employed in Study I (PLS and partition analysis) must be taken with caution ${ }^{2}$. Although these two techniques do not involve hard assumptions about the distribution of variables, the low number of data points has hinder

\footnotetext{
${ }^{2}$ The debate here concerns reliability of the obtained results from the quantitative analysis . Results from case study research always lack statistical generalization (regardless the data points on which the analysis has been generated). Therefore, the main difference between other case studies using quantitative techniques and large 'samples' (e.g., Parent \& Deephouse, 2007), and Study I (18 partners, sometimes offering only 13 data points) does not concern statistical generalization of results.
} 
methodological rigor ${ }^{3}$. In addition, these two techniques have only allowed us to "take pictures" during our "filming" on cooperative behavior (Langley, 1999). Concerning Study II, although data were gathered from key informants of both parties involved in each studied relationship, some research biases may arise from the use of a single-informant within each organization. The quality of the conclusions could be enhanced by triangulating already collected information with new data provided by other informants in each relationship.

On a more pure conceptual level, two main limitations should be noticed. First, a basic assertion in this dissertation has been that the building block of overall value creation is established during the formation stage of alliances (Zajac \& Olsen, 1993; Reuer, 2000), considering cooperation as a key factor for achieving success in MR\&D alliance formation (Ring et al., 2005). From this argument, an important theoretical assumption held in Study I has been that first efforts to build collaborative routines may yield value for partner firms. Although data collection and analysis efforts have offer some preliminary observations in this regard, further explanation is required to offer reliable conclusions. Second, Study II has focused on a particular kind of inter-organizational routines (i.e., knowledge-sharing routines), considered by prior research as key elements of the capability of partners to collaborate together (Dyer \& Singh, 1998; Dyer \& Nobeoka, 2000; Dyer \& Hatch, 2006). In doing so, however, the composite nature of alliance capabilities has been overlooked (De Man et al., 2010): alliance capabilities comprise a collection of interconnected collaborative routines (e.g., joint work and problem-solving routines).

\subsection{Future research}

Beyond large-sample tests of conclusions and other research efforts to overcome the abovediscussed limitations, this dissertation paves the way to undertake some interesting avenues of research. Some of these avenues have been already highlighted in the conclusion section of each empirical study. In the following, other four main lines for future research, more broadly derived from this dissertation, are presented.

Familiness and alliance culture. The five partners of the Acuisost Consortium showing strong cooperative efforts during the formation period were family-owned enterprises (and the lead firm as well). At the same time, other family-owned enterprises of the consortium behaved noncooperatively. These observations seem to reflect existing scholarly debate in the family business field: some scholars emphasize family-owned firms' values of integrity, long-term

\footnotetext{
${ }^{3}$ For example, partition analysis recursively analyses data to map out a 'decision tree' wherein the effect of all variables is simultaneously showed. However, partitions offered in this study were not emerged from a recursive process (due to the small sample, the software could not perform it), but were provided independently (one to one), the good-of-fit measures of the analysis likely having lost explanatory capacity.
} 
commitment, and warmness with suppliers, customers, and other external agents (Habbershon \& Williams, 1999), whereas others state that family firms prefer not to cooperate to avoid interferences from non-family members (Roessl, 2005). Familiness -i.e., the unique bundle of resources and capabilities a particular family-owned firms possesses because of interaction among the family and the business (Habbershon \& Williams, 1999)- and organizational capital (culture, structure, organizational learning processes) seem to be interconnected concepts, the latter having been considered as a potential source of competitive advantage (Martín-de-Castro, Navas-López, López-Suárez, \& Alama-Salazar, 2006). Given that family-owned firms are key actors in business landscape, future studies clarifying the links between familiness and alliance culture (De Man et al., 2010), could extend our understanding of collaboration dynamics of multi-partner alliances.

Relational governance in multi-partner alliances. Relational governance refers to the extent to which the alliance is managed through relational norms (Heide \& John, 1992; Sarkar et al., 2009). Relational norms may create an ideal atmosphere for cooperation by defining clearly which partners' behaviors will be acceptable and what is 'off-limits' (Dyer \& Singh, 1998). The Acuisost Consortium offers an interesting setting to explore this question in multi-partner contexts because two coordinating entities with two different governance styles coexisted: the triggering entity (non-relational governance style) and the lead firm (relational governance style). Although beyond the scope of this dissertation, we observed action-reaction loops between the two coordinating entities in the Acuisost Consortium, yielding intriguing effects on partners' cooperation and suggesting trade-offs between direct reciprocity (between each coordinating entity and the partners) and generalized reciprocity (among the multiple partners). Further exploration of these questions could contribute to understand the unique dynamics of cooperation of those MR\&D alliances which are created ad-hoc by a triggering entity and count on a formal alliance leader.

The relational and redeployable sides of collaborative routines in interaction. The redeployable side of collaborative routines has to do with the individual alliance capabilities of a particular organization, whereas the relational side has to do with the capability of some specific partners to collaborate together (Mesquita et al., 2008) ${ }^{4}$. In this regard, Study II has

\footnotetext{
${ }^{4}$ Mesquita et al. (2008), combining the resource-based and relational views, identify two basic components of value realization in alliances at the firm-level: the redeployable performance (average performance that a firm achieves by redeploying its collaborative routines across its alliance portfolio) and the relational performance (performance achieved by a firm with a specific partner). Concerning this distinction a clarification should be made. As defined by Mesquita et al. (2008), the redeployable component refers to the firm-level of analysis. Broadly speaking, redeployment is the process by which a firm individually transfers its existing resources and capabilities to a new strategic scenario (Anand \& Singh, 1997; Helfat \& Peteraf, 2003). Notice that in Study II.2 this concept has been extended to the inter-organizational level (Capron \& Mitchell, 1998), defining redeployment of familiar partners' routines as the process by which they jointly transfer their existing joint routines into a new focal alliance.
} 
exclusively focused on the relational side of inter-organizational collaborative routines, without exploring potential interactions among two sides. Existing research has not explored these issues either, and thus interesting questions remain open for further work. For example, in the context of the Acuisost Consortium, how did the new individual experiences the lead firm gained with new partners (e.g., OI and CRAI, Study II.1) affect the evolution of interorganizational collaborative routines with its familiar partners (e.g., CAH and MAR, Study II.2.)?

Psychological contracts of familiar partners. The OI-LF alliance (Study II.1) illustrates how unfamiliar partners could develop a shared psychological contract. Likewise, although beyond the scope of Study II.2, the CAH-LF and MAR-LF cases (familiar partners) suggest that successful collaborative relationships between familiar partners may be supported by a shared psychological contract. However, existing literature emphasizes the dynamic nature of psychological contracts (Morrison \& Robinson, 1997; Rousseau \& Tijoriwala, 1998). Therefore, familiar partners' psychological contracts may experience iterative cycles of convergence and divergence: beliefs may be continually shaped and reshaped as the familiar partners accumulate new experiences with different partners. These processes have not been enough explained by existing alliance research, and their examination could improve understanding in the dynamics of inter-organizational collaboration.

Real options reasoning in collaboration between unfamiliar partners. Study II.2 shows the usefulness of applying real options reasoning in the study of collaboration between partners with long histories of mutual interactions. Although beyond the scope of Study II.1, some indicators of such real options reasoning were also identified in the OI-LF alliance (unfamiliar partners). For example, when the partners decided to co-patent the jointly achieved (and thus protect them from the risk of pre-emption by rivals) and to deter full commitment of results until the right moment. Furthermore, Study II.1 illustrates how the two unfamiliar partners of this alliance were able to build effective routines of collaboration. Therefore, a promising line for further research could be studying in-depth the creation of alliance capabilities as real options (Kogut \& Kulatilaka, 2001), framing the 'testing the waters' strategy proposed by McCarter et al. (2011) in terms of 'building process of the capability of two partners to collaborate together'. 


\section{List of Appendixes}

\section{Appendixes Chapter 1}

Appendix I.1. Definitions of 'strategic alliances' 259

Appendix I.2. Strategic alliances from different theoretical frameworks...... 260

Appendix I.3. Alliance lifecycle stages................................ 263

Appendix I.4. Relational research on strategic alliances..................... 264

Appendix I.5. Definitions of 'multi-partner alliances' ...................... 269

Appendix I.6. R\&D Consortia: Definitions, formation pathways and casestudy research on R\&D consortia formation.................. 270

Appendix I.7. Definitions and 'intellectual core' of 'dynamic capabilities'.... 274

Appendix I.8. Characteristics and conceptualizations of routines.............. 276

Appendix I.9. Empirical research on dynamic capabilities....................... 277

Appendix I.10. Research on alliance capabilities....................... 280

\section{Appendixes Chapter 2}

Appendix II.1. Typologies of case studies............................... 283

Appendix II.2. Partner firms of the Acuisost Consortium................... 284

Appendix II.3. Research organizations of the Acuisost Consortium........... 287

Appendix II.4. Main sources of information (documents)................. 288

\section{Appendixes of Chapter 3}

Appendix III.1. Main sources of information (Study I).................... 291

Appendix III.2 Operationalization of variables and measures in prior research.. 293

Appendix III.3. Analysis of case study data............................ 305

\section{Appendixes of Chapter 4}

Appendix IV.1. Operationalization of theory-driven variables................. 309

Appendix IV.2. Data on theory-driven variables in Study II.1 ............... 314

Appendix IV.3. Operationalization of data-driven variables in Study II.1....... 319

Appendix IV.4. Data on theory-driven variables in Study II.2 ............... 320 


\section{Appendixes Chapter 1}

\section{Appendix I.1. Definitions of 'strategic alliances'}

\begin{tabular}{|c|c|}
\hline Study & Definition of 'strategic alliance/s' \\
\hline $\begin{array}{l}\text { Porter \& Fuller } \\
(1986)\end{array}$ & $\begin{array}{l}\text { Formal long-term alliances between firms that link aspects of their business but fall } \\
\text { short of merger. }\end{array}$ \\
\hline $\begin{array}{l}\text { Contractor \& } \\
\text { Lorange (1988) }\end{array}$ & $\begin{array}{l}\text { Any medium to long term cooperative relationship between otherwise independent } \\
\text { firms, whether based on an equity joint venture that the principals create, or a } \\
\text { handshake, or on a contractual relationship entailing frequent interactions between } \\
\text { the allied corporations }\end{array}$ \\
\hline $\begin{array}{l}\text { Parkhe }(1991 ; \\
\text { 1993) }\end{array}$ & $\begin{array}{l}\text { Relatively enduring interfirm cooperative arrangements, involving flows and } \\
\text { linkages that utilize resources and/or governance structures from autonomous } \\
\text { organizations, for the joint accomplishment of individual goals linked to the } \\
\text { corporate mission of each sponsoring firm }\end{array}$ \\
\hline $\begin{array}{l}\text { Mohr \& Spekman } \\
\text { (1994) }\end{array}$ & $\begin{array}{l}\text { A purposive strategic relationship between independent firms who share compatible } \\
\text { goals, strive for mutual benefit, and acknowledge a high level of mutual } \\
\text { interdependence }\end{array}$ \\
\hline $\begin{array}{l}\text { Gulati }(1995 ; \\
1998)\end{array}$ & $\begin{array}{l}\text { Any independently initiated interfirm link (a group of firms entering into a voluntary } \\
\text { arrangement) that involves exchange, sharing, or co-development of products, } \\
\text { technologies, or services }\end{array}$ \\
\hline $\begin{array}{l}\text { Das \& Teng } \\
(1998 ; 2000 a)\end{array}$ & $\begin{array}{l}\text { Interfirm cooperative arrangements aimed at achieving the strategic objectives of the } \\
\text { partners/ mutual strategic objectives }\end{array}$ \\
\hline $\begin{array}{l}\text { Garcia-Canal } \\
(1999)\end{array}$ & $\begin{array}{l}\text { Any kind of joint strategic decision made by two or more independent firms to } \\
\text { coordinate part of their actions in order to achieve a shared goal }\end{array}$ \\
\hline $\begin{array}{l}\text { Anand \& Khanna } \\
(2000)\end{array}$ & $\begin{array}{l}\text { An organizational form that allow otherwise independent firms to share resources of } \\
\text { a variety of shorts. Conceptually, an alliance is an intermediate form between } \\
\text { markets and hierarchies }\end{array}$ \\
\hline Ariño (2001) & $\begin{array}{l}\text { An explicit agreement between two (or more) firms to collaborate in a limited aspect } \\
\text { of their activity for a relatively long term, and this may or may not result in a } \\
\text { separate organizational entity }\end{array}$ \\
\hline $\begin{array}{l}\text { Ireland, Hitt \& } \\
\text { Vaidyanath } \\
\text { (2002) }\end{array}$ & $\begin{array}{l}\text { A cooperative arrangement between two or more firms to improve their competitive } \\
\text { position and performance by sharing resources }\end{array}$ \\
\hline
\end{tabular}

\footnotetext{
${ }^{1}$ An exhaustive review of the strategic alliances literature shows a variety in terms of terminology: strategic alliances (e.g., Parkhe, 1993), coalitions (e.g. Porter \& Fuller, 1986), cooperative/collaborative arrangements, ventures, or agreements (e.g. Ariño, 2001), inter-firm (inter-organizational) collaboration/cooperation (e.g. Madhok \& Tallman, 1998), or partnerships (e.g. Mohr \& Spekman, 1994). For simplification purposes, we consider all these terms as interchangeably, although 'strategic alliances' and 'collaboration' are preferred and used as umbrella terms in this dissertation.
} 


\section{Appendix I.2. Strategic alliances from different theoretical frameworks}

\begin{tabular}{|c|c|c|c|c|}
\hline \multicolumn{2}{|c|}{ Theoretical framework } & \multirow[b]{2}{*}{$\begin{array}{l}\text { Alliance rationale } \\
\text { Hybrid forms lying between the polar forms of } \\
\text { market (i.e., arm's-length transactions) and } \\
\text { hierarchy (i.e., organization within the firm } \\
\text { boundaries) that are created when the transaction } \\
\text { costs are intermediate and discourage thus arm's- } \\
\text { length transactions but are not high enough to } \\
\text { justify vertical integration }\end{array}$} & \multirow[b]{2}{*}{$\begin{array}{l}\text { Typical questions } \\
\text { - Choice between strategic alliances and make-or-buy decisions } \\
\text { - Alliance governance choices } \\
\text { - Trust, uncertainty, and opportunism } \\
\text { - Transaction costs and partners' selection } \\
\text { - Efficiency and alliance performance }\end{array}$} & \multirow[b]{2}{*}{$\begin{array}{l}\text { Illustrative references } \\
\text { (Hennart, 1988; Parkhe, } \\
\text { 1993; Dyer, 1997; Dyer, } \\
\text { 1997; Oxley, 1997; } \\
\text { Young-Ybarra \& } \\
\text { Wiersema, 1999; } \\
\text { Colombo, 2003; Yasuda, } \\
\text { 2005; Goerzen, 2007) }\end{array}$} \\
\hline \multirow{3}{*}{ 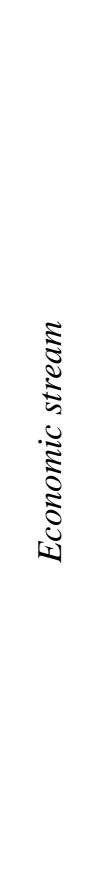 } & $\begin{array}{l}\text { Transaction } \\
\text { cost economics } \\
\text { (Williamson, } \\
\text { 1985) }\end{array}$ & & & \\
\hline & $\begin{array}{l}\text { Agency theory } \\
\text { (Jensen \& } \\
\text { Meckling, } \\
\text { 1976) }\end{array}$ & $\begin{array}{l}\text { Boundary-spanning transactions alliances (and } \\
\text { acquisitions) may be self-serving actions for } \\
\text { managers, to increase their power or prestige, or } \\
\text { simply to reduce their personal risk by minimizing } \\
\text { the overall firm risk. }\end{array}$ & $\begin{array}{l}\text { - Managers' incentives to pursue acquisitions over alliances and } \\
\text { alliances over divestitures } \\
\text { - Influence of agency problems (i.e., separation of ownership } \\
\text { and control) on the development of firms' alliance portfolios } \\
\text { - Alliance implications in terms of average abnormal returns } \\
\text { (shared-holders value) }\end{array}$ & $\begin{array}{l}\text { Reuer and Miller (1997); } \\
\text { Villalonga and McGahan } \\
\text { (2005); Reuer and } \\
\text { Ragzzino (2006) }\end{array}$ \\
\hline & $\begin{array}{l}\text { Game theory } \\
\text { (Axelrod, } \\
\text { 1984) }\end{array}$ & $\begin{array}{l}\text { Alliances entail a situation isomorphous to the } \\
\text { game of prisoner's dilemma: "Two players are } \\
\text { suspected of a hypothetical major crime [...]. They } \\
\text { are imprisoned and held incommunicado, so each } \\
\text { must decide whether to cooperate or to defect, } \\
\text { without knowing what the other will do" (Parkhe, } \\
\text { 1993: 796-797) }\end{array}$ & $\begin{array}{l}\text { - Incentives for cooperation vs. non-cooperation } \\
\text { - Implications of cooperation for alliance performance } \\
\text { - Reputation and behavioral uncertainty } \\
\text { - Repeated alliances between the same partners (iterated games) } \\
\text { - Alliance performance implications (positive sum games vs. } \\
\text { zero-sum games) }\end{array}$ & $\begin{array}{l}\text { (Parkhe, 1993; Hwang \& } \\
\text { Burgers, 1997; Kumar, } \\
\text { 2011) }\end{array}$ \\
\hline 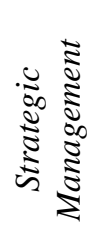 & $\begin{array}{l}\text { Strategic } \\
\text { Behavior } \\
\text { Approach } \\
\text { (Fuller \& } \\
\text { Porter, 1986) }\end{array}$ & $\begin{array}{l}\text { Coalitions are formal long-term agreements } \\
\text { between firms that link aspects of their business } \\
\text { but fall short of merger. Firms coalesce together } \\
\text { when this strategy maximizes profits by } \\
\text { improving a firm's competitive position in the } \\
\text { industry vis-à-vis rivals. }\end{array}$ & $\begin{array}{l}\text { - Coalitions as cost-sharing tools (scope and scale economies) } \\
\text { - Competition among coalitions (e.g., alliance constellations) } \\
\text { - Coalitions as tools to create/ overcome barriers of entry }\end{array}$ & $\begin{array}{l}\text { (Fuller \& Porter, 1986; } \\
\text { Kogut, 1988; Hagedoorn, } \\
\text { 1993; Lazzarini, 2007) }\end{array}$ \\
\hline
\end{tabular}




\begin{tabular}{|c|c|c|c|c|}
\hline & $\begin{array}{l}\text { Resource-based } \\
\text { view } \\
\text { (Barney, 1991) }\end{array}$ & $\begin{array}{l}\text { Strategic alliances are mechanisms of resources } \\
\text { and capabilities pooling, created by firms to gain } \\
\text { access to complementary resources they lack or to } \\
\text { enhance their existing resource endowment, } \\
\text { therefore to achieve competitive advantages } \\
\text { otherwise unattainable or to retain the existing } \\
\text { ones. }\end{array}$ & $\begin{array}{l}\text { - Resource inducements and opportunities of alliance formation } \\
\text { (and firm's propensity to alliance formation) } \\
\text { - Resource factors for partner selection and alliance } \\
\text { performance (e.g. complementarity, technology distance) } \\
\text { - Inter-firm learning performance issues } \\
\text { - Alliance capabilities and routines } \\
\text { - Creation of value (and resources) }\end{array}$ & $\begin{array}{l}\text { (Eisenhardt \& } \\
\text { Schoonhoven, 1996; } \\
\text { Ahuja, 2000; Anand \& } \\
\text { Khanna, 2000; Colombo, } \\
\text { 2003; Yasuda, 2005; } \\
\text { Mesquita et al., 2008) }\end{array}$ \\
\hline & $\begin{array}{l}\text { Real Options } \\
\text { Reasoning } \\
\text { (Myers, 1984) }\end{array}$ & $\begin{array}{l}\text { Strategic alliances are real options or investment } \\
\text { platforms which confer upon the partner firms the } \\
\text { potential to take advantage of future strategic } \\
\text { opportunities. Alliances are particularly valuable } \\
\text { tools in highly uncertain contexts since they } \\
\text { involve a relatively low loose of flexibility. }\end{array}$ & $\begin{array}{l}\text { - Choice between strategic alliances and alternative less flexible } \\
\text { forms (e.g. acquisition) } \\
\text { - Formation of alliances as acquistions of real options } \\
\text { - Flexibility-commitment trade-off in alliance governance } \\
\text { choices } \\
\text { - Valuation of real options embedded in alliances (e.g. partners' } \\
\text { buy out) and decisions to exercise them }\end{array}$ & $\begin{array}{l}\text { (Kogut, 1991; Kogut \& } \\
\text { Kulatilaka, 1994; Folta, } \\
\text { 1998; Vassolo et al., } \\
\text { 2004; Reuer \& Tong, } \\
\text { 2005) }\end{array}$ \\
\hline \multirow[b]{2}{*}{ 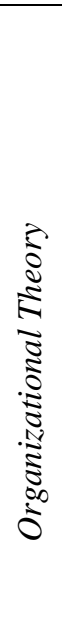 } & $\begin{array}{l}\text { Resource } \\
\text { Dependence } \\
\text { Theory } \\
\text { (Pfeffer \& } \\
\text { Salancik, 1978) }\end{array}$ & $\begin{array}{l}\text { Strategic alliances are formed as strategic } \\
\text { responses to the environmental uncertainty, } \\
\text { serving as mechanims to alleviate the firm's } \\
\text { resource dependence and thus to enhance firm's } \\
\text { power. Power-dependence relationships can } \\
\text { promote/limit a firm's alliance activity. }\end{array}$ & $\begin{array}{l}\text { - Dependence/Interdependence } \\
\text { - Power } \\
\text { - Influence } \\
\text { - Conflict }\end{array}$ & $\begin{array}{l}\text { (Kumar \& Seth, 1998; } \\
\text { Young-Ybarra \& } \\
\text { Wiersema, 1999; } \\
\text { Stephens et al., 2009) }\end{array}$ \\
\hline & $\begin{array}{l}\text { Institutional } \\
\text { Theory } \\
\text { (DiMaggio \& } \\
\text { Powell, 1983) }\end{array}$ & $\begin{array}{l}\text { Strategic alliances are strategic responses to the } \\
\text { pressures that the institutional environment } \\
\text { impose on the organizations to justify the } \\
\text { congruence between their actions and prevailing } \\
\text { norms and thus to maintain/enhance legitimacy. } \\
\text { Isomorphic forces (coercive, normative, and } \\
\text { mimetic) can both promote or hamper alliance } \\
\text { formation. }\end{array}$ & $\begin{array}{l}\text { - Constrains and opportunities for alliance formation } \\
\text { - Alliance formation and partner selection trends in institutional } \\
\text { environments } \\
\text { - Alliances and legitimacy implications }\end{array}$ & $\begin{array}{l}\text { (Oliver, 1991; Dacin et } \\
\text { al., 2007) }\end{array}$ \\
\hline
\end{tabular}




\begin{tabular}{|c|c|c|c|c|}
\hline \multirow{2}{*}{ 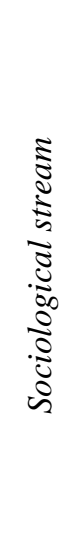 } & $\begin{array}{l}\text { Social Network } \\
\text { Theory } \\
\text { (Granovetter, } \\
\text { 1985) }\end{array}$ & $\begin{array}{l}\text { Networks are collections of alliances which are } \\
\text { created in pursuit of cooperative advantages and } \\
\text { evolve over time. Social and structural conditions } \\
\text { of the firm's network of prior ties influence the } \\
\text { creation of new alliances, their evolution, and } \\
\text { performance. }\end{array}$ & $\begin{array}{l}\text { - Alliance formation opportunities in connexion to the firm's } \\
\text { network (e.g., tie strength, structural holes, network position) } \\
\text { - Paradox of embeddedness and performance (e.g., in } \\
\text { innovation networks) } \\
\text { - Alliances as sources of social capital }\end{array}$ & $\begin{array}{l}\text { (Gulati, 1998; Tsai \& } \\
\text { Ghoshal, 1998; Ahuja, } \\
\text { 2000; Beckman et al., } \\
\text { 2004; Walter et al., 2006; } \\
\text { Goerzen, 2007; Phelps, } \\
\text { 2010) } \\
\end{array}$ \\
\hline & $\begin{array}{l}\text { Social } \\
\text { Exchange } \\
\text { Theory } \\
\text { (Blau, 1964) }\end{array}$ & $\begin{array}{l}\text { Strategic alliances are social exchange } \\
\text { relationships between partners motivated by the } \\
\text { benefits they are expected to bring over time, } \\
\text { characterized as ongoing reciprocal processes in } \\
\text { which partners actions and behaviors depend upon } \\
\text { social norms and are contingent on other partners' } \\
\text { rewarding reactions. }\end{array}$ & $\begin{array}{l}\text { - Emergence, behavioral and performance implications of } \\
\text { relational norms (reciprocity, flexibility, mutuality, solidarity, } \\
\text { information exchange) } \\
\text { - Cooperation vs. non-cooperation } \\
\text { - Interdependence, commitment, reciprocity and trust issues }\end{array}$ & $\begin{array}{l}\text { (Lusch \& Brown, 1996; } \\
\text { Young-Ybarra \& } \\
\text { Wiersema, 1999; Poppo } \\
\text { \& Zenger, 2002; } \\
\text { Muthusamy \& White, } \\
\text { 2005; Lado et al., 2008) }\end{array}$ \\
\hline
\end{tabular}




\section{Appendix I.3. Alliance lifecycle stages}

\begin{tabular}{|l|l|}
\hline \multicolumn{1}{|c|}{ Work } & \multicolumn{1}{c|}{ Alliance lifecycle stages } \\
\hline Forrest \& Martin (1992) & Courtship, negotiation, implementation, and operation \\
\hline Murray \& Mahon (1993) & Courtship, negotiation, start-up, maintenance, and ending \\
\hline Parkhe (1993) & Formation, maintenance, and dissolution. \\
\hline Kanter (1994) & $\begin{array}{l}\text { Partner selection and courtship, engagement, setting up housekeeping, } \\
\text { learning to collaborate, and internal change. }\end{array}$ \\
\hline Das \& Teng (2000b) & Formation, alliance preferences structuring, and performance. \\
\hline Reuer (2000) & $\begin{array}{l}\text { Formation (choice of collaborative strategy over alternative ones, } \\
\text { partner selection, negotiations), operation/execution, and termination. }\end{array}$ \\
\hline Shenkar \& Yan (2002) & $\begin{array}{l}\text { Pre-formation, formation, post-formation, crisis (in failure alliances), } \\
\text { and termination. }\end{array}$ \\
\hline
\end{tabular}




\section{Appendix I.4. Relational research on strategic alliances}

\begin{tabular}{|c|c|c|c|c|}
\hline Study & Research design & \multicolumn{2}{|c|}{ Main concepts and dimensions } & Remarks \\
\hline \multirow{5}{*}{$\begin{array}{l}\text { Anderson \& } \\
\text { Narus } \\
(1990)\end{array}$} & \multirow{5}{*}{$\begin{array}{l}\text { Distributor- } \\
\text { manufacturer } \\
\text { relationships; dyadic } \\
\text { perspective; } 249 \\
\text { distributors and } 213 \\
\text { manufacturers in the } \\
\text { U.S.; cross-sectional }\end{array}$} & \multicolumn{2}{|c|}{$\begin{array}{l}\text { Trust: one party's belief that the other party will perform beneficial actions and not unexpected } \\
\text { damaging actions }\end{array}$} & \multirow{5}{*}{$\begin{array}{l}\text { Cooperation, which is fostered by } \\
\text { communication, is an antecedent rather } \\
\text { than a consequence of trust. Trust } \\
\text { reduces the presence of negative } \\
\text { conflicts. Partners' satisfaction is } \\
\text { positively related to trust and negatively } \\
\text { to conflict }\end{array}$} \\
\hline & & \multicolumn{2}{|c|}{ Communication: formal and informal sharing of meaningful and timely information } & \\
\hline & & \multicolumn{2}{|c|}{$\begin{array}{l}\text { Cooperation: similar or complementary coordinated actions taken by firms to achieve mutual } \\
\text { outcomes or singular outcomes with expected reciprocity over time }\end{array}$} & \\
\hline & & \multicolumn{2}{|c|}{$\begin{array}{l}\text { Functionality of conflict: evaluative appraisal of the results of efforts made to resolve } \\
\text { disagreements }\end{array}$} & \\
\hline & & \multicolumn{2}{|c|}{ Satisfaction: a positive affective state resulting from the appraisal of all aspects of the relationship } & \\
\hline \multirow{3}{*}{$\begin{array}{l}\text { Heide \& } \\
\text { John }(1992)\end{array}$} & \multirow{3}{*}{$\begin{array}{l}\text { Manufacturer-supplier } \\
\text { relationships; dyadic } \\
\text { perspective; } 155 \text { buyer } \\
\text { firms and } 60 \text { supplier } \\
\text { firms in the U.S. }\end{array}$} & \multirow{3}{*}{$\begin{array}{l}\text { Relational norms: expectations about behavior } \\
\text { that are at least partially shared by the partners } \\
\text { and that govern the interfirm exchange } \\
\text { relationship }\end{array}$} & $\begin{array}{l}\text { - Flexibility: bilateral expectation of } \\
\text { willingness to make adaptations as } \\
\text { circumstances evolve }\end{array}$ & \multirow{3}{*}{$\begin{array}{l}\text { Contrary to transaction costs } \\
\text { predictions, the impact of investments } \\
\text { in specific assets on vertical control } \\
\text { depends on relational norms. If } \\
\text { relational norms are lacking, it is not } \\
\text { possible for partners to control other } \\
\text { partner's decisions. }\end{array}$} \\
\hline & & & $\begin{array}{l}\text { - Solidarity: bilateral expectation that a } \\
\text { high value is placed on the relationship }\end{array}$ & \\
\hline & & & $\begin{array}{l}\text { - Information exchange: bilateral } \\
\text { expectation that parties will proactively } \\
\text { provide useful information }\end{array}$ & \\
\hline \multirow{4}{*}{$\begin{array}{l}\text { Parkhe } \\
(1993)\end{array}$} & \multirow{4}{*}{$\begin{array}{l}\text { Strategic alliances; } 111 \\
\text { partner firms; U.S. } \\
\text { industries with } \\
\text { important alliance } \\
\text { activity (e.g. chemicals } \\
\text { and electronics); cross- } \\
\text { sectional }\end{array}$} & \multirow{3}{*}{$\begin{array}{l}\text { Shadow of the future: the bond between the } \\
\text { future benefits a firm anticipates, based on its } \\
\text { expectations of reciprocity and subsequent gains } \\
\text { from mutual cooperation, and its present actions }\end{array}$} & - Behavioral transparency & \multirow{4}{*}{$\begin{array}{l}\text { Alliance performance is positively } \\
\text { related to the length of the 'shadow of } \\
\text { the future' and negatively related to } \\
\text { perception of partner's opportunistic } \\
\text { behavior }\end{array}$} \\
\hline & & & - Frequency of interaction & \\
\hline & & & - Time horizon & \\
\hline & & \multicolumn{2}{|c|}{$\begin{array}{l}\text { Perceived partner's opportunistic behavior: extent to which the partner is perceived to exert } \\
\text { calculated efforts to mislead, distort, disguise, obfuscate or otherwise confuse }\end{array}$} & \\
\hline \multirow{3}{*}{$\begin{array}{l}\text { Mohr \& } \\
\text { Spekman } \\
(1994)\end{array}$} & \multirow{3}{*}{$\begin{array}{l}\text { Manufacturer-dealer } \\
\text { relationships (Vertical } \\
\text { alliances); } 102 \text { dealer } \\
\text { firms; personal } \\
\text { computer industry in } \\
\text { the U.S.; cross- } \\
\text { sectional }\end{array}$} & \multirow{3}{*}{ Partnership attributes } & $\begin{array}{l}\text { - Commitment: willingness of partners to } \\
\text { exert efforts on behalf of the relationship }\end{array}$ & \multirow{3}{*}{$\begin{array}{l}\text { Partnership success (both in terms of } \\
\text { dyadic sales and dealer's satisfaction) is } \\
\text { positively related to some partnership } \\
\text { attributes (trust, commitment, and } \\
\text { coordination) and it is affected by the } \\
\text { conflict resolution techniques used } \\
\text { (joint problem solving has positive }\end{array}$} \\
\hline & & & $\begin{array}{l}\text { - Coordination: set of tasks each party } \\
\text { expects the other to perform }\end{array}$ & \\
\hline & & & $\begin{array}{l}\text { - Trust: belief that a party's word is } \\
\text { reliable and that a party will fulfil its } \\
\text { obligations }\end{array}$ & \\
\hline
\end{tabular}




\begin{tabular}{|c|c|c|c|c|c|}
\hline & & & \multicolumn{2}{|c|}{$\begin{array}{l}\text { - Interdependence: extent to which } \\
\text { partners join forces to achieve mutually } \\
\text { beneficial goals }\end{array}$} & \multirow[t]{7}{*}{$\begin{array}{l}\text { effects while ignoring problems and } \\
\text { destructive methods have negative } \\
\text { impact) }\end{array}$} \\
\hline & & \multirow{3}{*}{ Communicative behavior } & \multicolumn{2}{|c|}{$\begin{array}{l}\text { Quality: extent to which accuracy, } \\
\text { timeliness, adequacy and credibility } \\
\text { characterized the information exchange }\end{array}$} & \\
\hline & & & \multicolumn{2}{|c|}{$\begin{array}{l}\text { - Information sharing: extent to which } \\
\text { critical, often proprietary, information is } \\
\text { shared }\end{array}$} & \\
\hline & & & \multicolumn{2}{|c|}{$\begin{array}{l}\text { - Participation: extent to which partners } \\
\text { engage in joint planning and goal setting }\end{array}$} & \\
\hline & & \multirow{3}{*}{ Conflict resolution techniques } & - Destr & ve techniques & \\
\hline & & & - Cons & ive techniques & \\
\hline & & & - Other & & \\
\hline \multirow{6}{*}{$\begin{array}{l}\text { Lusch \& } \\
\text { Brown } \\
(1996)\end{array}$} & \multirow{6}{*}{$\begin{array}{l}\text { Wholesaler- } \\
\text { distributors-supplier } \\
\text { relationships; } 454 \text { U.S. } \\
\text { wholesaler- } \\
\text { distributors; cross- } \\
\text { sectional. }\end{array}$} & \multicolumn{3}{|c|}{$\begin{array}{l}\text { Relational governance: set of relational norms that govern acceptable behavior between exchange } \\
\text { partners }\end{array}$} & \multirow{6}{*}{$\begin{array}{l}\text { Bilateral dependence positively affects } \\
\text { long-term orientation, relational } \\
\text { behavior and normative contracting). In } \\
\text { turn, long-term orientation is positively } \\
\text { related to relational behavior and the } \\
\text { latter factor and normative contracting } \\
\text { are interconnected. Relational behavior, } \\
\text { furthermore, affects positively the } \\
\text { relationship performance. }\end{array}$} \\
\hline & & \multicolumn{3}{|c|}{$\begin{array}{l}\text { Normative contracts: implicit or soft contracts which involves a set of mutual expectations and } \\
\text { understandings between the channel partners. Normative contracting involves attitudinal } \\
\text { commitment in which common identification and value congruence occurs. }\end{array}$} & \\
\hline & & \multirow{3}{*}{$\begin{array}{l}\text { Relational behavior: is the one consistent with } \\
\text { normative contracting (norms as Heide and John, } \\
\text { 1992) }\end{array}$} & \multirow{3}{*}{\multicolumn{2}{|c|}{$\begin{array}{ll}\text { - } & \text { Flexibility } \\
\text { - Information Exchange } \\
\text { - Solidarity } \\
\end{array}$}} & \\
\hline & & & & & \\
\hline & & & & & \\
\hline & & \multicolumn{3}{|l|}{ Long-term orientation } & \\
\hline \multirow{2}{*}{$\begin{array}{l}\text { Cullen, } \\
\text { Johnson \& } \\
\text { Sakano } \\
(2000)\end{array}$} & \multirow{2}{*}{$\begin{array}{l}\text { International alliances } \\
\text { (equity IJVs and non- } \\
\text { equity alliances); } \\
\text { dyadic perspective } \\
\text { (Japanese and foreign } \\
\text { partners); cross- } \\
\text { sectional. }\end{array}$} & \multirow{2}{*}{\multicolumn{2}{|c|}{$\begin{array}{l}\text { Relationship capital: represents the quality of the relationship, } \\
\text { consists of the positive socio-psychological aspects of the } \\
\text { alliance, and involves the pattern of partners' interaction that } \\
\text { facilitates the day-to-day functioning of the alliance }\end{array}$}} & - Trust & \multirow{2}{*}{$\begin{array}{l}\text { Strategic alliance management needs } \\
\text { pay attention to the soft side, namely } \\
\text { the building process of relational } \\
\text { capital, whose core components are } \\
\text { mutual trust and commitment. Mutual } \\
\text { trust and commitment are dynamically } \\
\text { built through partners' interaction and } \\
\text { adjustments and are constantly } \\
\text { interrelated. Building relational capital } \\
\text { favours the performance of alliances. }\end{array}$} \\
\hline & & & & - Commitment & \\
\hline
\end{tabular}




\begin{tabular}{|c|c|c|c|c|}
\hline \multirow{2}{*}{$\begin{array}{l}\text { Kale, Singh } \\
\& \\
\text { Perlmutter } \\
(2000)\end{array}$} & \multirow{2}{*}{$\begin{array}{l}\text { Strategic alliances } \\
\text { (equity and non- } \\
\text { equity); } 212 \text { U.S. firms } \\
\text { participating in } \\
\text { alliances; industries } \\
\text { with critical alliance } \\
\text { activity (e.g. computer, } \\
\text { electronics, pharma); } \\
\text { cross-sectional. }\end{array}$} & \multicolumn{2}{|c|}{$\begin{array}{l}\text { Relational capital: level of mutual trust, respect, and friendship that arises out of close interaction } \\
\text { at the individual level between alliance partner }\end{array}$} & \multirow{2}{*}{$\begin{array}{l}\text { Relational capital and integrative } \\
\text { conflict resolution methods increase the } \\
\text { willingness and ability of partners to } \\
\text { achieve reciprocal learning, Relational } \\
\text { capital fosters mutual exchange of } \\
\text { information and integrative conflict } \\
\text { resolution methods create a channel for } \\
\text { sharing information reinforce relational } \\
\text { capital. Also, relational capital prevents } \\
\text { the leakage of critical know-how by } \\
\text { curbing opportunistic behavior }\end{array}$} \\
\hline & & \multicolumn{2}{|c|}{$\begin{array}{l}\text { Integrative conflict management: extent to which existing conflicts between partners are deal with } \\
\text { through joint management, based on mutual concern for 'win-win', extensive communication- and } \\
\text { contact-intensive processes }\end{array}$} & \\
\hline \multirow{4}{*}{$\begin{array}{l}\text { Ariño } \\
\text { (2001) }\end{array}$} & \multirow{4}{*}{$\begin{array}{l}\text { Collaborative ventures } \\
\text { (domestic and } \\
\text { international); } 81 \\
\text { Spanish partner firms; } \\
\text { multiple industries; } \\
\text { cross-sectional. }\end{array}$} & \multirow{2}{*}{$\begin{array}{l}\text { Cooperative behavior: adjustment of a firm's } \\
\text { behavior to the actual or anticipated needs of its } \\
\text { partner }\end{array}$} & $\begin{array}{l}\text { - Veracity: extent to which a firm is } \\
\text { truthful in the relationship }\end{array}$ & \multirow{4}{*}{$\begin{array}{l}\text { A firm's perception of its partner's } \\
\text { veracity affects both the firm's veracity } \\
\text { and commitment. Partner's non- } \\
\text { cooperative behavior under the form of } \\
\text { commission (lack of veracity) has } \\
\text { stronger effects than partner's non- } \\
\text { cooperative behavior by omission (lack } \\
\text { of commitment) }\end{array}$} \\
\hline & & & $\begin{array}{l}\text { - Commitment: extent to which a firm } \\
\text { exerts the needed efforts to make the } \\
\text { relationship work }\end{array}$ & \\
\hline & & \multirow{2}{*}{ Non-cooperative behavior } & $\begin{array}{l}\text { - Commission (lack of veracity): } \\
\text { performing an action harmful to the } \\
\text { partner }\end{array}$ & \\
\hline & & & $\begin{array}{l}\text { - Omission: failing to perform an action } \\
\text { beneficial to the partner (lack of } \\
\text { commitment) }\end{array}$ & \\
\hline $\begin{array}{l}\text { Poppo \& - } \\
\text { Zenger } \\
(2002)\end{array}$ & $\begin{array}{l}\text { Information services } \\
\text { outsourcing } \\
\text { relationships; } 258 \text { U.S. } \\
\text { buyer firms; multiple } \\
\text { industries; cross- } \\
\text { sectional }\end{array}$ & \multicolumn{2}{|c|}{$\begin{array}{l}\text { Relational governance: extent to which the enforcement of obligations, promises, and } \\
\text { expectations in the relationship occurs through social processes that promote norms of flexibility, } \\
\text { solidarity, and information exchange }\end{array}$} & $\begin{array}{l}\text { Contracts and relational governance } \\
\text { function as complements. Greater levels } \\
\text { of relational norms are used as contracts } \\
\text { become increasingly customized. } \\
\text { Relational governance complements the } \\
\text { limits of contracts by fostering } \\
\text { continuance, mutuality and bilateralism. } \\
\text { Also, both mechanisms act as } \\
\text { complements in explaining satisfaction } \\
\text { with relationship performance }\end{array}$ \\
\hline Lado, Kant & Retailer-distributor & \multicolumn{2}{|c|}{ Trust: one's party confidence in the goodwill of an exchange } & In principal-agent \\
\hline
\end{tabular}




\begin{tabular}{|c|c|c|c|c|c|c|}
\hline \multirow{5}{*}{$\begin{array}{l}\& \text { Tekleab } \\
(2008)\end{array}$} & \multirow{5}{*}{$\begin{array}{l}\text { agents relationships; } \\
409 \text { catalogue } \\
\text { intermediates (agents) } \\
\text { affiliated to a focal } \\
\text { retail firm (the } \\
\text { principal); } \\
\text { longitudinal. }\end{array}$} & \multicolumn{3}{|l|}{ partner } & - Credibility & \multirow{5}{*}{$\begin{array}{l}\text { relationships, a minimum } \\
\text { level of trust is sufficient } \\
\text { to induce cooperation, as long as the } \\
\text { risk of opportunism is perceived to be } \\
\text { low. The presence of opportunism is not } \\
\text { sufficient to hamper the development of } \\
\text { relationalism as long as a minimum } \\
\text { level of trust is maintained }\end{array}$} \\
\hline & & \multicolumn{4}{|c|}{$\begin{array}{l}\text { Opportunism: a source of behavioral uncertainty that involves calculated efforts by an exchange } \\
\text { party to mislead, distort, disguise, obfuscate or otherwise confuse an exchange party }\end{array}$} & \\
\hline & & \multirow{3}{*}{\multicolumn{3}{|c|}{$\begin{array}{l}\text { Relationalism: a second order construct which characterizes } \\
\text { exchange parties' behaviors and involves the extent to which the } \\
\text { relationship is long-term oriented, reciprocal, and extending } \\
\text { beyond mere buying-selling. }\end{array}$}} & - Solidarity norms & \\
\hline & & & & & - Flexibility norms & \\
\hline & & & & & - Mutuality norms & \\
\hline \multirow[b]{2}{*}{ Luo (2008a) } & \multirow{2}{*}{$\begin{array}{l}168 \text { global alliances in } \\
\text { China; manufacturing } \\
\text { sectors; cross-sectional }\end{array}$} & \multicolumn{4}{|c|}{$\begin{array}{l}\text { Procedural fairness: extent to which the dynamics of the decision process are judged to be fair } \\
\text { and the ways in which the decision-making process influences the quality of exchange } \\
\text { relationships }\end{array}$} & \multirow{2}{*}{$\begin{array}{l}\text { Perceived procedural fairness directly } \\
\text { enhances alliance operational outcomes, } \\
\text { and indirectly increases financial } \\
\text { alliance performance, by enhancing } \\
\text { both interpersonal and inter- } \\
\text { organizational trust }\end{array}$} \\
\hline & & \multicolumn{4}{|c|}{$\begin{array}{l}\text { Trust: a high-order long-term attitude; a psychological state comprising the intention to accept } \\
\text { vulnerability based on positive expectations of the intentions or behavior of the partner; } \\
\text { willingness to take a risk in the partnership that is expected to create a higher payoff than pursuing } \\
\text { it alone }\end{array}$} & \\
\hline \multirow{5}{*}{ Luo (2008b) } & \multirow{5}{*}{$\begin{array}{l}198 \text { cross-cultural } \\
\text { alliances in China; } \\
\text { cross-sectional. }\end{array}$} & \multicolumn{4}{|c|}{$\begin{array}{l}\text { Economic integration: extent to which resources pooled by partners and subsequent operations are } \\
\text { combined such that if one partner withdraws the alliance will not survive and the other partners } \\
\text { will suffer great loss. }\end{array}$} & \multirow{5}{*}{$\begin{array}{l}\text { As economic integration increases, } \\
\text { interparty trust exerts a stronger positive } \\
\text { impact on both alliance profitability and } \\
\text { stability, procedural justice contributes } \\
\text { more to alliance profitability, and joint } \\
\text { governance maintains its positive } \\
\text { influence on alliance stability }\end{array}$} \\
\hline & & \multicolumn{4}{|c|}{$\begin{array}{l}\text { Interparty trust: economic and social binding in that reflects relational investments and increases } \\
\text { duration and reciprocity of the relationship }\end{array}$} & \\
\hline & & \multirow{2}{*}{\multicolumn{4}{|c|}{$\begin{array}{l}\text { Joint governance: extent to which alliance operations are purposefully and collectively guided, } \\
\text { monitored, and overseen in pursuit of maximum joint pay-off } \\
\text { Procedural justice: extent to which the alliance's decision-making process and procedures are } \\
\text { perceived as impartial and fair }\end{array}$}} & \\
\hline & & & & & & \\
\hline & & \multicolumn{4}{|c|}{$\begin{array}{l}\text { Alliance portfolio capital: aggregation of inter-organizational resources that are linked to a focal } \\
\text { firm through their participation in a set of alliances }\end{array}$} & \\
\hline $\begin{array}{l}\text { Li, Poppo \& } \\
\text { Zhou (2010) }\end{array}$ & $\begin{array}{l}\text { Local supplier-foreign } \\
\text { subsidiary } \\
\text { relationships in China; } \\
168 \text { foreign }\end{array}$ & Relational mechanisms & $\begin{array}{l}\text { Indirect } \\
\text { ties }\end{array}$ & $\begin{array}{l}\text { - Brokered access: } \\
\text { enables the foreig }\end{array}$ & $\begin{array}{l}\text { nt to which the focal supplier } \\
\text { bsidiary access to its network }\end{array}$ & $\begin{array}{l}\text { Shared goals and trust enhance the } \\
\text { foreign subsidiary capacity to acquire } \\
\text { tacit and explicit knowledge from the } \\
\text { local supplier, while brokered access }\end{array}$ \\
\hline
\end{tabular}




\begin{tabular}{|c|c|c|c|}
\hline \multirow[t]{2}{*}{$\begin{array}{l}\text { subsidiaries; } \\
\text { manufacturing sectors }\end{array}$} & \multirow{2}{*}{$\begin{array}{c}\text { Direct } \\
\text { interaction }\end{array}$} & $\begin{array}{l}\text { - Shared goals: bilateral understanding, approach, } \\
\text { and vision for achieving tasks and outcomes, } \\
\text { promoting interaction and long-term projection }\end{array}$ & \multirow{2}{*}{$\begin{array}{l}\text { has only effects on explicit knowledge } \\
\text { acquisition. Formal contracts strengthen } \\
\text { the positive effects of relational } \\
\text { mechanisms }\end{array}$} \\
\hline & & $\begin{array}{l}\text { - Trust: extent to which a firm believes that its } \\
\text { partner is honest and/or benevolent }\end{array}$ & \\
\hline
\end{tabular}




\section{Appendix I.5. Definitions of 'multi-partner alliances'}

\begin{tabular}{|c|c|}
\hline Study & Definitions of 'multi-partner alliance/s' \\
\hline $\begin{array}{l}\text { Hwang \& } \\
\text { Burgers (1997) }\end{array}$ & $\begin{array}{l}\text { These alliances join several companies in a single, larger, overarching relationship for } \\
\text { a common purpose }\end{array}$ \\
\hline $\begin{array}{l}\text { Das \& Teng } \\
(2002)\end{array}$ & $\begin{array}{l}\text { Strategic alliances formed by multiple partners to compete against other such groups } \\
\text { and against traditional single firms }\end{array}$ \\
\hline $\begin{array}{l}\text { Gomes-Casseres } \\
(2003)\end{array}$ & $\begin{array}{l}\text { A particular kind of organization created by a group of firms to pursue a particular } \\
\text { kind of strategy, representing an alternative to the single firm as a way of governing } \\
\text { bundle of capabilities }\end{array}$ \\
\hline $\begin{array}{l}\text { Zeng \& Chen } \\
(2003)\end{array}$ & Inter-organizational cooperative arrangements involving multiple partners \\
\hline $\begin{array}{l}\text { Lavie, Lechner } \\
\& \text { Singh (2007) }\end{array}$ & $\begin{array}{l}\text { A collective voluntary organizational association that interactively engages its } \\
\text { multiple members in multilateral value chain activities, such as collaborative } \\
\text { research, development, sourcing, production, or marketing of technologies, products, } \\
\text { or services. Forms include R\&D consortia, official and de facto standard-setting or - } \\
\text { promoting associations, multiparty production joint ventures, supplier networks, co- } \\
\text { marketing arrangements, and industry constellations }\end{array}$ \\
\hline Lazzarini (2007) & $\begin{array}{l}\text { Constellations are alliances among multiple autonomous firms, such that these groups } \\
\text { compete against each other in the same or similar industries for both clients and } \\
\text { members }\end{array}$ \\
\hline
\end{tabular}


Appendix I.6. R\&D Consortia:

Definitions, formation pathways and some case studies

\begin{tabular}{|c|c|}
\hline Study & Definition of ' $R \& D$ consortium/consortia' \\
\hline $\begin{array}{l}\text { Olk \& Young } \\
(1997)\end{array}$ & $\begin{array}{l}\text { Two or more companies sharing resources to create a new legal entity in order to } \\
\text { conduct cooperative research and development activities }\end{array}$ \\
\hline $\begin{array}{l}\text { Sakakibara } \\
(1997)\end{array}$ & $\begin{array}{l}\text { An agreement among a group of firms to share the costs and results of an } R \& D \\
\text { project prior to the execution of that project }\end{array}$ \\
\hline $\begin{array}{l}\text { Doz, Olk \& Ring } \\
(2000)\end{array}$ & $\begin{array}{l}\text { A legal entity established by two or more organizations that pool resources and share } \\
\text { decision making for cooperative research and development activities }\end{array}$ \\
\hline $\begin{array}{l}\text { Mothe \& Quelin } \\
(2001)\end{array}$ & A group of firms linked by a cooperation agreement and conducting R\&D together \\
\hline $\begin{array}{l}\text { Nakamura, } \\
\text { Nelson \& } \\
\text { Vertinsky (2003) }\end{array}$ & $\begin{array}{l}\text { The formation of a new entity jointly controlled by at least two firms, which may or } \\
\text { may not have equity stakes, for the purpose of conducting and jointly funding R\&D }\end{array}$ \\
\hline $\begin{array}{l}\text { Gogan, Gelinas } \\
\text { \& Rao (2007) }\end{array}$ & $\begin{array}{l}\text { A group of firms that have a similar need and band together to create a new entity to } \\
\text { satisfy a research need for all of them. Consortia usually have a large number of } \\
\text { participants and a central administrative office and some kind of management } \\
\text { structure }\end{array}$ \\
\hline $\begin{array}{l}\text { Eisner, Rahman } \\
\& \text { Korn (2009) }\end{array}$ & $\begin{array}{l}\text { A multi-party strategic alliance where member firms are responsible for specific parts } \\
\text { of the project vis-à -vis the entire project. }\end{array}$ \\
\hline & What \\
\hline \multicolumn{2}{|c|}{$\begin{array}{l}\text { Multi-partner R\&D alliance (Doz et al., 2000; Lavie et al., 2007): A R\&D consortium is a multi-partner } \\
\text { R\&D alliance. Compared to networks, its multiparty membership provides more complexity than a } \\
\text { collection of dyadic relationships, although their defined boundaries provide a limit to the analysis of the } \\
\text { full matrix of ties that comprise a network. }\end{array}$} \\
\hline \multicolumn{2}{|c|}{$\begin{array}{l}\text { Dynamic membership and diverse partners' involvement (Olk \& Young, 1997; Lavie et al., 2007): a } \\
\text { peculiarity of R\&D consortia is that the collaborative organization remains regardless the continuity of } \\
\text { their founder partners. In fact, membership configuration changes over time, as some partners depart and } \\
\text { other new join. Also, the level of involvement usually varies across partners. }\end{array}$} \\
\hline \multicolumn{2}{|c|}{$\begin{array}{l}\text { Flexibility in organization (Evan \& Olk, 1990; Mothe \& Quelin, 2001): A R\&D consortium represents a } \\
\text { collaborative organization, as such, is not completely detached from its partner firms, either strategically } \\
\text { or legally. However, it can either be a research joint venture (a new legal entity is created with shared } \\
\text { common facilities) or may have a more decentralized structure (contractual agreement). R\&D consortia } \\
\text { tend to have larger number of partners and less focused goals than multi-party joint ventures, due to } \\
\text { performance is highly uncertain and it is difficult to achieve consensus between too many partners (which } \\
\text { often are direct competitors). }\end{array}$} \\
\hline
\end{tabular}




\begin{tabular}{|c|c|c|c|}
\hline \multicolumn{4}{|c|}{ R\&D consortia formation pathways (Doz and colleagues) } \\
\hline Characteristic & Embedded process & Emergent process & Engineered process \\
\hline $\begin{array}{l}\text { Recognition } \\
\text { of the } \\
\text { opportunity }\end{array}$ & $\begin{array}{l}\text { R\&D alliance participants have } \\
\text { a strong sense of interest } \\
\text { similarity and environmental } \\
\text { interdependence. The } \\
\text { recognition of the opportunity } \\
\text { to collaborate dates back to a } \\
\text { long time ago. It is about a } \\
\text { well-established network (i.e., } \\
\text { the formation of the R\&D } \\
\text { consortium is just a further step } \\
\text { in the partners' collaborative } \\
\text { trajectory). }\end{array}$ & $\begin{array}{l}\text { Partners engage in the alliance } \\
\text { with the purpose of facing } \\
\text { environmental pressures and/or } \\
\text { because they perceive a strong } \\
\text { interest similarity. It is also } \\
\text { likely the pre-existence of } \\
\text { prior ties among the } \\
\text { participants but, unlike the } \\
\text { embedded case, it is not about } \\
\text { a well-established network. }\end{array}$ & $\begin{array}{l}\text { Potential partners do not } \\
\text { spontaneously recognise } \\
\text { interest similarity and } \\
\text { environmental } \\
\text { interdependence. A triggering } \\
\text { entity, which may be external } \\
\text { and unconnected to potential } \\
\text { partners, perceives the } \\
\text { opportunity to form the } \\
\text { consortium, and start to } \\
\text { persuade potential partners to } \\
\text { take advantage of it. It is about } \\
\text { of creating a new network. }\end{array}$ \\
\hline $\begin{array}{l}\text { Consortium's } \\
\text { scope }\end{array}$ & Exploration or exploitation & Exploitation & Exploration \\
\hline $\begin{array}{l}\text { Membership } \\
\text { configuration, } \\
\text { negotiations, } \\
\text { an structure }\end{array}$ & $\begin{array}{l}\text { Membership is usually } \\
\text { confined to the extant network. } \\
\text { Other 'external' members may } \\
\text { be allowed due to strategic } \\
\text { reasons. Negotiations are likely } \\
\text { to be relatively easy. Partners } \\
\text { trust each other and have } \\
\text { developed shared collaborative } \\
\text { routines. Thereby, many points } \\
\text { are already established. }\end{array}$ & $\begin{array}{l}\text { Information is intended to } \\
\text { reach all potentially interested } \\
\text { partners, (i.e., snowball effect } \\
\text { is likely to arise). While } \\
\text { seeking domain consensus on } \\
\text { boundaries is relatively easy, } \\
\text { negotiations are complex, } \\
\text { especially in the presence of } \\
\text { competitors. }\end{array}$ & $\begin{array}{l}\text { The triggering entity } \\
\text { approaches specific target } \\
\text { firms (hube and spoke } \\
\text { apprach) trying to convince } \\
\text { them. The most challenge part } \\
\text { of negotiations is the alignment } \\
\text { of interest among potential } \\
\text { partners. }\end{array}$ \\
\hline Start-up & $\begin{array}{l}\text { Once the formal aspects of the } \\
\text { new collaboration are defined, } \\
\text { partners are ready to go ahead } \\
\text { with joint R\&D activities. }\end{array}$ & $\begin{array}{l}\text { The effective beginning of the } \\
\text { collaboration is not } \\
\text { straightforward. It will be } \\
\text { necessary to definitively } \\
\text { overcome suspicious and build } \\
\text { a minimal level of } \\
\text { collaborative inertia. }\end{array}$ & $\begin{array}{l}\text { Starting effectively the } \\
\text { collaboration may take even } \\
\text { more time than in the emerged } \\
\text { case. Partners usually show } \\
\text { some scepticism on whether } \\
\text { they would be able to work } \\
\text { together on mutual interest. } \\
\text { The triggering entity takes the } \\
\text { responsibility of alliance } \\
\text { maintenance. }\end{array}$ \\
\hline $\begin{array}{l}\text { Expected } \\
\text { level of } \\
\text { outcomes }\end{array}$ & $\begin{array}{l}\text { Expectations of continuity: } \\
(++) \\
\text { Evidence of learning: }(++) \\
\text { Escalation of commitment and } \\
\text { satisfaction: }(++)\end{array}$ & $\begin{array}{l}\text { Expectations of continuity: }(+) \\
\text { Evidence of learning: }(+) \\
\text { Escalation of commitment and } \\
\text { satisfaction: }(+/-)\end{array}$ & $\begin{array}{l}\text { Expectations of continuity: (-) } \\
\text { Evidence of learning: (-) } \\
\text { Escalation of commitment and } \\
\text { satisfaction: (-) }\end{array}$ \\
\hline
\end{tabular}




\begin{tabular}{|c|c|c|}
\hline \multicolumn{3}{|c|}{ Illustrative case-study research on $R \& D$ consortia formation } \\
\hline Authors & Case study & Remarks on alliance formation ${ }^{2}$ \\
\hline $\begin{array}{l}\text { Browning, } \\
\text { Beyer, \& } \\
\text { Shetler (1995) }\end{array}$ & $\begin{array}{l}\text { SEMATECH, a R\&D } \\
\text { consortium in semiconductor } \\
\text { manufacturing technology, } \\
\text { formed in } 1987 \text { by } 14 \\
\text { semiconductor manufacturing } \\
\text { firms and the U.S. } \\
\text { government. }\end{array}$ & $\begin{array}{l}\text { Why? To pool resources (financial, technical and commercial } \\
\text { capital) in response to an external threat (i.e. Japanese } \\
\text { competition). } \\
\text { How? Long-term personal ties among key people impact } \\
\text { alliance formation. Some relevant events from } 1971 \text { acted as } \\
\text { the background of SEMATECH formation (pre-formation } \\
\text { stage). }\end{array}$ \\
\hline $\begin{array}{l}\text { Daellenbach } \\
\text { \& Davenport } \\
\text { (2004) }\end{array}$ & $\begin{array}{l}\text { A technological six-partner } \\
\text { consortium in the robotics } \\
\text { industry at the end of the } \\
\text { 1990's in New Zealand: Shiny } \\
\text { Robot Venture (SRV), whose } \\
\text { purpose is to bring a } \\
\text { promising robot prototype to } \\
\text { the market. }\end{array}$ & $\begin{array}{l}\text { Why? Partners' motivations varied. The prototype maker (a } \\
\text { public research institute) needed to ally to manufacture and } \\
\text { commercialize the robot because of resource constraints. } \\
\text { Some small firms provide their manufacturing and commercial } \\
\text { capital while seeking to enhance their reputation. An industry } \\
\text { funding body provided financial funds in exchange of } \\
\text { expected economic returns. } \\
\text { How? The research institute was the central node, starting the } \\
\text { search of potential partners (open solicitation). An interested } \\
\text { potential partner approached a funding body from its network } \\
\text { of prior relationships. By including other prestigious partners } \\
\text { (e.g. a very innovative start-up), partnership configuration was } \\
\text { completed. Trust-based expectations forged at the pre- } \\
\text { formation stage influence potential partners perception about } \\
\text { the alliance potential and, finally, their decision to participate. }\end{array}$ \\
\hline $\begin{array}{l}\text { Gogan, } \\
\text { Gelinas \& } \\
\text { Rao (2007) }\end{array}$ & $\begin{array}{l}\text { Financial Services Technology } \\
\text { Consortium, a R\&D } \\
\text { consortium formed in } 1994 \text { by } \\
65 \text { members, including } \\
\text { financial institutions, } \\
\text { technology vendors, private } \\
\text { research centres, and } \\
\text { government agencies. }\end{array}$ & $\begin{array}{l}\text { Why? To jointly develop and test a new electronic payment } \\
\text { tool in response to the rapid pace in the evolution of new } \\
\text { information technology developments and the rapid expansion } \\
\text { of electronic commerce. } \\
\text { How? During the formation stages of the life of an R\&D } \\
\text { alliance (i.e. selection of partners and structure of the } \\
\text { alliance), three 'competing tensions' (competition vs. } \\
\text { cooperation, rigidity vs. flexibility, and short-term vs. long- } \\
\text { term orientation) are in evidence and need to be carefully } \\
\text { managed since they imply alliance instability. Interestingly, } \\
\text { authors stress that it is difficult to draw a distinct line between } \\
\text { the two alliance formation stages. }\end{array}$ \\
\hline $\begin{array}{l}\text { Mahnke \& } \\
\text { Overby } \\
\text { (2008) }\end{array}$ & $\begin{array}{l}\text { A six-partner R\&D } \\
\text { consortium whose objective is } \\
\text { to develop advanced mobile } \\
\text { services (e.g. } 3 \mathrm{G} \text { technology). }\end{array}$ & $\begin{array}{l}\text { Why? To pool complementary technical capabilities in an } \\
\text { emerging high-tech market. Technological developments may } \\
\text { generate strategic interdependence between firms involved in } \\
\text { different business (e.g. hardware manufactures and telecom } \\
\text { network operators). Differences in individual interests, even } \\
\text { when they are not in conflict with the alliance purpose, may } \\
\text { make collective-action difficult. } \\
\text { How? At the pre-stage o alliance formation as well as at the } \\
\text { first phase of the collaboration it is critical to create an alliance } \\
\text { shared vision to the focus of the alliance to be clear. Different } \\
\text { strategic prioritisation and lack of shared vision at the alliance } \\
\text { inception may negatively affect the ongoing alliance } \\
\text { evolution. }\end{array}$ \\
\hline Mathe & A multi-case study approach & Why? Taiwan's R\&D consortia are formed in the pursuit of \\
\hline
\end{tabular}

\footnotetext{
${ }^{2}$ The scope of most of these case studies is not confined to alliance formation. Rather, they usually cover the whole life of the alliance.
} 


\begin{tabular}{|c|c|c|}
\hline (2002) & $\begin{array}{l}\text { on } 5 \text { representative Taiwan's } \\
\text { R\&D consortia formed in the } \\
\text { late } 1990 \text { s between local, } \\
\text { foreign firms, industry } \\
\text { associations and the } \\
\text { government: Laptop PC } \\
\text { Consortium, NewPC } \\
\text { Consortium, Ethernet data } \\
\text { switch, Four-cylinder } \\
\text { automotive engine, and } \\
\text { Electric scooter. }\end{array}$ & $\begin{array}{l}\text { technological learning, to upgrade technical capabilities and to } \\
\text { catch-up new development opportunities (e.g. to enhance } \\
\text { capabilities to use an emerging data technology or to be ready } \\
\text { for taking advantage of the opening of China's automotive } \\
\text { market). } \\
\text { How? Sometimes, industry firms feel the need to ally and } \\
\text { recognise by themselves the opportunity to do it (emergent } \\
\text { process). Other times, a public agency or an industry } \\
\text { association act as triggering entities (engineered process), } \\
\text { recognising the need and the opportunity, approaching } \\
\text { potential partners, negotiating and signing contracts, searching } \\
\text { financial support, etc. }\end{array}$ \\
\hline $\begin{array}{l}\text { Nakamura, } \\
\text { Nelson, \& } \\
\text { Vertinsky } \\
(2003)\end{array}$ & $\begin{array}{l}\text { Study of the cooperative R\&D } \\
\text { activity in the Canadian forest } \\
\text { products industry (Paprican } \\
\text { consortium in the pulp and } \\
\text { paper sector, Forintek in the } \\
\text { solid wood sector, and FERIC } \\
\text { in the harvesting sector). }\end{array}$ & $\begin{array}{l}\text { Why? To overcome size constraints, access R\&D capabilities } \\
\text { and new markets, share costs, reduce risks, and deal with } \\
\text { environmental challenges and regulations. } \\
\text { How? In low R\&D-intensity industries, government plays a } \\
\text { key role in alliance formation and structuring, for example, by } \\
\text { funding precompetitive research, supporting the infrastructure } \\
\text { of university-industry interaction and the search for } \\
\text { international partners, guiding information protection system. } \\
\text { Governance mechanisms (e.g. establishing research agenda by } \\
\text { consensus) influence the degree of partners' involvement. } \\
\text { Agency tensions may arise: R\&D consortia' objectives and } \\
\text { individual partners' objectives may be different and } \\
\text { competing. }\end{array}$ \\
\hline $\begin{array}{l}\text { Ouchi \& } \\
\text { Bolton (1988) }\end{array}$ & $\begin{array}{l}\text { A multi-case study on } 4 \text { well- } \\
\text { known R\&D alliances: The } \\
\text { VLSI Technology Research } \\
\text { Association (semiconductor- } \\
\text { computer industry, Japan), } \\
\text { Pump Research and } \\
\text { Development Company } \\
\text { (PRADCO, high-volume } \\
\text { pump industry, U.S.), } \\
\text { Corporation for Open Systems } \\
\text { (COS, IT industry, U.S.), and } \\
\text { Microelectronics and } \\
\text { Computer Technology } \\
\text { Corporation (MCC, } \\
\text { semiconductor-computer } \\
\text { industry, U.S.) }\end{array}$ & $\begin{array}{l}\text { Why? To pool technical resources and joint efforts in the face } \\
\text { of the next generation of industry technology and external } \\
\text { competition, as well as to accelerate the implementation of } \\
\text { industry standards and to reduce technical risk. } \\
\text { How? Industry associations often play a key role in R\&D } \\
\text { alliance formation, by directly promoting partnership } \\
\text { formation or supporting firms' initiative, for example, by } \\
\text { dialoguing with the government or guiding the negotiations } \\
\text { among potential partners. Government also takes part in R\&D } \\
\text { alliance formation, for example, by approving (hampering) } \\
\text { R\&D entities to conduct research activities or providing } \\
\text { financial support. }\end{array}$ \\
\hline $\begin{array}{l}\text { Stephens, } \\
\text { Fulk \& } \\
\text { Monge (2009) }\end{array}$ & $\begin{array}{l}\text { AllSoft, a cross-industry } \\
\text { Cooperative Research and } \\
\text { Development Agreement } \\
\text { (CRADA) between } 3 \text { U.S. } \\
\text { government research labs and } \\
4 \text { firms involved in various } \\
\text { aspects of digital technology. } \\
\text { The objective was to develop } \\
\text { an existing technology into a } \\
\text { viable commercial product. }\end{array}$ & $\begin{array}{l}\text { Why? 'Cupid alliances' are formed between 'target' firms at } \\
\text { the behest of a third 'cupid' organization on which target firms } \\
\text { are resource dependent, and which seeks to profit from the } \\
\text { alliance without participating in it. } \\
\text { How? Key alliance decisions (scope and partner choice) are } \\
\text { constrained by the cupid's requirements. Partners have more } \\
\text { freedom in negotiating the governance structure. During such } \\
\text { negotiations, the lack of interpersonal trust and relational } \\
\text { embeddedness between negotiators, as well as the lack of } \\
\text { partners' motivation to build a successful relationship make } \\
\text { alliance formation complex and uncertain. Multi-party cupid } \\
\text { alliances, in which the level of trust between partners may } \\
\text { vary, may also suffer from imbalance in reciprocity. }\end{array}$ \\
\hline
\end{tabular}




\section{Appendix I.7. Definitions and intellectual core of 'dynamic capabilities'}

\begin{tabular}{|c|c|c|}
\hline \multicolumn{3}{|c|}{ Definitions of dynamic capabilities } \\
\hline $\begin{array}{l}\text { Teece \& Pisano } \\
\text { (1994) }\end{array}$ & \multicolumn{2}{|c|}{$\begin{array}{l}\text { "the subset of the competences/capabilities which allow the firm to create new } \\
\text { products and processes and respond to changing market circumstances' (p. 541). }\end{array}$} \\
\hline $\begin{array}{l}\text { Teece, Pisano \& } \\
\text { Shuen (1997) }\end{array}$ & \multicolumn{2}{|c|}{$\begin{array}{l}\text { "the firm's ability to integrate, build, and reconfigure internal and external } \\
\text { competences to address rapidly changing environments" (p. 516) }\end{array}$} \\
\hline $\begin{array}{l}\text { Eisenhardt \& } \\
\text { Martin (2000) }\end{array}$ & \multicolumn{2}{|c|}{$\begin{array}{l}\text { "the firm's processes that use resources - specifically the processes to integrate, } \\
\text { reconfigure, gain and release resources -to match or even create market change. } \\
\text { Dynamic capabilities thus are the organizational and strategic routines by which } \\
\text { firms achieve new resources configurations as market emerge, collide, split, evolve } \\
\text { and die" (p. 1107) }\end{array}$} \\
\hline $\begin{array}{l}\text { Zollo \& Winter } \\
(2002)\end{array}$ & \multicolumn{2}{|c|}{$\begin{array}{l}\text { "a learned and stable pattern of collectively activity thorough which the } \\
\text { organization systematically generates and modifies its operating routines in pursuit } \\
\text { of improved effectiveness" (p.340) }\end{array}$} \\
\hline Winter (2003) & \multicolumn{2}{|c|}{$\begin{array}{l}\text { "those that operate to extend, modify or create ordinary (substantive) capabilities" } \\
\text { (p.991) }\end{array}$} \\
\hline $\begin{array}{l}\text { Zahra, Harry, \& } \\
\text { Sapienza (2006) }\end{array}$ & \multicolumn{2}{|c|}{$\begin{array}{l}\text { "the abilities to re-configure a firm's resources and routines in the manner } \\
\text { envisioned and deemed appropriate by its principal decision maker(s)" }\end{array}$} \\
\hline $\begin{array}{l}\text { Helfat, } \\
\text { Finkelstein, \& } \\
\text { Mitchell (2007) }\end{array}$ & \multicolumn{2}{|c|}{$\begin{array}{l}\text { "capacity of an organization to purposefully create, extend or modify its resource } \\
\text { base" (p. 4) }\end{array}$} \\
\hline \multicolumn{3}{|c|}{ The 'intellectual core' in the dynamic capabilities field } \\
\hline Approach & Main contributions & Main criticisms \\
\hline $\begin{array}{c}\text { Integrative } \\
\text { approach } \\
\text { Teece et al., } \\
\text { (1997) }\end{array}$ & $\begin{array}{l}\text { 1. DCs definition: “the firm's ability to integrate, } \\
\text { build, and reconfigure internal and external } \\
\text { competences to address rapidly changing } \\
\text { environments" (p. 516) } \\
\text { 2. Elements of DCs (units of analysis of the } \\
\text { framework): } \\
\text { - Processes: firm-specific routines playing the roles } \\
\text { of coordination/integration (static), learning } \\
\text { (dynamic) and reconfiguration (transformational) } \\
\text { - Position: current firm's specific endowment of } \\
\text { strategic resources (internal, external and } \\
\text { associated to firm's boundaries) } \\
\text { - Paths: strategic alternatives available for the firm } \\
\text { which depend on firm's history (i.e., path } \\
\text { dependency) and capability to seize and sense } \\
\text { technological opportunities from the industry } \\
\text { 3. DCs -Competitive advantage link: lies in } \\
\text { processes, which are shaped by positions and paths. } \\
\text { Its sustainability depends on processes' replication } \\
\text { and imitation difficulty }\end{array}$ & $\begin{array}{l}\text { - Important questions remain } \\
\text { open (e.g., what constitutes } \\
\text { abilities, how they can be } \\
\text { recognized and where they } \\
\text { come from) (Easterby- } \\
\text { Smith et al., 2009) } \\
\text { - Tautology: Direct } \\
\text { association between } \\
\text { capabilities and (a) } \\
\text { competitive advantage } \\
\text { (Helfat et al. 2007) and (b) } \\
\text { abilities (Eisenhard \& } \\
\text { Martin 2000; Zollo } \\
\text { \&Winter, 2002) } \\
\text { - Restriction of dynamic } \\
\text { capabilities to highly } \\
\text { dynamic environments } \\
\text { (Zollo \& Winter, 2002; } \\
\text { Arend \& Bromiley, 2009) }\end{array}$ \\
\hline
\end{tabular}




\begin{tabular}{|c|c|c|}
\hline $\begin{array}{c}\text { Dynamization } \\
\text { approach } \\
\text { Eisenhardt } \\
\text { and Martin } \\
\mathbf{( 2 0 0 0 )}\end{array}$ & $\begin{array}{l}\text { 1. DCs definition: "the firm's processes that use } \\
\text { resources - specifically the processes to integrate, } \\
\text { reconfigure, gain and release resources -to match or } \\
\text { even create market change." (p. 1107) } \\
\text { 2. Revision of DCs concept: consist of specific } \\
\text { identifiable organizational processes, idiosyncratic in } \\
\text { details, but presenting commonalities in key features } \\
\text { across firms (best practices and equifinality, more } \\
\text { substitutability than assumed) } \\
\text { 3. Relative logic according to market } \\
\text { dynamism:[(a) moderately dynamic markets; (b) } \\
\text { high-velocity environments] } \\
\text { - Nature of the processes: (a) detailed analytic } \\
\text { routines; (b) fragile experiential processes (rules } \\
\text { of thumb) } \\
\text { - DCs-competitive advantage link: (a) DCs' } \\
\text { outcomes predictable and threats from outside the } \\
\text { firm; (b) unpredictable outcomes and threats from } \\
\text { inside } \\
\text { - Experience, learning and systematic } \\
\text { routinization (a) traditional conception of } \\
\text { routines; (b) unstable processes that rely on real- } \\
\text { time information to adapt }\end{array}$ & $\begin{array}{l}\text { - Dynamic capabilities are } \\
\text { much more than best } \\
\text { practices (Zollo \& Winter, } \\
\text { 2002; Helfat et al., 2007), } \\
\text { "brilliant improvisation is } \\
\text { not a routine " (Winter, } \\
\text { 2003: 991) } \\
\text { - Whether dynamic } \\
\text { capabilities contribute to } \\
\text { competitive advantage can } \\
\text { be explained with the same } \\
\text { factors identified by the } \\
\text { RBV (Helfat et al., 2007) }\end{array}$ \\
\hline $\begin{array}{c}\text { Innovation } \\
\text { routines } \\
\text { approach } \\
\text { Zollo and } \\
\text { Winter, } \\
\text { (2002) }\end{array}$ & $\begin{array}{l}\text { 1. DCs definition: "a learned and stable pattern of } \\
\text { collectively activity thorough which the organization } \\
\text { systematically generates and modifies its operating } \\
\text { routines in pursuit of improved effectiveness" (p. 340) } \\
\text { 2. Revision of DCs concept (marked evolutionary } \\
\text { economics view): } \\
\text { - Constituent elements of DCs: 'search routines' } \\
\text { (innovation); object on which DCs operate: } \\
\text { 'operation routines' (functioning) } \\
\text { - Contexts of DCs relevance: high-speed and less } \\
\text { rapid change } \\
\text { - Routinization-experience link: experience } \\
\text { accumulation (behavioral learning) and } \\
\text { deliberate/ purposeful learning investments } \\
\text { (cognitive learning) } \\
\text { 3. Demystification of the DCs-competitive } \\
\text { advantage link: DCs may lead to 'improve } \\
\text { effectiveness'; contingent effects of capability } \\
\text { hierarchy: "if exogenous change is 'competence } \\
\text { destroying' at the level of first-order dynamic } \\
\text { capabilities, those who invest in routinizing the } \\
\text { response to familiar types of change may find } \\
\text { themselves disadvantaged relative to more flexible } \\
\text { players who had invested in higher-order capabilities" } \\
\text { (Winter, 2003: } 994 \text { ). }\end{array}$ & $\begin{array}{l}\text { - Capabilities are more than } \\
\text { routines: "'routines are the } \\
\text { building blocks of } \\
\text { capabilities'_although } \\
\text { routines are not the only } \\
\text { building blocks of } \\
\text { capabilities. A marketing } \\
\text { capability might require a } \\
\text { customer database, for } \\
\text { example, which is neither a } \\
\text { routine itself nor does it } \\
\text { resemble a routine in the } \\
\text { way that the working of } \\
\text { complex equipment } \\
\text { sometimes does" (Dosi et } \\
\text { al., 2000:4) }\end{array}$ \\
\hline
\end{tabular}




\section{Appendix I.8. Characteristics and conceptualizations of routines}

\begin{tabular}{|c|c|c|}
\hline \multicolumn{3}{|c|}{ Description of the main characteristics of routines (Based on Becker, 2004) } \\
\hline $\begin{array}{l}\text { Recurrent } \\
\text { Patterns }\end{array}$ & \multicolumn{2}{|c|}{$\begin{array}{l}\text { - Routines as behavioral regularities (activity level) and/or cognitive regularities (cognition } \\
\text { level) } \\
\text { - Routines involve regularity and (some degree) of stability }\end{array}$} \\
\hline Processess & \multicolumn{2}{|c|}{$\begin{array}{l}\text { - Routines as nexus between structure and outcomes } \\
\text { - Routines as sequences of events }\end{array}$} \\
\hline $\begin{array}{l}\text { Collective } \\
\text { phenomena }\end{array}$ & \multicolumn{2}{|c|}{$\begin{array}{l}\text { - Routines are recurrent interaction patterns } \\
\text { - Routines involve multiple actors }\end{array}$} \\
\hline $\begin{array}{l}\text { Context- } \\
\text { dependence, } \\
\text { embeddedness } \\
\text { and specificity }\end{array}$ & \multicolumn{2}{|c|}{$\begin{array}{l}\text { - Routines are embedded in organizational structures } \\
\text { - Routines, if removed from their original context, may prove meaningless }\end{array}$} \\
\hline Triggered nature & \multicolumn{2}{|c|}{ - Routine's executions represent organizational reactions to internal or external stimuli } \\
\hline $\begin{array}{l}\text { Mindlessness vs. } \\
\text { Effortful } \\
\text { accomplishments }\end{array}$ & \multicolumn{2}{|c|}{$\begin{array}{l}\text { - Routines executed in the realm of subconscious (automatically) vs. routines executed in the } \\
\text { realm of conscious (purposefully) }\end{array}$} \\
\hline Path-dependence & \multicolumn{2}{|c|}{$\begin{array}{l}\text { - Routines come from experience accumulation } \\
\text { - Routines are shaped by history }\end{array}$} \\
\hline \multicolumn{3}{|r|}{ Conceptualizations of routines } \\
\hline $\begin{array}{l}\text { Cohen \& Badayan } \\
(1994)\end{array}$ & Procedural memory & $\begin{array}{l}\text { Routines are reciprocally-triggered sequences of skilled actions that are } \\
\text { stored as procedural memory. Organizational procedural memory } \\
\text { concerns how things are done in the organization and it is relatively } \\
\text { automatic and inarticulate. }\end{array}$ \\
\hline $\begin{array}{l}\text { Pentland \& Rueter } \\
\text { (1994) }\end{array}$ & Grammars of action & $\begin{array}{l}\text { Routines, as 'grammars of action' define a set of possible patterns of } \\
\text { behavior, rather than prescribing a single pattern. }\end{array}$ \\
\hline $\begin{array}{l}\text { Feldman \& } \\
\text { Rafaeli (2002) }\end{array}$ & $\begin{array}{l}\text { Sources of } \\
\text { connections and } \\
\text { understandings }\end{array}$ & $\begin{array}{l}\text { Routines are collective phenomena whose implementation necessarily } \\
\text { involves interaction between the actors engaged in the development of } \\
\text { the routine and therefore routines create connections between them. } \\
\text { These connections in turn allow routine actors to gradually build mutual } \\
\text { understanding about what specific actions should be carried out and } \\
\text { how they relate to a larger organizational picture }\end{array}$ \\
\hline $\begin{array}{l}\text { Feldman \& } \\
\text { Pentland (2003) }\end{array}$ & Dual phenomena & $\begin{array}{l}\text { Organizational routines consist of two interrelated aspects: the ostensive } \\
\text { and the performative. Broadly speaking, 'the ostensive aspect is the } \\
\text { idea; the performative aspect is the enactment'. More specifically, the } \\
\text { ostensive aspect is the abstract schematic conceptualization of a routine, } \\
\text { whereas the performative aspect concerns the specific actions taken by } \\
\text { the specific actors involved in the routine. }\end{array}$ \\
\hline
\end{tabular}




\section{Appendix I.9. Empirical research on dynamic capabilities}

\begin{tabular}{|c|c|c|c|c|c|}
\hline Study & $\begin{array}{l}\text { Dynamic capability studied [with } \\
\text { representative quotes] }\end{array}$ & Research purpose & Research design & $\begin{array}{l}\text { Operationalization of } \\
\text { the dynamic capability }\end{array}$ & Remarks \\
\hline 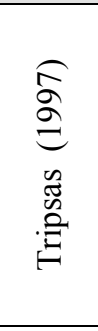 & $\begin{array}{l}\text { Technical capabilities } \\
\text { [“...when technological innovation builds upon } \\
\text { the capabilities of established firms, they have an } \\
\text { advantage over new entrants...(when) innovation } \\
\text { was radical...incumbents (have the) ability to } \\
\text { develop new capabilities... what Teece, Pisano, } \\
\text { and Shuen (1997) call 'dynamic capability' “ (p. } \\
\text { 121)] }\end{array}$ & $\begin{array}{l}\text { Examining the } \\
\text { development of } \\
\text { incumbent firms' } \\
\text { technological } \\
\text { capabilities to survive } \\
\text { radical innovation } \\
\text { through dynamic } \\
\text { capabilities }\end{array}$ & $\begin{array}{l}\text { Qualitative, quantitative } \\
\text { longitudinal: } \\
\text { firm- and product-level } \\
\text { data of the } 42 \text { firms } \\
\text { involved in the industry } \\
\text { along the period } 1886- \\
1990\end{array}$ & $\begin{array}{l}\text { Technical experience ( } 2 \\
\text { measures : a dummy } \\
\text { variable capturing } \\
\text { whether the firm is } \\
\text { incumbent and the stock } \\
\text { of prior experience) }\end{array}$ & $\begin{array}{l}\text { In the typesetter industry, undergone three } \\
\text { waves of 'creative destruction'. In one of } \\
\text { them, incumbents failed due to inferior } \\
\text { technical product performance (not due to } \\
\text { lack of investment in new products). In the } \\
\text { other two waves, incumbents retained their } \\
\text { market position thanks to complementary } \\
\text { assets (lacked by new entrants) }\end{array}$ \\
\hline 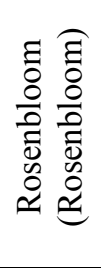 & $\begin{array}{l}\text { Dynamic capabilities (in general) } \\
\text { [“In today's world, it seems inevitable that a firm } \\
\text { will eventually encounter new technology that is } \\
\text { disruptive... firms should be able to adapt if they } \\
\text { possess sufficient 'dynamic capabilities'” ( } p \text {. } \\
\text { 1084)] }\end{array}$ & $\begin{array}{l}\text { Exploring how market } \\
\text { leaders can succeed in } \\
\text { the face of } \\
\text { revolutionary } \\
\text { technological change }\end{array}$ & $\begin{array}{l}\text { Qualitative, } \\
\text { longitudinal: } \\
\text { Single case study on a } \\
\text { multinational leading } \\
\text { industrial firm (NCR), } \\
\text { 1938-1978 }\end{array}$ & $\begin{array}{l}\text { No formal } \\
\text { operationalization } \\
\text { (narrative description of } \\
\text { strategic actions taken by } \\
\text { NCR) }\end{array}$ & $\begin{array}{l}\text { In dealing with the introduction of } \\
\text { electronics and digital computers to the } \\
\text { field of business equipment, NCR first } \\
\text { suffers a crisis (due to path-dependence) } \\
\text { and then solves it by refocusing its latent } \\
\text { dynamic capabilities }\end{array}$ \\
\hline 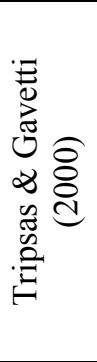 & $\begin{array}{l}\text { Technological dynamic capabilities } \\
\text { ["Organizational change is difficult. Even when } \\
\text { established firms recognize the need to change in } \\
\text { response to shifts in their external environment, } \\
\text { they are often unable to respond effectively...top } \\
\text { managers often have difficulty in adapting their } \\
\text { mental models, resulting in poor organizational } \\
\text { performance" (p.1147-1148)] }\end{array}$ & $\begin{array}{l}\text { Exploring how the } \\
\text { combination of } \\
\text { capabilities and } \\
\text { managerial cognition } \\
\text { explain inertia of } \\
\text { established firms in } \\
\text { the face of radical } \\
\text { technological change }\end{array}$ & $\begin{array}{l}\text { Qualitative, } \\
\text { longitudinal: } \\
\text { Case study on an } \\
\text { incumbent firm in } \\
\text { digital imaging } \\
\text { (Polaroid Corporation), } \\
\text { 1937-1980 and 1980s- } \\
\text { 1990s }\end{array}$ & $\begin{array}{l}\text { No formal } \\
\text { operationalization } \\
\text { (narrative description } \\
\text { actions, capabilities, and } \\
\text { managerial cognition at } \\
\text { Polaroid) }\end{array}$ & $\begin{array}{l}\text { In dealing with shift from analog to digital } \\
\text { imaging, Polaroid overcame path- } \\
\text { dependences and developed new } \\
\text { technological capabilities, due to early } \\
\text { investment in several technological areas. } \\
\text { However, the firm failed to adapt to the } \\
\text { radical changes in the industry. Managerial } \\
\text { cognition (at the senior level) caused such } \\
\text { fail by shaping search activities }\end{array}$ \\
\hline
\end{tabular}




\begin{tabular}{|c|c|c|c|c|c|}
\hline 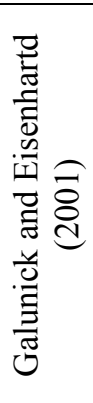 & $\begin{array}{l}\text { Architectural innovation (in multi-business } \\
\text { organizations) } \\
\text { ["By frequently revisiting the corporate } \\
\text { architecture as markets and divisions coevolved } \\
\text { (that is, by patching divisional resources with } \\
\text { charters), this charter change process become an } \\
\text { important dynamic capability" (p. 1230)] }\end{array}$ & $\begin{array}{l}\text { Exploring dynamic } \\
\text { capabilities at the } \\
\text { corporate-level by } \\
\text { focusing on processes } \\
\text { by which multi- } \\
\text { business firms } \\
\text { reconfigure its } \\
\text { divisions' resources } \\
\text { (i.e., architectural } \\
\text { innovation) }\end{array}$ & $\begin{array}{l}\text { Qualitative, } \\
\text { longitudinal: } \\
\text { A case study on a } \\
\text { multi-business } \\
\text { corporation involve in } \\
\text { various technology- } \\
\text { based industries }\end{array}$ & $\begin{array}{l}\text { No formal } \\
\text { operationalization } \\
\text { (narrative description of } \\
\text { the corporate-level } \\
\text { process by which the firm } \\
\text { reconfigure its divisions) }\end{array}$ & $\begin{array}{l}\text { A 'dynamic community' is formed by } \\
\text { several divisions interlinked by shared- } \\
\text { identity and whose charters and capabilities } \\
\text { are reconfigured to create new assets and } \\
\text { deal with changing markets. Dynamic } \\
\text { capabilities are shaped by both economic } \\
\text { and social logics }\end{array}$ \\
\hline 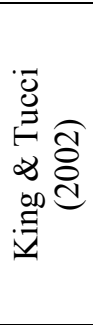 & $\begin{array}{l}\text { Incumbent entry into new markets } \\
\text { ["Technological change can cause market waves } \\
\text { that incumbent firms must master if they are to } \\
\text { survive.... The ability to respond to a new market } \\
\text { is part of organizational capabilities called } \\
\text { 'dynamic capabilities'” (p. 171)] }\end{array}$ & $\begin{array}{l}\text { Investigating the } \\
\text { effect of experience } \\
\text { with previous market } \\
\text { entry (static, } \\
\text { transformational) in } \\
\text { incumbent firms' } \\
\text { patterns of market } \\
\text { entry }\end{array}$ & $\begin{array}{l}\text { Quantitative, } \\
\text { longitudinal study: } 174 \\
\text { firms in drive-disk } \\
\text { industry, 1976-1995 }\end{array}$ & $\begin{array}{l}\text { Market entry (dummy } \\
\text { variables capturing } \\
\text { market entry) }\end{array}$ & $\begin{array}{l}\text { Experience in one market provide } \\
\text { competitive advantage in others (instead of } \\
\text { inertia), thus, when such value is recognized } \\
\text { by managers, static experience encourages } \\
\text { new market entry }\end{array}$ \\
\hline 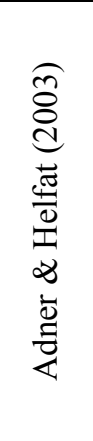 & $\begin{array}{l}\text { Dynamic managerial capabilities (i.e., } \\
\text { managerial human capital, social capital, and } \\
\text { cognition) } \\
\text { [“....are the capabilities with which managers } \\
\text { build, integrate, and reconfigure organizational } \\
\text { resources and competences.... a direct analogy } \\
\text { to more general organizational 'dynamic } \\
\text { capabilities'” (p. 1012)] }\end{array}$ & $\begin{array}{l}\text { Analyzing whether } \\
\text { corporate } \\
\text { management and } \\
\text { strategy affect the } \\
\text { variance of business } \\
\text { performance by } \\
\text { examining the impact } \\
\text { of corporate-level } \\
\text { decisions (dynamic } \\
\text { managerial } \\
\text { capabilities) over time }\end{array}$ & $\begin{array}{l}\text { Quantitative, } \\
\text { longitudinal: } \\
30 \text { firms in U.S. } \\
\text { petroleum industry } \\
1977-1997\end{array}$ & $\begin{array}{l}\text { Corporate-level } \\
\text { managerial decisions: } \\
\text { Downsizing decisions } \\
\text { (dummy variables coded } \\
\text { from press } \\
\text { announcements) }\end{array}$ & $\begin{array}{l}\text { In a single industry, when firms deal with } \\
\text { the same environmental threats, managers } \\
\text { may differ in their dynamic capabilities and } \\
\text { therefore may make different decisions } \\
\text { leading to variance in business performance }\end{array}$ \\
\hline
\end{tabular}




\begin{tabular}{|c|c|c|c|c|c|}
\hline 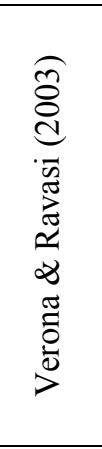 & $\begin{array}{l}\text { Continuous innovation capabilities (new } \\
\text { product development) } \\
\text { ["Introducing new products in the market on a } \\
\text { regular basis (is) the most effective way of } \\
\text { turning change into an endemic and continuous } \\
\text { process...The considerable number of new, high- } \\
\text { quality products introduced by the multinational } \\
\text { Danish company (Oticon) clearly demonstrate its } \\
\text { capacity to develop and launch new } \\
\text { products...the organizational basis of dynamic } \\
\text { capabilities" p.(577-578) ] }\end{array}$ & $\begin{array}{l}\text { Unbundling the } \\
\text { concept of dynamic } \\
\text { capabilities by } \\
\text { explaining how firms } \\
\text { develop continuous } \\
\text { product innovation } \\
\text { and thus deal with the } \\
\text { changing } \\
\text { technological } \\
\text { trajectories of their } \\
\text { industries }\end{array}$ & $\begin{array}{l}\text { Qualitative, } \\
\text { longitudinal: } \\
\text { Case study on a leading } \\
\text { Danish producer of } \\
\text { hearing aids (Oticon } \\
\text { S/A), 1988-1999 }\end{array}$ & $\begin{array}{l}\text { No formal } \\
\text { operationalization } \\
\text { (narrative description of } \\
\text { knowledge creation, } \\
\text { absorption, integration, } \\
\text { and reconfiguration } \\
\text { processes at Oticon) }\end{array}$ & $\begin{array}{l}\text { Dynamic capabilities, in order to sustain } \\
\text { continuous product innovation, should } \\
\text { comprise several knowledge processes } \\
\text { simultaneously: knowledge creation, } \\
\text { integration, absorption, and reconfiguration. } \\
\text { Reconfiguration is precisely the dimension } \\
\text { that supports continuous innovation in the } \\
\text { long run }\end{array}$ \\
\hline 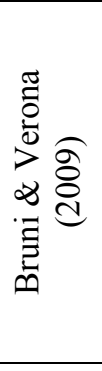 & $\begin{array}{l}\text { Dynamic marketing capabilities } \\
\text { ["Dynamic marketing capabilities pertain to the } \\
\text { broader set of dynamic managerial capabilities } \\
\text {.. specifically aimed at developing, releasing, } \\
\text { and integrating market knowledge" (p. 102)] }\end{array}$ & $\begin{array}{l}\text { Exploring whether } \\
\text { and how market } \\
\text { knowledge (hence, } \\
\text { dynamic marketing } \\
\text { capabilities) promotes } \\
\text { value creation in } \\
\text { science-based firms }\end{array}$ & $\begin{array}{l}\text { Qualitative, } \\
\text { longitudinal: multi-case } \\
\text { study on six high- } \\
\text { performing } \\
\text { pharmaceutical firms, } \\
\text { 2003-2005 }\end{array}$ & $\begin{array}{l}\text { No formal } \\
\text { operationalization } \\
\text { (narrative description of } \\
\text { capability components } \\
\text { and their value-creation } \\
\text { effects) }\end{array}$ & $\begin{array}{l}\text { Shifts in the competitive structure of the } \\
\text { pharmaceutical industry make necessary to } \\
\text { integrate marketing capabilities' } \\
\text { components (e.g., cognition, social capital, } \\
\text { human capital) into the new drug } \\
\text { development process. Dynamic marketing } \\
\text { capabilities promote new products } \\
\text { development and changes in firms' } \\
\text { capability base over time }\end{array}$ \\
\hline 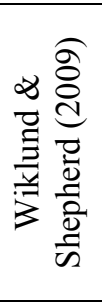 & $\begin{array}{l}\text { Resource combination in alliances and } \\
\text { acquisitions } \\
\text { [“.... firm's routines that bring in and integrate } \\
\text { newly accessed resources from alliances and } \\
\text { acquisitions constitute an important dynamic } \\
\text { capability...necessary to appropriate the } \\
\text { potential value residing in a firm's resource } \\
\text { portfolio” (p. 196-197)] }\end{array}$ & $\begin{array}{l}\text { Studying the } \\
\text { moderating role of } \\
\text { resource combination } \\
\text { activities on the } \\
\text { effectiveness of } \\
\text { alliances and } \\
\text { acquisitions }\end{array}$ & $\begin{array}{l}\text { Quantitative, cross- } \\
\text { sectional: } 319 \text { Swedish } \\
\text { small firms in multiple } \\
\text { industries }\end{array}$ & $\begin{array}{l}\text { Resource combination } \\
\text { activities: questionnaire } \\
\text { multi-item scale (i.e., self- } \\
\text { reported data about use, } \\
\text { development, acquisition, } \\
\text { and accumulation of } \\
\text { resources) }\end{array}$ & $\begin{array}{l}\text { Small firms' efforts devoted to conducting } \\
\text { resource combination activities positively } \\
\text { moderates the effect of alliances and } \\
\text { acquisitions }\end{array}$ \\
\hline 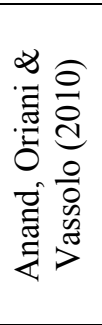 & $\begin{array}{l}\text { Alliance activity } \\
\text { [“...the ability of the firm to create and manage } \\
\text { new alliances in order to enter emerging } \\
\text { technological fields ... is considered a dynamic } \\
\text { capability.... by aiming at changing a firm's } \\
\text { existing bundle of resources and competencies to } \\
\text { fit emerging technological fields” (p. 1214)] }\end{array}$ & $\begin{array}{l}\text { Investigating how } \\
\text { technological } \\
\text { capabilities affect } \\
\text { firm's abilities to } \\
\text { enter emerging fields, } \\
\text { highlighting the role } \\
\text { of alliances in such } \\
\text { process }\end{array}$ & $\begin{array}{l}\text { Quantitative, } \\
\text { longitudinal: } 876 \\
\text { biotech entry decisions } \\
\text { by the } 19 \text { largest } \\
\text { pharmaceutical firms, } \\
\text { 1989-1999 }\end{array}$ & $\begin{array}{l}\text { Market entry (dummy } \\
\text { variable) and market } \\
\text { 90weentry mode (dummy } \\
\text { variable: internal } \\
\text { development and } \\
\text { alliances) }\end{array}$ & $\begin{array}{l}\text { Firms with the capability to form new } \\
\text { alliances overcome technological gaps in } \\
\text { entering emerging technology fields } \\
\text { (alliances as a mechanisms to access the } \\
\text { need capabilities) }\end{array}$ \\
\hline
\end{tabular}




\section{Appendix I.10. Research on alliance capabilities}

\begin{tabular}{|c|c|c|c|c|}
\hline Study & Research questions & Concept & Antecedents, mechanisms, dimensions, consequences & Remarks \\
\hline 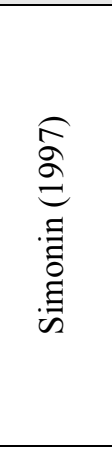 & $\begin{array}{l}\text { Do firms create collaborative } \\
\text { know-how from collaborative } \\
\text { experience? How collaborative } \\
\text { know-how and experience impact } \\
\text { firm's collaborative benefits? }\end{array}$ & $\begin{array}{l}\text { Collaborative know-how: A } \\
\text { multifaceted construct that } \\
\text { represents the extent to } \\
\text { which the firm has skills in } \\
\text { the main phases of the } \\
\text { collaborative cycle }\end{array}$ & $\begin{array}{l}\text { - Antecedents: Collaborative structural experience (e.g. } \\
\text { informal cooperation, contractual agreements, joint } \\
\text { ventures) and functional experience (e.g., R\&D, } \\
\text { marketing, production) } \\
\text { - Dimensions: Identifying and selecting potential } \\
\text { partners; negotiating the structure of the alliance; } \\
\text { monitoring, managing, and terminating the } \\
\text { collaboration } \\
\text { - Consequences: Tangible collaborative benefits (e.g. } \\
\text { firm's profits) and intangible collaborative benefits } \\
\text { (e.g. learning about interfirm cooperation) }\end{array}$ & $\begin{array}{l}\text { Collaborative experience itself does not } \\
\text { enhance tangible and intangible } \\
\text { collaborative benefits. Rather, } \\
\text { collaborative know-how, which is in turn } \\
\text { build upon experience, enhances firm's } \\
\text { benefits from alliances }\end{array}$ \\
\hline 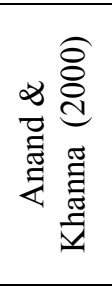 & $\begin{array}{l}\text { Do firms learn to create value } \\
\text { from alliances? } \\
\text { Are there persistent differences in } \\
\text { alliance capability across firms? }\end{array}$ & $\begin{array}{l}\text { Alliance capability: A firm's } \\
\text { ability to create value } \\
\text { through alliances by } \\
\text { anticipating alliance } \\
\text { contingencies and } \\
\text { responding to them in a } \\
\text { effective manner }\end{array}$ & $\begin{array}{l}\text { - Antecedents: Cumulative joint venture experience and } \\
\text { cumulative license experience } \\
\text { - Consequences: Abnormal stock market returns } \\
\text { surrounding alliance formation announcements }\end{array}$ & $\begin{array}{l}\text { Firms learn to create more value, } \\
\text { particularly, as they accumulate R\&D } \\
\text { joint venture experiences (abnormal stock } \\
\text { returns surrounding alliance } \\
\text { announcement). Firm's fixed effects show } \\
\text { persistent heterogeneity in alliance } \\
\text { capabilities across firms }\end{array}$ \\
\hline 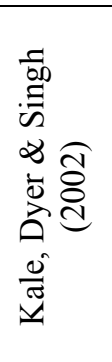 & $\begin{array}{l}\text { How alliance experience, alliance } \\
\text { function, and their interplay } \\
\text { impact alliance success and stock } \\
\text { market responses? } \\
\text { What is the relationship between } \\
\text { these two performance measures? }\end{array}$ & $\begin{array}{l}\text { Alliance capability: A firm- } \\
\text { level ability to manage } \\
\text { successfully alliances, which } \\
\text { rest upon how effectively the } \\
\text { firm is able to capture, share, } \\
\text { and disseminate the alliance } \\
\text { management know-how } \\
\text { acquired from prior alliance } \\
\text { experience }\end{array}$ & $\begin{array}{l}\text { - Antecedents: Alliance experience } \\
\text { - Mechanisms: Dedicated alliance function (a position to } \\
\text { manage or coordinate all firm's alliance-related } \\
\text { activity) } \\
\text { - Consequences: abnormal stock market gains following } \\
\text { alliance formation announcement and long-term } \\
\text { alliance success (harmony between partners, fulfilment } \\
\text { of alliance goals, enhancement of the firm's } \\
\text { competitive position, learning from partners) }\end{array}$ & $\begin{array}{l}\text { Firms with greater alliance experience } \\
\text { and, particularly, with a dedicated alliance } \\
\text { function, report greater alliance success } \\
\text { regarding the two considered measures, } \\
\text { which are positive correlated each other }\end{array}$ \\
\hline
\end{tabular}




\begin{tabular}{|c|c|c|c|c|}
\hline 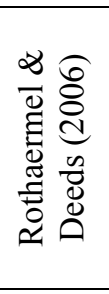 & $\begin{array}{l}\text { How cumulative alliance } \\
\text { experience influences firm's new } \\
\text { product development? } \\
\text { What is the role played by } \\
\text { alliance type in this relationship? }\end{array}$ & $\begin{array}{l}\text { Alliance management } \\
\text { capability: A firm-level } \\
\text { dynamic path dependent } \\
\text { capability that enables the } \\
\text { firm to effectively manage } \\
\text { multiple alliances }\end{array}$ & $\begin{array}{l}\text { - Antecedents: Alliance experience (cumulative sum of } \\
\text { the alliance duration for each of the firm's alliances) } \\
\text { - Consequences: Firm's new product development }\end{array}$ & $\begin{array}{l}\text { There is an inverted U-shaped relationship } \\
\text { between the number of alliances managed } \\
\text { simultaneously and firm's new product } \\
\text { development. Different alliance types } \\
\text { (upstream, horizontal and downstream } \\
\text { alliances) place differential managerial } \\
\text { demands }\end{array}$ \\
\hline 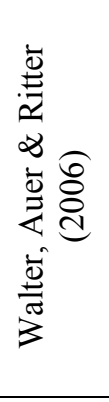 & $\begin{array}{l}\text { How network capabilities of spin- } \\
\text { off organizations influence their } \\
\text { performance? } \\
\text { Is there interplay between } \\
\text { network capabilities and the } \\
\text { entrepreneurial orientation of } \\
\text { spin-off organizations? }\end{array}$ & $\begin{array}{l}\text { Network capabilities: } \\
\text { dynamic processes and a } \\
\text { higher order resource } \\
\text { comprising abilities (of a } \\
\text { spin-off organization) to } \\
\text { initiate, maintain, and utilize } \\
\text { relationships with various } \\
\text { external partners }\end{array}$ & $\begin{array}{l}\text { - Dimensions: Coordination (synchronizing, planning, } \\
\text { and controlling inter-organizational activities); relations } \\
\text { skills (development of close relationships); partner } \\
\text { knowledge (availability of information on network } \\
\text { partners); and internal communication (communication } \\
\text { quality and information dissemination) } \\
\text { - Consequences: spin-off performance (sales growth rate, } \\
\text { sales per employee, profit attainment, perceived } \\
\text { customer relationship quality, realized competitive } \\
\text { advantages, and securing long-term survival) } \\
\end{array}$ & $\begin{array}{l}\text { University spin-offs performance is } \\
\text { positively and directly influenced by their } \\
\text { network capabilities, which also } \\
\text { strengthen the relationship between } \\
\text { entrepreneurial orientation and spin-off } \\
\text { performance }\end{array}$ \\
\hline 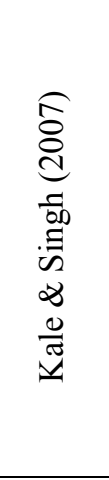 & $\begin{array}{l}\text { How can alliance learning } \\
\text { processes be conceptualized? } \\
\text { How such a process impact } \\
\text { firm's overall alliance success? } \\
\text { What is the relationship between } \\
\text { such a process, alliance } \\
\text { experience, and alliance } \\
\text { function? }\end{array}$ & $\begin{array}{l}\text { Alliance capability: First- } \\
\text { order partnering skills are } \\
\text { routines or practices to better } \\
\text { manage different phases in } \\
\text { the life cycle of any alliance } \\
\text { the firms' engage in, i.e., } \\
\text { alliance formation and } \\
\text { partner selection, alliance } \\
\text { negotiation, formulation of } \\
\text { alliance design, post- } \\
\text { formation alliance } \\
\text { management, etc. }\end{array}$ & $\begin{array}{l}\text { - Antecedents: Alliance experience } \\
\text { - Mechanisms: Dedicate alliance function; alliance } \\
\text { learning process (articulation, codification, sharing, and } \\
\text { internalization of alliance know-how) } \\
\text { - Consequences: firm’s overall alliance success (harmony } \\
\text { between partners, fulfilment of alliance goals, } \\
\text { enhancement of the firm's competitive position, } \\
\text { learning from partners) }\end{array}$ & $\begin{array}{l}\text { Learning processes are conceptualized in } \\
\text { terms of articulation, codification, sharing, } \\
\text { and internalization of alliance know-how. } \\
\text { There is a direct impact between them and } \\
\text { firm's overall alliance success. Alliance } \\
\text { learning processes mediate the } \\
\text { relationship between the alliance function } \\
\text { and alliance success. Experience is } \\
\text { directly related to the existence of an } \\
\text { alliance function but not to success }\end{array}$ \\
\hline
\end{tabular}




\begin{tabular}{|c|c|c|c|c|}
\hline 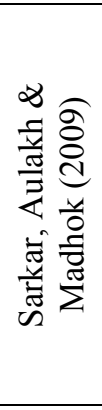 & $\begin{array}{l}\text { How can alliance portfolio } \\
\text { management capability be } \\
\text { conceptualized? } \\
\text { How such a capability impact } \\
\text { alliance portfolio capital? } \\
\text { What is the role played by } \\
\text { alliance function and portfolio } \\
\text { diversity? }\end{array}$ & $\begin{array}{l}\text { Alliance portfolio } \\
\text { management capability: } \\
\text { focal firm's rent-creating } \\
\text { routines that need to be } \\
\text { directed at alliance portfolio } \\
\text { formation, development, and } \\
\text { integration to create value by } \\
\text { enhancing alliance portfolio } \\
\text { capital }\end{array}$ & $\begin{array}{l}\text { - Dimensions: Partnering proactiveness (formation } \\
\text { routines of sensing and promoting alliance } \\
\text { opportunities); relational governance (relational } \\
\text { routines to enhance cooperation); portfolio coordination } \\
\text { (integration routines to foster knowledge transfer and } \\
\text { alignment) } \\
\text { - Mechanisms: Alliance function } \\
\text { - Consequences: Alliance portfolio capital (firm's } \\
\text { reputation as a partner of choice, portfolio competitive } \\
\text { strength, relationship strength) }\end{array}$ & $\begin{array}{l}\text { Alliance portfolio capability and its three } \\
\text { dimensions enhance alliance portfolio } \\
\text { capital, which in turn promotes firm } \\
\text { market performance. The impact of } \\
\text { partnering proactiveness and relational } \\
\text { governance is strengthened in the } \\
\text { presence of an alliance function. Benefits } \\
\text { from relational governance are } \\
\text { strengthened in diverse portfolios, but } \\
\text { those from coordination are weakened }\end{array}$ \\
\hline 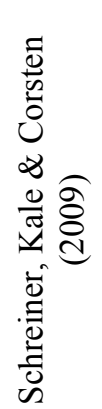 & $\begin{array}{l}\text { How can alliance (post- } \\
\text { formation) management } \\
\text { capability be conceptualized? } \\
\text { How alliance capability affects } \\
\text { post-formation alliance and firm } \\
\text { performance? }\end{array}$ & $\begin{array}{l}\text { Alliance management } \\
\text { capability: a } \\
\text { multidimensional construct } \\
\text { that comprises skills to } \\
\text { address three main aspects in } \\
\text { managing post-formation of } \\
\text { a given alliance: } \\
\text { coordination, } \\
\text { communication, and } \\
\text { bonding }\end{array}$ & $\begin{array}{l}\text { - Dimensions: coordination (management of the } \\
\text { interdependence between partners); communication } \\
\text { (formal and informal sharing of information); and } \\
\text { bonding (development of strong bonds) } \\
\text { - Consequences: joint action (quality of the relationship) } \\
\text { and alliance goals' fulfilment }\end{array}$ & $\begin{array}{l}\text { Alliance management capability can be } \\
\text { conceptualized as a second-order, } \\
\text { multidimensional construct that comprises } \\
\text { the proposed dimensions. Alliance } \\
\text { capability, and its three dimensions, plays } \\
\text { a key role in explaining alliance outcomes } \\
\text { in both at dyadic and firm levels }\end{array}$ \\
\hline
\end{tabular}




\section{Appendixes Chapter 2}

\section{Appendix II.1. Typologies of case studies}

\begin{tabular}{|c|c|c|}
\hline Criteria & References & Typology (description and case study examples) ${ }^{1}$ \\
\hline No. of cases & $\begin{array}{l}\text { Eisenhardt (1989); } \\
\text { Yin (2003) }\end{array}$ & $\begin{array}{l}\text { Single-case studies: the research question is addressed within an unique } \\
\text { case (e.g., Ariño \& de la Torre, 1998) } \\
\text { Multiple-case studies: the research question is addressed using two or more } \\
\text { cases, which allow either replication or comparison of findings (e.g., Doz, } \\
\text { 1996) }\end{array}$ \\
\hline $\begin{array}{l}\text { Levels of } \\
\text { analysis }\end{array}$ & Yin (2003) & $\begin{array}{l}\text { Holistic case studies: study conducted focusing on one unit of analysis } \\
\text { (e.g., Ariño \& de la Torre, 1998) } \\
\text { Embedded case studies: study conducted focusing on two or more units } \\
\text { (sub-units) of analysis. (e.g., Doz, 1996) }\end{array}$ \\
\hline \multirow{3}{*}{ Purpose } & Yin (2003) & $\begin{array}{l}\text { Descriptive case studies: studies aiming at describing a phenomenon within } \\
\text { its context (Browning et al., 1995) } \\
\text { Exploratory case studies: studies which aim to become familiar with a } \\
\text { phenomenon which lacks a established theoretical framework (e.g., Boon, } \\
\text { 2008) } \\
\text { Explanatory case studies aiming at explain the causes/processes } \\
\text { underlying a certain phenomenon (e.g., Faems et al., 2008) }\end{array}$ \\
\hline & Eisenhardt (1989) & $\begin{array}{l}\text { Descriptive case: studies aiming at describing a phenomenon within its } \\
\text { context (e.g., Browning et al., 1995) } \\
\text { Theory-testing case: studies aiming at verification of established } \\
\text { relationships of a certain theoretical framework (e.g., Kale, 1999) } \\
\text { Theory-building (inductive) case: studies that involve one or more cases to } \\
\text { create theoretical constructs, propositions and/or midrange theory (e.g., Doz, } \\
\text { 1996) }\end{array}$ \\
\hline & Siggelkow (2007) & $\begin{array}{l}\text { Motivation-seeking case: studies which aim to motivate a research } \\
\text { question (Siggelkow, 2002) } \\
\text { Inspiration-seeking case: studies entailing immersion in rich case data and } \\
\text { aiming at generating new ideas (inductive, theory-building) (e.g., Doz, } \\
\text { 1996) } \\
\text { Illustration-seeking case: studies which show the application of conceptual } \\
\text { arguments to one ore more empirical settings (e.g., Hennart, 2006) }\end{array}$ \\
\hline
\end{tabular}

\footnotetext{
${ }^{1}$ As can be appreciated from the repetition of some of the examples, typologies are not necessarily mutually exclusive.
} 


\section{Appendix II.2. Partner firms of the Acuisost Consortium}

\begin{tabular}{|c|c|c|c|c|c|c|}
\hline Firm & Industry & Region & Size $^{1}$ & $\mathrm{Age}^{2}$ & Involvement & Alliance goals \\
\hline BigFish & $\begin{array}{l}\text { Aquaculture and } \\
\text { Fisheries }\end{array}$ & Galicia & Large & Incumbent & Late entrance & Development of new fish-based food products \\
\hline BioMilk & Biotechnology & Galicia & $\begin{array}{l}\text { Micro- } \\
\text { enterprise }\end{array}$ & Incumbent & Founder partner & $\begin{array}{l}\text { To attain product innovation (probiotic strains for fish } \\
\text { nutrition) and become the pioneer producer in the domestic } \\
\text { market }\end{array}$ \\
\hline BioNaval & Biotechnology & Galicia & SME & Incumbent & $\begin{array}{l}\text { Founder partner } \\
\text { Early departure }\end{array}$ & $\begin{array}{l}\text { To develop protocols for implementing marine lactic bacteria } \\
\text { to the field of aquaculture nutrition }\end{array}$ \\
\hline BioNutrition & Biotechnology & Andalusia & $\begin{array}{l}\text { Micro- } \\
\text { enterprise }\end{array}$ & Start-up & $\begin{array}{l}\text { Founder partner } \\
\text { Early departure }\end{array}$ & $\begin{array}{l}\text { To attain product innovation (new additives to include in fish } \\
\text { feed formulae) }\end{array}$ \\
\hline Cantabrian Seafood & $\begin{array}{l}\text { Marine } \\
\text { aquaculture }\end{array}$ & Galicia & SME & Start-up & $\begin{array}{l}\text { Late entrance, } \\
\text { early departure }\end{array}$ & $\begin{array}{l}\text { Improvement of the quality, food security and performance in } \\
\text { the farming of marine cultivation of high-added value marine } \\
\text { products of (abalone) through the development of a new } \\
\text { artificial diet }\end{array}$ \\
\hline Chemics\&Proteins & Chenical & Catalonia & SME & Incumbent & Founder partner & $\begin{array}{l}\text { To attain product innovation (by applying protein hydrolyzed } \\
\text { in sea animals larvae's feed) }\end{array}$ \\
\hline Fish\&Meals & Food & Galicia & SME & Start-up & Founder partner & $\begin{array}{l}\text { To attain product innovation (revalorization of a highly protein } \\
\text { by-product and application in fish nutrition) }\end{array}$ \\
\hline Green Solutions & Chemical & Aragon & SME & Incumbent & Founder partner & $\begin{array}{l}\text { To attain product innovation (biocidal products for the } \\
\text { aquaculture field) }\end{array}$ \\
\hline Iberian Eels & $\begin{array}{l}\text { Continental } \\
\text { aquaculture }\end{array}$ & $\begin{array}{l}\text { Valencian } \\
\text { Community }\end{array}$ & SME & Incumbent & Founder partner & $\begin{array}{l}\text { To maintain the competitive advantage by increasing the } \\
\text { quality and performance of the main product (eel); waste } \\
\text { management and recovery and optimization of a secondary } \\
\text { process }\end{array}$ \\
\hline $\begin{array}{l}\text { Industrial Packages } \\
\text { Co. }\end{array}$ & $\begin{array}{l}\text { Industrial } \\
\text { Packaging }\end{array}$ & $\begin{array}{l}\text { Principality } \\
\text { of Asturias }\end{array}$ & Large & Incumbent & Founder partner & $\begin{array}{l}\text { To attain product innovation (specially-designed containers for } \\
\text { fish) containers designed for the fish and become the pioneer } \\
\text { producer in the domestic market }\end{array}$ \\
\hline
\end{tabular}




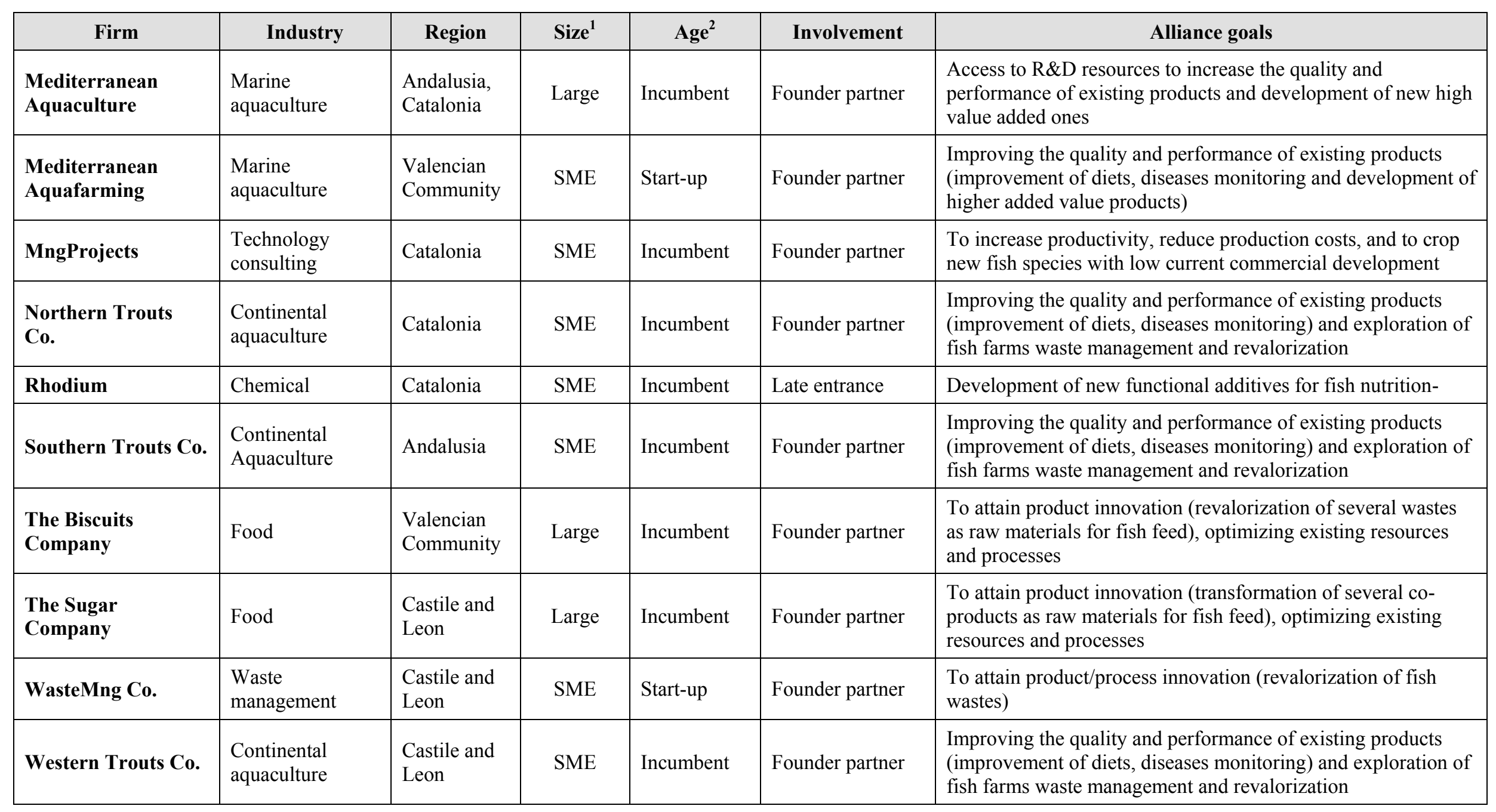




\section{Appendix II.2 Partner firms of the Acuisost Consortium (continued)}

Prior alliance experience of the partners of the Acuisost Consortium ${ }^{2}$

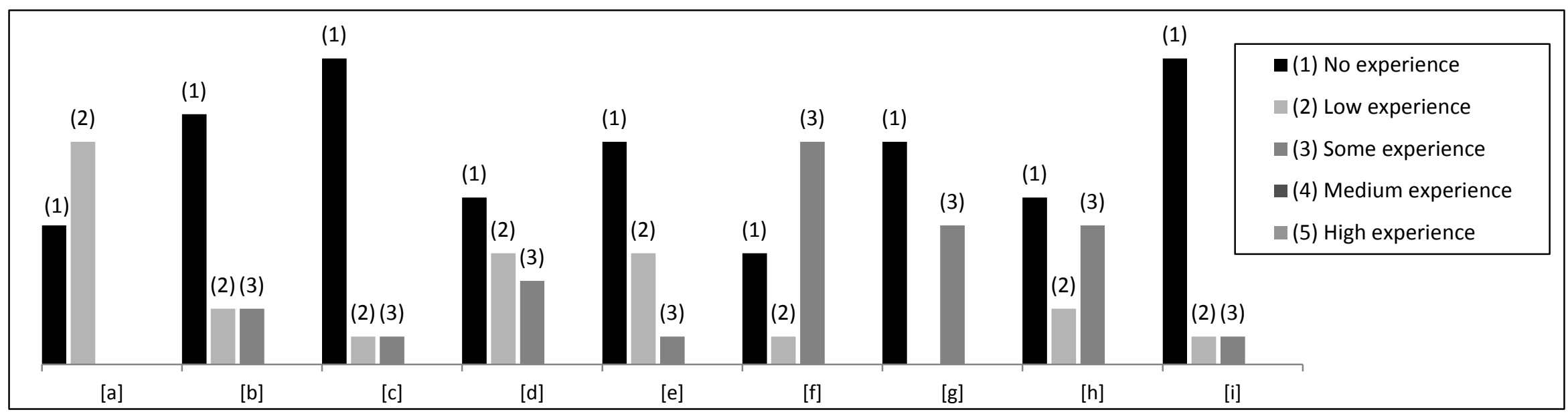

\begin{tabular}{|c|c|c|c|c|c|c|c|c|c|}
\hline & $\begin{array}{l}\text { [a] Overall } \\
\text { alliance } \\
\text { experience }\end{array}$ & $\begin{array}{l}\text { [b] Multi- } \\
\text { partner } \\
\text { alliances }\end{array}$ & $\begin{array}{c}\text { [c] R\&D } \\
\text { alliances with } \\
\text { competitors }\end{array}$ & $\begin{array}{c}\text { [d] R\&D } \\
\text { alliances with } \\
\text { Clients/Suppliers }\end{array}$ & $\begin{array}{c}\text { [e] R\&D } \\
\text { alliances with } \\
\text { other firms }\end{array}$ & $\begin{array}{c}\text { [f] R\&D } \\
\text { alliances with } \\
\text { Research } \\
\text { Organizations } \\
\end{array}$ & $\begin{array}{l}\text { [g] Marketing \& } \\
\text { Production } \\
\text { alliances }\end{array}$ & $\begin{array}{c}\text { [h]Government- } \\
\text { sponsored } \\
\text { alliances } \\
\text { (domestic) } \\
\end{array}$ & $\begin{array}{l}\text { [i] Government- } \\
\text { Sponsored } \\
\text { alliances } \\
\text { (international) }\end{array}$ \\
\hline (1) No experience & 5 partners & 9 partners & 11 partners & 6 partners & 8 partners & 4 partners & 8 partners & 6 partners & 11 partners \\
\hline (2) Low experience & 8 partners & 2 partners & 1 partner & 4 partners & 4 partners & 1 partner & 0 partners & 2 partners & 1 partner \\
\hline (3) Some experience & 0 partners & 2 partners & 1 partner & 3 partners & 1 partner & 8 partners & 5 partners & 5 partners & 1 partner \\
\hline \begin{tabular}{|l|} 
(4) Medium \\
experience
\end{tabular} & 0 partners & 0 partners & 0 partners & 0 partners & 0 partners & 0 partners & 0 partners & 0 partners & 0 partners \\
\hline (5) High experience & 0 partners & 0 partners & 0 partners & 0 partners & 0 partners & 0 partners & 0 partners & 0 partners & 0 partners \\
\hline
\end{tabular}

${ }^{2}$ Source: Questionnaire sent to partner firms. Although not all partner firms collaborated in the survey study, interviews with the LF's representatives helped us to extend the picture and corroborated the lack of significant alliance experience of all partner firms: "Starting the consortium's formation was highly complex [...] Everybody sinned by inexperience" 


\section{Appendix II.3. Research organizations of the Acuisost Consortium}

\begin{tabular}{|c|c|c|c|}
\hline $\begin{array}{c}\text { Research } \\
\text { organization }\end{array}$ & Type $^{3}$ & Main research fields & Region \\
\hline ANNA & URG & $\begin{array}{l}\text { Research in different areas using the ictiophysiology in farmed fish, } \\
\text { including physiopathological indicators of growth in aquaculture species }\end{array}$ & Catalonia \\
\hline ACUVI & URG & $\begin{array}{l}\text { Research on the utilization of currents in food-processing industries for } \\
\text { their reassessment and revalorization. }\end{array}$ & Galicia \\
\hline $\mathrm{BACO}$ & $\mathrm{TC}$ & $\begin{array}{l}\text { Food research: new fish-based food products, new formats and packaging, } \\
\text { processing technologies and conservation. }\end{array}$ & $\begin{array}{l}\text { Basque } \\
\text { Country }\end{array}$ \\
\hline $\mathrm{CAH}$ & PRA & $\begin{array}{l}\text { Research on animal health, food security and environment, bacteriological } \\
\text { diagnosis, epidemiological research and study, diagnosis and control of } \\
\text { contagious animal diseases. }\end{array}$ & Madrid \\
\hline CID & URG & $\begin{array}{l}\text { Research in the field of biotechnology and food sciences, with special } \\
\text { attention to chemical food processes. }\end{array}$ & $\begin{array}{l}\text { Castile and } \\
\text { Leon }\end{array}$ \\
\hline CRAI & $\mathrm{TC}$ & $\begin{array}{l}\text { Marine and food research: new fish food products, processing } \\
\text { technologies and conservation. }\end{array}$ & $\begin{array}{l}\text { Valencian } \\
\text { Comunity }\end{array}$ \\
\hline CRISof & $\mathrm{TC}$ & $\begin{array}{l}\text { Optimization and improvement of marine farming, water quality and } \\
\text { toxicity, new species, larval culture, nutrition, pathology and development } \\
\text { of new technologies. }\end{array}$ & Catalonia \\
\hline FOODS & URG & $\begin{array}{l}\text { Research on factors affecting the quality of meat, fish and their products: } \\
\text { Biochemical of ripening, cooling, packaging, preservation techniques, and } \\
\text { process technology. }\end{array}$ & Aragon \\
\hline LAGO & $\mathrm{TC}$ & $\begin{array}{l}\text { Agri-food area: productive process optimization, new ecological products } \\
\text { development, revalorization of agri-food by-products. Chemical area: } \\
\text { transference of new technologies involving more sustainable processes. }\end{array}$ & $\begin{array}{l}\text { Castile and } \\
\text { Leon }\end{array}$ \\
\hline LIDA & PRA & $\begin{array}{l}\text { Fish feed and nutrition, farming techniques, new fish species farming, } \\
\text { reproduction, animal healthy, new techniques for larva culture and } \\
\text { genetics. }\end{array}$ & $\begin{array}{l}\text { Canary } \\
\text { Islands }\end{array}$ \\
\hline MAR & URG & $\begin{array}{l}\text { Sustainability and environmental impact, new species in rural areas, } \\
\text { technology transfer, production of shellfish, fish, crustaceans, and } \\
\text { evaluation of the quality of aquaculture products. }\end{array}$ & $\begin{array}{l}\text { Valencian } \\
\text { Comunity }\end{array}$ \\
\hline MICROP & URG & $\begin{array}{l}\text { Research in the field of lactic acid bacteria (antibacterial activity and } \\
\text { applications). }\end{array}$ & Madrid \\
\hline NUTRI & URG & $\begin{array}{l}\text { Research in various processes and mode of action of prebiotic } \\
\text { compounds. }\end{array}$ & Madrid \\
\hline OI & PRA & Research on obtaining and application of vegetable proteins. & Andalusia \\
\hline PKS & URG & Research on the farming techniques of various fish species & Galicia \\
\hline POMP & URG & $\begin{array}{l}\text { Research on bacterial and viral diseases in aquaculture, diagnosis and } \\
\text { control, epidemiological analysis, transmission and bioaccumulation of } \\
\text { enteric viruses in shellfish, application of genomics and proteomics }\end{array}$ & Galicia \\
\hline REPRO & URG & Impact of feeding and handling conditions on aquaculture production & Aragon \\
\hline STHR & URG & $\begin{array}{l}\text { Research on biological processes for nutrient removal, treatment systems } \\
\text { and water control, advanced control of wastewater, degradation of organic } \\
\text { compounds, bioremediation of soils, life cycle analysis. }\end{array}$ & Galicia \\
\hline SUGTECH & $\mathrm{TC}$ & $\begin{array}{l}\text { Sugar technology and environmental processes, development of } \\
\text { alternative treatment of process flows, liquid effluents and solid waste. }\end{array}$ & $\begin{array}{l}\text { Castile and } \\
\text { Leon }\end{array}$ \\
\hline
\end{tabular}

\footnotetext{
${ }^{3}$ URG: University research group; PARA: Public research agency; TC: Technological center
} 


\section{Appendix II.4. Main sources of evidence (documents)}

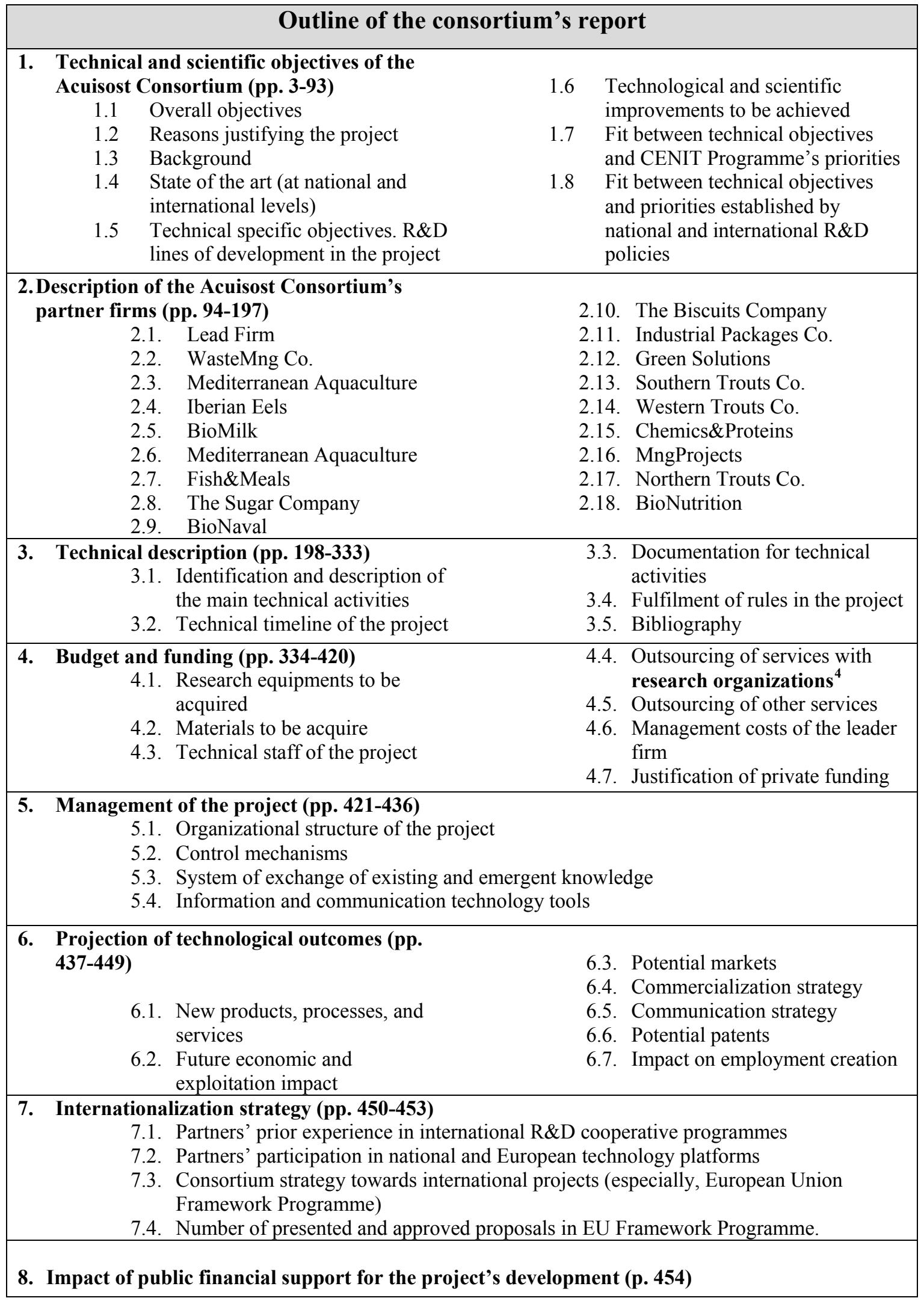

\footnotetext{
${ }^{4}$ In this section of the consortium's report, a brief description of each research organization is provided.
} 


\begin{tabular}{|c|c|}
\hline \multicolumn{2}{|r|}{$\begin{array}{l}\text { Outline of the consortium's agreement } \\
\text { (signed by partner firms) }\end{array}$} \\
\hline $\begin{array}{l}\text { General } \\
\text { description }\end{array}$ & $\begin{array}{l}\text { Is the contract governing the relationship among the multiple partners } \\
\text { of the Acuisost Consortium, signed on } 4^{\text {th }} \text { April, 2007. It comprises } 93 \\
\text { pages (including appendixes) and } 26 \text { clauses grouped into four main } \\
\text { sections ('Introduction', 'Consortium Management', 'Contributions', } \\
\text { 'Tasks and Budget', and 'Results and Property Rights') }\end{array}$ \\
\hline $\begin{array}{l}\text { Objective of the } \\
\text { agreement }\end{array}$ & $\begin{array}{l}\text { "The present Consortium Agreement }[. . .] \text { aims at regulating the } \\
\text { conditions of the relationship among the multiple parties }[\ldots] \text { in order } \\
\text { to guarantee an efficient and proper development of The Consortium } \\
{[\ldots] \text { under the framework of the CENIT Programme }[\ldots] \text { the parties }} \\
\text { acknowledge that this Consortium Agreement does not involve the } \\
\text { creation (neither the intention to create) a new shared-owned entity" }\end{array}$ \\
\hline Suspensive clause & $\begin{array}{l}\text { "The Condition is that the Official Resolution of the CENIT } \\
\text { Programme results favourable [...] if the Official Resolution of the } \\
\text { CENIT Programme results unfavourable the present Consortium } \\
\text { Agreement will be rescinded" }\end{array}$ \\
\hline Time Horizon & $\begin{array}{l}\text { "The present Consortium Agreement will take effect from the day when } \\
\text { The Condition fulfils (if so) until the date established as 'end date' by } \\
\text { the CENIT Programme's } 2006 \text { call" }\end{array}$ \\
\hline $\begin{array}{l}\text { Entry and } \\
\text { Departure of } \\
\text { Partners }\end{array}$ & $\begin{array}{l}\text { "...under conditions of breach of contract, the Steering Committee } \\
\text { could decide the expulsion of that partner }[\ldots] \text { the Steering Committee } \\
\text { could agree the entrance of new partners, prior approval of the CDTI } \\
{[\ldots] \text { partners could depart from The Consortium, prior consultation to }} \\
\text { the Steering Committee" }\end{array}$ \\
\hline $\begin{array}{l}\text { Partners' } \\
\text { contributions }\end{array}$ & $\begin{array}{l}\text { "Each of the partners agrees to contribute to The Consortium the } \\
\text { technical and economic resources detailed in Appendixes }[. . .] \text { Each of } \\
\text { the partners agrees to conduct the technical tasks detailed in the } \\
\text { scientific report attached to the present Consortium Agreement }[\ldots] \\
\text { (and) to provide timely documents and information }[\ldots] \text { (and) to } \\
\text { contribute to the proper development of The Consortium" }\end{array}$ \\
\hline $\begin{array}{l}\text { Organizational } \\
\text { structure: } \\
\text { Figures and } \\
\text { Roles }\end{array}$ & (see Table 2.6, section 2.2.1.3.3 in Chapter 2 for a description) \\
\hline $\begin{array}{l}\text { Private } \\
\text { Knowledge and } \\
\text { Results }\end{array}$ & $\begin{array}{l}\text { "...The property rights of the private knowledge of partners (developed } \\
\text { previously or concurrently to The Consortium) will be guaranteed }[\ldots] \\
\text { private knowledge of partners is detailed in Appendixes }[\ldots] \text { the rest of } \\
\text { partners agree on using only such private knowledge inside The } \\
\text { Consortium and agree on not disclosing it out of the boundaries of The } \\
\text { Consortium [...] Property rights of knowledge generated inside The } \\
\text { Consortium will correspond to the partner which has developed it }[\ldots] \\
\text { if two or more partners are involved }[\ldots] \text { property rights will be defined } \\
\text { through agreement between the parties }[\ldots] \text { the private contracts with } \\
\text { the research organizations will detail the property rights of emerging } \\
\text { results" }\end{array}$ \\
\hline
\end{tabular}




\begin{tabular}{|c|c|}
\hline \multicolumn{2}{|c|}{$\begin{array}{l}\text { Outline of the standard bilateral R\&D contract } \\
\text { (signed by partner firms and research organizations) }\end{array}$} \\
\hline Type of contract & $\begin{array}{l}\text { "The present contract }[. . .] \text { aims at regulating the conditions of the } \\
\text { collaboration between the parties to undertake research and } \\
\text { development" }\end{array}$ \\
\hline Framework & $\begin{array}{l}\text { "The firm will apply public financial support from the CENIT Program } \\
\text { to partially fund the development of the research project to which the } \\
\text { present contract refer and which is intended to be developed within the } \\
\text { Acuisost Consortium" }\end{array}$ \\
\hline Objectives & $\begin{array}{l}\text { "The firm agrees to guide the technological capacities and knowledge } \\
\text { of the research organization towards the development of new } \\
\text { technological knowledge to (a) industrially apply such new knowledge } \\
\text { into the production of new materials/products, and/or (b) design new } \\
\text { processes or production systems, and/or (c) improve pre-existing } \\
\text { materials, products, processes or systems" } \\
\text { "The research organization agrees to develop the research project } \\
\text { according to the terms and conditions established in the scientific } \\
\text { report attached to the present contract, which describes the specific } \\
\text { technical tasks to be carried out, the working plan, methodology, } \\
\text { budget, and timeline [...] the research team and the head researcher of } \\
\text { the project" }\end{array}$ \\
\hline Horizon & $\begin{array}{l}\text { "... a period of four years (corresponding to the period of the Acuisost } \\
\text { Consortium) split into four technical annuities" } \\
\text { "The starting date .will be agreed by the parties [...] once the condition } \\
\text { of the firm as beneficiary of the CENIT Program is confirmed" }\end{array}$ \\
\hline $\begin{array}{l}\text { Confidentiality } \\
\text { and property } \\
\text { rights }\end{array}$ & $\begin{array}{l}\text { "The research organization agrees not to disclose information provided } \\
\text { by the firm about its internal processes and technology during the } \\
\text { development of the research project under this contract" } \\
\text { "Ownership of the knowledge developed from the project under this } \\
\text { contract and of its final results will belong exclusively to the firm" }\end{array}$ \\
\hline $\begin{array}{l}\text { Budget and } \\
\text { payment } \\
\text { conditions }\end{array}$ & $\begin{array}{l}\text { Each contract details (a) the overall budget of the project (to be paid by } \\
\text { the firm to the research organization) and (b) the payment breakdown, } \\
\text { depending on the specific funded necessities of each project (e.g.,, } 5 \% \\
\text { at the starting date, and aprox. } 12 \% \text { every six months since). }\end{array}$ \\
\hline $\begin{array}{l}\text { Knowledge- } \\
\text { sharing } \\
\text { obligations }\end{array}$ & $\begin{array}{l}\text { "The parties agree to provide each other information about the status of } \\
\text { development of the activities related to the research project on a regular } \\
\text { basis " } \\
\text { "The research organization agrees to develop a technical report at the } \\
\text { end of each technical annuity in which the research project under this } \\
\text { contract is structured and to deliver it to the firm [...](that report should) } \\
\text { described the activities developed and the conclusions achieved" }\end{array}$ \\
\hline $\begin{array}{l}\text { Causes of } \\
\text { premature } \\
\text { termination }\end{array}$ & $\begin{array}{l}\text { "The parties can rescind the present contract under mutual agreement" } \\
\text { "The firm might rescind the present contract unilaterally if it does not } \\
\text { receive the condition of beneficiary of the CENIT Program (and) if it } \\
\text { observed continued technical failure" }\end{array}$ \\
\hline
\end{tabular}




\section{Appendixes of Chapter 3}

\section{Appendix III. 1. Main sources of information}

\section{Questionnaire (items used in this study)}

Strategic importance (five-point Likert scale, anchored by 'not at all important' and 'very important')

- Extent to which your firm's alliance strategy is aligned with the overall stragey of the Acuisost Consortium

- Extent to which your firm's overall strategy is reinforced by your firm's participation in the Acuisost Consortium

Learning orientation (five-point Likert scale, anchored by 'not at all important' and 'very important')

Learning-related expectations:

- Development of a technological innovation to improve the firm's competitive position

- Access to new valuable market knowledge

- Access to new valuable technological knowledge

- Learning of new management and/or manufacturing techniques

- Improvement of the firm's capability to manage complex strategic alliances in the future

Initial relationship with the LF. Interaction with the LF prior to the focal alliance (yes/no):

- Business relationships (buyer-supplier relationships)

- Collaborative ties (strategic alliances and collaborative projects)

- Other prior inter-firm relationships (joint participation in trade associations, professional forums, trade ferias, etc.).

\section{Interviews (main informants and topic addressed for this study)}

\section{Lead firm}

About the consortium:

- Rationale of the consortium (contributions to aquaculture and synergies with other industries)

- Partners of the consortium

- Contractual terms

- Technical and organizational structure

- Expectations about potential overall outcomes

- Internal management in the LF

About the formation process of the consortium:

- Relevant events and dates

- Criteria for main decisions (e.g., partners' selection, composition of alliance committees, partners' technical contributions)

- Bureaucratic process associated to the CENIT Programme

About the interaction patterns and mechanisms in the consortium (e.g., alliance meetings and activity meetings, bilateral and multilateral communication)

About partners' actual contributions and involvement in the consortium (e.g., attendance to and attitude in meetings, R\&D efforts, transparency, willingness to cooperate, fulfilment of agreements)

About each alliance activity (e.g., role of activity coordinator, alliance meetings, innovation potential and progresses achieved, partners' spirit of cooperation, evolution of the activity) 
Overall evaluation of the formation process of the consortium

- Milestones

- Main problems and difficulties

- $\quad$ SWOT analysis (strengths, weaknesses, opportunities and threats)

Partner firms:

About the partner's decision to join the consortium:

- Main motivations underlying the decision, alliance goals and initial expectations about potential outcomes (e.g., innovation, access to knowledge and financial support; enhancement of firm's reputation)

- Perception of the opportunity to join the consortium (through the LF, through the triggering entity, other)

- $\quad$ Relevant changes and events

About the formation process of the consortium:

- Relevant events and dates

- Bureaucratic process associated to the CENIT Programme

About the role played by the LF and the triggering entity (e.g., coordination, support, design decisions, resolution of problems)

About interaction patterns and mechanisms in the consortium (e.g., alliance meetings, bilateral and multilateral communication)

About the activity/es where the partner is involved (e.g., activity meetings, intra-activity interaction, other participants in the activity; technical evolution of the activity)

Overall evaluation of the formation process of the consortium

- Milestones

- Main problems and difficulties

- Outcomes achieved 


\section{Appendix III.2. Operationalization of variables and measurement in prior research}

\begin{tabular}{|c|c|c|c|c|c|c|c|c|c|c|}
\hline \multicolumn{11}{|c|}{ Operationalization of cooperative behavior: Multiple coding process } \\
\hline & Round 1 ( & Idividual codin & & & & & & & & \\
\hline \multirow[b]{2}{*}{ Partner firms } & \multicolumn{3}{|c|}{ Researcher 1} & \multicolumn{3}{|c|}{ Researcher 2} & \multicolumn{3}{|c|}{ Researcher 3} & \multirow{2}{*}{ Code } \\
\hline & Veracity & Commitment & Coop. behavior & Veracity & Commitment & Coop. behavior & Veracity & Commitment & Coop. behavior & \\
\hline WasteMng Co. & 3 & 3 & 3 & 3 & 3 & 3 & 3 & 3 & 3 & 3 \\
\hline $\begin{array}{l}\text { Mediterranean } \\
\text { Aquaculture }\end{array}$ & 1 & 1 & 1 & 1 & 1 & 1 & 1 & 1 & 1 & 1 \\
\hline Iberian Eels & 3 & 3 & 3 & 3 & 3 & 3 & 3 & 3 & 3 & 3 \\
\hline BioMilk & 3 & 3 & 3 & 3 & 3 & 3 & 3 & 3 & 3 & 3 \\
\hline $\begin{array}{l}\text { Mediterranean } \\
\text { Aquaculture }\end{array}$ & 2 & 2 & 2 & 2 & 1 & 2 & 2 & 2 & 2 & 2nd round \\
\hline Fish\&Meals & 1 & 1 & 1 & 1 & 1 & 1 & 1 & 1 & 1 & 1 \\
\hline The Sugar Company & 3 & 2 & 2 & 2 & 2 & 2 & 3 & 2 & 2 & 2nd round \\
\hline BioNaval & 1 & 1 & 1 & 1 & 1 & 1 & 1 & 1 & 1 & 1 \\
\hline The Biscuits Company & 3 & 3 & 3 & 3 & 3 & 3 & 3 & 3 & 3 & 3 \\
\hline Industrial Packages Co. & 1 & 1 & 1 & 1 & 1 & 1 & 1 & 1 & 1 & 1 \\
\hline Green Solutions & 2 & 1 & 1 & 2 & 1 & 1 & 1 & 1 & 1 & 2nd round \\
\hline Southern Trouts Co. & 1 & 1 & 1 & 1 & 1 & 1 & 1 & 1 & 1 & 1 \\
\hline Western Trouts Co. & 1 & $(?)$ & 1 & 2 & 1 & 2 & 2 & 1 & 2 & 2nd round \\
\hline Chemics\&Proteins & 3 & 3 & 3 & 3 & 3 & 3 & 3 & 3 & 3 & 3 \\
\hline MngProjects & 1 & 1 & 1 & 1 & 1 & 1 & 1 & 1 & 1 & 1 \\
\hline Northern Trouts Co. & 1 & $(?)$ & 1 & 1 & 1 & 1 & 1 & 1 & 1 & 2nd round \\
\hline BioNutrition & 1 & $(?)$ & 1 & 1 & 1 & 1 & 1 & 1 & 1 & 2nd round \\
\hline Cantabrian Seafood & 1 & 1 & 1 & 1 & 1 & 1 & 1 & 1 & 1 & 1 \\
\hline
\end{tabular}

Note: (?) indicates that the researcher is unable to code the information with the required precision; (---) indicates that re-coding the value is not needed, given that full agreement has been already achieved; highlighted in grey those values for which initially there is not full agreement (it may be partial or full disagreement ) 


\begin{tabular}{|c|c|c|c|c|c|c|c|c|c|c|}
\hline \multicolumn{10}{|c|}{ Operationalization of cooperative behavior: Multiple coding process (continued) } & \multirow{4}{*}{ Final code } \\
\hline & \multicolumn{9}{|c|}{ Round 2 (individual re-assessment + discussion) } & \\
\hline \multirow[t]{2}{*}{ Partner firms } & \multicolumn{3}{|c|}{ Researcher 1} & \multicolumn{3}{|c|}{ Researcher 2} & \multicolumn{3}{|c|}{ Researcher 3} & \\
\hline & Veracity & Commitment & Coop. behavior & Veracity & Commitment & Coop. behavior & Veracity & Commitment & Coop. behavior & \\
\hline WasteMng Co. & $(---)$ & $(---)$ & $(---)$ & $(---)$ & $(---)$ & $(---)$ & $(---)$ & $(---)$ & $(---)$ & 3 \\
\hline $\begin{array}{l}\text { Mediterranean } \\
\text { Aquaculture }\end{array}$ & $(---)$ & $(---)$ & $(--)$ & $(---)$ & $(---)$ & $(---)$ & $(---)$ & $(---)$ & $(--)$ & 1 \\
\hline Iberian Eels & $(---)$ & $(---)$ & $(---)$ & $(---)$ & $(---)$ & $(---)$ & $(---)$ & $(---)$ & $(---)$ & 3 \\
\hline BioMilk & $(--)$ & $(--)$ & $(---)$ & $(---)$ & $(---)$ & $(---)$ & $(---)$ & $(---)$ & $(---)$ & 3 \\
\hline $\begin{array}{l}\text { Mediterranean } \\
\text { Aquaculture } \\
\end{array}$ & 2 & 2 & 2 & 2 & 2 & 2 & 2 & 2 & 2 & 2 \\
\hline Fish\&Meals & $(---)$ & $(---)$ & $(---)$ & $(---)$ & $(---)$ & $(---)$ & $(---)$ & $(---)$ & $(---)$ & 1 \\
\hline The Sugar Company & 3 & 2 & 2 & 3 & 2 & 2 & 3 & 2 & 2 & 2 \\
\hline BioNaval & $(--)$ & $(---)$ & $(---)$ & $(--)$ & $(--)$ & $(--)$ & $(--)$ & $(--)$ & $(--)$ & 1 \\
\hline $\begin{array}{l}\text { The Biscuits } \\
\text { Company }\end{array}$ & $(---)$ & $(---)$ & $(---)$ & $(---)$ & $(---)$ & $(---)$ & $(---)$ & $(---)$ & $(---)$ & 3 \\
\hline $\begin{array}{l}\text { Industrial Packages } \\
\text { Co. }\end{array}$ & $(---)$ & $(---)$ & $(---)$ & $(---)$ & $(--)$ & $(---)$ & $(--)$ & $(---)$ & $(---)$ & 1 \\
\hline Green Solutions & 2 & 1 & 1 & 2 & 1 & 1 & 2 & 1 & 1 & 1 \\
\hline Southern Trouts Co. & $(--)$ & $(--)$ & $(--)$ & $(--)$ & $(--)$ & $(--)$ & $(--)$ & $(--)$ & $(--)$ & 1 \\
\hline Western Trouts Co. & 2 & 1 & 2 & 2 & 1 & 2 & 2 & 1 & 2 & 2 \\
\hline Chemics\&Proteins & $(--)$ & $(--)$ & $(--)$ & $(--)$ & $(---)$ & $(--)$ & $(--)$ & $(--)$ & $(--)$ & 3 \\
\hline MngProjects & $(---)$ & $(---)$ & $(---)$ & $(---)$ & $(--)$ & $(---)$ & $(---)$ & $(---)$ & $(--)$ & 1 \\
\hline Northern Trouts Co. & 1 & 1 & 1 & 1 & 1 & 1 & 1 & 1 & 1 & 1 \\
\hline BioNutrition & 1 & 1 & 1 & 1 & 1 & 1 & 1 & 1 & 1 & 1 \\
\hline Cantabrian Seafood & $(---)$ & $(---)$ & $(---)$ & $(---)$ & $(---)$ & $(---)$ & $(---)$ & $(---)$ & $(---)$ & 1 \\
\hline
\end{tabular}

Note: (---) indicates that re-coding the value is not needed, given that full agreement has been already achieved; highlighted in grey those values for which initially there was not full agreement (it may be partial or full disagreement ) 


\begin{tabular}{|c|c|c|c|c|c|c|c|c|c|}
\hline \multicolumn{10}{|c|}{ Operationalization of direct competition: Multiple coding process } \\
\hline \multirow[b]{2}{*}{ Partner firm } & \multicolumn{3}{|c|}{ Round 1 (individual coding) } & \multirow{2}{*}{ Final code } & \multirow[b]{2}{*}{ Partner firm } & \multicolumn{3}{|c|}{ Round 1 (individual coding) } & \multirow{2}{*}{ Final code } \\
\hline & Researcher 1 & Researcher 2 & Researcher 3 & & & Researcher 1 & Researcher 2 & Researcher 3 & \\
\hline WasteMng Co. & 2 & 2 & 2 & 2 & $\begin{array}{l}\text { Industrial } \\
\text { Packages Co. }\end{array}$ & 2 & 2 & 2 & 2 \\
\hline $\begin{array}{l}\text { Mediterranean } \\
\text { Aquaculture }\end{array}$ & 1 & 1 & 1 & 1 & Green Solutions & 2 & 2 & 2 & 2 \\
\hline Iberian Eels & 2 & 2 & 2 & 2 & \begin{tabular}{|l|} 
Southern Trouts \\
Co.
\end{tabular} & 1 & 1 & 1 & 1 \\
\hline BioMilk & 2 & 2 & 2 & 2 & $\begin{array}{l}\text { Western Trouts } \\
\text { Co. }\end{array}$ & 1 & 1 & 1 & 1 \\
\hline $\begin{array}{l}\text { Mediterranean } \\
\text { Aquaculture }\end{array}$ & 1 & 1 & 1 & 1 & Chemics\&Proteins & 2 & 2 & 2 & 2 \\
\hline Fish\&Meals & 2 & 2 & 2 & 2 & MngProjects & 2 & 2 & 2 & 2 \\
\hline $\begin{array}{l}\text { The Sugar } \\
\text { Company }\end{array}$ & 2 & 2 & 2 & 2 & $\begin{array}{l}\text { Northern Trouts } \\
\text { Co. }\end{array}$ & 1 & 1 & 1 & 1 \\
\hline BioNaval & 2 & 2 & 2 & 2 & BioNutrition & 2 & 2 & 2 & 2 \\
\hline $\begin{array}{l}\text { The Biscuits } \\
\text { Company }\end{array}$ & 2 & 2 & 2 & 2 & $\begin{array}{l}\text { Cantabrian } \\
\text { Seafood }\end{array}$ & 2 & 2 & 2 & 2 \\
\hline
\end{tabular}




\begin{tabular}{|c|c|c|c|c|c|c|c|}
\hline \multicolumn{8}{|c|}{ Operationalization of learning orientation: Multiple coding process } \\
\hline \multirow{2}{*}{ Partner firms } & \multicolumn{3}{|c|}{$\begin{array}{c}\text { Round } 1 \\
\text { (individual coding) }\end{array}$} & \multicolumn{3}{|c|}{$\begin{array}{c}\text { Round 2 } \\
\text { (individual re-assessment }+ \text { discussion) } \\
\end{array}$} & \multirow[t]{2}{*}{ Final code } \\
\hline & Researcher 1 & Researcher 2 & Researcher 3 & Researcher 1 & Researcher 2 & Researcher 3 & \\
\hline WasteMng Co. & 3 & 3 & 3 & $(---)$ & $(---)$ & $(---)$ & 3 \\
\hline Mediterranean Aquaculture & 3 & 3 & 2 & 3 & 3 & 3 & 3 \\
\hline Iberian Eels & 3 & 3 & 3 & $(---)$ & $(---)$ & $(---)$ & 3 \\
\hline BioMilk & 3 & 3 & 3 & $(--)$ & $(---)$ & $(--)$ & 3 \\
\hline Mediterranean Aquaculture & 2 & 2 & 2 & $(---)$ & $(---)$ & $(---)$ & 2 \\
\hline Fish\&Meals & 1 & 1 & 1 & $(---)$ & $(---)$ & $(---)$ & 1 \\
\hline The Sugar Company & 2 & 2 & 2 & $(--)$ & $(--)$ & $(--)$ & 2 \\
\hline BioNaval & 1 & $(?)$ & 1 & 1 & 1 & 1 & 1 \\
\hline The Biscuits Company & 3 & 2 & 3 & 3 & 3 & 3 & 3 \\
\hline Industrial Packages Co. & 1 & 1 & 1 & $(---)$ & $(--)$ & $(---)$ & 1 \\
\hline Green Solutions & 2 & 2 & 2 & $(--)$ & $(--)$ & $(--)$ & 2 \\
\hline Southern Trouts Co. & 3 & 3 & 3 & $(--)$ & $(--)$ & $(--)$ & 3 \\
\hline Western Trouts Co. & 1 & $(?)$ & 1 & 1 & 1 & 1 & 1 \\
\hline Chemics\&Proteins & 3 & 2 & 3 & 3 & 3 & 3 & 3 \\
\hline MngProjects & 1 & $(?)$ & 1 & 1 & 1 & 1 & 1 \\
\hline Northern Trouts Co. & 1 & $(?)$ & 1 & 1 & 1 & 1 & 1 \\
\hline BioNutrition & 3 & 3 & 2 & 3 & 3 & 3 & 3 \\
\hline Cantabrian Seafood & 1 & 1 & 2 & 2 & 2 & 2 & 2 \\
\hline
\end{tabular}

Note: (?) indicates that the researcher is unable to code the information with the required precision; (---) indicates that re-coding the value is not needed, given that full agreement has been already achieved; highlighted in grey those values for which initially there is not full agreement (it may be partial or full disagreement ) 


\begin{tabular}{|c|c|c|c|c|c|c|c|c|c|c|}
\hline \multicolumn{11}{|c|}{ Operationalization of strategic importance: Multiple coding process } \\
\hline \multirow[t]{2}{*}{ Partner firms } & \multicolumn{3}{|c|}{\begin{tabular}{|l} 
Round 1 \\
(individual coding)
\end{tabular}} & \multicolumn{3}{|c|}{\begin{tabular}{|l} 
Round 2 \\
(re-assessment and discussion)
\end{tabular}} & \multicolumn{3}{|c|}{\begin{tabular}{|l} 
Round 3 \\
(re-assessment and discusión)
\end{tabular}} & \multirow{2}{*}{$\begin{array}{l}\text { Fina } \\
\text { code }\end{array}$} \\
\hline & Researcher 1 & Researcher 2 & Researcher 3 & Researcher 1 & Researcher 2 & Researcher 3 & Researcher 1 & Researcher 2 & Researcher 3 & \\
\hline WasteMng Co. & 2 & 3 & 3 & 3 & 3 & 3 & $(--)$ & $(--)$ & $(---)$ & 3 \\
\hline $\begin{array}{l}\text { Mediterranean } \\
\text { Aquaculture }\end{array}$ & 3 & 3 & 3 & $(---)$ & $(---)$ & $(--)$ & $(---)$ & $(---)$ & $(---)$ & 3 \\
\hline Iberian Eels & 3 & 2 & 3 & 3 & 3 & 3 & $(---)$ & $(---)$ & $(---)$ & 3 \\
\hline BioMilk & 2 & 3 & 2 & 2 & 2 & 2 & $(---)$ & $(---)$ & $(---)$ & 2 \\
\hline $\begin{array}{l}\text { Mediterranean } \\
\text { Aquaculture }\end{array}$ & 3 & 3 & 3 & $(---)$ & $(--)$ & $(--)$ & $(---)$ & $(---)$ & $(---)$ & 3 \\
\hline Fish\&Meals & 2 & 3 & 3 & 3 & 3 & 3 & $(---)$ & $(---)$ & $(---)$ & 3 \\
\hline The Sugar Company & 2 & 2 & 2 & 1 & 1 & 1 & $(---)$ & $(--)$ & $(---)$ & 1 \\
\hline BioNaval & 2 & 2 & 2 & $(---)$ & $(--)$ & $(---)$ & $(---)$ & $(---)$ & $(---)$ & 2 \\
\hline $\begin{array}{l}\text { The Biscuits } \\
\text { Company }\end{array}$ & 2 & 2 & 2 & $(---)$ & $(---)$ & $(--)$ & $(---)$ & $(---)$ & $(---)$ & 2 \\
\hline $\begin{array}{l}\text { Industrial Packages } \\
\text { Co. }\end{array}$ & 2 & 2 & 2 & $(---)$ & $(---)$ & $(--)$ & $(---)$ & $(---)$ & $(---)$ & 2 \\
\hline Green Solutions & 1 & 3 & 2 & 1 & 2 & 1 & 1 & 1 & 1 & 1 \\
\hline \begin{tabular}{|l|} 
Southern Trouts Co. \\
\end{tabular} & 3 & 3 & 2 & 3 & 3 & 2 & 3 & 3 & 3 & 3 \\
\hline Western Trouts Co. & 1 & 2 & 1 & 1 & 1 & 1 & $(--)$ & $(--)$ & $(---)$ & 1 \\
\hline Chemics\&Proteins & 2 & 2 & 2 & $(---)$ & $(---)$ & $(--)$ & $(---)$ & $(---)$ & $(---)$ & 2 \\
\hline MngProjects & 3 & 2 & 2 & 2 & 2 & 2 & $(--)$ & $(---)$ & $(---)$ & 2 \\
\hline Northern Trouts Co. & 3 & 2 & 3 & 3 & 3 & 3 & $(--)$ & $(--)$ & $(---)$ & 3 \\
\hline BioNutrition & 2 & 1 & 2 & 2 & 2 & 2 & $(---)$ & $(---)$ & $(---)$ & 2 \\
\hline Cantabrian Seafood & 3 & 3 & 2 & 3 & 3 & 3 & $(---)$ & $(--)$ & $(---)$ & 3 \\
\hline
\end{tabular}

Note: (---) indicates that re-coding the value is not needed, given that full agreement has been already achieved; highlighted in grey those values for which initially there was not full agreement (it may be partial or full disagreement ) 


\begin{tabular}{|c|c|c|c|c|c|c|c|}
\hline \multicolumn{8}{|c|}{ Operationalization of initial relationship between partners and the LF: Multiple coding process (Tie strength) } \\
\hline \multirow{2}{*}{ Partner firms } & \multicolumn{3}{|c|}{ Round 1 (individual coding) } & \multicolumn{3}{|c|}{ Round 2 (re-assessment and discussion) } & \multirow{2}{*}{$\begin{array}{l}\text { Final } \\
\text { code }\end{array}$} \\
\hline & Researcher 1 & Researcher 2 & Researcher 3 & Researcher 1 & Researcher 2 & Researcher 3 & \\
\hline WasteMng Co. & 1 & (?) & 1 & 1 & 1 & 1 & 1 \\
\hline Mediterranean Aquaculture & 1 & $(?)$ & 1 & 1 & 1 & 1 & 1 \\
\hline Iberian Eels & 1 & (?) & 1 & 1 & 1 & 1 & 1 \\
\hline BioMilk & 2 & 2 & 2 & $(--)$ & $(--)$ & $(--)$ & 2 \\
\hline Mediterranean Aquaculture & 1 & 1 & 1 & $(--)$ & $(--)$ & $(--)$ & 1 \\
\hline Fish\&Meals & 2 & 2 & 2 & $(---)$ & $(--)$ & $(--)$ & 2 \\
\hline The Sugar Company & 2 & 2 & 2 & $(--)$ & $(--)$ & $(--)$ & 2 \\
\hline BioNaval & 2 & 2 & 2 & $(--)$ & $(--)$ & $(---)$ & 2 \\
\hline The Biscuits Company & 1 & 1 & 2 & 1 & 1 & 1 & 1 \\
\hline Industrial Packages Co. & 2 & 2 & 2 & $(--)$ & $(---)$ & $(---)$ & 2 \\
\hline Green Solutions & 2 & 2 & 2 & $(---)$ & $(--)$ & $(---)$ & 2 \\
\hline Southern Trouts Co. & 1 & 1 & 1 & $(---)$ & $(---)$ & $(---)$ & 1 \\
\hline Western Trouts Co. & 1 & 1 & 1 & $(---)$ & $(---)$ & $(---)$ & 1 \\
\hline Chemics\&Proteins & 2 & 2 & 2 & $(---)$ & $(---)$ & $(---)$ & 2 \\
\hline MngProjects & 2 & 2 & 2 & $(--)$ & $(--)$ & $(--)$ & 2 \\
\hline Northern Trouts Co. & 1 & 1 & 1 & $(--)$ & $(--)$ & $(--)$ & 1 \\
\hline BioNutrition & 2 & 2 & 2 & $(--)$ & $(--)$ & $(--)$ & 2 \\
\hline Cantabrian Seafood & 2 & 2 & 2 & $(---)$ & $(--)$ & $(---)$ & 2 \\
\hline
\end{tabular}

Note: (?) indicates that the researcher is unable to code the information with the required precision; (---) indicates that re-coding the value is not needed, given that full agreement has been already achieved; highlighted in grey those values for which initially there is not full agreement (it may be partial or full disagreement ) 


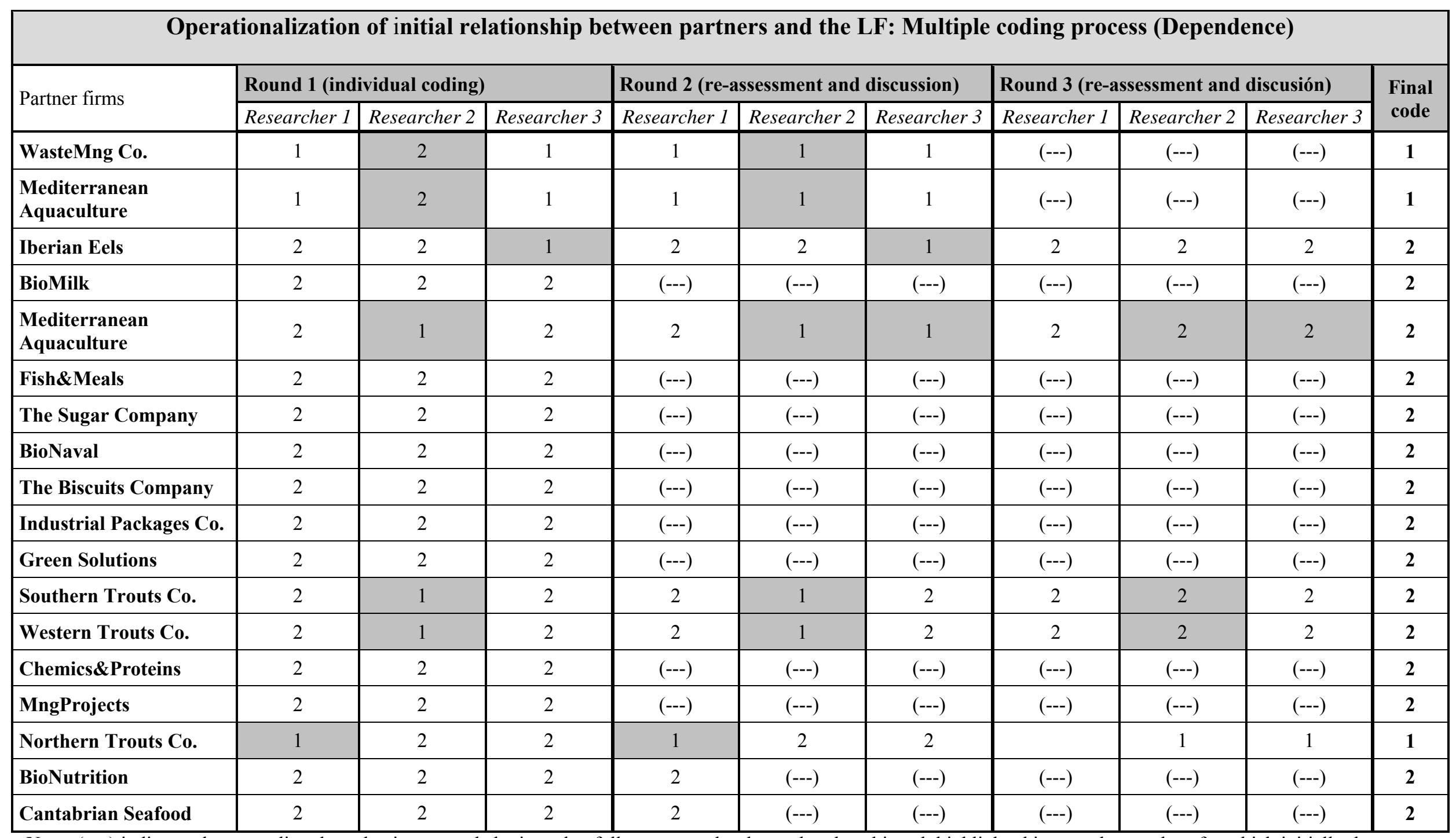

Note: (--- ) indicates that re-coding the value is not needed, given that full agreement has been already achieved; highlighted in grey those values for which initially there was not full agreement (it may be partial or full disagreement) 


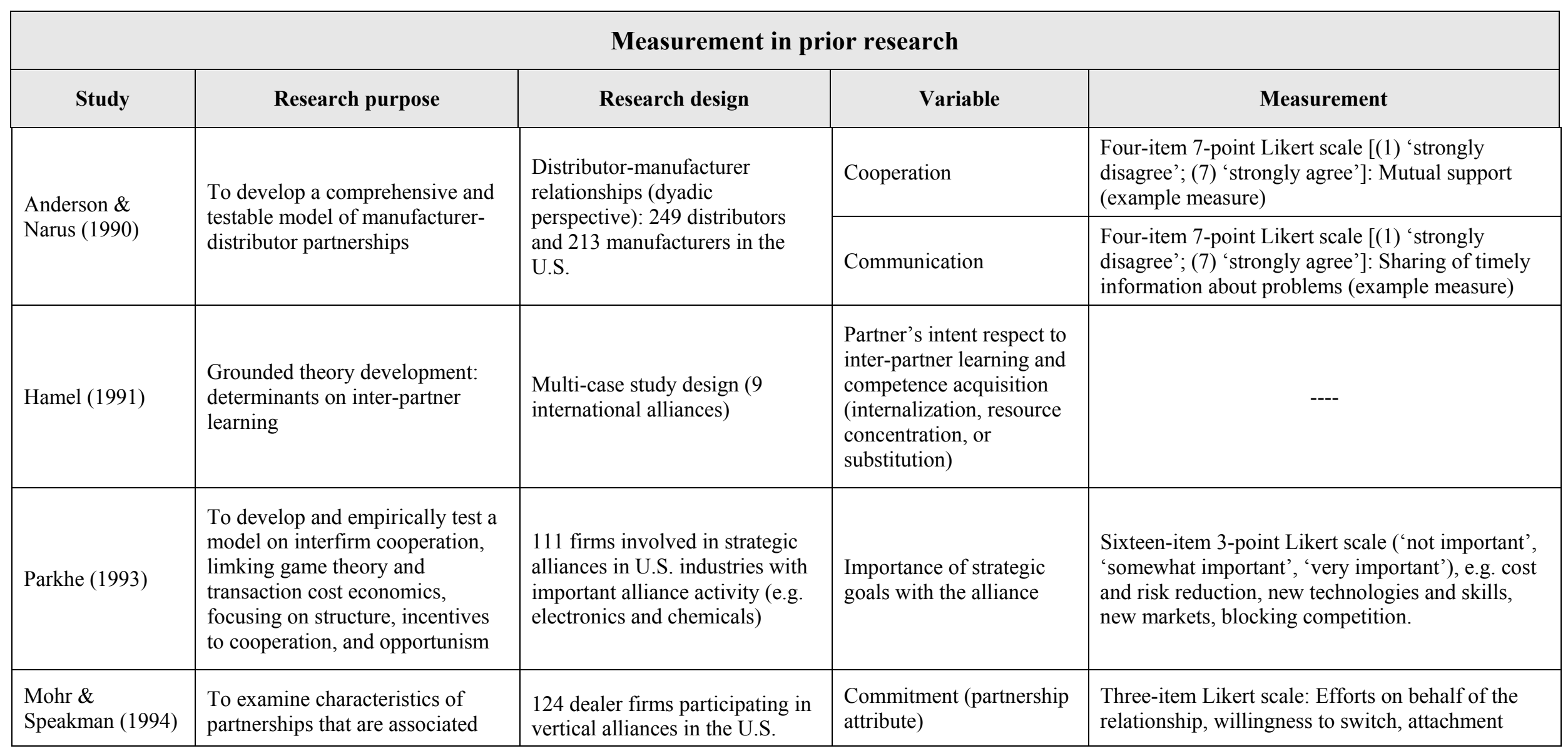




\begin{tabular}{|c|c|c|c|c|}
\hline & with their success & personal computer industry & $\begin{array}{l}\text { Communicative behavior } \\
\text { (quality, information } \\
\text { sharing, participation) }\end{array}$ & $\begin{array}{l}\text { Multi-item Likert scales } \\
\text { Quality: Timeliness, accuracy, adequacy, } \\
\text { credibility, completeness ( } 5 \text { items) } \\
\text { Mutual provision of proprietary and meaningful } \\
\text { information, information about changes, } \\
\text { information sharing beyond specifications ( } 8 \\
\text { items) } \\
\text { Dealer's participation in planning, goal setting, and } \\
\text { forecasting, manufacturer's consideration of } \\
\text { dealer's suggestions ( } 4 \text { items) }\end{array}$ \\
\hline $\begin{array}{l}\text { Cullen, Johnson } \\
\& \text { Sakano (1995) }\end{array}$ & $\begin{array}{l}\text { To examine antecedents of } \\
\text { partner' commitment in IJV }\end{array}$ & $\begin{array}{l}152 \text { firms participating in IJV, } \\
\text { local partners (multi-country } \\
\text { origin) and Japanese partners }\end{array}$ & $\begin{array}{l}\text { Strategic importance of } \\
\text { the IJV to the partner }\end{array}$ & $\begin{array}{l}\text { Single-item 5-point Likert scale [(1) 'not at all } \\
\text { important'; (5) 'very important'] }\end{array}$ \\
\hline $\begin{array}{l}\text { Park \& Russo } \\
\text { (1996) }\end{array}$ & $\begin{array}{l}\text { To examine conditions underlying } \\
\text { JV failure from transaction cost } \\
\text { economics }\end{array}$ & $\begin{array}{l}\text { Event history analysis } 204 \mathrm{JVs} \\
\text { (domestic and cross-border) in } \\
\text { the U.S. electronic industry }\end{array}$ & Direct competition & $\begin{array}{l}\text { Dummy variable capturing whether the partners } \\
\text { have the same } 4 \text {-digit SIC codes in their primary } \\
\text { industry }\end{array}$ \\
\hline $\begin{array}{l}\text { Hatfield, Pearce, } \\
\text { Sleeth \& Pitts } \\
\text { (1998) }\end{array}$ & $\begin{array}{l}\text { To empirically determine a } \\
\text { meaningful measure of JV } \\
\text { performance }\end{array}$ & $\begin{array}{l}83 \text { U.S. firms and subsidiaries } \\
\text { involved in } 50 \text { manufacturing } \\
\text { JVs }\end{array}$ & Importance of JV goals & $\begin{array}{l}\text { Twelve-item 5-point Likert scale ('none', } \\
\text { 'critical'): market expansion and entry, } \\
\text { product/technology development, acquisition and } \\
\text { knowledge and skills, economies of scale, risk } \\
\text { sharing, etc. }\end{array}$ \\
\hline
\end{tabular}




\begin{tabular}{|c|c|c|c|c|}
\hline Ariño (2001) & $\begin{array}{l}\text { To study how perceptions about } \\
\text { partners' behavior influences own } \\
\text { behavior in alliances, focusing on } \\
\text { non-cooperative behaviors } \\
\text { (ommision and commision) }\end{array}$ & $\begin{array}{l}\text { Collaborative ventures (domestic } \\
\text { and international) } 81 \text { Spanish } \\
\text { partner firms in multiple } \\
\text { industries }\end{array}$ & $\begin{array}{l}\text { Cooperative behavior: } \\
\text { Veracity and commitment } \\
\text { [Non cooperative } \\
\text { behavior: Commission, } \\
\text { lack of veracity, and } \\
\text { omission, lack of } \\
\text { commitment] }\end{array}$ & $\begin{array}{l}\text { Veracity, four-item 5-point Likert scale[(1) } \\
\text { 'never'; (5) 'always']: Alteration of facts, } \\
\text { unrealistic promises, truthful description of events } \\
\text { Commitment, two-item 5-point Likert scale [(1) } \\
\text { 'never'; (5) 'always']: Resources to help alliance } \\
\text { management teams, tolerance with the alliance } \\
\text { management team's mistakes }\end{array}$ \\
\hline \multirow{2}{*}{$\begin{array}{l}\text { Mothe \& Quelin } \\
\text { (2001) }\end{array}$} & \multirow{2}{*}{$\begin{array}{l}\text { To examine the process of new } \\
\text { resources creation in R\&D } \\
\text { consortia }\end{array}$} & \multirow{2}{*}{$\begin{array}{l}317 \text { firms participating in } \\
\text { international R\&D consortia } \\
\text { partially subsidized by European } \\
\text { public programmes (e.g. Eureka) }\end{array}$} & $\begin{array}{l}\text { Objective sought } \\
\text { (partner's main alliance } \\
\text { objective) }\end{array}$ & $\begin{array}{l}\text { Single-item scale, categorical variable: The } \\
\text { objective pursue by the partner is 'increase of } \\
\text { sales', 'increase of knowledge' or 'other } \\
\text { objectives' (e.g. improved image) }\end{array}$ \\
\hline & & & $\begin{array}{l}\text { Strategic importance of } \\
\text { the R\&D project } \\
\text { (consistency with firm's } \\
\text { strategic objectives) }\end{array}$ & $\begin{array}{l}\text { Single-item scale, categorical variable: } \\
\text { Relationship between the R\&D project and the } \\
\text { firm's technological strategy at the beginning of } \\
\text { the alliance: 'essential', 'important', or 'marginal' }\end{array}$ \\
\hline $\begin{array}{l}\text { Reuer, Zollo \& } \\
\text { Sing (2002) }\end{array}$ & $\begin{array}{l}\text { To study the occurrence and } \\
\text { determinants of post-formation } \\
\text { governance changes in strategic } \\
\text { alliances }\end{array}$ & $\begin{array}{l}145 \text { equity and non-equity } \\
\text { alliances between } \\
\text { biotechnological and } \\
\text { pharmaceutical firms }\end{array}$ & $\begin{array}{l}\text { Alliance relevance for } \\
\text { partner overall business }\end{array}$ & $\begin{array}{l}\text { Single-item scale, categorical variable: The } \\
\text { relevance of the alliance for the overall business of } \\
\text { the partner firm in terms of the amount of } \\
\text { resources committed: 'marginal', 'normal', } \\
\text { 'important' or 'critical' }\end{array}$ \\
\hline Ariño (2003) & $\begin{array}{l}\text { To evaluate construct validy of } \\
\text { alliance performance measures }\end{array}$ & $\begin{array}{l}\text { Firms participating in equity } \\
\text { (34) and contractual (45) } \\
\text { strategic alliances }\end{array}$ & $\begin{array}{l}\text { Importance of strategic } \\
\text { goals with the alliance }\end{array}$ & $\begin{array}{l}\text { Nine-item 5-point Likert scale ('minimal', 'vital): } \\
\text { cost and risk reduction, new technologies and } \\
\text { skills, new markets access, blocking competition, } \\
\text { government requirements, other. }\end{array}$ \\
\hline $\begin{array}{l}\text { García-Canal, } \\
\text { Valdés-Llaneza \& } \\
\text { Ariño (2003) }\end{array}$ & $\begin{array}{l}\text { To compare the influence of } \\
\text { tformal controls vs. relational } \\
\text { investments on JV effectiveness. }\end{array}$ & $\begin{array}{l}80 \text { firms involved in dyadic and } \\
\text { multi-party JV formed by at } \\
\text { least one Spanish partner in } \\
\text { multiple industries }\end{array}$ & Direct competition & $\begin{array}{l}\text { Dummy nominative variable: respondents were } \\
\text { asked to assess partners as direct competitors or } \\
\text { non-direct competitors }\end{array}$ \\
\hline $\begin{array}{l}\text { Oxley \& } \\
\text { Sampson (2004) }\end{array}$ & $\begin{array}{l}\text { To study alliance scope as a } \\
\text { mechanism to protect }\end{array}$ & $\begin{array}{l}208 \text { international and domestic } \\
\text { R\&D alliances involving fir ms }\end{array}$ & $\begin{array}{l}\text { Product market } \\
\text { competition }\end{array}$ & $\begin{array}{l}\text { Dummy variable capturing whether partners have } \\
\text { their primary operations in the same industry }\end{array}$ \\
\hline
\end{tabular}




\begin{tabular}{|c|c|c|c|c|}
\hline & $\begin{array}{l}\text { technological assets in R\&D } \\
\text { alliances }\end{array}$ & $\begin{array}{l}\text { in the electronics and } \\
\text { telecommunications }\end{array}$ & $\begin{array}{l}\text { Geographic market } \\
\text { competition }\end{array}$ & $\begin{array}{l}\text { Dummy variable capturing whether partners are } \\
\text { headquartered in the same country }\end{array}$ \\
\hline $\begin{array}{l}\text { Edmen, Yaprak \& } \\
\text { Cavusgil (2005) }\end{array}$ & $\begin{array}{l}\text { To examine the role of } \\
\text { organizational values (learning } \\
\text { orientation and commitment) in } \\
\text { learning from alliance experiences }\end{array}$ & $\begin{array}{l}184 \text { technology firms from } \\
\text { different industries participating } \\
\text { in international alliances }\end{array}$ & $\begin{array}{l}\text { Firm's learning } \\
\text { orientation (organizational } \\
\text { values that influence the } \\
\text { propensity of the firm to } \\
\text { create and use knowledge) }\end{array}$ & $\begin{array}{l}\text { Multi-item five-point Likert scale [(1) 'strongly } \\
\text { disagree'; (5) 'strongly agree']. Learning is key to } \\
\text { organizational survival; the sense around here is } \\
\text { that our ability to learn is key to remaining } \\
\text { competitive; we rarely question the way we } \\
\text { interpret market information }\end{array}$ \\
\hline
\end{tabular}




\begin{tabular}{|c|c|c|c|c|}
\hline $\begin{array}{l}\text { Lunnan \& } \\
\text { Haugland (2008) }\end{array}$ & $\begin{array}{l}\text { To improve the understanding of } \\
\text { alliance performance antecedents } \\
\text { and measurement }\end{array}$ & $\begin{array}{l}100 \text { strategic alliances formed by } \\
\text { Norwegian firms in engineering } \\
\text { industries }\end{array}$ & $\begin{array}{l}\text { Strategic importance of } \\
\text { the alliance to the current } \\
\text { and future firm's } \\
\text { development }\end{array}$ & $\begin{array}{l}\text { Four-item seven-point Likert scale, form (1) 'very } \\
\text { poor description' to (7) 'very good description']: } \\
\text { The content of this alliance is close to the firm's } \\
\text { core business areas; this alliance will be of } \\
\text { strategic importance in the future; this alliance will } \\
\text { provide valuable knowledge and competence for } \\
\text { the future development of the firm's core business } \\
\text { areas; it is important for the firm the continuity of } \\
\text { this relationship }\end{array}$ \\
\hline
\end{tabular}




\section{Appendix III. 3. Analysis of case study data}

\begin{tabular}{|c|c|c|c|c|c|}
\hline Variable & $\mathbf{N}$ & $\begin{array}{c}\text { Mean } \\
\text { (St. dev) }\end{array}$ & \multicolumn{2}{|c|}{ Frequency } & Illustrative quotes/actions \\
\hline \multirow{3}{*}{$\begin{array}{c}\text { Cooperative } \\
\text { behavior }\end{array}$} & \multirow{3}{*}{18} & \multirow{3}{*}{$\begin{array}{c}1.72 \\
(0.895)\end{array}$} & Weak (1) & $10(56 \%)$ & \multirow{3}{*}{$\begin{array}{l}\text { "One of the weaknesses of the consortium is that involvement widely varies across partners. There is a group of } \\
\text { partners which have no multilateral interaction with other partners; they only interact and communicate with the } \\
\text { lead firm [...] there are three companies that are "independent partners', with which even the leader does not keep } \\
\text { contact. In the best case, these partners do their research tasks, and develop reports to receive the subsidy. [...] A } \\
\text { strength is the existence of a consolidated group of partners that have stick together, with a clear sense of } \\
\text { belonging to the consortium and a truly collaborative spirit" }\end{array}$} \\
\hline & & & Medium (2) & $3(16 \%)$ & \\
\hline & & & Strong (3) & $5 \quad(28 \%)$ & \\
\hline \multirow[t]{3}{*}{ Veracity } & \multirow[t]{3}{*}{18} & \multirow{3}{*}{$\begin{array}{c}1.83 \\
(0.924)\end{array}$} & Weak (1) & $9(50 \%)$ & $\begin{array}{l}\text { - Delays in handing documents and not regular attendance to alliance meetings } \\
\text { - Fulfilment of initial goals in ways different from the initially established ones } \\
\text { - As activity coordinator, lack of efforts to organize activity meetings and promote multilateral interaction } \\
\text { - No detailed information in the alliance's report (e.g., overall firm's budget without itemization) and in } \\
\text { periodical technical reports, } \\
\text { - No willingness to share technical information with partners } \\
\text { - No frequent communication with the LF } \\
\text { - Omission of information about relevant firm's strategic changes }\end{array}$ \\
\hline & & & Medium (2) & $3(16 \%)$ & --- \\
\hline & & & Strong (3) & $6(33 \%)$ & $\begin{array}{l}\text { - Punctuality in handing documents and regular attendance to alliance meetings } \\
\text { - Making of efforts for technical progress } \\
\text { - As activity coordinator, efforts to organize activity meetings and promote multilateral interaction } \\
\text { - Detailed information in the alliance's report, in periodical technical reports, and about technical progress in } \\
\text { activity meetings } \\
\text { - Frequent communication with the LF }\end{array}$ \\
\hline \multirow[t]{2}{*}{ Commitment } & \multirow[t]{2}{*}{18} & \multirow[t]{2}{*}{$\begin{array}{c}1.67 \\
(0.907)\end{array}$} & Weak (1) & $11(61 \%)$ & $\begin{array}{l}\text { - Lack of alliance vision: priority given to private goals over common ones } \\
\text { - Overlooking of overall alliance problems } \\
\text { - Not willingness to cooperate with the leader and to channel R\&D efforts towards the mutual benefit } \\
\text { - Short-term orientation: Early departure from the consortium when it its perceive a change in the potential of } \\
\text { private benefits }\end{array}$ \\
\hline & & & Medium (2) & $2(11 \%)$ & --- \\
\hline
\end{tabular}




\begin{tabular}{|c|c|c|c|c|c|}
\hline & & & Strong (3) & $5(28 \%)$ & $\begin{array}{l}\text { - Alliance vision and long-term orientation: efforts to achieve common goals in the long-term } \\
\text { - Willingness to closely cooperate with the leader and to channel R\&D efforts towards mutual benefits } \\
\text { - Interest in solving overall alliance problems } \\
\text { - Altruist assistance to other partners and mediation in conflicts } \\
\text { - Increase of financial/technical involvement }\end{array}$ \\
\hline \multirow{2}{*}{$\begin{array}{l}\text { Direct } \\
\text { competition }\end{array}$} & \multirow{2}{*}{18} & \multirow{2}{*}{---} & $\begin{array}{l}\text { D. Compet. } \\
\text { (1) }\end{array}$ & $5(28 \%)$ & \multirow{2}{*}{$\begin{array}{l}\text { "There are no direct competitors in the consortium for the LF, as fish feed producer. The same occurs, for } \\
\text { example, for BioMilk, The Sugar Company, The Biscuits Company, or Chemics\&Proteins. However, there are } \\
\text { direct competitors of some firms of the leader's group [...]actual competition occurs between partners devoted to } \\
\text { fish farming" }\end{array}$} \\
\hline & & & $\begin{array}{l}\text { Non- } \\
\text { d.com.(2) }\end{array}$ & $13(72 \%)$ & \\
\hline \multirow{3}{*}{$\begin{array}{l}\text { Learning } \\
\text { orientation }\end{array}$} & \multirow{3}{*}{18} & \multirow{3}{*}{$\begin{array}{c}2.11 \\
(0.900)\end{array}$} & Low (1) & $6(33 \%)$ & $\begin{array}{l}\text { "We do not expect to learn from other alliance members, since our firm already has a wide market and R\&D } \\
\text { experience" }\end{array}$ \\
\hline & & & Medium (2) & $4(22 \%)$ & -- \\
\hline & & & High (3) & $8(45 \%)$ & $\begin{array}{l}\text { "This consortium will allow us to establish collaborative ties with important firms, both in aquaculture and other } \\
\text { sectors, promoting the exchange of information of a variety of shorts and the establishment of integrative systems" }\end{array}$ \\
\hline \multirow{3}{*}{$\begin{array}{l}\text { Strategic } \\
\text { importance }\end{array}$} & \multirow{3}{*}{18} & \multirow{3}{*}{$\begin{array}{c}2.28 \\
(0.752)\end{array}$} & Marginal (1) & $3(17 \%)$ & $\begin{array}{l}\text { "Although we feel that the revalorization of our by-products for aquaculture has certain long-term potential, the } \\
\text { project is not of strategic priority for us, since our main product is not related to aquaculture nutrition [...] If after } \\
\text { two years, we discover that our by-products have no application to the aquaculture field, we will consider whether } \\
\text { to leave the consortium" }\end{array}$ \\
\hline & & & $\begin{array}{l}\text { Important } \\
(2)\end{array}$ & $7(39 \%)$ & ---- \\
\hline & & & Critical (3) & $8(44 \%)$ & $\begin{array}{l}\text { "... Our initial goal is to achieve a tangible outcome from the research; specifically we seek to revalorize by- } \\
\text { products and wastes by applying them in aquaculture nutrition. It is very important for us since we generate } \\
1200 T n \text { of the main waste by month" }\end{array}$ \\
\hline \multirow[b]{2}{*}{ Tie strength } & \multirow[b]{2}{*}{18} & \multirow[b]{2}{*}{---} & Friends (1) & $10(56 \%)$ & \multirow{2}{*}{$\begin{array}{l}\text { "In the consortium there are internal and external clients of the LF }[\ldots] \text { but I would be a mistake having included } \\
\text { only known firms" }\end{array}$} \\
\hline & & & $\begin{array}{l}\text { Strangers } \\
(2)\end{array}$ & $8 \quad(44 \%)$ & \\
\hline \multirow[b]{2}{*}{ Dependence } & \multirow[b]{2}{*}{18} & \multirow[b]{2}{*}{---} & Depend. (1) & $3(17 \%)$ & " $100 \%$ of the firm's shares belongs to the leader's group, so our R\&D policies are established by the LF" \\
\hline & & & $\begin{array}{l}\text { Non-depen. } \\
(2)\end{array}$ & $15(83 \%)$ & $\begin{array}{l}\text { "The fact that the leader owns a part of the company does not imply that the leader determines our management. } \\
\text { Our management and operations are independent of those of the leader. Another thing is that we have to be } \\
\text { accountable to the leader, as to the rest of shareholders. The really important thing are the good business and } \\
\text { personal relationships we maintain from so many years ago" }\end{array}$ \\
\hline
\end{tabular}




\begin{tabular}{|c|c|c|c|c|}
\hline \multicolumn{5}{|c|}{ PLS results: Assessing the measurement model (I) } \\
\hline \multirow{2}{*}{$\begin{array}{l}\text { Latent constructs } \\
\text { (reflective indicators) }\end{array}$} & \multicolumn{3}{|c|}{ Convergent Validity } & \multirow{2}{*}{$\begin{array}{l}\text { Reliability } \\
\text { Loadings }\end{array}$} \\
\hline & $\begin{array}{l}\text { Composite } \\
\text { reliability }\left(\rho_{c}\right)\end{array}$ & \multicolumn{2}{|c|}{$\begin{array}{l}\text { Average variance } \\
\text { extracted (AVE) }\end{array}$} & \\
\hline Cooperative behavior & 0.9776 & \multicolumn{2}{|c|}{0.9562} & --- \\
\hline Veracity & --- & \multicolumn{2}{|l|}{---} & 0.9786 \\
\hline Commitment & --- & \multicolumn{2}{|l|}{---} & 0.9771 \\
\hline Direct competition & 1.0000 & \multicolumn{2}{|c|}{1.0000} & 1.0000 \\
\hline Learning orientation & 1.0000 & \multicolumn{2}{|c|}{1.0000} & 1.0000 \\
\hline Strategic importance & 1.0000 & \multicolumn{2}{|c|}{1.0000} & 1.0000 \\
\hline \multicolumn{5}{|c|}{$\begin{array}{l}\text { Note: Following the two-step approach suggested by Anderson and Gerbing (1988)(1988), before testing } \\
\text { and assessing the structural model, we analyse the reliability of the individual items (veracity and } \\
\text { commitment) for the variable cooperative behavior and the corresponding construct, as well as the } \\
\text { convergent validity of measures (Rodriguez-Pinto et al. 2008). As the previous table shows, the reflective } \\
\text { item loadings for cooperative behavior are significant and greater than } 0.6 \text {. We evaluate composite } \\
\text { reliability using the internal consistency measure }(\rho c) \text { developed by Fornell and Larcker (Fornell \& } \\
\text { Larcker, 1981) and the average variance extracted of each latent construct. All reflective constructs } \\
\text { exceed the conditions of } \rho \text { greater than } 0.7 \text { and average variance extracted greater than } 0.5 \text {. }\end{array}$} \\
\hline \multicolumn{5}{|c|}{ PLS results: Assessing the measurement model (II) } \\
\hline Discriminant validity & $\begin{array}{l}\text { Cooperative } \\
\text { behavior }\end{array}$ & $\begin{array}{c}\text { Direct } \\
\text { competition }\end{array}$ & $\begin{array}{c}\text { Learning } \\
\text { orientation }\end{array}$ & $\begin{array}{c}\text { Strategic } \\
\text { importance }\end{array}$ \\
\hline Cooperative behavior & 0.978 & --- & --- & --- \\
\hline Direct competition & -0.187 & 1.000 & --- & --- \\
\hline Learning orientation & 0.520 & -0.077 & 1.000 & --- \\
\hline Strategic importante & 0.097 & 0.340 & 0.204 & 1.000 \\
\hline $\begin{array}{l}\text { Note: Correlation matrix ( } \\
\text { root of the average varian } \\
\text { on the construct it intends } \\
\text { variable relates more to its }\end{array}$ & $\begin{array}{l}\text { arman's Rho corr } \\
\text { xtracted (AVE). } \\
\text { neasure (e.g. coor } \\
\text { n manifest variab }\end{array}$ & $\begin{array}{l}\text { ons) with diago } \\
\text { iminant validity } \\
\text { ve behavior) th } \\
\text { an to the other }\end{array}$ & $\begin{array}{l}\text { elements subs } \\
\text { ows that each } \\
\text { on any other v } \\
\text { ables }\end{array}$ & $\begin{array}{l}\text { uted by the square } \\
\text { ariable loads more } \\
\text { able and that each }\end{array}$ \\
\hline
\end{tabular}




\begin{tabular}{|c|c|c|}
\hline \multicolumn{3}{|c|}{ Cross-tabulation analysis. Summary of findings } \\
\hline Relation & Remarks & Measures of association \\
\hline $\begin{array}{l}\text { Direct competition } \\
\qquad \& \\
\text { Cooperative } \\
\text { behavior }\end{array}$ & $\begin{array}{l}\text { - When there is direct competition, } 60 \% \text { of partners } \\
\text { have weak cooperative behavior } \\
\text { - } 100 \% \text { of partners which strong cooperative } \\
\text { behavior do not face direct competition }\end{array}$ & $\begin{array}{l}\text { - The two variables may be } \\
\text { not independent } \\
\text { - If there is association, it is } \\
\text { medium and negative }\end{array}$ \\
\hline $\begin{array}{l}\text { Learning orientation } \\
\qquad \& \\
\text { Cooperative } \\
\text { behavior }\end{array}$ & $\begin{array}{l}\text { - When learning orientation is low, } 83.3 \% \text { of partners } \\
\text { have weak cooperative behavior } \\
\text { - Learning orientation is high for the } 100 \% \text { of } \\
\text { partners with strong cooperative behavior }\end{array}$ & $\begin{array}{l}\text { - The two variables are not } \\
\text { independent } \\
\text { - Association is strong and } \\
\text { positive }\end{array}$ \\
\hline $\begin{array}{l}\text { Strategic } \\
\text { importance } \\
\qquad \& \\
\text { Cooperative } \\
\text { behavior }\end{array}$ & $\begin{array}{l}\text { - When the alliance is critical, } 62.5 \% \text { of partners } \\
\text { have weak cooperative behavior } \\
\text { - The alliance is critical for the } 40 \% \text { of partners with } \\
\text { strong cooperative behavior }\end{array}$ & $\begin{array}{l}\text { - The two variables may be } \\
\text { independent } \\
\text { - If there is association, it is } \\
\text { weak and negative }\end{array}$ \\
\hline
\end{tabular}

Note: Conducted using SPSS.15.0. To reinforce the analysis, we accompany each contingency table with a series of measures of association. However, we need to interpret results with caution, due to the small number of partners. For ordinal variables (strategic importance and learning orientation), we include Somers'd, Kendall $T a u-b$, and Gamma coefficients, which range from -1 (perfect negative association) to 1 (perfect positive association). A value of zero indicates the absence of association. For dummy variables (direct competition), we included two proportional reduction in error (PRE) measures (Goodman-Kruskal's Tau and Uncertainty coefficient). PRE measures quantify the extent to which knowledge about one variable helps with the prediction of another variable. 


\section{Appendixes Chapter 4}

\section{Appendix IV.1. Operationalization of theory-driven variables in Study II.1 and Study II.2}

\section{Operationalization of inter-organizational knowledge-sharing routines}

The literature on organizational routines offers few clues as to how to operationalize properly routines and the associated processes (Becker, 2004; 2005), this deficiency extending to the inter-organizational context. Knowledge-related issues in alliances not always have been addressed explicitly from a routinesbased perspective (e.g., Mowery et al., 1996) and, even when this has been the case (e.g., Zollo et al., 2002), not all employed measures can be considered appropriate. For example, Zollo et al. (2002) 'deduce' the existence and magnitude of inter-organizational routines by demonstrating a link between prior collaborative experience between partners and alliance superior performance. Other attempts to capture knowledge sharing or knowledge- related issues in collaborative settings include dummy variables capturing whether knowledge flows exist between two actors (e.g., Tsai, 2002). Thus, we come back to the concepts of organizational and inter-organizational routines (Zollo et al., 2002; Zollo \& Winter, 2002), as well as those available empirical measures that better suit our research purposes (See below). We identify three dimensions to characterize the process of creation and redeployment 1 of knowledge-sharing routines in each alliance: frequency [frequency of contact between the firm and the RO during the alliance, both face-to-face and by email and phone, as well as formal and informal (e.g., Becerra et al., 2008; Sarkar et al., 2009)], intensity [extent to which knowledge in-flows and out-flows occurred between the firm and the RO, technological, managerial and market knowledge (e.g., Simonin, 1997; Sammarra \& Biggiero, 2008)], and willingness [extent to which actors showed willingness to share knowledge: flexibility to facilitate knowledge sharing and proactiveness to both transfer and receive knowledge (e.g., Hamel, 1991; Simonin, 2004)]. Furthermore, we asked informants about effectiveness of knowledge exchange [perceived relative absorptive capacity or extent to which the firm and the research organization were increasingly able to recognize and value, assimilated, and apply new knowledge from the other party (e.g., Lane \& Lubatkin, 1998; Dyer \& Hatch, 2006)]. Notice that Capron and Mitchell (1998) measure bilateral resources redeployment in the context of acquisitions by focusing on 'use of acquired business's resources' and 'transfer of resources to the acquired business'. Adapting this to our empirical context, redeployment may be operationalized by characterizing the application of existing routines into the focal alliance.

\footnotetext{
${ }^{1}$ Capron and Mitchell (1998) measure bilateral resources redeployment in the context of acquisitions by focusing on 'use of acquired business's resources' and 'transfer of resources to the acquired business'. Adapting this to our empirical context, redeployment may be operationalized by characterizing the application of existing routines into the focal alliance.
} 


\begin{tabular}{|c|c|c|c|}
\hline \multicolumn{4}{|c|}{ Operationalization of inter-organizational knowledge-sharing routines (continued) } \\
\hline Dimensions & Items & Informant $^{2}$ & $\begin{array}{c}\text { Theoretical and empirical } \\
\text { support }\end{array}$ \\
\hline $\begin{array}{l}\text { Frequency } \\
\text { of knowledge } \\
\text { sharing in the } \\
\text { alliance }\end{array}$ & $\begin{array}{l}\text { - Frequency of contact between the LF and the } \\
\text { RO by e-mail and phone } \\
\text { - Frequency of face-to-face contact between } \\
\text { the LF and the RO (official consortium } \\
\text { meetings and others) }\end{array}$ & $\begin{array}{l}\mathrm{LF} \\
\mathrm{RO}\end{array}$ & $\begin{array}{l}\text { Routines are 'recurrence } \\
\text { interaction patterns' or } \\
\text { 'behavioral regularities' } \\
\text { (Becker, 2004; Becker et al., } \\
\text { 2005; Becker, 2005) } \\
\text { [(Mora-Valentín et al., 2004; } \\
\text { Dyer \& Hatch, 2006; Becerra et } \\
\text { al., 2008; Sarkar et al., 2009)] } \\
\end{array}$ \\
\hline \multirow{2}{*}{$\begin{array}{l}\text { Willingness } \\
\text { to knowledge } \\
\text { sharing in } \\
\text { the alliance }\end{array}$} & $\begin{array}{l}\text { Willingness of the LF } \\
\text { - Flexibility showed by the LF to interact with } \\
\text { the RO and to adapt itself for the date/place } \\
\text { more convenient for both parties } \\
\text { - Proactiveness showed by the LF to provide } \\
\text { the RO with the needed support and } \\
\text { knowledge to make the project work., in a } \\
\text { timely, } \\
\text { - Proactiveness showed -by the LF to listen and } \\
\text { consider ideas, knowledge and necessities of } \\
\text { the RO }\end{array}$ & RO & \multirow{2}{*}{$\begin{array}{l}\text { Routines are 'effortful } \\
\text { accomplishments' and thus can } \\
\text { be also interpreted as } \\
\text { 'dispositions to express a certain } \\
\text { behavior that, 'when triggered, } \\
\text { lead to sequential behaviors' } \\
\text { (Becker, 2004; Becker et al., } \\
\text { 2005; Becker, 2005). } \\
\text { 'Transparency' of the } \\
\text { knowledge source and 'learning } \\
\text { intent' of the knowledge } \\
\text { recipient are key elements in } \\
\text { characterizing knowledge- } \\
\text { sharing routines (Hamel, 1991) } \\
\text { [(Becerra et al., 2008; Pérez- } \\
\text { Nordtvedt et al., 2008; Sarkar et } \\
\text { al., 2009; Schreiner et al., } \\
\text { 2009)] }\end{array}$} \\
\hline & $\begin{array}{l}\text { Willingness of the RO } \\
\text { - Flexibility showed by the RO to interact with } \\
\text { the LF and to adapt itself for the date/place } \\
\text { more convenient for both parties } \\
\text { - Proactiveness showed by the RO to provide } \\
\text { the LF with the needed support and } \\
\text { knowledge to make the project work. } \\
\text { - Proactiveness showed by the RO to listen and } \\
\text { consider ideas, knowledge and necessities of } \\
\text { the LF }\end{array}$ & LF & \\
\hline $\begin{array}{l}\text { Intensity of } \\
\text { knowledge } \\
\text { sharing in } \\
\text { the alliance }\end{array}$ & $\begin{array}{l}\text { Knowledge in-flows for the } R O \text { (knowledge out- } \\
\text { flows of the LF) } \\
\text { - The LF has provided us technological } \\
\text { knowledge relevant to the development of } \\
\text { this project } \\
\text { - The LF has provided us market knowledge } \\
\text { relevant to the development of this project } \\
\text { - The LF has provided us managerial } \\
\text { knowledge relevant to the development of } \\
\text { this project }\end{array}$ & RO & $\begin{array}{l}\text { Inter-organizational knowledge- } \\
\text { sharing routines involve a dual } \\
\text { active role for each party } \\
\text { [knowledge } \\
\text { source/donor/teacher and } \\
\text { seeker/ recipient/student] (Dyer } \\
\text { \& Nobeoka, 2000; Zollo et al., } \\
\text { 2002), being the "knowledge } \\
\text { seeker, at the dyadic level of } \\
\text { analysis, the best judge of the } \\
\text { value of knowledge received by }\end{array}$ \\
\hline
\end{tabular}

\footnotetext{
${ }^{2}$ LF: Lead firm; RO: research organization
} 


\begin{tabular}{|c|c|c|c|}
\hline & $\begin{array}{l}\text { Knowledge in-flows for the RO (knowledge out- } \\
\text { flows of the LF) } \\
\text { - The RO has provided us technological } \\
\text { knowledge relevant to the development of } \\
\text { this project } \\
\text { - The RO has provided us market knowledge } \\
\text { relevant to the development of this project } \\
\text { - The RO has provided us managerial } \\
\text { knowledge relevant to the development of } \\
\text { this project }\end{array}$ & $\mathrm{LF}$ & $\begin{array}{l}\text { a particular source" } \\
\text { [(Becerra et al., 2008)] }\end{array}$ \\
\hline $\begin{array}{l}\text { Effectiveness } \\
\text { of } \\
\text { knowledge } \\
\text { sharing in the } \\
\text { alliance }\end{array}$ & $\begin{array}{l}\text { Relative absorptive capacity } \\
\text { - As the project progressed, both the LF and } \\
\text { the RO have been increasingly able to } \\
\text { recognize and value new knowledge from the } \\
\text { other party } \\
\text { - As the project progressed, both the LF and } \\
\text { the RO have been increasingly able to } \\
\text { assimilated new knowledge from the other } \\
\text { party } \\
\text { - As the project progressed, both the LF and } \\
\text { the RO have been increasingly able to apply } \\
\text { new knowledge from the other party }\end{array}$ & $\begin{array}{l}\text { LF } \\
\text { RO }\end{array}$ & $\begin{array}{l}\text { Routines are built upon } \\
\text { 'purposefully learning } \\
\text { investments' (Zollo and Winter, } \\
2002 \text { ) and thus they cannot be } \\
\text { disregarded to the effectiveness } \\
\text { of their articulation (Dyer \& } \\
\text { Nobeoka, 2000; Becker, 2004). } \\
\text { Relative absorptive capacity is a } \\
\text { subprocess' intrinsically } \\
\text { associated to inter- } \\
\text { organizational knowledge- } \\
\text { sharing routines (Dyer \& Singh, } \\
\text { 1998) } \\
\text { [(Mowery et al., 1996; Simonin, } \\
\text { 1999; Simonin, 2004; Pérez- } \\
\text { Nordtvedt et al., 2008)] }\end{array}$ \\
\hline
\end{tabular}


Based on prior literature into strategic alliances in general (Parkhe, 1993; Glaister \& Buckley, 1998; Ariño, 2003) we identify several dimensions of value creation that accommodates the value-creation dynamics of R\&D alliances (e.g., Gulati et al., 2009) and firm-RO alliances (e.g., Mora-Valentín et al., 2004) (See below). To capture joint realization of value at the technological level, we asked informants to rate on a five-point Likert scale (1) the degree of fulfillment of the technical objectives of the alliance and (2) the extent to which a full innovation had been achieved, as well as to clarify (3) whether a patent has been achieved, and/or (4) whether scientific publications had been developed focusing on the results/processes of the focal project. To capture joint realization of value at the relational level, we asked informants to rate on a five-point Likert scale the extent to which the alliance had provided them with (1) new collaborative opportunities and/or (2) new business opportunities, the extent to which the alliance had enhanced (3) their image and reputation and (4) their organizational capability to collaborate with other organizations, as well as (5) to value their agreement/disagreement with several assertions about the continuity of the relationship with the partner of the focal alliance. In particular, (a) whether new join collaborations had been agreed, and (b) if not, whether future collaboration was perceived as probable/improbable; (c) if so, whether future collaboration would address the same or new research lines). Furthermore, as an integrative dimension capturing value at both relational and technological levels (Ariño, 2003), we asked informants to rate on a five-point Likert scale the degree of overall satisfaction they had gained with the focal alliance (explicitly asking them to consider both the achieved outcomes and the relationship developed between the partners). 


\begin{tabular}{|c|c|c|c|}
\hline \multicolumn{4}{|c|}{ Operationalization of joint value realization (continued) } \\
\hline Dimensions & Items & Informant $^{3}$ & References \\
\hline \multirow{4}{*}{ Innovation } & $\begin{array}{l}\text { Degree of technical goals' fulfillment } \\
\text { - To which extent the technical goals of the LF-RO project (as } \\
\text { established in the formal contract) have been achieved }\end{array}$ & $\begin{array}{l}\text { LF } \\
\text { RO }\end{array}$ & \multirow{4}{*}{$\begin{array}{l}{[(\text { Ariño, } 2003} \\
\text { Montoro- } \\
\text { Sánchez et al., } \\
\text { 2006)] }\end{array}$} \\
\hline & $\begin{array}{l}\text { Full innovation } \\
\text { - Has a full innovation been achieved during the LF-RO project in the } \\
\text { Acuisost Consortium? }\end{array}$ & $\begin{array}{l}\text { LF } \\
\text { RO }\end{array}$ & \\
\hline & $\begin{array}{l}\text { Patent } \\
\text { - If a full innovation has been achieved, has it been/will it be } \\
\text { patented? }\end{array}$ & $\begin{array}{l}\mathrm{LF} \\
\mathrm{RO}\end{array}$ & \\
\hline & $\begin{array}{l}\text { Publication } \\
\text { - Have/will the content, process, and/or results of the LF-RO project } \\
\text { been/be scientifically published? }\end{array}$ & $\begin{array}{l}\text { LF } \\
\text { RO }\end{array}$ & \\
\hline $\begin{array}{l}\text { Degree of } \\
\text { other } \\
\text { goals' } \\
\text { fulfillment }\end{array}$ & $\begin{array}{l}\text { RO/LF's outcomes with the LF-RO alliance in the Acuisost } \\
\text { Consortium } \\
\text { - New collaborative opportunities } \\
\text { - New business opportunities } \\
\text { - Enhancement of the organization's image and reputation (in the } \\
\text { market for the LF/ in the scientific community for the RO) } \\
\text { - Improvement of the capability to cooperate }\end{array}$ & $\begin{array}{l}\text { LF } \\
\text { RO }\end{array}$ & $\begin{array}{l}\text { [(Parkhe, 1993; } \\
\text { Simonin, 1997; } \\
\text { Ariño, 2003; } \\
\text { Montoro- } \\
\text { Sánchez et al., } \\
\text { 2006)] }\end{array}$ \\
\hline Satisfaction & $\begin{array}{l}\text { - Degree of global satisfaction with the LF-RO alliance in the } \\
\text { Acuisost Consortium (relational factors and outcomes obtained) }\end{array}$ & $\begin{array}{l}\mathrm{LF} \\
\mathrm{RO}\end{array}$ & $\begin{array}{l}\text { [(Parkhe, 1993; } \\
\text { Cullen et al., } \\
\text { 1995; Ariño, } \\
\text { 2003)(Mora- } \\
\text { Valentín et al., } \\
\text { 2004) ] }\end{array}$ \\
\hline Continuity & $\begin{array}{l}\text { - New joint projects have not been already agreed, but is probable } \\
\text { that the LF and the RO would collaborate again in future } \\
\text { - New joint projects have not been already agreed, and it is } \\
\text { improbable that the LF and the RO would collaborate again in } \\
\text { future } \\
\text { - New joint projects have been already agreed, and the LF and the RO } \\
\text { will collaborate again in future by extending the lines of research of } \\
\text { the A. Consortium } \\
\text { - New joint projects have been already agreed, and the LF and the RO } \\
\text { will collaborate again in future by undertaking new lines of research }\end{array}$ & $\begin{array}{l}\text { LF } \\
\text { RO }\end{array}$ & $\begin{array}{l}\text { [(Mora-Valentín } \\
\text { et al., 2004; } \\
\text { Reuer \& Zollo, } \\
\text { 2005)] }\end{array}$ \\
\hline
\end{tabular}

\footnotetext{
${ }^{3}$ LF: Lead firm; RO: research organization
} 


\section{Appendix IV.2 Data on theory-driven variables in Study II.1}

\begin{tabular}{|c|c|c|c|c|c|}
\hline \multicolumn{6}{|c|}{ Quantitative data: The OI-LF alliance } \\
\hline & $\mathbf{L F}$ & OI & $\begin{array}{c}\text { Aggregated } \\
\text { (Mean) }\end{array}$ & Disagreement & 1-3 Scale \\
\hline \multicolumn{6}{|l|}{ Knowledge-sharing dimensions } \\
\hline \multicolumn{6}{|l|}{ Frequency of contact } \\
\hline - Frequency of contact (e-mail and phone) & 4 & 5 & 4.5 & 1 & High \\
\hline - Frequency of contact (face-to-face) & 4 & 4 & 4 & 0 & High \\
\hline \multicolumn{6}{|l|}{ Willingness to share knowledge } \\
\hline - Flexibility & 5 & 4 & 4.5 & 1 & High \\
\hline - Proactiveness to share knowledge & 3 & 5 & 4 & 2 & High \\
\hline - Proactiveness to receive knowledge & 3 & 4 & 3.5 & 1 & High \\
\hline \multicolumn{6}{|l|}{ Intensity of knowledge sharing } \\
\hline - Technological knowledge in-flows & 5 & 4 & 4.5 & 1 & High \\
\hline - Market knowledge in-flows & 4 & 5 & 4.5 & 1 & High \\
\hline - Managerial knowledge in-flows & 4 & 2 & 3 & 3 & Medium \\
\hline \multicolumn{6}{|l|}{ Effectiveness in knowledge sharing } \\
\hline - Value and recognize new knowledge & 5 & 4 & 4.5 & 1 & High \\
\hline - Assimilate new knowledge & 4 & 4 & 4 & 1 & High \\
\hline - Apply new knowledge & 4 & 3 & 3.5 & 1 & High \\
\hline \multicolumn{6}{|l|}{ Value realizations } \\
\hline \multicolumn{6}{|l|}{ Innovation } \\
\hline - Degree of fulfillment of technical objectives & 5 & 5 & 5 & 0 & High \\
\hline - Full innovation & 4 & 3 & 3.5 & 1 & High \\
\hline - Patent & 5 & 5 & 5 & 0 & High \\
\hline - Publications & 1 & 1 & 1 & 0 & Low \\
\hline \multicolumn{6}{|l|}{ Other goals } \\
\hline - New collaborative opportunities & 5 & 4 & 4.5 & 1 & High \\
\hline - New business opportunities & 5 & 4 & 4.5 & 1 & High \\
\hline - Image and reputation & 4 & 5 & 4.5 & 1 & High \\
\hline Satisfaction & 5 & 4 & 4.5 & 1 & High \\
\hline \multicolumn{6}{|l|}{ Continuity } \\
\hline - No join projects, but probable & 1 & 1 & 1 & 0 & Low \\
\hline - No join projects, and improbable & 5 & 5 & 5 & 0 & High \\
\hline - New join projects, the same research lines & 1 & 1 & 1 & 0 & Low \\
\hline - New join projects, different research lines & 4 & 5 & 4.5 & 1 & High \\
\hline
\end{tabular}

Percentage of agreement [calculated as \% of (Rates of Informant ${ }_{\text {LF }}=$ Rates of Informant $\mathrm{OI}$ )/ Total No. Rates] $=34.78 \%$. Average disagreement [calculated as Sum of $\mid\left(\right.$ Rates of Informant LF $^{-}$Rates of Informant ${ }_{\mathrm{OI}} \mid$ )/ Total No. different rates] $=1.18$ 


\section{Quantitative data: The CRAI-LF alliance}

\begin{tabular}{|c|c|c|c|c|c|}
\hline & $\mathbf{L F}$ & CRAI & $\begin{array}{c}\text { Aggregated } \\
\text { (mean) }\end{array}$ & Disagreement & 1-3 Scale \\
\hline \multicolumn{6}{|l|}{ Knowledge-sharing dimensions } \\
\hline \multicolumn{6}{|l|}{ Frequency of contact } \\
\hline - Frequency of contact (e-mail and phone) & 4 & 4 & 4 & 0 & High \\
\hline - Frequency of contact (face-to-face) & 4 & 4 & 4 & 0 & High \\
\hline \multicolumn{6}{|l|}{ Willingness to share knowledge } \\
\hline - Flexibility & 5 & 4 & 4.5 & 1 & High \\
\hline - Proactiveness to share knowledge & 2 & 4 & 3 & 2 & Medium \\
\hline - Proactiveness to receive knowledge & 1 & 3 & 2 & 2 & Low \\
\hline \multicolumn{6}{|l|}{ Intensity of knowledge sharing } \\
\hline - Technological knowledge in-flows & 2 & 4 & 3 & 2 & Medium \\
\hline - Market knowledge in-flows & 1 & 4 & 2.5 & 3 & Medium \\
\hline - Managerial knowledge in-flows & 1 & 2 & 1.5 & 1 & Low \\
\hline \multicolumn{6}{|l|}{ Effectiveness in knowledge sharing } \\
\hline - Value and recognize new knowledge & 1 & 4 & 2.5 & 3 & Medium \\
\hline - Assimilate new knowledge & 1 & 4 & 2.5 & 3 & Medium \\
\hline - Apply new knowledge & 1 & 4 & 2.5 & 3 & Medium \\
\hline \multicolumn{6}{|l|}{ Vale realization } \\
\hline \multicolumn{6}{|l|}{ Innovation } \\
\hline - Degree of fulfillment of technical objectives & 1 & 3 & 2 & 2 & Low \\
\hline - Full innovation & 1 & $(---)$ & $(---)$ & $(---)$ & Low \\
\hline - Patent & 1 & 1 & 1 & 0 & Low \\
\hline - Publications & 1 & 1 & 1 & 0 & Low \\
\hline \multicolumn{6}{|l|}{ Other goals } \\
\hline - New collaborative opportunities & 1 & 4 & 2.5 & 3 & Medium \\
\hline - New business opportunities & 1 & 4 & 2.5 & 3 & Medium \\
\hline - Image and reputation & 3 & 2 & 2.5 & 1 & Medium \\
\hline Satisfaction & 1 & 4 & 2.5 & 3 & Medium \\
\hline \multicolumn{6}{|l|}{ Continuity } \\
\hline - No join projects, but probable & 1 & 3 & 2 & 2 & Low \\
\hline - No join projects, and improbable & 1 & 1 & 1 & 0 & Low \\
\hline - New join projects, the same research lines & 1 & 1 & 1 & 0 & Low \\
\hline - New join projects, different research lines & 1 & 1 & 1 & 0 & Low \\
\hline
\end{tabular}

Percentage of agreement [calculated as \% of (Rates of Informant ${ }_{\mathrm{LF}}=$ Rates of Informant ${ }_{\mathrm{CRAI}}$ )/ Total No. Rates] $=31.82 \%$. Average disagreement [calculated as Sum of $\mid\left(\right.$ Rates of Informant LF $^{-}$Rates of Informant $_{\mathrm{CRAI}} \mid$ )/ Total No. different rates $]=2.27$ 


\begin{tabular}{|c|c|c|}
\hline \multicolumn{3}{|c|}{ Qualitative data: Comparison of knowledge sharing evolution in the two cases } \\
\hline & OI-LF alliance & CRAI -LF alliance \\
\hline 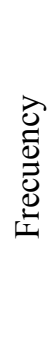 & $\begin{array}{l}\text { - S1: The LF starts thinking that contact it is not enough } \\
\text { frequent } \\
\text { - S2: Frequency notably increases (i.e., technological } \\
\text { meetings every 3months, regular email and phone } \\
\text { contact) } \\
\text { - S3: Frequency remained high until the project is } \\
\text { officially finished }\end{array}$ & $\begin{array}{l}\text { - S1: From the very beginning contact is quite frequent } \\
\text { (i.e., technological meetings every } 3 \text { months, regular } \\
\text { phone and email contact) } \\
\text { - S2: Contact remains equally frequent } \\
\text { - S3: The project is still officially ongoing when } \\
\text { frequency reduces at the minimum (i.e., no meetings, } \\
\text { only occasional phone calls/ emails to deal with } \\
\text { administrative aspects) }\end{array}$ \\
\hline 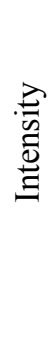 & $\begin{array}{l}\text { - S1: The LF thinks that not all the (technological) } \\
\text { knowledge the OI provides is relevant. } \\
\text { - S2: Intensity notably increases in all fronts } \\
\text { (technological, market and managerial knowledge) } \\
\text { and directions (i.e., LF in-flows and OI in-flows) } \\
\text { - S3: Once the project is officially finished, both } \\
\text { partners continue transferring relevant (particularly, } \\
\text { technological) knowledge }\end{array}$ & $\begin{array}{l}\text { - S1: From the very beginning, both partners exchange } \\
\text { relevant (technological and market) knowledge } \\
\text { - S2: The LF gradually perceives that (technological) } \\
\text { knowledge provided by CRAI is not relevant } \\
\text { - S3: Although the project is still officially ongoing } \\
\text { intensity significantly reduces (particularly } \\
\text { concerning technological knowledge) }\end{array}$ \\
\hline 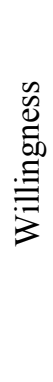 & $\begin{array}{l}\text { - S1: Both partners show flexibility to share knowledge. } \\
\text { Yet, at first, the LF thinks that the OI is not enough } \\
\text { proactive (i.e., it does not provide relevant } \\
\text { technological knowledge). } \\
\text { - S2: Flexibility of the LF reduces but proactiveness of } \\
\text { both partners remains strong } \\
\text { - Once the project is officially finished, both partners } \\
\text { continue showing strong willingness to share| receive } \\
\text { knowledge }\end{array}$ & $\begin{array}{l}\text { - S1: Both partners show mutual flexibility and } \\
\text { proactiveness to exchange knowledge } \\
\text { - S2: Flexibility maintains but the LF thinks that CRAI } \\
\text { is not proactive (i.e., it does not provide relevant } \\
\text { technological knowledge) } \\
\text { - S3: The LF's willingness to share knowledge reduces } \\
\text { at the minimum }\end{array}$ \\
\hline 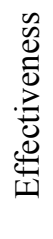 & $\begin{array}{l}\text { - S1: knowledge sharing can be described as ineffective } \\
\text { (partners do not know each other) } \\
\text { - S2: Knowledge sharing can be described as effective } \\
\text { - S3: Once the project is officially finished, knowledge } \\
\text { sharing remains effective }\end{array}$ & $\begin{array}{l}\text { - S1: Knowledge sharing can be described as } \\
\text { ineffective (partners do not know each other). } \\
\text { - S2: Knowledge sharing remains ineffective } \\
\text { - S3: Knowledge sharing can be described as } \\
\text { ineffective. }\end{array}$ \\
\hline
\end{tabular}

Note: S1: Start-up stage (January2008-December 2008); S2: Execution stage (December 2008-December 2009); S3: Termination stage (December 2009-December 2010) 


\begin{tabular}{|c|c|c|}
\hline \multicolumn{3}{|c|}{ Qualitative data: Comparison of the technological evolution in the two cases } \\
\hline & OI-LF alliance & CRAI -LF alliance \\
\hline 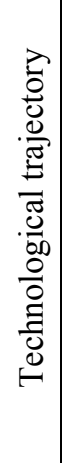 & $\begin{array}{l}\text { - S1: Initial technical efforts and initial changes to deal } \\
\text { with lack of feasibility of one initial objective (i.e., } \\
\text { one raw material) } \\
\text { - S2: Changes to enhance chances of industrial success } \\
\text { of the other two initial objectives. First successful } \\
\text { achievements. New technical objectives (i.e., new raw } \\
\text { materials not initially considered) and a new working } \\
\text { methodology to accomplish them. } \\
\text { - S3: Successful achievements that are co-patented } \\
\text { Extension of the contract, new objectives (i.e., } \\
\text { technical support for LF's day-to-day activities) }\end{array}$ & $\begin{array}{l}\text { - S1: Initial technical efforts and promising preliminary } \\
\text { results (T1, T2, T3). Initial changes (T2) to facilitate } \\
\text { the progress of the research. Subsequent technical } \\
\text { efforts result partially successful (promising result in } \\
\text { T3 but failure in T1 and T2) } \\
\text { - S2: Technical efforts continued unsuccessful (T1 and } \\
\text { T2) and major changes (reformulation of technical } \\
\text { objectives) are applied due to lack of feasibility. } \\
\text { Technical failure. } \\
\text { - S3: Initial objectives are retaken but technical failure. }\end{array}$ \\
\hline 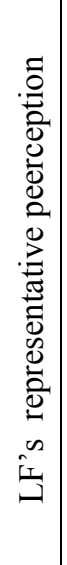 & $\begin{array}{l}\text { - S1: High potential of the project (i.e, it could yield } \\
\text { industrially 'applicable' results). Technical deviations } \\
\text { are normal in R\&D and changes needed to enhance } \\
\text { likelihood of success. OI's technological capabilities } \\
\text { are stronger than expected } \\
\text { - S2: Feasibility of the project and the strong OI's } \\
\text { technological capabilities are both confirmed. } \\
\text { - S3: The project has already yielded useful technical } \\
\text { results (though industrial application is not already } \\
\text { possible). Technical support from the OI contributes } \\
\text { positively to the development of the firm's day-to-day } \\
\text { activities }\end{array}$ & $\begin{array}{l}\text { - S1: High potential of the project (to yield innovative } \\
\text { outcomes for the firm).. Technical deviations are } \\
\text { normal in R\&D and changes needed to enhance } \\
\text { likelihood of success. CRAI's technological } \\
\text { capabilities are as strong as expected } \\
\text { - S2: Lack of feasibility of the initial technical } \\
\text { objectives of the project (as shown by recurrent } \\
\text { technical failure). CRAI's lack the required } \\
\text { technological capabilities to successfully accomplish } \\
\text { the reformulated objectives } \\
\text { - S3: The project lacks potential to yield any technical } \\
\text { results that may be useful for the firm, and CRAI will } \\
\text { not be able to propose any technological alternative }\end{array}$ \\
\hline 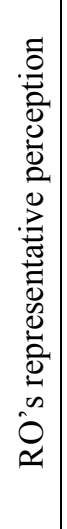 & $\begin{array}{l}\text { - S1: High potential of the project (i.e, it could yield } \\
\text { industrially 'applicable' results). Firm's industrial } \\
\text { needs are becoming understood. Technical deviations } \\
\text { are normal in R\&D and changes needed to enhance } \\
\text { likelihood of success. LF's scientific capabilities are } \\
\text { stronger than expected } \\
\text { - S2: Feasibility of the project and the strong LF's } \\
\text { scientific capabilities are both confirmed. } \\
\text { - S3: The project has already yielded useful technical } \\
\text { results . Until industrial application of achieved } \\
\text { results is completed, the project will remain } \\
\text { unfinished. Providing technical support to the LF's } \\
\text { day-to-day activities is part of the project. }\end{array}$ & $\begin{array}{l}\text { - S1: High potential of the project (i.e., it concerns high } \\
\text { innovative objectives). Technical deviations are } \\
\text { normal in so innovative R\&D projects and changes } \\
\text { needed to satisfy technological needs of the LF } \\
\text { - S2: Technical deviations are normal in so innovative } \\
\text { R\&D projects and changes needed to satisfy } \\
\text { technological needs of the LF } \\
\text { - S3: Risk of technical failure is inherent in so } \\
\text { innovative R\&D projects. The project's achievements } \\
\text { are highly interesting, even susceptible to be patented, } \\
\text { and the project is successful (i.e., learning about what } \\
\text { is not feasible) }\end{array}$ \\
\hline
\end{tabular}

Note: S1: Start-up stage (January2008-December 2008); S2: Execution stage (December 2008-December 2009); S3: Termination stage (December 2009-December 2010) 


\begin{tabular}{|c|c|c|}
\hline \multicolumn{3}{|c|}{ Qualitative data: Comparison of the relational evolution in the two cases } \\
\hline & OI-LF alliance & CRAI - LF alliance \\
\hline 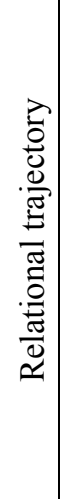 & $\begin{array}{l}\text { - S1: Collaboration does not start with intense } \\
\text { interaction but disagreement does not emerge from } \\
\text { initial collaborative interactions } \\
\text { - S2: Disagreements emerged and are early corrected. A } \\
\text { positive relational basis is early created. Intense } \\
\text { collaborative interactions reinforce mutual } \\
\text { understanding and commitment. Relationship } \\
\text { gradually strengthens (e.g., the partners start to talk } \\
\text { about continuity) } \\
\text { - S3: Relationship consolidates at both organizational } \\
\text { and individual levels. The partners agree new joint } \\
\text { R\&D projects }\end{array}$ & $\begin{array}{l}\text { - S1: Collaboration starts with intense interaction and } \\
\text { disagreement does not emerge from initial } \\
\text { collaborative interactions. } \\
\text { - S2: Intense collaborative interactions lead to } \\
\text { important misunderstandings. Relationship gradually } \\
\text { weakens } \\
\text { - S3: Collaborative interactions are practically } \\
\text { inexistent. Relationship breaks up at both } \\
\text { organizational and individual levels }\end{array}$ \\
\hline 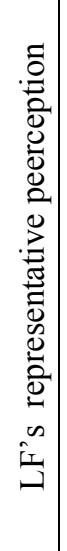 & $\begin{array}{l}\text { - S1: No significant (neither positive nor negative) } \\
\text { relational perceptions are identified } \\
\text { - S2: The OI makes significant efforts to understand the } \\
\text { firm needs and thus starts to change its working style } \\
\text { OI is making significant efforts and proposes } \\
\text { technological solutions/alternatives, it places a } \\
\text { premium on firm's industrial needs and thus does real } \\
\text { 'applied research'. There is a total mutual } \\
\text { understanding. } \\
\text { - S3: The OI is a 'new' technological partner (and its } \\
\text { head researcher is becoming a personal friend). } \\
\text { Agreed new join projects are initial steps of the long- } \\
\text { term relationship that has been created }\end{array}$ & $\begin{array}{l}\text { - S1: No significant (neither positive nor negative) } \\
\text { relational perceptions are identified } \\
\text { - S2: Collaboration is intense to save the project. CRAI } \\
\text { is neither making enough efforts nor proposing } \\
\text { technological solutions/alternatives, in the absence of } \\
\text { other instructions it limits to follow the initial } \\
\text { proposal even though it lacks feasibility and thus only } \\
\text { does 'basic research'. There is total lack of mutual } \\
\text { understanding } \\
\text { - S3: Once the ongoing project officially finishes, the } \\
\text { relationship will not continue. New joint projects are } \\
\text { totally improbable. CRAI is responsible for technical } \\
\text { failure }\end{array}$ \\
\hline 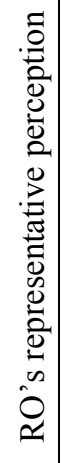 & $\begin{array}{l}\text { - S1: The LF (and its R\&D Manager in particular) } \\
\text { shares the same vision of research and recognizes and } \\
\text { value the technical expertise of the center } \\
\text { - S2: The LF will strive to bring the project } \\
\text { achievements to life. Technical success is being } \\
\text { achieved by means of joint work with the LF. There is } \\
\text { a total mutual understanding. } \\
\text { - S3: The LF is a 'new' industrial partner (and its R\&D } \\
\text { manager is becoming a personal friend) Agreed new } \\
\text { join projects are initial steps of the long-term } \\
\text { relationship that has been created }\end{array}$ & $\begin{array}{l}\text { - S1: No significant (neither positive nor negative) } \\
\text { relational perceptions are identified } \\
\text { - S2: Collaboration is intense because both partners } \\
\text { want to contribute to the development of the project. } \\
\text { Decision-making power resides exclusively in the LF } \\
\text { Mutual understanding has emerged } \\
\text { - S3: New joint projects are not already agreed but are } \\
\text { highly probable in future. Both partners share } \\
\text { responsibilities concerning project's results }\end{array}$ \\
\hline
\end{tabular}

Note: S1: Start-up stage (January2008-December 2008); S2: Execution stage (December 2008-December 2009); S3: Termination stage (December 2009-December 2010) 


\section{Appendix IV.3 Operationalization of data-driven variables in Study II.1}

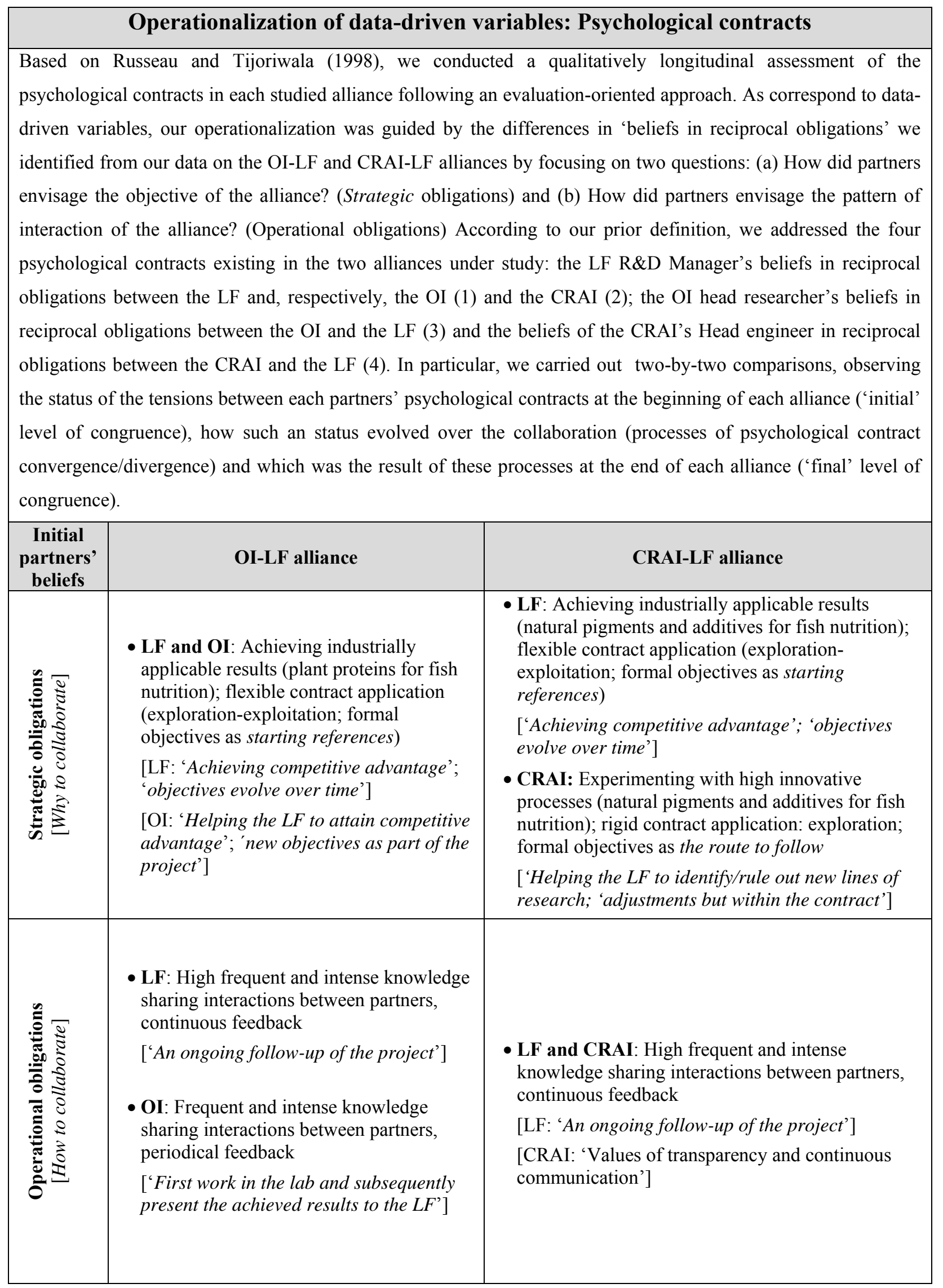




\section{Appendix IV.4 Data on theory-driven variables in Study II.2}

\begin{tabular}{|c|c|c|c|c|c|}
\hline \multicolumn{6}{|c|}{ Redeployment of the CAH-LF's knowledge-sharing routines } \\
\hline \multicolumn{2}{|r|}{$\begin{array}{c}\text { Knowledge-sharing } \\
\text { dimension }\end{array}$} & $\mathbf{L F}$ & CAH & $\begin{array}{c}\text { Aggregated } \\
\text { (Mean) }\end{array}$ & \multirow{3}{*}{$\begin{array}{l}\text { Illustrative interview quotes } \\
\text { “... contact by email and phone almost on a daily } \\
\text { basis, meetings are also held when needed“ (LF's } \\
\text { R\&D Manager)ñ } \\
\text { “...communication flows fluently in the two } \\
\text { directions, especially by email and phone, once a } \\
\text { week at a minimum” (CAH's Head) }\end{array}$} \\
\hline \multirow{2}{*}{ 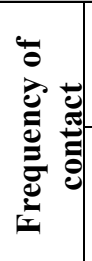 } & $\begin{array}{l}\text { - Frequency of contact } \\
\text { (e-mail, phone) }\end{array}$ & 5 & 5 & 5 & \\
\hline & $\begin{array}{l}\text { - Frequency of contact } \\
\text { (face-to-face) }\end{array}$ & 4 & 5 & 4.5 & \\
\hline \multirow{3}{*}{ 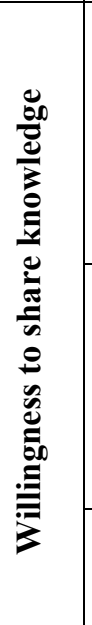 } & - Flexibility & 5 & 5 & 5 & $\begin{array}{l}\text { “... they are more flexible than us, they adapt to our } \\
\text { agenda" (LF's R\&D Manager) } \\
\text { "...the LF's availability has reduced as it has grown, } \\
\text { but what is important always fits in their schedule } \\
\text { [...] we meet wherever, even in the LF's clients } \\
\text { facilities if needed " (CAH's Head) }\end{array}$ \\
\hline & $\begin{array}{l}\text { - Proactiveness to } \\
\text { share knowledge }\end{array}$ & 5 & 4 & 4.5 & \multirow{2}{*}{$\begin{array}{l}\text { “... when we pose a problem, they study it and } \\
\text { always offer us a solution” (LF's R\&D Manager) } \\
\text {...we adapt to the LF's necessities and the LF's adapt } \\
\text { to ours }[\ldots . .] \text { they rely on our expertise and follow our } \\
\text { advice }[\ldots] \text { when an information need arises, we ask } \\
\text { them openly [...] we discuss a question as much as } \\
\text { needed until consensus is reached, if one party } \\
\text { disagrees, it is not carried out (CAH's Head) }\end{array}$} \\
\hline & $\begin{array}{l}\text { - Proactiveness to } \\
\text { receive knowledge }\end{array}$ & 5 & 4 & 4.5 & \\
\hline \multirow{3}{*}{ 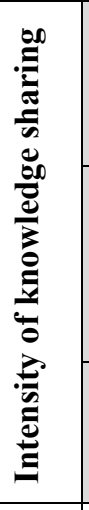 } & $\begin{array}{l}\text { - Technological } \\
\text { knowledge in-flows }\end{array}$ & 5 & 5 & 5 & \multirow{3}{*}{$\begin{array}{l}\text { “... they put all their technological knowledge at our } \\
\text { disposal [...] Sometimes they have provide us } \\
\text { relevant market knowledge, for example, about new } \\
\text { product development trends }[\ldots] \text { The transfer of } \\
\text { managerial knowledge is not relevant (LF's R\&D } \\
\text { Manager) } \\
\text { “...technological information flows have been and } \\
\text { still are highly intense in both directions [...] LF’s } \\
\text { technological process }[\ldots . .] \text { this technical knowledge } \\
\text { has allowed us to know the national aquaculture } \\
\text { market }[\ldots . .] \text { it is not possible to extrapolate a firm's } \\
\text { managerial model to our context” (CAH's Head) }\end{array}$} \\
\hline & $\begin{array}{l}\text { - Market knowledge } \\
\text { in-flows }\end{array}$ & 3 & 4 & 3.5 & \\
\hline & $\begin{array}{l}\text { - Managerial } \\
\text { knowledge in-flows }\end{array}$ & 1 & 2 & 1.5 & \\
\hline \multirow{3}{*}{ 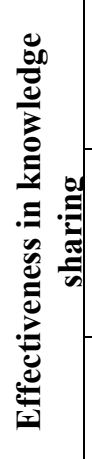 } & $\begin{array}{l}\text { - Value and recognize } \\
\text { new knowledge }\end{array}$ & 5 & 5 & 5 & \multirow{3}{*}{$\begin{array}{l}\text { “...we use the same language. After all, I come from } \\
\text { CAH [...] mutual understanding allows us to arrive at } \\
\text { important achievements [...]research at the CAH } \\
\text { reflects into our activities" (LF's R\&D Manager) } \\
\text { “...We are a tool of the LF. We acquire knowledge } \\
\text { from the LF to find out its necessities, then we } \\
\text { assimilate and apply this knowledge into our research } \\
{[\ldots] \text { we in turn transfer knowledge we generate to the }} \\
\text { LF, which finally applies it in its products and } \\
\text { processes }[. . .] " \text { (CAH's Head) }\end{array}$} \\
\hline & $\begin{array}{l}\text { - Assimilate new } \\
\text { knowledge }\end{array}$ & 5 & 5 & 5 & \\
\hline & $\begin{array}{l}\text { - Apply new } \\
\text { knowledge }\end{array}$ & 5 & 5 & 5 & \\
\hline
\end{tabular}


Note: Highlighted in grey values for subsequent cross-case comparison. Percentage of agreement

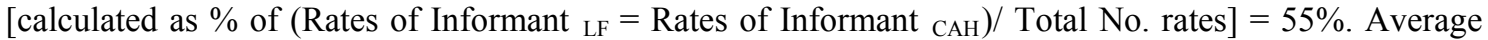
disagreement [calculated as Sum of $\mid$ (Rates of Informant ${ }_{L F}-$ Rates of Informant $\left.{ }_{C A H} \mid\right) /$ Total No. different rates $]=1$

\section{Joint value realization between CAH and the LF}

\begin{tabular}{|c|c|c|c|c|c|}
\hline & $\begin{array}{l}\text { Joint value } \\
\text { dimensions }\end{array}$ & $\mathbf{L F}$ & САН & $\begin{array}{c}\text { Aggregated } \\
\text { (1-3 Scale) }\end{array}$ & Illustrative interview quotes/data \\
\hline \multirow{4}{*}{ : } & $\begin{array}{l}\text { - Degree of } \\
\text { fulfillment } \\
\text { of technical } \\
\text { objectives }\end{array}$ & 4 & 4 & 4 & $\begin{array}{l}\text { "... initial technical objectives have been fulfilled to a } \\
80 \% \text { degree, the main part of the process was completed } \\
\text { earlier than planned and then because we started doing } \\
\text { other interesting things" (LF's R\&D Manager) } \\
\text { "... the objectives that we initial considered for this } \\
\text { project have been met to a } 80 \% \text { degree, some tasks have } \\
\text { been changed, others removed [...] changes are needed in } \\
\text { any R\&D project, working in something that will not be } \\
\text { useful for the firm does not make sense for us" (CAH's } \\
\text { Head) }\end{array}$ \\
\hline & $\begin{array}{l}\text { - Full } \\
\text { innovation }\end{array}$ & 3 & 3 & 3 & $\begin{array}{l}\text { [Both informants agreed that a full innovation occurs } \\
\text { when results are "industrially applied to commercial } \\
\text { ends"] } \\
\text { "... it is not a full innovation because we have not } \\
\text { already started commercializing it, but we consider to do } \\
\text { it in the near future [...] it is not worth patenting it" (LF's } \\
\text { R\&D Manager) }\end{array}$ \\
\hline & - Patent & 1 & 1 & 1 & $\begin{array}{l}\text { “...results achieved are included in the category of } \\
\text { 'results that are not worth patenting' [...] many times } \\
\text { firms prefer not patenting as a mean of protection or } \\
\text { simply because it is not a profitable investment" (CAH's } \\
\text { Head) }\end{array}$ \\
\hline & - Publications & 3 & 4 & 3.5 & $\begin{array}{l}\text { "... we have developed important academic results, some } \\
\text { publications are co-authored by the LF's R\&D Manager, } \\
\text { but it is difficult to say that they came strictly from the } \\
\text { Acuisost Consortium, maybe come from our relationship } \\
\text { with the LF in general" (CAH's Head) }\end{array}$ \\
\hline \multirow{3}{*}{ 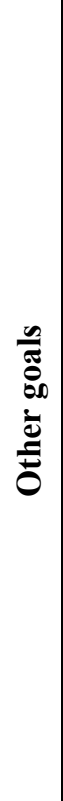 } & $\begin{array}{l}\text { - New } \\
\text { collaborative } \\
\text { opportunities }\end{array}$ & 5 & 2 & 3.5 & \multirow{2}{*}{$\begin{array}{l}\text { "...CAH have provided us many new opportunities } \\
\text { overtime, and I am sure CAH will remain providing them } \\
\text { to us }[\ldots] \text { if they cannot provide us a solution, they } \\
\text { search among its network of contacts and remit us to } \\
\text { another research center [...] they have put us in contact } \\
\text { with some organizations of other fields with which they } \\
\text { previously collaborated and with which we currently } \\
\text { collaborate too [...] CAH is key to us because its } \\
\text { multidisciplinary activity " (LF's R\&D Manager) } \\
\text { "... our relationship with the LF is strategic and the } \\
\text { aquaculture sector knows it [...] it has provided a lot of } \\
\text { opportunities overtime [...] we collaborate with most of } \\
\text { the LF's client firms but none of the LF's competitors } \\
\text { has asked us our services [... ] advantages outperform } \\
\text { disadvantages" (CAH's Head) }\end{array}$} \\
\hline & $\begin{array}{l}\text { - New } \\
\text { business } \\
\text { opportunities }\end{array}$ & 5 & 2 & 3.5 & \\
\hline & $\begin{array}{l}\text { Image and } \\
\text { reputation }\end{array}$ & 3 & 2 & 3 & $\begin{array}{l}\text { [Both informants considered that the Acuisost } \\
\text { Consortium in general has been a more important source } \\
\text { of image and reputation than the CAH-LF collaboration } \\
\text { in the Acuisost Consortium in particular] }\end{array}$ \\
\hline
\end{tabular}




\begin{tabular}{|c|c|c|c|c|c|}
\hline \multicolumn{2}{|c|}{ Satisfaction } & 5 & 4 & 4.5 & $\begin{array}{l}\text { “... highly satisfactory, as usual” (LF's R\&D Manager) } \\
\text { “... we can say ‘total satisfaction', concerning not the } \\
\text { Acuisost Consortium but our relationship in general” } \\
\text { (CAH's Head) }\end{array}$ \\
\hline \multirow{4}{*}{ ن } & $\begin{array}{l}\text { - No join } \\
\text { projects, but } \\
\text { probable }\end{array}$ & 1 & 1 & 1 & \multirow{4}{*}{$\begin{array}{l}\text { The MAR and the LF decided not to commit more } \\
\text { resources by the moment in the industrial implementation } \\
\text { (up-scaling) of this methodology. Before their } \\
\text { collaboration under the Acuisost Consortium finished, } \\
\text { the two partners started experimenting in new areas } \\
\text { (aquaculture nutrition and pet biosecurity) and agreed } \\
\text { two new joint projects for future (, one of them with } \\
\text { MAR). Both informants took for granted the continuity } \\
\text { of their collaboration beyond the Acuisost Consortium } \\
\text { and considered that "this research line is exhausted, } \\
\text { nothing else can be get from it" (LF's R\&D Manager) }\end{array}$} \\
\hline & $\begin{array}{l}\text { - No join } \\
\text { projects, and } \\
\text { improbable } \\
\end{array}$ & 1 & 1 & 1 & \\
\hline & $\begin{array}{l}\text { - New join } \\
\text { projects, the } \\
\text { same lines }\end{array}$ & 1 & 1 & 1 & \\
\hline & $\begin{array}{l}\text { - New join } \\
\text { projects, } \\
\text { different } \\
\text { lines }\end{array}$ & 5 & 5 & 5 & \\
\hline
\end{tabular}

Notes: Highlighted in grey values for subsequent cross-case comparison. Percentage of agreement [calculated as \% of (Rates of Informant ${ }_{\mathrm{LF}}=$ Rates of Informant $\left.{ }_{\mathrm{CAH}}\right) /$ Total No. rates] $=58 \%$. Average disagreement [calculated as Sum of $\mid\left(\right.$ Rates of Informant $_{\mathrm{LF}^{-}}$- Rates of Informant $\left.{ }_{\mathrm{CAH}} \mid\right) /$ Total No. different rates $]=1.8$ 


\begin{tabular}{|c|c|c|c|c|c|}
\hline \multicolumn{6}{|c|}{ Redeployment of MAR-LF's knowledge-sharing routines } \\
\hline \multicolumn{2}{|r|}{$\begin{array}{c}\text { Knowledge-sharing } \\
\text { dimension }\end{array}$} & $\mathbf{L F}$ & MAR & $\begin{array}{c}\text { Aggregated } \\
\text { (Mean) }\end{array}$ & Illustrative interview quotes \\
\hline \multirow{2}{*}{ 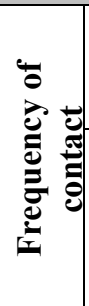 } & $\begin{array}{l}\text { - Frequency of contact } \\
\text { (e-mail, phone) }\end{array}$ & 4 & 5 & 4.5 & $\begin{array}{l}\text { “... contact by email and, particularly, by phone is quite } \\
\text { frequent }[\ldots] \text { we meet together whenever possible "(LF's } \\
\text { R\&D Manager) }\end{array}$ \\
\hline & $\begin{array}{l}\text { - Frequency of contact } \\
\text { (face-to-face) }\end{array}$ & 4 & 3 & 3.5 & $\begin{array}{l}\text { “...communication with the LF's Manager is effective } \\
\text { and fluent, by phone and email, and phone once a week } \\
\text { at a minimum [...] we have also meetings, quite but } \\
\text { obviously less frequently" (MAR's Head) }\end{array}$ \\
\hline \multirow{3}{*}{ 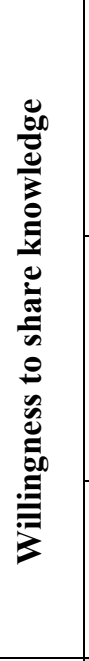 } & - Flexibility & 5 & 5 & 5 & $\begin{array}{l}\text { “... MAR shows total flexibility in this regard ” (LF's } \\
\text { R\&D Manager) } \\
\text { “...we must adapt to the LF's necessities }[\ldots] \text { try to be } \\
\text { totally flexible }[\ldots] \text { meetings whenever and wherever } \\
\text { they can (MAR’s Head) }\end{array}$ \\
\hline & $\begin{array}{l}\text { - Proactiveness to } \\
\text { share knowledge }\end{array}$ & 4 & 4 & 4 & $\begin{array}{l}\text { “... MAR's Head shows always proactive to give us } \\
\text { information }[. . .] \text { important decisions by consensus" (LF's } \\
\text { R\&D Manager) } \\
\text { "...we listen the LF's necessities that act as the guide for } \\
\text { our actions to try to provide them a solution }[\ldots] \text { the }\end{array}$ \\
\hline & $\begin{array}{l}\text { - Proactiveness to } \\
\text { receive knowledge }\end{array}$ & 4 & 4 & 4 & $\begin{array}{l}\text { something is thinking in the firm's interests, it is also } \\
\text { beneficial for the MAR in the long-term [...] the LF's is } \\
\text { always transparent with us, providing all the information } \\
\text { we require to provide them solutions" (MAR's Head) }\end{array}$ \\
\hline \multirow{3}{*}{ 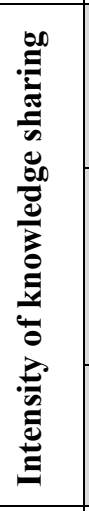 } & $\begin{array}{l}\text { - Technological } \\
\text { knowledge in-flows }\end{array}$ & 3 & 3 & 3 & \multirow{3}{*}{$\begin{array}{l}\text { “... they especially provided us relevant market } \\
\text { knowledge }[\ldots] \text { technological knowledge generated in } \\
\text { this project has been relatively simple }[\ldots] \text { exchange of } \\
\text { managerial knowledge is not significant" (LF's R\&D } \\
\text { Manager) } \\
\text { "...technical knowledge always flows without obstacles } \\
\text { between the two parties }[\ldots] \text { intensity depends on the } \\
\text { characteristics of the project at hand }[\ldots] \text { I already knew } \\
\text { the aquaculture market when we started with algae }[\ldots] \\
\text { our experience in the consortium has served us to confirm } \\
\text { our ideas on how to collaborate with firms: flexibility and } \\
\text { useful solutions" (MAR's Head) }\end{array}$} \\
\hline & $\begin{array}{l}\text { - Market knowledge } \\
\text { in-flows }\end{array}$ & 5 & 4 & 4.5 & \\
\hline & $\begin{array}{l}\text { - Managerial } \\
\text { knowledge in-flows }\end{array}$ & 2 & 4 & 3 & \\
\hline \multirow{3}{*}{ 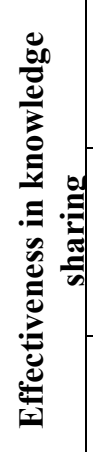 } & $\begin{array}{l}\text { - Value and recognize } \\
\text { new knowledge }\end{array}$ & 4 & 4 & 4 (High) & \multirow{3}{*}{$\begin{array}{l}\text { "...the LF resort to us because it needs solutions }[\ldots] \text { we } \\
\text { understand it and do real applied research }[\ldots] \text { if the LF } \\
\text { do not develop new products from the consortium, it will } \\
\text { make no sense }[\ldots] \text { the most important thing in } \\
\text { collaboration is always the personal relationship, and we } \\
\text { understand each other perfectly" (MAR's Head) }\end{array}$} \\
\hline & $\begin{array}{l}\text { - Assimilate new } \\
\text { knowledge }\end{array}$ & 4 & 4 & 4 (High) & \\
\hline & $\begin{array}{l}\text { - Apply new } \\
\text { knowledge }\end{array}$ & 4 & 4 & 4 (High) & \\
\hline
\end{tabular}

Notes: Highlighted in grey values for cross-case comparison. Percentage of agreement [calculated as \% of $\left(\right.$ Rates of Informant ${ }_{\mathrm{LF}}=$ Rates of Informant $\left.{ }_{\mathrm{MAR}}\right) /$ Total No. Rates] $=55 \%$. Average disagreement [calculated as $\mid\left(\right.$ Rates of Informant ${ }_{\text {LF- }}$ Rates of Informant $\left.{ }_{\mathrm{MAR}} \mid\right) /$ Total No. different rates] $=1.17$ 


\begin{tabular}{|c|c|c|c|c|c|}
\hline \multicolumn{6}{|c|}{ Joint value realization between MAR and the $L F$} \\
\hline & $\begin{array}{l}\text { Joint value } \\
\text { dimension }\end{array}$ & $\mathbf{L F}$ & RO & $\begin{array}{c}\text { Aggregated } \\
\text { (Mean) }\end{array}$ & Illustrative interview quotes/data \\
\hline \multirow{4}{*}{ 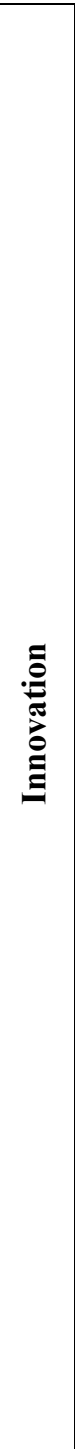 } & $\begin{array}{l}\text { - Degree of } \\
\text { fulfillment } \\
\text { of technical } \\
\text { objectives }\end{array}$ & 5 & 4 & 4 & $\begin{array}{l}\text { “...although at the beginning we had some unexpected } \\
\text { problems delaying the project, we rapidly solved them and from } \\
\text { then on the project progressed at a quite good pace, the whole } \\
\text { project being completed earlier than planned" (LF's R\&D } \\
\text { Manager) } \\
\text { “...the objectives initially established to this project has been } \\
\text { met to an acceptable degree, there have been some deviations } \\
\text { but be expected in any R\&D project. On a technical level, } \\
\text { results are very interesting: we have confirmed the viability of } \\
\text { algae ("MAR's Head) }\end{array}$ \\
\hline & $\begin{array}{l}\text { - Full } \\
\text { innovation }\end{array}$ & 3 & 3 & 3 & $\begin{array}{l}\text { [Both informants agreed that a full innovation occurs when } \\
\text { results are "industrially applied to commercial ends"] } \\
\text { "... (to achieve full innovation) it would be required to build a } \\
\text { new production plant (to avoid transportation costs) [...] the } \\
\text { current economic situation discourages the LF from investing in } \\
\text { it now" (LF's R\&D Manager) } \\
\text { “... a full innovation has not been achieved insofar the costs of } \\
\text { the last step (transportation) render the whole process unviable" } \\
\text { ( MAR's Head) }\end{array}$ \\
\hline & - Patent & 1 & 1 & 1 & $\begin{array}{l}\text { "... it is not worth to patent the results we have achieved [...] } \\
\text { results are very interesting but the process is relatively simple } \\
{[\ldots] \text { if a competitor started experimenting and arrived at the }} \\
\text { same results, we would be ready to invest immediately" (LF's } \\
\text { R\&D Manager) } \\
\text { “... it is not about patenting for the sake of patenting [...] you } \\
\text { can invent something totally new but totally useless" (MAR's } \\
\text { Head) }\end{array}$ \\
\hline & - Publications & 1 & 1 & 1 & $\begin{array}{l}\text { "... MAR never publishes results from ongoing projects. Now } \\
\text { that the project is finished, we start considering with the Lf if } \\
\text { we can published something [...] I will supervise the doctoral } \\
\text { dissertation of a employee of the LF's marketing staff" } \\
\text { (MAR's Head) }\end{array}$ \\
\hline 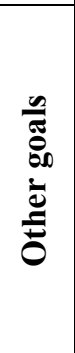 & $\begin{array}{l}\text { - New } \\
\text { collaborative } \\
\text { opportunities }\end{array}$ & 4 & 5 & 4.5 & $\begin{array}{l}\text { Both informants described other results that they perceived to } \\
\text { be mutual benefits coming from their collaboration under the } \\
\text { Acuisost Consortium, even though these results were not } \\
\text { directly related to their project under the Acuisost Consortium: } \\
\text { - New lines of research } \\
\text { - Creation of an university professorship in aquaculture } \\
\text { sponsored by the LF and managed by the MAR Head } \\
\text { - A collaboration agreement with the Spanish Ministry of }\end{array}$ \\
\hline
\end{tabular}




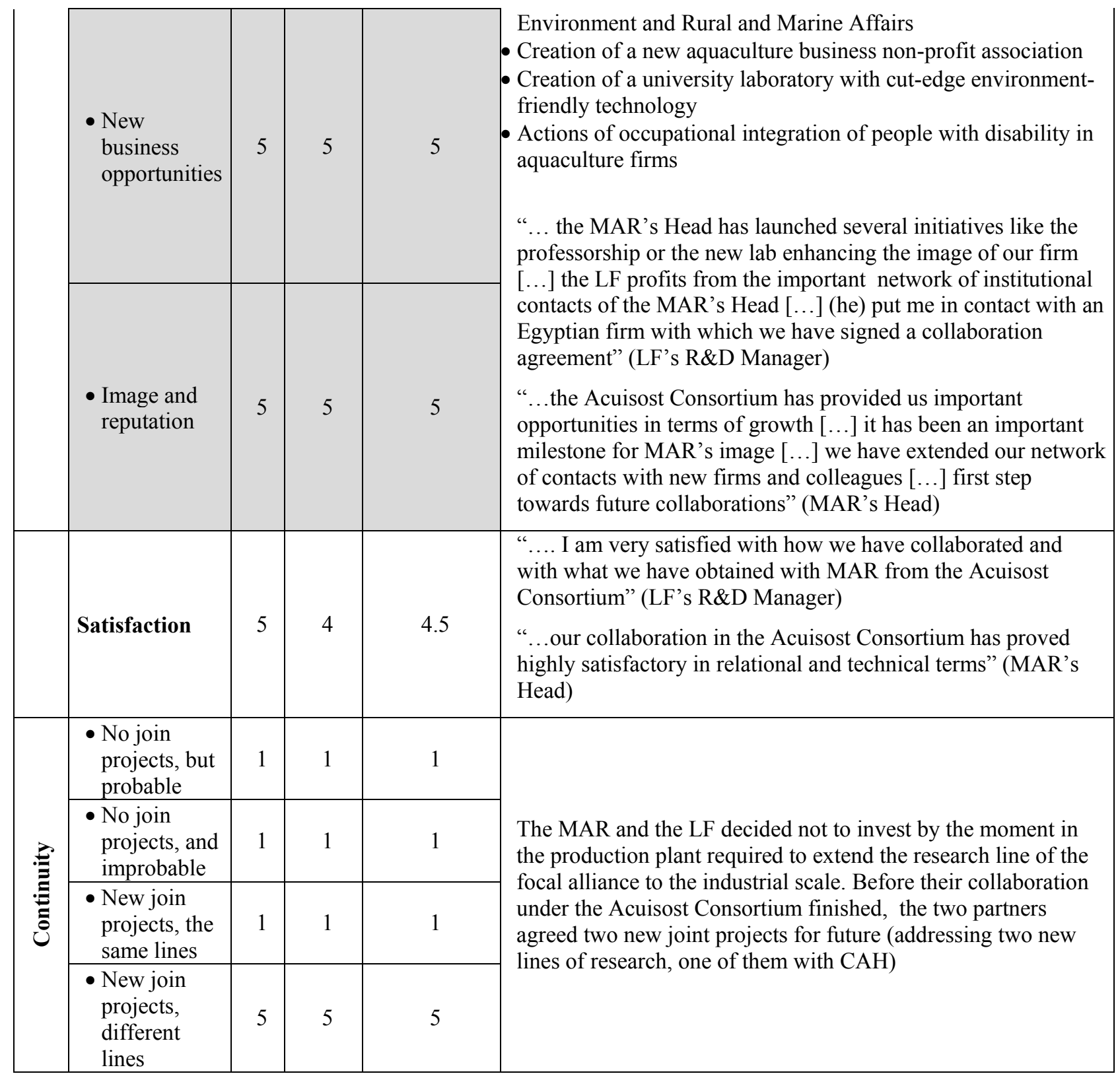

Notes: Highlighted in grey values for cross-case comparison. Percentage of agreement [calculated as $\%$ of (Rates of Informant ${ }_{\mathrm{LF}}=$ Rates of Informant ${ }_{\mathrm{MAR}}$ ) $/$ Total No. rates $]=75 \%$. Average disagreement

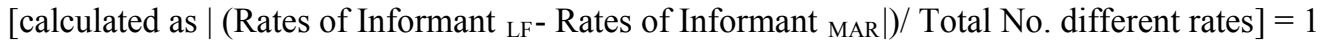





\section{References}

Adner, R. (2007). Real options and resource reallocation processes. Advances in Strategic Management, 24, 363-372.

Adner, R., \& Helfat, C. E. (2003). Corporate effects and dynamic managerial capabilities. Strategic Management Journal, 24(10), 1011-1025.

Adner, R., \& Levinthal, D. A. (2004). What is not a real option: Considering boundaries for the application of real options to business strategy. The Academy of Management Review, 29(1), 74-85.

Ahuja, G. (2000). The duality of collaboration: Inducements and opportunities in the formation of interfirm linkages. Strategic Management Journal, 21(3), 317-343.

Ambrosini, V., \& Bowman, C. (2009). What are dynamic capabilities and are they a useful construct in strategic management? International Journal of Management Reviews, 11(1), $29-49$.

Amit, R., \& Schoemaker, P. J. H. (1993). Strategic assets and organizational rent. Strategic Management Journal, 14(1), 33-46.

Anand, B. N., \& Khanna, T. (2000). Do firms learn to create value? the case of alliances. Strategic Management Journal, 21(3), 295-315.

Anand, J., Oriani, R., \& Vassolo, R. S. (2010). Alliance activity as a dynamic capability in the face of a discontinuous technological change. Organization Science, 21(6), 1213-1232.

Anand, J., \& Singh, H. (1997). Asset redeployment, acquisitions and corporate strategy in declining industries. Strategic Management Journal, 18(1), 99-118.

Anderson, J. C., \& Gerbing, D. W. (1988). Structural equation modeling in practice: A review and recommended two-step approach. Psychological Bulletin, 103(3), 411.

Anderson, J. C., \& Narus, J. A. (1990). A model of distributor firm and manufacturer firm working partnerships. The Journal of Marketing, 54(1), 42-58.

Arend, R. J., \& Bromiley, P. (2009). Assessing the dynamic capabilities view: Spare change, everyone? Strategic Organization, 7(1), 75-90.

Ariño, A. (2001). To do or not to do? Noncooperative behavior by commission and omission in interfirm ventures. Group \& Organization Management, 26(1), 4-23.

Ariño, A. (2003). Measures of strategic alliance performance: An analysis of construct validity. Journal of International Business Studies, 33(1), 1-14.

Ariño, A., \& De La Torre, J. (1998). Learning from failure: Towards an evolutionary model of collaborative ventures. Organization Science, 9(3), 306-325.

Ariño, A., \& Doz, Y. (2000). Rescuing troubled alliances... before it's too late. European Management Journal, 18(2), 173-182. 
Ariño, A., \& Ring, P. S. (2010). The role of fairness in alliance formation. Strategic Management Journal, 31(10), 1054-1087.

Axelrod, R. (1984). The evolution of cooperation. New York: Basic Books.

Baldwin, C., Hienerth, C., \& von Hippel, E. (2006). How user innovations become commercial products: A theoretical investigation and case study. Research Policy, 35(9), 1291-1313.

Barney, J. (1991). Firm resources and sustained competitive advantage. Journal of Management, 17(1), 99-120.

Barringer, B. R., \& Harrison, J. S. (2000). Walking a tightrope: Creating value through interorganizational relationships. Journal of Management, 26(3), 367-403.

Bayona, C., Garcia-Marco, T., \& Huerta, E. (2001). Firms' motivations for cooperative R\&D: An empirical analysis of spanish firms. Research Policy, 30(8), 1289-1307.

Becerra, M., Lunnan, R., \& Huemer, L. (2008). Trustworthiness, risk, and the transfer of tacit and explicit knowledge between alliance partners. Journal of Management Studies, 45(4), 691-713.

Becker, M. C. (2004). Organizational routines: A review of the literature. Industrial and Corporate Change, 13(4), 643.

Becker, M. C. (2005). A framework for applying organizational routines in empirical research: Linking antecedents, characteristics and performance outcomes of recurrent interaction patterns. Industrial and Corporate Change, 14(5), 817-846.

Becker, M. C., Lazaric, N., Nelson, R. R., \& Winter, S. G. (2005). Applying organizational routines in understanding organizational change. Industrial and Corporate Change, 14(5), $775-791$

Beckman, C. M., Haunschild, P. R., \& Phillips, D. J. (2004). Friends or strangers? firm-specific uncertainty, market uncertainty, and network partner selection. Organization Science, 15(3), 259-275.

Bell, J., Den Ouden, B., \& Ziggers, G. W. (2006). Dynamics of cooperation: At the brink of irrelevance. Journal of Management Studies, 43(7), 1607-1619.

Bercovitz, J. E. L., \& Feldman, M. P. (2007). Fishing upstream: Firm innovation strategy and university research alliances. Research Policy, 36(7), 930-948.

Blau, P. M. (1964). Exchange and power in social life. New York: Wiley.

Bonache, J. (1999). El estudio de casos como estrategia de construcción teórica: Características, críticas y defensas. Cuadernos De Economía y Dirección De La Empresa, (3), 123-140.

Boon, C. (2008). HRM and fit. survival of the fittest!? Doctoral dissertation. Rotterdam School of Management. Erasmus University.

Bowman, E. H., \& Hurry, D. (1993). Strategy through the option lens: An integrated view of resource investments and the incremental-choice process. Academy of Management Review, 18(4), 760-782. 
Bresser, R. K. F. (1988). Matching collective and competitive strategies. Strategic Management Journal, 9(4), 375-385.

Browning, L. D., Beyer, J. M., \& Shetler, J. C. (1995). Building cooperation in a competitive industry: SEMATECH and the semiconductor industry. Academy of Management Journal, 38(1), 113-151.

Bruni, D. S., \& Verona, G. (2009). Dynamic marketing capabilities in Science-based firms: An exploratory investigation of the pharmaceutical industry. British Journal of Management, 20(S1), S101-S117.

Bueno, E., Rodriguez Anton, J. M., \& Salmador, M. P. (2008). Knowledge creation as a dynamic capability: Implications for innovation management and organisational design. International Journal of Technology Management, 41(1), 155-168.

Camarero-Izquierdo, C., \& Gutiérrez-Cillán, J. (2004). The interaction of dependence and trust in long-term industrial relationships. European Journal of Marketing, 38(8), 974-994.

Camuffo, A., \& Volpato, G. (1996). Dynamic capabilities and manufacturing automation: Organizational learning in the Italian automobile industry. Industrial and Corporate Change, 5(3), 813-838.

Capaldo, A. (2007). Network structure and innovation: The leveraging of a dual network as a distinctive relational capability. Strategic Management Journal, 28(6), 585-608.

Capron, L., Dussauge, P., \& Mitchell, W. (1998). Resource redeployment following horizontal acquisitions in Europe and north America, 1988-1992. Strategic Management Journal, 19(7), 631-661.

Capron, L., \& Mitchell, W. (1998). Bilateral resource redeployment and capabilities improvement following horizontal acquisitions. Industrial and Corporate Change, 7(3), 453-484.

Cassimon, D., Engelen, P. J., Thomassen, L., \& Van Wouwe, M. (2004). The valuation of a NDA using a 6-fold compound option. Research Policy, 33(1), 41-51.

Cohen, M. D., \& Bacdayan, P. (1994). Organizational routines are stored as procedural memory: Evidence from a laboratory study. Organization Science, 5(4), 554-568.

Cohen, W. M., \& Levinthal, D. A. (1990). Absorptive capacity: A new perspective on learning and innovation. Administrative Science Quarterly, 35(1), 128-152.

Collis, D. J. (1994). Research note: How valuable are organizational capabilities? Strategic Management Journal, 15(S1), 143-152.

Colombo, M. G. (2003). Alliance form: A test of the contractual and competence perspectives. Strategic Management Journal, 24(12), 1209-1229.

Colquitt, J. A., \& Zapata-Phelan, C. P. (2007). Trends in theory building and theory testing: A five-decade study of the academy of management journal. Academy of Management Journal, 50(6), 1281-1303. 
Comino, S., Mariel, P., \& Sandonís, J. (2007). Joint ventures versus contractual agreements: An empirical investigation. Spanish Economic Review, 9(3), 159-175.

Contractor, F. J. (2005). Alliance structure and process: Will the two research streams ever meet in alliance research? European Management Review, 2(2), 123-129.

Contractor, F. J., \& Lorange, P. (1988). Cooperative strategies in international business: Joint ventures and technology partnerships between firms. New York: Pergamon.

Cropanzano, R., \& Mitchell, M. S. (2005). Social exchange theory: An interdisciplinary review. Journal of Management, 31(6), 874-900.

Cullen, J. B., Johnson, J. L., \& Sakano, T. (1995). Japanese and local partner commitment to IJVs: Psychological consequences of outcomes and investments in the IJV relationship. Journal of International Business Studies, 26(1), 91-115.

Cullen, J. B., Johnson, J. L., \& Sakano, T. (2000). Success through commitment and trust: The soft side of strategic alliance management. Journal of World Business, 35(3), 223-240.

Culpan, R. (2009). A fresh look at strategic alliances: Research issues and future directions. International Journal of Strategic Business Alliances, 1(1), 4-23.

Dacin, M. T., Oliver, C., \& Roy, J. P. (2007). The legitimacy of strategic alliances: An institutional perspective. Strategic Management Journal, 28(2), 169-187.

Daellenbach, U. S., \& Davenport, S. J. (2004). Establishing trust during the formation of technology alliances. The Journal of Technology Transfer, 29(2), 187-202.

Danneels, E. (2002). The dynamics of product innovation and firm competences. Strategic Management Journal, 23(12), 1095-1121.

Danneels, E. (2008). Organizational antecedents of second-order competences. Strategic Management Journal, 29(5), 519-543.

Darr, E. D., \& Kurtzberg, T. R. (2000). An investigation of partner similarity dimensions on knowledge transfer. Organizational Behavior and Human Decision Processes, 82(1), 2844.

Das, T. K., \& Kumar, R. (2010). Interpartner sensemaking in strategic alliances: Managing cultural differences and internal tensions. Management Decision, 48(1), 17-36.

Das, T. K., \& Teng, B. S. (1998a). Between trust and control: Developing confidence in partner cooperation in alliances. Academy of Management Review, 23(3), 491-512.

Das, T. K., \& Teng, B. S. (1998b). Resource and risk management in the strategic alliance making process. Journal of Management, 24(1), 21-42.

Das, T. K., \& Teng, B. S. (2000a). Instabilities of strategic alliances: An internal tensions perspective. Organization Science, 11(1), 77-101.

Das, T. K., \& Teng, B. S. (2000b). A resource-based theory of strategic alliances. Journal of Management, 26(1), 31-61. 
Das, T. K., \& Teng, B. S. (2002). Alliance constellations: A social exchange perspective. Academy of Management Review, 27(3), 445-456.

Das, T. K., \& Kumar, R. (2011). Regulatory focus and opportunism in the alliance development process. Journal of Management, 37(3), 682-708.

De Andrés-Alonso, P., Azofra-Palenzuela, V., \& De La Fuente-Herrero, G. (2006). The real options component of firm market value: The case of the technological corporation. Journal of Business Finance \& Accounting, 33(1-2), 203-219.

De Man, A. P., \& Duysters, G. (2005). Collaboration and innovation: A review of the effects of mergers, acquisitions and alliances on innovation. Technovation, 25(12), 1377-1387.

De Man, A. P., Duysters, G., \& Saebi, T. (2010). Alliance capability as an emergent theme: Past, present, future. In T. K. Das (Ed.), Researching strategic alliances (pp. 57-76). Charlotte, NC: Information Age Publishing Inc.

De Rond, M., \& Bouchikhi, H. (2004). On the dialectics of strategic alliances. Organization Science, 15(1), 56-69.

Deeds, D. L., DeCarolis, D., \& Coombs, J. (2000). Dynamic capabilities and new product development in high technology ventures: An empirical analysis of new biotechnology firms. Journal of Business Venturing, 15(3), 211-229.

Deeds, D. L., \& Rothaermel, F. T. (2003). Honeymoons and liabilities: The relationship between age and performance in research and development alliances. Journal of Product Innovation Management, 20(6), 468-484.

Dhanaraj, C., \& Parkhe, A. (2006). Orchestrating innovation networks. Academy of Management Review, 31(3), 659-679.

Di Stefano, G., Peteraf, M., \& Verona, G. (2010). Dynamic capabilities deconstructed: A bibliographic investigation into the origins, development, and future directions of the research domain. Industrial and Corporate Change, 19(4), 1187-1204.

DiMaggio, P. J., \& Powell, W. W. (1983). The iron cage revisited: Institutional isomorphism and collective rationality in organizational fields. American Sociological Review, 48(2), $147-160$.

Dosi, G., Nelson, R. R., \& Winter, S. G. (2000). The nature and dynamics of organizational capabilities Oxford University Press, USA.

Doz, Y. L. (1996). The evolution of cooperation in strategic alliances: Initial conditions or learning processes? Strategic Management Journal, 17(Summer special issue), 55-83.

Doz, Y. L., Olk, P. M., \& Ring, P. S. (2000). Formation processes of R\&D consortia: Which path to take? where does it lead? Strategic Management Journal, 21(3), 239-266.

Draulans, J., De Man, A. P., \& Volberda, H. W. (2003). Building alliance capability: Management techniques for superior alliance performance. Long Range Planning, 36(2), 151-166. 
Drnevich, P. L., \& Kriauciunas, A. P. (2011). Clarifying the conditions and limits of the contributions of ordinary and dynamic capabilities to relative firm performance. Strategic Management Journal, 32(3), 254-279.

Dutta, S., Narasimhan, O., \& Rajiv, S. (2005). Conceptualizing and measuring capabilities: Methodology and empirical application. Strategic Management Journal, 26(3), 277-285.

Dyer, J. H. (1997). Effective interim collaboration: How firms minimize transaction costs and maximise transaction value. Strategic Management Journal, 18(7), 535-556.

Dyer, J. H., \& Hatch, N. W. (2006). Relation-specific capabilities and barriers to knowledge transfers: Creating advantage through network relationships. Strategic Management Journal, 27(8), 701-719.

Dyer, J. H., \& Nobeoka, K. (2000). Creating and managing a high-performance knowledgesharing network: The toyota case. Strategic Management Journal, 21(3), 345-367.

Dyer, J. H., \& Singh, H. (1998). The relational view: Cooperative strategy and sources of interorganizational competitive advantage. Academy of Management Review, 23(4), 660679 .

Dyer, W. G., \& Wilkins, A. L. (1991). Better stories, not better constructs, to generate better theory: A rejoinder to Eisenhardt. The Academy of Management Review, 16(3), 613-619.

Easterby-Smith, M., Lyles, M. A., \& Peteraf, M. A. (2009). Dynamic capabilities: Current debates and future directions. British Journal of Management, 20(S1), S1-S8.

Easterby-Smith, M., \& Prieto, I. M. (2008). Dynamic capabilities and knowledge management: An integrative role for learning? British Journal of Management, 19(3), 235-249.

Edmondson, A. C., Bohmer, R. M., \& Pisano, G. P. (2001). Disrupted routines: Team learning and new technology implementation in hospitals. Administrative Science Quarterly, 46(4), 685-716.

Eisenhardt, K. M. (1989). Building theories from case study research. Academy of Management Review, 14(4), 532-550.

Eisenhardt, K. M. (1991). Better stories and better constructs: The case for rigor and comparative logic. Academy of Management Review, 16(3), 620-627.

Eisenhardt, K. M., \& Graebner, M. E. (2007). Theory building from cases: Opportunities and challenges. Academy of Management Journal, 50(1), 25-32.

Eisenhardt, K. M., \& Martin, J. A. (2000). Dynamic capabilities: What are they? Strategic Management Journal, 21(10-11), 1105-1121.

Eisenhardt, K. M., \& Schoonhoven, C. B. (1996). Resource-based view of strategic alliance formation: Strategic and social effects in entrepreneurial firms. Organization Science, $7(2)$, 136-150.

Eisner, A. B., Rahman, N., \& Korn, H. J. (2009). Formation conditions, innovation, and learning in R\&D consortia. Management Decision, 47(6), 851-871. 
Emden, Z., Yaprak, A., \& Cavusgil, S. T. (2005). Learning from experience in international alliances: Antecedents and firm performance implications. Journal of Business Research, 58(7), 883-892.

Escribá-Esteve, A. (2002). Procesos de generación de confianza en los acuerdos de cooperación: Una aproximación desde el comportamiento de las empresas participantes. Cuadernos De Economía y Dirección De La Empresa, (13), 469-498.

Escribá-Esteve, A., \& Urra-Urbieta, J. A. (2002). An analysis of co-operative agreements from a knowledge-based perspective: An integrative conceptual framework. Journal of Knowledge Management, 6(4), 330-346.

Estrada, I., de la Fuente, G., \& Martín-Cruz, N. (2010). Technological joint venture formation under the real options approach. Research Policy, 39(9), 1185-1197.

Evan, W. M., \& Olk, P. (1990). R\&D consortia: A new US organizational form. Sloan Management Review, 31(3), 37-46.

Faems, D. (2006). Collaboration for innovation: Processes of governance and learning in R\&D alliances. Doctoral dissertation. Katholieke Universiteit Leuven.

Faems, D., Janssens, M., Madhok, A., \& Van Looy, B. (2008). Toward an integrative perspective on alliance governance: Connecting contract design, trust dynamics, and contract application. Academy of Management Journal, 51(6), 1053-1078.

Faems, D., Janssens, M., \& Van Looy, B. (2007). The initiation and evolution of interfirm knowledge transfer in R\&D relationships. Organization Studies, 28(11), 1699-1728.

Faems, D., \& Madhok, A. (2009). Transitional governance: A critical review of implicit process assumptions. In S. Finkelstein, \& C. Cooper (Eds.), Advances and mergers and acquisitions (pp. 61-78) Emerald Group Publishing Limited.

Feldman, M. S. (2000). Organizational routines as a source of continuous change. Organization Science, 11(6), 611-629.

Feldman, M. S., \& Pentland, B. T. (2003). Reconceptualizing organizational routines as a source of flexibility and change. Administrative Science Quarterly, 48(1), 94-121.

Feldman, M. S., \& Rafaeli, A. (2002). Organizational routines as sources of connections and understandings. Journal of Management Studies, 39(3), 309-331.

Fichman, M., \& Levinthal, D. A. (1991). Honeymoons and the liability of adolescence: A new perspective on duration dependence in social and organizational relationships. Academy of Management Review, 16(2), 442-468.

Filippini, R., Güttel, W. H., \& Nosella, A. (2011). Ambidexterity and the evolution of knowledge management initiatives. Journal of Business Research, 65(3), 317-324.

Fiss, P. C. (2007). A set-theoretic approach to organizational configurations. The Academy of Management Review, 32(4), 1180-1198.

Folta, T. B. (1998). Governance and uncertainty: The tradeoff between administrative control and commitment. Strategic Management Journal, 19(11), 1007-1028. 
Folta, T. B., \& Miller, K. D. (2002). Real options in equity partnerships. Strategic Management Journal, 23(1), 77-88.

Fornell, C., \& Larcker, D. F. (1981). Evaluating structural equation models with unobservable variables and measurement error. Journal of Marketing Research, 18(1), 39-50.

Forrest, J. E., \& Martin, M. J. C. (1992). Strategic alliances between large and small research intensive organizations: Experiences in the biotechnology industry. R\&D Management, 22(1), 41-54.

Fritsch, M., \& Lukas, R. (2001). Who cooperates on R\&D? Research Policy, 30(2), 297-312.

Fuentelsaz, L., \& Gómez, J. (2006). Multipoint competition, strategic similarity and entry into geographic markets. Strategic Management Journal, 27(5), 477-499.

Fuller, M. B., \& Porter, M. E. (1986). Coalitions and global strategy. In M. E. Porter (Ed.), Competition in global industries (pp. 315-343). Boston: Harvard Business School Press.

Galende-del-Canto, J., \& Suárez-González, I. (1999). A resource-based analysis of the factors determining a firm's R\&D activities. Research Policy, 28(8), 891-905.

Galunic, D. C., \& Eisenhardt, K. M. (2001). Architectural innovation and modular corporate forms. Academy of Management Journal, 18(1), 1229-1249.

García Falcón, J. M., \& Medina Muñoz, D. R. (1998). Enfoques teóricos sobre las relaciones interorganizativas: Una revisión comparativa. Revista Europea De Dirección y Economía De La Empresa, 7(3), 31-52.

García Muina, F. E., Martin De Castro, G., López Saez, P., \& Navas López, J. E. (2006). The complexity in technological capabilities: Evidence from biotechnological Spanish firms. International Journal of Technology Management, 35(1), 224-240.

García-Canal, E. (1996). Contractual form in domestic and international strategic alliances. Organization Studies, 17(5), 773-794.

García-Canal, E. (1999). Cooperative agreements in Spain after its integration into the European union. European Business Review, 99(2), 105-114.

García-Canal, E., Valdés-Llaneza, A., \& Ariño, A. (2003). Effectiveness of dyadic and multiparty joint ventures. Organization Studies, 24(5), 743-770.

García-Canal, E., Valdés-Llaneza, A., \& Sánchez-Lorda, P. (2008). Technological flows and choice of joint ventures in technology alliances. Research Policy, 37(1), 97-114.

Gavetti, G. (2005). Cognition and hierarchy: Rethinking the microfoundations of capabilities' development. Organization Science, 16(6), 599-617.

Gephart, R. (2004). From the editors: Qualitative research and the academy management journal. Academy of Management Journal, 47(4), 454-462.

Geringer, J. M. (1991). Strategic determinants of partner selection criteria in international joint ventures. Journal of International Business Studies, 22(1), 41-62. 
Geringer, J. M., \& Hebert, L. (1991). Measuring performance of international joint ventures. Journal of International Business Studies, 22(2), 249-263.

Gibbert, M., Ruigrok, W., \& Wicki, B. (2008). What passes as a rigorous case study? Strategic Management Journal, 29(13), 1465-1474.

Gilbert, C. G. (2006). Change in the presence of residual fit: Can competing frames coexist? Organization Science, 17(1), 150-167.

Gioia, D. A., \& Chittipeddi, K. (1991). Sensemaking and sensegiving in strategic change initiation. Strategic Management Journal, 12(6), 433-448.

Glaister, K. W., \& Buckley, P. J. (1998). Measures of performance in UK international alliances. Organization Studies, 19(1), 89-118.

Goerzen, A. (2007). Alliance networks and firm performance: The impact of repeated partnerships. Strategic Management Journal, 28(5), 487-509.

Gogan, J. L., Gelinas Jr, U. J., \& Rao, A. (2007). Learning in a consortium: A longitudinal case study. International Journal of Technology Management, 38(1), 90-112.

Gomes-Casseres, B. (2003). Competitive advantage in alliance constellations. Strategic Organization, 1(3), 327-335.

Gong, Y., Shenkar, O., Luo, Y., \& Nyaw, M. K. (2007). Do multiple parents help or hinder international joint venture performance? the mediating roles of contract completeness and partner cooperation. Strategic Management Journal, 28(10), 1021-1034.

González-Benito, J., Suárez-González, I., \& Spring, M. (2000). Complementarities between JIT purchasing practices: An economic analysis based on transaction costs. International Journal of Production Economics, 67(3), 279-293.

Grandori, A., \& Soda, G. (1995). Inter-firm networks: Antecedents, mechanisms and forms. Organization Studies, 16(2), 183-214.

Granovetter, M. S. (1973). The strength of weak ties. American Journal of Sociology, 78(6), 1360-1380.

Granovetter, M. S. (1985). Economic action and social structure: The problem of embeddedness. American Journal of Sociology, 91(3), 481-510.

Grant, R. M. (1996). Toward a knowledge-based theory of the firm. Strategic Management Journal, 17(Winter Special Issue), 109-122.

Grant, R. M., \& Baden-Fuller, C. (2004). A knowledge accessing theory of strategic alliances. Journal of Management Studies, 41(1), 61-84.

Gray, B., \& Wood, D. J. (1991). Collaborative alliances: Moving from practice to theory. The Journal of Applied Behavioral Science, 27(1), 3-22.

Gulati, R. (1995). Does familiarity breed trust? the implications of repeated ties for contractual choice in alliances. Academy of Management Journal, 38(1), 85-112. 
Gulati, R. (1998). Alliances and networks. Strategic Management Journal, 19(4), 293-317.

Gulati, R. (1999). Network location and learning: The influence of network resources and firm capabilities on alliance formation. Strategic Management Journal, 20(5), 397-420.

Gulati, R., \& Gargiulo, M. (1999). Where do interorganizational networks come from? American Journal of Sociology, 104(5), 1398-1438.

Gulati, R., Lavie, D., \& Singh, H. (2009). The nature of partnering experience and the gains from alliances. Strategic Management Journal, 30(11), 1213-1233.

Gulati, R., Nohria, N., \& Zaheer, A. (2000). Strategic networks. Strategic Management Journal, 21(3), 203-215.

Gulati, R., \& Singh, H. (1998). The architecture of cooperation: Managing coordination costs and appropriation concerns in strategic alliances. Administrative Science Quarterly, 43(4), $781-784$

Gupta, A. K., Smith, K. G., \& Shalley, C. E. (2006). The interplay between exploration and exploitation. Academy of Management Journal, 49(4), 693-706.

Habbershon, T. G., \& Williams, M. L. (1999). A resource-based framework for assessing the strategic advantages of family firms. Family Business Review, 12(1), 1-25.

Hagedoorn, J. (1993). Understanding the rationale of strategic technology partnering: Interorganizational modes of cooperation and sectoral differences. Strategic Management Journal, 14(5), 371-385.

Hagedoorn, J. (2002). Inter-firm R\&D partnerships: An overview of major trends and patterns since 1960. Research Policy, 31(4), 477-492.

Hagedoorn, J. (2006). Understanding the cross-level embeddedness of interfirm partnership formation. Academy of Management Review, 31(3), 670-680.

Hagedoorn, J., Link, A. N., \& Vonortas, N. S. (2000). Research partnerships1. Research Policy, 29(4-5), 567-586.

Hamel, G. (1991). Competition for competence and interpartner learning within international strategic alliances. Strategic Management Journal, 12(Special issue on global strategy), 83-103.

Hartmann, M., \& Hassan, A. (2006). Application of real options analysis for pharmaceutical R\&D project valuation: Empirical results from a survey. Research Policy, 35(3), 343-354.

Hatfield, L., Pearce, J. A., Sleeth, R. G., \& Pitts, M. W. (1998). Toward validation of partner goal achievement as a measure of joint venture performance. Journal of Managerial Issues, 10(3), 355-372.

Heide, J. B., \& John, G. (1992). Do norms matter in marketing relationships? The Journal of Marketing, 56(2), 32-44.

Heidl, R. (2010). The stability of multi-partner alliances: A resource dependence and social embeddedness perspective. Doctoral dissertation. University of Washington. 
Heimeriks, K. H., \& Duysters, G. (2007). Alliance capability as a mediator between experience and alliance performance: An empirical investigation into the alliance capability development process. Journal of Management Studies, 44(1), 25-49.

Helfat, C. E. (1997). Know-how and asset complementarity and dynamic capability accumulation: The case of R\&D. Strategic Management Journal, 18(5), 339-360.

Helfat, C. E., Finkelstein, S., \& Mitchell, W. (2007). Dynamic capabilities: Understanding strategic change in organizations Wiley-Blackwell.

Helfat, C. E., \& Peteraf, M. A. (2003). The dynamic resource-based view: Capability lifecycles. Strategic Management Journal, 24(10), 997-1010.

Hennart, J. F. (1988). A transaction costs theory of equity joint ventures. Strategic Management Journal, 9(4), 361-374.

Hennart, J. F. (2006). Alliance research: Less is more. Journal of Management Studies, 43(7), $1621-1628$.

Hennart, J. F., \& Reddy, S. (1997). The choice between mergers/acquisitions and joint ventures: The case of japanese investors in the united states. Strategic Management Journal, 18(1), $1-12$.

Herrera, L., \& Nieto, M. (2008). The national innovation policy effect according to firm location. Technovation, 28(8), 540-550.

Hill, J. A., Eckerd, S., Wilson, D., \& Greer, B. (2009). The effect of unethical behavior on trust in a buyer-supplier relationship: The mediating role of psychological contract violation. Journal of Operations Management, 27(4), 281-293.

Hoang, H., \& Rothaermel, F. T. (2005). The effect of general and partner-specific alliance experience on joint R\&D project performance. Academy of Management Journal, 48(2), $332-345$.

Hoang, H., \& Rothaermel, F. T. (2010). Leveraging internal and external experience: Exploration, exploitation, and R\&D project performance. Strategic Management Journal, 31(7), 734-758.

Hoffmann, W. H. (2007). Strategies for managing a portfolio of alliances. Strategic Management Journal, 28(8), 827-856.

Hwang, P., \& Burgers, W. P. (1997). The many faces of multi-firm alliances: Lessons for managers. California Management Review, 39(3), 101-117.

Inkpen, A. C. (1998). Learning and knowledge acquisition through international strategic alliances. Academy of Management Executive, 12(4), 69-80.

Inkpen, A. C., \& Beamish, P. W. (1997). Knowledge, bargaining power, and the instability of international joint ventures. Academy of Management Review, 22(1), 177-202.

Inkpen, A. C., \& Currall, S. C. (2004). The coevolution of trust, control, and learning in joint ventures. Organization Science, 15(5), 586-599. 
Ireland, R. D., Hitt, M. A., \& Vaidyanath, D. (2002). Alliance management as a source of competitive advantage. Journal of Management, 28(3), 413-446.

Jacobsen, S. F., \& Tschoegl, A. E. (1999). The Norwegian banks in the Nordic consortia: A case of international strategic alliances in banking. Industrial and Corporate Change, 8(1), 137.

Jensen, M. C., \& Meckling, W. H. (1976). Theory of the firm: Managerial behavior, agency costs and ownership structure. Journal of Financial Economics, 3(4), 305-360.

Kale, P. (1999). Alliance capability and success: A knowledge-based approach. Doctoral dissertation. University of Pennylvania.

Kale, P., Dyer, J. H., \& Singh, H. (2002). Alliance capability, stock market response, and longterm alliance success: The role of the alliance function. Strategic Management Journal, 23(8), 747-767.

Kale, P., \& Singh, H. (2007). Building firm capabilities through learning: The role of the alliance learning process in alliance capability and firm-level alliance success. Strategic Management Journal, 28(10), 981-1000.

Kale, P., \& Singh, H. (2009). Managing strategic alliances: What do we know now, and where do we go from here? Academy of Management Perspectives, 23(3), 45-62.

Kale, P., Singh, H., \& Perlmutter, H. (2000). Learning and protection of proprietary assets in strategic alliances: Building relational capital. Strategic Management Journal, 21(3), 217237.

Kanter, R. M. (1994). Collaborative advantage: The art of alliances. Harvard Business Review, 72(4), 96-108.

Kaulio, M. A., \& Uppvall, L. (2009). Critical incidents in RD alliances: Uncovering leadership roles. European Management Review, 6(3), 195-205.

Khanna, T., Gulati, R., \& Nohria, N. (1998). The dynamics of learning alliances: Competition, cooperation, and relative scope. Strategic Management Journal, 19(3), 193-210.

Kim, C. S., \& Inkpen, A. C. (2005). Cross-border R\&D alliances, absorptive capacity and technology learning. Journal of International Management, 11(3), 313-329.

King, A. A., \& Tucci, C. L. (2002). Incumbent entry into new market niches: The role of experience and managerial choice in the creation of dynamic capabilities. Management Science, 48(2), 171-186.

Kogut, B. (1988). Joint ventures: Theoretical and empirical perspectives. Strategic Management Journal, 9(4), 319-332.

Kogut, B. (1991). Joint ventures and the option to expand and acquire. Management Science, 37(1), 19-33.

Kogut, B., \& Kulatilaka, N. (1994). Options thinking and platform investments: Investing in opportunity. California Management Review, 36(2), 52-71. 
Kogut, B., \& Kulatilaka, N. (2001). Capabilities as real options. Organization Science, 12(6), 744-758.

Kogut, B., \& Zander, U. (1996). What firms do? coordination, identity, and learning. Organization Science, 7(5), 502-518.

Koza, M. P., \& Lewin, A. Y. (1998). The co-evolution of strategic alliances. Organization Science, 9(3), 255-264.

Kumar, M. V. (2011). Are joint ventures positive sum games? the relative effects of cooperative and noncooperative behavior. Strategic Management Journal, 32(1), 32-54.

Kumar, R., \& Nti, K. O. (1998). Differential learning and interaction in alliance dynamics: A process and outcome discrepancy model. Organization Science, 9(3), 356-367.

Kumar, R., \& Nti, K. O. (2004). National cultural values and the evolution of process and outcome discrepancies in international strategic alliances. The Journal of Applied Behavioral Science, 40(3), 344-361.

Kumar, S. (2010). The causes of joint venture termination: A real options perspective. In T. K. Das (Ed.), Researching strategic alliances (pp. 155-180). Charlotte, NC: Information Age Publishing Inc.

Kumar, S., \& Seth, A. (1998). The design of coordination and control mechanisms for managing joint venture-parent relationships. Strategic Management Journal, 19(6), 579599.

Lacetera, N. (2009). Different missions and commitment power in R\&D organizations: Theory and evidence on industry-university alliances. Organization Science, 20(3), 565-582.

Lado, A. A., Boyd, N. G., \& Hanlon, S. C. (1997). Competition, cooperation, and the search for economic rents: A syncretic model. The Academy of Management Review, 22(1), 110-141.

Lado, A. A., Dant, R. R., \& Tekleab, A. G. (2008). Trust-opportunism paradox, relationalism, and performance in interfirm relationships: Evidence from the retail industry. Strategic Management Journal, 29(4), 401-423.

Lane, P. J., \& Lubatkin, M. (1998). Relative absorptive capacity and interorganizational learning. Strategic Management Journal, 19(5), 461-477.

Langley, A. (1999). Strategies for theorizing from process data. Academy of Management Review, 24(4), 691-710.

Larsson, R. (1993). Case survey methodology: Quantitative analysis of patterns across case studies. Academy of Management Journal, 36(6), 1515-1546.

Larsson, R., Bengtsson, L., Henriksson, K., \& Sparks, J. (1998). The interorganizational learning dilemma: Collective knowledge development in strategic alliances. Organization Science, 9(3), 285-305.

Laursen, K., \& Salter, A. (2006). Open for innovation: The role of openness in explaining innovation performance among UK manufacturing firms. Strategic Management Journal, 27(2), 131-150. 
Lavie, D. (2006). The competitive advantage of interconnected firms: An extension of the resource-based view. Academy of Management Review, 31(3), 638-658.

Lavie, D. (2007). Alliance portfolios and firm performance: A study of value creation and appropriation in the US software industry. Strategic Management Journal, 28(12), 11871212.

Lavie, D., Lechner, C., \& Singh, H. (2007). The performance implications of timing of entry and involvement in multi-partner alliances. Academy of Management Journal, 50(3), 578604.

Lavie, D., \& Rosenkopf, L. (2006). Balancing exploration and exploitation in alliance formation. The Academy of Management Journal, 49(4), 797-818.

Lazzarini, S. G. (2007). The impact of membership in competing alliance constellations: Evidence on the operational performance of global airlines. Strategic Management Journal, 28(4), 345-367.

Leonard-Barton, D. (1990). A dual methodology for case studies: Synergistic use of a longitudinal single site with replicated multiple sites. Organization Science, 1(3), 248-266.

Levinthal, D. A., \& March, J. G. (1993). The myopia of learning. Strategic Management Journal, 14(Special issue on Organizations, Decision Making and Strategy), 95-112.

Li, D., Eden, L., Hitt, M. A., \& Ireland, R. D. (2008). Friends, acquaintances, or strangers? partner selection in R\&D alliances. Academy of Management Journal, 51(2), 315-334.

Li, J. J., Poppo, L., \& Zhou, K. Z. (2010). Relational mechanisms, formal contracts, and local knowledge acquisition by international subsidiaries. Strategic Management Journal, 31(4), 349-370.

Loohuis, R. P. A., \& Groen, A. J. (2011). Towards a multidimensional view on collaborative processess. A case study on a international alliance formation. The changing paradigm of consulting: Adjusting to the fast-paced world (pp. 157-184). USA: Information Age Publishing, Inc.

Lubatkin, M., Florin, J., \& Lane, P. (2001). Learning together and apart: A model of reciprocal interfirm learning. Human Relations, 54(10), 1353-1382.

Lumineau, F., \& Fréchet, M. (2008). Managing discrepancies between formal and psychological sides of alliance contracting. Paper presented at Academy of Management Annual Meeting.

Lunnan, R., \& Barth, T. (2003). Managing the exploration vs. exploitation dilemma in transnational. Journal of World Business, 38(2), 110-126.

Lunnan, R., \& Haugland, S. A. (2008). Predicting and measuring alliance performance: A multidimensional analysis. Strategic Management Journal, 29(5), 545-556.

Luo, Y. (2008a). Procedural fairness and interfirm cooperation in strategic alliances. Strategic Management Journal, 29(1), 27-46.

Luo, Y. (2008b). Structuring interorganizational cooperation: The role of economic integration in strategic alliances. Strategic Management Journal, 29(6), 617-637. 
Lusch, R. F., \& Brown, J. R. (1996). Interdependency, contracting, and relational behavior in marketing channels. Journal of Marketing, 60(4), 19-38.

Macmillan, I. C. (1989). Delineating a forum for business policy scholars. Strategic Management Journal, 10(4), 391-395.

Madhok, A. (1995). Opportunism and trust in joint venture relationships: An exploratory study and a model. Scandinavian Journal of Management, 11(1), 57-74.

Madhok, A. (1996). The organization of economic activity: Transaction costs, firm capabilities, and the nature of governance. Organization Science, 7(5), 577-590.

Madhok, A. (2002). Reassessing the fundamentals and beyond: Ronald Coase, the transaction cost and resource-based theories of the firm and the institutional structure of production. Strategic Management Journal, 23(6), 535-550.

Madhok, A., \& Tallman, S. B. (1998). Resources, transactions and rents: Managing value through interfirm collaborative relationships. Organization Science, 9(3), 326-339.

Mahnke, V., \& Overby, M. L. (2008). Failure sources in R\&D consortia: The case of mobile service development. International Journal of Technology Management, 44(1), 160-178.

Makadok, R. (2001). Toward a synthesis of the resource-based and dynamic-capability views of rent creation. Strategic Management Journal, 22(5), 387-401.

March, J. G. (1991). Exploration and exploitation in organizational learning. Organization Science, 2(1), 71-87.

Martín-de-Castro, G., Navas-López, J. E., \& López-Sáez, P. (2006a). Business and social reputation: Exploring the concept and main dimensions of corporate reputation. Journal of Business Ethics, 63(4), 361-370.

Martín-de-Castro, G., Navas-López, J. E., López-Sáez, P., \& Alama-Salazar, E. (2006b). Organizational capital as competitive advantage of the firm. Journal of Intellectual Capital, 7(3), 324-337.

Martín-de-Castro, G., Navas-López, J. E., López-Sáez, P., \& Delgado-Verde, M. (2009). La reputación corporativa y las alianzas en el contexto de las industrias emergentes. Revista Europea De Dirección y Economía De La Empresa, 18(4), 139-154.

Mathews, J. A. (2002). The origins and dynamics of Taiwan's R\&D consortia. Research Policy, $31(4), 633-651$.

McCarter, M. W., Mahoney, J. T., \& Northcraft, G. B. (2011). Testing the waters: Using collective real options to manage the social dilemma of strategic alliances. Academy of Management Review, 36(4), 621-640.

McGrath, R., \& Nerkar, A. (2004). Real options reasoning and a new look at the R\&D investment strategies of pharmaceutical firms. Strategic Management Journal, 25(1), 1-21.

McGrath, R. G. (1997). A real options logic for initiating technology positioning investments. Academy of Management Review, 22(4), 974-996. 
McGrath, R. G., Ferrier, W. J., \& Mendelow, A. L. (2004). Real options as engines of choice and heterogeneity. The Academy of Management Review, 29(1), 86-101.

McKelvie, A., \& Davidsson, P. (2009). From resource base to dynamic capabilities: An investigation of new firms. British Journal of Management, 20(S1), S63-S80.

Mesquita, L. F., Anand, J., \& Brush, T. H. (2008). Comparing the resource-based and relational views: Knowledge transfer and spillover in vertical alliances. Strategic Management Journal, 29(9), 913-941.

Mohr, J., \& Spekman, R. (1994). Characteristics of partnership success: Partnership attributes, communication behavior, and conflict resolution techniques. Strategic Management Journal, 15(2), 135-152.

Molina, J., Dyer, J. H., \& Singh, H. (1999). On the relational view/response to relational view commentary. Academy of Management Review, 24(2), 184-186.

Montoro-Sánchez, M. Á. (2005). La cooperación internacional en investigación y desarrollo. Revista De Economía Aplicada, 13(39), 21-46.

Montoro-Sánchez, M. Á., \& Guerras-Martín, L. A. (2004). La coordinación en los acuerdos de cooperación empresarial: Un análisis empírico basado en el modelo de procesamiento de información. Cuadernos De Economía y Dirección De La Empresa, (19), 55-80.

Montoro-Sánchez, M. Á., Mora-Valentin, E. M., \& Guerras-Martín, L. A. (2006). R\&D cooperative agreements between firms and research organisations: A comparative analysis of the characteristics and reasons depending on the nature of the partner. International Journal of Technology Management, 35(1), 156-181.

Montoro-Sánchez, M. Á., Ortiz-de-Urbina-Criado, M., \& Romero-Martínez, A. M. (2009). The decision to use alliances as corporate entrepreneurship: The role of resources and skills. Group Decision and Negotiation, 18(5), 431-448.

Moran, P. (2005). Structural vs. relational embeddedness: Social capital and managerial performance. Strategic Management Journal, 26(12), 1129-1151.

Mora-Valentín, E. M., Montoro-Sánchez, M. Á., \& Guerras-Martín, L. A. (2004). Determining factors in the success of R\&D cooperative agreements between firms and research organizations. Research Policy, 33(1), 17-40.

Morrison, E. W., \& Robinson, S. L. (1997). When employees feel betrayed: A model of how psychological contract violation develops. Academy of Management Review, 22(1), 226256.

Morrison, E. W., \& Robinson, S. L. (2004). The employment relationship from two sides: Incongruence in employees' and employers' perceptions of obligations. In J. A. M. CoyleShapiro, L. M. Shore, M. S. Taylor \& L. E. Tetrick (Eds.), The employment relationship: Examining psychological and contextual perspectives (pp. 161). Oxford, U.K.: Oxford University Press.

Mosakowski, E., \& Earley, P. C. (2000). A selective review of time assumptions in strategy research. Academy of Management Review, 25(4), 796-812. 
Mothe, C., \& Quelin, B. V. (2001). Resource creation and partnership in R\&D consortia. The Journal of High Technology Management Research, 12(1), 113-138.

Mowery, D. C., Oxley, J. E., \& Silverman, B. S. (1996). Strategic alliances and interfirm knowledge transfer. Strategic Management Journal, 17(Special issue: Knowledge and the Firm), 77-91.

Murray, E. A., \& Mahon, J. F. (1993). Strategic alliances: Gateway to the new Europe? Long Range Planning, 26(4), 102-111.

Muthusamy, S. K., \& White, M. A. (2005). Learning and knowledge transfer in strategic alliances: A social exchange view. Organization Studies, 26(3), 415-441.

Myers, S. C. (1984). Finance theory and financial strategy. Interfaces, January- February, 126137.

Nadkarni, S., \& Barr, P. S. (2008). Environmental context, managerial cognition, and strategic action: An integrated view. Strategic Management Journal, 29(13), 1395-1427.

Nahapiet, J., \& Ghoshal, S. (1998). Social capital, intellectual capital, and the organizational advantage. Academy of Management Review, 23(2), 242-266.

Nakamura, M., Nelson, H., \& Vertinsky, I. (2003). Cooperative R\&D and the canadian forest products industry. Managerial and Decision Economics, 24(2-3), 147-169.

Nelson, R. R., \& Winter, S. G. (1982). An evolutionary theory of economic change. Cambridge: Belknap Press.

Newbert, S. L. (2005). New firm formation: A dynamic capability perspective. Journal of Small Business Management, 43(1), 55-77.

Nicholson, N., \& Johns, G. (1985). The absence culture and the psychological contract-who's in control of absence? Academy of Management Review, 10(3), 397-407.

Nielsen, B. B. (2010). Multilevel issues in strategic alliance research. In T. K. Das (Ed.), Researching strategic alliances (pp. 57-76). Charlotte, NC: Information Age Publishing Inc.

Nieto, M. (2004). Basic propositions for the study of the technological innovation process in the firm. European Journal of Innovation Management, 7(4), 314-324.

Nieto, M., \& Pérez, W. (2000). The development of theories from the analysis of the organisation: Case studies by the patterns of behaviour. Management Decision, 38(10), 723-734.

Nieto, M., \& Quevedo, P. (2005). Absorptive capacity, technological opportunity, knowledge spillovers, and innovative effort. Technovation, 25(10), 1141-1157.

Nonaka, I., \& Takeuchi, H. (1995). The knowledge-creating company: How Japanese companies create the dynamics of innovation. New York: Oxford University Press.

Oliver, C. (1991). Strategic responses to institutional processes. The Academy of Management Review, 16(1), 145-179. 
Olk, P., \& Young, C. (1997). Why members stay in or leave an R\&D consortium: Performance and conditions of membership as determinants of continuity. Strategic Management Journal, 18(11), 855-877.

Ouchi, W. G., \& Bolton, M. K. (1988). The logic of joint research and development. California Management Review, 30(3), 9-33.

Oxley, J. E. (1997). Appropriability hazards and governance in strategic alliances: A transaction cost approach. Journal of Law, Economics, and Organization, 13(2), 387.

Oxley, J. E., \& Sampson, R. C. (2004). The scope and governance of international R\&D alliances. Strategic Management Journal, 25(8-9), 723-749.

Parent, M. M., \& Deephouse, D. L. (2007). A case study of stakeholder identification and prioritization by managers. Journal of Business Ethics, 75(1), 1-23.

Park, S. H., \& Russo, M. V. (1996). When competition eclipses cooperation: An event history analysis of joint venture failure. Management Science, 42(6), 875-890.

Park, S. H., \& Ungson, G. R. (2001). Interfirm rivalry and managerial complexity: A conceptual framework of alliance failure. Organization Science, 12(1), 37-53.

Parkhe, A. (1991). Interfirm diversity, organizational learning, and longevity in global strategic alliances. Journal of International Business Studies, 22(4), 579-601.

Parkhe, A. (1993). Strategic alliance structuring: A game theoretic and transaction cost examination of interfirm cooperation. Academy of Management Journal, 36(4), 794-829.

Patton, M. Q. (2002). Qualitative research and evaluation methods. Thousand Oaks, CA.: Sage Publications.

Pentland, B. T. (1999). Building process theory with narrative: From description to explanation. Academy of Management Review, 24(4), 711-724.

Pentland, B. T., \& Feldman, M. S. (2005). Organizational routines as a unit of analysis. Industrial and Corporate Change, 14(5), 793-815.

Pentland, B. T., \& Rueter, H. H. (1994). Organizational routines as grammars of action. Administrative Science Quarterly, 39(3), 484-510.

Pérez-Luño, A., Valle Cabrera, R., \& Wiklund, J. (2009). De la creatividad al lanzamiento de productos. Cuadernos De Economía y Dirección De La Empresa, (38), 95.

Pérez-Nordtvedt, L., Kedia, B. L., Datta, D. K., \& Rasheed, A. A. (2008). Effectiveness and efficiency of Cross-Border knowledge transfer: An empirical examination. Journal of Management Studies, 45(4), 714-744.

Peteraf, M. A. (1993). The cornerstones of competitive advantage: A resource-based view. Strategic Management Journal, 14(3), 179-191.

Petroni, A. (1998). The analysis of dynamic capabilities in a competence-oriented organization. Technovation, 18(3), 179-189. 
Pettigrew, A. M. (1990). Longitudinal field research on change: Theory and practice. Organization Science, 1(3), 267-292.

Pfeffer, J., \& Salancik, G. R. (1978). The external control of organizations. New York: Harper \& Row.

Phelps, C. C. (2010). A longitudinal study of the influence of alliance network structure and composition on firm exploratory innovation. Academy of Management Journal, 53(4), 890913.

Pisano, G. P. (2000). In search of dynamic capabilities: The origins of R\&D competence in biopharmaceuticals. In G. Dosi, R. R. Nelson \& S. G. Winter (Eds.), The nature and dynamics of organizational capabilities (pp. 127-129) Oxford University Press.

Podsakoff, P. M., MacKenzie, S. B., Lee, J. Y., \& Podsakoff, N. P. (2003). Common method biases in behavioral research: A critical review of the literature and recommended remedies. Journal of Applied Psychology, 88(5), 879-903.

Poppo, L., \& Zenger, T. (2002). Do formal contracts and relational governance function as substitutes or complements? Strategic Management Journal, 23(8), 707-725.

Poppo, L., Zhou, K. Z., \& Ryu, S. (2008). Alternative origins to interorganizational trust: An interdependence perspective on the shadow of the past and the shadow of the future. Organization Science, 19(1), 39-55.

Powell, W. W., Koput, K. W., \& Smith-Doerr, L. (1996). Interorganizational collaboration and the locus of innovation: Networks of learning in biotechnology. Administrative Science Quarterly, 41(1), 116-145.

Priem, R. L., \& Butler, J. E. (2001). Is the resource-based" view" a useful perspective for strategic management research? Academy of Management Review, 26(1), 22-40.

Prieto, I. M., Revilla, E., \& Rodríguez-Prado, B. (2009). Building dynamic capabilities in product development: How do contextual antecedents matter? Scandinavian Journal of Management, 25(3), 313-326.

Rerup, C., \& Feldman, M. S. (2011). Routines as a source of change in organizational schemata: The role of trial-and-error learning. Academy of Management Journal, 54(3), 577-610.

Reuer, J. J. (2000). Parent firm performance across international joint venture life-cycle stages. Journal of International Business Studies, 31(1), 1-20.

Reuer, J. J., \& Ariño, A. (2007). Strategic alliance contracts: Dimensions and determinants of contractual complexity. Strategic Management Journal, 28(3), 313-330.

Reuer, J. J., \& Tong, T. W. (2005). Real options in international joint ventures. Journal of Management, 31(3), 403-423.

Reuer, J. J., \& Zollo, M. (2005). Termination outcomes of research alliances. Research Policy, 34(1), 101-115.

Reuer, J. J., Zollo, M., \& Singh, H. (2002). Post-formation dynamics in strategic alliances. Strategic Management Journal, 23(2), 135-151. 
Rindova, V. P., \& Kotha, S. (2001). Continuous" morphing": Competing through dynamic capabilities, form, and function. Academy of Management Journal, 44(6), 1263-1280.

Ring, P. S., Doz, Y. L., \& Olk, P. M. (2005). Managing formation processes in R\&D consortia. California Management Review, 47(4), 137-156.

Ring, P. S., \& Van de Ven, A. H. (1994). Developmental processes of cooperative interorganizational relationships. Academy of Management Review, 19(1), 90-118.

Ringle, C. M., Wende, S., \& Will, A. (2005). SmartPLS 2.0 (beta). Www.Smartpls.De, Hamburg, Germany. Accesed November 2010,

Rodríguez-Pinto, J., Rodríguez-Escudero, A. I., \& Gutiérrez-Cillán, J. (2008). Order, positioning, scope and outcomes of market entry. Industrial Marketing Management, 37(2), 154-166.

Roessl, D. (2005). Family businesses and interfirm cooperation. Family Business Review, 18(3), 203-214.

Rosenbloom, R. S. (2000). Leadership, capabilities, and technological change: The transformation of NCR in the electronic era. Strategic Management Journal, 21(10-11), 1083-1103.

Rothaermel, F. T., \& Deeds, D. L. (2006). Alliance type, alliance experience and alliance management capability in high-technology ventures. Journal of Business Venturing, 21(4), $429-460$.

Rousseau, D. M. (1995). Psychological contracts in organizations: Understanding written and unwritten agreements SAGE Publications, Inc.

Rousseau, D. M., \& Tijoriwala, S. A. (1998). Assessing psychological contracts: Issues, alternatives and measures. Journal of Organizational Behavior, 19(1), 679-695.

Ryall, M. D., \& Sampson, R. C. (2009). Formal contracts in the presence of relational enforcement mechanisms: Evidence from technology development projects. Management Science, 55(6), 906-925.

Sakakibara, M. (1997). Heterogeneity of firm capabilities and cooperative research and development: An empirical examination of motives. Strategic Management Journal, 18(1), 143-164.

Salk, J. E. (2005). Often called for but rarely chosen: Alliance research that directly studies process. European Management Review, 2(2), 117-122.

Sammarra, A., \& Biggiero, L. (2008). Heterogeneity and specificity of Inter-Firm knowledge flows in innovation networks. Journal of Management Studies, 45(4), 800-829.

Sampson, R. C. (2005). Experience effects and collaborative returns in R\&D alliances. Strategic Management Journal, 26(11), 1009-1031.

Sampson, R. C. (2007). R\&D alliances and firm performance: The impact of technological diversity and alliance organization on innovation. Academy of Management Journal, 50(2), 364-386. 
Sánchez-González, G., González-Álvarez, N., \& Nieto, M. (2008). The effects of cooperating with users concerning the type of innovation developed. Innovar, 18(32), 87-110.

Sánchez-González, G., González-Álvarez, N., \& Nieto, M. (2009). Sticky information and heterogeneous needs as determining factors of $\mathrm{R} \& \mathrm{D}$ cooperation with customers. Research Policy, 38(10), 1590-1603.

Sánchez-Peinado, L., Sánchez-Peinado, E., \& Escribá-Esteve, A. (2010). Factores determinantes de la intención de cambio estratégico: El papel de los equipos directivos. Cuadernos De Economía y Dirección De La Empresa, (42), 75-112.

Sankaran, J. K., \& Mouly, V. S. (2006). Value-chain innovation in aquaculture: Insights from a new zealand case study. $R \& D$ Management, 36(4), 387-401.

Sarkar, M. B., Aulakh, P. S., \& Madhok, A. (2009). Process capabilities and value generation in alliance portfolios. Organization Science, 20(3), 583-600.

Sarkar, M. B., Echambadi, R., Cavusgil, S. T., \& Aulakh, P. S. (2001a). The influence of complementarity, compatibility, and relationship capital on alliance performance. Journal of the Academy of Marketing Science, 29(4), 358-373.

Sarkar, M. B., Echambadi, R., \& Harrison, J. S. (2001b). Alliance entrepreneurship and firm market performance. Strategic Management Journal, 22(6-7), 701-711.

Saxton, T. (1997). The effects of partner and relationship characteristics on alliance outcomes. Academy of Management Journal, 40(2), 443-461.

Schilke, O. (2007). Organizational routines as alliance capabilities: The missing link. Paper presented at Academy of Management Annual Meeting.

Schilke, O., \& Goerzen, A. (2010). Alliance management capability: An investigation of the construct and its measurement. Journal of Management, 36(5), 1192-1219.

Schreiner, M., Kale, P., \& Corsten, D. (2009). What really is alliance management capability and how does it impact alliance outcomes and success? Strategic Management Journal, 30(13), 1395-1419.

Schreyögg, G., \& Kliesch-Eberl, M. (2007). How dynamic can organizational capabilities be? towards a dual-process model of capability dynamization. Strategic Management Journal, 28(9), 913-933.

Shenkar, O., \& Yan, A. (2002). Failure as a consequence of partner politics: Learning from the life and death of an international cooperative venture. Human Relations, 55(5), 565-601.

Siggelkow, N. (2002). Evolution toward fit. Administrative Science Quarterly, 47(1), 125-159.

Siggelkow, N. (2007). Persuasion with case studies. Academy of Management Journal, 50(1), $20-24$.

Silva, M. J., Leitao, J., \& Raposo, M. (2008). Barriers to innovation faced by manufacturing firms in portugal: How to overcome it for fostering business excellence? International Journal of Business Excellence, 1(1), 92-105. 
Simonin, B. L. (1997). The importance of collaborative know-how: An empirical test of the learning organization. Academy of Management Journal, 40(5), 1150-1174.

Simonin, B. L. (1999). Ambiguity and the process of knowledge transfer in strategic alliances. Strategic Management Journal, 20(7), 595-623.

Simonin, B. L. (2004). An empirical investigation of the process of knowledge transfer in international strategic alliances. Journal of International Business Studies, 35(5), 407-427.

Smith, K. G., Carroll, S. J., \& Ashford, S. J. (1995). Intra-and interorganizational cooperation: Toward a research agenda. Academy of Management Journal, 38(1), 7-23.

Stephens, K. J., Fulk, J., \& Monge, P. R. (2009). Constrained choices in alliance formations: Cupids and organizational marriages. Human Relations, 62(4), 501.

Strauss, A., \& Corbin, J. (1998). Basics of qualitative research: Grounded theory procedures and techniques (2nd Edition ed.). NewburyPark, London.: Sage.

Stuart, T. E. (2000). Interorganizational alliances and the performance of firms: A study of growth and innovation rates in a high-technology industry. Strategic Management Journal, 21(8), 791-811.

Teece, D. J. (1986). Profiting from technological innovation: Implications for integration, collaboration, licensing and public policy. Research Policy, 15(6), 285-305.

Teece, D. J. (2007). Explicating dynamic capabilities: The nature and microfoundations of (sustainable) enterprise performance. Strategic Management Journal, 28(13), 1319-1350.

Teece, D. J., \& Pisano, G. (1994). The dynamic capabilities of firms: An introduction. Industrial and Corporate Change, 3(3), 537-556.

Teece, D. J., Pisano, G., \& Shuen, A. (1997). Dynamic capabilities and strategic management. Strategic Management Journal, 18(7), 509-533.

Thorgren, S., Wincent, J., \& Eriksson, J. (2010). Too small or too large to trust your partners in multipartner alliances? the role of effort in initiating generalized exchanges. Scandinavian Journal of Management, 27(1), 99-112.

Tiwana, A. (2008). Do bridging ties complement strong ties? an empirical examination of alliance ambidexterity. Strategic Management Journal, 29(3), 251-272.

Tjemkes, B., \& Furrer, O. (2010). The antecedents of response strategies in strategic alliances. Management Decision, 48(7), 1103-1133.

Tong, T. W., Reuer, J. J., \& Peng, M. W. (2008). International joint ventures and the value of growth options. Academy of Management Journal, 51(5), 1014-1029.

Tripsas, M. (1997a). Surviving radical technological change through dynamic capability: Evidence from the typesetter industry. Industrial and Corporate Change, 6(2), 341-377.

Tripsas, M. (1997b). Unraveling the process of creative destruction: Complementary assets and incumbent survival in the typesetter industry. Strategic Management Journal, 18(S1), 119142. 
Tripsas, M., \& Gavetti, G. (2000). Capabilities, cognition, and inertia: Evidence from digital imaging. Strategic Management Journal, 21(10-11), 1147-1161.

Tsai, W. (2002). Social structure of 'coopetition' within a multiunit organization: Coordination, competition, and intraorganizational knowledge sharing. Organization Science, 13(2), 179190.

Tsai, W., \& Ghoshal, S. (1998). Social capital and value creation: The role of intrafirm networks. Academy of Management Journal, 41(4), 464-476.

Uzzi, B. (1997). Social structure and competition in interfirm networks: The paradox of embeddedness. Administrative Science Quarterly, 42(1), 35-67.

Valdés-Llaneza, A., \& García-Canal, E. (2006). Direct competition, number of partners and the longevity of stakes in joint ventures. Management International Review, 46(3), 307-326.

Van de Ven, A. H. (1992). Suggestions for studying strategy process: A research note. Strategic Management Journal, 13(5), 169-188.

Van Driel, H., \& Dolfsma, W. (2009). Path dependence, initial conditions, and routines in organizations: The toyota production system re-examined. Journal of Organizational Change Management, 22(1), 49-72.

Vassolo, R. S., Anand, J., \& Folta, T. B. (2004). Non-additivity in portfolios of exploration activities: A real options-based analysis of equity alliances in biotechnology. Strategic Management Journal, 25(11), 1045-1061.

Verona, G., \& Ravasi, D. (2003). Unbundling dynamic capabilities: An exploratory study of continuous product innovation. Industrial and Corporate Change, 12(3), 577.

Villalonga, B., \& McGahan, A. M. (2005). The choice among acquisitions, alliances, and divestitures. Strategic Management Journal, 26(13), 1183-1208.

Walter, A., Auer, M., \& Ritter, T. (2006). The impact of network capabilities and entrepreneurial orientation on university spin-off performance. Journal of Business Venturing, 21(4), 541-567.

Wang, L., \& Zajac, E. J. (2007). Alliance or acquisition? A dyadic perspective on interfirm resource combinations. Strategic Management Journal, 28(13), 1291-1317.

Weick, K. E. (1989). Theory construction as disciplined imagination. Academy of Management Review, 14(4), 516-531.

Weick, K. E., Sutcliffe, K. M., \& Obstfeld, D. (2005). Organizing and the process of sensemaking. Organization Science, 16(4), 409-421.

Wernerfelt, B. (1984). A resource-based view of the firm. Strategic Management Journal, 5(2), 171-180.

Wiklund, J., \& Shepherd, D. A. (2009). The effectiveness of alliances and acquisitions: The role of resource combination activities. Entrepreneurship Theory and Practice, 33(1), 193-212. 
Williamson, O. E. (1985). The economic institutions of capitalism. firms, markets, relational contracting.

Williamson, O. E. (1991). Comparative economic organization: The analysis of discrete structural alternatives. Administrative Science Quarterly, 36(2), 269-296.

Winter, S. G. (2003). Understanding dynamic capabilities. Strategic Management Journal, 24(10), 991-995.

Wolfgang, G. H., \& Stefan, K. W. (2010). "Organizational routines between change and stability: Linking empirical research to recent theoretical debates". Paper presented at Fourth International Conference on Organizational Routines.

Wu, F., \& Cavusgil, S. T. (2006). Organizational learning, commitment, and joint value creation in interfirm relationships. Journal of Business Research, 59(1), 81-89.

Yasuda, H. (2005). Formation of strategic alliances in high-technology industries: Comparative study of the resource-based theory and the transaction-cost theory. Technovation, 25(7), 763-770.

Yin, R. K. (1981). The case study crisis: Some answers. Administrative Science Quarterly, 26(1), 58-65.

Yin, R. K. (2003). Case study research, design and methods. Thousand Oaks, CA.: Sage publications.

Young-Ybarra, C., \& Wiersema, M. (1999). Strategic flexibility in information technology alliances: The influence of transaction cost economics and social exchange theory. Organization Science, 10(4), 439-459.

Zaheer, A., Gözübüyük, R., \& Milanov, H. (2010). It's the connections: The network perspective in interorganizational research. Academy of Management Perspectives, 24(1), 62-77.

Zahra, S. A., \& George, G. (2002). Absorptive capacity: A review, reconceptualization, and extension. Academy of Management Review, 27(2), 185-203.

Zahra, S. A., Sapienza, H. J., \& Davidsson, P. (2006). Entrepreneurship and dynamic capabilities: A review, model and research agenda. Journal of Management Studies, 43(4), 917-955.

Zajac, E. J., \& Olsen, C. P. (1993). From transaction cost to transactional value analysis: Implications for the study of interorganizational strategies. Journal of Management Studies, 30(1), 131-145.

Zeng, M., \& Chen, X. P. (2003). Achieving cooperation in multiparty alliances: A social dilemma approach to partnership management. Academy of Management Review, 28(4), 587-605.

Ziggers, G. W., \& Tjemkes, B. (2010). Dynamics in inter-firm collaboration: The impact of alliance capabilities on performance. International Journal on Food System Dynamics, $1(2), 151-166$. 
Zollo, M., Reuer, J. J., \& Singh, H. (2002). Interorganizational routines and performance in strategic alliances. Organization Science, 13(6), 701-713.

Zollo, M., \& Winter, S. G. (2002). Deliberate learning and the evolution of dynamic capabilities. Organization Science, 13(3), 339-351.

Zúñiga-Vicente, J. Á., de la Fuente-Sabaté, J. M., \& Suárez-González, I. (2005). Facilitating and inhibiting factors behind strategic change: Evidence in the Spanish private banking industry, 1983-1997. Scandinavian Journal of Management, 21(3), 235-265. 


\section{Scientific diffusion of the empirical studies of this dissertation}

\begin{tabular}{|c|c|c|c|}
\hline Study & Version & Forum & Status \\
\hline \multirow{5}{*}{$\begin{array}{l}\text { Study } \\
\text { I }\end{array}$} & $\begin{array}{l}\text { 'Dynamic cooperative capabilities in the formation stage of } \\
\text { a multi-partner R\&D alliance: The case of the Acuisost } \\
\text { Consortium' }\end{array}$ & $\begin{array}{l}\text { Workshop In-Depth Case Studies in Entrepreneurship and Small } \\
\text { Business Management (EIASM); Brussels (Belgium); December, } \\
2010\end{array}$ & Presented \\
\hline & $\begin{array}{l}\text { 'Rethinking cooperative behavior for inexperienced firms } \\
\text { during the formation stage of multi-partner R\&D alliances' }\end{array}$ & $\begin{array}{l}\text { Seminars I\&O (SOM Research Institute, University of Groningen); } \\
\text { Groningen (The Netherlands); June } 2011\end{array}$ & Presented \\
\hline & $\begin{array}{l}\text { 'Building dynamic cooperative capabilities in R\&D } \\
\text { consortia: A longitudinal case study' }\end{array}$ & $\begin{array}{l}\text { Academy of Management Annual Meeting, San Antonio (Tx., } \\
\text { USA); August, } 2011\end{array}$ & Presented \\
\hline & $\begin{array}{l}\text { 'Antecedents and consequences of building dynamic } \\
\text { cooperative capabilities in R\&D Consortia. A multi-case } \\
\text { longitudinal study' }\end{array}$ & $\begin{array}{l}\text { Congreso Nacional ACEDE (Spanish Scientific Association of } \\
\text { Economics and Management Annual Conference); Barcelona } \\
\text { (Spain); September, } 2011\end{array}$ & Presented \\
\hline & $\begin{array}{l}\text { 'Why inexperienced firms cooperate in the formation of } \\
\text { MR\&D alliances? A multi-case study in the aquaculture } \\
\text { sector in Spain' }\end{array}$ & 2012 INBAM Annual Conference; Valencia (Spain); March, 2012 & $\begin{array}{l}\text { Accepted for } \\
\text { presentation }\end{array}$ \\
\hline \multirow{2}{*}{$\begin{array}{l}\text { Study } \\
\text { II.1. }\end{array}$} & $\begin{array}{l}\text { 'Dancing in the dark: Value realization in explorative } \\
\text { alliances between unfamiliar partners' }\end{array}$ & $\begin{array}{l}\text { Academy of Management Annual Meeting, Boston (Mass., USA); } \\
\text { August, } 2012\end{array}$ & $\begin{array}{l}\text { Submitted } \\
\text { for } \\
\text { consideration }\end{array}$ \\
\hline & $\begin{array}{l}\text { 'How unfamiliar partners succeed in explorative alliances? } \\
\text { An analysis of knowledge-sharing routines and } \\
\text { psychological contracts co-evolution }\end{array}$ & $\begin{array}{l}\text { International Conference on Organizational Learning, Knowledge } \\
\text { and Capabilities (OKLC), Valencia (Spain); April, } 2012\end{array}$ & $\begin{array}{l}\text { Accepted for } \\
\text { presentation }\end{array}$ \\
\hline \multirow{2}{*}{$\begin{array}{l}\text { Study } \\
\text { II.2. }\end{array}$} & \multirow{2}{*}{$\begin{array}{l}\text { 'How exploitative and explorative alliances between } \\
\text { familiar partners succeed? } \\
\text { Real options reasoning and knowledge-sharing routines } \\
\text { redeployment' }\end{array}$} & $\begin{array}{l}\text { PhD Seminar 'Business Economics' (University of Valladolid); } \\
\text { Valladolid (Spain); December, } 2011\end{array}$ & Presented \\
\hline & & $\begin{array}{l}\text { Taller de Estrategia Empresarial de ACEDE (Workshop Business } \\
\text { Strategy, Spanish Scientific Association of Economics and } \\
\text { Management); Valencia (Spain); January, } 2012\end{array}$ & Presented \\
\hline
\end{tabular}




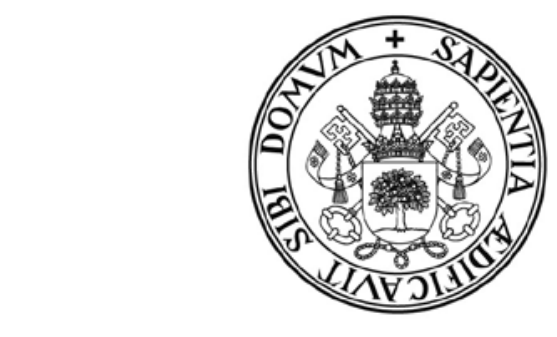

\section{Universidad deValladolid}

FACULTAD DE CIENCIAS ECONÓMICAS Y EMPRESARIALES

DEPARTAMENTO DE ORGANIZACIÓN DE EMPRESAS Y COMERCIALIZACIÓN E INVESTIGACIÓN DE MERCADOS

TESIS DOCTORAL:

\section{DINÁMICAS DE COLABORACIÓN Y CREACIÓN DE VALOR EN LAS ALIANZAS MULTISOCIO DE I+D: UN ESTUDIO DE CASO LONGITUDINAL SOBRE EL CONSORCIO ACUISOST}

Presentada por Isabel Estrada Vaquero para optar al grado de doctor con 'mención europea'por la Universidad de Valladolid

Dirigida por:

Dra. Da Natalia Martín Cruz

Dra. Da María Pilar Pérez Santana 



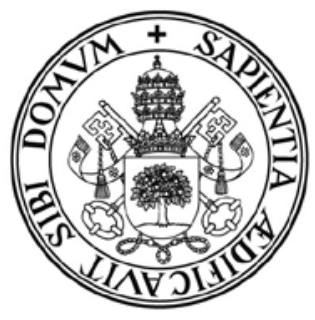

\section{Universidad deValladolid}

FACULTAD DE CIENCIAS ECONÓMICAS Y EMPRESARIALES

DEPARTAMENTO DE ORGANIZACIÓN DE EMPRESAS

Y COMERCIALIZACIÓN E INVESTIGACIÓN DE

MERCADOS

\section{DINÁMICAS DE COLABORACIÓN Y CREACIÓN DE VALOR EN LAS ALIANZAS MULTISOCIO DE I+D: UN ESTUDIO DE CASO LONGITUDINAL SOBRE EL CONSORCIO ACUISOST}

Valladolid, 2012 



\section{Agradecimientos}

En su curioso discurso de las armas y las letras, decía Don Quijote que el trabajo del estudiante es "principalmente pobreza... pero, con todo eso, no es tanta, que no coma, aunque sea un poco más tarde de lo que se usa... y no les falta algún ajeno brasero o chimenea, que, si no callenta, a lo menos entibie su frío... aunque es mucho mayor el trabajo del soldado, es mucho menor el premio”. Sirvan estas ingeniosas líneas para introducir las que aquí siguen.

El primer agradecimiento para las doctoras $D^{a}$ Natalia Martín Cruz y D $D^{a}$ Pilar Pérez Santana, directoras de esta tesis doctoral, maestras de tantos descubrimientos en estos años, que me han transmitido su pasión por la investigación, la importancia del rigor y la constancia. Su empuje, su comportamiento cooperativo y su compromiso han hecho de esta tesis una verdadera 'alianza multisocio', con un marcado matiz de 'relación de colaboración a largo plazo’.

En segundo lugar, agradezco a las personas del Grupo Dibaq, empresa líder del Proyecto Acuisost. A su Presidente, D. Carlos Tejedor, al Director de Dibaq Acuicultura, D. Álvaro Rodríguez, y, muy especialmente, al Director de I+D+i, D. José Luis Tejedor. Esta tesis doctoral no habría sido posible sin su confianza y apoyo. Extiendo estas palabras a todos los participantes del consorcio que han colaborado desinteresadamente en esta investigación. Igualmente, agradezco la financiación recibida de la Junta de Castilla y León (Contrato de Personal Investigador de Reciente Titulación 2009-2012 y Proyecto Ref. VA 30A11-1). 
Es de ley agradecer a los miembros del antiguo Departamento de Economía de la Empresa de la Universidad de Valladolid, por sus enseñanzas y apoyo, primero como profesores de licenciatura y doctorado, y ahora ya como compañeros. Una mención especial para el doctor D. Juan Hernangómez Barahona, por sus lecciones magistrales de dirección estratégica y aquellas otras, tan útiles, sobre 'cómo pensar con la cabeza'. Igualmente, agradezco al doctor Don Gabriel de la Fuente Herrero, por guiarme durante mi primera etapa doctoral (para mí, la opción de seguir colaborando juntos es más que real).

Quisiera también agradecer al Departamento de Dirección de Empresas 'Juan José Renau Piqueras' de la Universidad de Valencia, por brindarme la oportunidad de asistir a las Segunda y Tercera Ediciones de la Valencia Summer School, y de realizar una breve estancia al principio de mi periodo doctoral. Igualmente, quisiera agradecer al doctor D. Dries Faems, por permitirme vivir esa fructífera estancia en el Departamento de Innovación y Estrategia de la Universidad de Groningen y por su implicación en esta investigación.

Con un especial cariño, a mis compañeros del 'tercer módulo', por todas aquellas conversaciones sobre lo humano, lo divino, y lo académico. A mis siempre compañeros de despacho, Pablo Zarzuela y Víctor Martín, que han vivido las penurias y alegrías de esta tesis cual consanguíneos; a Celia Martín, mi gran confidente y amiga; a Rebeca San José y Javier Rodríguez, por sus siempre cariñosos consejos; a Víctor Hermano, por traer su frescura al área de Organización (te paso el testigo).

En un plano aún más personal, me dirijo a mis chicas, por poner ese punto de sal (y alguna que otra princesa) en mi vida, y en especial a Leti, por nuestros eternos paseos 
por el lago. También a mi amigo Luisja, por amenizar las noches de sábado con buen cubalibre y mejor conversación.

Las más emotivas de mis palabras para mis padres y Ana, mi hermana. Sin ellas, esta tesis doctoral quedaría profundamente inacabada, aunque supongan una incursión en el ámbito de lo privado. Por su sabiduría, por su cariño, por su paciencia infinita, por su cooperación, por ser los 'fieles escuderos’ en este viaje (y en todos), por hacer de mí lo que soy (sólo lo bueno).

Como no podría ser de otra manera, finalizo asumiendo la responsabilidad única de todos los errores que pudieran contener las páginas que siguen. 



\section{Índice de Contenidos (de la Tesis Doctoral)}

INTRODUCCIÓN.

Motivación y objetivo general de la tesis..................................... 3

Estructura de la tesis ............................................... 8

CAPÍTULO 1. 'Revisión de la Literatura y Objetivos de Investigación’ 11

1.1. Revisión de la literatura ............................................. 13

1.1.1. Literatura de alianzas estratégicas ........................................ 14

1.1.1.1. Marcos teóricos de la investigación en alianzas......................... 15

1.1.1.2. Temas de investigación en alianzas................................... 24

1.1.1.3. Perspectivas de la investigación en alianzas............................ 29

1.1.1.4. Niveles de análisis en la investigación en alianzas ........................ 33

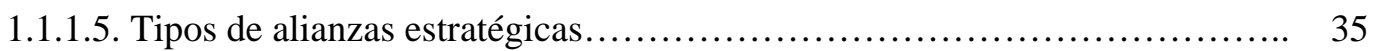

1.1.1.6. Investigación en alianzas multisocio de I+D .......................... 36

1.1.2. Literatura de capacidades dinámicas ................................... 43

1.1.2.1. Orígenes y desarrollo de la visión de capacidades dinámicas............... 43

1.1.2.1.1. El concepto de rutinas: ¿Inercia o flexibilidad?................................ 46

1.1.2.1.2. Creación y desarrollo de capacidades dinámicas: El ciclo de vida de las capacidades y otras ideas complementarias ...................... 47

1.1.2.2. Investigación empírica en capacidades dinámicas.......................... 49

1.1.2.3. Principales limitaciones del enfoque de capacidades dinámicas............... 52

1.1.3. Vinculando las capacidades dinámicas y las alianzas estratégicas ............ 54

1.1.3.1. Capacidades de alianzas: Revisión de la investigación ..................... 55

1.1.3.2. Capacidades de alianzas: Contribuciones y limitaciones .................. 57

1.1.3.3. Capacidades de alianzas como capacidades dinámicas: Las rutinas de colaboración..................................................... 58

1.1.3.3.1. Rutinas de colaboración: Dos niveles de análisis.................... 61

1.2. Objetivos de Investigación de la tesis.................................. 63

1.2.1. Proceso de definición de objetivos de investigación..................................... 63

1.2.2. Lagunas y objetivos de investigación. Introducción a los estudios.............. 64

CAPÍTULO 2. ‘Metodología y Diseño de la Investigación. Recogida y Análisis de Datos'................................................. 71

2.1. Metodología del estudio de caso y diseño de investigación............. 73 
2.2. Contexto de la investigación.......................................... 75

2.2.1. Selección y descripción del Consorcio Acuisost ............................ 76

2.2.1.1. Panorámica general del Consorcio Acuisost ................................ 76

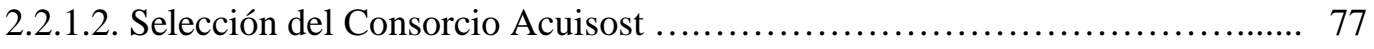

2.2.1.3. Descripción del Consorcio Acuisost......................................... 80

2.2.1.3.1. Marco Institucional: El Programa CENIT ................................. 80

2.2.1.3.2. Marco Industrial: El sector de acuicultura en España................... 82

2.2.1.3.3. Objetivos y estructura técnica y organizativa del consorcio............. 84

2.2.1.3.4. Participantes del Consorcio Acuisost .............................. 88

2.2.1.4. Descripción longitudinal del Consorcio Acuisost ............................. 95

2.2.1.4.1. Etapa de formación................................................ 96

2.2.1.4.2. Etapa de ejecución..................................................... 104

2.2.1.4.3. Etapa final.................................................... 104

2.2.2. Selección de diferentes casos para diferentes estudios........................ 105

2.3. Recogida y análisis de datos: Calidad de la investigación.............. 106

2.3.1. Recogida de datos: Principios y proceso................................... 106

2.3.1.1. Principios de la recogida de datos..................................... 106

2.3.1.2. Proceso de la recogida de datos........................................... 109

2.3.2. Análisis de datos: Proceso, niveles y métodos............................... 114

2.3.2.1. Selección de diferentes niveles de análisis: Investigación multinivel......... 115

2.3.2.2. Selección de diferentes métodos de análisis: Investigación multimétodo.... 116

2.3.3. Pruebas de la calidad de la investigación................................ 118

2.4. Esquema de la metodología.......................................... 121

CAPÍTULO 3. 'Etapa de Formación del Consorcio Acuisost'.............. 123

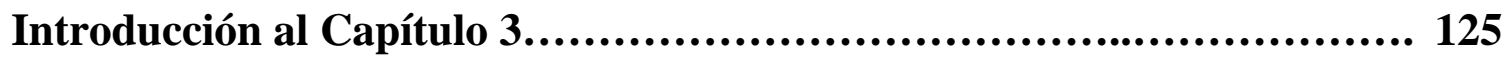

Estudio I. Comportamiento Cooperativo de las Empresas Inexpertas en la Etapa de Formación de las Alianzas de Multisocio de I+D............. 127

3.1. Introducción............................................................... 127

3.2. Marco teórico y proposiciones ............................................ 129

3.2.1. Competencia directa y comportamiento cooperativo................................... 133

3.2.2. Orientación al aprendizaje y comportamiento cooperativo......................... 134

3.2.3. Importancia estratégica y comportamiento cooperativo............................ 135

3.3. Diseño y metodología empírica......................................... 136

3.3.1. Contexto de la investigación y casos de estudio............................. 137

3.3.2. Recogida y análisis de datos............................................... 138 
3.3.3. Medición de variables. 140

3.4. Análisis de los casos

3.4.1. Análisis intra-caso.

3.4.2. Análisis inter-casos

3.5. Discusión y conclusions.

3.5.1. Discusión de resultados

3.5.2. Implicaciones de investigación.

3.5.3. Implicaciones para la práctica empresarial e institucional.................... 164

3.5.4. Limitaciones y futura investigación...................................... 164

CAPÍTULO 4. 'Colaboración entre Empresas y Centros de Investigación en el Consorcio Acuisost'.

Introducción al Capítulo 4

4.1. Estudio II.1. Claves del éxito en alianzas exploratorias de I+D entre socios 'no familiares' Contratos Psicológicos y Creación de Rutinas de Intercambio de Conocimiento.

4.1.1. Introducción.

4.1.2. Marco teórico.

4.1.2.1. Dos corrientes de investigación en alianzas exploratorias de I+D: La necesidad de estudiar los procesos.

4.1.2.2. Contratos psicológicos en alianzas exploratorias de I+D entre socios 'no familiares'.

4.1.2.3. Rutinas interorganizativas de intercambio de conocimiento y contratos psicológicos contracts.................................................................... 178

4.1.3. Metodología............................................................... 179

4.1.3.1. Contexto de investigación y casos de estudio............................. 179

4.1.3.2. Recogida y análisis de datos............................................ 182

4.1.4. Análisis de casos: Las alianzas OI-LF y CRAI-LF......................... 183

4.1.4.1. Inicio de las alianzas...................................................... 183

4.1.4.2. La alianza OI-LF................................................. 184

4.1.4.3. La alianza CRAI-LF................................................ 189

4.1.5. Discusión: Las matrimonios OI-LF y CRAI-LF ..................................... 194

4.1.5.1. Comienzo de la alianza: La luna de miel ............................... 195

4.1.5.2. Los primeros problemas: Superación vs. crisis............................. 197

4.1.5.3. Final de la alianza: Consolidación matrimonial vs. divorcio ................ 200

4.1.6. Conclusiones e implicaciones ................................................. 202

4.1.6.1. Implicaciones para la investigación................................. 202

4.1.6.2. Implicaciones para la práctica empresarial................................ 203

4.1.6.3. Limitaciones..................................................... 203 
4.2. Estudio II.2. Claves del éxito en alianzas de I+D de exploración y de explotación entre socios 'familiares'. Filosofía de opciones reales y redeployment de las rutinas de intercambio de conocimiento

4.2.1. Introducción.

4.2.2. Marco teórico.

4.2.2.1. Alianzas de $\mathrm{I}+\mathrm{D}$ bajo el enfoque de opciones reales

4.2.2.2. Alianzas de I+D entre socios 'familiares' y opciones reales................ 210

4.2.2.3. Opciones reales y redeployment de rutinas interorganizativas.............. 210

4.2.3. Metodología..................................................................... 213

4.2.3.1. Contexto de investigación y casos de estudio........................... 213

4.2.3.2. Recogida y análisis de datos..................................... 214

4.2.4. Análisis de los casos: Las alianzas CAH-LF y MAR-LF................................. 216

4.2.4.1. El caso CAH-LF............................................... 216

4.2.4.2. El caso MAR-LF .................................................. 221

4.2.5. Discusión: Opciones reales en las alianzas CAH-LF y MAR-LF................. 226

4.2.5.1. Redeployment: Exploración-explotación de opciones reales colectivas..... 226

4.2.5.2. Cognición directiva y la identificación de opciones reales colectivas........ 228

4.2.5.3. Redeployment y creación de valor: Gestión de la incertidumbre desde la flexibilidad...................................................... 229

4.2.6. Conclusiones e Implicaciones ................................................... 231

4.2.6.1. Implicaciones para la investigación................................... 232

4.2.6.2. Implicaciones para la práctica empresarial................................ 233

4.2.6.3. Limitaciones.................................................. 234

4.2.6.4. Investigación futura................................................ 234

CAPÍTULO 5. Conclusiones, Implicaciones, Limitaciones, e Investigaciói Futura.............................................. 237

5.1. Resumen de resultados y principales implicaciones .................. 240

5.1.1. Estudio I.: La creación de rutinas organizativas de colaboración .............. 240

5.1.1.1. ¿Por qué algunos socios inexpertos son más cooperativos que otros en la etapa de formación de la alianza multisocio de I+D?.............................. 240

5.1.1.2. Contribuciones al objetivo (I) .................................. 240

5.1.2. Estudio II.: Dinámicas de creación de valor de las alianzas de I+D: Creación y evolución de las rutinas interorganizativas de colaboración

5.1.2.1. Estudio II.1: Claves del éxito en alianzas exploratorias entre socios 'no familiares': Creación de rutinas de intercambio de conocimiento.

5.1.2.2. Estudio II.2: Claves del éxito en alianzas de exploración y explotación entre socios ‘familiares': Redeployment de rutinas de conocimiento ........ 
5.1.2.3. Contribuciones al objetivo (II)

5.1.3. Contribuciones metodológicas.

5.1.4. Conclusión general: Hacia una visión más completa de las dinámicas de creación de valor y colaboración en las alianzas de I+D multisocio.

5.2. Implicaciones para la práctica.

5.2.1. Recomendaciones empresariales.

5.2.2. Recomendaciones institucionales.

5.3. Limitaciones.

APÉNDICES 


\section{Lista de Tablas de este Resumen}

Tabla I Objetivos y preguntas de investigación de la tesis doctoral................... 329

Tabla II Revisión de la literatura en esta tesis doctoral............................. 331

Tabla III El Consorcio Acuisost.............................................. 331

Tabla IV Diseño de los tres estudios empíricos de esta tesis doctoral.................. 332 
Título de la tesis doctoral (traducido):

“Dinámicas de colaboración y creación de valor en las alianzas multisocio de I+D: Un estudio de caso longitudinal sobre el Consorcio Acuisost”

\section{Motivación y Objetivo General de Investigación}

Las alianzas estratégicas de $\mathrm{I}+\mathrm{D}$ entre múltiples socios son poderosas herramientas estratégicas para hacer frente a los desafíos competitivos: permiten a las empresas explorar y explotar oportunidades de innovación, mediante la creación de foros de discusión multilateral y la combinación de múltiples recursos (Doz et al., 2000; Mothe y Quelin, 2001; Lavie et al., 2007). Dado el potencial de innovación que ofrecen este tipo de alianzas, los gobiernos de todo el mundo están implementando políticas para el fomento de su creación, con indiscutible énfasis en un tipo particular de alianzas multisocio: los consorcios de I+D. (Sakakibara, 1997; Mothe y Quelin, 2001). En esta línea se sitúan los programas en el marco de la Estrategia de Lisboa de la Unión Europea, tales como el Programa de 'Consorcios Estratégicos Nacionales para la Investigación Técnica’ (Programa CENIT) en España. Como resultado de este impulso público, las alianzas multisocio de I+D son cada vez más frecuentes en la panorama empresarial.

Frente a dicho potencial, la otra cara de la moneda es la enorme complejidad en la gestión de las alianzas multisocio de I+D (Das y Teng, 2002; García-Canal et al., 2003; Zeng y Chen, 2003; Valdés-Llaneza y García-Canal, 2006). En estas alianzas, coexisten dos tipos de relaciones de colaboración, con diferentes patrones de intercambio y reciprocidad (Das y Teng, 2002; Thorgren et al., 2010). 
Por un lado, las alianzas multisocio de I+D implican intercambios bilaterales entre pares de socios encargados de llevar a cabo conjuntamente una parte específica del proyecto de $I+D$. En estas relaciones, se espera que las contribuciones de los dos socios sean mutuamente recíprocas (es decir, reciprocidad bilateral o directa).

Por otro lado, las alianzas multisocio de I+D implican intercambios multilaterales entre los socios. En estas relaciones, las contribuciones de un socio revierten sobre 'la alianza’ como un todo, con la que el socio espera una relación quid pro quo (y no necesariamente con otro socio en particular). Por lo tanto, la complejidad causada por la naturaleza misma de las actividades de $\mathrm{I}+\mathrm{D}$ es mayor en presencia de mútiples socios (Sampson, 2005; Mahnke y Overby, 2008). La existencia múltiples y diversos socios que se agrupan y forman un conjunto de relaciones diádicas de I+D genera un escenario, por sí mismo, complejo para la interacción (Parkhe, 1991; Lavie et al, 2007).

Además, estas alianzas están amenazadas por la posibilidad de desequilibrio en las contribuciones de los socios, siendo a menudo difícil inferir el nivel de esfuerzo individual de cada socio y detectar 'fugas' no deseadas de recursos valiosos (Das y Teng, 2002; Zeng y Chen, 2003; Sampson, 2005).

Una conclusión de todo lo anterior es que el desequilibrio que existe en las alianzas estratégicas entre el gran potencial para crear valor y la consecución efectiva de dicho valor se magnifica en el contexto de las alianzas multisocio de I+D (Madhok y Tallman, 1998). En este contexto de colaboración, la consecución efectiva del valor depende de (1) la capacidad individual de los socios a colaborar con otras organizaciones, y (2) la capacidad colectiva de los socios para colaborar juntos (Dyer y Singh, 1998; Madhok y Tallman, 1998; Anand y Khanna, 2000). Ambos tipos de capacidades representan 
conjuntos de rutinas de colaboración (Zollo et al., 2002) o patrones estables de comportamiento e interacción en el contexto de colaboración que se han desarrollado a partir de la acumulación de experiencias de alianza, la primera a nivel de un socio individual y la segunda en el nivel interorganizativo (Simonin, 1997; Dyer y Nobeoka, 2000).

Aunque la literatura existente ha ofrecido algunas contribuciones importantes sobre el fenómeno de las alianzas multisocio de I+D (e.g., Doz et al., 2000; Lavie et al., 2007), la investigación empírica en este campo es especialmente escasa y son todavía muchos los interrogantes que permanecen abiertos. Así, una visión completa sobre las dinámicas de colaboración y creación de valor en las alianzas multisocio de I+D está aún por desarrollar. Esto motiva, en líneas generales, el desarrollo de esta tesis doctoral, que se centra en el estudio de un consorcio de I+D real: el Consorcio Acuisost.

Objetivo general de la

Tesis Doctoral
Contribuir al desarrollo de una perspectiva más completa sobre las dinámicas de colaboración y creación de valor en las alianzas multisocio de $I+D$. 


\section{Estructura de la Tesis Doctoral}

Esta tesis doctoral se compone de cinco capítulos. Tras presentar la introducción general, el primero capítulo se dedica, primero, a revisar las literaturas científicas relevantes para el desarrollo de esta investigación. Este primer capítulo finaliza esbozando los objetivos de investigación de -la presente tesis doctoral.

El segundo capítulo se dedica a presentar la metodología de investigación y diseño empírico utilizados en esta tesis. Por tanto, entre otros contenidos, este capítulo presenta una descripción detallada del Consorcio Acuisost, el caso real sobre el cual versa la parte empírica de esta tesis doctoral.

Los dos siguientes capítulos contienen los tres estudios empíricos de la tesis doctoral. En particular, el capítulo tercero recoge el primer estudio de la tesis, que versa sobre el comportamiento cooperativo de los socios durante la etapa de formación del Consorcio Acuisost (Estudio I). El capítulo cuarto, por su parte, recoge el segundo estudio de la tesis (Estudio II), centrado en las relaciones de colaboración entre empresas y centros de investigación en el Consorcio Acuisost. Este segundo estudio está, a su vez, dividido en dos estudios más específicos: el primero de ellos (Estudio II.1) aborda la creación de rutinas de intercambio de conocimiento y sus implicaciones cuando los socios no tienen experiencia conjunta previa (no familiares), mientras que el segundo estudio (Estudio II.2) examina cómo socios que sí tienen experiencia conjunta previa (familiares) transfieren sus rutinas ya creadas al ámbito de una nueva alianza.

Por último, el capítulo quinto presenta un resumen de los principales resultados, implicaciones y limitaciones del trabajo desarrollado en esta tesis, así como algunas líneas de investigación futura. 
En primer lugar, se ha revisado en profundidad la extensa literatura sobre las alianzas estratégicas (atendiendo a los principales marcos teóricos aplicados al fenómeno de las alianzas estratégicas, los principales temas de investigación, la perspectiva de investigación y nivel/es de análisis adoptado/s en los estudios sobre alianzas estratégicas, y tipos de alianzas estratégicas estudiadas). Al término de esta exhaustiva revisión, se dedica un epígrafe al tipo particular de alianzas más importante para el desarrollo de esta tesis doctoral: las alianzas de I+D multisocio.

En segundo lugar, se ha revisado en profundidad la literatura sobre capacidades dinámicas, primero explicando sus fundamentos teóricos y, posteriormente, examinando cómo dichos fundamentos se han llevado al terreno empírico (atendiendo la interpretación del concepto de capacidades dinámicas y a los principales rasgos del diseño empírico de estos estudios).

Por último, ambas literaturas se conectan en una sección dedicada a revisar la literatura existente sobre ‘capacidades de alianzas', que en esta tesis son consideradas como un tipo particular de capacidades dinámicas. La revisión de esta literatura termina enfatizando la importancia de las rutinas de colaboración como principales elementos constitutivos de las capacidades de alianzas. 
Tabla II. Revisión de la literatura en esta tesis doctoral

\begin{tabular}{|c|c|}
\hline $\begin{array}{l}\text { Rama de Literatura } \\
\text { Objeto de Revisión }\end{array}$ & $\begin{array}{l}\text { Ejemplos de estudios } \\
\text { revisados para esta tesis }\end{array}$ \\
\hline Alianzas estratégicas & $\begin{array}{l}\text { Kogut (1988; 1991); Parke (1991); Gulati (1995; } \\
\text { 1998); Ariño y de la Torre (1998); Madhok y } \\
\text { Tallman (1998); Dyer y Singh (1998); Ahuja } \\
\text { (2000); Das y Teng (2000, 2002); Ariño (2001; } \\
\text { 2003); Mora-Valentín et al. (2004); Lavie (2006); } \\
\text { Faems et al. (2008); García-Canal et al. (2003; } \\
\text { 2008); Ariño y Ring (2010) }\end{array}$ \\
\hline Alianzas de I+D multisocio & $\begin{array}{l}\text { Doz et al., (2000); Mothe y Quelin, (2001); } \\
\text { García-Canal et al., (2003); Lavie et al., (2007); } \\
\text { Thorgren et al., (2010) }\end{array}$ \\
\hline Capacidades dinámicas & $\begin{array}{l}\text { Teece et al. (1997); Tripsas (1997); Eisenhardt y } \\
\text { Martin (2000); Galunick y Eisenhardt (2001); } \\
\text { Zollo y Winter (2002); Helfat y Peteraf (2003); } \\
\text { Teece (2007) }\end{array}$ \\
\hline $\begin{array}{l}\text { Capacidades de alianzas y } \\
\text { rutinas de colaboración }\end{array}$ & $\begin{array}{l}\text { Simonin (1997); Anand y Khanna (2000); Zollo et } \\
\text { al. (2000); Dyer y Nobeoka (2000); Sarkar et al. } \\
\text { (2009); De Man et al. (2010); Schilke y Goerzen } \\
\text { (2010) }\end{array}$ \\
\hline
\end{tabular}

La combinación de revisión de la literatura y recogida y análisis de datos, ha permitido ir paulatinamente moldeando estas ideas y definir otros objetivos de investigación más 
específicos, que guían la definición de preguntas de investigación concretas y, por tanto, la realización de los tres estudios empíricos de esta tesis (ver Tabla I).

Tabla I. Objetivos y preguntas de investigación de la tesis doctoral

\begin{tabular}{|c|c|}
\hline $\begin{array}{c}\text { Objetivo } \\
\text { específico (I) }\end{array}$ & $\begin{array}{l}\text { En el contexto de las alianzas multisocio de I+D, el Estudio I de esta } \\
\text { tesis doctoral tiene por objetivo mejorar el conocimiento existente } \\
\text { sobre la creación de rutinas organizativas de colaboración cuando } \\
\text { los socios no poseen experiencia significativa en alianzas. }\end{array}$ \\
\hline $\begin{array}{l}\text { Pregunta de } \\
\text { investigación }\end{array}$ & $\begin{array}{l}\text { Estudio I. Durante la etapa de formación de las alianzas multisocio } \\
\text { de I+D creadas por socios que no poseen experiencia, ¿por qué } \\
\text { algunos socios se comportan de forma más cooperativa que otros? }\end{array}$ \\
\hline $\begin{array}{c}\text { Objetivo } \\
\text { específico (II) }\end{array}$ & $\begin{array}{l}\text { En el contexto de las alianzas multisocio de I+D, el Estudio II de } \\
\text { esta tesis doctoral tiene por objetivo mejorar el conocimiento } \\
\text { existente sobre la creación de valor en las alianzas de I+D a través } \\
\text { del estudio de la creación y evolución de las rutinas } \\
\text { interorganizativas de colaboración. }\end{array}$ \\
\hline $\begin{array}{l}\text { Preguntas de } \\
\text { investigación }\end{array}$ & $\begin{array}{l}\text { Estudio II.1. En las alianzas de I+D enfocadas a la exploración, } \\
\text { creadas entre socios que no se conocen previamente, ¿cómo se } \\
\text { puede crear valor conjunto a través de la creación de nuevas } \\
\text { rutinas de intercambio de conocimientos efectivas? }\end{array}$ \\
\hline
\end{tabular}


CAPÍTULO 2. 'METODOLOGÍA Y DISEÑO DE LA INVESTIGACIÓN. RECOGIDA Y ANÁLISIS DE DATOS' 
Esta tesis doctoral se basa en la metodología del estudio de caso (Eisenhardt, 1989; Yin, 2003). Para ello, se han estudiado de forma longitudinal y en profundidad diferentes partes del Consorcio Acuisost en los diferentes estudios, con lo que se ha desarrollado una investigación orientada a los procesos de colaboración (Salk, 2005) y de carácter multinivel (Nielsen, 2010). Las Tablas III y IV presentan, respectivamente, las principales características del Consorcio Acuisost y del diseño de los estudios empíricos de esta tesis. 
Tabla III. El Consorcio Acuisost

\begin{tabular}{|c|c|}
\hline $\begin{array}{c}\text { Tipo de alianza } \\
\text { estratégica }\end{array}$ & $\begin{array}{ll}\bullet \text { Consorcio de I+D } & \bullet \text { Doméstica } \\
\text { • Contractual } & \bullet \text { Financiada públicamente } \\
\text { - Multisocio } & \bullet \text { Creada 'ad-hoc' por una } \\
& \text { consultora externa }\end{array}$ \\
\hline Objetivo general & $\begin{array}{l}\text { Potenciar un desarrollo racional y sostenible de la } \\
\text { acuicultura en España, a través de esfuerzos conjuntos en } \\
\text { actividades de I+D }\end{array}$ \\
\hline Participantes & $\begin{array}{l}\text { Empresa líder del consorcio, empresas socio y centros de } \\
\text { investigación }\end{array}$ \\
\hline $\begin{array}{l}\text { Marco institucional, } \\
\text { industrial y geográfico }\end{array}$ & Programa español CENIT; acuicultura de peces en España \\
\hline $\begin{array}{l}\text { Presupuesto y } \\
\text { financiación }\end{array}$ & $\begin{array}{l}21 \text { millones de euros para todo el periodo [ } 44.5 \% \text { fondos } \\
\text { públicos; } 55.5 \% \text { fondos privados aportados por las } \\
\text { empresas socio] }\end{array}$ \\
\hline Ciclo de vida & $\begin{array}{l}\text { Enero 2006- Octubre 2011; } 3 \text { etapas: formación, ejecución } \\
\text { y terminación }\end{array}$ \\
\hline Estructura técnica & $\begin{array}{l}\text { Siete actividades técnicas (subproyectos): } \\
\text { 'Materias primas', ‘Aditivos y encapsulación’, 'Sistemas } \\
\text { biotecnológicos’, ‘Bioseguridad’, ‘Cultivo de especies’, } \\
\text { 'Residuos’ y ‘Alimentos preparados'. }\end{array}$ \\
\hline
\end{tabular}


Tabla IV. Diseño de los tres estudios empíricos de esta tesis doctoral

\begin{tabular}{|c|c|c|c|}
\hline & Estudio I & Estudio II.1. & Estudio II.2. \\
\hline $\begin{array}{l}\text { Diseño del estudio } \\
\text { de caso }\end{array}$ & Estudio multi-caso & $\begin{array}{l}\text { Estudio de caso comparativo } \\
\text { (dos casos) }\end{array}$ & $\begin{array}{l}\text { Estudio de caso comparativo } \\
\text { (dos casos) }\end{array}$ \\
\hline $\begin{array}{l}\text { Pregunta de } \\
\text { investigación }\end{array}$ & $\begin{array}{l}\text { Durante la etapa de formación de } \\
\text { las alianzas multisocio de I+D } \\
\text { creadas por socios que no poseen } \\
\text { experiencia significativa, ¿por } \\
\text { qué algunos socios se comportan } \\
\text { de forma más cooperativa que } \\
\text { otros? }\end{array}$ & $\begin{array}{l}\text { En las alianzas de I+D enfocadas a la } \\
\text { exploración, creadas entre socios que } \\
\text { no se conocen previamente, ¿cómo se } \\
\text { puede crear valor conjunto a través } \\
\text { de la creación de nuevas rutinas de } \\
\text { intercambio de conocimientos } \\
\text { efectivas? }\end{array}$ & $\begin{array}{l}\text { En las alianzas de I+D enfocadas a la } \\
\text { exploración o explotación, creadas } \\
\text { entre socios que ya se conocen } \\
\text { previamente, ¿cómo se puede crear } \\
\text { valor conjunto a través de la } \\
\text { aplicación efectiva de las rutinas de } \\
\text { intercambio de conocimientos ya } \\
\text { existentes? }\end{array}$ \\
\hline Nivel de análisis & Nivel de socio & $\begin{array}{l}\text { Nivel interorganizativo } \\
\text { (alianza 'focal') }\end{array}$ & $\begin{array}{l}\text { Nivel interorganizativo } \\
\text { (relación de colaboración y } \\
\text { alianza 'focal’) }\end{array}$ \\
\hline $\begin{array}{l}\text { Ciclo de vida del } \\
\text { consorcio }\end{array}$ & Etapa de formación & $\begin{array}{l}\text { Todo el ciclo } \\
\text { (formación, ejecución, y terminación) }\end{array}$ & $\begin{array}{l}\text { Todo el ciclo } \\
\text { (formación, ejecución, y terminación) }\end{array}$ \\
\hline
\end{tabular}




\begin{tabular}{|c|c|c|c|}
\hline & Estudio I & Estudio II.1. & Estudio II.2. \\
\hline $\begin{array}{l}\text { Fuentes de } \\
\text { información }\end{array}$ & $\begin{array}{l}\text { - Entrevistas } \\
\text { - Cuestionario } \\
\text { - Documentos }\end{array}$ & $\begin{array}{l}\text { - Entrevistas } \\
\text { - Cuestionario presencial } \\
\text { - Documentos }\end{array}$ & $\begin{array}{l}\text { - Entrevistas } \\
\text { - Cuestionario presencial } \\
\text { - Documentos }\end{array}$ \\
\hline Enfoque analítico & $\begin{array}{l}\text { ‘Construcción de explicación’, } \\
\text { verificación y construcción de } \\
\text { nueva teoría }\end{array}$ & $\begin{array}{l}\text { ‘Exploración de patrones’, inductivo, } \\
\text { construcción de nueva teoría }\end{array}$ & $\begin{array}{l}\text { ‘Exploración de patrones’, inductivo, } \\
\text { construcción de nueva teoría }\end{array}$ \\
\hline $\begin{array}{l}\text { Casos } \\
\text { seleccionados } \\
\text { para su estudio } \\
\text { en profundidad }\end{array}$ & $\begin{array}{l}\text { - Mediterranean Aquaculture } \\
\text { - Fish\&Meals } \\
\text { - Cantabrian Seafood } \\
\text { - Iberian Eels } \\
\text { - BioMilk }\end{array}$ & $\begin{array}{l}\text { - La alianza OI-LF } \\
\text { - La alianza CRAI-LF }\end{array}$ & $\begin{array}{l}\text { - La alianza CAH-LF } \\
\text { - La alianza MAR-LF }\end{array}$ \\
\hline
\end{tabular}


CAPÍTULO 3.

'LA ETAPA DE FORMACIÓN DEL CONSORCIO

\section{ACUISOST'}




\section{Estudio I. Comportamiento Cooperativo de las Empresas Inexpertas en la Etapa de Formación de las Alianzas Multisocio de I+D}

El primer estudio muestra que la percepción del riesgo de fugas de conocimiento debido a la presencia de competidores directos en el consorcio, desincentivó la cooperación. Este efecto se produjo de forma directa e indirecta: la existencia de competidores directos debilitó también los incentivos relacionados con el aprendizaje y otras motivaciones estratégicas.

La evidencia sobre el Consorcio Acuisost muestra también que ciertos acontecimientos externos (por ejemplo, problemas financieros de la empresa o su participación simultánea en otros proyectos), afectaron la motivación de ciertos socios para comportarse de forma cooperativa. Además, el estudio que concluye que, en ausencia de competencia directa y otros acontecimientos externos negativos, los socios más cooperativos del Consorcio Acuisost estaban fuertemente orientados al aprendizaje y percibían que ese aprendizaje era de importancia estratégica, ya fuera para mejorar su posición en el mercado actual (aprendizaje para la explotación) o para beneficiarse de nuevas oportunidades de mercado en el futuro (el aprendizaje para la exploración).

Estos resultados enriquecen el conocimiento existente sobre la creación de rutinas organizativas de colaboración cuando los socios no tienen experiencia significativa. En este sentido, el Estudio I muestra que el comportamiento cooperativo podría ser entendido mejor como una rutina creada proactivamente por los socios, y que se refiere al lado 'soft' de las capacidades de alianza (Simonin, 1997; Zollo et al., 2002; De Man et al., 2010). 
CAPÍTULO 4.

'COLABORACIÓN ENTRE EMPRESAS Y CENTROS DE INVESTIGACIÓN EN EL CONSORCIO ACUISOST' 


\section{Estudio II. Colaboración entre Empresas y Centros de Investigación en el Consorcio Acuisost}

El Estudio II.1 ofrece tres resultados principales. En primer lugar, la complementariedad tecnológica percibida por los socios no familiares en el inicio de la alianza puede animarles a intercambiar activamente su conocimiento, reduciendo el impacto negativo de sus diferencias relacionales (período de 'luna de miel'). En segundo lugar, la calidad de las interacciones posteriores (una vez que la 'luna de miel' termina) depende de la naturaleza de las diferencias relacionales entre los socios no familiares: la divergencia en las creencias de los socios puede ser reparable cuando se refiere a los aspectos operativos de la alianza (es decir, la forma de colaborar), mientras que puede ser difícil de superar si las divergencias se refieren a aspectos estratégicos de la alianza (es decir, el porqué de la colaboración). En tercer lugar, sólo si las diferencias relacionales se resuelven progresivamente a medida que la colaboración se desarrolla, los socios seguirán percibiendo complementariedades tecnológicas en niveles suficientemente altos como para motivar la continuidad de compromisos en la colaboración, lo que a su vez permite la realización conjunta de valor.

Por su parte, el Estudio II.2 ofrece otros tres resultados principales. Primero, los socios familiares pueden haber desarrollado rutinas 'ambidiestras' a lo largo de su historia de colaboración mutua. Por tanto, la aplicación de sus rutinas en un nuevo acuerdo de I+D (independientemente de su orientación formal) puede suponer tanto la exploración como la explotación de oportunidades tecnológicas. En segundo lugar, los factores de cognición directiva son más relevantes para explicar la heterogeneidad en la aplicación de las rutinas colaborativas de socios familiares que la orientación de la alianza. Tercero, los socios familiares pueden ser capaces de crear valor conjunto en sus 
alianzas, tanto de exploración como de explotación, cuando aplican una estrategia flexible que les permite gestionar la incertidumbre exógena a lo largo del tiempo, después de haber superado ya la incertidumbre social entre ellos. 
'CAPÍTULO 5. CONCLUSIONES, IMPLICACIONES, LIMITACIONES E INVESTIGACIÓN FUTURA' 
El Estudio I concluye que la decisión de socio para empezar a construir rutinas de colaboración (1) es una cuestión de expectativas de creación de valor (Adner y Helfat de 2003, Ambrosini y Bowman, 2009), y (2) implica la comparación de posibles beneficios y costes por parte del directivo (Winter, 2003). Así, el estudio apoya las conclusiones de estudios anteriores que sugieren que la competencia directa entre los socios eclipsa la cooperación (Park y Russo, 1996; García-Canal et al., 2003;; Oxley y Sampson, 2004; Valdés-Llaneza y García-Canal, 2006), que la orientación al aprendizaje y la importancia estratégica pueden fomentar la cooperación (Hamel, 1991; Parkhe, 1993; Cullen et al., 1995; Olk y Young, 1997; Mothe y Quelin, 2001; Wu y Cavusgil , 2006), y que la dinámica interna de una alianza coevoluciona con factores externos del contexto de dicha alianza (Ariño y De La Torre, 1998; Koza y Lewin, 1998).

El Estudio II.1 y el Estudio II.2 contribuyen conjuntamente a mejorar el conocimiento sobre las dinámicas de creación de valor de la las alianzas de I+D, mediante la explicación de (1) cómo los socios no familiares pueden tener éxito en la exploración mediante la creación efectiva s rutinas de colaboración interorganizativas, y (2) cómo los socios familiares s pueden tener éxito tanto en contextos de exploración como de explotación cuando redistribuyen sus rutinas de colaboración de forma efectiva. De este modo, el Estudio II arroja alguna luz sobre los procesos de desarrollo de la capacidad dinámica de dos socios para colaborar juntos (Madhok y Tallman, 1998; Helfat y Peteraf, 2003), estudiando cómo la experiencia mutua se va acumulando y va afectando a los elementos constitutivos de dicha capacidad (Zollo et al., 2002; Hoang y Rothaermel, 2005). Por lo tanto, el Estudio II se contribuye a extender la 'perspectiva micro’ de las capacidades dinámicas (Teece, 2007) al campo de las capacidades de alianza (Kale y Singh, 2009; Schreiner et al., 2009; De Man et al, 2010). 


\section{'REFERENCIAS BIBLIOGRÁFICAS'}




\section{REFERENCIAS UTILIZADAS EN ESTE RESUMEN}

Adner, R., \& Helfat, C. E. (2003). Corporate effects and dynamic managerial capabilities. Strategic Management Journal, 24(10), 1011-1025.

Ambrosini, V., \& Bowman, C. (2009). What are dynamic capabilities and are they a useful construct in strategic management? International Journal of Management Reviews, 11(1), 29-49.

Anand, B. N., \& Khanna, T. (2000). Do firms learn to create value? the case of alliances. Strategic Management Journal, 21(3), 295-315.

Ariño, A. (2001). To do or not to do? Noncooperative behavior by commission and omission in interfirm ventures. Group \& Organization Management, 26(1), 4-23.

Ariño, A. (2003). Measures of strategic alliance performance: An analysis of construct validity. Journal of International Business Studies, 33(1), 1-14.

Ariño, A., \& De La Torre, J. (1998). Learning from failure: Towards an evolutionary model of collaborative ventures. Organization Science, 9(3), 306-325.

Ariño, A., \& Ring, P. S. (2010). The role of fairness in alliance formation. Strategic Management Journal, 31(10), 1054-1087.

Cullen, J. B., Johnson, J. L., \& Sakano, T. (1995). Japanese and local partner commitment to IJVs: Psychological consequences of outcomes and investments in the IJV relationship. Journal of International Business Studies, 26(1), 91-115.

Das, T. K., \& Teng, B. S. (2002). Alliance constellations: A social exchange perspective. Academy of Management Review, 27(3), 445-456.

De Man, A. P., Duysters, G., \& Saebi, T. (2010). Alliance capability as an emergent theme: Past, present, future. In T. K. Das (Ed.), Researching strategic alliances (pp. 57-76). Charlotte, NC: Information Age Publishing Inc.

Doz, Y. L., Olk, P. M., \& Ring, P. S. (2000). Formation processes of R\&D consortia: Which path to take? where does it lead? Strategic Management Journal, 21(3), 239-266.

Dyer, J. H., \& Nobeoka, K. (2000). Creating and managing a high-performance knowledgesharing network: The toyota case. Strategic Management Journal, 21(3), 345-367.

Dyer, J. H., \& Singh, H. (1998). The relational view: Cooperative strategy and sources of interorganizational competitive advantage. Academy of Management Review, 23(4), 660679.

Eisenhardt, K. M., \& Martin, J. A. (2000). Dynamic capabilities: What are they? Strategic Management Journal, 21(10-11), 1105-1121.

Eisenhardt, K. M., \& Schoonhoven, C. B. (1996). Resource-based view of strategic alliance formation: Strategic and social effects in entrepreneurial firms. Organization Science, 7(2), 136-150. 
Faems, D., Janssens, M., Madhok, A., \& Van Looy, B. (2008). Toward an integrative perspective on alliance governance: Connecting contract design, trust dynamics, and contract application. Academy of Management Journal, 51(6), 1053-1078.

Galunic, D. C., \& Eisenhardt, K. M. (2001). Architectural innovation and modular corporate forms. Academy of Management Journal, 18(1), 1229-1249.

García-Canal, E., Valdés-Llaneza, A., \& Ariño, A. (2003). Effectiveness of dyadic and multiparty joint ventures. Organization Studies, 24(5), 743-770.

Gulati, R. (1995). Does familiarity breed trust? the implications of repeated ties for contractual choice in alliances. Academy of Management Journal, 38(1), 85-112.

Gulati, R. (1998). Alliances and networks. Strategic Management Journal, 19(4), 293-317.

Hamel, G. (1991). Competition for competence and interpartner learning within international strategic alliances. Strategic Management Journal, 12(Special issue on global strategy), 83-103.

Helfat, C. E., \& Peteraf, M. A. (2003). The dynamic resource-based view: Capability lifecycles. Strategic Management Journal, 24(10), 997-1010.

Hoang, H., \& Rothaermel, F. T. (2005). The effect of general and partner-specific alliance experience on joint R\&D project performance. Academy of Management Journal, 48(2), 332-345.

Kale, P., \& Singh, H. (2007). Building firm capabilities through learning: The role of the alliance learning process in alliance capability and firm - level alliance success. Strategic Management Journal, 28(10), 981-1000.

Kogut, B., \& Zander, U. (1996). What firms do? coordination, identity, and learning. Organization Science, 7(5), 502-518.

Koza, M. P., \& Lewin, A. Y. (1998). The co-evolution of strategic alliances. Organization Science, 9(3), 255-264.

Madhok, A., \& Tallman, S. B. (1998). Resources, transactions and rents: Managing value through interfirm collaborative relationships. Organization Science, 9(3), 326-339.

Mahnke, V., \& Overby, M. L. (2008). Failure sources in R\&D consortia: The case of mobile service development. International Journal of Technology Management, 44(1), 160-178.

Mora-Valentín, E. M., Montoro-Sánchez, M. Á., \& Guerras-Martín, L. A. (2004). Determining factors in the success of R\&D cooperative agreements between firms and research organizations. Research Policy, 33(1), 17-40.

Mothe, C., \& Quelin, B. V. (2001). Resource creation and partnership in R\&D consortia. The Journal of High Technology Management Research, 12(1), 113-138.

Nielsen, B. B. (2010). Multilevel issues in strategic alliance research. In T. K. Das (Ed.), Researching strategic alliances (pp. 57-76). Charlotte, NC: Information Age Publishing Inc. 
Oliver, C. (1991). Strategic responses to institutional processes. The Academy of Management Review, 16(1), 145-179.

Olk, P., \& Young, C. (1997). Why members stay in or leave an R\&D consortium: Performance and conditions of membership as determinants of continuity. Strategic Management Journal, 18(11), 855-877.

Oxley, J. E., \& Sampson, R. C. (2004). The scope and governance of international R\&D alliances. Strategic Management Journal, 25(8-9), 723-749.

Park, S. H., \& Russo, M. V. (1996). When competition eclipses cooperation: An event history analysis of joint venture failure. Management Science, 42(6), 875-890.

Park, S. H., \& Ungson, G. R. (2001). Interfirm rivalry and managerial complexity: A conceptual framework of alliance failure. Organization Science, 12(1), 37-53.

Parkhe, A. (1991). Interfirm diversity, organizational learning, and longevity in global strategic alliances. Journal of International Business Studies, 22(4), 579-601.

Sakakibara, M. (1997). Heterogeneity of firm capabilities and cooperative research and development: An empirical examination of motives. Strategic Management Journal, 18(1), 143-164.

Salk, J. E. (2005). Often called for but rarely chosen: Alliance research that directly studies process. European Management Review, 2(2), 117-122.

Sampson, R. C. (2005). Experience effects and collaborative returns in R\&D alliances. Strategic Management Journal, 26(11), 1009-1031.

Sampson, R. C. (2007). R\&D alliances and firm performance: The impact of technological diversity and alliance organization on innovation. Academy of Management Journal, 50(2), 364-386.

Sarkar, M. B., Aulakh, P. S., \& Madhok, A. (2009). Process capabilities and value generation in alliance portfolios. Organization Science, 20(3), 583-600.

Schilke, O., \& Goerzen, A. (2010). Alliance management capability: An investigation of the construct and its measurement. Journal of Management, 36(5), 1192-1219.

Schreiner, M., Kale, P., \& Corsten, D. (2009). What really is alliance management capability and how does it impact alliance outcomes and success? Strategic Management Journal, 30(13), 1395-1419.

Simonin, B. L. (1997). The importance of collaborative know-how: An empirical test of the learning organization. Academy of Management Journal, 40(5), 1150-1174.

Teece, D. J. (2007). Explicating dynamic capabilities: The nature and microfoundations of (sustainable) enterprise performance. Strategic Management Journal, 28(13), 1319-1350.

Teece, D. J., Pisano, G., \& Shuen, A. (1997). Dynamic capabilities and strategic management. Strategic Management Journal, 18(7), 509-533. 
Thorgren, S., Wincent, J., \& Eriksson, J. (2010). Too small or too large to trust your partners in multipartner alliances? the role of effort in initiating generalized exchanges. Scandinavian Journal of Management, 27(1), 99-112.

Tripsas, M. (1997a). Surviving radical technological change through dynamic capability: Evidence from the typesetter industry. Industrial and Corporate Change, 6(2), 341-377.

Valdés-Llaneza, A., \& García-Canal, E. (2006). Direct competition, number of partners and the longevity of stakes in joint ventures. Management International Review, 46(3), 307-326.

Winter, S. G. (2003). Understanding dynamic capabilities. Strategic Management Journal, 24(10), 991-995.

Wu, F., \& Cavusgil, S. T. (2006). Organizational learning, commitment, and joint value creation in interfirm relationships. Journal of Business Research, 59(1), 81-89.

Yin, R. K. (2003). Case study research, design and methods. Thousand Oaks, CA.: Sage publications.

Zeng, M., \& Chen, X. P. (2003). Achieving cooperation in multiparty alliances: A social dilemma approach to partnership management. Academy of Management Review, 28(4), 587-605.

Zollo, M., Reuer, J. J., \& Singh, H. (2002). Interorganizational routines and performance in strategic alliances. Organization Science, 13(6), 701-713.

Zollo, M., \& Winter, S. G. (2002). Deliberate learning and the evolution of dynamic capabilities. Organization Science, 13(3), 339-351. 


\section{REFRENCIAS UTILIZADAS EN LA TESIS DOCTORAL}

Adner, R. (2007). Real options and resource reallocation processes. Advances in Strategic Management, 24, 363-372.

Adner, R., y Helfat, C. E. (2003). Corporate effects and dynamic managerial capabilities. Strategic Management Journal, 24(10), 1011-1025.

Adner, R., y Levinthal, D. A. (2004). What is not a real option: Considering boundaries for the application of real options to business strategy. The Academy of Management Review, 29(1), 74-85.

Ahuja, G. (2000). The duality of collaboration: Inducements and opportunities in the formation of interfirm linkages. Strategic Management Journal, 21(3), 317-343.

Ambrosini, V., y Bowman, C. (2009). What are dynamic capabilities and are they a useful construct in strategic management? International Journal of Management Reviews, 11(1), 29-49.

Amit, R., y Schoemaker, P. J. H. (1993). Strategic assets and organizational rent. Strategic Management Journal, 14(1), 33-46.

Anand, B. N., y Khanna, T. (2000). Do firms learn to create value? the case of alliances. Strategic Management Journal, 21(3), 295-315.

Anand, J., Oriani, R., y Vassolo, R. S. (2010). Alliance activity as a dynamic capability in the face of a discontinuous technological change. Organization Science, 21(6), 1213-1232.

Anand, J., y Singh, H. (1997). Asset redeployment, acquisitions and corporate strategy in declining industries. Strategic Management Journal, 18(1), 99-118.

Anderson, J. C., y Gerbing, D. W. (1988). Structural equation modeling in practice: A review and recommended two-step approach. Psychological Bulletin, 103(3), 411.

Anderson, J. C., y Narus, J. A. (1990). A model of distributor firm and manufacturer firm working partnerships. The Journal of Marketing, 54(1), 42-58.

Arend, R. J., y Bromiley, P. (2009). Assessing the dynamic capabilities view: Spare change, everyone? Strategic Organization, 7(1), 75-90. 
Ariño, A. (2001). To do or not to do? Noncooperative behavior by commission and omission in interfirm ventures. Group y Organization Management, 26(1), 4-23.

Ariño, A. (2003). Measures of strategic alliance performance: An analysis of construct validity. Journal of International Business Studies, 33(1), 1-14.

Ariño, A., y De La Torre, J. (1998). Learning from failure: Towards an evolutionary model of collaborative ventures. Organization Science, 9(3), 306-325.

Ariño, A., y Doz, Y. (2000). Rescuing troubled alliances... before it's too late. European Management Journal, 18(2), 173-182.

Ariño, A., y Ring, P. S. (2010). The role of fairness in alliance formation. Strategic Management Journal, 31(10), 1054-1087.

Axelrod, R. (1984). The evolution of cooperation. New York: Basic Books.

Baldwin, C., Hienerth, C., y von Hippel, E. (2006). How user innovations become commercial products: A theoretical investigation and case study. Research Policy, 35(9), 1291-1313.

Barney, J. (1991). Firm resources and sustained competitive advantage. Journal of Management, 17(1), 99-120.

Barringer, B. R., y Harrison, J. S. (2000). Walking a tightrope: Creating value through interorganizational relationships. Journal of Management, 26(3), 367-403.

Bayona, C., Garcia-Marco, T., y Huerta, E. (2001). Firms' motivations for cooperative R\&D: An empirical analysis of spanish firms. Research Policy, 30(8), 1289-1307.

Becerra, M., Lunnan, R., y Huemer, L. (2008). Trustworthiness, risk, and the transfer of tacit and explicit knowledge between alliance partners. Journal of Management Studies, 45(4), 691-713.

Becker, M. C. (2004). Organizational routines: A review of the literature. Industrial and Corporate Change, 13(4), 643.

Becker, M. C. (2005). A framework for applying organizational routines in empirical research: Linking antecedents, characteristics and performance outcomes of recurrent interaction patterns. Industrial and Corporate Change, 14(5), 817-846. 
Becker, M. C., Lazaric, N., Nelson, R. R., y Winter, S. G. (2005). Applying organizational routines in understanding organizational change. Industrial and Corporate Change, 14(5), 775-791.

Beckman, C. M., Haunschild, P. R., y Phillips, D. J. (2004). Friends or strangers? firm-specific uncertainty, market uncertainty, and network partner selection. Organization Science, 15(3), 259-275.

Bell, J., Den Ouden, B., y Ziggers, G. W. (2006). Dynamics of cooperation: At the brink of irrelevance. Journal of Management Studies, 43(7), 1607-1619.

Bercovitz, J. E. L., y Feldman, M. P. (2007). Fishing upstream: Firm innovation strategy and university research alliances. Research Policy, 36(7), 930-948.

Blau, P. M. (1964). Exchange and power in social life. New York: Wiley.

Bonache, J. (1999). El estudio de casos como estrategia de construcción teórica: Características, críticas y defensas. Cuadernos De Economía y Dirección De La Empresa, (3), 123-140.

Boon, C. (2008). HRM and fit. survival of the fittest!? Doctoral dissertation. Rotterdam School of Management. Erasmus University.

Bowman, E. H., y Hurry, D. (1993). Strategy through the option lens: An integrated view of resource investments and the incremental-choice process. Academy of Management Review, 18(4), 760-782.

Bresser, R. K. F. (1988). Matching collective and competitive strategies. Strategic Management Journal, 9(4), 375-385.

Browning, L. D., Beyer, J. M., y Shetler, J. C. (1995). Building cooperation in a competitive industry: SEMATECH and the semiconductor industry. Academy of Management Journal, 38(1), 113-151.

Bruni, D. S., y Verona, G. (2009). Dynamic marketing capabilities in Science - based firms: An exploratory investigation of the pharmaceutical industry. British Journal of Management, 20(S1), S101-S117. 
Bueno, E., Rodriguez Anton, J. M., y Salmador, M. P. (2008). Knowledge creation as a dynamic capability: Implications for innovation management and organisational design. International Journal of Technology Management, 41(1), 155-168.

Camarero-Izquierdo, C., y Gutiérrez-Cillán, J. (2004). The interaction of dependence and trust in long-term industrial relationships. European Journal of Marketing, 38(8), 974-994.

Camuffo, A., y Volpato, G. (1996). Dynamic capabilities and manufacturing automation: Organizational learning in the Italian automobile industry. Industrial and Corporate Change, 5(3), 813-838.

Capaldo, A. (2007). Network structure and innovation: The leveraging of a dual network as a distinctive relational capability. Strategic Management Journal, 28(6), 585-608.

Capron, L., Dussauge, P., y Mitchell, W. (1998). Resource redeployment following horizontal acquisitions in Europe and north America, 1988-1992. Strategic Management Journal, 19(7), 631-661.

Capron, L., y Mitchell, W. (1998). Bilateral resource redeployment and capabilities improvement following horizontal acquisitions. Industrial and Corporate Change, 7(3), 453-484.

Cassimon, D., Engelen, P. J., Thomassen, L., y Van Wouwe, M. (2004). The valuation of a NDA using a 6-fold compound option. Research Policy, 33(1), 41-51.

Cohen, M. D., y Bacdayan, P. (1994). Organizational routines are stored as procedural memory: Evidence from a laboratory study. Organization Science, 5(4), 554-568.

Cohen, W. M., y Levinthal, D. A. (1990). Absorptive capacity: A new perspective on learning and innovation. Administrative Science Quarterly, 35(1), 128-152.

Collis, D. J. (1994). Research note: How valuable are organizational capabilities? Strategic Management Journal, 15(S1), 143-152.

Colombo, M. G. (2003). Alliance form: A test of the contractual and competence perspectives. Strategic Management Journal, 24(12), 1209-1229. 
Colquitt, J. A., y Zapata-Phelan, C. P. (2007). Trends in theory building and theory testing: A five-decade study of the academy of management journal. Academy of Management Journal, 50(6), 1281-1303.

Comino, S., Mariel, P., y Sandonís, J. (2007). Joint ventures versus contractual agreements: An empirical investigation. Spanish Economic Review, 9(3), 159-175.

Contractor, F. J. (2005). Alliance structure and process: Will the two research streams ever meet in alliance research? European Management Review, 2(2), 123-129.

Contractor, F. J., y Lorange, P. (1988). Cooperative strategies in international business: Joint ventures and technology partnerships between firms. New York: Pergamon.

Cropanzano, R., y Mitchell, M. S. (2005). Social exchange theory: An interdisciplinary review. Journal of Management, 31(6), 874-900.

Cullen, J. B., Johnson, J. L., y Sakano, T. (1995). Japanese and local partner commitment to IJVs: Psychological consequences of outcomes and investments in the IJV relationship. Journal of International Business Studies, 26(1), 91-115.

Cullen, J. B., Johnson, J. L., y Sakano, T. (2000). Success through commitment and trust: The soft side of strategic alliance management. Journal of World Business, 35(3), 223-240.

Culpan, R. (2009). A fresh look at strategic alliances: Research issues and future directions. International Journal of Strategic Business Alliances, 1(1), 4-23.

Dacin, M. T., Oliver, C., y Roy, J. P. (2007). The legitimacy of strategic alliances: An institutional perspective. Strategic Management Journal, 28(2), 169-187.

Daellenbach, U. S., y Davenport, S. J. (2004). Establishing trust during the formation of technology alliances. The Journal of Technology Transfer, 29(2), 187-202.

Danneels, E. (2002). The dynamics of product innovation and firm competences. Strategic Management Journal, 23(12), 1095-1121.

Danneels, E. (2008). Organizational antecedents of second - order competences. Strategic Management Journal, 29(5), 519-543. 
Darr, E. D., y Kurtzberg, T. R. (2000). An investigation of partner similarity dimensions on knowledge transfer. Organizational Behavior and Human Decision Processes, 82(1), 2844.

Das, T. K., y Kumar, R. (2010). Interpartner sensemaking in strategic alliances: Managing cultural differences and internal tensions. Management Decision, 48(1), 17-36.

Das, T. K., y Teng, B. S. (1998a). Between trust and control: Developing confidence in partner cooperation in alliances. Academy of Management Review, 23(3), 491-512.

Das, T. K., y Teng, B. S. (1998b). Resource and risk management in the strategic alliance making process. Journal of Management, 24(1), 21-42.

Das, T. K., y Teng, B. S. (2000a). Instabilities of strategic alliances: An internal tensions perspective. Organization Science, 11(1), 77-101.

Das, T. K., y Teng, B. S. (2000b). A resource-based theory of strategic alliances. Journal of Management, 26(1), 31-61.

Das, T. K., y Teng, B. S. (2002). Alliance constellations: A social exchange perspective. Academy of Management Review, 27(3), 445-456.

Das, T. K., y Kumar, R. (2011). Regulatory focus and opportunism in the alliance development process. Journal of Management, 37(3), 682-708.

De Andrés - Alonso, P., Azofra - Palenzuela, V., y De La Fuente - Herrero, G. (2006). The real options component of firm market value: The case of the technological corporation. Journal of Business Finance and Accounting, 33(1 - 2), 203-219.

De Man, A. P., y Duysters, G. (2005). Collaboration and innovation: A review of the effects of mergers, acquisitions and alliances on innovation. Technovation, 25(12), 1377-1387.

De Man, A. P., Duysters, G., y Saebi, T. (2010). Alliance capability as an emergent theme: Past, present, future. In T. K. Das (Ed.), Researching strategic alliances (pp. 57-76). Charlotte, NC: Information Age Publishing Inc.

De Rond, M., y Bouchikhi, H. (2004). On the dialectics of strategic alliances. Organization Science, 15(1), 56-69. 
Deeds, D. L., DeCarolis, D., y Coombs, J. (2000). Dynamic capabilities and new product development in high technology ventures: An empirical analysis of new biotechnology firms. Journal of Business Venturing, 15(3), 211-229.

Deeds, D. L., y Rothaermel, F. T. (2003). Honeymoons and liabilities: The relationship between age and performance in research and development alliances. Journal of Product Innovation Management, 20(6), 468-484.

Dhanaraj, C., y Parkhe, A. (2006). Orchestrating innovation networks. Academy of Management Review, 31(3), 659-679.

Di Stefano, G., Peteraf, M., y Verona, G. (2010). Dynamic capabilities deconstructed: A bibliographic investigation into the origins, development, and future directions of the research domain. Industrial and Corporate Change, 19(4), 1187-1204.

DiMaggio, P. J., y Powell, W. W. (1983). The iron cage revisited: Institutional isomorphism and collective rationality in organizational fields. American Sociological Review, 48(2), 147160.

Dosi, G., Nelson, R. R., y Winter, S. G. (2000). The nature and dynamics of organizational capabilities Oxford University Press, USA.

Doz, Y. L. (1996). The evolution of cooperation in strategic alliances: Initial conditions or learning processes? Strategic Management Journal, 17(Summer special issue), 55-83.

Doz, Y. L., Olk, P. M., y Ring, P. S. (2000). Formation processes of R\&D consortia: Which path to take? where does it lead? Strategic Management Journal, 21(3), 239-266.

Draulans, J., De Man, A. P., y Volberda, H. W. (2003). Building alliance capability: Management techniques for superior alliance performance. Long Range Planning, 36(2), 151-166.

Drnevich, P. L., y Kriauciunas, A. P. (2011). Clarifying the conditions and limits of the contributions of ordinary and dynamic capabilities to relative firm performance. Strategic Management Journal, 32(3), 254-279.

Dutta, S., Narasimhan, O., y Rajiv, S. (2005). Conceptualizing and measuring capabilities: Methodology and empirical application. Strategic Management Journal, 26(3), 277-285. 
Dyer, J. H. (1997). Effective interim collaboration: How firms minimize transaction costs and maximise transaction value. Strategic Management Journal, 18(7), 535-556.

Dyer, J. H., y Hatch, N. W. (2006). Relation-specific capabilities and barriers to knowledge transfers: Creating advantage through network relationships. Strategic Management Journal, 27(8), 701-719.

Dyer, J. H., y Nobeoka, K. (2000). Creating and managing a high-performance knowledgesharing network: The toyota case. Strategic Management Journal, 21(3), 345-367.

Dyer, J. H., y Singh, H. (1998). The relational view: Cooperative strategy and sources of interorganizational competitive advantage. Academy of Management Review, 23(4), 660679.

Dyer, W. G., y Wilkins, A. L. (1991). Better stories, not better constructs, to generate better theory: A rejoinder to Eisenhardt. The Academy of Management Review, 16(3), 613-619.

Easterby - Smith, M., Lyles, M. A., y Peteraf, M. A. (2009). Dynamic capabilities: Current debates and future directions. British Journal of Management, 20(S1), S1-S8.

Easterby - Smith, M., y Prieto, I. M. (2008). Dynamic capabilities and knowledge management: An integrative role for learning? British Journal of Management, 19(3), 235-249.

Edmondson, A. C., Bohmer, R. M., y Pisano, G. P. (2001). Disrupted routines: Team learning and new technology implementation in hospitals. Administrative Science Quarterly, 46(4), 685-716.

Eisenhardt, K. M. (1989). Building theories from case study research. Academy of Management Review, 14(4), 532-550.

Eisenhardt, K. M. (1991). Better stories and better constructs: The case for rigor and comparative logic. Academy of Management Review, 16(3), 620-627.

Eisenhardt, K. M., y Graebner, M. E. (2007). Theory building from cases: Opportunities and challenges. Academy of Management Journal, 50(1), 25-32.

Eisenhardt, K. M., y Martin, J. A. (2000). Dynamic capabilities: What are they? Strategic Management Journal, 21(10-11), 1105-1121. 
Eisenhardt, K. M., y Schoonhoven, C. B. (1996). Resource-based view of strategic alliance formation: Strategic and social effects in entrepreneurial firms. Organization Science, 7(2), $136-150$.

Eisner, A. B., Rahman, N., y Korn, H. J. (2009). Formation conditions, innovation, and learning in R\&D consortia. Management Decision, 47(6), 851-871.

Emden, Z., Yaprak, A., y Cavusgil, S. T. (2005). Learning from experience in international alliances: Antecedents and firm performance implications. Journal of Business Research, 58(7), 883-892.

Escribá-Esteve, A. (2002). Procesos de generación de confianza en los acuerdos de cooperación: Una aproximación desde el comportamiento de las empresas participantes. Cuadernos De Economía y Dirección De La Empresa, (13), 469-498.

Escribá-Esteve, A., y Urra-Urbieta, J. A. (2002). An analysis of co-operative agreements from a knowledge-based perspective: An integrative conceptual framework. Journal of Knowledge Management, 6(4), 330-346.

Estrada, I., de la Fuente, G., y Martín-Cruz, N. (2010). Technological joint venture formation under the real options approach. Research Policy, 39(9), 1185-1197.

Evan, W. M., y Olk, P. (1990). R\&D consortia: A new US organizational form. Sloan Management Review, 31(3), 37-46.

Faems, D. (2006). Collaboration for innovation: Processes of governance and learning in R\&D alliances. Doctoral dissertation. Katholieke Universiteit Leuven.

Faems, D., Janssens, M., Madhok, A., y Van Looy, B. (2008). Toward an integrative perspective on alliance governance: Connecting contract design, trust dynamics, and contract application. Academy of Management Journal, 51(6), 1053-1078.

Faems, D., Janssens, M., y Van Looy, B. (2007). The initiation and evolution of interfirm knowledge transfer in R\&D relationships. Organization Studies, 28(11), 1699-1728.

Faems, D., y Madhok, A. (2009). Transitional governance: A critical review of implicit process assumptions. In S. Finkelstein, y C. Cooper (Eds.), Advances and mergers and acquisitions (pp. 61-78) Emerald Group Publishing Limited. 
Feldman, M. S. (2000). Organizational routines as a source of continuous change. Organization Science, 11(6), 611-629.

Feldman, M. S., y Pentland, B. T. (2003). Reconceptualizing organizational routines as a source of flexibility and change. Administrative Science Quarterly, 48(1), 94-121.

Feldman, M. S., y Rafaeli, A. (2002). Organizational routines as sources of connections and understandings. Journal of Management Studies, 39(3), 309-331.

Fichman, M., y Levinthal, D. A. (1991). Honeymoons and the liability of adolescence: A new perspective on duration dependence in social and organizational relationships. Academy of Management Review, 16(2), 442-468.

Filippini, R., Güttel, W. H., y Nosella, A. (2011). Ambidexterity and the evolution of knowledge management initiatives. Journal of Business Research, 65(3), 317-324.

Fiss, P. C. (2007). A set-theoretic approach to organizational configurations. The Academy of Management Review, 32(4), 1180-1198.

Folta, T. B. (1998). Governance and uncertainty: The tradeoff between administrative control and commitment. Strategic Management Journal, 19(11), 1007-1028.

Folta, T. B., y Miller, K. D. (2002). Real options in equity partnerships. Strategic Management Journal, 23(1), 77-88.

Fornell, C., y Larcker, D. F. (1981). Evaluating structural equation models with unobservable variables and measurement error. Journal of Marketing Research, 18(1), 39-50.

Forrest, J. E., y Martin, M. J. C. (1992). Strategic alliances between large and small research intensive organizations: Experiences in the biotechnology industry. R\&D Management, 22(1), 41-54.

Fritsch, M., y Lukas, R. (2001). Who cooperates on R\&D? Research Policy, 30(2), 297-312.

Fuentelsaz, L., y Gómez, J. (2006). Multipoint competition, strategic similarity and entry into geographic markets. Strategic Management Journal, 27(5), 477-499.

Fuller, M. B., y Porter, M. E. (1986). Coalitions and global strategy. In M. E. Porter (Ed.), Competition in global industries (pp. 315-343). Boston: Harvard Business School Press. 
Galende-del-Canto, J., y Suárez-González, I. (1999). A resource-based analysis of the factors determining a firm's R\&D activities. Research Policy, 28(8), 891-905.

Galunic, D. C., y Eisenhardt, K. M. (2001). Architectural innovation and modular corporate forms. Academy of Management Journal, 18(1), 1229-1249.

García Falcón, J. M., y Medina Muñoz, D. R. (1998). Enfoques teóricos sobre las relaciones interorganizativas: Una revisión comparativa. Revista Europea De Dirección y Economía De La Empresa, 7(3), 31-52.

García Muina, F. E., Martin De Castro, G., López Saez, P., y Navas López, J. E. (2006). The complexity in technological capabilities: Evidence from biotechnological Spanish firms. International Journal of Technology Management, 35(1), 224-240.

García-Canal, E. (1996). Contractual form in domestic and international strategic alliances. Organization Studies, 17(5), 773-794.

García-Canal, E. (1999). Cooperative agreements in Spain after its integration into the European union. European Business Review, 99(2), 105-114.

García-Canal, E., Valdés-Llaneza, A., y Ariño, A. (2003). Effectiveness of dyadic and multiparty joint ventures. Organization Studies, 24(5), 743-770.

García-Canal, E., Valdés-Llaneza, A., y Sánchez-Lorda, P. (2008). Technological flows and choice of joint ventures in technology alliances. Research Policy, 37(1), 97-114.

Gavetti, G. (2005). Cognition and hierarchy: Rethinking the microfoundations of capabilities' development. Organization Science, 16(6), 599-617.

Gephart, R. (2004). From the editors: Qualitative research and the academy management journal. Academy of Management Journal, 47(4), 454-462.

Geringer, J. M. (1991). Strategic determinants of partner selection criteria in international joint ventures. Journal of International Business Studies, 22(1), 41-62.

Geringer, J. M., y Hebert, L. (1991). Measuring performance of international joint ventures. Journal of International Business Studies, 22(2), 249-263. 
Gibbert, M., Ruigrok, W., y Wicki, B. (2008). What passes as a rigorous case study? Strategic Management Journal, 29(13), 1465-1474.

Gilbert, C. G. (2006). Change in the presence of residual fit: Can competing frames coexist? Organization Science, 17(1), 150-167.

Gioia, D. A., y Chittipeddi, K. (1991). Sensemaking and sensegiving in strategic change initiation. Strategic Management Journal, 12(6), 433-448.

Glaister, K. W., y Buckley, P. J. (1998). Measures of performance in UK international alliances. Organization Studies, 19(1), 89-118.

Goerzen, A. (2007). Alliance networks and firm performance: The impact of repeated partnerships. Strategic Management Journal, 28(5), 487-509.

Gogan, J. L., Gelinas Jr, U. J., y Rao, A. (2007). Learning in a consortium: A longitudinal case study. International Journal of Technology Management, 38(1), 90-112.

Gomes-Casseres, B. (2003). Competitive advantage in alliance constellations. Strategic Organization, 1(3), 327-335.

Gong, Y., Shenkar, O., Luo, Y., y Nyaw, M. K. (2007). Do multiple parents help or hinder international joint venture performance? the mediating roles of contract completeness and partner cooperation. Strategic Management Journal, 28(10), 1021-1034.

González-Benito, J., Suárez-González, I., y Spring, M. (2000). Complementarities between JIT purchasing practices: An economic analysis based on transaction costs. International Journal of Production Economics, 67(3), 279-293.

Grandori, A., y Soda, G. (1995). Inter-firm networks: Antecedents, mechanisms and forms. Organization Studies, 16(2), 183-214.

Granovetter, M. S. (1973). The strength of weak ties. American Journal of Sociology, 78(6), 1360-1380.

Granovetter, M. S. (1985). Economic action and social structure: The problem of embeddedness. American Journal of Sociology, 91(3), 481-510. 
Grant, R. M. (1996). Toward a knowledge-based theory of the firm. Strategic Management Journal, 17(Winter Special Issue), 109-122.

Grant, R. M., y Baden - Fuller, C. (2004). A knowledge accessing theory of strategic alliances. Journal of Management Studies, 41(1), 61-84.

Gray, B., y Wood, D. J. (1991). Collaborative alliances: Moving from practice to theory. The Journal of Applied Behavioral Science, 27(1), 3-22.

Gulati, R. (1995). Does familiarity breed trust? the implications of repeated ties for contractual choice in alliances. Academy of Management Journal, 38(1), 85-112.

Gulati, R. (1998). Alliances and networks. Strategic Management Journal, 19(4), 293-317.

Gulati, R. (1999). Network location and learning: The influence of network resources and firm capabilities on alliance formation. Strategic Management Journal, 20(5), 397-420.

Gulati, R., y Gargiulo, M. (1999). Where do interorganizational networks come from? American Journal of Sociology, 104(5), 1398-1438.

Gulati, R., Lavie, D., y Singh, H. (2009). The nature of partnering experience and the gains from alliances. Strategic Management Journal, 30(11), 1213-1233.

Gulati, R., Nohria, N., y Zaheer, A. (2000). Strategic networks. Strategic Management Journal, 21(3), 203-215.

Gulati, R., y Singh, H. (1998). The architecture of cooperation: Managing coordination costs and appropriation concerns in strategic alliances. Administrative Science Quarterly, 43(4), 781-784.

Gupta, A. K., Smith, K. G., y Shalley, C. E. (2006). The interplay between exploration and exploitation. Academy of Management Journal, 49(4), 693-706.

Habbershon, T. G., y Williams, M. L. (1999). A resource-based framework for assessing the strategic advantages of family firms. Family Business Review, 12(1), 1-25.

Hagedoorn, J. (1993). Understanding the rationale of strategic technology partnering: Interorganizational modes of cooperation and sectoral differences. Strategic Management Journal, 14(5), 371-385. 
Hagedoorn, J. (2002). Inter-firm R\&D partnerships: An overview of major trends and patterns since 1960. Research Policy, 31(4), 477-492.

Hagedoorn, J. (2006). Understanding the cross-level embeddedness of interfirm partnership formation. Academy of Management Review, 31(3), 670-680.

Hagedoorn, J., Link, A. N., y Vonortas, N. S. (2000). Research partnerships1. Research Policy, 29(4-5), 567-586.

Hamel, G. (1991). Competition for competence and interpartner learning within international strategic alliances. Strategic Management Journal, 12(Special issue on global strategy), 83-103.

Hartmann, M., y Hassan, A. (2006). Application of real options analysis for pharmaceutical R\&D project valuation: Empirical results from a survey. Research Policy, 35(3), 343-354.

Hatfield, L., Pearce, J. A., Sleeth, R. G., y Pitts, M. W. (1998). Toward validation of partner goal achievement as a measure of joint venture performance. Journal of Managerial Issues, 10(3), 355-372.

Heide, J. B., y John, G. (1992). Do norms matter in marketing relationships? The Journal of Marketing, 56(2), 32-44.

Heidl, R. (2010). The stability of multi-partner alliances: A resource dependence and social embeddedness perspective. Doctoral dissertation. University of Washington.

Heimeriks, K. H., y Duysters, G. (2007). Alliance capability as a mediator between experience and alliance performance: An empirical investigation into the alliance capability development process. Journal of Management Studies, 44(1), 25-49.

Helfat, C. E. (1997). Know-how and asset complementarity and dynamic capability accumulation: The case of R\&D. Strategic Management Journal, 18(5), 339-360.

Helfat, C. E., Finkelstein, S., y Mitchell, W. (2007). Dynamic capabilities: Understanding strategic change in organizations Wiley-Blackwell.

Helfat, C. E., y Peteraf, M. A. (2003). The dynamic resource-based view: Capability lifecycles. Strategic Management Journal, 24(10), 997-1010. 
Hennart, J. F. (1988). A transaction costs theory of equity joint ventures. Strategic Management Journal, 9(4), 361-374.

Hennart, J. F. (2006). Alliance research: Less is more. Journal of Management Studies, 43(7), 1621-1628.

Hennart, J. F., y Reddy, S. (1997). The choice between mergers/acquisitions and joint ventures: The case of japanese investors in the united states. Strategic Management Journal, 18(1), $1-12$.

Herrera, L., y Nieto, M. (2008). The national innovation policy effect according to firm location. Technovation, 28(8), 540-550.

Hill, J. A., Eckerd, S., Wilson, D., y Greer, B. (2009). The effect of unethical behavior on trust in a buyer-supplier relationship: The mediating role of psychological contract violation. Journal of Operations Management, 27(4), 281-293.

Hoang, H., y Rothaermel, F. T. (2005). The effect of general and partner-specific alliance experience on joint R\&D project performance. Academy of Management Journal, 48(2), 332-345.

Hoang, H., y Rothaermel, F. T. (2010). Leveraging internal and external experience: Exploration, exploitation, and R\&D project performance. Strategic Management Journal, 31(7), 734-758.

Hoffmann, W. H. (2007). Strategies for managing a portfolio of alliances. Strategic Management Journal, 28(8), 827-856.

Hwang, P., y Burgers, W. P. (1997). The many faces of multi-firm alliances: Lessons for managers. California Management Review, 39(3), 101-117.

Inkpen, A. C. (1998). Learning and knowledge acquisition through international strategic alliances. Academy of Management Executive, 12(4), 69-80.

Inkpen, A. C., y Beamish, P. W. (1997). Knowledge, bargaining power, and the instability of international joint ventures. Academy of Management Review, 22(1), 177-202.

Inkpen, A. C., y Currall, S. C. (2004). The coevolution of trust, control, and learning in joint ventures. Organization Science, 15(5), 586-599. 
Ireland, R. D., Hitt, M. A., y Vaidyanath, D. (2002). Alliance management as a source of competitive advantage. Journal of Management, 28(3), 413-446.

Jacobsen, S. F., y Tschoegl, A. E. (1999). The Norwegian banks in the Nordic consortia: A case of international strategic alliances in banking. Industrial and Corporate Change, 8(1), 137.

Jensen, M. C., y Meckling, W. H. (1976). Theory of the firm: Managerial behavior, agency costs and ownership structure. Journal of Financial Economics, 3(4), 305-360.

Kale, P. (1999). Alliance capability and success: A knowledge-based approach. Doctoral dissertation. University of Pennylvania.

Kale, P., Dyer, J. H., y Singh, H. (2002). Alliance capability, stock market response, and longterm alliance success: The role of the alliance function. Strategic Management Journal, 23(8), 747-767.

Kale, P., y Singh, H. (2007). Building firm capabilities through learning: The role of the alliance learning process in alliance capability and firm-level alliance success. Strategic Management Journal, 28(10), 981-1000.

Kale, P., y Singh, H. (2009). Managing strategic alliances: What do we know now, and where do we go from here? Academy of Management Perspectives, 23(3), 45-62.

Kale, P., Singh, H., y Perlmutter, H. (2000). Learning and protection of proprietary assets in strategic alliances: Building relational capital. Strategic Management Journal, 21(3), 217237.

Kanter, R. M. (1994). Collaborative advantage: The art of alliances. Harvard Business Review, 72(4), 96-108.

Kaulio, M. A., y Uppvall, L. (2009). Critical incidents in RD alliances: Uncovering leadership roles. European Management Review, 6(3), 195-205.

Khanna, T., Gulati, R., y Nohria, N. (1998). The dynamics of learning alliances: Competition, cooperation, and relative scope. Strategic Management Journal, 19(3), 193-210.

Kim, C. S., y Inkpen, A. C. (2005). Cross-border R\&D alliances, absorptive capacity and technology learning. Journal of International Management, 11(3), 313-329. 
King, A. A., y Tucci, C. L. (2002). Incumbent entry into new market niches: The role of experience and managerial choice in the creation of dynamic capabilities. Management Science, 48(2), 171-186.

Kogut, B. (1988). Joint ventures: Theoretical and empirical perspectives. Strategic Management Journal, 9(4), 319-332.

Kogut, B. (1991). Joint ventures and the option to expand and acquire. Management Science, 37(1), 19-33.

Kogut, B., y Kulatilaka, N. (1994). Options thinking and platform investments: Investing in opportunity. California Management Review, 36(2), 52-71.

Kogut, B., y Kulatilaka, N. (2001). Capabilities as real options. Organization Science, 12(6), 744-758.

Kogut, B., y Zander, U. (1996). What firms do? coordination, identity, and learning. Organization Science, 7(5), 502-518.

Koza, M. P., y Lewin, A. Y. (1998). The co-evolution of strategic alliances. Organization Science, 9(3), 255-264.

Kumar, M. V. (2011). Are joint ventures positive sum games? the relative effects of cooperative and noncooperative behavior. Strategic Management Journal, 32(1), 32-54.

Kumar, R., y Nti, K. O. (1998). Differential learning and interaction in alliance dynamics: A process and outcome discrepancy model. Organization Science, 9(3), 356-367.

Kumar, R., y Nti, K. O. (2004). National cultural values and the evolution of process and outcome discrepancies in international strategic alliances. The Journal of Applied Behavioral Science, 40(3), 344-361.

Kumar, S. (2010). The causes of joint venture termination: A real options perspective. In T. K. Das (Ed.), Researching strategic alliances (pp. 155-180). Charlotte, NC: Information Age Publishing Inc.

Kumar, S., y Seth, A. (1998). The design of coordination and control mechanisms for managing joint venture-parent relationships. Strategic Management Journal, 19(6), 579-599. 
Lacetera, N. (2009). Different missions and commitment power in R\&D organizations: Theory and evidence on industry-university alliances. Organization Science, 20(3), 565-582.

Lado, A. A., Boyd, N. G., y Hanlon, S. C. (1997). Competition, cooperation, and the search for economic rents: A syncretic model. The Academy of Management Review, 22(1), 110-141.

Lado, A. A., Dant, R. R., y Tekleab, A. G. (2008). Trust - opportunism paradox, relationalism, and performance in interfirm relationships: Evidence from the retail industry. Strategic Management Journal, 29(4), 401-423.

Lane, P. J., y Lubatkin, M. (1998). Relative absorptive capacity and interorganizational learning. Strategic Management Journal, 19(5), 461-477.

Langley, A. (1999). Strategies for theorizing from process data. Academy of Management Review, 24(4), 691-710.

Larsson, R. (1993). Case survey methodology: Quantitative analysis of patterns across case studies. Academy of Management Journal, 36(6), 1515-1546.

Larsson, R., Bengtsson, L., Henriksson, K., y Sparks, J. (1998). The interorganizational learning dilemma: Collective knowledge development in strategic alliances. Organization Science, 9(3), 285-305.

Laursen, K., y Salter, A. (2006). Open for innovation: The role of openness in explaining innovation performance among UK manufacturing firms. Strategic Management Journal, 27(2), 131-150.

Lavie, D. (2006). The competitive advantage of interconnected firms: An extension of the resource-based view. Academy of Management Review, 31(3), 638-658.

Lavie, D. (2007). Alliance portfolios and firm performance: A study of value creation and appropriation in the US software industry. Strategic Management Journal, 28(12), 11871212.

Lavie, D., Lechner, C., y Singh, H. (2007). The performance implications of timing of entry and involvement in multi-partner alliances. Academy of Management Journal, 50(3), 578-604.

Lavie, D., y Rosenkopf, L. (2006). Balancing exploration and exploitation in alliance formation. The Academy of Management Journal, 49(4), 797-818. 
Lazzarini, S. G. (2007). The impact of membership in competing alliance constellations: Evidence on the operational performance of global airlines. Strategic Management Journal, 28(4), 345-367.

Leonard-Barton, D. (1990). A dual methodology for case studies: Synergistic use of a longitudinal single site with replicated multiple sites. Organization Science, 1(3), 248-266.

Levinthal, D. A., y March, J. G. (1993). The myopia of learning. Strategic Management Journal, 14(Special issue on Organizations, Decision Making and Strategy), 95-112.

Li, D., Eden, L., Hitt, M. A., y Ireland, R. D. (2008). Friends, acquaintances, or strangers? partner selection in R\&D alliances. Academy of Management Journal, 51(2), 315-334.

Li, J. J., Poppo, L., y Zhou, K. Z. (2010). Relational mechanisms, formal contracts, and local knowledge acquisition by international subsidiaries. Strategic Management Journal, 31(4), 349-370.

Loohuis, R. P. A., y Groen, A. J. (2011). Towards a multidimensional view on collaborative processess. A case study on a international alliance formation. The changing paradigm of consulting: Adjusting to the fast-paced world (pp. 157-184). USA: Information Age Publishing, Inc.

Lubatkin, M., Florin, J., y Lane, P. (2001). Learning together and apart: A model of reciprocal interfirm learning. Human Relations, 54(10), 1353-1382.

Lumineau, F., y Fréchet, M. (2008). Managing discrepancies between formal and psychological sides of alliance contracting. Paper presented at Academy of Management Annual Meeting.

Lunnan, R., y Barth, T. (2003). Managing the exploration vs. exploitation dilemma in transnational. Journal of World Business, 38(2), 110-126.

Lunnan, R., y Haugland, S. A. (2008). Predicting and measuring alliance performance: A multidimensional analysis. Strategic Management Journal, 29(5), 545-556.

Luo, Y. (2008a). Procedural fairness and interfirm cooperation in strategic alliances. Strategic Management Journal, 29(1), 27-46.

Luo, Y. (2008b). Structuring interorganizational cooperation: The role of economic integration in strategic alliances. Strategic Management Journal, 29(6), 617-637. 
Lusch, R. F., y Brown, J. R. (1996). Interdependency, contracting, and relational behavior in marketing channels. Journal of Marketing, 60(4), 19-38.

Macmillan, I. C. (1989). Delineating a forum for business policy scholars. Strategic Management Journal, 10(4), 391-395.

Madhok, A. (1995). Opportunism and trust in joint venture relationships: An exploratory study and a model. Scandinavian Journal of Management, 11(1), 57-74.

Madhok, A. (1996). The organization of economic activity: Transaction costs, firm capabilities, and the nature of governance. Organization Science, 7(5), 577-590.

Madhok, A. (2002). Reassessing the fundamentals and beyond: Ronald Coase, the transaction cost and resource - based theories of the firm and the institutional structure of production. Strategic Management Journal, 23(6), 535-550.

Madhok, A., y Tallman, S. B. (1998). Resources, transactions and rents: Managing value through interfirm collaborative relationships. Organization Science, 9(3), 326-339.

Mahnke, V., y Overby, M. L. (2008). Failure sources in R\&D consortia: The case of mobile service development. International Journal of Technology Management, 44(1), 160-178.

Makadok, R. (2001). Toward a synthesis of the resource - based and dynamic - capability views of rent creation. Strategic Management Journal, 22(5), 387-401.

March, J. G. (1991). Exploration and exploitation in organizational learning. Organization Science, 2(1), 71-87.

Martín-de-Castro, G., Navas-López, J. E., y López-Sáez, P. (2006a). Business and social reputation: Exploring the concept and main dimensions of corporate reputation. Journal of Business Ethics, 63(4), 361-370.

Martín-de-Castro, G., Navas-López, J. E., López-Sáez, P., y Alama-Salazar, E. (2006b). Organizational capital as competitive advantage of the firm. Journal of Intellectual Capital, 7(3), 324-337.

Martín-de-Castro, G., Navas-López, J. E., López-Sáez, P., y Delgado-Verde, M. (2009). La reputación corporativa y las alianzas en el contexto de las industrias emergentes. Revista Europea De Dirección y Economía De La Empresa, 18(4), 139-154. 
Mathews, J. A. (2002). The origins and dynamics of Taiwan's R\&D consortia. Research Policy, 31(4), 633-651.

McCarter, M. W., Mahoney, J. T., y Northcraft, G. B. (2011). Testing the waters: Using collective real options to manage the social dilemma of strategic alliances. Academy of Management Review, 36(4), 621-640.

McGrath, R., y Nerkar, A. (2004). Real options reasoning and a new look at the R\&D investment strategies of pharmaceutical firms. Strategic Management Journal, 25(1), 1-21.

McGrath, R. G. (1997). A real options logic for initiating technology positioning investments. Academy of Management Review, 22(4), 974-996.

McGrath, R. G., Ferrier, W. J., y Mendelow, A. L. (2004). Real options as engines of choice and heterogeneity. The Academy of Management Review, 29(1), 86-101.

McKelvie, A., y Davidsson, P. (2009). From resource base to dynamic capabilities: An investigation of new firms. British Journal of Management, 20(S1), S63-S80.

Mesquita, L. F., Anand, J., y Brush, T. H. (2008). Comparing the resource - based and relational views: Knowledge transfer and spillover in vertical alliances. Strategic Management Journal, 29(9), 913-941.

Mohr, J., y Spekman, R. (1994). Characteristics of partnership success: Partnership attributes, communication behavior, and conflict resolution techniques. Strategic Management Journal, 15(2), 135-152.

Molina, J., Dyer, J. H., y Singh, H. (1999). On the relational view/response to relational view commentary. Academy of Management Review, 24(2), 184-186.

Montoro-Sánchez, M. Á. (2005). La cooperación internacional en investigación y desarrollo. Revista De Economía Aplicada, 13(39), 21-46.

Montoro-Sánchez, M. Á., y Guerras-Martín, L. A. (2004). La coordinación en los acuerdos de cooperación empresarial: Un análisis empírico basado en el modelo de procesamiento de información. Cuadernos De Economía y Dirección De La Empresa, (19), 55-80.

Montoro-Sánchez, M. Á., Mora-Valentin, E. M., y Guerras-Martín, L. A. (2006). R\&D cooperative agreements between firms and research organisations: A comparative analysis 
of the characteristics and reasons depending on the nature of the partner. International Journal of Technology Management, 35(1), 156-181.

Montoro-Sánchez, M. Á., Ortiz-de-Urbina-Criado, M., y Romero-Martínez, A. M. (2009). The decision to use alliances as corporate entrepreneurship: The role of resources and skills. Group Decision and Negotiation, 18(5), 431-448.

Moran, P. (2005). Structural vs. relational embeddedness: Social capital and managerial performance. Strategic Management Journal, 26(12), 1129-1151.

Mora-Valentín, E. M., Montoro-Sánchez, M. Á., y Guerras-Martín, L. A. (2004). Determining factors in the success of $R \& D$ cooperative agreements between firms and research organizations. Research Policy, 33(1), 17-40.

Morrison, E. W., y Robinson, S. L. (1997). When employees feel betrayed: A model of how psychological contract violation develops. Academy of Management Review, 22(1), 226256.

Morrison, E. W., y Robinson, S. L. (2004). The employment relationship from two sides: Incongruence in employees' and employers' perceptions of obligations. In J. A. M. CoyleShapiro, L. M. Shore, M. S. Taylor y L. E. Tetrick (Eds.), The employment relationship: Examining psychological and contextual perspectives (pp. 161). Oxford, U.K.: Oxford University Press.

Mosakowski, E., y Earley, P. C. (2000). A selective review of time assumptions in strategy research. Academy of Management Review, 25(4), 796-812.

Mothe, C., y Quelin, B. V. (2001). Resource creation and partnership in R\&D consortia. The Journal of High Technology Management Research, 12(1), 113-138.

Mowery, D. C., Oxley, J. E., y Silverman, B. S. (1996). Strategic alliances and interfirm knowledge transfer. Strategic Management Journal, 17(Special issue: Knowledge and the Firm), 77-91.

Murray, E. A., y Mahon, J. F. (1993). Strategic alliances: Gateway to the new Europe? Long Range Planning, 26(4), 102-111.

Muthusamy, S. K., y White, M. A. (2005). Learning and knowledge transfer in strategic alliances: A social exchange view. Organization Studies, 26(3), 415-441. 
Myers, S. C. (1984). Finance theory and financial strategy. Interfaces, January- February, 126137.

Nadkarni, S., y Barr, P. S. (2008). Environmental context, managerial cognition, and strategic action: An integrated view. Strategic Management Journal, 29(13), 1395-1427.

Nahapiet, J., y Ghoshal, S. (1998). Social capital, intellectual capital, and the organizational advantage. Academy of Management Review, 23(2), 242-266.

Nakamura, M., Nelson, H., y Vertinsky, I. (2003). Cooperative R\&D and the canadian forest products industry. Managerial and Decision Economics, 24(2 - 3), 147-169.

Nelson, R. R., y Winter, S. G. (1982). An evolutionary theory of economic change. Cambridge: Belknap Press.

Newbert, S. L. (2005). New firm formation: A dynamic capability perspective. Journal of Small Business Management, 43(1), 55-77.

Nicholson, N., y Johns, G. (1985). The absence culture and the psychological contract-who's in control of absence? Academy of Management Review, 10(3), 397-407.

Nielsen, B. B. (2010). Multilevel issues in strategic alliance research. In T. K. Das (Ed.), Researching strategic alliances (pp. 57-76). Charlotte, NC: Information Age Publishing Inc.

Nieto, M. (2004). Basic propositions for the study of the technological innovation process in the firm. European Journal of Innovation Management, 7(4), 314-324.

Nieto, M., y Pérez, W. (2000). The development of theories from the analysis of the organisation: Case studies by the patterns of behaviour. Management Decision, 38(10), 723-734.

Nieto, M., y Quevedo, P. (2005). Absorptive capacity, technological opportunity, knowledge spillovers, and innovative effort. Technovation, 25(10), 1141-1157.

Nonaka, I., y Takeuchi, H. (1995). The knowledge-creating company: How Japanese companies create the dynamics of innovation. New York: Oxford University Press. 
Oliver, C. (1991). Strategic responses to institutional processes. The Academy of Management Review, 16(1), 145-179.

Olk, P., y Young, C. (1997). Why members stay in or leave an R\&D consortium: Performance and conditions of membership as determinants of continuity. Strategic Management Journal, 18(11), 855-877.

Ouchi, W. G., y Bolton, M. K. (1988). The logic of joint research and development. California Management Review, 30(3), 9-33.

Oxley, J. E. (1997). Appropriability hazards and governance in strategic alliances: A transaction cost approach. Journal of Law, Economics, and Organization, 13(2), 387.

Oxley, J. E., y Sampson, R. C. (2004). The scope and governance of international R\&D alliances. Strategic Management Journal, 25(8-9), 723-749.

Parent, M. M., y Deephouse, D. L. (2007). A case study of stakeholder identification and prioritization by managers. Journal of Business Ethics, 75(1), 1-23.

Park, S. H., y Russo, M. V. (1996). When competition eclipses cooperation: An event history analysis of joint venture failure. Management Science, 42(6), 875-890.

Park, S. H., y Ungson, G. R. (2001). Interfirm rivalry and managerial complexity: A conceptual framework of alliance failure. Organization Science, 12(1), 37-53.

Parkhe, A. (1991). Interfirm diversity, organizational learning, and longevity in global strategic alliances. Journal of International Business Studies, 22(4), 579-601.

Parkhe, A. (1993). Strategic alliance structuring: A game theoretic and transaction cost examination of interfirm cooperation. Academy of Management Journal, 36(4), 794-829.

Patton, M. Q. (2002). Qualitative research and evaluation methods. Thousand Oaks, CA.: Sage Publications.

Pentland, B. T. (1999). Building process theory with narrative: From description to explanation. Academy of Management Review, 24(4), 711-724.

Pentland, B. T., y Feldman, M. S. (2005). Organizational routines as a unit of analysis. Industrial and Corporate Change, 14(5), 793-815. 
Pentland, B. T., y Rueter, H. H. (1994). Organizational routines as grammars of action. Administrative Science Quarterly, 39(3), 484-510.

Pérez-Luño, A., Valle Cabrera, R., y Wiklund, J. (2009). De la creatividad al lanzamiento de productos. Cuadernos De Economía y Dirección De La Empresa, (38), 95.

Pérez - Nordtvedt, L., Kedia, B. L., Datta, D. K., y Rasheed, A. A. (2008). Effectiveness and efficiency of Cross - Border knowledge transfer: An empirical examination. Journal of Management Studies, 45(4), 714-744.

Peteraf, M. A. (1993). The cornerstones of competitive advantage: A resource-based view. Strategic Management Journal, 14(3), 179-191.

Petroni, A. (1998). The analysis of dynamic capabilities in a competence-oriented organization. Technovation, 18(3), 179-189.

Pettigrew, A. M. (1990). Longitudinal field research on change: Theory and practice. Organization Science, 1(3), 267-292.

Pfeffer, J., y Salancik, G. R. (1978). The external control of organizations. New York: Harper y Row.

Phelps, C. C. (2010). A longitudinal study of the influence of alliance network structure and composition on firm exploratory innovation. Academy of Management Journal, 53(4), 890913.

Pisano, G. P. (2000). In search of dynamic capabilities: The origins of R\&D competence in biopharmaceuticals. In G. Dosi, R. R. Nelson y S. G. Winter (Eds.), The nature and dynamics of organizational capabilities (pp. 127-129) Oxford University Press.

Podsakoff, P. M., MacKenzie, S. B., Lee, J. Y., y Podsakoff, N. P. (2003). Common method biases in behavioral research: A critical review of the literature and recommended remedies. Journal of Applied Psychology, 88(5), 879-903.

Poppo, L., y Zenger, T. (2002). Do formal contracts and relational governance function as substitutes or complements? Strategic Management Journal, 23(8), 707-725. 
Poppo, L., Zhou, K. Z., y Ryu, S. (2008). Alternative origins to interorganizational trust: An interdependence perspective on the shadow of the past and the shadow of the future. Organization Science, 19(1), 39-55.

Powell, W. W., Koput, K. W., y Smith-Doerr, L. (1996). Interorganizational collaboration and the locus of innovation: Networks of learning in biotechnology. Administrative Science Quarterly, 41(1), 116-145.

Priem, R. L., y Butler, J. E. (2001). Is the resource-based" view" a useful perspective for strategic management research? Academy of Management Review, 26(1), 22-40.

Prieto, I. M., Revilla, E., y Rodríguez-Prado, B. (2009). Building dynamic capabilities in product development: How do contextual antecedents matter? Scandinavian Journal of Management, 25(3), 313-326.

Rerup, C., y Feldman, M. S. (2011). Routines as a source of change in organizational schemata: The role of trial-and-error learning. Academy of Management Journal, 54(3), 577-610.

Reuer, J. J. (2000). Parent firm performance across international joint venture life-cycle stages. Journal of International Business Studies, 31(1), 1-20.

Reuer, J. J., y Ariño, A. (2007). Strategic alliance contracts: Dimensions and determinants of contractual complexity. Strategic Management Journal, 28(3), 313-330.

Reuer, J. J., y Tong, T. W. (2005). Real options in international joint ventures. Journal of Management, 31(3), 403-423.

Reuer, J. J., y Zollo, M. (2005). Termination outcomes of research alliances. Research Policy, 34(1), 101-115.

Reuer, J. J., Zollo, M., y Singh, H. (2002). Post-formation dynamics in strategic alliances. Strategic Management Journal, 23(2), 135-151.

Rindova, V. P., y Kotha, S. (2001). Continuous" morphing": Competing through dynamic capabilities, form, and function. Academy of Management Journal, 44(6), 1263-1280.

Ring, P. S., Doz, Y. L., y Olk, P. M. (2005). Managing formation processes in R\&D consortia. California Management Review, 47(4), 137-156. 
Ring, P. S., y Van de Ven, A. H. (1994). Developmental processes of cooperative interorganizational relationships. Academy of Management Review, 19(1), 90-118.

Ringle, C. M., Wende, S., y Will, A. (2005). SmartPLS 2.0 (beta). Www.Smartpls.De, Hamburg, Germany. Accesed November 2010,

Rodríguez-Pinto, J., Rodríguez-Escudero, A. I., y Gutiérrez-Cillán, J. (2008). Order, positioning, scope and outcomes of market entry. Industrial Marketing Management, 37(2), 154-166.

Roessl, D. (2005). Family businesses and interfirm cooperation. Family Business Review, 18(3), 203-214.

Rosenbloom, R. S. (2000). Leadership, capabilities, and technological change: The transformation of NCR in the electronic era. Strategic Management Journal, 21(10-11), 1083-1103.

Rothaermel, F. T., y Deeds, D. L. (2006). Alliance type, alliance experience and alliance management capability in high-technology ventures. Journal of Business Venturing, 21(4), 429-460.

Rousseau, D. M. (1995). Psychological contracts in organizations: Understanding written and unwritten agreements SAGE Publications, Inc.

Rousseau, D. M., y Tijoriwala, S. A. (1998). Assessing psychological contracts: Issues, alternatives and measures. Journal of Organizational Behavior, 19(1), 679-695.

Ryall, M. D., y Sampson, R. C. (2009). Formal contracts in the presence of relational enforcement mechanisms: Evidence from technology development projects. Management Science, 55(6), 906-925.

Sakakibara, M. (1997). Heterogeneity of firm capabilities and cooperative research and development: An empirical examination of motives. Strategic Management Journal, 18(1), 143-164.

Salk, J. E. (2005). Often called for but rarely chosen: Alliance research that directly studies process. European Management Review, 2(2), 117-122. 
Sammarra, A., y Biggiero, L. (2008). Heterogeneity and specificity of Inter - Firm knowledge flows in innovation networks. Journal of Management Studies, 45(4), 800-829.

Sampson, R. C. (2005). Experience effects and collaborative returns in R\&D alliances. Strategic Management Journal, 26(11), 1009-1031.

Sampson, R. C. (2007). R\&D alliances and firm performance: The impact of technological diversity and alliance organization on innovation. Academy of Management Journal, 50(2), 364-386.

Sánchez-González, G., González-Álvarez, N., y Nieto, M. (2008). The effects of cooperating with users concerning the type of innovation developed. Innovar, 18(32), 87-110.

Sánchez-González, G., González-Álvarez, N., y Nieto, M. (2009). Sticky information and heterogeneous needs as determining factors of $R \& D$ cooperation with customers. Research Policy, 38(10), 1590-1603.

Sánchez-Peinado, L., Sánchez-Peinado, E., y Escribá-Esteve, A. (2010). Factores determinantes de la intención de cambio estratégico: El papel de los equipos directivos. Cuadernos De Economía y Dirección De La Empresa, (42), 75-112.

Sankaran, J. K., y Mouly, V. S. (2006). Value-chain innovation in aquaculture: Insights from a new zealand case study. $R \& D$ Management, 36(4), 387-401.

Sarkar, M. B., Aulakh, P. S., y Madhok, A. (2009). Process capabilities and value generation in alliance portfolios. Organization Science, 20(3), 583-600.

Sarkar, M. B., Echambadi, R., Cavusgil, S. T., y Aulakh, P. S. (2001a). The influence of complementarity, compatibility, and relationship capital on alliance performance. Journal of the Academy of Marketing Science, 29(4), 358-373.

Sarkar, M. B., Echambadi, R., y Harrison, J. S. (2001b). Alliance entrepreneurship and firm market performance. Strategic Management Journal, 22(6 - 7), 701-711.

Saxton, T. (1997). The effects of partner and relationship characteristics on alliance outcomes. Academy of Management Journal, 40(2), 443-461.

Schilke, O. (2007). Organizational routines as alliance capabilities: The missing link. Paper presented at Academy of Management Annual Meeting. 
Schilke, O., y Goerzen, A. (2010). Alliance management capability: An investigation of the construct and its measurement. Journal of Management, 36(5), 1192-1219.

Schreiner, M., Kale, P., y Corsten, D. (2009). What really is alliance management capability and how does it impact alliance outcomes and success? Strategic Management Journal, 30(13), 1395-1419.

Schreyögg, G., y Kliesch-Eberl, M. (2007). How dynamic can organizational capabilities be? towards a dual-process model of capability dynamization. Strategic Management Journal, 28(9), 913-933.

Shenkar, O., y Yan, A. (2002). Failure as a consequence of partner politics: Learning from the life and death of an international cooperative venture. Human Relations, 55(5), 565-601.

Siggelkow, N. (2002). Evolution toward fit. Administrative Science Quarterly, 47(1), 125-159.

Siggelkow, N. (2007). Persuasion with case studies. Academy of Management Journal, 50(1), 20-24.

Silva, M. J., Leitao, J., y Raposo, M. (2008). Barriers to innovation faced by manufacturing firms in portugal: How to overcome it for fostering business excellence? International Journal of Business Excellence, 1(1), 92-105.

Simonin, B. L. (1997). The importance of collaborative know-how: An empirical test of the learning organization. Academy of Management Journal, 40(5), 1150-1174.

Simonin, B. L. (1999). Ambiguity and the process of knowledge transfer in strategic alliances. Strategic Management Journal, 20(7), 595-623.

Simonin, B. L. (2004). An empirical investigation of the process of knowledge transfer in international strategic alliances. Journal of International Business Studies, 35(5), 407-427.

Smith, K. G., Carroll, S. J., y Ashford, S. J. (1995). Intra-and interorganizational cooperation: Toward a research agenda. Academy of Management Journal, 38(1), 7-23.

Stephens, K. J., Fulk, J., y Monge, P. R. (2009). Constrained choices in alliance formations: Cupids and organizational marriages. Human Relations, 62(4), 501. 
Strauss, A., y Corbin, J. (1998). Basics of qualitative research: Grounded theory procedures and techniques (2nd Edition ed.). NewburyPark, London.: Sage.

Stuart, T. E. (2000). Interorganizational alliances and the performance of firms: A study of growth and innovation rates in a high-technology industry. Strategic Management Journal, 21(8), 791-811.

Teece, D. J. (1986). Profiting from technological innovation: Implications for integration, collaboration, licensing and public policy. Research Policy, 15(6), 285-305.

Teece, D. J. (2007). Explicating dynamic capabilities: The nature and microfoundations of (sustainable) enterprise performance. Strategic Management Journal, 28(13), 1319-1350.

Teece, D. J., y Pisano, G. (1994). The dynamic capabilities of firms: An introduction. Industrial and Corporate Change, 3(3), 537-556.

Teece, D. J., Pisano, G., y Shuen, A. (1997). Dynamic capabilities and strategic management. Strategic Management Journal, 18(7), 509-533.

Thorgren, S., Wincent, J., y Eriksson, J. (2010). Too small or too large to trust your partners in multipartner alliances? the role of effort in initiating generalized exchanges. Scandinavian Journal of Management, 27(1), 99-112.

Tiwana, A. (2008). Do bridging ties complement strong ties? an empirical examination of alliance ambidexterity. Strategic Management Journal, 29(3), 251-272.

Tjemkes, B., y Furrer, O. (2010). The antecedents of response strategies in strategic alliances. Management Decision, 48(7), 1103-1133.

Tong, T. W., Reuer, J. J., y Peng, M. W. (2008). International joint ventures and the value of growth options. Academy of Management Journal, 51(5), 1014-1029.

Tripsas, M. (1997a). Surviving radical technological change through dynamic capability: Evidence from the typesetter industry. Industrial and Corporate Change, 6(2), 341-377.

Tripsas, M. (1997b). Unraveling the process of creative destruction: Complementary assets and incumbent survival in the typesetter industry. Strategic Management Journal, 18(S1), 119142. 
Tripsas, M., y Gavetti, G. (2000). Capabilities, cognition, and inertia: Evidence from digital imaging. Strategic Management Journal, 21(10-11), 1147-1161.

Tsai, W. (2002). Social structure of 'coopetition' within a multiunit organization: Coordination, competition, and intraorganizational knowledge sharing. Organization Science, 13(2), 179190.

Tsai, W., y Ghoshal, S. (1998). Social capital and value creation: The role of intrafirm networks. Academy of Management Journal, 41(4), 464-476.

Uzzi, B. (1997). Social structure and competition in interfirm networks: The paradox of embeddedness. Administrative Science Quarterly, 42(1), 35-67.

Valdés-Llaneza, A., y García-Canal, E. (2006). Direct competition, number of partners and the longevity of stakes in joint ventures. Management International Review, 46(3), 307-326.

Van de Ven, A. H. (1992). Suggestions for studying strategy process: A research note. Strategic Management Journal, 13(5), 169-188.

Van Driel, H., y Dolfsma, W. (2009). Path dependence, initial conditions, and routines in organizations: The toyota production system re-examined. Journal of Organizational Change Management, 22(1), 49-72.

Vassolo, R. S., Anand, J., y Folta, T. B. (2004). Non - additivity in portfolios of exploration activities: A real options - based analysis of equity alliances in biotechnology. Strategic Management Journal, 25(11), 1045-1061.

Verona, G., y Ravasi, D. (2003). Unbundling dynamic capabilities: An exploratory study of continuous product innovation. Industrial and Corporate Change, 12(3), 577.

Villalonga, B., y McGahan, A. M. (2005). The choice among acquisitions, alliances, and divestitures. Strategic Management Journal, 26(13), 1183-1208.

Walter, A., Auer, M., y Ritter, T. (2006). The impact of network capabilities and entrepreneurial orientation on university spin-off performance. Journal of Business Venturing, 21(4), 541567.

Wang, L., y Zajac, E. J. (2007). Alliance or acquisition? A dyadic perspective on interfirm resource combinations. Strategic Management Journal, 28(13), 1291-1317. 
Weick, K. E. (1989). Theory construction as disciplined imagination. Academy of Management Review, 14(4), 516-531.

Weick, K. E., Sutcliffe, K. M., y Obstfeld, D. (2005). Organizing and the process of sensemaking. Organization Science, 16(4), 409-421.

Wernerfelt, B. (1984). A resource-based view of the firm. Strategic Management Journal, 5(2), $171-180$

Wiklund, J., y Shepherd, D. A. (2009). The effectiveness of alliances and acquisitions: The role of resource combination activities. Entrepreneurship Theory and Practice, 33(1), 193-212.

Williamson, O. E. (1985). The economic institutions of capitalism. firms, markets, relational contracting.

Williamson, O. E. (1991). Comparative economic organization: The analysis of discrete structural alternatives. Administrative Science Quarterly, 36(2), 269-296.

Winter, S. G. (2003). Understanding dynamic capabilities. Strategic Management Journal, 24(10), 991-995.

Wolfgang, G. H., y Stefan, K. W. (2010). "Organizational routines between change and stability: Linking empirical research to recent theoretical debates". Paper presented at Fourth International Conference on Organizational Routines.

Wu, F., y Cavusgil, S. T. (2006). Organizational learning, commitment, and joint value creation in interfirm relationships. Journal of Business Research, 59(1), 81-89.

Yasuda, H. (2005). Formation of strategic alliances in high-technology industries: Comparative study of the resource-based theory and the transaction-cost theory. Technovation, 25(7), 763-770.

Yin, R. K. (1981). The case study crisis: Some answers. Administrative Science Quarterly, 26(1), 58-65.

Yin, R. K. (2003). Case study research, design and methods. Thousand Oaks, CA.: Sage publications. 
Young-Ybarra, C., y Wiersema, M. (1999). Strategic flexibility in information technology alliances: The influence of transaction cost economics and social exchange theory. Organization Science, 10(4), 439-459.

Zaheer, A., Gözübüyük, R., y Milanov, H. (2010). It's the connections: The network perspective in interorganizational research. Academy of Management Perspectives, 24(1), 62-77.

Zahra, S. A., y George, G. (2002). Absorptive capacity: A review, reconceptualization, and extension. Academy of Management Review, 27(2), 185-203.

Zahra, S. A., Sapienza, H. J., y Davidsson, P. (2006). Entrepreneurship and dynamic capabilities: A review, model and research agenda. Journal of Management Studies, 43(4), 917-955.

Zajac, E. J., y Olsen, C. P. (1993). From transaction cost to transactional value analysis: Implications for the study of interorganizational strategies. Journal of Management Studies, 30(1), 131-145.

Zeng, M., y Chen, X. P. (2003). Achieving cooperation in multiparty alliances: A social dilemma approach to partnership management. Academy of Management Review, 28(4), 587-605.

Ziggers, G. W., y Tjemkes, B. (2010). Dynamics in inter-firm collaboration: The impact of alliance capabilities on performance. International Journal on Food System Dynamics, 1(2), 151-166.

Zollo, M., Reuer, J. J., y Singh, H. (2002). Interorganizational routines and performance in strategic alliances. Organization Science, 13(6), 701-713.

Zollo, M., y Winter, S. G. (2002). Deliberate learning and the evolution of dynamic capabilities. Organization Science, 13(3), 339-351.

Zúñiga-Vicente, J. Á., de la Fuente-Sabaté, J. M., y Suárez-González, I. (2005). Facilitating and inhibiting factors behind strategic change: Evidence in the Spanish private banking industry, 1983-1997. Scandinavian Journal of Management, 21(3), 235-265. 